\author{
Alex Hubbe
}

Análise morfológica craniana de Xenarthra atuais e extintos: inferências evolutivas e funcionais

Skull morphological analysis of extant and extinct Xenarthra: evolutionary and functional inferences

São Paulo 


\section{Alex Hubbe}

\section{Análise morfológica craniana de Xenarthra atuais e extintos: inferências evolutivas e funcionais}

\section{Extant and extinct Xenarthran skull morphological analysis: evolutionary and functional inferences}

Tese apresentada ao Instituto de Biociências da Universidade de São Paulo, para a obtenção de Título de Doutor em Ciências, na Área de Genética e Biologia Evolutiva

Orientador(a): Gabriel Marroig

São Paulo 
Hubbe, Alex

Análise morfológica craniana de Xenarthra atuais e extintos: inferências evolutivas e funcionais

267 páginas

Tese (Doutorado) - Instituto de Biociências da Universidade de São Paulo. Departamento de Genética e Biologia Evolutiva.

1. Genética quantitativa 2. Seleção natural 3. Modularidade I. Universidade de São Paulo. Instituto de Biociências.

Departamento de Genética e Biologia Evolutiva.

\section{Comissão Julgadora:}

Prof(a). Dr(a).

Prof(a). Dr(a).
Prof(a). Dr(a).

Prof(a). Dr(a).

Prof(a). Dr(a).

Orientador(a) 
Cantar e cantar e cantar A beleza de ser um eterno aprendiz! 


\section{Agradecimentos}

Ao longo da minha trajetória acadêmica passei a nutrir cada vez mais prazer pela leitura dos agradecimentos de trabalhos científicos, especialmente de teses e dissertações, mas também de artigos. Acho que eles me ajudam a lembrar que por traz dos textos, por vezes bastante complexos, existe um ser humano... Muitas destas pessoas, além de cientistas de qualidade são capazes de redigir agradecimentos belíssimos e emocionantes.

Gostaria de ter a inspiração ou mesmo a habilidade literária para produzir um agradecimento grandioso, que gerasse, em outras pessoas, o mesmo tipo de sentimento que tenho ao ler os agradecimentos alheios. De qualquer forma, gostaria que as pessoas lessem meus agradecimentos pensando que se eu fosse um Charles Darwin ou um Graciliano Ramos, dentre tantas outras pessoas talentosas, expressaria de forma muito calorosa e elegante o meu mais sincero obrigado!

Tendo esclarecido isto, agradeço:

Ao Gabriel Marroig pela orientação, pela preocupação e pela incrível clareza ao explicar coisas por vezes tão complexas para mim. Um especial obrigado por dividir comigo parte do seu colossal conhecimento sobre evolução e genética quantitativa.

Ao Walter Neves, por encarar o início desta empreitada.

Ao assessor FAPESP pelas valiosas contribuições para a melhoria do meu trabalho.

Não teria chegado aqui se não fosse a valiosa companhia dos integrantes do LEM. Ousaria dizer que não existe lugar mais favorável no planeta ao desenvolvimento de uma tese do que o LEM. Tanto os integrantes atuais (Harley, Ogro, Pato, Lugar, Aninha, Paulinha, Papete, Monique, Edgar, Tafinha, Dani e Wally) quanto os passados (Arthur, Fino e Leila) foram vitais para o meu trabalho.

À FAPESP, CAPES e Field Museum's visiting scholar program pelas bolsas concedidas.

À Dra. Regina Netto, entre outros motivos, pela ajuda na solicitação da bolsa sanduiche CAPES.

Aos funcionários que tanto ajudaram na hora de resolver as burocracias acadêmicas: Helenice, Deise, Helder e Erika.

Ao Tony Barnosky por ser o responsável pelo meu estágio sanduiche.

Aos queridos amigos de dentro e de fora da biologia.

Aos responsáveis pelo curso introdutório do R, Paulo Inácio, Alexandre e Rodrigo. Seus ensinamentos encurtaram muitas distâncias! 
Aos curadores e aos responsáveis pelas coleções visitadas, assim como aos alunos/estagiários que muito me ajudaram no labiríntico mundo das várias gavetas dos muitos armários perdidos em quase infinitos corredores das coleções dos diversos museus visitados: Judith Galkin, Robert Voss e Eileen Westwig (AMNH); Maureen Flannery e Alicia Goode (CAS); Alejandra Rojas, Richard Fariña e Daniel Hernández (FC); William Simpson, Bruce Patterson e Stephanie Ware (FMNH); Sueli Aguiar e José Abílio Ohana (MPEG); Mary Thompson (IMNH); Jim Dines e Xiaoming Wang (LACM); John Harris e Aisling Farrell (LACMHC); Alejandro Kramarz e Davi Flores (MACN); Castor Cartelle, Luciano Vilaboim e André Vasconcelos (MCN-PUC-MG); Tomaz Aguzzoli e Daniela Sanfelice (MCNRGS); Itatí Olivares e Marcelo Reguero (MLP); Solange Bermudez, Ana Laura e Andrés (MMC); Andrés Rinderknecht, Enrique Gonzalez, Anita e Victor Scarabino (MNHN); Leandro de Oliveira e Stella Franco (MNRJ); Jim Patton e Chris Conroy (MVZ); Tomaz Aguzzoli e Daniela Sanfelice (MCNRGS); Andy Currant, Louise Tomsett e Paula Jenkins (NHM); Pat Holroyd (UCMP); Candace McCaffery, Richard Hulbert, Bruce MacFadden, David Reed e Kyle Finn (UF); Michael Brett-Surman, Darrin Lunde e Linda Gordon (USNM); Mário de Vivo, Juliana Gualda e Fábio Nascimento (MZUSP). Além disso me beneficie das coleções particulares de Mauro Teixeira e Paulo Aurrichio.

Durante minhas idas e vindas a todas estas coleções e cidades tive apoio de diversas pessoas (companhia, risadas, caronas, passeios, casa, comida, dicas...), as quais gostaria de agradecer imensamente. Gostaria também de agradecer bons amigos que contribuíram direta ou indiretamente ao longo do doutoramento. Vamos aos nomes: Sílvia Pavan, Pedro Peloso, David Candiani, Nancy Lo Man Hun, Bruce Lander, Howell Thomas, Mariela Castro, Beethoven Piló, Gepeto Muller, Thais Lavagnolli, Tony Barnosky, Susumu Tomiya, Kaitlin Maguire, Allison Stegner, Emily Lindsey, Marc Carrasco, Donald Grayson, Felipe, Rui Murrieta, Rodrigo, Charles, Ian, o povo do 01N, Thiago Quental, Leonardo Pacheco, Ivan Nunes, Marco Antônio Ribeiro, Ana Almeida e Lu, Roberta Damasceno, Zé Wly, Ângela Ribeiro, Jon Fong, Jay McEntee, Mike e Gabi.

Especial obrigado a Nadia de Moraes, ao Ángel Miño-Boilini, ao Abílio Ohana, ao Jim Patton e a Flávia Miranda pelas construtivas discussões relacionadas aos queridos Xenarthra e ao Arthur Porto por me ensinar como coletar os marcos anatômicos.

Ao meu irmão (Mark), pelas sempre importantes contribuições.

Evidentemente a minha mãe (Verônica), pai (Klaus) e irmã (Kaká) por propiciarem o ambiente perfeito para eu poder virar um doutor.

Por último, mas não menos importante, agradeço imensamente e do fundo do meu coração à minha paixão, Oli, que leu com muito afinco cada letra desta tese. Se o texto ficou compreensível, devo isto em grande parte a você! 
Acho muito provável ter esquecido de agradecer alguém (mas espero que não...). Para você, esquecido, minhas desculpas e meu muito obrigado! 


\section{Índice}

Introdução Geral

09

Capítulo I. Padrões e magnitudes das relações morfológicas cranianas de Xenarthra atuais e extintos

Capítulo II. Diversificação morfológica craniana dos Xenarthra: deriva genética versus seleção natural

Capítulo III. Magnitude geral de integração e padrão da modularidade craniana dos Xenarthra

Capítulo IV. A dieta e a extinção dos Xenarthra fósseis do Quaternário Tardio

Conclusões Gerais

Resumo

Abstract

Anexos 


\section{Introdução Geral}

O interesse formal pela história natural remonta aos Sumérios, há mais de 5000 mil anos atrás. No entanto, foram os gregos que fundaram as ciências naturais, entre os séculos V e IV a.C.. Eles iniciaram a longa trajetória de estudos relacionados à vida na Terra, como mostram os trabalhos dos filósofos Aristóteles e Theophractus (Huxley, 2007). Apesar da extensa história de pesquisas envolvendo a vida como tema central, o conceito "evolução" é relativamente recente. Até o século XIX, a ideia melhor aceita era a da imutabilidade dos seres vivos, sendo toda a vida criada por Deus. Opiniões que iam contra essa visão de mundo eram fortemente reprimidas ou desencorajadas pela igreja (Grayson, 1984; Futuyma, 1998; Huxley, 2007).

Entre os séculos XVIII e XIX, alguns naturalistas foram pioneiros ao propor ideias que desafiavam esse olhar dogmático sobre a vida (Futuyma, 1998; Huxley, 2007; Pigliucci, 2007). No entanto, coube a Charles Darwin e Alfred Wallace (Darwin e Wallace, 1858; Darwin, 1859), somente no início da segunda metade do século XIX, propor um dos mecanismos fundamentais pelo qual os seres vivos evoluem: a seleção natural, que mudou para sempre a forma como a humanidade enxerga a vida. No entanto, os conceitos propostos pelos dois naturalistas não foram aceitos de imediato. O clero e os leigos viam esta ideia como um ataque a religião. Entre os cientistas, uma parcela deles não acreditava na seleção natural devido a sua visão religiosa. Outra parte não concebia que o processo de seleção natural, agindo sobre a diversidade das populações, seria capaz de gerar mudanças importantes. Até as primeiras décadas do século XX, a grande maioria da comunidade científica refutava a ideia de seleção natural (Futuyma, 1998). As principais teorias que eram contrárias à visão darwiniana de evolução embasavam seus argumentos na evidência paleontológica e na genética mendeliana. Segundo alguns pesquisadores, o registro paleontológico, que permite observar as mudanças que ocorrem no 
nível da espécie ou acima dele (macroevolução) e não somente as mudanças que ocorrem em populações ou dentro de espécies (microevolução), não estavam de acordo com as previsões de Darwin e Wallace, de que a evolução das espécies ocorria de forma lenta e gradual. Após a redescoberta dos trabalhos de Gregor Mendel no início do século XX, alguns cientistas diziam que os princípios da genética mendeliana também não corroboravam a evolução lenta e gradual decorrente da seleção natural (Futuyma, 1998).

Contudo, na primeira metade do século XX, Ronald Fisher, Sewall Wright, John Haldane, Theodosius Dobzansky, Ernst Mayr, George Simpson, entre outros cientistas, integraram e conciliaram a teoria da seleção natural à genética mendeliana e à paleontologia. A união dessas três vertentes do conhecimento ficou conhecida como síntese evolutiva moderna (Futuyma, 1998). Além da seleção natural, outro importante mecanismo de evolução, proposto na primeira metade do século XX, integra esta síntese: a deriva genética, pela qual as populações evoluem através de variações aleatórias na frequência dos alelos devido ao tamanho populacional finito (Hagedoorn e Hagedoorn - Vorstheuvel La Brand, 1921; Wright, 1931; Wallace, 2004). Após a sua concepção, a síntese moderna passou a ser o paradigma vigente (Futuyma, 1998; Pigliucci, 2007).

A partir dela, a biologia evolutiva desenvolveu-se sob um arcabouço teórico cada vez mais sólido. Neste contexto, floresceu a genética quantitativa. Ela permite compreender os processos microevolutivos que moldaram as estruturas fenotípicas definidas por caracteres contínuos, em oposição aos qualitativos. Esses caracteres são, por sua vez, geralmente determinados por vários genes de efeito pequeno (Falconer e MacKay, 1996). Além disso, através dela é possível acessar as consequências evolutivas da arquitetura genética na evolução dos fenótipos (Marroig et al., 2009; Porto et al., 2009). A base teórica da genética quantitativa 
está na extensão das leis da genética mendeliana à escala populacional, na segregação simultânea de genes em muitos loci e nas diferentes propriedades desses genes, denominadas dominância, epistasia, pleiotropia, desequilíbrio de ligação e mutação (Falconer e Mackay, 1996).

Russel Lande, no final da década de 1970 (Lande, 1979), derivou a importante equação da resposta multivariada à seleção, apresentada abaixo.

$$
\Delta \bar{z}=\boldsymbol{G} \beta
$$

onde $\Delta \bar{z}$ é o vetor que representa a resposta evolutiva nas médias dos caracteres, $\mathbf{G}$ é a matriz que representa as relações (covariâncias) genéticas aditivas entre os caracteres (i.e., matriz-G) e $\beta$ é o vetor que representa a força da seleção direcional atuando independentemente sobre cada caráter. Com base nesta equação, passou a ser possível compreender quais processos evolutivos atuaram na diversificação morfológica de caracteres contínuos e como linhagens evolutivas respondem à pressão seletiva direcional (Phillips e McGuigan, 2006).

A equação proposta por Lande evidencia que a matriz de variância/covariância genética aditiva (matriz-G) é de aspecto central nos estudos de genética quantitativa. Ela representa a contribuição dos efeitos genéticos aditivos para a variância e a covariância entre caracteres quantitativos. Ou seja, ela representa a parcela da variância/covariância herdável e, consequentemente, a quantidade de variação disponível para a evolução dos fenótipos (Lande, 1979; Cheverud, 1988; Falconer e MacKay, 1996; Steppan et al., 2002; Phillips e McGuigan, 2006). Na prática, no entanto, as matrizes-G são de difícil obtenção, pois necessitam de um grande número de indivíduos aparentados em genealogias conhecidas (Cheverud, 1988). Por outro lado a matriz de variância/covariância fenotípica (matrizes-P) é estimada com algum grau de precisão e confiança de forma muito mais fácil do que a matriz-G. Quando houver 
semelhança estrutural ou proporcionalidade entre a matrizes-P e a matriz-G, a primeira pode ser utilizada como substituta da segunda (Cheverud, 1988; Falconer e MacKay, 1996; Steppan et al., 2002).

Após a síntese moderna, o desenvolvimento da genética quantitativa e a derivação da equação da resposta multivariada à seleção, tornou-se possível investigar em detalhes a influencia de diferentes aspectos da matriz-G (ou matriz-P) na evolução morfológica. A intensidade global das correlações entre os caracteres (i.e., magnitude geral de integração) e a estrutura (i.e., padrão) da matriz-G ou da matriz-P são características da matriz que podem influir na evolução do fenótipo médio. A magnitude geral de integração pode ser entendida como a intensidade das associações entre os caracteres. Já o padrão expressa as relações entre os caracteres (Marroig e Cheverud, 2001). Na Figura 1, por exemplo, os casos A e B apresentam o mesmo padrão para os quatro caracteres representados. As correlações positivas entre I e II e entre III e IV são mais fortes do que as demais correlações. Por outro lado, a magnitude geral de integração difere entre os dois casos. Em A, a magnitude geral de integração é relativamente baixa (média de todas as correlações pequena). Já em B, ela é maior, como mostram as correlações elevadas.

A

\begin{tabular}{|c|c|c|c|c|}
\hline & I & II & III & IV \\
\hline I & 1 & 0.3 & 0.1 & 0.1 \\
\hline II & 0.3 & 1 & 0.1 & 0.1 \\
\hline III & 0.1 & 0.1 & 1 & 0.3 \\
\hline IV & 0.1 & 0.1 & 0.3 & 1 \\
\hline
\end{tabular}

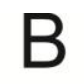

\begin{tabular}{|c|c|c|c|c|}
\hline & I & II & III & IV \\
\hline I & 1 & 0.8 & 0.4 & 0.4 \\
\hline II & 0.8 & 1 & 0.4 & 0.4 \\
\hline III & 0.4 & 0.4 & 1 & 0.8 \\
\hline IV & 0.4 & 0.4 & 0.8 & 1 \\
\hline
\end{tabular}
B).

Figura 1 - Correlação hipotética entre quatro caracteres (I, II, III e IV) para dois taxa (A e

Essas duas características (magnitude geral de integração e padrão) se relacionam com a taxa, a magnitude e a direção da evolução de caracteres sob seleção natural (Figura 2). Para 
entender a influência da matriz-G na evolução dos fenótipos será discutido, em detalhes, o conteudo da Figura 2. Contudo, para compreender a Figura 2, convém explicar o conceito de linha de menor resistência evolutiva (Schluter, 1996; Marroig e Cheverud, 2005). Esta linha representa a dimensão multivariada de maior variância genética (ou fenotípica) de uma população. Sobre esta dimensão, a evolução é facilitada, simplesmente porque ela contém a maior parcela de variação disponível para mudanças (Schluter, 1996).

A Figura 2 apresenta as matrizes-G (elipses cinzas) de quatro populações ("a", "b", "c" e "d") em uma paisagem adaptativa (elipses pontilhadas) para dois caracteres (x e y). As quatro populações apresentam o mesmo padrão, correlação positiva entre as variáveis x e y. No entanto a população "d" apresenta magnitude geral de integração maior que as demais. Nas quatro populações o gradiente de seleção ( $\beta$ ) atua no sentido de deslocar as populações para a aptidão máxima (ver lado esquerdo da Figura 2). No entanto, as respostas evolutivas $(\Delta \bar{z})$ diferem entre as quatro populações em termos da taxa, da magnitude e da direção da evolução (ver lado direito da Figura 2). As populações "a", "b" e "d" respondem de forma alinhada a pressão de seleção, ou seja, na mesma direção dela. Repare, no entanto, que a taxa e a magnitude das mudanças entre as gerações variam entre as populações. A população "d" evolui de forma mais rápida, pois apresenta grande parte da variação genética alinhada à direção da seleção. A população "a" evolui de forma um pouco mais lenta. Embora a direção da seleção seja a mesma da linha de menor resistência evolutiva, essa contém menos variação do que na população "d". A população "b", evolui de forma mais lenta do que as outras duas, pois é o seu segundo eixo de maior variação que está alinhado a direção da seleção e ele contém menos variação que o eixo de maior variação das outras duas populações. Por outro lado, a população "c" evolui por algumas gerações de forma curvilinea e não alinhada a pressão de seleção. Além disso, a magnitude de 
mudança nas médias dos caracteres variam entre as gerações. Isso porque no início a população respondeu no sentido da linha de menor resistência evolutiva, apesar da seleção ser em outra direção, e consequentemente evoluiu de forma rápida. Após algumas gerações, a média da população foi alterada de forma que o segundo eixo de maior variação passou a estar alinhado à direção de seleção. Nesse novo cenário, a evolução ocorreu de maneira alinhada à pressão de seleção, mas apresentou magnitude menor nas mudanças entre as gerações. O exemplo apresentado na Figura 2 mostra como a interação entre a matriz-G e a seleção moldam a evolução do fenótipo médio das populações. Essa figura elucida como o padrão e a magnitude geral de integração da matriz-G podem agir restringindo ou facilitando a evolução de uma determinada população em função da pressão seletiva imposta (Marroig e Cheverud, 2010).

As características da matriz-G (ou matriz-P quando assume-se que esta é uma aproximação razoável da matriz-G) também explicitam quais caracteres de uma mesma estrutura são herdados conjuntamente (covariância elevada). A partir das relações entre os caracteres, torna-se possível compreender como caracteres evoluem de forma semelhante, mesmo que a grande maioria deles não estejam sofrendo qualquer tipo de pressão para mudança, ou mesmo que parte deles estejam sofrendo pressão para mudar em direção diferente da que eles efetivamente evoluem (Figura 1; Lande, 1979; Steppan et al., 2002; Phillips e McGuigan, 2006). Isto fica evidente ao observar o caso B da Figura 1. Suponha que ocorra seleção apenas para o carater I. Neste cenário, o carater II evoluirá de forma similar ao carater I, dado que eles são bastante correlacionados. Por outro lado, os caracteres III e IV, devido as baixas correlações com o carater I, não sofrerão mudanças necessariamente semelhantes a ele. 

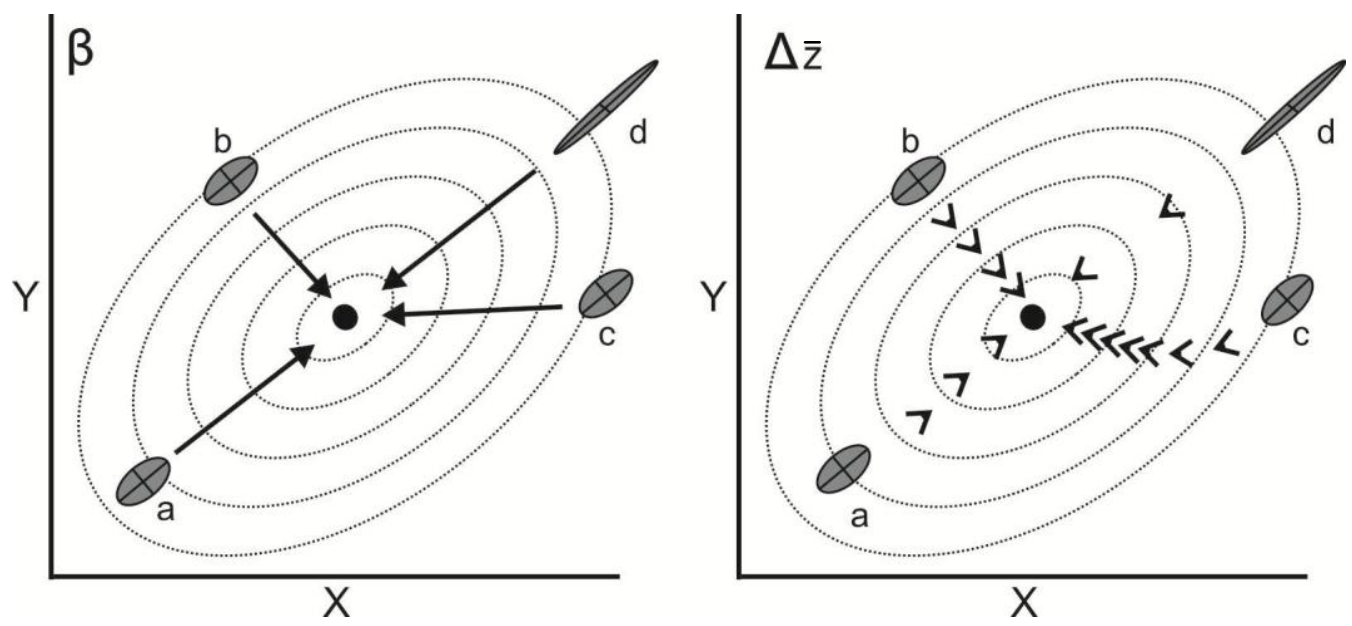

Figura 2 - Paisagem adaptativa (elipses pontilhadas) para dois caracteres hipotéticos (X e Y). Quanto mais interna for a elipse pontilhada maior é a aptidão. A aptidão máxima está representada pelo ponto preto. As matrizes-G (elipses cinzas) de quatro populações fictícias estão representadas (a, b, c, e d). O centro de cada matriz-G representa a média da população nos caracteres X e Y. Os dois eixos representados em cada matriz-G equivalem as duas dimensões de maior variância. As matrizes-G das populações a, b e c são idênticas. Do lado esquerdo observase o gradiente de seleção ( $\beta$; setas) atuando em cada população. Na direita, encontram-se as respostas evolutivas $(\Delta \bar{z}$; setas) de cada população por geração. A orientação dessas setas indica a direção da evolução. A distância entre cada seta representa a magnitude de resposta evolutiva. Adaptado de Marroig e Cheverud (2010).

Por último, as matrizes-G (ou matrizes-P) também podem contribuir para a compreensão da evolução no contexto macroevolutivo. Isso só é valido, contudo, se as matrizes das diferentes linhagens em estudo forem similares. Caso elas sejam semelhantes, torna-se possivel, por exemplo, testar se a evolução das médias dos fenótipos ocorreu através de seleção natural ou de deriva genética (Lande, 1979; Lofsvold, 1988; Ackermann e Cheverud, 2002; Marroig e Cheverud, 2004), e também facilita estudar a influência da linha de menor resistência evolutiva na diversificação das linhagens (Marroig e Cheverud, 2005).

\section{Objeto de estudo: crânio de mamíferos}

Infelizmente, não é possível estudar todos os aspectos e caracteres de um organismo, sendo algum nível de generalização exigido (Phillips e McGuigan, 2006). Para estudos envolvendo a evolução morfológica de caracteres contínuos, o crânio de mamíferos vem se 
mostrando um bom modelo (Cheverud, 1982; Marroig e Cheverud, 2001; Ackermann e Cheverud, 2004), por três motivos. Primeiramente, é uma estrutura formada por diversos ossos, o que permite representar a forma do crânio de maneira precisa através dos encontros entre suturas, ou localização de foramens, ou áreas de inserção muscular (Elbroch, 2006). Segundo, que esses ossos são majoritariamente homólogos entre praticamente todos os mamíferos, permitindo comparações em larga escala (Smith, 1996; Elbroch, 2006). Terceiro, seu desenvolvimento é complexo e as funções que exerce são múltiplas. Por exemplo, alimentação, proteção do cérebro. Toda essa complexidade observada nos crânios de mamíferos, permite explorar ampla diversidade de assuntos vinculados à sua evolução (Cheverud, 1995; Ackermann e Cheverud, 2004; Marroig e Cheverud, 2005; Marroig et al., 2009; Porto et al., 2009).

Análises detalhadas sobre a evolução morfológica craniana dos mamíferos, embasadas na teoria da genética quantitativa, foram realizadas apenas com os marsupiais do novo mundo (Marsupialia; da Silva, 2010; Shirai e Marroig, 2010) e com os macacos do novo e do velho mundo (Euarchontoglires; Eutheria; Cheverud, 1995, 1996; Marroig e Cheverud, 2001, 2005, 2009, 2010; Ackermann, 2002; Marroig et al., 2004a, 2004b, 2011, 2012; Oliveira et al., 2009). Embora estudos lidando com os Xenarthra, tanto recentes quanto fósseis, sejam volumosos, abrangendo tópicos como ecologia, filogenia, taxonomia, anatomia, genética, medicina, fisiologia, desenvolvimento, história natural, parasitologia, conservação, evolução, entre outros (Kirchheimer et al., 1972; Simpson, 1980; Eisenberg e Redford, 1999; McDonald, 2005; Gardner, 2007; Superina et al., 2009; Hautier et al., 2011; Delsuc et al., 2012; Zimbres et al., 2012), pouco se sabe sobre a evolução de sua morfologia.

O objetivo geral desta tese, portanto, foi iniciar o processo de compreensão da diversificação morfológica craniana dos Xenarthra, tanto atuais quanto extintos, através da ótica 
da genética quantitativa evolutiva comparativa. As justificativas para a execução deste trabalho foram: 1) a escassez deste tipo de estudo para os Xenarthra; e 2) o fato dos Xenarthra corresponderem a um dos quatro grandes clados dos mamíferos eutérios (Xenarthra, Afrotheria, Euarchontoglires e Laurasiatheria; Delsuc et al., 2002) de modo que as análises realizadas nesta tese ampliaram de forma estratégica o conhecimento sobre a evolução morfológica craniana dos mamíferos. Isso porque ela abordou justamente um grupo de eutérios distante do já estudado em detalhes; no caso, os primatas (Euarchontoglires).

\section{Grupo de estudo: Xenarthra}

Os Xenarthra correspondem a uma magnaordem muito peculiar de mamíferos. Estes animais compartilham: uma articulação extra nas vértebras torácicas e lombares, articulação entre o ísquio e a coluna vertebral, esqueleto apendicular bem desenvolvido, patas providas de fortes garras e metabolismo basal relativamente lento. Além disto, os dentes, quando existentes, são sem esmalte e com superfícies oclusais simples (Simpson, 1980; Eisenberg e Redford, 1999; McDonald, 2005; Superina e Loughry, 2012).

A origem dessa magnaordem é incerta, mas antecede os 60 milhões de anos e pode ter ocorrido em torno de 100 milhões de anos atrás (Simpson, 1980; Bininda-Emonds et al., 2007; Delsuc et al., 2012). Grande parte da diversificação desse grupo ocorreu na América do Sul, quando esta era isolada da América do Norte e da Antártica. Por volta de três milhões de anos atrás, desenvolveu-se uma conexão contínua de terra entre a América do Sul e a do Norte, através do soerguimento da América Central. Por consequência, ocorreu um grande intercâmbio entre as faunas autóctones dos dois subcontinentes e nessa nova configuração geológica, os Xenarthra adquiriram ampla distribuição geográfica. Eles passaram a ocorrer ao longo de todo o 
continente Americano (Simpson, 1980; Benton, 2000; McDonald, 2005), desde o Alasca (Stock, 1942) até a Patagônia (Borrero et al., 1998).

Entre o Pleistoceno e o Holoceno, um processo de extinção reduziu drasticamente a diversidade de espécies dessa magnaordem, sendo extintas principalmente as linhagens de grande porte (Simpson, 1980; Koch e Barnosky, 2006; Barnosky e Lindsey, 2010). Só no Brasil, por exemplo, ao menos 20 espécies entre preguiças, tatus e gliptodontes deixaram de existir após esta época (Cartelle, 1999; Cartelle et al., 2008), tendo algumas delas chegado a pesar mais de uma tonelada (Toledo, 1998). Atualmente, este outrora diverso grupo é representado por apenas 31 espécies (21 tatus, 6 preguiças e 4 tamanduás) que variam entre 100 g e 40 kg (Eisenberg e Redford, 1999; Delsuc et al., 2012). Além da diminuição na diversidade, a distribuição geográfica do grupo também foi restringida. Hoje em dia os Xenarthra ocorrem em praticamente toda a América do Sul, a América Central e apenas uma espécie habita a porção sul da América do Norte (Gardner, 2007). No entanto, mesmo após a extinção Quaternária, os animais ocupam uma série bem diversificada de habitats (por exemplo, floresta, savana, caatinga, campo) e apresentam hábitos alimentares que variam desde mirmecófagos especializados, passando por carnívoro-onívoros até herbívoros (Eisenberg e Redford, 1999).

Apesar da relação de parentesco dos Xenarthra com outros grupos não estar bem resolvida (Delsuc et al., 2001; Murphy et al., 2001; Bininda-Emonds et al., 2007; Goloboff et al., 2009), o monofiletismo da magnaordem é sustentado tanto por dados morfológicos (Engelman, 1985; Gaudin, 2004), quanto por moleculares (van Dijk et al., 1999; Delsuc et al., 2003; BinindaEmonds et al., 2007). Os Xenarthra podem ser subdivididos em três grupos marcadamente distintos em sua morfologia (tanto craniana quanto pós-craniana) assim como em sua ecologia (Figura 3; Paula Couto, 1979; Simpson, 1980; Gaudin, 2004; Gardner, 2007): (1) Folivora, 


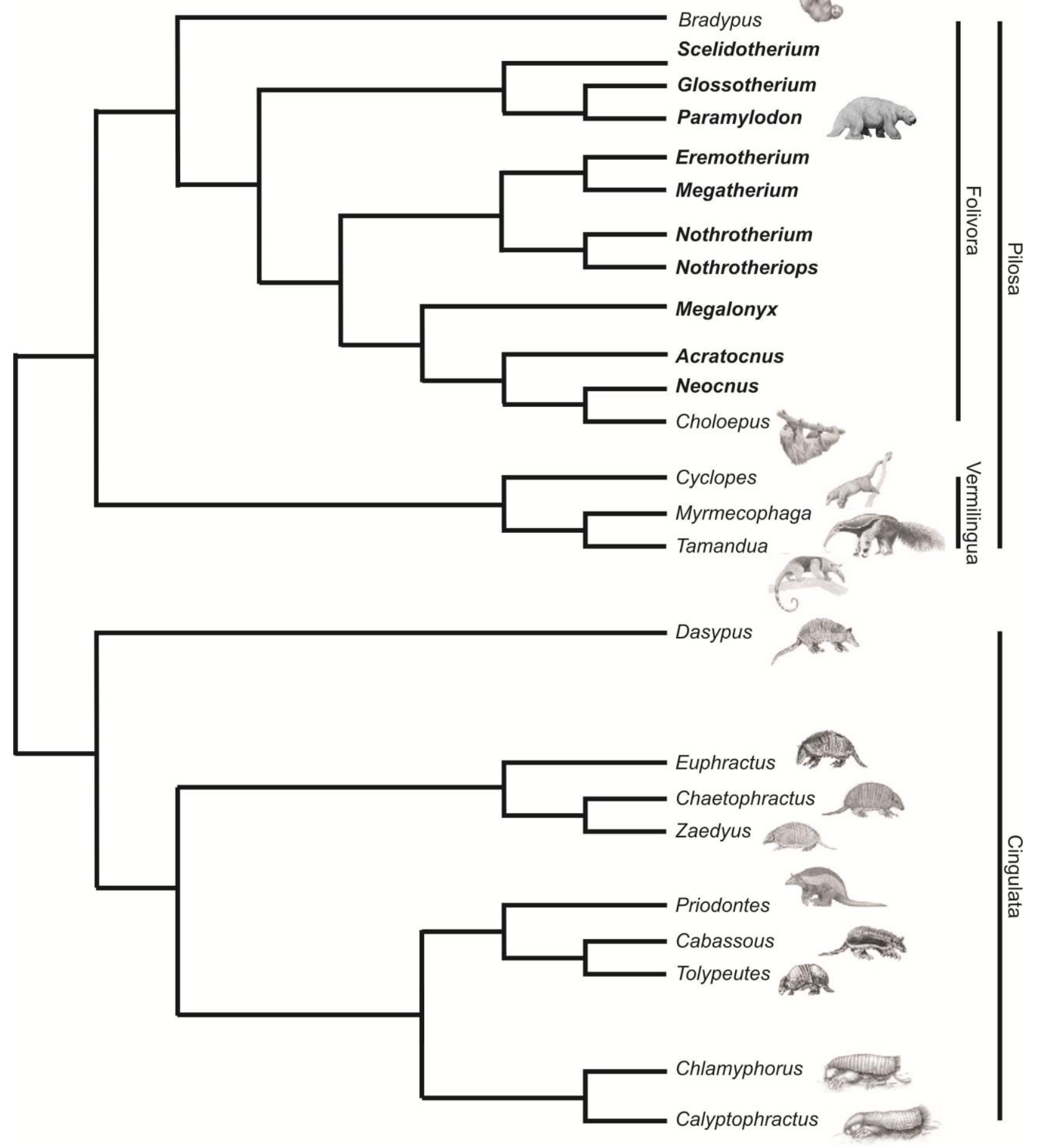

Figura 3 - Hipótese filogenética para todos os gêneros de Xenarthra atuais (segundo Delsuc et al., 2012) e para os gêneros de Folivora extintos (em negrito) analisados neste trabalho (segundo estudos morfológicos; Gaudin, 2004). Um Cingulata fóssil (Holmesina) também foi analisado neste trabalho, mas não está representado na figura por falta de consenso nas informações sobre sua relação de parentesco com os demais tatus. 
correspondente às preguiças atuais e às extintas; (2) Cingulata, grupo composto pelos tatus atuais e extintos e pelos também extintos gliptodontes; e (3) Vermilingua, representados pelos tamanduás atuais e extintos.

Os Folivora foram muito diversificados no passado, apresentando muitas espécies de preguiças terrestres, que hoje se encontram extintas. Atualmente restam apenas dois gêneros neste grupo. Ambos são arborícolas, majoritariamente folívoros e de pequeno porte: Bradypus (preguiça de três dedos; Bradypodidae) e Choloepus (preguiça de dois dedos; Megalonychidae). Dentre as preguiças extintas encontram-se as famílias Mylodontidae, Megalonychidae, Nothroteriidae e Megatheriidae (Gaudin, 2004). As espécies destas famílias tinham, muitas vezes, dimensões agigantadas (Toledo, 1998; Vizcaino et al., 2008). Acredita-se que a diversidade alimentar dos diferentes grupos extintos era ampla, podendo incluir folhas, gramíneas, frutos, tubérculos e raízes. Algumas espécies eram capazes de escavar o solo e ao menos uma espécie era semiaquática (Muizon e McDonald, 1995; Bargo et al., 2000, 2006a, 2006b; Ruez, 2005; Green, 2009).

A relação filogenética das linhagens dessa subordem, quando se inclui os fósseis, é pouco clara, apresentando análises morfológicas e moleculares não concordantes (Gaudin, 2004; Clark, 2010). Em relação aos gêneros viventes, eles são classificados como famílias diferentes (Bradypodidae e Megalonychidae) e dependendo do trabalho são alocados em posições distintas da filogenia (Redford e Eisenberg, 1992; Greenwood et al., 2001; Gaudin, 2004; Clark, 2010). De qualquer forma, independente da proximidade filogenética, os dois gêneros de preguiças atuais apresentam uma série de convergências relacionadas ao habito de vida arborícola e herbívoro (Simpson, 1980; Gaudin, 2004). 
Os Cingulata são o grupo mais antigo e que apresenta o maior número de espécies fósseis e atuais descritas. Essa ordem tem como particularidade marcante a presença de uma carapaça óssea que recobre o animal quase em sua totalidade. Todas as espécies atuais estão agrupadas na família Dasypodidae e assim como os tatus extintos apresentam bandas móveis na carapaça que recobre o corpo, o que permite maior capacidade de movimentação (Paula Couto, 1979; MöllerKrull et al., 2007). Uma característica bastante emblemática do grupo é a capacidade de escavar o subsolo com facilidade, sendo inclusive encontrados vastos vestígios de tocas de animais de tempos pretéritos, conhecidas como paleotocas e crotovinas (Buckmann et al. 2009). O peso médio das espécies atuais varia de $100 \mathrm{~g} \mathrm{a} 27 \mathrm{~kg}$. Além disto, elas apresentam relativa diversidade de hábitos alimentares (variando entre insetívoras e carnívoro-onívoras), ocupam ampla área geográfica e, consequentemente, diversos habitats do continente Americano. A única espécie da magnaordem que habita a América do Norte é o tatu galinha, Dasypus novencinctus (Redford, 1985; Eisenberg e Redford, 1999; Gardner, 2007). A relação filogenética dos gêneros atuais foi recentemente elucidada (Figura 3; Delsuc et al., 2012), mas a relação deles com os fósseis é pouco conhecida (Möller-Krull et al., 2007; Delsuc et al., 2012). As espécies atuais estão divididas em quatro grandes linhagens, Dasypodinae (Dasypus), Euphractinae (Euphractus, Chaetophractus e Zaedyus), Tolypeutinae (Priodontes, Cabassous e Tolypeutes) e Chlamyphorinae (Chlamyphorus e Calyptophractus).

Em relação aos tatus extintos, grande diversidade de espécies já foi descrita (representados principalmente por osteodermos; Cartelle e Mahecha, 1985; Paula-Couto, 1979). Espécies de tamanho muito superior à maior espécie atual foram descritas, algumas se aproximando dos 200 kg (Vizcaino et al., 1998). Ao contrário dos gêneros atuais, uma parcela 
dos grupos extintos era considerada graminívora/pastadora (Vizcaino et al., 1998; McDonald, 2005).

Entre os Cingulata, há um grupo representado apenas por animais fósseis, conhecidos como gliptodontes e agrupados na família Glyptodontidae (Paula Couto, 1979). Essa família é facilmente distinguível dos demais Cingulata pela ausência de bandas móveis na espessa carapaça óssea. Esta característica faz com que se interprete que esses animais eram muito lentos e tinham pouquíssima mobilidade (Simpson, 1980; Benton, 2000).

O conhecimento sobre os Vermilingua se restringe aos grupos atuais, dada sua escassez no registro fóssil (Paula Couto, 1979; Simpson, 1980; Eisenberg e Redford, 1999; Benton, 2000). As linhagens evolutivas viventes são representadas por três gêneros de tamanduás que variam em

peso entre 300 g e $40 \mathrm{~kg}$ e são mirmecófagos especializados. O menor gênero, Cyclopes, é arborícola. O gênero de porte intermediário, Tamandua, apresenta hábito semiarborícola. O maior de todos os tamanduás, Myrmecophaga, é estritamente terrestre. Assim como outros Xenarthra, eles apresentam capacidade de escavar o subsolo, embora ela seja menor que a dos Cingulata.

\section{Objetivos}

Este trabalho apresentou quatro objetivos, que foram abordados em capítulos distintos e apresentam-se listados abaixo:

1) Avaliar empiricamente se as matrizes-P dos diversos gêneros estudados podem ser utilizadas como substitutas das respectivas matrizes-G (uma vez que não existem matrizes-G para os Xenarthra). Outro objetivo desse capítulo foi avaliar se as matrizes-P podem ser utilizadas em estudos macroevolutivos. 
2) Testar a hipótese nula de que a diversificação morfológica craniana dos Xenarthra ocorreu unicamente através de deriva genética, sem a ação da seleção natural. Com isto buscouse determinar quais processos estiveram envolvidos na evolução morfológica dos fenótipos.

3) Compreender a estrutura modular craniana dos diferentes gêneros de Xenarthra, suas magnitudes gerais de integração e as potenciais consequências desses fatores na evolução morfológica dos Xenarthra.

4) Realizar inferências funcionais sobre os hábitos alimentares de algumas espécies extintas de Xenarthra Quaternários para contribuir com o entendimento da extinção destas linhagens.

\section{Referências}

Ackermann, R.R., 2002. Patterns of covariation in the hominoid craniofacial skeleton: implications for paleoanthropological models. Journal of Human Evolution 43, 167-187.

Ackermann, R.R., Cheverud, J.M., 2002. Discerning evolutionary processes in patterns of tamarin (genus Saguinus) craniofacial variation. American Journal of Physical Anthropology $117,260-271$.

Ackermann, R.R., Cheverud, J.M., 2004. Detecting genetic drift versus selection in human evolution. Proceedings of the National Academy of Sciences of the United States of America 101, 17946-17951.

Bargo, M.S., De Iuliis, G., Vizcaino, S.F., 2006a. Hypsodonty in Pleistocene ground sloths. Acta Palaeontologica Polonica 51, 53-61. 
Bargo, M.S., Toledo, N., Vizcaino, S.F., 2006b. Muzzle of South American Pleistocene ground sloths (Xenarthra, Tardigrada). Journal of Morphology 267, 248-263.

Bargo, M.S., Vizcaino, S.F., Archuby, F.M., Blanco, R.E., 2000. Limb bone proportions, strength and digging in some Lujanian (Late Pleistocene-Early Holocene) mylodontid ground sloths (Mammalia, Xenarthra). Journal of Vertebrate Paleontology 20, 601610.

Barnosky, A.D., Lindsey, E.L., 2010. Timing of Quaternary megafaunal extinction in South America in relation to human arrival and climate change. Quaternary International 217, $10-29$.

Benton, M.J., 2000. Vertebrate paleontology. Blackwell Science, Oxford.

Bininda-Emonds, O.R.P., Cardillo, M., Jones, K.E., MacPhee, R.D.E., Beck, R.M.D., Grenyer, R., Price, S.A., Vos, R.A., Gittleman, J.L., Purvis, A., 2007. The delayed rise of present-day mammals. Nature 446, 507-512.

Borrero, L.A., Zárate, M., Miotti, L., Massone, M., 1998. The Pleistocene - Holocene transition and human occupations in the southern cone of South America. Quaternary International 49/50, 191-199.

Buchmann, F.S., Lopes, R.P., Caron, F., 2009. Incnofósseis (paleotocas e crotovinas) atribuídos a mamíferos extintos no sudeste e sul do Brasil. Revista Brasileira de Paleontologia $12,247-256$. 
Cartelle, C., 1999. Pleistocene mammals of the cerrado and caatinga of Brazil. Em: Eisenberg, J.F.,Redford, K.H. (Ed.), Mammals of the Neotropics - The Central Neotropics. University of Chicago Press, Chicago, pp. 27-46.

Cartelle, C., De Iuliis, G., Pujos, F., 2008. A new species of Megalonychidae (Mammalia, Xenarthra) from the Quaternary of Poço Azul (Bahia, Brazil). Comptes Rendus Palevol 7, 335346.

Cartelle, C., Mahecha, G.A.B., 1985. Pampatherium paulacoutoi, uma nova espécie de tatu gigante da Bahia, Brasil (Edentata, Dasipodidae). Revista Brasileira de Zoologia 2, 229-254.

Cheverud, J.M., 1982. Phenotypic, genetic, and environmental morphological integration in the cranium. Evolution 36, 499-516.

Cheverud, J.M., 1988. A comparison of genetic and phenotypic correlations. Evolution 42, 958-968.

Cheverud, J.M., 1995. Morphological integration in the Saddle-back Tamarin (Saguinusfuscicollis) cranium. American Naturalist 145, 63-89.

Cheverud, J.M., 1996. Quantitative genetic analysis of cranial morphology in the cottontop (Saguinus oedipus) and saddle-back (S. fuscicollis) tamarins. Journal of Evolutionary Biology 9, 5-42.

Clark, A.A., 2010. "Ancient DNA from the extinct folivorous Xenarthrans, or sloths, with specific attention toward the Greater Antillean Megalonychids and the Patagonian Mylodontid, Mylodon darwinii." Unpublished PhD Thesis, McMaster University. 
da Silva, H.S., 2010. "Evolução morfológica em marsupiais (Mammalia, Dedelphimorphia) do Novo Mundo". Tese de Doutorado. Universidade de São Paulo.

Darwin, C.R., 1859. On the origin of the species by means of natural selection, or the preservation of favoured races in the struggle for life. John Murray, London.

Darwin, C.R., Wallace, A.F., 1858. On the tendecy of species to form variates; and on the perpetuation of varietes and species by natural means of selection. Journal of the Proceedings of the Linean Society of London. Zoology 3, 45-62.

Delsuc, F., Catzeflis, F.M., Stanhope, M.J., Douzery, E.J.P., 2001. The evolution of armadillos, anteaters and sloths depicted by nuclear and mitochondrial phylogenies: implications for the status of the enigmatic fossil Eurotamandua. Proceedings of the Royal Society of London Series B-Biological Sciences 268, 1605-1615.

Delsuc, F., Scally, M., Madsen, O., Stanhope, M.J., de Jong, W.W., Catzeflis, F.M., Springer, M.S., Douzery, E.J.P., 2002. Molecular phylogeny of living xenarthrans and the impact of character and taxon sampling on the placental tree rooting. Molecular Biology and Evolution 19, 1656-1671.

Delsuc, F., Stanhope, M.J., Douzery, E.J.P., 2003. Molecular systematics of armadillos (Xenarthra, Dasypodidae): contribution of maximum likelihood and Bayesian analyses of mitochondrial and nuclear genes. Molecular Phylogenetics and Evolution 28, 261-275.

Delsuc, F., Superina, M., Tilak, M.-K., Douzery, E.J.P., Hassanin, A., 2012. Molecular phylogenetics unveils the ancient evolutionary origins of the enigmatic fairy armadillos. Molecular Phylogenetics and Evolution 62, 673-680. 
Eisenberg, J.F., Redford, K.H., 1999. Mammals of the Neotropics, Volume 3: The Central Neotropics: Ecuador, Peru, Bolivia, Brazil. The University of Chicago Press, Chicago.

Elbroch, M., 2006. Animal skulls: a guide to North American species. Stackpole Books, Mechanicsburg.

Engelman, G.F., 1985. The phylogeny of the Xenarthra. Em: Montgomery, G.G. (Ed.), The evolution and ecology of armadillos sloths and vermilinguas. Smithsonian Institution, Washington DC.

Falconer, D.S., MacKay, T.F.C., 1996. Introduction to quantitative genetics. Longman, New York.

Futuyma, D.J., 1998. Evolutionary Biology. Sinauer Associates, Inc., Sunderland, Massachusetts.

Gardner, A.L., 2007. Mammals of South America: volume 1: Marsupials, Xenarthrans, Shrews, and Bats. The University of Chicago Press, Chicago and London.

Gaudin, T.J., 2004. Phylogenetic relationships among sloths (Mammalia, Xenarthra, Tardigrada): the craniodental evidence. Zoological Journal of the Linnean Society 140, 255-305.

Goloboff, P.A., Catalano, S.A., Marcos Mirande, J., Szumik, C.A., Salvador Arias, J., Källersjö, M., Farris, J.S., 2009. Phylogenetic analysis of 73060 taxa corroborates major eukaryotic groups. Cladistics 25, 211-230.

Grayson, D.K., 1984. Nineteenth-century explanations of Pleistocene extinctions: a review and analysis. Em: Martin, P.S., Klein, R.G. (Ed.), Quaternary extinctions: a Prehistoric Revolution. University of Arizona Press, Tucson, pp. 5-39. 
Green, J.L., 2009. Dental microwear in the orthodentine of the Xenarthra (Mammalia) and its use in reconstructing the palaeodiet of extinct taxa: the case study of Nothrotheriops shastensis (Xenarthra, Tardigrada, Nothrotheriidae). Zoological Journal of the Linnean Society $156,201-222$.

Greenwood, A.D., Castresana, J., Feldmaier-Fuchs, G., Pääbo, S., 2001. A molecular phylogeny of two extinct sloths. Molecular Phylogenetics and Evolution 18, 94-103.

Hagedoorn, A.L., Hagedoorn Vorstheuvel La Brand, A.C., 1921. The relative value of the processes causing evolution. The Hage: Martinus Nijhoff.

Hautier, L., Weisbecker, V., Goswami, A., Knight, F., Kardjilov, N., Asher, R.J., 2011. Skeletal ossification and sequence heterochrony in xenarthran evolution. Evolution \& Development 13, 460-476.

Huxley, R., 2007. The Great Naturalists. Thames \& Hudson in association with the Natural History Museum, London.

Kirchheimer, W.F., Storrs, E.E., Binford, C.H., 1972. Attempts to establish the Armadillo (D. novemcinctus Linn) as animal model for the study of leprosy. Histopathologic and bacteriologic post mortum findings in lepromatous leprosy in Armadillo. International Journal of Leprosy 40, 229-242.

Koch, P.L., Barnosky, A.D., 2006. Late quaternary extinctions: State of the debate(Ed.), Annual Review of Ecology Evolution and Systematics. Annual Review of Ecology Evolution and Systematics, pp. 215-250. 
Lande, R., 1979. Quantitative genetic analysis of multivariate evolution, applied to brain body size allometry. Evolution 33, 402-416.

Lofsvold, D., 1988. Quantitative genetics of morphological-differentiation in peromyscus .2. analysis of selection and drift. Evolution 42, 54-67.

Marroig, G., Cheverud, J., 2010. Size as a line of least resistance ii: direct selection on size or correlated response due to constraints? Evolution 64, 1470-1488.

Marroig, G., Cheverud, J.M., 2001. A comparison of phenotypic variation and covariation patterns and the role of phylogeny. Ecology, and ontogeny during cranial evolution of new world monkeys. Evolution 55, 2576-2600.

Marroig, G., Cheverud, J.M., 2004. Did natural selection or genetic drift produce the cranial diversification of neotropical monkeys? American Naturalist 163, 417-428.

Marroig, G., Cheverud, J.M., 2005. Size as a line of least evolutionary resistance: Diet and adaptive morphological radiation in new world monkeys. Evolution 59, 1128-1142.

Marroig, G., Cheverud, J.M., 2009. Size and shape in Callimico and Marmoset skulls: allometry and heterochrony in the morphological evolution of small anthropoids. Em: Ford, S.M., Porter, L.M.,Davis, L.C. (Ed.), The smallest anthropoids: The marmoset/callimico radiation. . Springer, New York, pp. 331-353.

Marroig, G., Cropp, S., Cheverud, J.M., 2004a. Systematics and evolution of the Jacchus group of marmosets (Platyrrhini). American Journal of Physical Anthropology 123, 11-22. 
Marroig, G., de Vivo, M., Cheverud, J.M., 2004b. Cranial evolution in sakis ( Pithecia , Platyrrhini ) II : evolutionary processes and morphological integration. Journal of Evolutionary Biology 17, 144-155.

Marroig, G., Melo, D., Porto, A., Sebastiao, H., Garcia, G., 2011. Selection response decomposition (SRD): A new tool for dissecting differences and similarities between matrices. Evolutionary Biology 38, 225-241.

Marroig, G., Melo, D.A.R., Garcia, G., 2012. Modularity, noise, and natural selection. Evolution 66, 1506-1524.

Marroig, G., Shirai, L.T., Porto, A., de Oliveira, F.B., De Conto, V., 2009. The evolution of modularity in the mammalian skull II: evolutionary consequences. Evolutionary Biology 36, 136-148.

McDonald, H.G., 2005. Paleoecology of extinct xenarthrans and the great American biotic interchange. Bulletin of the Florida Museum of Natural History 45, 313-333.

Möller-Krull, M., Delsuc, F., Churakov, G., Marker, C., Superina, M., Brosius, J., Douzery, E.J.P., Schmitz, J., 2007. Retroposed elements and their flanking regions resolve the evolutionary history of xenarthran mammals (armadillos, anteaters, and sloths). Molecular Biology and Evolution 24, 2573-2582.

Muizon, C., McDonald, H.G., 1995. An aquatic sloth from Pliocene of Peru. Nature 375, 224-227.

Murphy, W.J., Eizirik, E., Johnson, W.E., Zhang, Y.P., Ryder, O.A., O'Brien, S.J., 2001. Molecular phylogenetics and the origins of placental mammals. Nature 409, 614-618. 
Oliveira, F.B., Porto, A., Marroig, G., 2009. Covariance structure in the skull of Catarrhini: a case of pattern stasis and magnitude evolution. Journal of Human Evolution 56, 417-430.

Paula Couto, C., 1979. Tratado de Paleomastozoologia. Academia Brasileira de Ciências, Rio de Janeiro.

Phillips, P.C., McGuigan, K.L., 2006. Evolution of genetic variance-covariance structure. Em: Fox, C.W.,Wolf, J.B. (Ed.), Evolutionary Genetics: Concepts and Case Studies. Oxford University Press, Oxford, pp. 310-325.

Pigliucci, M., 2007. Do we need an extended evolutionary synthesis? Evolution 61, 27432749.

Porto, A., Oliveira, F.B.D., Shirai, L.T., Conto, V.D., Marroig, G., 2009. The evolution of modularity in the mammalian skull I: morphological integration patterns and magnitudes. Evolutionary Biology 36, 118-135.

Redford, K.H., 1985. Food habits of armadillos (Xenarthra: Dasypodidae). Em: Montgomery, G.G. (Ed.), The evolution and ecology of armadillos, sloths and vermilinguas. Smithsonian Institution Press, Washington and London, pp. 429-437.

Redford, K.H., Eisenberg, J.F., 1992. Mammals of the neotropics. The southern cone. Volume 2. Chile, Argentina, Uruguay, Paraguay. The University of Chicago Press, Chicago.

Ruez, D.R., 2005. Diet of Pleistocene Paramylodon Harlani (Xenarthra : Mylodontidae): review of methods and preliminary use of carbon isotopes. Texas Journal of Science 57, 329344. 
Schluter, D., 1996. Adaptive radiation along genetic lines of least resistance. Evolution 50, 1766-1774.

Shirai, L.T., Marroig, G., 2010. Skull modularity in neotropical marsupials and monkeys: Size variation and evolutionary constraint and flexibility. Journal of Experimental Zoology Part B-Molecular and Developmental Evolution 314B, 663-683.

Simpson, G.G., 1980. Splendid isolation: The curious history of South American mammals. Yale University Press, New Haven and London.

Smith, K.K., 1996. Integration of craniofacial structures during development in mammals. American Zoologist 36, 70-79.

Steppan, S.J., Phillips, P.C., Houle, D., 2002. Comparative quantitative genetics: evolution of the G matrix. Trends in Ecology \& Evolution 17, 320-327.

Stock, C., 1942. A ground sloth in Alaska. Science 95, 552-553.

Superina, M., Garner, M.M., Aquilar, R.F., 2009. Health evaluation of free-ranging and captive pichis (Zaedyus pichiy; Mammalia, Dasypodidae), in Mendoza Province, Argentina. Journal of Wildlife Diseases 45, 174-183.

Superina, M., Loughry, W.J., 2012. Life on the Half-Shell: Consequences of a Carapace in the Evolution of Armadillos (Xenarthra: Cingulata). Journal of Mammalian Evolution 19, 217 224.

Toledo, P.M.d., 1998. Locomotory Patterns within the Pleistocene Sloths. Museu Paraense Emílio Goeldi Press, Belém. 
van Dijk, M.A.M., Paradis, E., Catzeflis, F., de Jong, W.W., 1999. The virtues of gaps: Xenarthran (Edentate) monophyly supported by a unique deletion in alpha A-crystallin. Systematic Biology 48, 94-106.

Vizcaino, S.F., Bargo, M.S., Farina, R.A., 2008. Form, function, and paleobiology in Xenarthrans. Em: Vizcaino, S.F.,Loughry, W.J. (Ed.), The biology of the Xenarthra. University Press of Florida, Gainesville, pp. 86-99.

Vizcaino, S.F., De Iuliis, G., Bargo, M.S., 1998. Skull shape, masticatory apparatus, and diet of Vassallia and Holmesina (Mammalia: Xenarthra: Pampatheriidae): when anatomy constrains destiny. Journal of Mammalian Evolution 5, 291-322.

Wallace, D.R., 2004. Beasts of Eden: walking whales, dawn horses, and other enigmas of mammal evolution. University of California Press, Berkeley, Los Angeles, London.

Wright, S., 1931. Evolution in Mendelian populations. Genetics 16, 0097-0159.

Zimbres, B.Q.C., Uchoa de Aquino, P.D.P., Machado, R.B., Silveira, L., Jacomo, A.T.A., Sollmann, R., Torres, N.M., Furtado, M.M., Marinho-Filho, J., 2012. Range shifts under climate change and the role of protected areas for armadillos and anteaters. Biological Conservation 152, 53-61. 


\section{Capítulo I - Padrões e magnitudes das relações morfológicas cranianas de Xenarthra atuais e extintos}

\section{Introdução}

A genética quantitativa desenvolveu o arcabouço teórico e analítico para estudar a evolução dos fenótipos determinados por diversos caracteres contínuos. O cerne desses estudos é a matriz de variância/covariância genética aditiva (matriz-G). Essa matriz descreve conjuntamente a quantidade de variação genética aditiva de cada caráter e a covariância entre os diferentes caracteres (Lande, 1979; Cheverud, 1988; Falconer e MacKay, 1996; Steppan et al., 2002). O padrão e a magnitude geral de integração da matriz-G influenciam a direção, a taxa e a magnitude da evolução sob seleção natural (ver detalhes na Introdução Geral) e deriva genética (ver Capítulo II). Por consequência, essa matriz é indispensável no entendimento da evolução dos fenótipos definidos por múltiplos caracteres contínuos (Lande, 1979; Schluter, 1996; Ackermann e Cheverud, 2002; Steppan et al., 2002; Klingenberg e Monteiro, 2005; Phillips e McGuigan, 2006; Marroig et al., 2009; Porto et al., 2009). Do ponto de vista macroevolutivo a genética quantitativa é igualmente informativa desde que as matrizes-G dos diferentes taxa em estudo sejam semelhantes ou proporcionais (Steppan et al., 2002). Neste contexto, determinar o grau de similaridade (ou proporcionalidade) entre as diversas matrizes-G em estudo é fundamental no entendimento da evolução dos fenótipos (Steppan et al., 2002).

No entanto, a matriz-G é de difícil obtenção e praticamente impossível de ser estimada para cada táxon em um estudo macroevolutivo. Uma alternativa é utilizar nas inferências evolutivas a matriz de variância/covariância fenotípica (matriz-P). Essa matriz, ao contrário da matriz-G, é relativamente simples de ser estimada. Além disso, ela é estimada com muito menos erro que a matriz-G (Cheverud, 1988; Falconer e MacKay, 1996; Steppan et al., 2002). No 
entanto, esta alternativa é válida somente se cada matriz-P for similar ou proporcional à sua respectiva matriz-G e sob a ótica macroevolutiva se as diferentes matrizes-P dos taxa forem semelhantes ou proporcionais entre si (Cheverud, 1988; Steppan et al., 2002). Para caracteres morfológicos cranianos de mamíferos, o que se observou até o momento é que as matrizes-P são relativamente proporcionais entre si e representativas das matrizes-G (Marroig e Cheverud, 2001; Oliveira et al., 2009; Porto et al., 2009; Shirai e Marroig, 2010). Contudo, não há consenso tanto teórico (Lande, 1979; Turelli, 1988; Barton e Turelli, 1989) quanto empírico (Arnold e Phillips, 1999; Marroig e Cheverud, 2001; Ackermann e Cheverud, 2002; Game e Caley, 2006) sobre a constância (similaridade ou proporcionalidade) entre as matrizes-G ou matrizes-P de diferentes taxa. Em função da falta de concordância na teoria e na prática, é fortemente recomendado que se avalie empiricamente as relações entre as matrizes-P e as matrizes-G para cada grupo estudado antes de utilizar a primeira como substituta da segunda, ou de realizar estudos macroevolutivos com aquelas (Marroig e Cheverud, 2001).

Devido à dificuldade em se obter matrizes-G, muitos grupos estudados não possuem estimativas para esse tipo de matriz (Marroig e Cheverud, 2001). Os Xenarthra, por exemplo, não apresentam matrizes-G. Em função disso, o objetivo principal desse capítulo foi, com base em uma amostra compreensiva da diversidade moderna e alguns representantes fósseis de Xenarthra, testar empiricamente as relações entre as matrizes-P dos diversos gêneros estudados. Com a comparação das diferentes matrizes-P buscou-se avaliar a possibilidade tanto de usá-las como substitutas das matrizes-G quanto de aplicá-las nos estudos macroevolutivos. Essa tarefa foi realizada observando-se o padrão de similaridade entre as diversas matrizes-P, uma para cada gênero. Se as matrizes-P dos gêneros forem similares (ou proporcionais) isso muito provavelmente se deve ao fato de elas compartilharem uma estrutura de variância/covariância 
genética aditiva (matriz-G) comum. Dado que o fenótipo é principalmente determinado pelo efeito genético aditivo somado à variação do ambiente $(\mathbf{P}=\mathbf{G}+\mathbf{E}$; Falconer e MacKay, 1996), existem duas explicações para justificar a similaridade entre as matrizes-P. A primeira delas seria que as matrizes-G seriam relativamente constantes. Logo, as semelhanças das matrizes-P seriam em função de uma base genética comum. A outra interpretação possível seria que as matrizes-G são distintas. Nesse cenário, as matrizes-E de cada gênero seriam capazes de compensar de maneira precisa os efeitos das respectivas matrizes-G de forma a sempre gerar matrizes-P com estruturas semelhantes. A segunda opção é bastante improvável (Marroig e Cheverud, 2001). Ainda mais num contexto em que se compara uma grande quantidade de taxa que apresentam uma longa história evolutiva (Marroig e Cheverud, 2001), como é o caso dos Xenarthra (Delsuc et al., 2012). Além disso, trabalhos empíricos com primatas (Cheverud, 1996) e serpentes (Arnold e Phillips, 1999) mostraram que as matrizes-E aparentemente não seriam capazes de gerar o efeito apresentado acima.

Como apresentado na Introdução Geral, a magnitude geral de integração é uma característica da matriz-G que, em associação ao padrão estrutural da matriz, pode influir na evolução do fenótipo médio. Visando melhor entender a evolução morfológica craniana dos Xenarthra, esse capítulo, além de avaliar a semelhança entre as diversas matrizes-P, teve como objetivo compreender as magnitudes gerais de integração das diferentes matrizes-P. Por último, variações no padrão e na magnitude geral de integração das matrizes-P podem estar associadas a diferentes aspectos biológicos dos taxa (Marroig e Cheverud, 2001). Será que a proximidade filogenética entre as linhagens evolutivas favorece padrões e magnitudes mais similares? Em outras palavras, grupos filogeneticamente próximos apresentam matrizes-P mais semelhantes do que grupos distantes na filogenia? Qual a influência da morfologia ou da ecologia de cada taxa 
nas suas respectivas matrizes-P? Em função dessas perguntas, também foi objetivo desse capítulo explorar a influência das semelhanças filogenéticas, morfológicas e ecológicos (dieta) entre os taxa na determinação das matrizes-P.

\section{Material e Métodos}

\section{Taxonomia}

Todas as análises empregadas nesse trabalho foram realizadas no nível taxonômico de gênero. Exceção foram os estudos do padrão de similaridade entre taxa. Esses estudos foram realizados em diferentes níveis taxonômicos, do genérico ao ordinal (gênero, subfamília, família, subordem e ordem), segundo a hierarquia apresentada na Figura 1.1. Salienta-se que essa figura segue tanto a hierarquia taxonômica quanto a filogenética. Espécies não foram consideradas unidades de trabalho devido a limitações amostrais encontradas para muitas delas. Outro fator que dificulta análises no nível específico é não existir até o momento uma filogenia neste nível para a grande maioria dos Xenarthra. A nomenclatura dos gêneros atuais seguiu a proposta de Gardner (2007). Nos níveis supragenéricos, Gardner (2007) não considerou a existência de subfamílias para Cyclopedidae, Myrmecophagidae, Bradypodidae e Megalonychidae. Para esses clados, as análises entre subfamílias foram realizadas considerando "Cyclopedinae", "Myrmecophaginae", "Bradypodinae" e "Megalonychinae" como sendo idênticas às suas respectivas famílias (Figura 1.1). Além disso, o mesmo autor também não definiu uma subordem para a ordem Cingulata. Portanto, as análises do nível familiar ao ordinal nessa ordem foram realizadas com o mesmo conjunto de dados (Figura 1.1). Em relação aos fósseis, apenas dois gêneros apresentaram quantidade mínima de espécimes para a realização das análises aqui empregadas (ver Tabela 1.1). A nomenclatura utilizada para esses gêneros e para os níveis 
supragenéricos seguiram as propostas de Gaudin (2004), McAfee (2009) e Miño-Boilini e Carlini (2009).

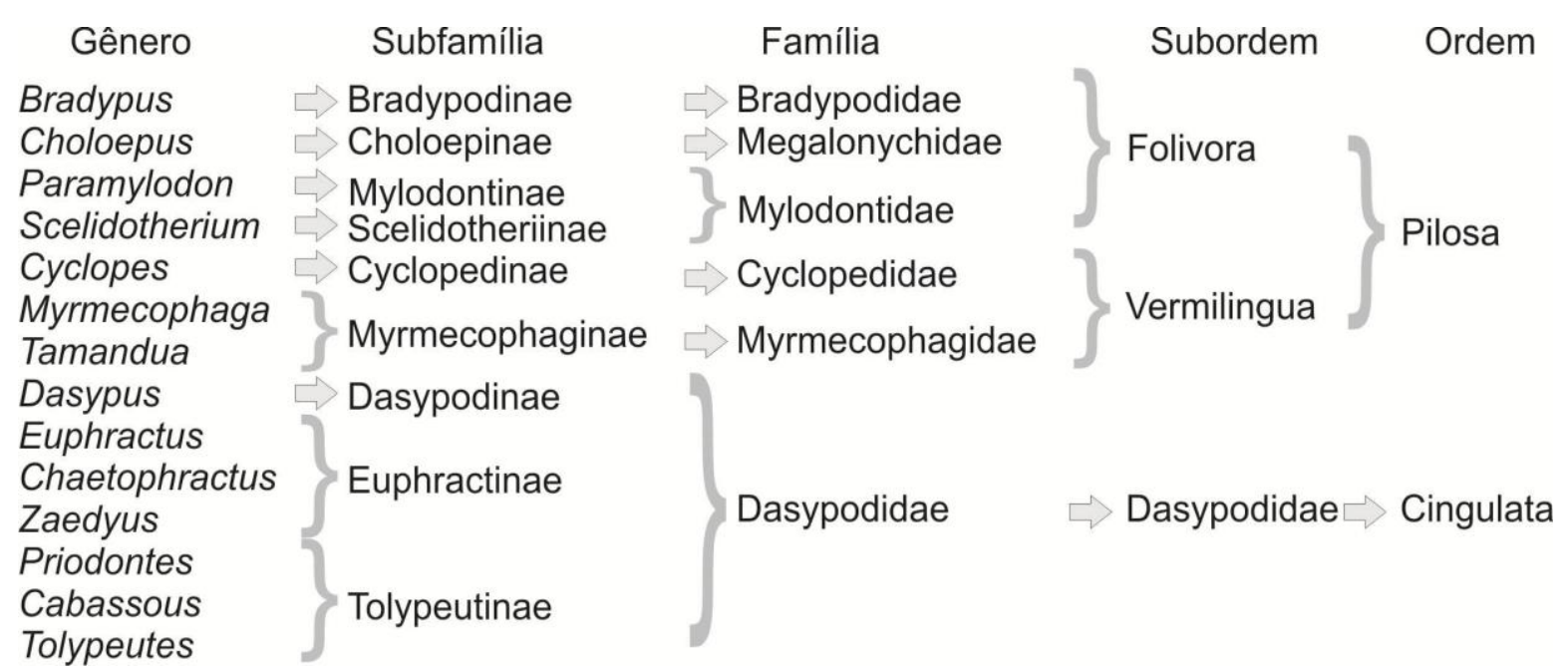

Figura 1.1 - Hierarquia taxonômica/filogenética adotada nesse trabalho. 
Tabela 1.1 - Gêneros e respectivas amostras para cada conjunto de distâncias utilizadas nesse trabalho (ver item "Conjunto de Distâncias" para maiores detalhes).

\begin{tabular}{|c|c|c|c|c|c|}
\hline Hierarquia & Taxon & $35 D^{a}$ & $32 D^{b}$ & $28 D^{c}$ & $25 D^{d}$ \\
\hline \multirow{14}{*}{ 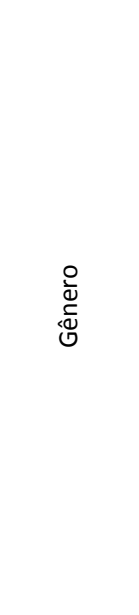 } & Bradypus & 51 & 140 & 140 & 140 \\
\hline & Choloepus & 39 & 54 & 54 & 54 \\
\hline & Cyclopes & 13 & 91 & 91 & 91 \\
\hline & Myrmecophaga & 26 & 85 & 85 & 85 \\
\hline & Tamandua & 138 & 138 & 138 & 138 \\
\hline & Dasypus & 219 & 219 & 219 & 219 \\
\hline & Euphractus & 86 & 86 & 86 & 86 \\
\hline & Chaetophractus & 92 & 92 & 92 & 92 \\
\hline & Zaedyus & 42 & 42 & 42 & 42 \\
\hline & Priondontes & 29 & 29 & 29 & 29 \\
\hline & Cabassous & 47 & 47 & 47 & 47 \\
\hline & Tolypeutes & 49 & 49 & 49 & 49 \\
\hline & Scelidotherium & - & - & - & 17 \\
\hline & Paramylodon & - & - & 32 & 37 \\
\hline \multirow{9}{*}{ 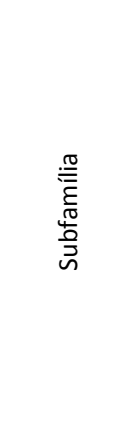 } & Bradypodinae & 51 & 140 & 140 & 140 \\
\hline & Choloepinae & 39 & 54 & 54 & 54 \\
\hline & Cyclopedinae & 13 & 91 & 91 & 91 \\
\hline & Myrmecophaginae & 164 & 164 & 164 & 164 \\
\hline & Dasypodinae & 219 & 219 & 219 & 219 \\
\hline & Euphractinae & 220 & 220 & 220 & 220 \\
\hline & Tolypeutinae & 125 & 125 & 125 & 125 \\
\hline & Scelidotheriinae & - & - & - & 17 \\
\hline & Mylodontinae & - & - & 40 & 46 \\
\hline \multirow{6}{*}{ 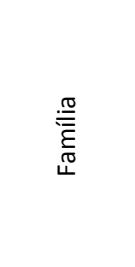 } & Bradypodidae & 51 & 140 & 140 & 140 \\
\hline & Megalonychidae & 39 & 54 & 54 & 54 \\
\hline & Cyclopedidae & 13 & 91 & 91 & 91 \\
\hline & Myrmecophagidae & 164 & 164 & 164 & 164 \\
\hline & Dasypodidae & 564 & 564 & 564 & 564 \\
\hline & Mylodontidae & - & - & 40 & 63 \\
\hline \multirow{3}{*}{ Subordem } & Folivora & 88 & 150 & 234 & 256 \\
\hline & Vermilingua & 135 & 213 & 213 & 213 \\
\hline & Cingulata & 564 & 564 & 564 & 564 \\
\hline \multirow{2}{*}{ Ordem } & Pilosa & 223 & 363 & 489 & 511 \\
\hline & Cingulata & 564 & 564 & 564 & 564 \\
\hline
\end{tabular}

a considerando as 35 distâncias.

${ }^{\mathrm{b}}$ sem considerar ISPM, ISNSL e ISPNS.

c sem considerar ISPM, ISNSL, ISPNS, PTZYGO, ZIZYGO, EAMZYGO e ZYGOTSP.

${ }^{\mathrm{d}}$ sem considerar ISPM, ISNSL, ISPNS, PTZYGO, ZIZYGO, EAMZYGO, ZYGOTSP, NSLNA, NSLZS e NSLZI. 


\section{Amostras}

Ao todo foram medidos 2667 crânios de Xenarthra, incluindo espécimes de diferentes estágios ontogenéticos. Desses, foram utilizados nessa etapa 1135 espécimes adultos pertencentes a 15 gêneros (ver Tabela 1.1 para detalhes quanto aos taxa e suas respectivas amostras). Espécimes foram considerados adultos quando o basisfenóide estava fusionado ao basioccipital e a textura dos ossos era lisa e uniforme (Cheverud, 1995; Elbroch, 2006; Porto et al., 2009). Os crânios analisados neste trabalho estão tombados nas seguintes instituições: American Museum of Natural History (AMNH, Nova York, EUA), California Academy of Science (CAS, São Francisco, EUA), Faculdad de Ciencias de la Universidad de la Republica (FC, Montevideo, Uruguai), Field Museum of Natural History (FMNH, Chicago, EUA), Museu Paraense Emílio Goeldi (MPEG, Belém, Brasil), Idaho Museum of Natural History (IMNH, Pocatelo, EUA), Los Angeles County Museum (LACM, Los Angeles, EUA), Page Museum (LACMHC, Los Angeles, EUA), Museo Argentino de Ciencias Naturales (MACN, Buenos Aires, Argentina), Museu de Ciências Naturais da PUC-MINAS (MCN, Belo Horizonte, Brasil), Museu de Ciências Naturais da Fundação Zoobotânica do Rio Grande do Sul (MCNRGS, Porto Alegre, Brasil), Museo de La Plata (MLP, La Plata, Argentina), Museo Municipal de Colonia (MMC, Colonia de Sacramento, Uruguai), Museu Nacional de Historia Natural de Montevideo (MNHN, Montevideo, Uruguai), Museu Nacional da Universidade Federal do Rio de Janeiro (MNRJ, Rio de Janeiro, Brasil), University of California Museum of Vertebrate Zoology (MVZ, Berkeley, EUA), Museu de Zoologia da Universidade de São Paulo (MZUSP, São Paulo, Brasil), Natural History Museum (NHM, Londres, Inglaterra), University of California Museum of Paleontology (UCMP, Berkeley, EUA), Florida Museum of Natural History (UF, Gainesville, EUA), Smithsonian National Museum of Natural History (USNM, Wahington DC, EUA). Além 
do material depositado nestas instituições, foram medidos seis crânios de coleções particulares (dois de Mauro Teixeira - São Paulo, Brasil e quatro de Paulo Auricchio - São Paulo, Brasil).

\section{Distâncias}

De cada crânio foram tomadas coordenadas em três dimensões de 34 pontos (Tabela 1.2; Figura 1.2; Porto et al., 2009) com um digitalizador Microscribe (MX ou MLX). Para alguns marcos anatômicos, houve variação na determinação do local de coleta do ponto em função do

grupo estudado (para detalhes ver Tabela 1.2). Vale notar que os pontos ZS e ZI em Cyclopes e ZYGO em Pilosa não puderam ser determinados pelo encontro das suturas presentes nos demais grupos devido à ausência (ou redução) de um osso. Por consequência, foram considerados como sendo apenas parcialmente homólogos aos mesmos pontos encontrados no restante dos taxa. 
Tabela 1.2 - Definição dos pontos coletados nos crânios de Xenarthra.

\begin{tabular}{|c|c|}
\hline Ponto & Descrição \\
\hline \multicolumn{2}{|l|}{ Sagitais } \\
\hline IS & extremidade anterior da sutura entre os pré-maxilares \\
\hline NSL & extremidade anterior da sutura entre os nasais \\
\hline NA & sutura entre frontais e nasais \\
\hline $\mathrm{BR}$ & sutura entre frontais e parietais \\
\hline LD & sutura entre parietais e supraoccipital \\
\hline BA & ponto sagital ventral da margem do forâmen magno \\
\hline OPI & ponto sagital dorsal da margem do forâmen magno \\
\hline PNS & extremidade posterior da sutura entre os palatinos \\
\hline \multicolumn{2}{|c|}{ Bilaterais } \\
\hline PM & extremidade latero-ventral da sutura entre pré-maxilar e maxilar \\
\hline ZS & sutura entre lacrimal, maxilar e jugal ${ }^{\mathrm{a}}$ \\
\hline PT & sutura entre frontal, parietal e esquamosal ${ }^{b}$ ou alisfenóide ${ }^{c}$ \\
\hline TSP & sutura entre esquamosal, alisfenóide e parietal ${ }^{b}$ ou frontal ${ }^{c}$ \\
\hline AS & sutura entre esquamosal, parietal e supraoccipital \\
\hline $\mathrm{ZI}$ & extremidade ventral da sutura entre maxilar e jugal $^{d}$ \\
\hline MT & extremidade ventro-posterior da sutura entre maxilar e palatino \\
\hline APET & extremidade lateral da sutura entre baseoccipital e basesfenóide \\
\hline $\mathrm{JP}$ & extremidade ventral da sutura entre baseoccipital e esquamosal no foramen jugular \\
\hline TS & extremidade posterior da sutura entre esquamosal e alisfenóide \\
\hline EAM & meato auditivo externo anterior \\
\hline ZYGO & extremidade ventral da sutura entre esquamosal e jugal ${ }^{\mathrm{e}}$ \\
\hline
\end{tabular}

${ }^{a}$ em Cyclopes, extremidade lateral da sutura entre lacrimal e maxilar.

bem Cingulata, Megalonychidae e Mylodontidae.

cem Bradypodidae e Vermilingua.

dem Cyclopes, extremidade latero-ventral do braço maxilar do arco zigomático.

em Pilosa é a extremidade anterior do braço esquamosal do arco zigomático. 

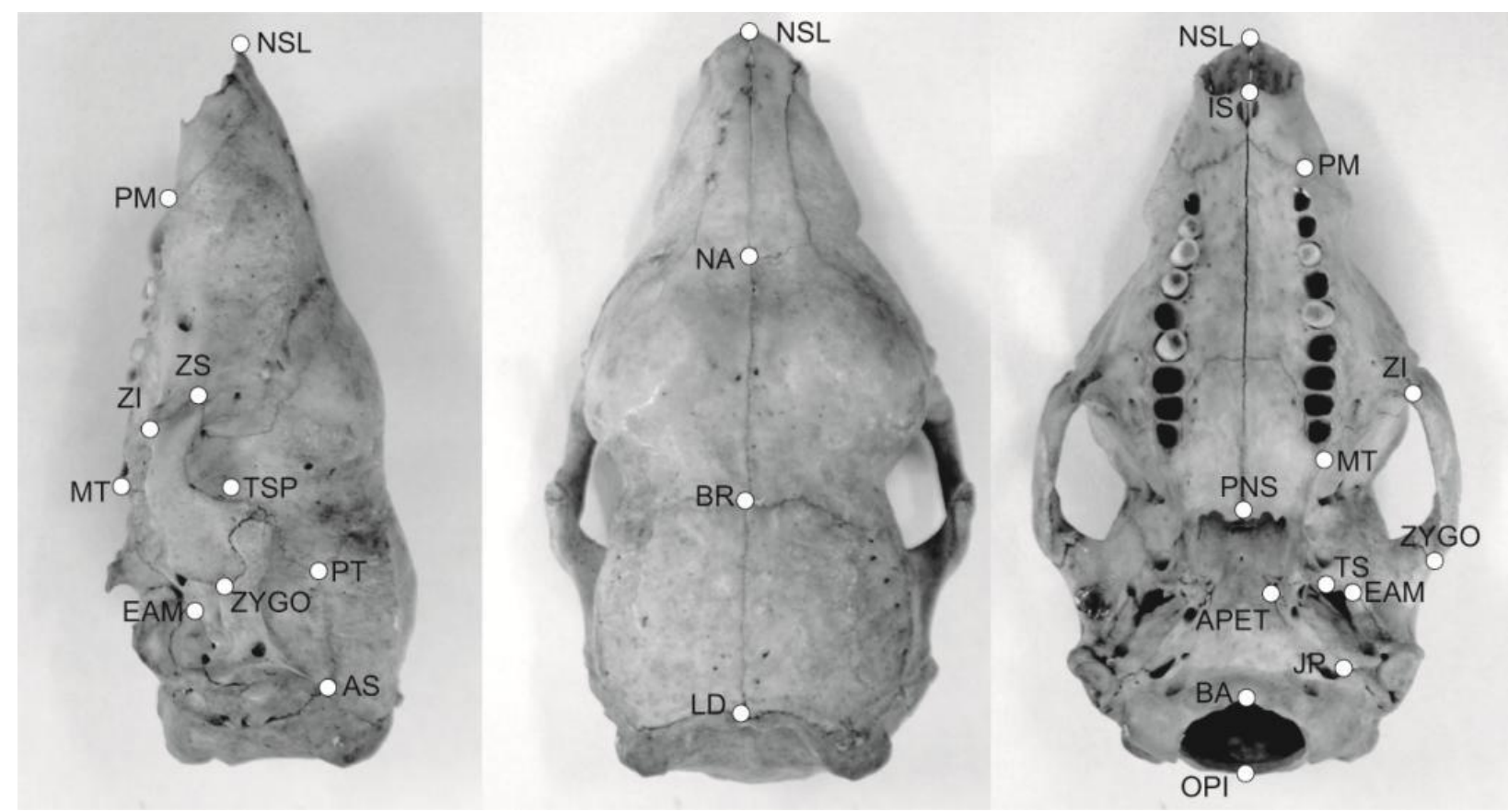

Figura 1.2 - Representação em crânio de Cabassous (tatu de rabo mole) dos pontos utilizados. Da esquerda para a direita, vistas lateral, dorsal e ventral. Na vista ventral os pontos bilaterais estão representados apenas do lado direito da imagem.

A partir do conjunto de pontos foram obtidas 35 distâncias lineares (Tabela 1.3). Para as distâncias bilaterais foi utilizada a média entre os valores de cada lado. Na eventualidade de não haver uma delas, a outra foi utilizada como representativa da distância. O conjunto de distâncias utilizado aqui teve por objetivo representar tanto a forma do crânio em sua totalidade quanto importantes relações funcionais e de desenvolvimento (Cheverud, 1982; Marroig e Cheverud, 2001). Esse mesmo conjunto de pontos vêm sendo utilizado em outros estudos com mamíferos. Isso permite a direta comparação dos resultados obtidos através dos diferentes trabalhos (Marroig e Cheverud, 2004; Oliveira et al., 2009; Porto et al., 2009; Shirai e Marroig, 2010). 
Tabela 1.3 - Distâncias euclidianas definidas a partir dos pontos medidos.

\begin{tabular}{|c|c|c|c|c|c|}
\hline Distância & Região anatômica & Disposição & Distância & Região anatômica & Disposição \\
\hline ISPM & face & bilateral & ZSZI & face & Bilateral \\
\hline ISNSL & face & unilateral & ZIMT & face & Bilateral \\
\hline ISPNS & face & unilateral & ZIZYGO & face & Bilateral \\
\hline PMZS & face & bilateral & ZITSP & face & Bilateral \\
\hline PMZI & face & bilateral & MTPNS & face & Bilateral \\
\hline PMMT & face & bilateral & PNSAPET & neurocrânio & Bilateral \\
\hline NSLNA & face & unilateral & APETBA & neurocrânio & Bilateral \\
\hline NSLZS & face & bilateral & APETTS & neurocrânio & Bilateral \\
\hline NSLZI & face & bilateral & BAEAM & neurocrânio & Bilateral \\
\hline NABR & neurocrânio & unilateral & EAMZYGO & face & Bilateral \\
\hline NAPNS & face & unilateral & ZYGOTSP & face & Bilateral \\
\hline BRPT & neurocrânio & bilateral & LDAS & neurocrânio & Bilateral \\
\hline BRAPET & neurocrânio & bilateral & BRLD & neurocrânio & Unilateral \\
\hline PTAPET & neurocrânio & bilateral & OPILD & neurocrânio & Unilateral \\
\hline PTBA & neurocrânio & bilateral & PTAS & neurocrânio & Bilateral \\
\hline PTEAM & neurocrânio & bilateral & JPAS & neurocrânio & Bilateral \\
\hline PTZYGO & face & bilateral & BAOPI & neurocrânio & Unilateral \\
\hline PTTSP & $\begin{array}{l}\text { neurocrânio e } \\
\text { face }\end{array}$ & bilateral & & & \\
\hline
\end{tabular}

Cada espécime foi medido duas vezes para viabilizar o cálculo da repetibilidade das medidas. Essa estatística descreve a proporção da variância de um caráter que ocorre entre espécimes e não intraespécimes (Lessells e Boag, 1987). Ou seja, ela mede a proporção da variância total que é devida ao erro. A variância total é a soma da variância existente entre os espécimes da população e da variância associada ao erro na coleda dos dados. Para simplicidade, a variância entre espécimes será chamada de variância real e a variância entre as duas medidas de cada espécime de variância erro. Quanto maior for a variância erro em relação à variância real, menor será a repetibilidade. As repetibilidades obtidas para cada distância de cada gênero variaram entre 0,77 e 1 com média de 0,98 e desvio padrão de 0,03 . Salienta-se que as repetibilidades mais baixas $(<0,85)$ estiveram associadas a desvios padrões pequenos nas respectivas distâncias (ver Figura 1.3 como exemplo) e não a desvios padrões grandes associados 
ao erro. Em função disso, elas não refletiram imprecisão na estimativa dessas distâncias. Isso porque a repetibilidade é a razão entre a variância real e a variação total (real + erro). Ao diminuir a variância real, mesmo mantendo a variância do erro baixa, a repetibilidade também diminui. A variância real é dependente da escala da distância. Quanto maior a média de uma determinada distância, maior será sua variância e vice-versa. As 35 distâncias medidas apresentam tamanhos absolutos diferentes, desde poucos milímetros até vários centímetros. Logo, é natural que haja grandes diferenças na variância entre as distâncias. Para deixar clara essa questão, suponha duas distâncias A e B com variâncias reais iguais a 5 e a 0,8 , respectivamente. Em ambos os casos a variância erro foi 0,05. A repetibilidade para A foi 0,99 $(5 / 5,05)$, enquanto a de B foi de $0,94(0,8 / 0,85)$.

Com base nesse raciocínio, foi considerado que o erro associado à determinação das distâncias em todos os gêneros não interferiu nas análises subsequentes. O restante das análises foi realizado com base nas médias das distâncias entre as duas mensurações.

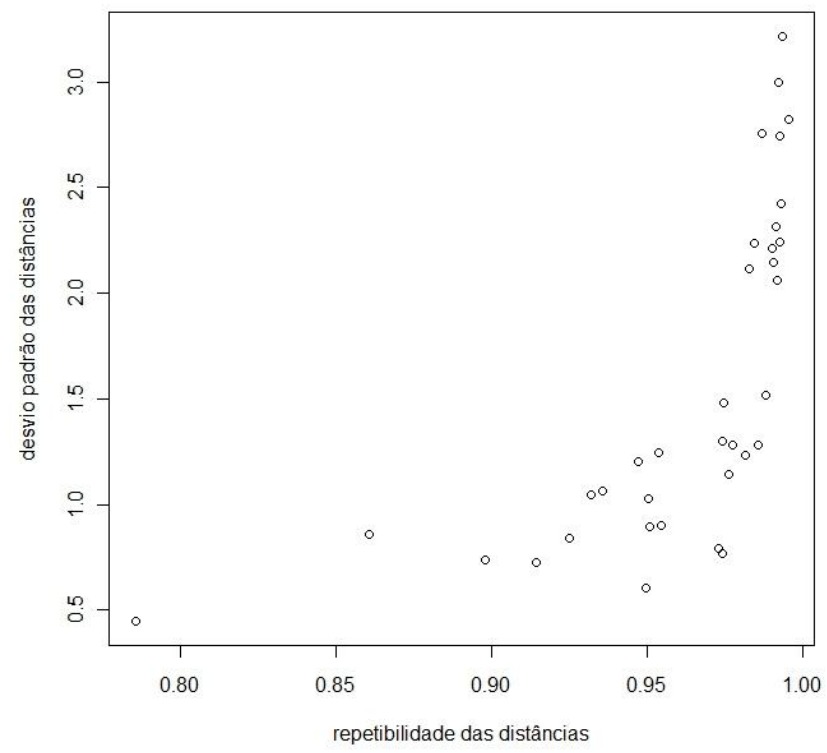

Figura 1.3 - Relação entre as repetibilidades e os desvios padrões de cada distância para o gênero Tolypeutes. 


\section{Reflexão dos pontos de distâncias bilaterais}

Os crânios medidos das espécies fósseis raramente encontravam-se íntegros. A consequência disto foi que em muitos casos não foi possível coletar os pontos necessários para o cálculo de todas as distâncias. No caso das distâncias bilaterais compostas por dois pontos fora do plano sagital (PMZS, PMZI, PMMT, PTAPET, PTEAM, PTZYGO, PTTSP, ZSZI, ZIMT, ZIZYGO, ZITSP, APETTS, EAMZYGO, ZYGOTSP, PTAS e JPAS) uma medida mitigatória

foi adotada quando o crânio só possuía um dos pontos do lado direito e o outro do lado esquerdo ou vice-versa. A estratégia utilizada foi: 1) refletir um dos pontos existentes em relação ao plano sagital do crânio. Esse ponto foi chamado de ponto refletido, em contraste ao outro que foi o ponto original; 2) a partir do par de pontos, um original e outro refletido, calcular a respectiva distância. Para tanto, com base nos pontos BR, OPI e PNS calculou-se a equação do plano sagital do crânio definida por:

$$
A x+B y+c Z+D=0
$$

onde, dados três pontos no espaço (x1, y1, z1), (x2, y2, z2), (x3, y3, z3),

$$
\begin{gathered}
A=y 1(z 2-z 3)+y 2(z 3-z 1)+y 3(z 1-z 2) \\
B=z 1(x 2-x 3)+z 2(x 3-x 1)+z 3(x 1-x 2) \\
C=x 1(y 2-y 3)+x 2(y 3-y 1)+x 3(y 1-y 2) \\
D=x 1(y 2 z 3-y 3 z 2)+x 2(y 3 z 1-y 1 z 3)+x 3(y 1 z 2-y 2 z 1)
\end{gathered}
$$

Através da equação do plano obteve-se a matriz de reflexão $\mathbf{F}$ : 


$$
\boldsymbol{F}=\left[\begin{array}{cccc}
1-2\left(A^{2} /\left(A^{2}+B^{2}+C^{2}\right)\right) & -2\left(A B /\left(A^{2}+B^{2}+C^{2}\right)\right) & -2\left(A C /\left(A^{2}+B^{2}+C^{2}\right)\right) & -2\left(A D /\left(A^{2}+B^{2}+C^{2}\right)\right) \\
-2\left(A B /\left(A^{2}+B^{2}+C^{2}\right)\right) & 1-2\left(B^{2} /\left(A^{2}+B^{2}+C^{2}\right)\right) & -2\left(B C /\left(A^{2}+B^{2}+C^{2}\right)\right) & -2\left(B D /\left(A^{2}+B^{2}+C^{2}\right)\right) \\
-2\left(A C /\left(A^{2}+B^{2}+C^{2}\right)\right) & -2\left(B C /\left(A^{2}+B^{2}+C^{2}\right)\right) & 1-2\left(C^{2} /\left(A^{2}+B^{2}+C^{2}\right)\right) & -2\left(C D /\left(A^{2}+B^{2}+C^{2}\right)\right) \\
0 & 0 & 0 & 1
\end{array}\right]
$$

Com base em $\mathbf{F}$ e na equação apresentada abaixo se obteve o vetor de coordenadas do ponto refletido. Esse vetor que foi utilizado então como o substituto do ponto original ausente.

$$
\boldsymbol{F}\left[x_{o}, y_{o}, z_{o}, 1\right]^{t}=\left[x_{r}, y_{r}, z_{r}, 1\right]^{t}
$$

onde $\mathrm{x}_{\mathrm{o}}, \mathrm{y}_{\mathrm{o}}$ e $\mathrm{z}_{\mathrm{o}}$ são as coordenadas do ponto original e $\mathrm{x}_{\mathrm{r}}, \mathrm{y}_{\mathrm{r}}$ e $\mathrm{z}_{\mathrm{r}}$ são as coordenadas do ponto refletido em relação ao plano sagital e t sobrescrito representa o vetor transposto.

Crânios não são perfeitamente simétricos. Refletir um ponto em relação ao plano sagital pode não representar de forma acurada a posição de seu ponto original. Em função disso, a qualidade das distâncias geradas através de um ponto refletido e de um original precisou ser avaliada. Neste intuito, a seguinte análise foi desenvolvida: 1) o gênero melhor amostrado de cada clado principal de Xenarthra foi selecionado; Dasypus (Cingulata), Bradypus (Folivora) e Tamandua (Vermilingua). Desses gêneros, apenas espécimes que apresentavam todos os pontos foram utilizados; 2) com base nesse conjunto de dados, calculou-se as distâncias baseadas nos pontos originais e baseadas em um ponto original e um refletido. Ou seja, quatro distâncias foram geradas. Duas denominadas originais, uma para o lado esquerdo e outra para o lado direito, e duas denominadas refletidas, sendo uma entre o ponto original direito e o refletido direito (obtido através do original esquerdo) e a outra o oposto, o original esquerdo e o refletido esquerdo. Com base nestas distâncias, realizou-se: 1) análises através de gráficos de caixa (boxplot) nas quais os resultados para as quatro distâncias foram comparados simultaneamente; 2) gráficos de dispersão entre a distância original e a refletida para ambos os lados; 3) histogramas das diferenças absolutas entre as distâncias originais e refletidas para cada lado; e 4) 
o cálculo das similaridades entre as quatro matrizes de variância/covariância e de correlação fenotípica (matriz-P) geradas a partir do conjunto de distâncias originais direita e esquerda e das refletidas também direita e esquerda. A similaridade entre as matrizes foi acessada através dos métodos das adagas casualizadas, projeção de Krzanowski e da correlação de matrizes elemento a elemento (ver detalhes no item "Similaridade entre matrizes").

\section{Conjuntos de distâncias}

Outra questão relevante é que os Pilosa (tamanduá e preguiça) possuem o premaxilar frouxamente ligado ao maxilar. Em muitos espécimes analisados esse osso não estava presente. Por consequência, ao medi-los não foi possível coletar as coordenadas do ponto IS. Em alguns gêneros isso foi um problema, uma vez que só foi possível calcular as 35 distâncias propostas para uma quantidade muito pequena de espécimes. Além disso, os crânios de animais fósseis se mostraram extremamente frágeis no braço do arco zigomático do esquamosal onde se encontra o ponto ZYGO e na extremidade anterior dos nasais onde se localiza o ponto NSL. Frente a esses problemas e devido ao princípio de utilizar somente espécimes sem dados faltantes nas análises deste trabalho optou-se por realizar todas as análises com quatro conjuntos de distâncias distintos, sendo eles: 1) com 35 distâncias, considerando todas as distâncias (para simplificar foi denominado 35D); 2) com 32 distâncias, sem considerar ISPM, ISNSL e ISPNS (32D); 3) com 28 distâncias, sem considerar ISPM, ISNSL, ISPNS, PTZYGO, ZIZYGO, EAMZYGO e ZYGOTSP (28D); e 4) com 25 distâncias, sem considerar ISPM, ISNSL, ISPNS, PTZYGO, ZIZYGO, EAMZYGO, ZYGOTSP, NSLNA, NSLZS e NSLZI (25D).

A justificativa para isso foi maximizar a amostragem em determinados gêneros (ver Tabela 1.1), possibilitando a inclusão de espécimes que não dispunham de todas as distâncias. 
Por consequência, ao elevar a amostra dos grupos estudados, a distorção das matrizes de covariância e de correlação em função de amostras pequenas foi minimizada (Marroig e Cheverud, 2001; Oliveira et al., 2009). Por outro lado, ao reduzir o numero de distâncias, para aumentar a amostra, a representação da forma do crânio foi simplificada. As regiões mais prejudicadas foram a do arco zigomático (28D e 25D) e a da face (25D). Todas as análises subsequentes foram aplicadas a esses quatro conjuntos de distâncias (35D, 32D, 28D e 25D).

\section{Estimativas das matrizes de variância/covariância e de correlação}

Antes de estimar as matrizes de variância/covariância (daqui em diante apenas covariância) e de correlação fenotípicas para cada gênero, foi necessário avaliar o efeito de fatores que poderiam atuar como fontes de variação nas médias dos caracteres e que não eram de interesse neste estudo. Ou seja, que alterariam as variâncias dos caracteres e as covariâncias e correlações entre eles. Os fatores avaliados foram sexo, espécie, variação intraespecífica em função de localidade e animal cativo ou não. A Tabela 1.4 apresenta um quadro resumo dos fatores testados e controlados para cada gênero. $\mathrm{O}$ efeito destes fatores, e das interações entre eles, sobre os caracteres foi testado através de análises de variância multivariadas (MANOVA). Análises de variância univariadas (ANOVA) também foram empregadas no sentido de complementar as MANOVAs. A análise univariada também substituiu a multivariada nos casos em que a amostra para os gêneros foram pequenas e não permitiram aplicar as MANOVAS (ver Tabela 1.4).

Os fatores foram considerados como tendo influência na média dos caracteres quando as MANOVAs foram significativas $(\mathrm{p}<0,05)$ e/ou as ANOVAs foram significativas $(\mathrm{p}<0,01)$ para mais do que dois caracteres. O critério de exigir ao menos dois caracteres com resultados 
significativos nas ANOVAs se deve ao fato que este teste é suscetível ao erro do tipo I em função da colinearidade entre os caracteres. Quando os testes multi e univariados foram significativos, os efeitos dos respectivos fatores e/ou interação entre eles foram controlados. Esse controle foi realizado através da técnica de modelos lineares generalizados (GLM). Os resíduos e graus de liberdades resultantes dos GLMs foram utilizados para estimar as matrizes de covariância e correlação.

Tabela 1.4 - Fatores testados (x) e controlados ( $)$ para cada gênero. Não houve efeito significativo nas médias dos caracteres das interações entre quaisquer fatores testados.

\begin{tabular}{|c|c|c|c|c|c|}
\hline & Espécie & Sexo & $\begin{array}{c}\text { Variação } \\
\text { intraespecífica }\end{array}$ & $\begin{array}{l}\text { Animais } \\
\text { cativos }\end{array}$ & Observação \\
\hline Zaedyus & & $x$ & & 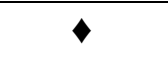 & \\
\hline Tolypeutes & $\diamond$ & $x$ & & $\diamond$ & análises realizadas par a par \\
\hline Priodontes & & $x$ & & $\bullet$ & apenas testes univariados \\
\hline Euphractus & & $x$ & & $\bullet$ & \\
\hline Dasypus & $\diamond$ & $x$ & & & \\
\hline Chaetophractus & $\bullet$ & $x$ & & & \\
\hline Cabassous & $\bullet$ & $x$ & & & \\
\hline Cyclopes & & $\bullet$ & $\diamond$ & & testado no conjunto 32D \\
\hline Myrmecophaga & & $x$ & & $\bullet$ & testado no conjunto $32 \mathrm{D}$ \\
\hline Tamandua & $\bullet$ & $x$ & & & \\
\hline Bradypus & $\bullet$ & $x$ & & & testado no conjunto 32D \\
\hline Choloepus & $\bullet$ & $\bullet$ & & $\bullet$ & $\begin{array}{l}\text { testado no conjunto 32D; } \\
\text { análises realizadas par a par }\end{array}$ \\
\hline Scelidotherium & $\bullet$ & & & & $\begin{array}{l}\text { testado no conjunto } 25 \mathrm{D} ; \\
\text { apenas testes univariados }\end{array}$ \\
\hline Paramylodon & & & & & \\
\hline
\end{tabular}




\section{Similaridade entre matrizes}

A similaridade entre duas matrizes foi determinada de maneira distinta para as matrizes de covariância e de correlação. Para a primeira, foi utilizado o método das adagas casualizadas (random skewers; RS). O RS que é apropriado para determinar a similaridade global entre duas matrizes de covariância (Cheverud, 1996; Cheverud e Marroig, 2007; Marroig et al., 2011) e se fundamenta na equação da resposta multivariada à seleção proposta por Lande (1979):

$$
\Delta \bar{z}=\boldsymbol{G} \beta
$$

onde $\Delta \bar{z}$ é o vetor que representa a resposta evolutiva nas médias dos caracteres, $\mathbf{G}$ é a matriz que representa as relações (covariâncias) entre os caracteres e $\beta$ é o vetor que representa a força da seleção direcional aplicada independentemente a cada caráter (Cheverud e Marroig, 2007).

Esse método consiste basicamente em multiplicar cada uma das matrizes-P pelos mesmos 10000 vetores aleatórios. Note que as matrizes-P substituem as matrizes-G na equação e cada vetor aleatório serve como um gradiente $\beta$. Estes vetores foram obtidos através de uma distribuição normal com média zero e desvio padrão um e com o mesmo número de elementos que o posto das matrizes. Posteriormente eles foram normalizados para uma norma de 1. Em seguida, a média das correlações entre os vetores respostas, equivalentes a $\Delta \bar{z}$ na equação, foi computada. Essa média representa a similaridade entre as matrizes. A significância estatística foi acessada produzindo-se uma distribuição empírica de correlações entre 10000 vetores aleatórios gerados da mesma forma que os utilizados nas RS e também com o mesmo número de elementos. Baseado nesta distribuição nula temos o intervalo em $95 \%$ no qual correlações ao acaso entre vetores com o mesmo número de elementos utilizados no teste RS ocorrem. Quando o valor da similaridade entre duas matrizes excedeu 95\% (ou 99\%) da distribuição empírica ao acaso, ela foi considerada significativa (Cheverud, 1996). A Tabela 1.5 apresenta os valores de 
significância para $\mathrm{p}<0,01 \mathrm{e} \mathrm{p}<0,05$ para os quatro conjuntos de distâncias utilizadas neste trabalho. Valores menores ou maiores do que os apresentados foram considerados significativos.

Tabela 1.5 - valores de significância para o método das adagas casualizadas para os quatro conjuntos de distâncias utilizados.

\begin{tabular}{ccc}
\hline & $\boldsymbol{p}<\mathbf{0 , 0 1}$ & $\mathbf{p}<\mathbf{0 , 0 5}$ \\
\hline \multirow{2}{*}{ 35D } & $>0,429$ & $>0,331$ \\
& $<-0,429$ & $<-0,331$ \\
32D & $>0,443$ & $>0,345$ \\
& $<-0,443$ & $<-0,345$ \\
28D & $>0,479$ & $>0,372$ \\
& $<-0,479$ & $<-0,372$ \\
25D & $>0,498$ & $>0,389$ \\
& $<-0,498$ & $<-0,389$ \\
\hline
\end{tabular}

Além das RS, para as matrizes de covariância utilizou-se o método da decomposição de resposta à seleção (selection response decomposition; SRD). Esse método é uma extensão das RS (Marroig et al., 2011) e permite avaliar em quais caracteres concentram-se as diferenças entre o par de matrizes comparado. Em outras palavras, a SRD detecta quais caracteres apresentam um padrão diferente entre um par de matrizes. Na SRD também se multiplicou 10000 vetores aleatórios de seleção, como os utilizados nas RS, por cada matriz comparada. Nesse método, no entanto, cada elemento do vetor resposta $(\Delta \bar{z})$ foi decomposto nos diferentes termos que o constituem, obtendo assim um novo conjunto de vetores caráter-específico. Ou seja, como cada elemento do $\Delta \bar{z}$ está relacionado a um caráter, a decomposição do mesmo em seus componentes de resposta direta (aquela devida a seleção atuando diretamente sobre ele e sua variância) e indireta à seleção (aquela devida a seleção atuando sobre os outros caracteres e a covariância destes com o caráter em questão) resulta em vetores relacionados especificamente com um determinado caráter. Em suma, na SRD para cada caráter haverá um vetor caráter-específico resultante de cada vetor aleatório e, por consequência, um total de 10000 vetores caráterespecífico por caráter. 
Cada vetor caráter-específico foi comparado entre o par de matrizes através da correlação de vetores. Em seguida, cada caráter foi comparado entre as duas matrizes através da distribuição formada pelas 10000 correlações do seu vetor caráter-específico entre o par de matrizes. Se o caráter for semelhante entre as duas matrizes quanto à resposta direta e indireta à seleção, a média da distribuição das correlações será alta e a variância dessa distribuição será pequena. Por outro lado, se o caráter diferir entre o par de matrizes, o oposto será observado; a média dessa distribuição será baixa e a variância elevada (Marroig et al., 2011).

Através do SRD, também foi possível testar estatisticamente para desvios significativos dos caracteres entre as matrizes. Para tanto, calculou-se, para cada caráter, a diferença entre a média da distribuição das correlações dos vetores caráter-específico e a média global (considerando todos os caracteres conjuntamente), denominado $\mu$ Dev. Também foi calculada a diferença entre o desvio padrão da distribuição das correlações dos vetores caráter-específico e o desvio padrão global (considerando todas as distribuições de todos os caracteres conjuntamente), denominado $\sigma$ Dev. Em seguida, foi obtido o primeiro componente principal (PC1) das duas novas variáveis ( $\mu$ Dev e $\sigma$ Dev). O PC1 que representa a distribuição conjunta delas. Os escores dos caracteres no subespaço representado pelo PC1 apresentam média zero e desvio padrão um, e o intervalo de confiança (95\%) pode ser facilmente obtido. Caracteres com valores abaixo do intervalo de confiança (95\%) foram considerados significativamente diferentes entre as matrizes (para detalhes ver Marroig et al., 2011).

Com base nos resultados do teste estatístico para detectar caracteres significativamente diferentes entre as matrizes, foram determinadas razões para cada distância e gênero, sendo: o numerador o número de vezes que um determinado gênero diferiu significativamente em relação aos demais para uma distância específica e o denominador o número total de comparações de 
cada gênero em relação aos demais para cada distância. Por exemplo, em 35D Zaedyus diferiu significativamente na distância ISPM apenas de Tolypeutes. Portanto, não foi diferente dos 10 demais gêneros. Assim, a razão para essa distância nesse gênero foi de 0,09 (1/11). Ou seja, para cada distância em cada gênero foi obtido um valor entre zero e um. O valor um indica que o respectivo gênero diferiu em relação a todos os demais quanto à determinada distância. Essa métrica foi chamada de índice de diferença no SRD.

Ainda para as matrizes de covariância, outra forma de determinação da similaridade global foi utilizada. O método da projeção de Krzanowski (KRZ; Krzanowski, 1979, Blows et al., 2004, Marroig e Cheverud, 2010). Em comparação com as RS e a SRD, a KRZ apresenta o benefício de diminuir a influência do erro associado à estimativa das matrizes na determinação do índice de similaridade, ao considerar em seus cálculos um subespaço k do espaço original. Esse subespaço $\mathrm{k}$ foi determinado por uma parcela dos primeiros componentes principais (PC) extraídos da matriz de covariância. Uma característica da análise de PC é que o erro se acumula nos últimos PCs (Hair et al., 2010). Ao exclui-los do subespaço k, portanto, retira-se uma parcela do erro associado aos dados originais. O subespaço $\mathrm{k}$ foi determinado pelos primeiros PCs da parte inteira da metade das dimensões originais subtraídas de mais uma dimensão. Por exemplo, para as matrizes 35D foram obtidos $35 \mathrm{PCs}$, sendo $\mathrm{k}=16$ (parte inteira de 35/2 -1). Os $\mathrm{k}$ PCs normalizados e ordenados em colunas das duas matrizes, denominados de $\mathbf{A}$ e $\mathbf{B}$, foram utilizados para obter a matriz-S. Essa matriz encontra os ângulos mínimos entre os vetores de A e B através da equação:

\section{$\boldsymbol{S}=\boldsymbol{A}^{t} \boldsymbol{B} \boldsymbol{B}^{t} \boldsymbol{A}$}

onde $\mathrm{t}$ sobreposto representa a matriz transposta. A soma dos autovalores de $\mathbf{S}$ dividida por $\mathrm{k}$ determinou a similaridade global entre as matrizes. Essa razão apresenta valores entre zero e um 
(Blows et al., 2004; Marroig e Cheverud, 2010). Quanto maior o valor desse índice, mais semelhantes são as matrizes.

Em relação às matrizes de correlação, a similaridade foi acessada através do método da correlação de matrizes elemento a elemento (CM; Cheverud et al., 1989). A correlação entre as matrizes par a par foi obtida através da equação abaixo (Sneath e Sokal, 1972; Cheverud et al., 1989):

$$
\tau_{A B}=\frac{\sum_{i<j}\left(a_{i j} b_{i j}\right)}{\sqrt{\sum_{i<j}\left(a_{i j} a_{i j}\right) \sum_{i<j}\left(b_{i j} b_{i j}\right)}}
$$

onde $a_{i j}$ e $b_{i j}$ representam os elementos das matrizes A e $\mathbf{B}$, respectivamente. A significância estatística foi verificada através do teste de Mantel, que consistiu em: 1) correlacionar uma das matrizes originais com 10000 matrizes geradas através da permutação de linhas e colunas da outra matriz original; 2) a correlação entre as duas matrizes originais foi comparada com a distribuição empírica de correlações gerada a partir do procedimento descrito acima. Se tal correlação excedeu 95\% (ou 99\%) da distribuição ela foi considerada significativa (Cheverud, 1988; Cheverud et al., 1989).

Além de determinar a similaridade entre as matrizes-P de covariância e correlação dos Xenarthra, essas matrizes foram comparadas com as matrizes-G dos roedores Akodon (de Conto, 2007) e Calomys (Garcia, 2010) e com as matrizes-P dos marsupiais Caluromys, Didelphis e Metachirus (da Silva, 2010) através das RS, da KRZ e da CM. A justificativa para comparar as matrizes de Xenarthra com as matrizes-P ou matrizes-G de outras ordens foi que: caso a similaridade entre essas matrizes seja elevada, a interpretação de que as matrizes-P (e matrizesG) se mantiveram constantes ao longo da evolução dos mamíferos é favorecida (Porto et al., 2009). 


\section{Repetibilidade das matrizes}

Dada a natureza finita das amostras, as matrizes de covariância e correlação sempre estarão sujeitas a erros em suas estimativas. Uma das implicações disso é que a similaridade máxima entre duas matrizes não pode ser um. Para contornar esse problema, se obteve a correlação ajustada $\left(\mathrm{r}_{\mathrm{aju}}\right)$ do valor da correlação observada $\left(\mathrm{r}_{\mathrm{obs}}\right)$ entre duas matrizes em função da correlação máxima entre elas $\left[\left(\mathrm{t}_{1} \times \mathrm{t}_{2}\right)^{1 / 2}\right]$, conforme Cheverud (1996):

$$
r_{a j u}=\frac{r_{o b s}}{\left(t_{1} t_{2}\right)^{1 / 2}}
$$

onde $t_{1}$ e $t_{2}$ são as repetibilidades das matrizes envolvidas na respectiva correlação. $\mathrm{O}$ cálculo das repetibilidades, tanto para as matrizes de covariância quanto para as de correlação, foi realizado através da autocorrelação de matrizes (Marroig e Cheverud, 2001). A partir do procedimento de reamostragem com reposição (bootstrap) dos resíduos dos GLMs dos espécimes de cada gênero, 500 novos conjuntos de dados foram gerados, com o mesmo número de espécimes que os originais. Para cada um deles determinou-se as matrizes de covariância e de correlação. Em seguida, através da RS, da KRZ e da CM foram calculadas as similaridades entre as matrizes originais e as reamostradas. A média destas similaridades determinou o valor da repetibilidade (t) para cada um dos métodos.

Para as matrizes de correlação, a repetibilidade foi alternativamente calculada através da forma analítica proposta por Cheverud (1996). Os resultados entre os dois métodos, o da simulação por reamostragem e o analítico, foram comparados. O método analítico consiste em determinar a repetibilidade $(\mathrm{t})$ através da variância nos elementos observados $\left(\mathrm{V}_{\text {obs }}\right)$ excluindo a variância devido ao erro de amostragem ( $\left.\mathrm{V}_{\text {erro}}\right)$, segundo (Cheverud, 1996; Oliveira et al., 2009): 


$$
t=\frac{V_{o b s}-V_{e r r o}}{V_{o b s}}
$$

onde $\mathrm{V}_{\text {erro }}$ é definido como o quadrado do erro padrão da correlação média dentro da matriz.

\section{Magnitude geral de integração}

O estudo da magnitude geral da integração foi conduzido utilizando as matrizes de correlação (Pavlicev et al., 2009). Ela foi medida através do método da variância relativa dos autovalores (relative variance of the eigenvalues; rVE; Pavlicev et al., 2009). O rVE, para matrizes de correlação, como as utilizadas aqui, equivale à média das correlações ao quadrado (i.e., coeficiente de determinação ${ }^{2}$; Pavlicev et al., 2009; Haber, 2011).

O rVE foi determinado segundo a equação:

$$
r V E=\frac{\operatorname{Var}(\lambda)}{\operatorname{Var}_{\max }(\lambda)}
$$

onde o numerador representa a variância dos autovalores da matriz em questão e o denominador representa a variância máxima teórica dos autovalores. Essa foi definida como sendo a variância de todos os autovalores iguais a zero, com exceção do primeiro que continha toda a variância da matriz (Pavlicev et al., 2009). Para matrizes de correlação, $\operatorname{Var}_{\max }(\lambda)$ equivale ao número total de caracteres ou posto da matriz.

\section{Distâncias filogenéticas, morfológicas e de dieta}

A proximidade filogenética e/ou a similaridade morfológica e/ou semelhanças ecológicas (dieta) entre os taxa podem ter relação com o padrão de similaridade entre eles e com a magnitude geral de integração entre os caracteres de cada um deles (Marroig e Cheverud, 2001). Para se avaliar estas questões, matrizes de distâncias filogenéticas, morfológicas e de dieta foram 
correlacionadas através da CM com as matrizes dos padrões de similaridade e com matrizes de distância das magnitudes gerais de integração entre os taxa. A significância estatística foi obtida através do teste de Mantel.

Para cada conjunto de distâncias (35D, 32D, 28D, 25D), procedimentos diferentes foram utilizados na determinação das matrizes de distâncias filogenéticas. Para 35D e 32D, em que somente gêneros atuais foram considerados, utilizou-se, para cada par de taxa, os comprimentos dos ramos correspondentes, segundo a proposta filogenética molecular de Möller-Krull e colaboradores (2007). O comprimento do ramo foi a quantidade de substituições por sítio no respectivo ramo. Para 35D e 32D também se calculou a distância filogenética considerando os comprimentos dos ramos como sendo iguais. Cada ramo da filogenia proposta por Möller-Krull e colaboradores (2007) foi considerado como tendo comprimento igual a um. A justificativa para isso foi que para 28D e 25D, que consideraram também os gêneros fósseis, não foi possível determinar as distâncias filogenéticas com base em dados moleculares. Portanto, o tamanho de todos os ramos foram considerados como arbitrários e iguais a um nesses conjuntos de distância.

Para 28D e 25D duas matrizes distintas foram calculadas. A primeira delas considerou as relações dentre os Folivora como sendo politômicas, já que hipóteses baseadas em dados morfológicos (Gaudin, 2004) e moleculares (Clark, 2010) são discordantes. A segunda foi calculada considerando os gêneros extintos aqui analisados (pertencentes à família Mylodontidae, Folivora) como sendo grupo irmão de Choloepus (Megalonychidae) e estas duas famílias sendo o grupo irmão de Bradypus. Essa proposta adveio do fato que considerando apenas os gêneros e famílias analisados neste estudo, as hipóteses filogenéticas morfológicas e moleculares são concordantes e expressam a relação acima apresentada. 
Em relação ao grau de dissimilaridade morfológica, foram computadas distâncias morfológicas. Em todos os conjuntos de distâncias (35D, 32D, 28D e 25D), foram construídas matrizes de distâncias de Mahalanobis $\left(\mathbf{D}^{2}\right)$ segundo a fórmula:

$$
\boldsymbol{D}_{i j}^{2}=\left(\mu_{i}-\mu_{j}\right) W^{-1}\left(\mu_{i}-\mu_{j}\right)
$$

onde $\mu_{\mathrm{i}}$ e $\mu_{\mathrm{j}}$ são os vetores de médias de cada caráter dos taxa comparados, $\mathbf{W}$ é a matriz de covariância ponderada pelo número de indivíduos de cada gênero entre todos os taxa em estudo, t sobrescrito representa a matriz transposta e -1 sobrescrito a inversa da matriz (Ackermann, 2002). Para os conjuntos $28 \mathrm{D}$ e $25 \mathrm{D}$ duas $\mathbf{W}$ foram computadas. Uma considerando a politomia entre Folivora e a outra com a hipótese da árvore filogenética completamente resolvida.

A matriz de distância de dieta foi gerada apenas para os gêneros atuais e é a mesma para 35D e 32D. Com base na literatura (Redford, 1985; Redford e Eisenberg, 1992; Eisenberg e Redford, 1999; Gardner, 2007) classificou-se cada gênero nas categorias alimentares folha, demais fontes vegetais, insetos, demais invertebrados, vertebrados e carne em decomposição. Cada gênero foi definido em uma ou mais categorias assumindo os seguintes estágios de utilização do recurso: não consome (0), consome pouco (1), consome majoritariamente (2) e consome exclusivamente (3) (Tabela 1.6). 
Tabela 1.6 - Categorias de dieta dos gêneros atuais de Xenarthra baseado em (Redford, 1985; Redford e Eisenberg, 1992; Eisenberg e Redford, 1999; Gardner, 2007). 0: não consome; 1: consome pouco; 2: consome majoritariamente; 3: consome exclusivamente.

\begin{tabular}{ccccccc}
\hline & Folha & $\begin{array}{c}\text { Demais fontes } \\
\text { vegetais }\end{array}$ & Inseto & $\begin{array}{c}\text { Demais } \\
\text { invertebrados }\end{array}$ & Vertebrado & $\begin{array}{c}\text { Carne em } \\
\text { decomposição }\end{array}$ \\
\hline Bradypus & 3 & 0 & 0 & 0 & 0 & 0 \\
Choloepus & 2 & 1 & 0 & 0 & 0 & 0 \\
Cyclopes & 0 & 0 & 3 & 0 & 0 & 0 \\
Myrmecophaga & 0 & 0 & 3 & 0 & 0 & 0 \\
Tamandua & 0 & 0 & 3 & 0 & 0 & 0 \\
Dasypus & 0 & 1 & 2 & 1 & 1 & 1 \\
Euphractus & 0 & 2 & 2 & 1 & 1 & 1 \\
Chaetophractus & 0 & 2 & 2 & 1 & 1 & 1 \\
Zaedyus & 0 & 2 & 2 & 1 & 1 & 1 \\
Priodontes & 0 & 0 & 3 & 0 & 0 & 0 \\
Cabassous & 0 & 0 & 3 & 0 & 0 & 0 \\
Tolypeutes & 0 & 1 & 2 & 1 & 1 & 0 \\
\hline
\end{tabular}

A distância entre cada par de gêneros foi definida através da seguinte forma: para cada categoria alimentar em que ao menos um dos gêneros tem entrada diferente de zero, foi computada a diferença absoluta entre os valores dos dois gêneros. Exceção a essa regra foi que a diferença entre zero e qualquer outro número foi considerada como máxima, ou seja, três. Em seguida, essas diferenças foram somadas. Por último, a soma foi dividida pelo número total de comparações. As distâncias entre gêneros variaram entre zero (idênticos) e três (totalmente divergentes). Para ilustrar, o cálculo da distância entre Bradypus e Choloepus é apresentado a seguir: $(|3-2|+|0-3|) / 2=2$. Note que a segunda subtração apresentada difere da esperada $(|0-1|)$, pois como o estágio de utilização de "demais fontes alimentares" em Bradypus é zero, a diferença nesse caso passa a ser 3. Salienta-se que o princípio de representar a diferença entre zero e qualquer outro número como sendo máxima foi o seguinte: fazer com que a distância entre gêneros que não compartilham nenhum item alimentar seja máxima. Utilizando essa lógica, a distância entre qualquer Folivora e qualquer Vermilingua é sempre três. Isso faz sentido dado que Folívora alimenta-se exclusivamente de material vegetal e Vermilingua exclusivamente de 
formigas e cupins. Caso não fosse utilizada essa correção, a diferença entre Bradypus e os Vermilingua seria três e entre Choloepus e Vermilingua seria dois.

As matrizes dos padrões de similaridade para todos os conjuntos de distâncias foram obtidas para as matrizes de covariância através das RS e KRZ e para as matrizes de correlação através da CM. Por último, matrizes de distância das magnitudes gerais de integração entre gêneros foram determinadas para todos os conjuntos de distâncias através da diferença absoluta dos rVEs dos taxa. As matrizes de distância filogenética, morfológica e ecológica podem ser observadas nas Tabelas A1-A3 dos anexos.

Todas as análises realizadas nesse capítulo foram desenvolvidas através do $\mathrm{R}$ ( $\mathrm{R}$ Development Core Team, 2011).

\section{Resultados}

\section{Reflexão dos pontos de distâncias bilaterais}

Os resultados obtidos para Tamandua, Dasypus e Bradypus foram semelhantes e aqui serão apresentados apenas os resultados de Tamandua. A análise dos gráficos de caixa (Figura 1.4) mostrou que as distâncias originais e refletidas não diferiram em termos populacionais. Por exemplo, as distâncias PMZS originais (DO e EO; em branco) e refletidas (DR e ER; em cinza) apresentaram gráficos semelhantes em todos os aspectos considerados, sendo eles: $1^{\circ}, 2^{\circ}$ e $3^{\circ}$ quartil e valores mínimo e máximo. O mesmo foi observado para as demais distâncias. Contudo, a semelhança populacional não garante que as distâncias originais e refletidas de cada indivíduo sejam semelhantes. Para avaliar o caráter individual das reflexões, as distâncias originais foram

plotadas em relação às refletidas. Caso elas fossem idênticas todos os pontos se alinhariam ao longo da bissetriz dos eixos X e Y de cada gráfico. 


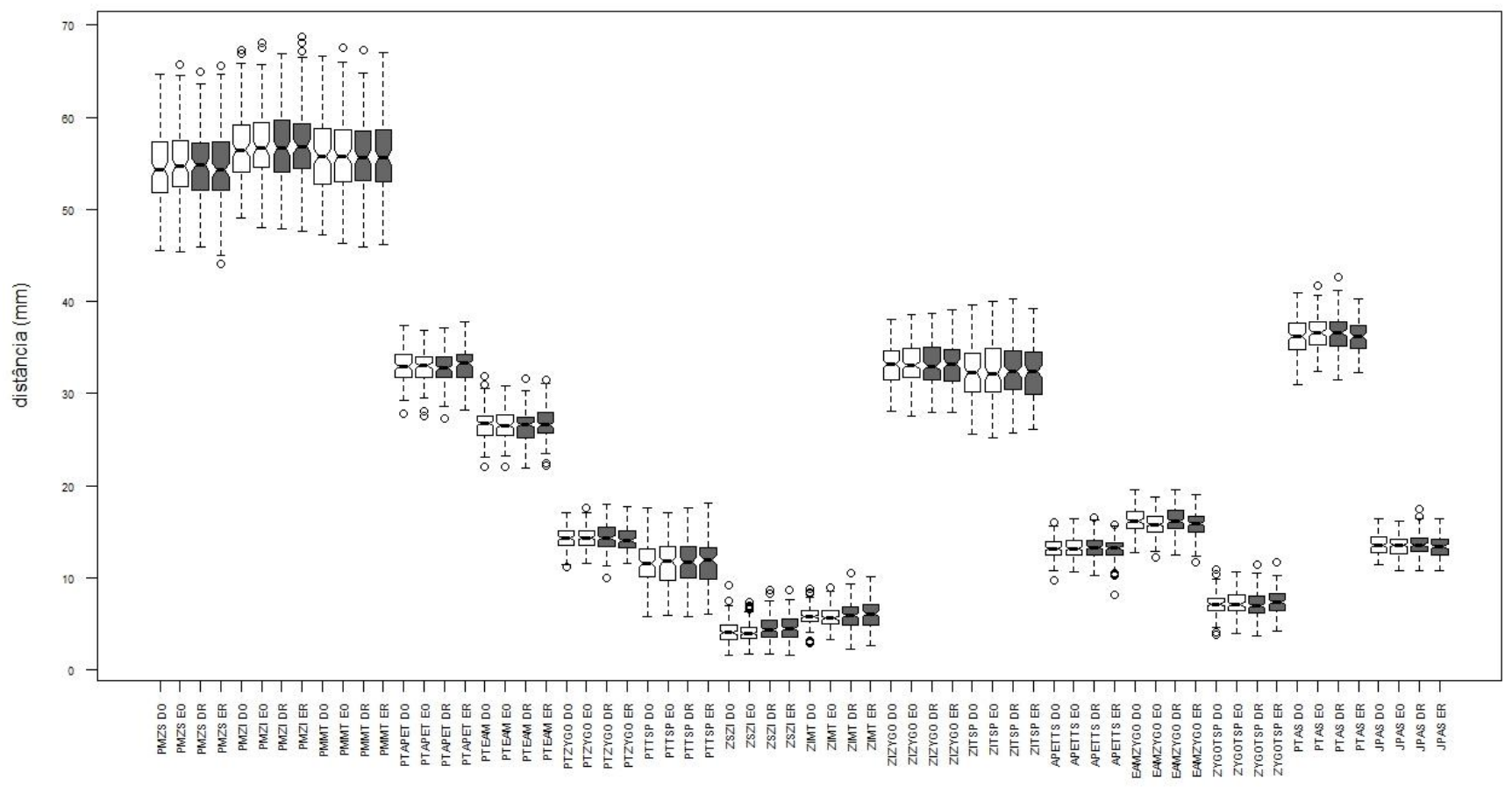

Figura 1.4 - Gráficos de caixa para cada distância original (em branco) e refletida (em cinza) de Tamandua. Distâncias originais, tanto do lado direito (DO) quanto esquerdo (EO), foram baseadas nos pontos originais. Distâncias refletidas de ambos os lados (direito, DR; esquerdo ER) foram obtidas através da reflexão de um dos pontos originais.

As Figuras 1.5 e 1.6 apresentam os conjuntos de gráficos das distâncias originais contra as refletidas para o lado direito e esquerdo, respectivamente. Observa-se que os pontos em todos os gráficos não estão perfeitamente alinhados na bissetriz. Essas diferenças implicam que em alguns indivíduos as distâncias refletidas superestimaram as distâncias originais, pontos acima da bissetriz. Enquanto que para outros elas subestimaram as distâncias originais, pontos abaixo da bissetriz. O motivo desta discrepância se deveu principalmente pela assimetria craniana associada a cada distância. A Figura 1.7, na qual foram plotadas as distâncias originais direitas e esquerdas, mostra a existência de diferenças entre os lados do crânio para cada distância.

Para quantificar quão discrepantes foram as estimativas das distâncias refletidas em comparação com as originais, foram produzidos histogramas das diferenças absolutas entre as distâncias originais e as refletidas (Figuras 1.8 e 1.9). Como pode ser observado, na grande 
maioria dos casos as diferenças foram pequenas, menores do que $1 \mathrm{~mm}$. No entanto, ocorreram vários casos com diferenças entre 1 e $2 \mathrm{~mm}$ e alguns com diferenças maiores do que $3 \mathrm{~mm}$. Inclusive, houve uma diferença que se aproximou de $5 \mathrm{~mm}$ (ZIMT). As diferenças absolutas dentro de um mesmo espécime variaram muito de distância para distância, não havendo uma clara associação entre erros maiores e determinados espécimes (Tabela 1.7). Por exemplo, o espécime 1 da Tabela 1.7 apresentou diferenças que variaram entre 0,09 e 2,56 mm. Por último, a similaridade das matrizes de covariância e correlação calculadas com base nas distâncias originais direitas e esquerdas e refletidas também de ambos os lados foi estimada. Estas se mostraram altamente semelhantes, com valores de similaridade superiores a 0,92 em todos os casos (Tabela 1.8).
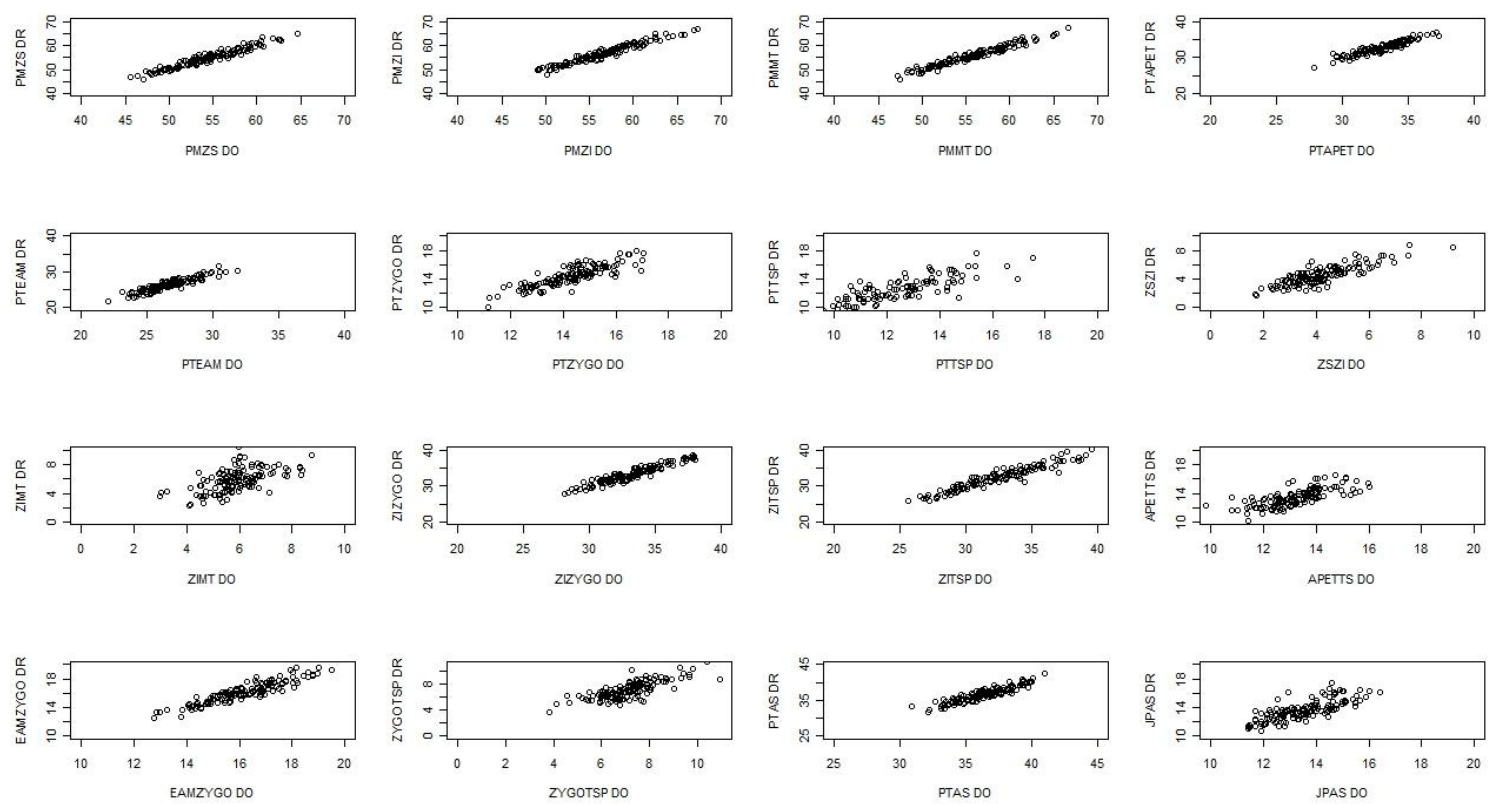

Figura 1.5 - Distâncias direitas originais (DO) plotadas em relação às distâncias direitas refletidas (DR) para todos os Tamandua analisados. As distâncias estão representadas em mm. 

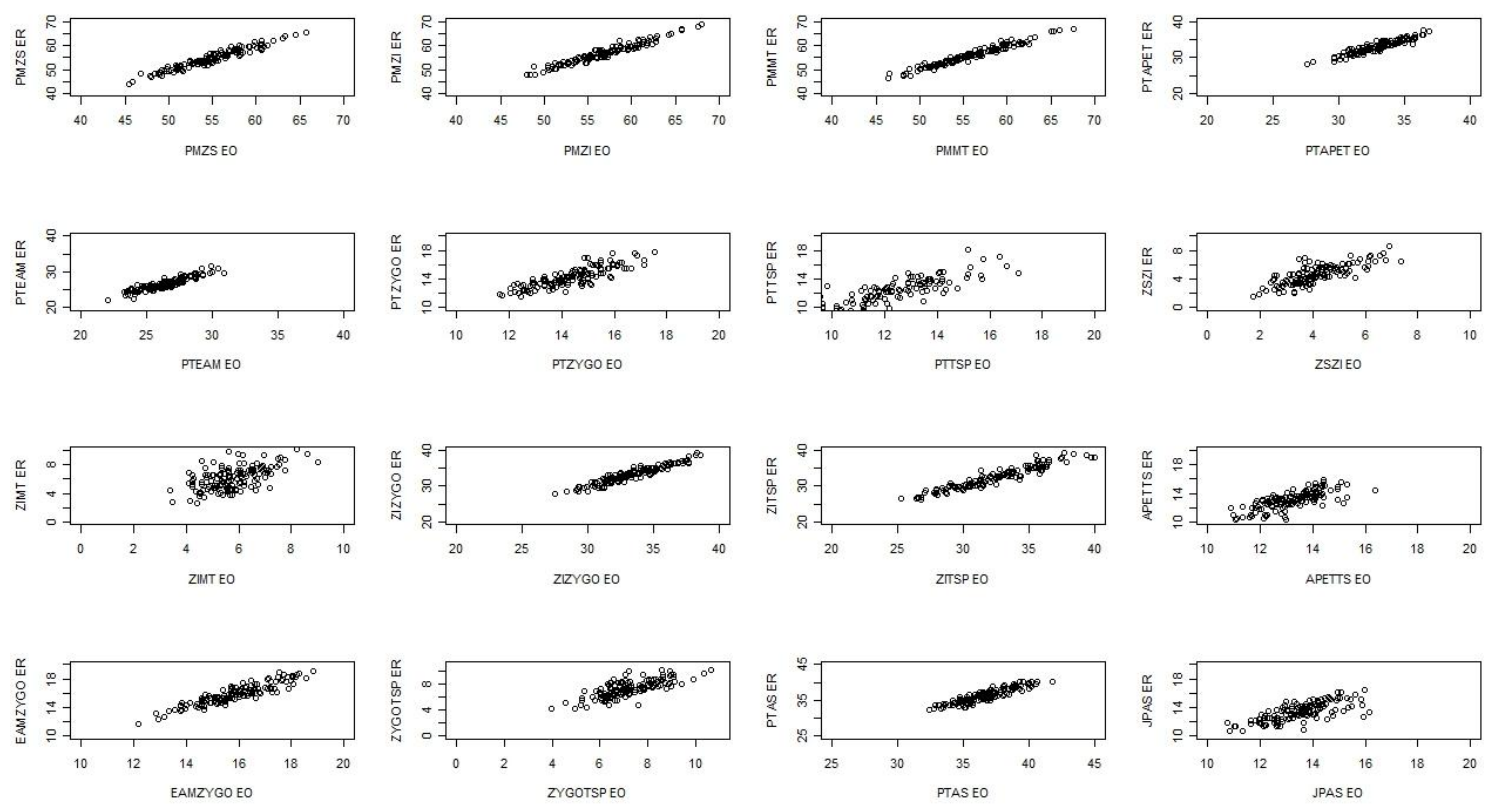

Figura 1.6 - Distâncias esquerdas originais (EO) plotadas em relação às distâncias esquerdas refletidas (ER) para todos os Tamandua analisados. As distâncias estão representadas em mm.
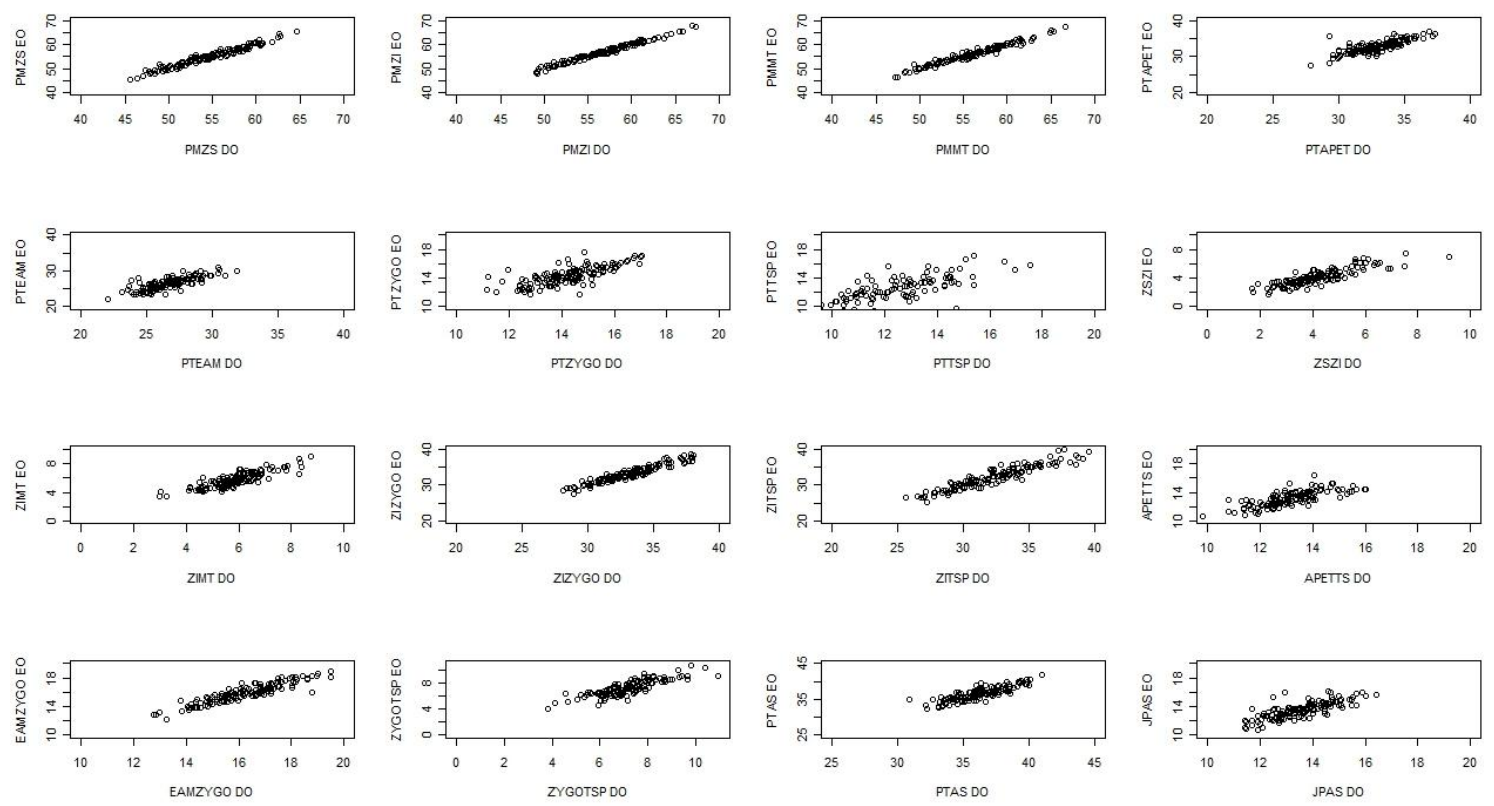

Figura 1.7 - Distâncias esquerdas originais (EO) plotadas em relação às distâncias direitas originais (DO) para todos os Tamandua analisados. As distâncias estão representadas em $\mathrm{mm}$. 


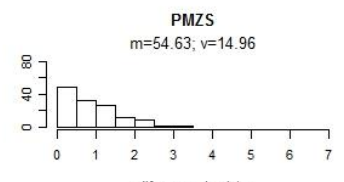

diferença absoluta

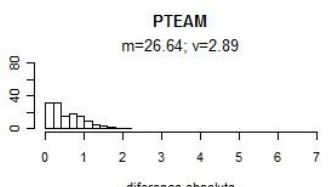

diferença absoluta

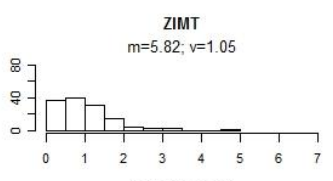

diferença absoluta

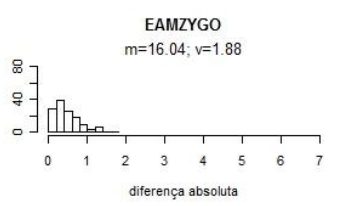

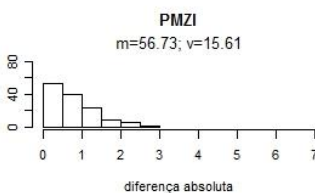
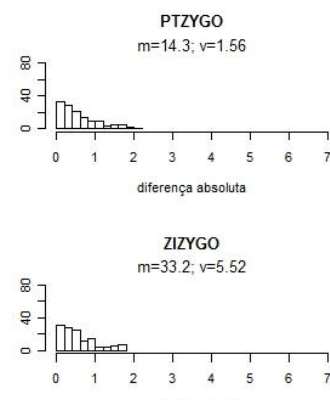

diferença absoluta

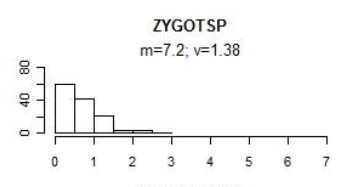

diferença absoluta
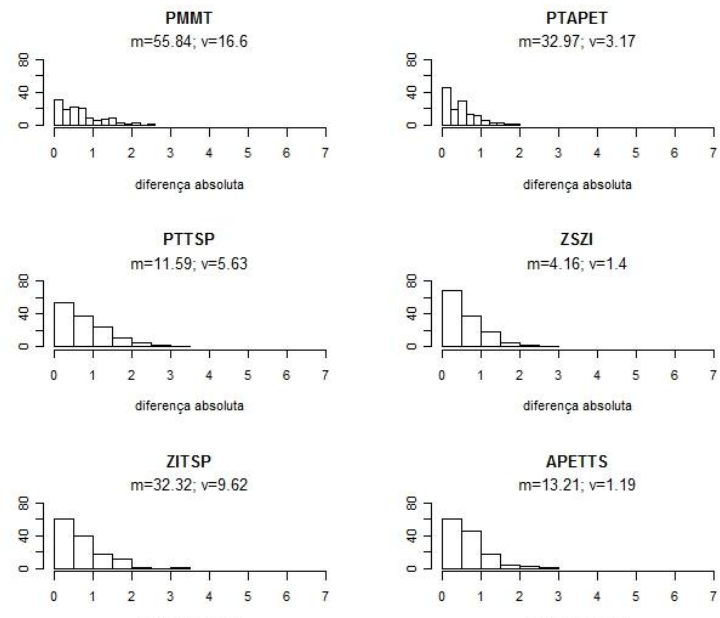

diferença absoluta

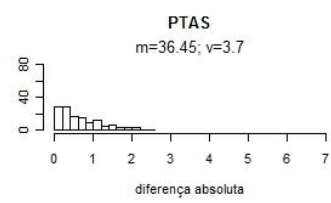

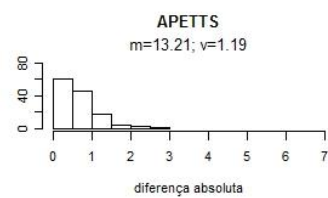

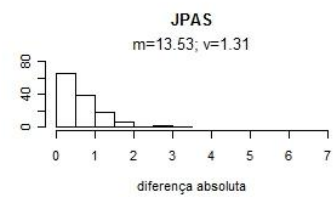

Figura 1.8 - Histogramas das diferenças absolutas entre as distâncias direitas originais e refletidas. A média (m) e a variância (v) de cada distância foram calculadas a partir das distâncias originais médias entre ambos os lados para todos os Tamandua analisados. As diferenças absolutas estão representadas em $\mathrm{mm}$.

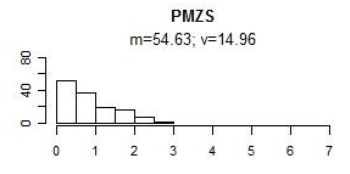

diferença absoluta

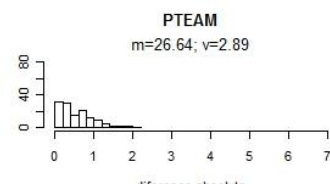

ZIMT
$\mathrm{m}=5.82 ; \mathrm{v}=1.05$

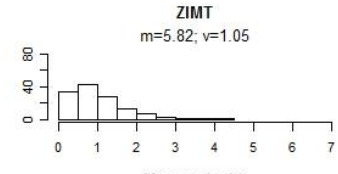

diferença absoluta

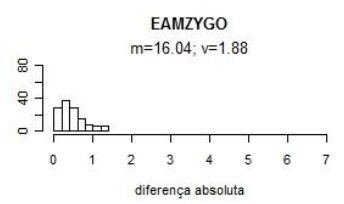

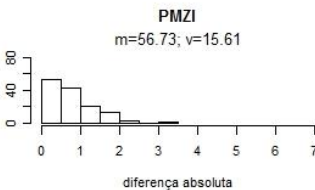
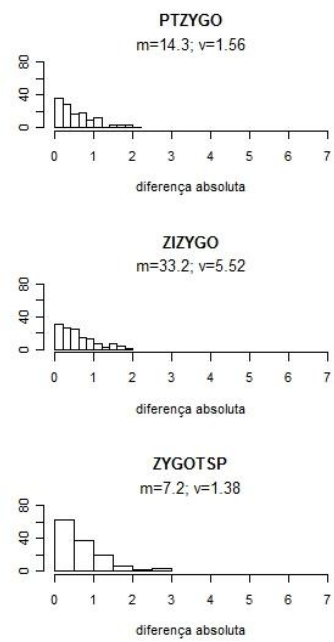
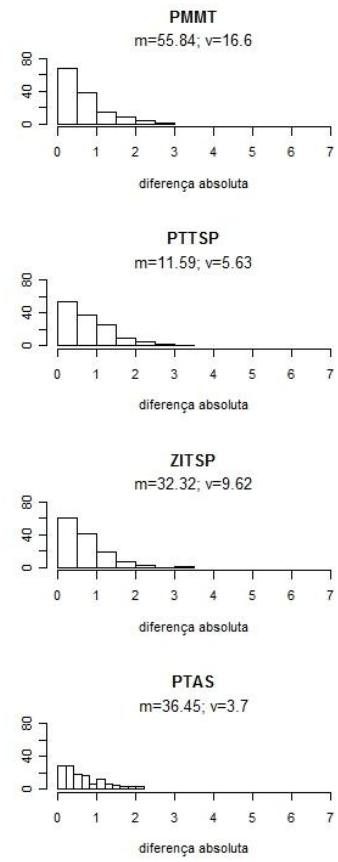
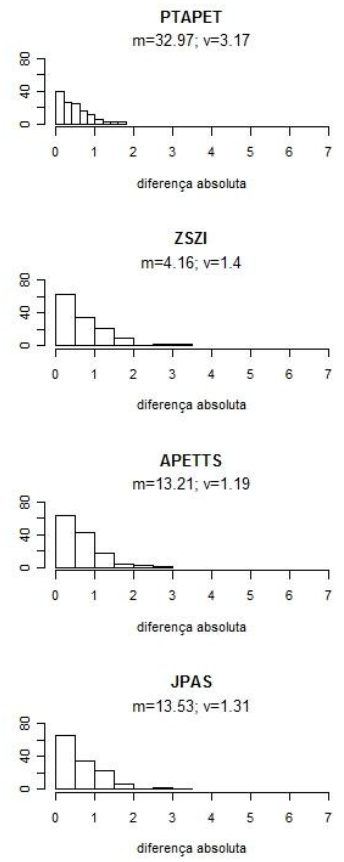

Figura 1.9 - Histogramas das diferenças absolutas entre as distâncias esquerdas originais e refletidas. A média (m) e a variância (v) de cada distância foram calculadas a partir das distâncias médias entre ambos os lados para todos os Tamandua analisados. As diferenças absolutas estão representadas em $\mathrm{mm}$. 
Tabela 1.7 - Diferenças absolutas $(\mathrm{mm})$ entre parte das distâncias originais e refletidas direitas para cinco espécimes de Tamandua.

\begin{tabular}{ccccccccccc}
\hline Espécime & PMZS & PMZI & PMMT & PTAPET & PTEAM & PTZYGO & PTTSP & ZSZI & ZIMT & ZIZYGO \\
\hline 1 & 1,32 & 0,09 & 0,67 & 2,56 & 3,3 & 0,71 & 1,15 & 0,69 & 0,47 & 0,61 \\
2 & 0,04 & 0,02 & 0,83 & 0,62 & 0,67 & 0,15 & 1,57 & 0,44 & 0,72 & 0,87 \\
3 & 0,43 & 0,43 & 0,04 & 1,76 & 2,86 & 3,07 & 2,91 & 1,01 & 0,09 & 0,81 \\
4 & 0,07 & 0,22 & 0,16 & 0,49 & 1,12 & 0,92 & 1,23 & 0,01 & 0,1 & 0,64 \\
5 & 1,37 & 0,6 & 0,07 & 1,59 & 0,17 & 0,35 & 0 & 0,76 & 0,37 & 0,72 \\
\hline
\end{tabular}

Tabela 1.8 - Média das correlações de vetores resposta das matrizes de covariância (abaixo da diagonal) e correlação entre matrizes de correlação (acima da diagonal).

\begin{tabular}{cccccc}
\hline & & \multicolumn{2}{c}{ Original } & \multicolumn{2}{c}{ Refletida } \\
& & direita & esquerda & direita & esquerda \\
\hline \multirow{2}{*}{ Original } & Direita & 1 & 0,967 & 0,937 & 0,920 \\
& Esquerda & 0,993 & 1 & 0,940 & 0,931 \\
\multirow{2}{*}{ Refletida } & Direita & 0,989 & 0,991 & 1 & 0,948 \\
& Esquerda & 0,987 & 0,987 & 0,989 & 1 \\
\hline
\end{tabular}

Embora esse capítulo tenha sido organizado em sessões distintas para os resultados e a discussão, a discussão referente à reflexão dos pontos bilaterais será apresentada aqui, pois convém mostrar ao leitor os motivos que levaram a inclusão dos espécimes fósseis com pontos refletidos no restante das análises.

Os resultados obtidos mostraram que as distâncias refletidas superestimaram ou subestimaram as distâncias originais em diferentes intensidades. $\mathrm{Na}$ maioria dos casos a diferença nas estimativas foi pequena (inferior a um $\mathrm{mm}$ ). No entanto, houve também uma parcela relativamente grande de diferenças maiores do que dois $\mathrm{mm}$ e algumas superiores a três mm. Além disso, as dimensões dos erros de estimativa das distâncias refletidas em relação às originais não aparentaram estar associadas a espécimes específicos. Ou seja, as distâncias refletidas representaram as originais com algum grau de imprecisão sendo ele difícil de determinar a priori para cada espécime e distância. No entanto, apesar dos erros envolvidos na estimativa das distâncias refletidas, seus padrões de covariância e correlação foram bastante similares aos das distâncias originais. Isso sugere que os erros associados à estimativa dessas 
distâncias não influenciam de maneira contundente as matrizes de covariância e correlação. Frente a isso, optou-se por adotar a técnica de refletir pontos para obter distâncias bilaterais para os gêneros fósseis em estudo. O intuito de utilizar espécimes com pontos refletidos foi viabilizar amostras maiores para esses gêneros. As demais análises foram realizadas considerando os animais com pontos refletidos. A Tabela 1.9 apresenta os espécimes e as respectivas distâncias que foram refletidas. Como pode ser observado, relativamente poucos espécimes e principalmente poucas distâncias foram refletidas. Em teoria, isso favorece a ideia de que a influência do erro das distâncias refletidas nas matrizes de covariância e correlação seja diminuída.

Para avaliar o efeito real da reflexão dos pontos nas análises realizadas nesse trabalho, uma última análise foi realizada: obteve-se a similaridade entre as matrizes de covariância e de correlação obtidas somente com espécimes de Paramylodon que não possuem pontos refletidos $(n=27)$ e com todos os espécimes $(n=32)$ em 32D. As comparações foram realizadas através dos métodos das RS, KRZ e CM. Os resultados obtidos foram similaridades de 0,98, 0,97 e 0,97 para cada método, respectivamente. Ou seja, a inclusão ou não dos espécimes com pontos refletidos elevam a amostra, mas não alteram a estrutura das matrizes. 
Tabela 1.9 - Espécimes utilizados nesse trabalho que tiveram distâncias refletidas substituindo as originais.

\begin{tabular}{ccc}
\hline Espécie & ID & Distâncias refletidas \\
\hline Paramylodon harlani & LACMHC645 & PMMT \\
Paramylodon harlani & LACMHC827 & PTAS \\
Paramylodon harlani & LACMHC831 & PTAS \\
Paramylodon harlani & UCMP21172 & PTZYGO, ZYGOTSP \\
Paramylodon harlani & UCMP23009 & PTAPET, PTTSP, ZYGOTSP \\
Paramylodon harlani & UCMP23006 & PTAPET \\
Paramylodon harlani & UCMP21170 & PTTSP, PTEAM \\
Paramylodon harlanil & MNH15273 & ZITSP \\
Scelidotherium bravardi & NHM37626 & ZIMT \\
Scelidotherium leptocephalum & FMNHP14274 & ZSZI, ZITSP \\
Scelidotherium leptocephalum & MLP3_408 & ZIZYGO \\
Scelidotherium leptocephalum & MACN2215 & PMZI, PMMT, ZITSP \\
Scelidotherium leptocephalum & MLP3_420 & ZIMT \\
Scelidotherium leptocephalum & MLP3_770 & PMZS, ZSZI \\
Scelidotherium leptocephalum & MLP35_III_1_1 & PMMT \\
Scelidotherium leptocephalum & NHM32995 & PMMT, PMZI, PMZS, PTEAM, JPAS \\
\hline
\end{tabular}

\section{Similaridade entre matrizes}

Em todos os conjuntos de distâncias (35D, 32D, 28D e 25D), a grande maioria das similaridades observadas para RS e KRZ foi superior a 0,6. As similaridades ajustadas foram majoritariamente superiores a 0,7 . Por outro lado, os resultados observados para CM raramente ultrapassaram 0,6 e poucos valores ajustados foram superiores a 0,7 (Figuras 1.10 e 1.11; Tabelas 1.10-1.13). De modo geral, as similaridades observadas e ajustadas para RS e KRZ foram semelhantes dentro e entre os conjuntos de distâncias. Por outro lado, as similaridades tanto observadas quanto ajustadas da CM variaram bastante dentro dos conjuntos de distância, mas foram relativamente semelhantes entre eles (Figuras 1.10 e 1.11).

Exceções às elevadas similaridades $(<0,6)$ para RS e KRZ, foram observadas para Cyclopes, Myrmecophaga, Bradypus e Choloepus em 35D, Paramylodon, Priodontes e Scelidotherium para todos os conjuntos de distâncias passíveis de análise. Para CM os valores 
mais baixos estiveram relacionados aos mesmos gêneros e conjuntos de distâncias dos outros métodos. Valores menores de similaridade nesses casos se deveram, pelo menos em parte, à relativa baixa amostragem desses gêneros nos respectivos conjuntos de distâncias. Essa afirmação fundamenta-se na correlação de moderada a alta observada em muitos casos entre o tamanho amostral e o valor médio das similaridades de cada gênero (Tabela 1.14).

Qualitativamente também foi possível observar o efeito do tamanho da amostra na estimativa das similaridades. Os gêneros que apresentaram variação do tamanho amostral entre os conjuntos de distâncias (Cyclopes, Myrmecophaga, Bradypus, Choloepus e Paramylodon; Tabela 1.1) mostraram valores distintos de similaridade em cada um desses conjuntos. Essa métrica foi elevada com o incremento da amostra. Por outro lado, os gêneros que não sofreram alterações no tamanho amostral (Tolypeutes, Cabassous, Zaedyus, Chaetophractus, Euphractus, Dasypus e Tamandua) apresentaram similaridades relativamente constantes ao longo de todos os conjuntos de distâncias. De modo geral, tanto para RS quanto para CM a maioria das similaridades em todos os conjuntos de distância (35D, 32D, 28D e 25D) foram significativas (Tabelas 1.10-1.13). Apenas dois valores de similaridade para CM em 25D não foram significativas ao nível de 5\% (Tabela 1.13). 

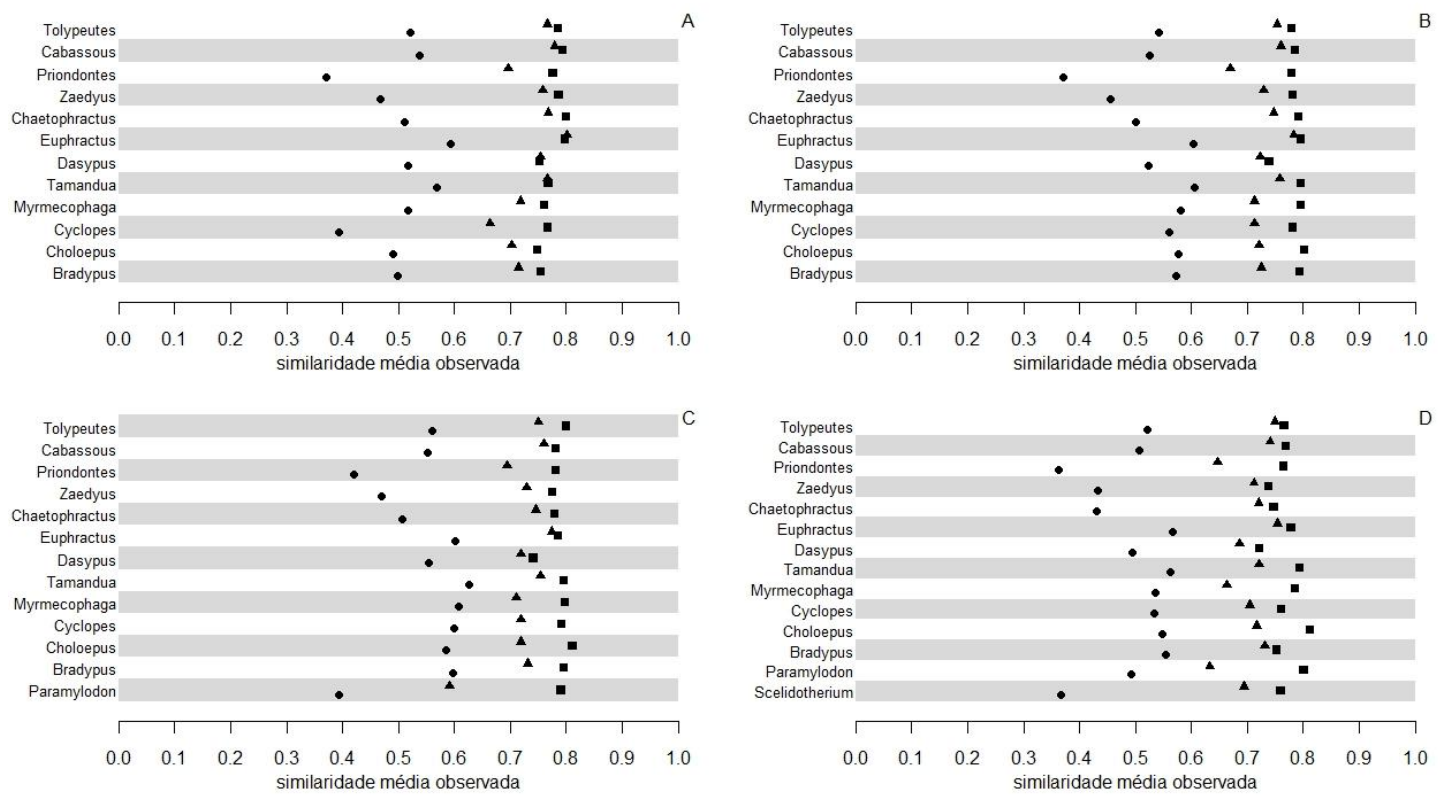

Figura 1.10 - Similaridade média observada para cada gênero através das RS (triângulo), da CM (círculo) e da KRZ (quadrado). A: 35D; B: 32D; C: 28D; D: $25 \mathrm{D}$.
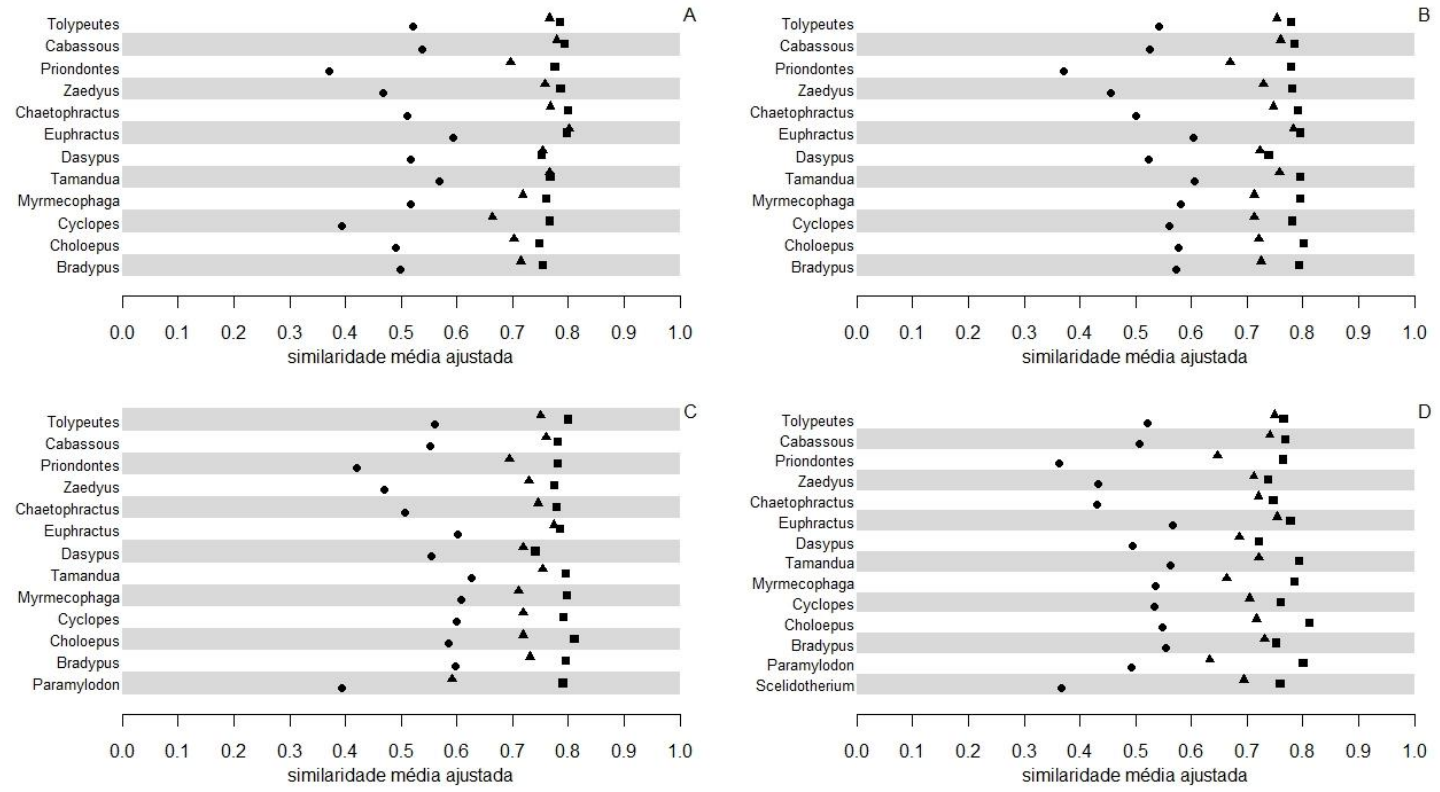

Figura 1.11 - Similaridade média ajustada para cada gênero através das RS (triângulo), da CM (círculo) e da KRZ (quadrado). A: 35D; B: 32D; C: 28D; D: $25 \mathrm{D}$. 
Tabela 1.10 - Similaridade observada (abaixo da diagonal) através das adagas casualizadas (RS), da correlação de matrizes (CM) e da projeção de Krzanowski (KRZ) para as matrizes 35D dos gêneros de Xenarthra. A diagonal contém a repetibilidade de cada matriz e acima dela estão os valores de similaridade ajustados. Valores em negrito foram significativos para $\alpha=0.01$ e valores em negrito e sublinhado foram significativos para $\alpha=0.05$. Note que para KRZ não houve teste de significância.

\begin{tabular}{|c|c|c|c|c|c|c|c|c|c|c|c|c|}
\hline RS & 1 & 2 & 3 & 4 & 5 & 6 & 7 & 8 & 9 & 10 & 11 & 12 \\
\hline 1, Zaedyus & 0,944 & 0,801 & 0,720 & 0,871 & 0,839 & 0,822 & 0,775 & 0,767 & 0,618 & 0,761 & 0,671 & 0,685 \\
\hline 2, Tolypeutes & 0,754 & 0,938 & 0,727 & 0,846 & 0,778 & 0,772 & 0,821 & 0,756 & 0,689 & 0,715 & 0,745 & 0,777 \\
\hline 3, Priodontes & 0,661 & 0,665 & 0,892 & 0,747 & 0,727 & 0,747 & 0,731 & 0,721 & 0,615 & 0,633 & 0,619 & 0,672 \\
\hline 4, Euphractus & 0,835 & 0,808 & 0,696 & 0,973 & 0,809 & 0,869 & 0,848 & 0,807 & 0,711 & 0,741 & 0,783 & 0,787 \\
\hline 5, Dasypus & 0,811 & 0,750 & 0,683 & 0,794 & 0,989 & 0,804 & 0,777 & 0,855 & 0,599 & 0,877 & 0,629 & 0,591 \\
\hline 6, Chaetophractus & 0,782 & 0,732 & 0,691 & 0,839 & 0,782 & 0,958 & 0,841 & 0,797 & 0,615 & 0,739 & 0,731 & 0,703 \\
\hline 7, Cabassous & 0,731 & 0,772 & 0,671 & 0,812 & 0,750 & 0,799 & 0,942 & 0,807 & 0,694 & 0,750 & 0,788 & 0,739 \\
\hline 8, Tamandua & 0,741 & 0,728 & 0,676 & 0,791 & 0,845 & 0,775 & 0,778 & 0,987 & 0,684 & 0,896 & 0,708 & 0,635 \\
\hline 9, Cyclopes & 0,558 & 0,619 & 0,539 & 0,651 & 0,553 & 0,558 & 0,625 & 0,630 & 0,861 & 0,622 & 0,721 & 0,737 \\
\hline 10, Myrmecophaga & 0,727 & 0,681 & 0,588 & 0,719 & 0,857 & 0,711 & 0,716 & 0,875 & 0,567 & 0,966 & 0,609 & 0,553 \\
\hline 11, Bradypus & 0,635 & 0,703 & 0,570 & 0,753 & 0,610 & 0,698 & 0,745 & 0,686 & 0,652 & 0,583 & 0,950 & 0,850 \\
\hline 12, Choloepus & 0,637 & 0,720 & 0,608 & 0,743 & 0,562 & 0,659 & 0,687 & 0,604 & 0,654 & 0,520 & 0,792 & 0,916 \\
\hline CM & 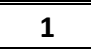 & 2 & 3 & 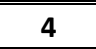 & 5 & 6 & 7 & 8 & 9 & 10 & 11 & 12 \\
\hline 1, Zaedyus & 0,88 & 0,487 & 0,418 & 0,655 & 0,579 & 0,591 & 0,495 & 0,433 & $\underline{0,263}$ & 0,434 & 0,338 & 0,449 \\
\hline 2, Tolypeutes & 0,428 & 0,876 & 0,401 & 0,617 & 0,566 & 0,465 & 0,557 & 0,573 & 0,369 & 0,451 & 0,625 & 0,625 \\
\hline 3, Priodontes & 0,358 & 0,342 & 0,833 & 0,464 & 0,414 & 0,41 & 0,484 & 0,407 & $\underline{0,239}$ & 0,317 & $\underline{0,163}$ & 0,37 \\
\hline 4, Euphractus & 0,594 & 0,559 & 0,409 & 0,934 & 0,582 & 0,694 & 0,601 & 0,633 & 0,418 & 0,605 & 0,559 & 0,688 \\
\hline 5, Dasypus & 0,532 & 0,52 & 0,371 & 0,551 & 0,962 & 0,525 & 0,572 & 0,562 & 0,382 & 0,616 & 0,483 & 0,401 \\
\hline 6, Chaetophractus & 0,527 & 0,413 & 0,356 & 0,638 & 0,49 & 0,903 & 0,675 & 0,579 & $\underline{0,282}$ & 0,461 & 0,477 & 0,468 \\
\hline 7, Cabassous & 0,432 & 0,485 & 0,411 & 0,54 & 0,522 & 0,596 & 0,865 & 0,551 & 0,405 & 0,498 & 0,593 & 0,484 \\
\hline 8, Tamandua & 0,396 & 0,524 & 0,363 & 0,597 & 0,538 & 0,537 & 0,501 & 0,954 & 0,565 & 0,747 & 0,656 & 0,538 \\
\hline 9, Cyclopes & $\underline{0,22}$ & 0,307 & $\underline{0,194}$ & 0,359 & 0,334 & $\underline{0,238}$ & 0,335 & 0,491 & 0,792 & 0,633 & 0,432 & 0,35 \\
\hline 10, Myrmecophaga & 0,378 & 0,392 & 0,269 & 0,543 & 0,561 & 0,407 & 0,43 & 0,677 & 0,523 & 0,861 & 0,526 & $\underline{0,394}$ \\
\hline 11, Bradypus & $\underline{0,303}$ & 0,56 & $\underline{0,143}$ & 0,517 & 0,453 & 0,434 & 0,528 & 0,613 & 0,368 & 0,467 & 0,916 & $\overline{0,626}$ \\
\hline 12, Choloepus & 0,392 & 0,544 & 0,315 & 0,619 & 0,366 & 0,414 & 0,419 & 0,489 & 0,29 & $\underline{0,34}$ & 0,558 & 0,866 \\
\hline KRZ & 1 & 2 & 3 & 4 & 5 & 6 & 7 & 8 & 9 & 10 & 11 & 12 \\
\hline 1, Zaedyus & 0,860 & 0,846 & 0,790 & 0,842 & 0,786 & 0,870 & 0,859 & 0,736 & 0,738 & 0,729 & 0,730 & 0,729 \\
\hline 2, Tolypeutes & 0,736 & 0,880 & 0,777 & 0,809 & 0,773 & 0,857 & 0,811 & 0,739 & 0,810 & 0,741 & 0,756 & 0,722 \\
\hline 3, Priodontes & 0,671 & 0,668 & 0,839 & 0,793 & 0,761 & 0,788 & 0,820 & 0,804 & 0,737 & 0,793 & 0,718 & 0,759 \\
\hline 4, Euphractus & 0,751 & 0,730 & 0,699 & 0,925 & 0,809 & 0,906 & 0,838 & 0,780 & 0,747 & 0,758 & 0,740 & 0,756 \\
\hline 5, Dasypus & 0,709 & 0,705 & 0,678 & 0,757 & 0,946 & 0,800 & 0,857 & 0,713 & 0,713 & 0,710 & 0,682 & 0,679 \\
\hline 6, Chaetophractus & 0,766 & 0,763 & 0,685 & 0,827 & 0,739 & 0,901 & 0,835 & 0,740 & 0,766 & 0,724 & 0,757 & 0,750 \\
\hline 7, Cabassous & 0,745 & 0,711 & 0,702 & 0,753 & 0,779 & 0,740 & 0,873 & 0,751 & 0,724 & 0,734 & 0,758 & 0,739 \\
\hline 8, Tamandua & 0,653 & 0,663 & 0,704 & 0,717 & 0,663 & 0,672 & 0,671 & 0,915 & 0,764 & 0,841 & 0,807 & 0,775 \\
\hline 9, Cyclopes & 0,546 & 0,606 & 0,538 & 0,573 & 0,552 & 0,580 & 0,539 & 0,583 & 0,635 & 0,844 & 0,811 & 0,782 \\
\hline 10, Myrmecophaga & 0,624 & 0,641 & 0,670 & 0,672 & 0,637 & 0,634 & 0,632 & 0,742 & 0,620 & 0,851 & 0,743 & 0,747 \\
\hline 11, Bradypus & 0,636 & 0,666 & 0,617 & 0,668 & 0,623 & 0,675 & 0,665 & 0,724 & 0,607 & 0,644 & 0,881 & 0,800 \\
\hline 12, Choloepus & 0,629 & 0,630 & 0,646 & 0,676 & 0,614 & 0,662 & 0,643 & 0,689 & 0,579 & 0,641 & 0,698 & 0,865 \\
\hline
\end{tabular}


Tabela 1.11 - Similaridade observada (abaixo da diagonal) através das adagas casualizadas (RS), da correlação de matrizes (CM) e da projeção de Krzanowski (KRZ) para as matrizes 32D dos gêneros de Xenarthra. A diagonal contém a repetibilidade de cada matriz e acima dela estão os valores de similaridade ajustados. Valores em negrito foram significativos para $\alpha=0.01$. Note que para KRZ não houve teste de significância.

\begin{tabular}{|c|c|c|c|c|c|c|c|c|c|c|c|c|}
\hline RS & 1 & 2 & 3 & 4 & 5 & 6 & 7 & 8 & 9 & 10 & 11 & 12 \\
\hline 1, Zaedyus & 0,946 & 0,795 & 0,713 & 0,859 & 0,825 & 0,810 & 0,761 & 0,761 & 0,654 & 0,768 & 0,663 & 0,670 \\
\hline 2, Tolypeutes & 0,748 & 0,937 & 0,711 & 0,846 & 0,765 & 0,763 & 0,818 & 0,757 & 0,707 & 0,732 & 0,750 & 0,756 \\
\hline 3, Priodontes & 0,655 & 0,649 & 0,890 & 0,728 & 0,705 & 0,734 & 0,698 & 0,696 & 0,649 & 0,671 & 0,607 & 0,679 \\
\hline 4, Euphractus & 0,824 & 0,808 & 0,677 & 0,972 & 0,791 & 0,858 & 0,838 & 0,801 & 0,736 & 0,748 & 0,775 & 0,779 \\
\hline 5, Dasypus & 0,798 & 0,736 & 0,662 & 0,776 & 0,989 & 0,795 & 0,762 & 0,856 & 0,638 & 0,895 & 0,598 & 0,573 \\
\hline 6, Chaetophractus & 0,771 & 0,723 & 0,678 & 0,828 & 0,774 & 0,958 & 0,837 & 0,810 & 0,689 & 0,744 & 0,712 & 0,714 \\
\hline 7, Cabassous & 0,717 & 0,768 & 0,638 & 0,801 & 0,734 & 0,794 & 0,940 & 0,796 & 0,688 & 0,734 & 0,780 & 0,731 \\
\hline 8, Tamandua & 0,735 & 0,727 & 0,652 & 0,784 & 0,846 & 0,788 & 0,766 & 0,986 & 0,750 & 0,913 & 0,686 & 0,634 \\
\hline 9, Cyclopes & 0,623 & 0,671 & 0,600 & 0,711 & 0,622 & 0,661 & 0,653 & 0,729 & 0,960 & 0,639 & 0,757 & 0,771 \\
\hline 10, Myrmecophaga & 0,741 & 0,703 & 0,628 & 0,732 & 0,883 & 0,723 & 0,706 & 0,899 & 0,621 & 0,984 & 0,582 & 0,542 \\
\hline 11, Bradypus & 0,638 & 0,718 & 0,566 & 0,756 & 0,589 & 0,689 & 0,748 & 0,673 & 0,734 & 0,571 & 0,978 & 0,838 \\
\hline 12, Choloepus & 0,631 & 0,709 & 0,621 & 0,744 & 0,552 & 0,677 & 0,687 & 0,610 & 0,732 & 0,521 & 0,803 & 0,939 \\
\hline CM & 1 & 2 & 3 & 4 & 5 & 6 & 7 & 8 & 9 & 10 & 11 & 12 \\
\hline 1, Zaedyus & 0,882 & 0,497 & 0,407 & 0,663 & 0,566 & 0,572 & 0,487 & 0,429 & 0,345 & 0,502 & 0,416 & 0,493 \\
\hline 2, Tolypeutes & 0,438 & 0,881 & 0,404 & 0,649 & 0,57 & 0,473 & 0,542 & 0,55 & 0,532 & 0,532 & 0,643 & 0,649 \\
\hline 3, Priodontes & 0,348 & 0,345 & 0,829 & 0,446 & 0,404 & 0,395 & 0,443 & 0,43 & 0,345 & 0,496 & 0,237 & 0,421 \\
\hline 4, Euphractus & 0,602 & 0,589 & 0,393 & 0,935 & 0,583 & 0,68 & 0,591 & 0,653 & 0,569 & 0,631 & 0,622 & 0,679 \\
\hline 5, Dasypus & 0,521 & 0,525 & 0,361 & & 0,962 & 0,52 & 0,555 & 0,568 & 0,55 & 0,597 & 0,525 & 0,467 \\
\hline 6, Chaetophractus & 0,509 & 0,421 & 0,341 & 0,623 & 0,484 & 0,898 & 0,677 & 0,577 & 0,425 & 0,53 & 0,496 & 0,498 \\
\hline 7, Cabassous & 0,426 & 0,475 & 0,376 & 0,533 & 0,508 & 0,598 & 0,869 & 0,549 & 0,437 & 0,488 & 0,605 & 0,482 \\
\hline 8, Tamandua & 0,393 & 0,504 & 0,382 & 0,617 & 0,544 & 0,534 & 0,5 & 0,953 & 0,761 & 0,797 & 0,636 & 0,603 \\
\hline 9, Cyclopes & 0,313 & 0,483 & 0,304 & 0,531 & 0,521 & 0,389 & 0,394 & 0,718 & 0,934 & 0,7 & 0,59 & 0,602 \\
\hline 10, Myrmecophaga & 0,453 & 0,479 & 0,434 & 0,586 & 0,562 & 0,482 & 0,437 & 0,747 & 0,65 & 0,922 & 0,51 & 0,5 \\
\hline 11, Bradypus & 0,382 & 0,589 & 0,211 & 0,588 & 0,503 & 0,46 & 0,551 & 0,607 & 0,557 & 0,479 & 0,955 & 0,677 \\
\hline 12, Choloepus & 0,434 & 0,571 & 0,359 & 0,616 & 0,43 & 0,443 & 0,421 & 0,552 & 0,546 & 0,45 & 0,62 & 0,879 \\
\hline KRZ & 1 & 2 & 3 & 4 & 5 & 6 & 7 & 8 & 9 & 10 & 11 & 12 \\
\hline 1, Zaedyus & 0,862 & 0,845 & 0,782 & 0,838 & 0,770 & 0,864 & 0,838 & 0,752 & 0,716 & 0,712 & 0,755 & 0,792 \\
\hline 2, Tolypeutes & 0,742 & 0,893 & 0,756 & 0,816 & 0,778 & 0,846 & 0,821 & 0,758 & 0,733 & 0,751 & 0,757 & 0,746 \\
\hline 3, Priodontes & 0,669 & 0,659 & 0,850 & 0,780 & 0,744 & 0,762 & 0,822 & 0,802 & 0,783 & 0,804 & 0,738 & 0,795 \\
\hline 4, Euphractus & 0,747 & 0,741 & 0,691 & 0,923 & 0,773 & 0,907 & 0,833 & 0,779 & 0,745 & 0,773 & 0,799 & 0,809 \\
\hline 5, Dasypus & 0,700 & 0,720 & 0,671 & 0,727 & 0,958 & 0,757 & 0,842 & 0,739 & 0,680 & 0,719 & 0,701 & 0,708 \\
\hline 6, Chaetophractus & 0,760 & 0,758 & 0,666 & 0,826 & 0,702 & 0,899 & 0,816 & 0,747 & 0,732 & 0,755 & 0,804 & 0,792 \\
\hline 7, Cabassous & 0,726 & 0,724 & 0,707 & 0,746 & 0,769 & 0,722 & 0,870 & 0,770 & 0,711 & 0,744 & 0,742 & 0,781 \\
\hline 8, Tamandua & 0,671 & 0,688 & 0,711 & 0,719 & 0,695 & 0,680 & 0,690 & 0,923 & 0,881 & 0,879 & 0,784 & 0,779 \\
\hline 9, Cyclopes & 0,640 & 0,666 & 0,695 & 0,688 & 0,640 & 0,668 & 0,638 & 0,814 & 0,925 & 0,862 & 0,777 & 0,785 \\
\hline 10, Myrmecophaga & 0,640 & 0,688 & 0,718 & 0,719 & 0,682 & 0,693 & 0,673 & 0,818 & 0,803 & 0,938 & 0,814 & 0,766 \\
\hline 11, Bradypus & 0,674 & 0,688 & 0,655 & 0,738 & 0,660 & 0,733 & 0,665 & 0,724 & 0,719 & 0,758 & 0,925 & 0,859 \\
\hline 12, Choloepus & 0,693 & 0,664 & 0,690 & 0,732 & 0,653 & 0,707 & 0,687 & 0,705 & 0,712 & 0,699 & 0,779 & 0,888 \\
\hline
\end{tabular}


Tabela 1.12 - Similaridade observada (abaixo da diagonal) através das adagas casualizadas (RS), da correlação de matrizes (CM) e da projeção de Krzanowski (KRZ) para as matrizes 28D dos gêneros de Xenarthra. A diagonal contém a repetibilidade de cada matriz e acima dela estão os valores de similaridade ajustados. Valores em negrito foram significativos para $\alpha=0.01$ e valores em negrito e sublinhado foram significativos para $\alpha=0.05$. Note que para KRZ não houve teste de significância.

\begin{tabular}{|c|c|c|c|c|c|c|c|c|c|c|c|c|c|}
\hline RS & 1 & 2 & 3 & 4 & 5 & 6 & 7 & 8 & 9 & 10 & 11 & 12 & 13 \\
\hline 1, Zaedyus & 0,947 & 0,801 & 0,753 & 0,870 & 0,836 & 0,825 & 0,767 & 0,770 & 0,677 & 0,775 & 0,683 & 0,675 & 0,531 \\
\hline 2, Tolypeutes & 0,755 & 0,937 & 0,744 & 0,853 & 0,774 & 0,773 & 0,824 & 0,764 & 0,716 & 0,745 & 0,752 & 0,761 & 0,589 \\
\hline 3, Priodontes & 0,693 & 0,682 & 0,895 & 0,762 & 0,739 & 0,771 & 0,715 & 0,730 & 0,682 & 0,710 & 0,640 & 0,703 & 0,585 \\
\hline 4, Euphractus & 0,836 & 0,815 & 0,711 & 0,974 & 0,804 & 0,857 & 0,834 & 0,807 & 0,742 & 0,753 & 0,777 & 0,772 & 0,574 \\
\hline 5, Dasypus & 0,810 & 0,746 & 0,696 & 0,789 & 0,990 & 0,804 & 0,762 & 0,867 & 0,644 & 0,902 & 0,603 & 0,575 & 0,534 \\
\hline 6, Chaetophractus & 0,787 & 0,734 & 0,714 & 0,829 & 0,784 & 0,960 & 0,832 & 0,816 & 0,703 & 0,767 & 0,724 & 0,703 & 0,622 \\
\hline 7, Cabassous & 0,726 & 0,775 & 0,657 & 0,800 & 0,737 & 0,792 & 0,944 & 0,797 & 0,709 & 0,744 & 0,810 & 0,732 & 0,661 \\
\hline 8, Tamandua & 0,744 & 0,735 & 0,686 & 0,791 & 0,857 & 0,795 & 0,769 & 0,987 & 0,755 & 0,922 & 0,700 & 0,632 & 0,599 \\
\hline 9, Cyclopes & 0,647 & 0,681 & 0,633 & 0,719 & 0,629 & 0,676 & 0,677 & 0,737 & 0,964 & 0,649 & 0,767 & 0,774 & 0,604 \\
\hline 10, Myrmecophaga & 0,749 & 0,716 & 0,667 & 0,738 & 0,890 & 0,746 & 0,717 & 0,909 & 0,632 & 0,985 & 0,595 & 0,551 & 0,523 \\
\hline 11, Bradypus & 0,657 & 0,720 & 0,599 & 0,759 & 0,594 & 0,702 & 0,778 & 0,688 & 0,745 & 0,585 & 0,979 & 0,848 & 0,653 \\
\hline 12, Choloepus & 0,637 & 0,715 & 0,646 & 0,740 & 0,555 & 0,669 & 0,690 & 0,610 & 0,737 & 0,531 & 0,814 & 0,942 & 0,642 \\
\hline 13, Paramylodon & 0,496 & 0,546 & 0,531 & 0,543 & 0,509 & 0,584 & 0,615 & 0,570 & 0,569 & 0,497 & 0,620 & 0,597 & 0,919 \\
\hline $\mathrm{CM}$ & 1 & 2 & 3 & 4 & 5 & 6 & 7 & 8 & 9 & 10 & 11 & 12 & 13 \\
\hline 1, Zaedyus & 0,889 & 0,506 & 0,45 & 0,666 & 0,599 & 0,579 & 0,423 & 0,468 & 0,426 & 0,527 & 0,446 & 0,513 & 0,389 \\
\hline 2, Tolypeutes & 0,447 & 0,879 & 0,468 & 0,667 & 0,617 & 0,513 & 0,596 & 0,578 & 0,59 & 0,585 & 0,645 & 0,664 & 0,393 \\
\hline 3, Priodontes & 0,387 & 0,399 & 0,829 & 0,491 & 0,46 & 0,421 & 0,473 & 0,464 & 0,408 & 0,565 & $\underline{0,276}$ & 0,467 & 0,435 \\
\hline 4, Euphractus & 0,609 & 0,607 & 0,434 & 0,941 & 0,606 & 0,667 & 0,599 & 0,674 & 0,614 & 0,669 & 0,639 & 0,67 & 0,362 \\
\hline & 0,555 & 0,568 & 0,411 & 0,577 & 0,965 & 0,53 & 0,596 & 0,627 & 0,622 & 0,661 & 0,546 & 0,498 & 0,402 \\
\hline 6, Chaetophractus & 0,518 & 0,457 & 0,364 & 0,614 & 0,494 & 0,903 & 0,665 & 0,615 & 0,494 & 0,588 & 0,527 & 0,493 & 0,366 \\
\hline 7, Cabassous & 0,373 & 0,523 & 0,403 & 0,544 & 0,548 & 0,591 & 0,874 & 0,599 & 0,522 & 0,524 & 0,685 & 0,517 & 0,5 \\
\hline 8, Tamandua & 0,432 & 0,531 & 0,414 & 0,64 & 0,603 & 0,572 & 0,548 & 0,958 & 0,798 & 0,817 & 0,68 & 0,621 & 0,453 \\
\hline 9, Cyclopes & 0,39 & 0,536 & 0,36 & 0,577 & 0,592 & 0,455 & 0,473 & 0,758 & 0,94 & 0,746 & 0,65 & 0,63 & 0,359 \\
\hline 10, Myrmecophaga & 0,479 & 0,529 & 0,496 & 0,626 & 0,626 & 0,538 & 0,472 & 0,771 & 0,697 & 0,929 & 0,568 & 0,541 & 0,435 \\
\hline 11, Bradypus & 0,412 & 0,592 & $\underline{0,246}$ & 0,607 & 0,525 & 0,49 & 0,626 & 0,652 & 0,617 & 0,536 & 0,958 & 0,692 & 0,432 \\
\hline 12, Choloepus & 0,456 & 0,587 & 0,401 & 0,614 & 0,461 & 0,442 & 0,456 & 0,574 & 0,576 & 0,492 & 0,639 & 0,89 & 0,421 \\
\hline 13, Paramylodon & 0,341 & 0,342 & 0,368 & 0,327 & 0,366 & 0,323 & 0,434 & 0,412 & 0,323 & 0,389 & 0,392 & 0,369 & 0,863 \\
\hline KRZ & 1 & 2 & 3 & 4 & 5 & 6 & 7 & 8 & 9 & 10 & 11 & 12 & 13 \\
\hline 1, Zaedyus & 0,862 & 0,868 & 0,794 & 0,828 & 0,741 & 0,846 & 0,827 & 0,730 & 0,728 & 0,713 & 0,732 & 0,777 & 0,755 \\
\hline 2, Tolypeutes & 0,761 & 0,892 & 0,794 & 0,835 & 0,754 & 0,856 & 0,868 & 0,781 & 0,767 & 0,769 & 0,775 & 0,796 & 0,772 \\
\hline 3, Priodontes & 0,680 & 0,692 & 0,851 & 0,764 & 0,729 & 0,745 & 0,813 & 0,817 & 0,785 & 0,802 & 0,738 & 0,794 & 0,793 \\
\hline 4, Euphractus & 0,738 & 0,757 & 0,677 & 0,921 & 0,759 & 0,872 & 0,818 & 0,757 & 0,757 & 0,755 & 0,786 & 0,779 & 0,769 \\
\hline 5, Dasypus & 0,670 & 0,693 & 0,655 & 0,709 & 0,948 & 0,705 & 0,818 & 0,751 & 0,723 & 0,766 & 0,709 & 0,705 & 0,768 \\
\hline 6, Chaetophractus & 0,752 & 0,774 & 0,658 & 0,801 & 0,657 & 0,916 & 0,797 & 0,727 & 0,742 & 0,755 & 0,797 & 0,797 & 0,759 \\
\hline 7, Cabassous & 0,722 & 0,771 & 0,705 & 0,738 & 0,749 & 0,717 & 0,884 & 0,762 & 0,726 & 0,766 & 0,728 & 0,772 & 0,790 \\
\hline 8, Tamandua & 0,655 & 0,713 & 0,729 & 0,703 & 0,707 & 0,672 & 0,692 & 0,935 & 0,882 & 0,884 & 0,786 & 0,796 & 0,778 \\
\hline 9, Cyclopes & 0,649 & 0,695 & 0,695 & 0,697 & 0,675 & 0,681 & 0,655 & 0,818 & 0,920 & 0,846 & 0,788 & 0,803 & 0,784 \\
\hline 10, Myrmecophaga & 0,645 & 0,707 & 0,721 & 0,706 & 0,727 & 0,704 & 0,701 & 0,832 & 0,790 & 0,949 & 0,805 & 0,774 & 0,774 \\
\hline 11, Bradypus & 0,653 & 0,702 & 0,654 & 0,724 & 0,663 & 0,733 & 0,657 & 0,730 & 0,726 & 0,753 & 0,922 & 0,854 & 0,803 \\
\hline 12, Choloepus & 0,682 & 0,710 & 0,693 & 0,707 & 0,649 & 0,722 & 0,687 & 0,728 & 0,729 & 0,712 & 0,775 & 0,894 & 0,859 \\
\hline 13, Paramylodon & 0,652 & 0,678 & 0,681 & 0,687 & 0,696 & 0,676 & 0,691 & 0,700 & 0,699 & 0,701 & 0,717 & 0,756 & 0,865 \\
\hline
\end{tabular}


Tabela 1.13 - Similaridade observada (abaixo da diagonal) através das adagas casualizadas (RS), da correlação de matrizes (CM) e da projeção de Krzanowski (KRZ) para as matrizes 25D dos gêneros de Xenarthra. A diagonal contém a repetibilidade de cada matriz e acima dela estão os valores de similaridade ajustados. Valores em negrito foram significativos para $\alpha=0.01$ e valores em negrito e sublinhado foram significativos para $\alpha=0.05$. Note que para KRZ não houve teste de significância.

\begin{tabular}{|c|c|c|c|c|c|c|c|c|c|c|c|c|c|c|}
\hline RS & 1 & 2 & 3 & 4 & 5 & 6 & 7 & 8 & 9 & 10 & 11 & 12 & 13 & 14 \\
\hline 1, Zaedyus & 939 & 814 & 0,713 & 0,862 &, 791 & 810 & 0,752 & 0,735 & 0,674 & 0,707 & 0,730 & 0,722 &, 584 & 0,620 \\
\hline 2, Tolypeutes & 764 & 937 & 0,710 & 0,844 & ,777 &, 802 & 0,860 &, 769 & 0,712 &, 736 & 0,782 &, 789 &, 634 & 0,720 \\
\hline 3 , Priodontes & 0,654 &, 651 & 0,898 &, 724 & ,686 &, 717 & 0,687 &, 672 &, 649 &, 649 &, 622 & 688 & 561 & 0,559 \\
\hline 5, Dasypus & 0,762 & 0,747 & 0,646 & 0,758 & 0,988 & 0,728 & 0,707 & 0,857 & 0,650 & 0,884 & 0,603 & 575 & ,536 & 0,614 \\
\hline 6, Chaetophractu & 0,766 & 0,758 & 0,663 & 0,820 & 0,706 & 0,952 & 0,815 & 0,740 & 0,702 & 0,656 & 0,762 & 746 & 0,642 & 0,665 \\
\hline & 0,641 & 0,676 & 0,604 & 0,711 & 0,634 & 0,672 & 0,667 & 0,739 & 0,964 & 0,633 & 0,759 & 0,769 & 0,593 & 0,731 \\
\hline $\begin{array}{c}10, \\
\text { Iyrmecophaga }\end{array}$ & 679 & ,706 & 0.610 & 0,692 & 871 & 0,634 & 0,652 & 0,887 & 615 & 982 & 8 & ,534 & 497 & 605 \\
\hline & 0,701 &, 749 & 0,584 & 0,790 & 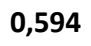 & 0,736 & 0,801 & 0,681 & 0,738 & 0,558 & & 0,831 & 0,676 & 0,02 \\
\hline 12 & 0,679 & & & 0,760 & & 0,707 & 0,696 & 0,602 & & & & 0,943 & & 0,733 \\
\hline 2, Tolypeutes & 0,395 & 0,873 & 0,414 & 0,609 & 0,59 & 0,466 & 0,603 & & & & & & 74 & \\
\hline & & & 0,84 & 0 & & $\underline{0,328}$ & & & & & & & & \\
\hline $4, E$ & 0,561 & 0,551 & 0,407 & 0,936 & 0,565 & 0,661 & 0,617 & 0,669 & 0,582 & 0 & 0, & 0,65 & 3 & $\underline{0,361}$ \\
\hline 5, Dasypus & 0,498 & 0,54 & 0,347 & 0,536 & 0,96 & 0,446 & 0,564 & 0,573 & 0,569 & 0,597 & 0,492 &, 445 & 0,416 & 0,447 \\
\hline 6, Cha & 0,503 & 11 & $\underline{0,283}$ & 0,603 & 0,412 & 0,89 & 0,629 & & & & & & & \\
\hline & & & & & & & & & & & & & & \\
\hline $8, T a$ & 0,407 & 0,493 & 0,369 & 0,632 & 0,548 & 0,496 & 0,479 & 0,953 & 0,769 & 0,793 & 0,655 & ,573 & 0,492 & $\underline{0,246}$ \\
\hline lopes & 0,326 & 0,485 & $\underline{0,29}$ & 0,544 & 0,539 & 0,368 & 0,414 & 0,726 & 0,936 & 0,703 & 0.63 & 0,591 & 0,356 & 0,394 \\
\hline $\begin{array}{c}10, \\
\text { Myrmecophaga }\end{array}$ & 80 & 469 & 123 & 58 & 0,561 & 02 & 9 & 3 & 0,652 & 01 & ,515 & ,482 & 51 & $\underline{0,296}$ \\
\hline 3, $\operatorname{Pr}$ & & & & & & & & & & & & & & \\
\hline & 0,758 & 0,736 & 0,656 & 0,899 & 3 & 885 & 0,843 & 46 & 7 & 0 & & & & \\
\hline & 0,631 & 0,645 & 0,655 & 0,672 & 0,936 & 0,694 & 0,817 & 0,753 & 84 & 0,751 & 0,672 & 0,717 & 58 & 0,703 \\
\hline 6, Chaetophrac & 0,683 & 0,734 & 0,629 & 0,800 & & 0,908 & 0,769 & 0,727 & & & & & & \\
\hline 7, Cabassous & 0,683 & 0,724 & 0,697 & 0,744 & 0,736 & 0,682 & 0,867 & 0,780 & & & & & & 0,766 \\
\hline & & & & & & & & & & & & & & 0,749 \\
\hline 9, Cyclopes & 0,601 & 0,655 & 0,700 & 0,640 & 0,641 & 0,654 & 0,615 & 0,805 & 0,936 & 0,846 & 0,770 & 0,795 & 0,748 & 0,717 \\
\hline 10 & 0,619 & 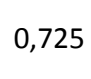 & 0,716 & 0,685 & C & 8 & c & c & 0,792 & 0 & 728 & 7 & 3 & (5) \\
\hline 11, Bradypus & - & & & & & & & & & & & 0,833 & & $0,1,0$ \\
\hline 12, Choloepus & 0,674 & 0,682 & & & & & & & & & & & 0,858 & 0,802 \\
\hline 13, Paramylodon & 0,638 & 0,652 & 0,663 & 0,701 & 0,685 & 0,668 & 0,689 & 0,699 & & & & 0,760 & 0,874 & 0,827 \\
\hline 14, Scelidotherium & 0,616 & 0,609 & 0,622 & 0,658 & 0,614 & 0,633 & 0,645 & 0,654 & 0,627 & 0,637 & 0,651 & 0,686 & 0,699 & 0,817 \\
\hline
\end{tabular}


Tabela 1.14 - Coeficientes de correlação de Pearson entre o log do n amostral e o log das similaridades médias observadas e ajustadas e das repetibilidades (t) para cada método (adagas casualizadas: RS; correlação de matrizes: CM; projeção de Krzanowsky: KRZ) em cada conjunto de distâncias. Valores em negrito representam correlações significativas para $\alpha=0,05$.

\begin{tabular}{|c|c|c|c|c|c|c|c|c|c|c|}
\hline & & \multicolumn{3}{|c|}{ RS } & \multicolumn{3}{|c|}{$\mathrm{CM}$} & \multicolumn{3}{|c|}{ KRZ } \\
\hline & & observada & ajustada & $\mathbf{t}$ & observada & ajustada & $\mathbf{t}$ & observada & ajustada & $\mathbf{t}$ \\
\hline \multirow{4}{*}{ 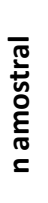 } & 35D & 0,77 & 0,70 & 0,90 & 0,73 & 0,66 & 0,94 & 0,71 & 0,06 & 0,81 \\
\hline & 32D & 0,37 & 0,16 & 0,89 & 0,67 & 0,59 & 0,94 & 0,35 & $-0,43$ & 0,92 \\
\hline & 28D & 0,50 & 0,37 & 0,91 & 0,76 & 0,69 & 0,94 & 0,27 & $-0,55$ & 0,91 \\
\hline & 25D & 0,52 & 0,35 & 0,96 & 0,77 & 0,71 & 0,91 & 0,33 & 0.29 & 0,93 \\
\hline
\end{tabular}

As repetibilidades (t) das matrizes (Tabelas 1.10-1.13; Figura 1.12) se mostraram elevadas. Elas foram geralmente superiores a 0,85 , mesmo para os gêneros pior amostrados. Esse resultado sugere elevada precisão na determinação das matrizes de covariância e correlação. Apenas a repetibilidade de Cyclopes em 35D para o método da KRZ apresentou valor relativamente baixo para $\mathrm{t}(0,64)$. Assim como para as similaridades, os valores de $\mathrm{t}$ dos diferentes métodos foram consistentes dentro e entre os conjuntos de distâncias.

Embora tenha sido observada correlação elevada entre tamanho da amostra e a repetibilidade (Tabela 1.14), a técnica de reamostragem utilizada no método de autocorrelação não reflete adequadamente os erros de estimativa nas matrizes determinadas a partir de amostras pequenas. Em outras palavras, as repetibilidades geradas são sempre elevadas. Isso se deve ao fato que o procedimento de reamostragem para as amostras pequenas estima consistentemente a estrutura da matriz daquela amostra, gerando repetibilidades elevadas. No entanto, ele não é capaz de detectar se esse padrão se aproxima do populacional. Isso porque esse procedimento não aumenta a quantidade de informação nos dados originais e tão pouco leva em consideração explicitamente o problema do tamanho amostral. Pode ser que as matrizes estimadas com poucos indivíduos, como a de Cyclopes ou Scelidotherium, embora apresentem repetibilidades elevadas 
divirjam substancialmente dos parâmetros populacionais. Essa divergência justificaria suas similaridades com as demais matrizes serem relativamente baixas.

A estimativa de matrizes de covariância ou correlação com amostras pequenas em relação ao número de parâmetros, neste caso as distâncias, está sujeita a quantidade substancial de erros (Marroig et al., 2012). Por exemplo, suponha que se obteve uma amostra de poucos espécimes (20) de uma população representada por 35 caracteres independentes. A partir dessa amostra foi calculada a matriz de correlação. Em teoria a correlação média dessa matriz deveria ser zero, afinal, os caracteres são independentes. Na prática, no entanto, ela pode variar bastante da expectativa teórica, simplesmente devido ao erro associado à estimativa da matriz (Marroig et al., 2012). Inclusive, quanto menor for o tamanho da amostra em relação à quantidade de variáveis, mais pervasivo será este efeito (ver Figura 1B de Marroig et al., 2012).

Isso fica evidente ao comparar as repetibilidades determinadas pela autocorrelação e pela forma analítica proposta por Cheverud (1996). A forma analítica incorpora explicitamente o efeito do tamanho amostral em seu cálculo. A Figura 1.13 apresenta os resultados obtidos para os dois métodos para as matrizes de correlação em todos os conjuntos de distâncias. Como pode ser observado, para amostras pequenas a forma analítica gerou resultados de repetibilidade muito inferiores aos da autocorrelação. À medida que o tamanho das amostras aumentou os valores obtidos através dos dois métodos se aproximaram. Ou seja, a repetibilidade adotada aqui foi potencialmente superestimada, principalmente para as amostras pequenas. $\mathrm{O}$ resultado prático disso foi que as similaridades ajustadas estiveram provavelmente subestimadas. Consequentemente, as matrizes são provavelmente mais similares do que o retratado (ver Tabela A4 nos anexos para detalhes quanto aos valores ajustados através da forma analítica para CM). 
Nos níveis supragenéricos, os resultados obtidos foram semelhantes aos apresentados acima (Tabelas 1.15-1.18). As similaridades observadas foram em sua maioria superiores a 0,6. Enquanto as ajustadas foram em geral acima de 0,7 . De modo geral esses resultados suportaram os resultados obtidos para as análises realizadas nos gêneros. A maior diferença observada entre os resultados nos níveis supragenéricos e os apresentados para os gêneros foi uma sensível elevação nos valores obtidos através das CMs. Valores mais baixos de similaridade estiveram novamente associados a grupos piores amostrados (Cyclopedinae, Bradypodinae, Choloepinae, Cyclopedidae, Bradypodidae e Megalonychidae em 35D, Mylodontinae e Mylodontidae em 28D e 25D e Scelidotherinae em 25D). Folivora, em 28D e 25D, apesar de ter uma amostra considerável (Tabela 1.1), apresentou valores baixos para as similaridades em RS e CM. Isso se deve principalmente à presença do gênero fóssil Scelidotherium que foi relativamente mal amostrados. Na ausência dele (35D e 32D), os valores de similaridade dessa subordem com as demais foram elevados.
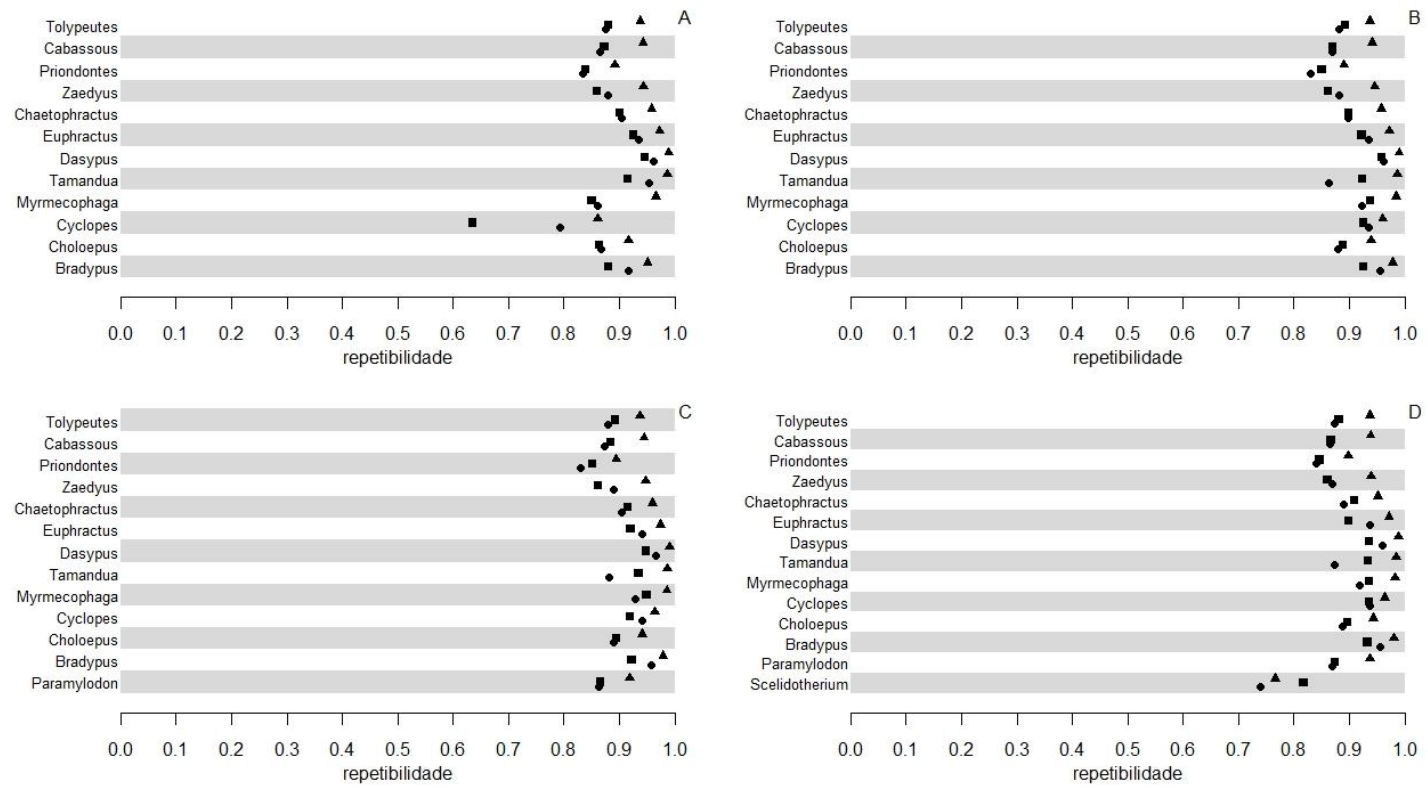

Figura 1.12 - Repetibilidade das matrizes para cada gênero através das RS (triângulo), da CM (círculo) e da KRZ (quadrado). A: 35D; B: 32D; C: 28D; D: 25D. 

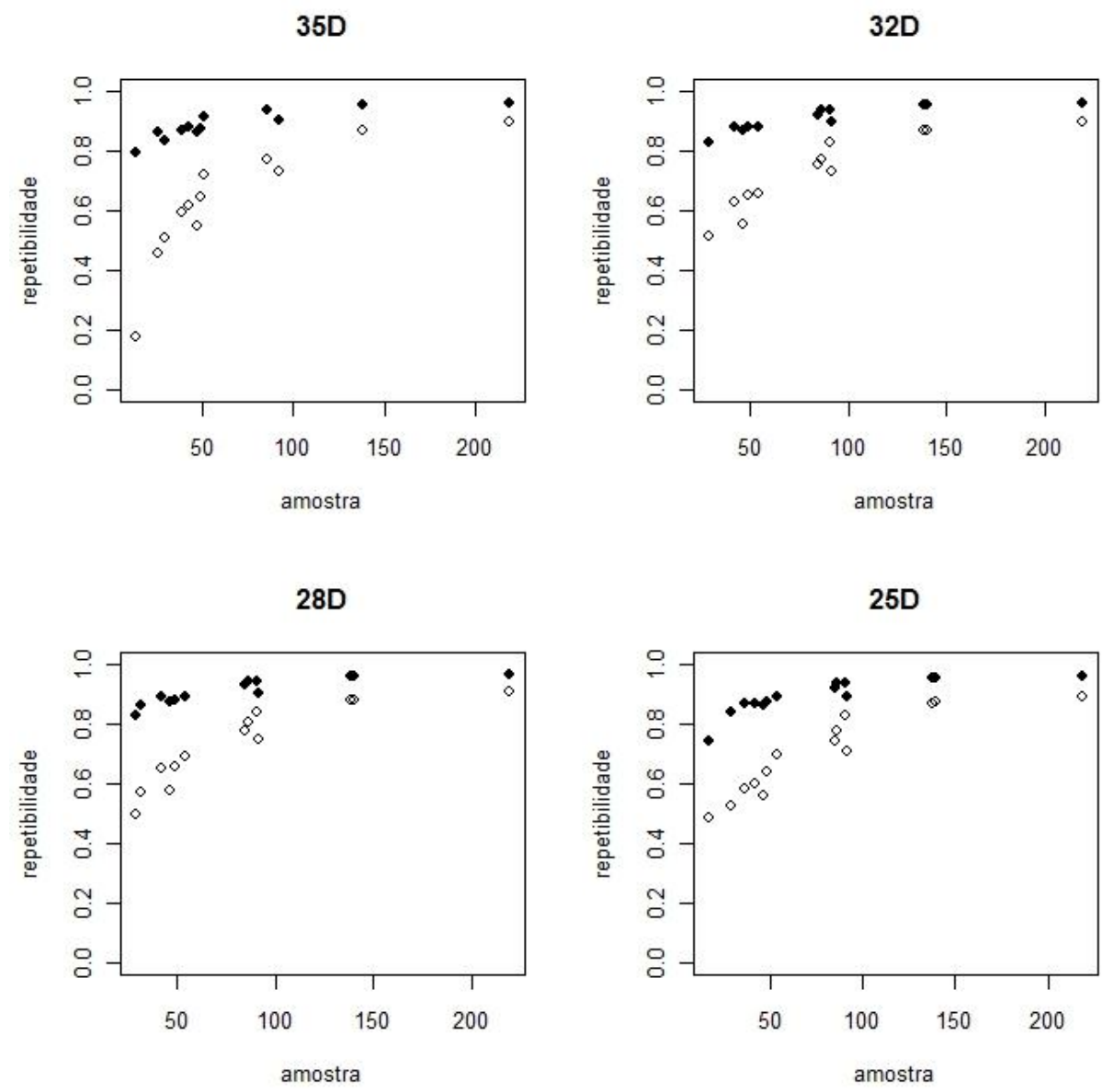

Figura 1.13 - Repetibilidade das matrizes de correlação para cada gênero através dos métodos da autocorrelação (losango escuro) e analítico (losango claro). 
Tabela 1.15 - Similaridade observada (abaixo da diagonal) através das adagas casualizadas (RS), da correlação de matrizes (CM) e da projeção de Krzanowski (KRZ) para as matrizes 35D dos níveis supragenéricos de Xenarthra. A diagonal contém a repetibilidade de cada matriz e acima dela estão os valores de similaridade ajustados.

\begin{tabular}{|c|c|c|c|c|c|c|c|c|c|c|c|c|c|c|c|c|c|}
\hline RS & 1 & 2 & 3 & 4 & 5 & 6 & 7 & 8 & 9 & 10 & 11 & 12 & 13 & 14 & 15 & 16 & 17 \\
\hline 1, Euphractinae & 0,98 & 0,90 & 0,83 & 0,78 & 0,69 & 0,78 & 0,78 & & & & & & & & & & \\
\hline 3, Dasypodinae & 0,82 & 0,80 & 0,99 & 0,89 & 0,60 & 0,59 & 0,63 & & & & & & & & & & \\
\hline 5, Cyclopedinae & 0,63 & 0,65 & 0,55 & 0,60 & 0,85 & 0,74 & 0,72 & & & & & & & & & & \\
\hline 6 , Choloepinae & 0,74 & 0,73 & 0,56 & 0,56 & 0,65 & 0,92 & 0,85 & & & & & & & & & & \\
\hline 7, Bradypodinae & 0,75 & 0,73 & 0,61 & 0,62 & 0,65 & 0,80 & 0,95 & & & & & & & & & & \\
\hline 10, Cyclopedidae & & & & & & & & 0,62 & 0,60 & 0,86 & 0,74 & 0,73 & & & & & \\
\hline 11, Megalonychidae & & & & & & & & 0,68 & 0,56 & 0,65 & 0,92 & 0,85 & & & & & \\
\hline 12, Bradypodidae & & & & & & & & 0,70 & 0,63 & 0,66 & 0,79 & 0,95 & & & & & \\
\hline 13, Dasypodidae & & & & & & & & & & & & & 0,99 & 0,86 & 0,73 & & \\
\hline 14, Vermilingua & & & & & & & & & & & & & 0,85 & 0,98 & 0,63 & & \\
\hline $\mathrm{CM}$ & 1 & 2 & 3 & 4 & 5 & 6 & 7 & 8 & 9 & 10 & 11 & 12 & 13 & 14 & 15 & 16 & 17 \\
\hline 1, Euphractinae & 0,96 & 0,73 & 0,63 & 0,68 & 0,41 & 0,67 & 0,57 & & & & & & & & & & \\
\hline 2, Tolypeutinae & 0,68 & 0,91 & 0,64 & 0,63 & 0,42 & 0,58 & 0,52 & & & & & & & & & & \\
\hline 3, Dasypodinae & 0,60 & 0,59 & 0,96 & 0,64 & 0,38 & 0,40 & 0,48 & & & & & & & & & & \\
\hline 4, Myrmecophaginae & 0,65 & 0,58 & 0,61 & 0,94 & 0,64 & 0,50 & 0,64 & & & & & & & & & & \\
\hline 5, Cyclopedinae & 0,36 & 0,36 & 0,33 & 0,55 & 0,79 & 0,35 & 0,43 & & & & & & & & & & \\
\hline 6, Choloepinae & 0,61 & 0,51 & 0,37 & 0,45 & 0,29 & 0,87 & 0,63 & & & & & & & & & & \\
\hline 7, Bradypodinae & 0,54 & 0,47 & 0,45 & 0,59 & 0,37 & 0,56 & 0,92 & & & & & & & & & & \\
\hline 8, Dasypodidae & & & & & & & & 0,97 & 0,75 & 0,48 & 0,61 & 0,60 & & & & & \\
\hline 9, Myrmecophagidae & & & & & & & & 0,72 & 0,94 & 0,64 & 0,50 & 0,64 & & & & & \\
\hline 10, Cyclopedidae & & & & & & & & 0,43 & 0,55 & 0,79 & 0,35 & 0,43 & & & & & \\
\hline KRZ & 1 & 2 & 3 & 4 & 5 & 6 & 7 & 8 & 9 & 10 & 11 & 12 & 13 & 14 & 15 & 16 & 17 \\
\hline 1, Euphractinae & 0,96 & 0,87 & 0,81 & 0,76 & 0,74 & 0,74 & 0,73 & & & & & & & & & & \\
\hline 2, Tolypeutinae & 0,82 & 0,92 & 0,84 & 0,81 & 0,74 & 0,74 & 0,75 & & & & & & & & & & \\
\hline 3, Dasypodinae & 0,77 & 0,79 & 0,94 & 0,71 & 0,71 & 0,68 & 0,68 & & & & & & & & & & \\
\hline 4, Myrmecophaginae & 0,71 & 0,75 & 0,66 & 0,93 & 0,83 & 0,78 & 0,80 & & & & & & & & & & \\
\hline 5, Cyclopedinae & 0,58 & 0,57 & 0,55 & 0,64 & 0,63 & 0,78 & 0,81 & & & & & & & & & & \\
\hline 6, Choloepinae & 0,68 & 0,66 & 0,61 & 0,70 & 0,58 & 0,86 & 0,80 & & & & & & & & & & \\
\hline 7, Bradypodinae & 0,67 & 0,67 & 0,62 & 0,72 & 0,61 & 0,70 & 0,88 & & & & & & & & & & \\
\hline 8, Dasypodidae & & & & & & & & 0,97 & 0,78 & 0,72 & 0,73 & 0,71 & & & & & \\
\hline 9, Myrmecophagidae & & & & & & & & 0,74 & 0,93 & 0,83 & 0,78 & 0,80 & & & & & \\
\hline 10, Cyclopedidae & & & & & & & & 0,57 & 0,64 & 0,64 & 0,78 & 0,81 & & & & & \\
\hline 11, Megalonychidae & & & & & & & & 0,67 & 0,70 & 0,58 & 0,86 & 0,80 & & & & & \\
\hline 12, Bradypodidae & & & & & & & & 0,65 & 0,72 & 0,61 & 0,70 & 0,88 & & & & & \\
\hline 13, Dasypodidae & & & & & & & & & & & & & 0,97 & 0,76 & 0,73 & & \\
\hline 14, Vermilingua & & & & & & & & & & & & & 0,72 & 0,92 & 0,83 & & \\
\hline 15, Folivora & & & & & & & & & & & & & 0,68 & 0,76 & 0,91 & & \\
\hline 16, Cingulata & & & & & & & & & & & & & & & & 0,97 & 0,76 \\
\hline 17, Pilosa & & & & & & & & & & & & & & & & 0,73 & 0,94 \\
\hline
\end{tabular}


Tabela 1.16 - Similaridade observada (abaixo da diagonal) através das adagas casualizadas (RS), da correlação de matrizes (CM) e da projeção de Krzanowski (KRZ) para as matrizes 32D dos níveis supragenéricos de Xenarthra. A diagonal contém a repetibilidade de cada matriz e acima dela estão os valores de similaridade ajustados.

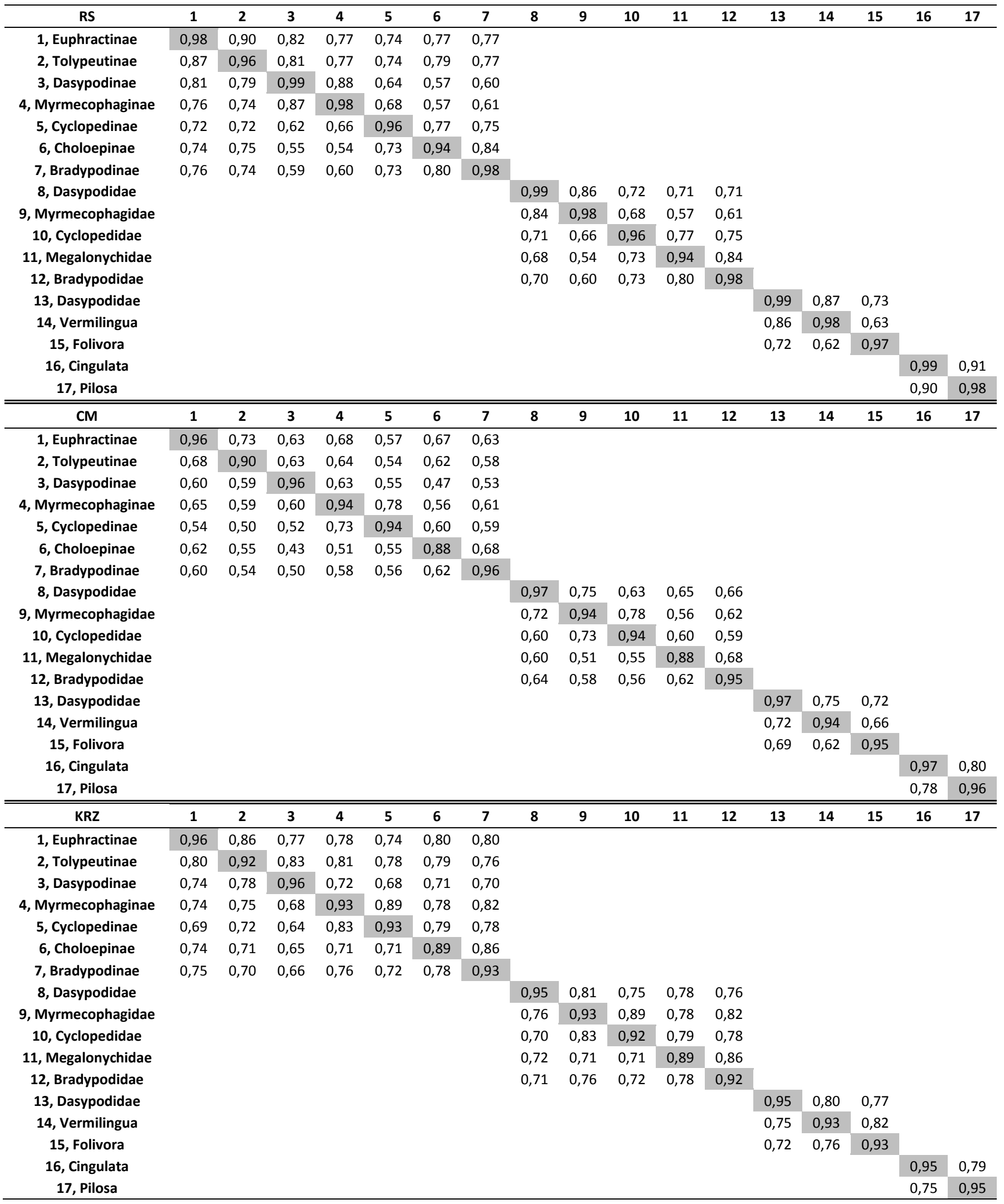


Tabela 1.17 - Similaridade observada (abaixo da diagonal) através das adagas casualizadas (RS), da correlação de matrizes (CM) e da projeção de Krzanowski (KRZ) para as matrizes 28D dos níveis supragenéricos de Xenarthra. A diagonal contém a repetibilidade de cada matriz e acima dela estão os valores de similaridade ajustados.

\begin{tabular}{|c|c|c|c|c|c|c|c|c|c|c|c|c|c|c|c|c|c|c|c|}
\hline RS & 1 & 2 & 3 & 4 & 5 & 6 & 7 & 8 & 9 & 10 & 11 & 12 & 13 & 14 & 15 & 16 & 17 & 18 & 19 \\
\hline 1, Euphractinae & 0,98 & 0,91 & 0,83 & 0,77 & 0,75 & 0,77 & 0,78 & 0,48 & & & & & & & & & & & \\
\hline 2, Tolypeutinae & 0,89 & 0,96 & 0,82 & 0,78 & 0,77 & 0,80 & 0,80 & 0,54 & & & & & & & & & & & \\
\hline 3, Dasypodinae & 0,82 & 0,80 & 0,99 & 0,89 & 0,65 & 0,58 & 0,60 & 0,42 & & & & & & & & & & & \\
\hline 4, Myrmecophaginae & 0,76 & 0,76 & 0,88 & 0,98 & 0,68 & 0,57 & 0,61 & 0,40 & & & & & & & & & & & \\
\hline 5, Cyclopedinae & 0,73 & 0,74 & 0,63 & 0,67 & 0,96 & 0,77 & 0,77 & 0,50 & & & & & & & & & & & \\
\hline 6, Choloepinae & 0,74 & 0,76 & 0,56 & 0,54 & 0,74 & 0,94 & 0,85 & 0,55 & & & & & & & & & & & \\
\hline 7, Bradypodinae & 0,76 & 0,78 & 0,60 & 0,60 & 0,75 & 0,81 & 0,98 & 0,52 & & & & & & & & & & & \\
\hline 8, Mylodontinae & 0,46 & 0,51 & 0,40 & 0,38 & 0,47 & 0,51 & 0,50 & 0,93 & & & & & & & & & & & \\
\hline 9, Dasypodidae & & & & & & & & & 0,99 & 0,86 & 0,73 & 0,70 & 0,71 & 0,49 & & & & & \\
\hline 10, Myrmecophagidae & & & & & & & & & 0,85 & 0,98 & 0,68 & 0,57 & 0,61 & 0,40 & & & & & \\
\hline 11, Cyclopedidae & & & & & & & & & 0,71 & 0,67 & 0,96 & 0,77 & 0,77 & 0,49 & & & & & \\
\hline 12, Megalonychidae & & & & & & & & & 0,68 & 0,54 & 0,74 & 0,94 & 0,85 & 0,55 & & & & & \\
\hline 13, Bradypodidae & & & & & & & & & 0,71 & 0,60 & 0,75 & 0,82 & 0,98 & 0,52 & & & & & \\
\hline 14, Mylodontidae & & & & & & & & & 0,47 & 0,38 & 0,47 & 0,52 & 0,50 & 0,93 & & & & & \\
\hline 15, Dasypodidae & & & & & & & & & & & & & & & 0,99 & 0,87 & 0,54 & & \\
\hline 16 , Vermilingua & & & & & & & & & & & & & & & 0,86 & 0,98 & 0,45 & & \\
\hline 17, Folivora & & & & & & & & & & & & & & & 0,52 & 0,43 & 0,94 & & \\
\hline 18 , Cingulata & & & & & & & & & & & & & & & & & & 0,99 & 0,73 \\
\hline 19, Pilosa & & & & & & & & & & & & & & & & & & 0,71 & 0,96 \\
\hline CM & 1 & 2 & 3 & 4 & 5 & 6 & 7 & 8 & 9 & 10 & 11 & 12 & 13 & 14 & 15 & 16 & 17 & 18 & 19 \\
\hline 1, Euphractinae & 0,96 & 0,76 & 0,65 & 0,70 & 0,63 & 0,67 & 0,65 & 0,34 & & & & & & & & & & & \\
\hline 2, Tolypeutinae & 0,71 & 0,91 & 0,69 & 0,68 & 0,62 & 0,66 & 0,64 & 0,42 & & & & & & & & & & & \\
\hline 3, Dasypodinae & 0,62 & 0,65 & 0,97 & 0,68 & 0,62 & 0,50 & 0,55 & 0,28 & & & & & & & & & & & \\
\hline 4, Myrmecophaginae & 0,67 & 0,63 & 0,65 & 0,95 & 0,83 & 0,58 & 0,66 & 0,35 & & & & & & & & & & & \\
\hline 5, Cyclopedinae & 0,60 & 0,58 & 0,59 & 0,78 & 0,94 & 0,63 & 0,65 & 0,31 & & & & & & & & & & & \\
\hline 6, Choloepinae & 0,62 & 0,59 & 0,46 & 0,53 & 0,58 & 0,89 & 0,69 & 0,41 & & & & & & & & & & & \\
\hline 7, Bradypodinae & 0,63 & 0,59 & 0,53 & 0,63 & 0,62 & 0,64 & 0,96 & 0,37 & & & & & & & & & & & \\
\hline 8, Mylodontinae & 0,31 & 0,37 & 0,25 & 0,32 & 0,28 & 0,36 & 0,33 & 0,87 & & & & & & & & & & & \\
\hline 9, Dasypodidae & & & & & & & & & 0,98 & 0,78 & 0,70 & 0,66 & 0,69 & 0,38 & & & & & \\
\hline 10, Myrmecophagidae & & & & & & & & & 0,75 & 0,95 & 0,83 & 0,58 & 0,66 & 0,35 & & & & & \\
\hline 11, Cyclopedidae & & & & & & & & & 0,67 & 0,78 & 0,94 & 0,63 & 0,65 & 0,31 & & & & & \\
\hline 12, Megalonychidae & & & & & & & & & 0,62 & 0,53 & 0,58 & 0,89 & 0,69 & 0,41 & & & & & \\
\hline 13, Bradypodidae & & & & & & & & & 0,67 & 0,63 & 0,62 & 0,64 & 0,96 & 0,37 & & & & & \\
\hline 14, Mylodontidae & & & & & & & & & 0,35 & 0,32 & 0,28 & 0,36 & 0,33 & 0,86 & & & & & \\
\hline 15, Dasypodidae & & & & & & & & & & & & & & & 0,98 & 0,78 & 0,45 & & \\
\hline 16 , Vermilingua & & & & & & & & & & & & & & & 0,75 & 0,95 & 0,38 & & \\
\hline 17, Folivora & & & & & & & & & & & & & & & 0,42 & 0,35 & 0,89 & & \\
\hline 18 , Cingulata & & & & & & & & & & & & & & & & & & 0,98 & 0,60 \\
\hline 19, Pilosa & & & & & & & & & & & & & & & & & & 0,57 & 0,93 \\
\hline KRZ & 1 & 2 & 3 & 4 & 5 & 6 & 7 & 8 & 9 & 10 & 11 & 12 & 13 & 14 & 15 & 16 & 17 & 18 & 19 \\
\hline 1, Euphractinae & 0,95 & 0,88 & 0,75 & 0,81 & 0,78 & 0,81 & 0,81 & 0,78 & & & & & & & & & & & \\
\hline 2, Tolypeutinae & 0,82 & 0,92 & 0,81 & 0,86 & 0,81 & 0,82 & 0,77 & 0,80 & & & & & & & & & & & \\
\hline 3, Dasypodinae & 0,71 & 0,75 & 0,95 & 0,75 & 0,72 & 0,71 & 0,71 & 0,74 & & & & & & & & & & & \\
\hline 4, Myrmecophaginae & 0,77 & 0,81 & 0,71 & 0,95 & 0,89 & 0,81 & 0,82 & 0,77 & & & & & & & & & & & \\
\hline 5, Cyclopedinae & 0,73 & 0,74 & 0,68 & 0,83 & 0,92 & 0,80 & 0,79 & 0,76 & & & & & & & & & & & \\
\hline 6, Choloepinae & 0,75 & 0,74 & 0,65 & 0,75 & 0,73 & 0,89 & 0,85 & 0,82 & & & & & & & & & & & \\
\hline 7, Bradypodinae & 0,76 & 0,71 & 0,66 & 0,76 & 0,73 & 0,78 & 0,92 & 0,80 & & & & & & & & & & & \\
\hline 8, Mylodontinae & 0,72 & 0,72 & 0,68 & 0,71 & 0,69 & 0,74 & 0,73 & 0,90 & & & & & & & & & & & \\
\hline 9, Dasypodidae & & & & & & & & & 0,93 & 0,83 & 0,79 & 0,79 & 0,76 & 0,78 & & & & & \\
\hline 10, Myrmecophagidae & & & & & & & & & 0,78 & 0,95 & 0,89 & 0,81 & 0,82 & 0,77 & & & & & \\
\hline 11, Cyclopedidae & & & & & & & & & 0,73 & 0,83 & 0,92 & 0,80 & 0,79 & 0,76 & & & & & \\
\hline 12, Megalonychidae & & & & & & & & & 0,72 & 0,75 & 0,73 & 0,89 & 0,85 & 0,82 & & & & & \\
\hline 13, Bradypodidae & & & & & & & & & 0,70 & 0,76 & 0,73 & 0,78 & 0,92 & 0,80 & & & & & \\
\hline 14, Mylodontidae & & & & & & & & & 0,72 & 0,71 & 0,69 & 0,74 & 0,73 & 0,90 & & & & & \\
\hline 15, Dasypodidae & & & & & & & & & & & & & & & 0,93 & 0,80 & 0,78 & & \\
\hline 16 , Vermilingua & & & & & & & & & & & & & & & 0,76 & 0,95 & 0,75 & & \\
\hline 17, Folivora & & & & & & & & & & & & & & & 0,72 & 0,70 & 0,92 & & \\
\hline 18 , Cingulata & & & & & & & & & & & & & & & & & & 0,93 & 0,80 \\
\hline 19, Pilosa & & & & & & & & & & & & & & & & & & 0,75 & 0,94 \\
\hline
\end{tabular}


Tabela 1.18 - Similaridade observada (abaixo da diagonal) através das adagas casualizadas (RS), da correlação de matrizes (CM) e da projeção de Krzanowski (KRZ) para as matrizes 25D dos níveis supragenéricos de Xenarthra. A diagonal contém a repetibilidade de cada matriz e acima dela estão os valores de similaridade ajustados.

\begin{tabular}{|c|c|c|c|c|c|c|c|c|c|c|c|c|c|c|c|c|c|c|c|c|}
\hline RS & 1 & 2 & 3 & 4 & 5 & 6 & 7 & 8 & 9 & 10 & 11 & 12 & 13 & 14 & 15 & 16 & 17 & 18 & 19 & 20 \\
\hline 1, Euphractinae & 0,98 & 0,90 & 0,79 & 0,72 & 0,74 & 0,80 & 0,81 & 0,59 & 0,62 & & & & & & & & & & & \\
\hline 2, Tolypeutinae & 0,87 & 0,96 & 0,79 & 0,73 & 0,76 & 0,80 & 0,81 & 0,62 & 0,68 & & & & & & & & & & & \\
\hline 3, Dasypodinae & 0,78 & 0,77 & 0,99 & 0,88 & 0,65 & 0,57 & 0,61 & 0,49 & 0,66 & & & & & & & & & & & \\
\hline 4, Myrmecophaginae & 0,70 & 0,71 & 0,87 & 0,98 & 0,68 & 0,54 & 0,60 & 0,45 & 0,62 & & & & & & & & & & & \\
\hline 5, Cyclopedinae & 0,72 & 0,73 & 0,64 & 0,66 & 0,97 & 0,77 & 0,76 & 0,54 & 0,79 & & & & & & & & & & & \\
\hline 6, Choloepinae & 0,77 & 0,76 & 0,55 & 0,52 & 0,73 & 0,94 & 0,83 & 0,63 & 0,79 & & & & & & & & & & & \\
\hline 7, Bradypodinae & 0,79 & 0,78 & 0,60 & 0,59 & 0,74 & 0,80 & 0,98 & 0,61 & 0,78 & & & & & & & & & & & \\
\hline 8, Mylodontinae & 0,51 & 0,54 & 0,43 & 0,40 & 0,47 & 0,54 & 0,53 & 0,79 & 0,90 & & & & & & & & & & & \\
\hline 9, Scelidotheriinae & 0,54 & 0,59 & 0,57 & 0,54 & 0,68 & 0,67 & 0,68 & 0,70 & 0,77 & & & & & & & & & & & \\
\hline 10, Dasypodidae & & & & & & & & & & 0,99 & 0,82 & 0,74 & 0,73 & 0,74 & 0,32 & & & & & \\
\hline 11, Myrmecophagidae & & & & & & & & & & 0,81 & 0,98 & 0,68 & 0,54 & 0,60 & 0,29 & & & & & \\
\hline 12, Cyclopedidae & & & & & & & & & & 0,73 & 0,66 & 0,96 & 0,77 & 0,76 & 0,38 & & & & & \\
\hline 13, Megalonychidae & & & & & & & & & & 0,71 & 0,52 & 0,73 & 0,94 & 0,83 & 0,45 & & & & & \\
\hline 14, Bradypodidae & & & & & & & & & & 0,73 & 0,59 & 0,74 & 0,80 & 0,98 & 0,46 & & & & & \\
\hline 15, Mylodontidae & & & & & & & & & & 0,30 & 0,27 & 0,36 & 0,42 & 0,44 & 0,91 & & & & & \\
\hline 16, Dasypodidae & & & & & & & & & & & & & & & & 0,99 & 0,83 & 0,35 & & \\
\hline 17, Vermilingua & & & & & & & & & & & & & & & & 0,82 & 0,98 & 0,31 & & \\
\hline 18 , Folivora & & & & & & & & & & & & & & & & 0,33 & 0,30 & 0,92 & & \\
\hline 19, Cingulata & & & & & & & & & & & & & & & & & & & 0,99 & 0,74 \\
\hline 20, Pilosa & & & & & & & & & & & & & & & & & & & 0,71 & 0,93 \\
\hline CM & 1 & 2 & 3 & 4 & 5 & 6 & 7 & 8 & 9 & 10 & 11 & 12 & 13 & 14 & 15 & 16 & 17 & 18 & 19 & 20 \\
\hline 1, Euphractinae & 0,95 & 0,74 & 0,60 & 0,68 & 0,58 & 0,64 & 0,63 & 0,50 & 0,27 & & & & & & & & & & & \\
\hline 2, Tolypeutinae & 0,68 & 0,91 & 0,63 & 0,61 & 0,55 & 0,62 & 0,59 & 0,52 & 0,37 & & & & & & & & & & & \\
\hline 3, Dasypodinae & 0,57 & 0,59 & 0,96 & 0,62 & 0,57 & 0,44 & 0,49 & 0,31 & 0,47 & & & & & & & & & & & \\
\hline 4, Myrmecophaginae & 0,65 & 0,56 & 0,59 & 0,94 & 0,80 & 0,52 & 0,64 & 0,43 & 0,24 & & & & & & & & & & & \\
\hline 5, Cyclopedinae & 0,55 & 0,50 & 0,54 & 0,75 & 0,94 & 0,59 & 0,63 & 0,33 & 0,41 & & & & & & & & & & & \\
\hline 6 , Choloepinae & 0,59 & 0,56 & 0,41 & 0,48 & 0,54 & 0,89 & 0,67 & 0,56 & 0,55 & & & & & & & & & & & \\
\hline 7, Bradypodinae & 0,60 & 0,55 & 0,47 & 0,61 & 0,60 & 0,62 & 0,96 & 0,44 & 0,39 & & & & & & & & & & & \\
\hline 8, Mylodontinae & 0,43 & 0,43 & 0,27 & 0,36 & 0,28 & 0,46 & 0,37 & 0,76 & 0,50 & & & & & & & & & & & \\
\hline 9, Scelidotheriinae & 0,23 & 0,30 & 0,40 & 0,20 & 0,35 & 0,44 & 0,33 & 0,38 & 0,74 & & & & & & & & & & & \\
\hline 10, Dasypodidae & & & & & & & & & & 0,97 & 0,75 & 0,65 & 0,63 & 0,65 & 0,45 & & & & & \\
\hline 11, Myrmecophagidae & & & & & & & & & & 0,72 & 0,95 & 0,80 & 0,52 & 0,64 & 0,35 & & & & & \\
\hline 12, Cyclopedidae & & & & & & & & & & 0,62 & 0,75 & 0,93 & 0,59 & 0,63 & 0,24 & & & & & \\
\hline 13, Megalonychidae & & & & & & & & & & 0,59 & 0,48 & 0,54 & 0,89 & 0,67 & 0,43 & & & & & \\
\hline 14, Bradypodidae & & & & & & & & & & 0,63 & 0,61 & 0,60 & 0,62 & 0,96 & 0,31 & & & & & \\
\hline 15, Mylodontidae & & & & & & & & & & 0,41 & 0,32 & 0,22 & 0,38 & 0,29 & 0,88 & & & & & \\
\hline 16, Dasypodidae & & & & & & & & & & & & & & & & 0,98 & 0,74 & 0,49 & & \\
\hline 17 , Vermilingua & & & & & & & & & & & & & & & & 0,71 & 0,95 & 0,39 & & \\
\hline 18, Folivora & & & & & & & & & & & & & & & & 0,46 & 0,36 & 0,89 & & \\
\hline 19 , Cingulata & & & & & & & & & & & & & & & & & & & 0,97 & 0,57 \\
\hline 20, Pilosa & & & & & & & & & & & & & & & & & & & 0,53 & 0,90 \\
\hline KRZ & 1 & 2 & 3 & 4 & 5 & 6 & 7 & 8 & 9 & 10 & 11 & 12 & 13 & 14 & 15 & 16 & 17 & 18 & 19 & 20 \\
\hline 1, Euphractinae & 0,95 & 0,84 & 0,72 & 0,76 & 0,70 & 0,82 & 0,72 & 0,81 & 0,74 & & & & & & & & & & & \\
\hline 2, Tolypeutinae & 0,78 & 0,90 & 0,78 & 0,85 & 0,76 & 0,81 & 0,70 & 0,84 & 0,76 & & & & & & & & & & & \\
\hline 3, Dasypodinae & 0,68 & 0,72 & 0,94 & 0,71 & 0,68 & 0,72 & 0,67 & 0,79 & 0,70 & & & & & & & & & & & \\
\hline 4, Myrmecophaginae & 0,72 & 0,79 & 0,67 & 0,96 & 0,86 & 0,84 & 0,75 & 0,81 & 0,74 & & & & & & & & & & & \\
\hline 5, Cyclopedinae & 0,66 & 0,70 & 0,64 & 0,81 & 0,94 & 0,79 & 0,77 & 0,76 & 0,72 & & & & & & & & & & & \\
\hline 6, Choloepinae & 0,75 & 0,73 & 0,66 & 0,78 & 0,73 & 0,90 & 0,83 & 0,88 & 0,80 & & & & & & & & & & & \\
\hline 7, Bradypodinae & 0,68 & 0,64 & 0,63 & 0,71 & 0,72 & 0,76 & 0,93 & 0,80 & 0,74 & & & & & & & & & & & \\
\hline 8, Mylodontinae & 0,71 & 0,72 & 0,69 & 0,72 & 0,67 & 0,76 & 0,70 & 0,82 & 0,85 & & & & & & & & & & & \\
\hline 9, Scelidotheriinae & 0,65 & 0,66 & 0,61 & 0,66 & 0,63 & 0,69 & 0,65 & 0,70 & 0,82 & & & & & & & & & & & \\
\hline 10, Dasypodidae & & & & & & & & & & 0,94 & 0,79 & 0,74 & 0,80 & 0,67 & 0,79 & & & & & \\
\hline 11, Myrmecophagidae & & & & & & & & & & 0,75 & 0,96 & 0,85 & 0,84 & 0,75 & 0,80 & & & & & \\
\hline 12, Cyclopedidae & & & & & & & & & & 0,69 & 0,81 & 0,94 & 0,79 & 0,77 & 0,73 & & & & & \\
\hline 13, Megalonychidae & & & & & & & & & & 0,73 & 0,78 & 0,73 & 0,90 & 0,83 & 0,85 & & & & & \\
\hline 14, Bradypodidae & & & & & & & & & & 0,63 & 0,71 & 0,72 & 0,76 & 0,93 & 0,77 & & & & & \\
\hline 15, Mylodontidae & & & & & & & & & & 0,74 & 0,75 & 0,69 & 0,78 & 0,72 & 0,94 & & & & & \\
\hline 16, Dasypodidae & & & & & & & & & & & & & & & & 0,93 & 0,81 & 0,81 & & \\
\hline 17, Vermilingua & & & & & & & & & & & & & & & & 0,77 & 0,95 & 0,83 & & \\
\hline 18, Folivora & & & & & & & & & & & & & & & & 0,76 & 0,79 & 0 & & \\
\hline 19, Cingulata & & & & & & & & & & & & & & & & & & & 0,94 & 0,80 \\
\hline 20, Pilosa & & & & & & & & & & & & & & & & & & & 0,76 & 0,95 \\
\hline
\end{tabular}


Em relação à SRD, os índices de diferença no SRD para cada distância permitiram classificá-las entre os extremos pouco divergentes e muito divergentes (Figura 1.14; Tabelas 1.19-1.22). Por um lado, 12 distâncias (ISPNS, NSLZS, NSLZI, ZITSP, PMZS, PMZI, PMMT, NABR, NAPNS, BRAPET, BAEAM e OPILD) foram consideradas pouco divergentes, pois estiveram consistentemente associadas a índices de variação pequenos (ou nulos). Por outro lado, foram encontradas cinco distâncias bastante divergentes, com índices de diferença no SRD elevados, para todos os gêneros, sendo elas: PTTSP, ZSZI, APETTS, BRLD e BAOPI. As 18 distâncias restantes apresentaram valores intermediários para o índice de diferença no SRD (ISPM, ISNSL, NSLNA, BRPT, PTEAM, PTZYGO, ZIMT, MTPNS, EAMZYGO, ZYGOTSP, LDAS, PTAPET, PTBA, ZIZYGO, PNSAPET, APETBA, PTAS e JPAS). Assim como para as análises de similaridade global através das RS, da CM e da KRZ, os resultados da SRD para os diferentes conjuntos de distâncias foram semelhantes. Ainda, o índice de diferença no SRD para as diversas distâncias não esteve claramente associado a nenhuma parte do crânio (face e neucrocrânio; Tabela 1.3). Em outras palavras, as distâncias com maiores ou menores índices de diferença no SRD não se relacionaram preferencialmente com a face ou o neurocrânio. Também não foi observado qualitativamente um padrão nos índices de diferença no SRD em relação à estrutura filogenética. Por exemplo, dentro de Tolypeutinae, enquanto Tolypeutes apresentou um índice de diferença no SRD de 0,91 em 35D para ISPM, Cabassous apresentou um valor de 0,27. Já para LDAS os valores foram 0,36 e 0,73 , respectivamente.

Por último, as similaridades observadas para as comparações entre as matrizes-G de roedores (Akodon e Calomys) e matrizes-P de marsupiais (Caluromys, Dydelphis e Metachirus) com as matrizes-P de Xenarthra foram geralmente elevadas nas comparações de matrizes de covariância (Tabelas 1.23-1.26). Por outro lado, os valore encontrados através da CM foram 
geralmente de intermediários a baixos. À exceção dos valores encontrados para CM, as similaridades observadas foram geralmente superiores a 0,5 . Levando em conta somente as similaridades entre as matrizes-P dos marsupiais e dos Xenarthra nenhum valor foi inferior a 0,6 para RS e KRZ. Como nos demais resultados para as similaridades entre matrizes, não houve diferenças marcantes entre os diferentes conjuntos de distâncias. 


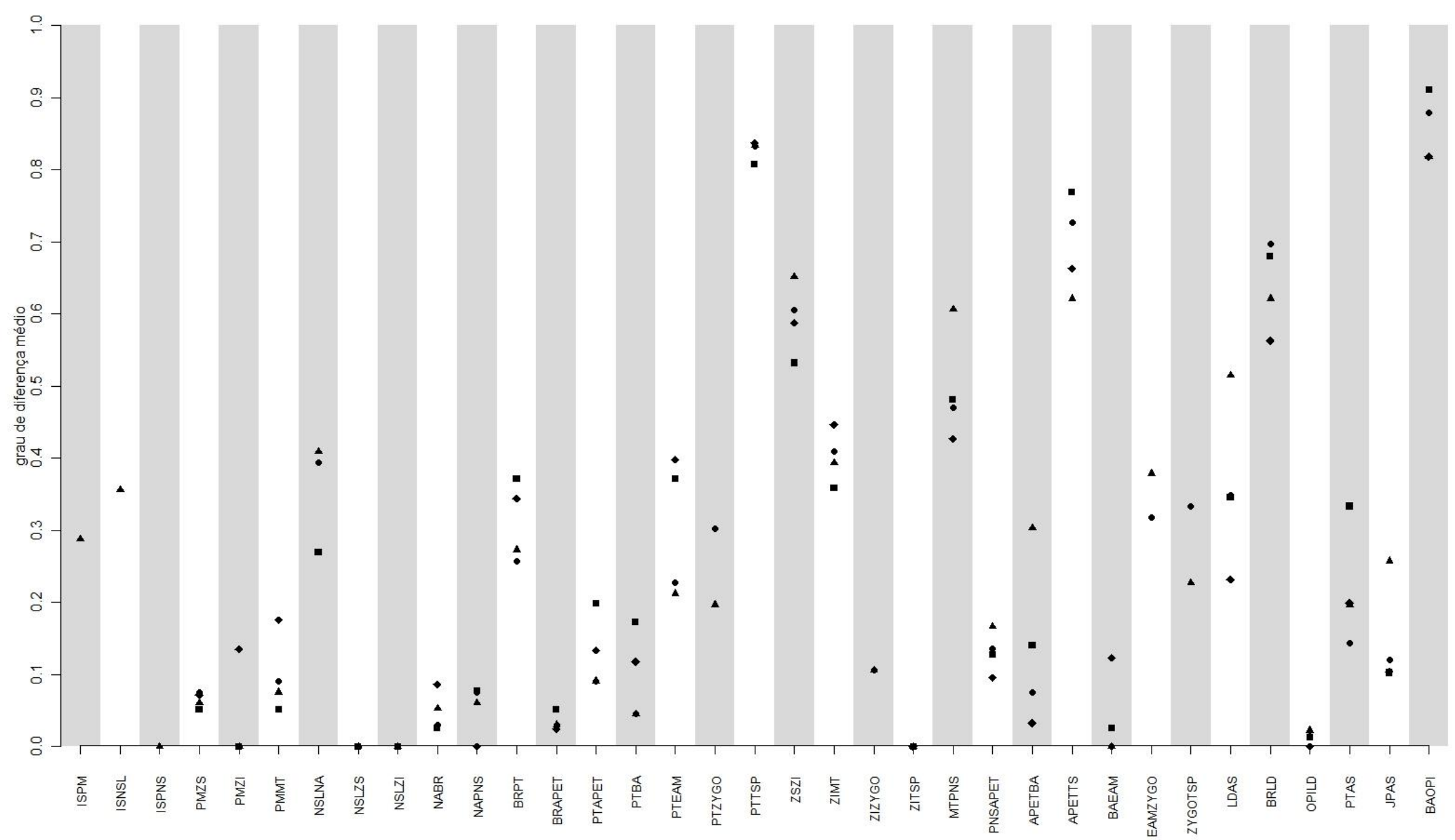

Figura 1.14 - índice de diferença no SRD para todos os gêneros. Triângulo: 35D; círculo: 32D; quadrado: 28D; e losango: 25D. 
Tabela 1.19 - Índice de diferença no SRD para cada gênero e distância em 35D.

\begin{tabular}{|c|c|c|c|c|c|c|c|c|c|c|c|c|c|c|c|c|c|c|}
\hline & ISPM & ISNSL & ISPNS & PMZS & PMZI & РMMT & NSLNA & NSLZS & NSLZI & NABR & NAPNS & BRPT & BRAPET & PTAPET & PTBA & PTEAM & PTZYGO & PTTSP \\
\hline Zaedyus & 0,09 & 0,18 & 0,00 & 0,00 & 0,00 & 0,00 & 0,82 & 0,00 & 0,00 & 0,00 & 0,00 & 0,45 & 0,00 & 0,09 & 0,00 & 0,82 & 0,18 & 1,00 \\
\hline Tolypeutes & 0,91 & 0,27 & 0,00 & 0,00 & 0,00 & 0,00 & 0,73 & 0,00 & 0,00 & 0,00 & 0,00 & 0,36 & 0,00 & 0,00 & 0,00 & 0,00 & 0,09 & 1,00 \\
\hline Priodontes & 0,09 & 0,09 & 0,00 & 0,27 & 0,00 & 0,45 & 0,09 & 0,00 & 0,00 & 0,00 & 0,00 & 0,00 & 0,18 & 0,45 & 0,27 & 0,45 & 1,00 & 0,91 \\
\hline Euphractus & 0,18 & 0,18 & 0,00 & 0,18 & 0,00 & 0,09 & 0,73 & 0,00 & 0,00 & 0,00 & 0,00 & 0,18 & 0,00 & 0,09 & 0,00 & 0,18 & 0,09 & 1,00 \\
\hline Dasypus & 0,18 & 0,27 & 0,00 & 0,00 & 0,00 & 0,00 & 0,27 & 0,00 & 0,00 & 0,00 & 0,00 & 0,09 & 0,09 & 0,09 & 0,09 & 0,18 & 0,18 & 0,82 \\
\hline Chaetophractus & 0,09 & 0,18 & 0,00 & 0,09 & 0,00 & 0,09 & 0,45 & 0,00 & 0,00 & 0,27 & 0,36 & 0,91 & 0,00 & 0,09 & 0,00 & 0,18 & 0,09 & 0,55 \\
\hline Cabassous & 0,27 & 0,36 & 0,00 & 0,00 & 0,00 & 0,09 & 0,36 & 0,00 & 0,00 & 0,09 & 0,09 & 0,36 & 0,00 & 0,00 & 0,00 & 0,09 & 0,09 & 0,73 \\
\hline Tamandua & 0,18 & 0,45 & 0,00 & 0,00 & 0,00 & 0,00 & 0,18 & 0,00 & 0,00 & 0,00 & 0,00 & 0,27 & 0,00 & 0,09 & 0,09 & 0,18 & 0,09 & 0,73 \\
\hline Cyclopes & 0,27 & 1,00 & 0,00 & 0,00 & 0,00 & 0,00 & 0,27 & 0,00 & 0,00 & 0,09 & 0,00 & 0,09 & 0,00 & 0,00 & 0,00 & 0,09 & 0,18 & 0,64 \\
\hline Myrmecophaga & 0,55 & 0,27 & 0,00 & 0,00 & 0,00 & 0,00 & 0,18 & 0,00 & 0,00 & 0,09 & 0,09 & 0,18 & 0,09 & 0,09 & 0,09 & 0,18 & 0,18 & 1,00 \\
\hline Bradypus & 0,55 & 0,18 & 0,00 & 0,09 & 0,00 & 0,09 & 0,36 & 0,00 & 0,00 & 0,09 & 0,09 & 0,18 & 0,00 & 0,00 & 0,00 & 0,09 & 0,09 & 0,73 \\
\hline \multirow[t]{2}{*}{ Choloepus } & 0,09 & 0,82 & 0,00 & 0,09 & 0,00 & 0,09 & 0,45 & 0,00 & 0,00 & 0,00 & 0,09 & 0,18 & 0,00 & 0,09 & 0,00 & 0,09 & 0,09 & 0,91 \\
\hline & zszı & ZIMT & ZIZYGO & ZITSP & MTPNS & PNSAPET & APETBA & APETTS & BAEAM & EAMZYGO & ZYGOTSP & LDAS & BRLD & OPILD & PTAS & JPAS & BAOPI & \\
\hline Zaedyus & 0,45 & 0,18 & 0,00 & 0,00 & 0,64 & 0,82 & 0,18 & 0,36 & 0,00 & 0,82 & 0,36 & 0,18 & 1,00 & 0,09 & 0,82 & 0,09 & 0,73 & \\
\hline Tolypeutes & 1,00 & 0,27 & 0,18 & 0,00 & 0,36 & 0,09 & 0,18 & 1,00 & 0,00 & 0,09 & 0,09 & 0,64 & 0,45 & 0,00 & 0,00 & 0,09 & 0,82 & \\
\hline Priodontes & 0,45 & 0,91 & 0,00 & 0,00 & 0,09 & 0,18 & 0,27 & 0,82 & 0,00 & 1,00 & 1,00 & 0,36 & 0,64 & 0,00 & 0,00 & 0,09 & 1,00 & \\
\hline Euphractus & 0,45 & 0,36 & 0,09 & 0,00 & 0,55 & 0,09 & 0,18 & 0,64 & 0,00 & 0,27 & 0,09 & 0,36 & 0,64 & 0,00 & 0,09 & 0,18 & 0,82 & \\
\hline Dasypus & 0,91 & 0,45 & 0,45 & 0,00 & 0,91 & 0,18 & 0,18 & 0,55 & 0,00 & 0,27 & 0,18 & 0,55 & 0,73 & 0,00 & 0,36 & 0,09 & 0,82 & \\
\hline Chaetophractus & 0,45 & 0,82 & 0,09 & 0,00 & 0,55 & 0,09 & 0,18 & 0,64 & 0,00 & 0,55 & 0,09 & 0,45 & 0,91 & 0,00 & 0,27 & 0,09 & 1,00 & \\
\hline Cabassous & 0,55 & 0,36 & 0,09 & 0,00 & 0,55 & 0,18 & 0,27 & 1,00 & 0,00 & 0,27 & 0,09 & 0,91 & 0,55 & 0,09 & 0,18 & 0,18 & 0,73 & \\
\hline Tamandua & 0,45 & 0,27 & 0,18 & 0,00 & 0,45 & 0,09 & 0,18 & 0,36 & 0,00 & 0,36 & 0,27 & 0,27 & 0,82 & 0,00 & 0,27 & 0,27 & 1,00 & \\
\hline Cyclopes & 1,00 & 0,09 & 0,00 & 0,00 & 0,91 & 0,00 & 0,91 & 0,36 & 0,00 & 0,18 & 0,09 & 0,64 & 0,64 & 0,00 & 0,09 & 1,00 & 0,36 & \\
\hline Myrmecophaga & 0,91 & 0,73 & 0,18 & 0,00 & 0,91 & 0,09 & 0,73 & 0,36 & 0,00 & 0,45 & 0,18 & 0,45 & 0,55 & 0,00 & 0,09 & 0,55 & 0,64 & \\
\hline Bradypus & 0,45 & 0,18 & 0,00 & 0,00 & 1,00 & 0,09 & 0,27 & 0,36 & 0,00 & 0,18 & 0,18 & 0,91 & 0,27 & 0,09 & 0,09 & 0,18 & 1,00 & \\
\hline Choloepus & 0,73 & 0,09 & 0,00 & 0,00 & 0,36 & 0,09 & 0,09 & 1,00 & 0,00 & 0,09 & 0,09 & 0,45 & 0,27 & 0,00 & 0,09 & 0,27 & 0,91 & \\
\hline
\end{tabular}


Tabela 1.20 - Índice de diferença no SRD para cada gênero e distância em 32D.

\begin{tabular}{|c|c|c|c|c|c|c|c|c|c|c|c|c|c|c|c|c|}
\hline & PMZS & PMZI & PMMT & NSLNA & NSLZS & NSLZI & NABR & NAPNS & BRPT & BRAPET & PTAPET & PTBA & PTEAM & PTZYGO & PTTSP & zszI \\
\hline Zaedyus & 0,00 & 0,00 & 0,00 & 0,73 & 0,00 & 0,00 & 0,00 & 0,00 & 0,45 & 0,00 & 0,09 & 0,00 & 0,82 & 0,18 & 1,00 & 0,36 \\
\hline Tolypeutes & 0,00 & 0,00 & 0,09 & 0,64 & 0,00 & 0,00 & 0,00 & 0,00 & 0,27 & 0,00 & 0,00 & 0,00 & 0,00 & 0,18 & 1,00 & 1,00 \\
\hline Priodontes & 0,27 & 0,00 & 0,55 & 0,09 & 0,00 & 0,00 & 0,00 & 0,00 & 0,00 & 0,18 & 0,55 & 0,27 & 0,45 & 0,91 & 0,91 & 0,45 \\
\hline Euphractus & 0,18 & 0,00 & 0,09 & 0,64 & 0,00 & 0,00 & 0,00 & 0,00 & 0,18 & 0,00 & 0,09 & 0,00 & 0,27 & 0,18 & 1,00 & 0,36 \\
\hline Dasypus & 0,00 & 0,00 & 0,00 & 0,27 & 0,00 & 0,00 & 0,00 & 0,00 & 0,09 & 0,09 & 0,09 & 0,09 & 0,18 & 0,18 & 0,82 & 0,91 \\
\hline Chaetophractus & 0,18 & 0,00 & 0,09 & 0,45 & 0,00 & 0,00 & 0,18 & 0,45 & 0,91 & 0,00 & 0,00 & 0,00 & 0,18 & 0,18 & 0,64 & 0,36 \\
\hline Cabassous & 0,00 & 0,00 & 0,09 & 0,36 & 0,00 & 0,00 & 0,09 & 0,09 & 0,36 & 0,00 & 0,00 & 0,00 & 0,09 & 0,18 & 0,82 & 0,45 \\
\hline Tamandua & 0,00 & 0,00 & 0,00 & 0,18 & 0,00 & 0,00 & 0,00 & 0,09 & 0,27 & 0,00 & 0,09 & 0,09 & 0,18 & 0,18 & 0,73 & 0,55 \\
\hline Cyclopes & 0,00 & 0,00 & 0,00 & 0,00 & 0,00 & 0,00 & 0,00 & 0,00 & 0,18 & 0,00 & 0,00 & 0,00 & 0,18 & 0,91 & 0,82 & 1,00 \\
\hline Myrmecophaga & 0,00 & 0,00 & 0,00 & 0,36 & 0,00 & 0,00 & 0,09 & 0,09 & 0,09 & 0,00 & 0,09 & 0,09 & 0,18 & 0,18 & 0,73 & 0,45 \\
\hline Bradypus & 0,18 & 0,00 & 0,09 & 0,45 & 0,00 & 0,00 & 0,00 & 0,09 & 0,09 & 0,00 & 0,00 & 0,00 & 0,09 & 0,18 & 0,64 & 0,45 \\
\hline \multirow[t]{2}{*}{ Choloepus } & 0,09 & 0,00 & 0,09 & 0,55 & 0,00 & 0,00 & 0,00 & 0,09 & 0,18 & 0,09 & 0,09 & 0,00 & 0,09 & 0,18 & 0,91 & 0,91 \\
\hline & ZIMT & ZIZYGO & ZITSP & MTPNS & PNSAPET & AРETBA & APETTS & BAEAM & EAMZYGO & ZYGOTSP & LDAS & BRLD & OPILD & PTAS & JPAS & BAOP \\
\hline Zaedyus & 0,27 & 0,00 & 0,00 & 0,36 & 0,82 & 0,00 & 0,45 & 0,00 & 0,73 & 0,55 & 0,27 & 1,00 & 0,00 & 0,64 & 0,09 & 0,82 \\
\hline Tolypeutes & 0,27 & 0,18 & 0,00 & 0,27 & 0,09 & 0,00 & 1,00 & 0,00 & 0,09 & 0,09 & 0,36 & 0,55 & 0,00 & 0,00 & 0,00 & 0,91 \\
\hline Priodontes & 0,91 & 0,00 & 0,00 & 0,09 & 0,00 & 0,27 & 0,73 & 0,00 & 1,00 & 1,00 & 0,36 & 0,64 & 0,00 & 0,00 & 0,09 & 0,82 \\
\hline Euphractus & 0,36 & 0,09 & 0,00 & 0,55 & 0,09 & 0,09 & 0,82 & 0,00 & 0,18 & 0,09 & 0,18 & 0,55 & 0,00 & 0,09 & 0,00 & 0,91 \\
\hline Dasypus & 0,45 & 0,45 & 0,00 & 0,91 & 0,09 & 0,09 & 0,64 & 0,00 & 0,18 & 0,18 & 0,45 & 0,64 & 0,00 & 0,27 & 0,09 & 0,82 \\
\hline Chaetophractus & 0,73 & 0,09 & 0,00 & 0,36 & 0,09 & 0,09 & 0,73 & 0,00 & 0,45 & 0,09 & 0,36 & 0,91 & 0,00 & 0,18 & 0,09 & 1,00 \\
\hline Cabassous & 0,36 & 0,09 & 0,00 & 0,45 & 0,09 & 0,09 & 1,00 & 0,00 & 0,27 & 0,27 & 0,73 & 0,55 & 0,09 & 0,18 & 0,00 & 0,82 \\
\hline Tamandua & 0,27 & 0,18 & 0,00 & 0,27 & 0,09 & 0,00 & 0,45 & 0,00 & 0,27 & 0,36 & 0,27 & 0,91 & 0,00 & 0,18 & 0,18 & 0,91 \\
\hline Cyclopes & 0,09 & 0,00 & 0,00 & 0,91 & 0,00 & 0,00 & 1,00 & 0,00 & 0,09 & 0,36 & 0,00 & 0,91 & 0,00 & 0,00 & 0,36 & 1,00 \\
\hline Myrmecophaga & 0,82 & 0,18 & 0,00 & 0,36 & 0,09 & 0,27 & 0,45 & 0,00 & 0,27 & 0,45 & 0,36 & 0,45 & 0,00 & 0,09 & 0,18 & 0,73 \\
\hline Bradypus & 0,18 & 0,00 & 0,00 & 0,82 & 0,09 & 0,00 & 0,45 & 0,00 & 0,18 & 0,36 & 0,73 & 0,45 & 0,09 & 0,09 & 0,00 & 0,91 \\
\hline Choloepus & 0,18 & 0,00 & 0,00 & 0,27 & 0,09 & 0,00 & 1,00 & 0,00 & 0,09 & 0,18 & 0,09 & 0,82 & 0,00 & 0,00 & 0,36 & 0,91 \\
\hline
\end{tabular}


Tabela 1.21 - Índice de diferença no SRD para cada gênero e distância em 28D.

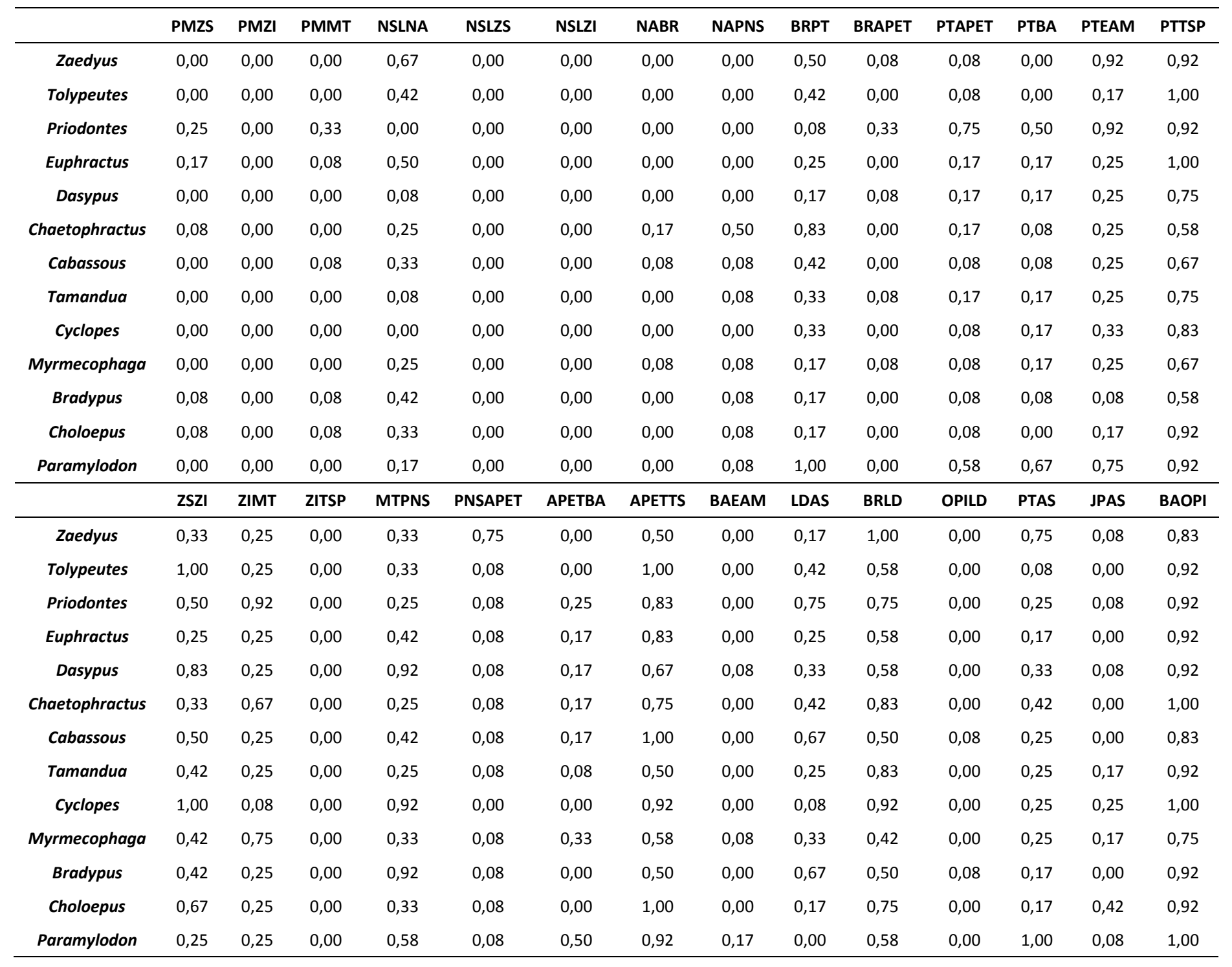


Tabela 1.22 - Índice de diferença no SRD para cada gênero e distância em 25D.

\begin{tabular}{|c|c|c|c|c|c|c|c|c|c|c|c|c|c|}
\hline & PMZS & PMZI & РMMT & NABR & NAPNS & BRPT & BRAPET & PTAPET & PTBA & PTEAM & PTTSP & ZszI & ZIMT \\
\hline Zaedyus & 0,00 & 0,00 & 0,08 & 0,00 & 0,00 & 0,77 & 0,15 & 0,08 & 0,00 & 0,54 & 0,92 & 0,31 & 0,23 \\
\hline Tolypeutes & 0,08 & 0,00 & 0,08 & 0,15 & 0,00 & 0,31 & 0,00 & 0,00 & 0,00 & 0,08 & 1,00 & 1,00 & 0,23 \\
\hline Priodontes & 0,69 & 0,15 & 0,85 & 0,00 & 0,00 & 0,00 & 0,23 & 0,46 & 0,15 & 0,31 & 0,92 & 0,23 & 0,92 \\
\hline Euphractus & 0,15 & 0,00 & 0,08 & 0,08 & 0,00 & 0,31 & 0,00 & 0,15 & 0,08 & 0,38 & 1,00 & 0,31 & 0,31 \\
\hline Dasypus & 0,00 & 0,00 & 0,00 & 0,08 & 0,00 & 0,15 & 0,08 & 0,23 & 0,15 & 0,31 & 0,77 & 0,92 & 0,31 \\
\hline Chaetophractus & 0,15 & 0,00 & 0,08 & 0,08 & 0,00 & 0,85 & 0,00 & 0,15 & 0,08 & 0,15 & 0,62 & 0,38 & 0,54 \\
\hline Cabassous & 0,08 & 0,00 & 0,08 & 0,08 & 0,00 & 0,38 & 0,00 & 0,08 & 0,08 & 0,15 & 0,85 & 0,38 & 0,15 \\
\hline Tamandua & 0,00 & 0,00 & 0,08 & 0,00 & 0,00 & 0,31 & 0,00 & 0,15 & 0,08 & 0,31 & 0,77 & 0,38 & 0,23 \\
\hline Cyclopes & 0,08 & 0,00 & 0,08 & 0,00 & 0,00 & 0,46 & 0,00 & 0,08 & 0,08 & 0,38 & 0,92 & 1,00 & 0,08 \\
\hline Myrmecophaga & 0,00 & 0,00 & 0,00 & 0,08 & 0,00 & 0,15 & 0,08 & 0,08 & 0,15 & 0,38 & 0,77 & 0,46 & 0,85 \\
\hline Bradypus & 0,15 & 0,08 & 0,08 & 0,08 & 0,00 & 0,23 & 0,00 & 0,00 & 0,00 & 0,15 & 0,62 & 0,38 & 0,31 \\
\hline Choloepus & 0,08 & 0,08 & 0,08 & 0,15 & 0,00 & 0,15 & 0,08 & 0,08 & 0,00 & 0,00 & 0,92 & 0,69 & 0,23 \\
\hline Paramylodon & 0,08 & 0,00 & 0,08 & 0,08 & 0,00 & 0,85 & 0,00 & 0,54 & 0,54 & 0,69 & 0,92 & 0,31 & 0,46 \\
\hline \multirow[t]{2}{*}{ Scelidotherium } & 0,08 & 0,85 & 0,85 & 0,23 & 0,00 & 0,23 & 0,00 & 0,00 & 0,00 & 0,92 & 0,92 & 0,92 & 1,00 \\
\hline & ZITSP & MTPNS & PNSAPET & APETBA & APETTS & BAEAM & LDAS & BRLD & OPILD & PTAS & JPAS & BAOPI & \\
\hline Zaedyus & 0,00 & 0,15 & 0,92 & 0,00 & 0,46 & 0,00 & 0,23 & 0,85 & 0,00 & 0,54 & 0,08 & 0,85 & \\
\hline Tolypeutes & 0,00 & 0,15 & 0,08 & 0,00 & 1,00 & 0,00 & 0,38 & 0,46 & 0,00 & 0,08 & 0,00 & 0,92 & \\
\hline Priodontes & 0,00 & 0,00 & 0,15 & 0,08 & 0,62 & 0,00 & 0,69 & 0,46 & 0,00 & 0,00 & 0,08 & 0,92 & \\
\hline Euphractus & 0,00 & 0,23 & 0,08 & 0,08 & 0,69 & 0,00 & 0,23 & 0,62 & 0,00 & 0,23 & 0,00 & 0,92 & \\
\hline Dasypus & 0,00 & 0,77 & 0,08 & 0,00 & 0,69 & 0,00 & 0,31 & 0,62 & 0,00 & 0,15 & 0,00 & 0,77 & \\
\hline Chaetophractus & 0,00 & 0,15 & 0,08 & 0,00 & 0,62 & 0,00 & 0,38 & 0,77 & 0,00 & 0,31 & 0,00 & 1,00 & \\
\hline Cabassous & 0,00 & 0,23 & 0,08 & 0,08 & 1,00 & 0,00 & 0,69 & 0,46 & 0,00 & 0,23 & 0,00 & 0,85 & \\
\hline Tamandua & 0,00 & 0,23 & 0,08 & 0,00 & 0,31 & 0,00 & 0,23 & 0,77 & 0,00 & 0,23 & 0,15 & 0,92 & \\
\hline Cyclopes & 0,00 & 0,92 & 0,00 & 0,00 & 0,85 & 0,00 & 0,08 & 0,92 & 0,00 & 0,08 & 0,23 & 1,00 & \\
\hline Myrmecophaga & 0,00 & 0,23 & 0,08 & 0,15 & 0,31 & 0,00 & 0,31 & 0,31 & 0,00 & 0,23 & 0,15 & 0,69 & \\
\hline Bradypus & 0,00 & 0,54 & 0,08 & 0,08 & 0,54 & 0,00 & 0,69 & 0,46 & 0,00 & 0,08 & 0,00 & 0,85 & \\
\hline Choloepus & 0,00 & 0,15 & 0,15 & 0,00 & 1,00 & 0,00 & 0,15 & 0,69 & 0,00 & 0,00 & 0,23 & 0,77 & \\
\hline Paramylodon & 0,00 & 0,23 & 0,23 & 0,00 & 0,62 & 0,08 & 0,00 & 0,54 & 0,00 & 0,77 & 0,00 & 1,00 & \\
\hline Scelidotherium & 0,00 & 0,85 & 0,00 & 0,00 & 1,00 & 0,92 & 0,08 & 0,15 & 0,00 & 0,00 & 0,00 & 0,46 & \\
\hline
\end{tabular}


Tabela 1.23 - Similaridade observada através das adagas casualizadas (RS), da correlação de matrizes (CM) e da projeção de Krzanowski (KRZ) entre as matrizes-G de roedores e matrizes-P de marsupiais com as matrizes-P de Xenarthra em 35D.

\begin{tabular}{|c|c|c|c|c|c|c|c|c|c|c|c|c|c|}
\hline RS & Zaedyus & Tolypeutes & Priodontes & Euphractus & Dasypus & Chaetophractus & Cabassous & Tamandua & Cyclopes & Myrmecophaga & Bradypus & Choloepus & Média \\
\hline Calomys (G) & 0,659 & 0,669 & 0,530 & 0,736 & 0,687 & 0,711 & 0,780 & 0,705 & 0,589 & 0,675 & 0,752 & 0,645 & 0,678 \\
\hline Akodon (G) & 0,586 & 0,580 & 0,506 & 0,633 & 0,572 & 0,628 & 0,625 & 0,556 & 0,510 & 0,512 & 0,619 & 0,580 & 0,576 \\
\hline Caluromys (P) & 0,686 & 0,730 & 0,594 & 0,788 & 0,716 & 0,758 & 0,812 & 0,785 & 0,681 & 0,721 & 0,779 & 0,726 & 0,731 \\
\hline Didelphis (P) & 0,692 & 0,704 & 0,606 & 0,791 & 0,716 & 0,745 & 0,795 & 0,782 & 0,715 & 0,712 & 0,769 & 0,733 & 0,730 \\
\hline Metachirus (P) & 0,713 & 0,694 & 0,642 & 0,773 & 0,742 & 0,791 & 0,797 & 0,820 & 0,672 & 0,750 & 0,733 & 0,697 & 0,735 \\
\hline CM & Zaedyus & Tolypeutes & Priodontes & Euphractus & Dasypus & Chaetophractus & Cabassous & Tamandua & Cyclopes & Myrmecophaga & Bradypus & Choloepus & Média \\
\hline Calomys (G) & 0,219 & 0,345 & 0,189 & 0,408 & 0,387 & 0,419 & 0,471 & 0,475 & 0,217 & 0,371 & 0,559 & 0,334 & 0,366 \\
\hline Akodon (G) & 0,213 & 0,203 & 0,120 & 0,185 & 0,335 & 0,280 & 0,297 & 0,241 & 0,167 & 0,300 & 0,251 & 0,133 & 0,227 \\
\hline Caluromys (P) & 0,316 & 0,470 & 0,246 & 0,515 & 0,390 & 0,560 & 0,517 & 0,672 & 0,310 & 0,366 & 0,664 & 0,545 & 0,464 \\
\hline Didelphis (P) & 0,332 & 0,477 & 0,332 & 0,545 & 0,436 & 0,485 & 0,448 & 0,734 & 0,359 & 0,534 & 0,645 & 0,557 & 0,490 \\
\hline Metachirus (P) & 0,388 & 0,360 & 0,372 & 0,542 & 0,372 & 0,541 & 0,436 & 0,659 & 0,323 & 0,475 & 0,508 & 0,537 & 0,460 \\
\hline KRZ & Zaedyus & Tolypeutes & Priodontes & Euphractus & Dasypus & Chaetophractus & Cabassous & Tamandua & Cyclopes & Myrmecophaga & Bradypus & Choloepus & Média \\
\hline Calomys (G) & 0,575 & 0,556 & 0,558 & 0,605 & 0,616 & 0,600 & 0,552 & 0,570 & 0,494 & 0,552 & 0,597 & 0,579 & 0,571 \\
\hline Akodon (G) & 0,589 & 0,586 & 0,551 & 0,631 & 0,589 & 0,609 & 0,584 & 0,567 & 0,507 & 0,549 & 0,586 & 0,548 & 0,575 \\
\hline Caluromys (P) & 0,684 & 0,724 & 0,668 & 0,713 & 0,725 & 0,714 & 0,698 & 0,710 & 0,588 & 0,683 & 0,686 & 0,662 & 0,688 \\
\hline Didelphis (P) & 0,617 & 0,673 & 0,681 & 0,708 & 0,765 & 0,663 & 0,697 & 0,729 & 0,602 & 0,690 & 0,666 & 0,638 & 0,678 \\
\hline Metachirus (P) & 0,654 & 0,701 & 0,669 & 0,701 & 0,728 & 0,713 & 0,709 & 0,731 & 0,598 & 0,688 & 0,697 & 0,676 & 0,689 \\
\hline
\end{tabular}

Tabela 1.24 - Similaridade observada através das adagas casualizadas (RS), da correlação de matrizes (CM) e da projeção de Krzanowski (KRZ) entre as matrizes-G de roedores e matrizes-P de marsupiais com as matrizes-P de Xenarthra em 32D.

\begin{tabular}{|c|c|c|c|c|c|c|c|c|c|c|c|c|c|}
\hline RS & Zaedyus & Tolypeutes & Priodontes & Euphractus & Dasypus & Chaetophractus & Cabassous & Tamandua & Cyclopes & Myrmecophaga & Bradypus & Choloepus & Média \\
\hline Calomys (G) & 0,633 & 0,662 & 0,490 & 0,717 & 0,666 & 0,691 & 0,767 & 0,693 & 0,632 & 0,643 & 0,734 & 0,619 & 0,662 \\
\hline Akodon (G) & 0,586 & 0,582 & 0,502 & 0,634 & 0,562 & 0,637 & 0,642 & 0,572 & 0,577 & 0,518 & 0,642 & 0,587 & 0,587 \\
\hline Caluromys (P) & 0,661 & 0,719 & 0,561 & 0,774 & 0,689 & 0,742 & 0,803 & 0,778 & 0,723 & 0,693 & 0,763 & 0,721 & 0,719 \\
\hline Didelphis (P) & 0,665 & 0,692 & 0,572 & 0,780 & 0,686 & 0,729 & 0,786 & 0,770 & 0,740 & 0,680 & 0,753 & 0,744 & 0,717 \\
\hline Metachirus (P) & 0,696 & 0,685 & 0,621 & 0,763 & 0,718 & 0,785 & 0,785 & 0,811 & 0,740 & 0,731 & 0,716 & 0,716 & 0,731 \\
\hline CM & Zaedyus & Tolypeutes & Priodontes & Euphractus & Dasypus & Chaetophractus & Cabassous & Tamandua & Cyclopes & Myrmecophaga & Bradypus & Choloepus & Média \\
\hline Calomys (G) & 0,204 & 0,366 & 0,158 & 0,382 & 0,383 & 0,385 & 0,463 & 0,499 & 0,416 & 0,422 & 0,574 & 0,280 & 0,378 \\
\hline Akodon (G) & 0,245 & 0,190 & 0,139 & 0,186 & 0,332 & 0,307 & 0,315 & 0,241 & 0,228 & 0,266 & 0,253 & 0,177 & 0,240 \\
\hline Caluromys (P) & 0,318 & 0,447 & 0,248 & 0,525 & 0,378 & 0,560 & 0,519 & 0,649 & 0,525 & 0,464 & 0,608 & 0,589 & 0,486 \\
\hline Didelphis (P) & 0,341 & 0,442 & 0,339 & 0,568 & 0,426 & 0,502 & 0,447 & 0,723 & 0,605 & 0,575 & 0,608 & 0,655 & 0,519 \\
\hline Metachirus $(\mathrm{P})$ & 0,380 & 0,367 & 0,348 & 0,528 & 0,351 & 0,522 & 0,422 & 0,666 & 0,572 & 0,538 & 0,499 & 0,620 & 0,484 \\
\hline KRZ & Zaedyus & Tolypeutes & Priodontes & Euphractus & Dasypus & Chaetophractus & Cabassous & Tamandua & Cyclopes & Myrmecophaga & Bradypus & Choloepus & Média \\
\hline Calomys (G) & 0,583 & 0,573 & 0,554 & 0,606 & 0,615 & 0,608 & 0,563 & 0,572 & 0,553 & 0,591 & 0,639 & 0,581 & 0,586 \\
\hline Akodon (G) & 0,595 & 0,594 & 0,553 & 0,603 & 0,594 & 0,603 & 0,579 & 0,576 & 0,570 & 0,570 & 0,619 & 0,561 & 0,585 \\
\hline Caluromys (P) & 0,703 & 0,733 & 0,666 & 0,718 & 0,739 & 0,696 & 0,696 & 0,733 & 0,695 & 0,729 & 0,716 & 0,686 & 0,709 \\
\hline Didelphis (P) & 0,637 & 0,694 & 0,671 & 0,705 & 0,775 & 0,656 & 0,704 & 0,743 & 0,692 & 0,765 & 0,714 & 0,671 & 0,702 \\
\hline Metachirus (P) & 0,688 & 0,724 & 0,661 & 0,717 & 0,737 & 0,704 & 0,708 & 0,749 & 0,703 & 0,763 & 0,721 & 0,709 & 0,715 \\
\hline
\end{tabular}


Tabela 1.25 - Similaridade observada através das adagas casualizadas (RS), da correlação de matrizes (CM) e da projeção de Krzanowski (KRZ) entre as matrizes-G de roedores e matrizes-P de marsupiais com as matrizes-P de Xenarthra em 28D.

\begin{tabular}{|c|c|c|c|c|c|c|c|c|c|c|c|c|c|c|}
\hline RS & Zaedyus & Tolypeutes & Priodontes & Euphractus & Dasypus & Chaetophractus & Cabassous & Tamandua & Cyclopes & Myrmecophaga & Bradypus & Choloepus & Paramylodon & Média \\
\hline Calomys (G) & 0,644 & 0,665 & 0,531 & 0,722 & 0,675 & 0,698 & 0,789 & 0,708 & 0,642 & 0,651 & 0,737 & 0,624 & 0,531 & 0,663 \\
\hline Akodon (G) & 0,605 & 0,600 & 0,543 & 0,641 & 0,573 & 0,635 & 0,636 & 0,577 & 0,592 & 0,527 & 0,660 & 0,593 & 0,552 & 0,595 \\
\hline Caluromys (P) & 0,680 & 0,734 & 0,589 & 0,770 & 0,706 & 0,738 & 0,812 & 0,783 & 0,744 & 0,712 & 0,785 & 0,724 & 0,560 & 0,718 \\
\hline Didelphis (P) & 0,697 & 0,708 & 0,615 & 0,785 & 0,713 & 0,734 & 0,800 & 0,795 & 0,779 & 0,704 & 0,783 & 0,751 & 0,587 & 0,727 \\
\hline Metachirus (P) & 0,719 & 0,696 & 0,645 & 0,766 & 0,739 & 0,787 & 0,791 & 0,818 & 0,746 & 0,746 & 0,730 & 0,722 & 0,594 & 0,731 \\
\hline CM & Zaedyus & Tolypeutes & Priodontes & Euphractus & Dasypus & Chaetophractus & Cabassous & Tamandua & Cyclopes & Myrmecophaga & Bradypus & Choloepus & Paramylodon & Média \\
\hline Calomys (G) & 0,222 & 0,404 & 0,224 & 0,410 & 0,412 & 0,449 & 0,569 & 0,523 & 0,466 & 0,438 & 0,603 & 0,312 & 0,289 & 0,409 \\
\hline Akodon (G) & 0,280 & 0,233 & 0,206 & 0,185 & 0,379 & 0,280 & 0,305 & 0,299 & 0,282 & 0,331 & 0,284 & 0,188 & 0,277 & 0,272 \\
\hline Caluromys (P) & 0,333 & 0,454 & 0,285 & 0,526 & 0,424 & 0,579 & 0,556 & 0,666 & 0,572 & 0,493 & 0,635 & 0,610 & 0,310 & 0,496 \\
\hline Didelphis (P) & 0,407 & 0,443 & 0,429 & 0,585 & 0,497 & 0,542 & 0,519 & 0,759 & 0,682 & 0,645 & 0,642 & 0,667 & 0,342 & 0,551 \\
\hline Metachirus (P) & 0,423 & 0,390 & 0,371 & 0,535 & 0,408 & 0,541 & 0,448 & 0,683 & 0,613 & 0,567 & 0,524 & 0,636 & 0,356 & 0,500 \\
\hline KRZ & Zaedyus & Tolypeutes & Priodontes & Euphractus & Dasypus & Chaetophractus & Cabassous & Tamandua & Cyclopes & Myrmecophaga & Bradypus & Choloepus & Paramylodon & Média \\
\hline Calomys (G) & 0,612 & 0,588 & 0,552 & 0,609 & 0,592 & 0,607 & 0,579 & 0,576 & 0,585 & 0,586 & 0,622 & 0,592 & 0,586 & 0,591 \\
\hline Akodon (G) & 0,584 & 0,610 & 0,554 & 0,611 & 0,592 & 0,591 & 0,574 & 0,553 & 0,557 & 0,549 & 0,605 & 0,568 & 0,604 & 0,581 \\
\hline Caluromys (P) & 0,666 & 0,730 & 0,660 & 0,734 & 0,734 & 0,692 & 0,715 & 0,761 & 0,703 & 0,730 & 0,758 & 0,716 & 0,673 & 0,713 \\
\hline Didelphis (P) & 0,632 & 0,690 & 0,658 & 0,710 & 0,782 & 0,662 & 0,705 & 0,733 & 0,726 & 0,765 & 0,721 & 0,686 & 0,713 & 0,706 \\
\hline Metachirus (P) & 0,685 & 0,720 & 0,680 & 0,723 & 0,738 & 0,692 & 0,726 & 0,746 & 0,717 & 0,782 & 0,745 & 0,724 & 0,681 & 0,720 \\
\hline
\end{tabular}

Tabela 1.26 - Similaridade observada através das adagas casualizadas (RS), da correlação de matrizes (CM) e da projeção de Krzanowski (KRZ) entre as matrizes-G de roedores e matrizes-P de marsupiais com as matrizes-P de Xenarthra em 25D.

\begin{tabular}{|c|c|c|c|c|c|c|c|c|c|c|c|c|c|c|c|}
\hline RS & Zaedyus & Tolypeutes & Priodontes & Euphractus & Dasypus & Chaetophractus & Cabassous & Tamandua & Cyclopes & Myrmecophaga & Bradypus & Choloepus & Paramylodon & Scelidotherium & Média \\
\hline Calomys (G) & 0,619 & 0,684 & 0,502 & 0,707 & 0,585 & 0,653 & 0,738 & 0,631 & 0,643 & 0,546 & 0,787 & 0,624 & 0,579 & 0,632 & 0,638 \\
\hline Akodon (G) & 0,649 & 0,591 & 0,526 & 0,627 & 0,533 & 0,626 & 0,598 & 0,520 & 0,575 & 0,459 & 0,658 & 0,587 & 0,562 & 0,519 & 0,547 \\
\hline Caluromys (P) & 0,681 & 0,751 & 0,559 & 0,775 & 0,666 & 0,713 & 0,768 & 0,748 & 0,761 & 0,652 & 0,814 & 0,740 & 0,572 & 0,734 & 0,710 \\
\hline Didelphis (P) & 0,694 & 0,728 & 0,596 & 0,792 & 0,681 & 0,713 & 0,763 & 0,765 & 0,791 & 0,650 & 0,800 & 0,760 & 0,596 & 0,739 & 0,719 \\
\hline Metachirus (P) & 0,718 & 0,725 & 0,618 & 0,773 & 0,701 & 0,744 & 0,759 & 0,782 & 0,779 & 0,680 & 0,764 & 0,760 & 0,613 & 0,719 & 0,724 \\
\hline CM & Zaedyus & Tolypeutes & Priodontes & Euphractus & Dasypus & Chaetophractus & Cabassous & Tamandua & Cyclopes & Myrmecophaga & Bradypus & Choloepus & Paramylodon & Scelidotherium & Média \\
\hline Calomys (G) & 0,217 & 0,403 & 0,208 & 0,418 & 0,367 & 0,412 & 0,524 & 0,467 & 0,395 & 0,397 & 0,582 & 0,248 & 0,277 & 0,056 & 0,355 \\
\hline Akodon (G) & 0,344 & 0,191 & 0,205 & 0,173 & 0,365 & 0,237 & 0,281 & 0,260 & 0,235 & 0,306 & 0,253 & 0,154 & 0,262 & 0,078 & 0,239 \\
\hline Caluromys (P) & 0,359 & 0,462 & 0,268 & 0,553 & 0,387 & 0,526 & 0,487 & 0,638 & 0,547 & 0,449 & 0,645 & 0,592 & 0,328 & 0,148 & 0,456 \\
\hline Didelphis (P) & 0,404 & 0,444 & 0,417 & 0,600 & 0,470 & 0,492 & 0,455 & 0,754 & 0,655 & 0,622 & 0,646 & 0,642 & 0,431 & 0,185 & 0,516 \\
\hline Metachirus (P) & 0,440 & 0,371 & 0,349 & 0,544 & 0,355 & 0,458 & 0,375 & 0,652 & 0,557 & 0,506 & 0,527 & 0,620 & 0,442 & 0,267 & 0,462 \\
\hline KRZ & Zaedyus & Tolypeutes & Priodontes & Euphractus & Dasypus & Chaetophractus & Cabassous & Tamandua & Cyclopes & Myrmecophaga & Bradypus & Choloepus & Paramylodon & Scelidotherium & Média \\
\hline Calomys (G) & 0,604 & 0,604 & 0,561 & 0,608 & 0,624 & 0,615 & 0,571 & 0,605 & 0,590 & 0,568 & 0,653 & 0,594 & 0,562 & 0,541 & 0,593 \\
\hline Akodon (G) & 0,625 & 0,583 & 0,546 & 0,619 & 0,588 & 0,606 & 0,584 & 0,585 & 0,553 & 0,571 & 0,600 & 0,586 & 0,619 & 0,575 & 0,589 \\
\hline Caluromys (P) & 0,675 & 0,719 & 0,637 & 0,728 & 0,703 & 0,707 & 0,692 & 0,715 & 0,696 & 0,663 & 0,749 & 0,715 & 0,651 & 0,589 & 0,689 \\
\hline Didelphis (P) & 0,561 & 0,667 & 0,647 & 0,662 & 0,782 & 0,635 & 0,693 & 0,727 & 0,734 & 0,767 & 0,663 & 0,650 & 0,669 & 0,583 & 0,674 \\
\hline Metachirus (P) & 0,642 & 0,692 & 0,647 & 0,717 & 0,700 & 0,661 & 0,702 & 0,717 & 0,678 & 0,710 & 0,717 & 0,688 & 0,668 & 0,592 & 0,681 \\
\hline
\end{tabular}




\section{Magnitude geral de integração}

As magnitudes gerais de integração morfológica, medidas através da variância relativa dos autovalores, variaram entre 0,09 e 0,24 com médias para cada conjunto de distâncias de $\sim 0,15$ e desvios padrão de $\sim 0,04$ (Tabela 1.27; Figura 1.15). Os valores para cada gênero entre os conjuntos de distâncias foram semelhantes, à exceção de Cyclopes, Myrmecophaga, Bradypus, Choloepus e Paramylodon. Esses gêneros apresentaram variação no tamanho amostral nos diferentes conjuntos de distâncias (Tabela 1.1). Os dois primeiros gêneros citados apresentaram as maiores diferenças e também foram os que, além de terem um incremento sensível no tamanho amostral entre 35D e os demais conjuntos de distâncias, estiveram muito mal representados $(\mathrm{n}<30)$ em 35D. Os quatro primeiros gêneros mencionados diminuíram os valores dos rVEs com o aumento da amostra, enquanto que em Paramylodon o oposto foi observado. Considerando todos os gêneros em cada conjunto de distâncias, não houve correlações significativas entre o tamanho da amostra e as magnitudes gerais de integração (Tabela 1.28).

Tabela 1.27 - Magnitude geral de integração (variância relativa dos autovalores; rVE) para cada gênero em cada conjunto de distâncias.

\begin{tabular}{ccccc}
\hline & \multicolumn{4}{c}{ rVE } \\
& 35D & 32D & 28D & 25D \\
\hline Zaedyus & 0,158 & 0,155 & 0,167 & 0,150 \\
Tolypeutes & 0,123 & 0,127 & 0,123 & 0,118 \\
Priodontes & 0,099 & 0,094 & 0,095 & 0,098 \\
Euphractus & 0,224 & 0,214 & 0,217 & 0,206 \\
Dasypus & 0,146 & 0,140 & 0,152 & 0,135 \\
Chaetophractus & 0,110 & 0,103 & 0,104 & 0,090 \\
Cabassous & 0,189 & 0,183 & 0,188 & 0,168 \\
Tamandua & 0,156 & 0,161 & 0,165 & 0,142 \\
Cyclopes & 0,190 & 0,107 & 0,114 & 0,102 \\
Myrmecophaga & 0,206 & 0,159 & 0,170 & 0,155 \\
Bradypus & 0,204 & 0,177 & 0,179 & 0,171 \\
Choloepus & 0,158 & 0,135 & 0,134 & 0,126 \\
Paramylodon & - & - & 0,108 & 0,124 \\
Scelidotherium & - & - & - & 0,237 \\
$\quad$ Média & 0,164 & 0,146 & 0,147 & 0,143 \\
Desvio padrão & 0,040 & 0,036 & 0,037 & 0,038 \\
\hline
\end{tabular}



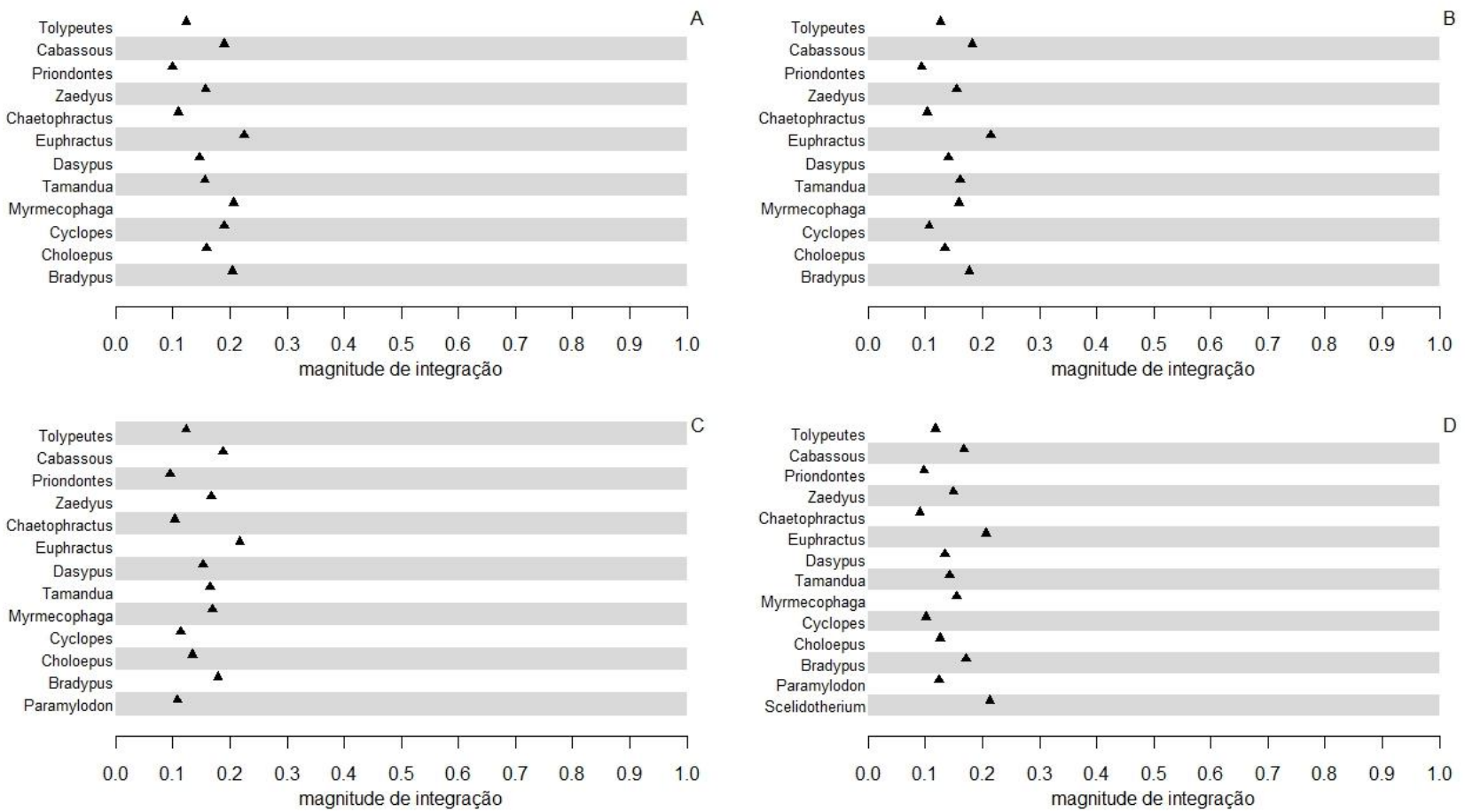

Figura 1.15 - Magnitude geral de integração (variância relativa dos autovalores) para cada gênero em cada conjunto de distâncias. A: 35D; B: 32D; C: 28D; D: 25D.

Tabela 1.28 - Coeficientes de correlação de Pearson entre o log do n amostral e o log da variância relativa dos autovalores (rVE) em cada conjunto de distâncias. Nenhuma correlação foi significativa para $\alpha=0,05$.

\begin{tabular}{|c|c|c|}
\hline & & rVE \\
\hline \multirow{4}{*}{ 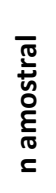 } & 35D & $-0,14$ \\
\hline & 32D & 0,27 \\
\hline & $28 \mathrm{D}$ & 0,40 \\
\hline & 25D & $-0,10$ \\
\hline
\end{tabular}

Para avaliar de forma mais aprofundada o efeito do tamanho da amostra nos valores dos rVEs, foi realizado o seguinte procedimento: a partir dos resíduos do GLM de Dasypus selecionou-se aleatoriamente com reposição (bootstrap) um número pré-determinado de espécimes e calculou-se o rVE. Para cada número pré-determinado de espécimes o procedimento foi realizado 1000 vezes. Em seguida computou-se a média dos 1000 rVEs para cada número pré-determinado de espécimes. Os números pré-determinado de espécimes foram: cinco, 10, 15, $20,25,30,35,40,45,50,60,70,80,90,100,120,140,160,180,200$ e 219. Os resultados 
obtidos foram expressos na forma gráfica (Figura 1.16). Eles mostram que amostras pequenas geram resultados consistentemente maiores que os obtidos com amostras maiores. Os valores dos rVEs tendem a se estabilizar a partir de amostras com mais de 25 - 30 espécimes. O mesmo procedimento foi realizado com Tamandua e resultados semelhantes foram obtidos (não apresentados).

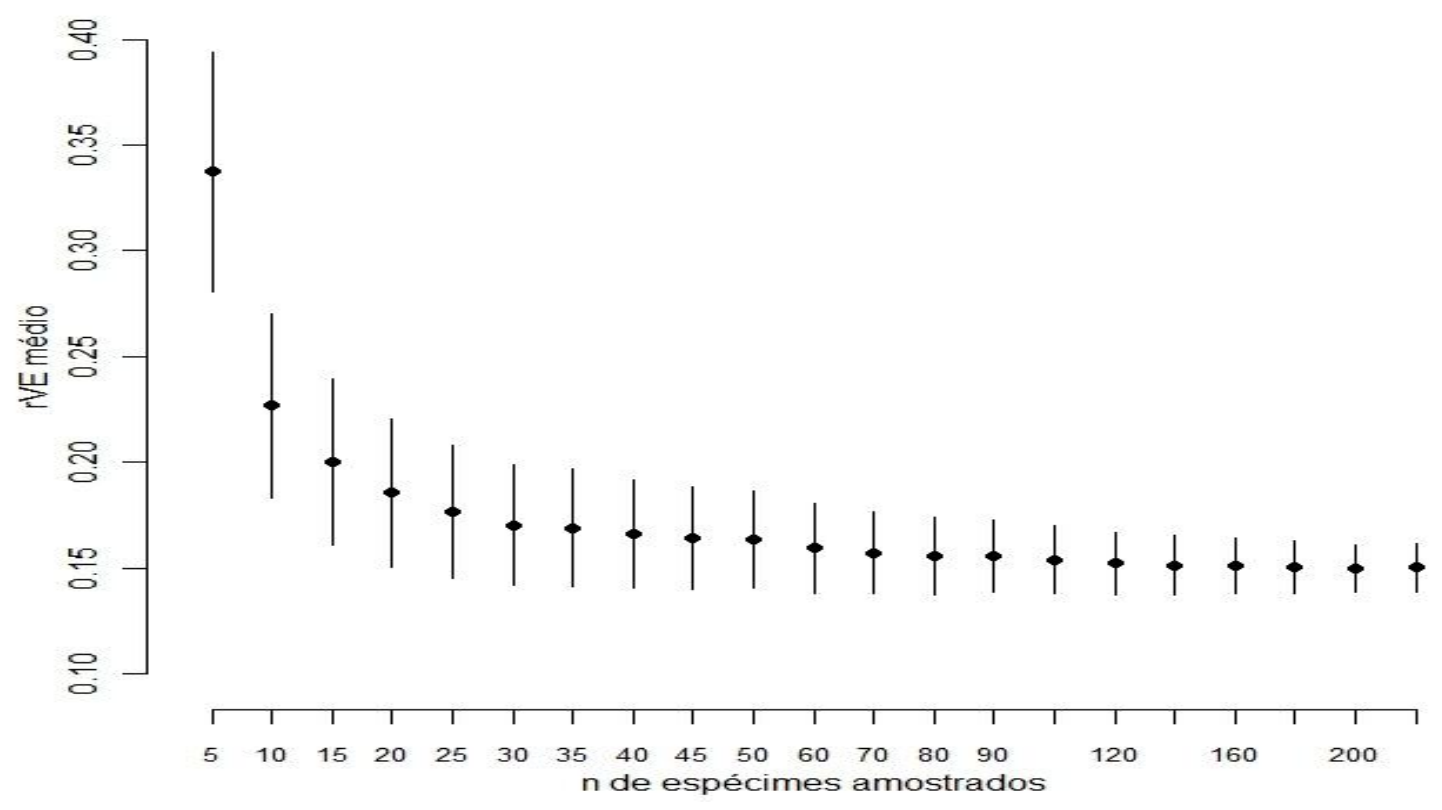

Figura 1.16 - Magnitude geral de integração média das 1000 reamostragens realizadas com cada conjunto pré-determinado de espécimes de Dasypus. As linhas verticais representam um desvio padrão a mais e a menos da média.

\section{Distâncias filogenéticas, morfológicas e de dieta}

As matrizes de distância filogenética estiveram de moderado a fortemente correlacionadas às matrizes de semelhança dos padrões das matrizes-P e fracamente correlacionadas a matriz de diferenças na magnitude geral de integração (Tabela 1.29). As matrizes de distâncias filogenéticas com ramos de tamanhos iguais a um em 35D e 32D apresentaram resultados semelhantes aos das distâncias filogenéticas moleculares (resultados não 
apresentados) e foram fortemente correlacionadas a elas ( $r=0,89 ; \mathrm{p}<0,01$; em 35D e 32D). Não houve diferença contundente nos resultados para 28D e 25D entre as correlações realizadas utilizando as distâncias filogenéticas obtidas através da filogenia completamente resolvida e a filogenia considerando a politomia de Folivora (resultados para a segunda não apresentados) e elas foram fortemente correlacionadas $(r=0,94 ; \mathrm{p}<0,01$; em 28D e 25D).

Não foram encontradas correlações significativas entre as distâncias morfológicas ou de dieta em relação aos padrões de similaridade e as diferenças na magnitude geral de integração em nenhum conjunto de distâncias (Tabela 1.29). As distâncias morfológicas estiveram de fraca a moderadamente correlacionadas às distâncias filogenéticas em todos os conjuntos de distâncias $(\mathrm{r}<0,4)$. De qualquer forma, mesmo matrizes de distâncias morfológicas controladas para o efeito da filogenia não foram significativamente correlacionadas aos padrões de similaridade e as distâncias da magnitude geral de integração (Tabela 1.29). Para controlar o efeito da filogenia em relação à morfologia foram realizadas regressões lineares das distâncias morfológicas em relação às distâncias filogenéticas para cada conjunto de distâncias e os resíduos foram utilizados nas correlações subsequentes.

Os resultados foram semelhantes tanto para as correlações baseadas nas distâncias morfológicas definidas para a filogenia completamente resolvida ou para a filogenia considerando a politomia em Folivora (resultados não apresentados) para 28D e 25D. Por último, as distâncias das magnitudes gerais de integração não foram correlacionadas com os padrões de similaridade em 35D, 28D e 25D. Em 32D, elas também não se correlacionaram com RS e CM, mas foram fracamente correlacionadas a KRZ. 
Tabela 1.29 - Correlações das matrizes de distâncias filogenéticas molecular (para 35D e 32D) e ramos de tamanhos iguais para a filogenia completamente resolvida (para 28D e 25D), morfológicas, morfológicas corrigidas para o efeito da filogenia (residual), magnitude geral de integração e de dieta e as matrizes de similaridade obtidas através das adagas casualizadas (RS), da projeção de Krzanowski (KRZ) e da correlação de matrizes (CM) para os quatro conjuntos de distâncias (35D, 32D, 28D e 25D). Valores em negrito foram significativos a 5\%.

\begin{tabular}{|c|c|c|c|c|c|c|c|}
\hline 35D & RS observada & $\begin{array}{c}\text { RS } \\
\text { ajustada }\end{array}$ & CM observada & $\begin{array}{c}\text { CM } \\
\text { ajustada }\end{array}$ & KRZ observada & $\begin{array}{c}\text { KRZ } \\
\text { ajustada } \\
\end{array}$ & $\begin{array}{r}\text { Distância } \\
\text { magnitude }\end{array}$ \\
\hline distância morfológica & $-0,236$ & $-0,294$ & $-0,092$ & $-0,064$ & $-0,255$ & $-0,314$ & $-0,002$ \\
\hline $\begin{array}{c}\text { distância morfológica } \\
\text { residual }\end{array}$ & $-0,109$ & $-0,149$ & 0,018 & 0,058 & $-0,028$ & $-0,045$ & 0,052 \\
\hline $\begin{array}{l}\text { distância filogenética } \\
\text { molecular }\end{array}$ & $-0,386$ & $-0,444$ & $-0,312$ & $-0,343$ & $-0,662$ & $-0,784$ & $-0,146$ \\
\hline distância magnitude & 0,046 & 0,060 & 0,060 & 0,058 & 0,184 & 0,188 & 1,000 \\
\hline distância de dieta & 0,034 & 0,047 & 0,063 & 0,077 & 0,103 & 0,173 & $-0,157$ \\
\hline 32D & RS observada & $\begin{array}{c}\text { RS } \\
\text { ajustada }\end{array}$ & CM observada & $\begin{array}{c}\mathrm{CM} \\
\text { ajustada }\end{array}$ & KRZ observada & $\begin{array}{c}\text { KRZ } \\
\text { ajustada }\end{array}$ & $\begin{array}{c}\text { Distância } \\
\text { magnitude }\end{array}$ \\
\hline distância morfológica & $-0,248$ & $-0,287$ & $-0,068$ & $-0,072$ & $-0,109$ & $-0,187$ & $-0,134$ \\
\hline $\begin{array}{c}\text { distância morfológica } \\
\text { residual }\end{array}$ & $-0,140$ & $-0,148$ & $-0,018$ & 0,004 & 0,119 & 0,096 & $-0,036$ \\
\hline $\begin{array}{c}\text { distância filogenética } \\
\text { molecular }\end{array}$ & $-0,302$ & $-0,382$ & $-0,131$ & $-0,191$ & $-0,553$ & $-0,699$ & $-0,257$ \\
\hline distância magnitude & 0,057 & 0,091 & 0,042 & 0,059 & 0,219 & 0,257 & 1,000 \\
\hline distância de dieta & 0,092 & 0,121 & $-0,009$ & 0,015 & 0,038 & 0,121 & $-0,150$ \\
\hline 28D & RS observada & $\begin{array}{c}\text { RS } \\
\text { ajustada }\end{array}$ & CM observada & $\begin{array}{c}\mathrm{CM} \\
\text { ajustada }\end{array}$ & KRZ observada & $\begin{array}{c}\text { KRZ } \\
\text { ajustada }\end{array}$ & $\begin{array}{c}\text { Distância } \\
\text { magnitude }\end{array}$ \\
\hline distância morfológica & $-0,256$ & $-0,285$ & $-0,054$ & $-0,084$ & $-0,145$ & $-0,033$ & $-0,004$ \\
\hline $\begin{array}{l}\text { distância morfológica } \\
\text { residual }\end{array}$ & $-0,133$ & $-0,143$ & $-0,019$ & $-0,003$ & $-0,052$ & 0,072 & 0,021 \\
\hline $\begin{array}{l}\text { distância filogenética } \\
\text { ramos iguais }\end{array}$ & $-0,299$ & $-0,337$ & $-0,208$ & $-0,247$ & $-0,646$ & $-0,720$ & $-0,174$ \\
\hline distância magnitude & 0,024 & 0,047 & $-0,002$ & 0,017 & 0,112 & 0,160 & 1,000 \\
\hline 25D & RS observada & $\begin{array}{c}\text { RS } \\
\text { ajustada }\end{array}$ & CM observada & $\begin{array}{c}\mathrm{CM} \\
\text { ajustada }\end{array}$ & KRZ observada & $\begin{array}{c}\text { KRZ } \\
\text { ajustada }\end{array}$ & $\begin{array}{c}\text { Distância } \\
\text { magnitude }\end{array}$ \\
\hline distância morfológica & $-0,219$ & $-0,210$ & $-0,042$ & $-0,025$ & $-0,140$ & $-0,0027$ & 0,023 \\
\hline $\begin{array}{l}\text { distância morfológica } \\
\text { residual }\end{array}$ & $-0,101$ & $-0,116$ & $-0,033$ & $-0,005$ & $-0,050$ & 0,078 & 0,049 \\
\hline $\begin{array}{l}\text { distância filogenética } \\
\text { ramos iguais }\end{array}$ & $-0,310$ & $-0,348$ & $-0,243$ & $-0,280$ & $-0,525$ & $-0,608$ & $-0,143$ \\
\hline distância magnitude & 0,031 & 0,075 & $-0,116$ & $-0,106$ & $-0,092$ & 0,025 & 1,000 \\
\hline
\end{tabular}




\section{Discussão}

\section{Similaridade entre matrizes}

Os gêneros estudados de Xenarthra apresentaram, via de regra, matrizes de covariância bastante semelhantes entre si, independentemente do conjunto de distâncias considerado. Em outras palavras as matrizes de covariância apresentaram valores de similaridades elevados e, quando testados, estatisticamente significativos. Valores menores para as similaridades entre essas matrizes estiveram associados a gêneros com amostras menores ou pequenas. Isso favorece a interpretação de que similaridades mais baixas se deveram, pelo menos em parte, a problemas nas estimativas das matrizes vinculados ao tamanho da amostra e não propriamente a diferenças inerentes aos sistemas biológicos em estudo. Qualquer matriz de covariância ou correlação obtida a partir da amostragem de uma população será estimada com ruido (erro). Quanto menor for a razão entre tamanho amostral e quantidade de caracteres medidos, mais intenso será esse ruído. Consequentemente, a matriz estimada representará de maneira cada vez mais inacurada os parâmetros populacionais (Meyer e Kirkpatrick, 2008; Marroig et al., 2012).

Apesar da razão entre tamanho amostral e quantidade de caracteres ter sido baixa $(<1)$ para alguns gêneros (Myrmecophaga e Cyclopes em 35D, Paramylodon em 28D, Scelidotherium em 25D e Priodontes em todos os conjuntos de distâncias), mesmo eles apresentaram valores de similaridade elevados para a KRZ tanto nas similaridades observadas quanto nas ajustadas. À exceção do resultado das RS para Scelidotherium, as similaridades ajustadas para todos os gêneros foram, em média, superiores a 0,6, sendo a maioria acima de 0,8. Em suma, os resultados obtidos para as matrizes de covariância sugerem a existência de um padrão comum de covariância dos caracteres cranianos de Xenarthra. 
Note que embora as matrizes de covariância sejam bastante semelhantes, elas não são idênticas. Isso já era esperado. Matrizes são estruturalmente idênticas quando o produto de uma matriz pela inversa da outra matriz resulta em uma matriz identidade multiplicada por um escalar $\left(\boldsymbol{A} \boldsymbol{B}^{-\mathbf{1}}=k \boldsymbol{I}\right.$; Klingenberg e Monteiro, 2005). Caso o escalar seja um, as matrizes são idênticas. Caso ele seja outro valor, as matrizes são proporcionais. Qualquer matriz obtida a partir da amostragem de uma população é estimada com erro. Esse erro já é o suficiente para garantir que as matrizes comparadas não sejam estritamente idênticas (Cheverud e Marroig, 2007). Além disso, cada população é única. Os indivíduos de cada população apresentam uma diversidade genética que é distinta em algum grau das demais populações. Ou seja, existe alguma variação genética aditiva entre populações (Falconer e MacKay, 1996). Isso também contribui para que duas matrizes-P não sejam exatamente idênticas. Consequentemente, a pergunta mais pertinente não é se as matrizes são idênticas ou não, mas sim: quanta similaridade estrutural é necessária entre as matrizes-P para que elas possam ser utilizadas em estudos macroevolutivos?

Não existe concenso entre pesquisadores quanto ao valor mínimo de similaridade entre matrizes necessário para realizar análises macroevolutivas com elas (Cheverud, 1988; Arnold e Phillips, 1999; Marroig e Cheverud 2001; Cheverud e Marroig, 2007). No entanto, pesquisadores concluíram que: se houver similaridade de moderada a elavada entre as matrizes, as diferenças entre as matrizes terão efeito pequeno nos resultados dos estudos macroevolutivos de genética quantitativa (Manly, 1986; Marroig e Cheverud, 2001; Cheverud e Marroig, 2007; Prôa et al., 2012). Salienta-se que o RS vai direto ao cerne desta questão, por ser uma extensão da equação de resposta multivariada à seleção. Ele avalia se duas matrizes de covariância geram, para um mesmo gradiente de seleção, respostas evolutivas semelhantes. No geral, os resultados dessa 
análise indicam que as matrizes-P de covariância dos Xenarthra tendem a responder de forma bastante semelhante a diferentes gradientes de seleção.

A similaridade das matrizes de covariância entre os Xenarthra foi reforçada pelos resultados obtidos nos níveis supragenéricos. Nesses níveis, os resultados para RS e KRZ foram semelhantes aos obtidos no nível genérico. Ainda, a elevada similaridade entre as matrizes-P de covariância de Xenarthra e as matrizes-G de covariância de roedores e matrizes-P de covariância de marsupiais favorecem a interpretação da similaridade dessas matrizes nos Xenarthra. A semelhança entre as matrizes das diferentes ordens suporta também a ideia que todos os mamíferos compartilham um padrão comum das variâncias e covariâncias dos caracteres cranianos. A justificativa para tal argumento é que gêneros de grupos bastante distintos, como os comparados aqui, apresentaram valores elevados de similaridade (Porto et al., 2009).

Ao contrário dos resultados obtidos para as matrizes de covariância, que sugerem grande similaridade estrutural entre esse tipo de matriz, os resultados obtidos para as matrizes de correlação indicaram grau moderado de similaridade entre elas. Os valores ajustados foram em sua maioria superiores a 0,5, mas inferiores a 0,6. As correlações foram, à exceção de sete valores, significativas a 5\%. Assim como para as RS e a KRZ, não houve diferenças marcantes entre os resultados da CM para os diferentes conjuntos de distâncias. As menores correlações também estiveram associadas aos gêneros piores amostrados. Os valores para CM nos níveis supragenéricos foram maiores que os obtidos para a comparação entre os gêneros, indicando uma similaridade de moderada a alta entre as matrizes. Embora os valores de CM nesses níveis taxonômicos ainda tenham sido inferiores aos dos outros dois métodos, observou-se que o incremento da amostra resultou em uma elevação sensível nos resultados da CM. Esse resultado sugere que parte da discrepância entre os valores dos três métodos seja em função da CM ser 
mais sensível a erros de amostragem (Steppan, 1997; Oliveira, 2009). E esse erro fica mais pronunciado em matrizes estimadas através de amostras pequenas. A evidência para essa última afirmação é que valores menores para a similaridade estiveram novamente associados a grupos piores amostrados ou que contiveram amostras de gêneros pouco representados (como foi o caso de Folivora em 28D e 25D). Ou seja, pelo menos em parte, os valores baixos obtidos através da CM não são fruto de diferenças inerentes à estrutura das matrizes de covariância e correlação. A influência do $\mathrm{n}$ amostral nos resultados da similaridade obtida através da CM também fica evindente nas fortes correlações de Pearson entre os valores de similaridades médias observadas e ajustadas obtidas através da CM e o n amostral em todos os conjuntos de distância.

Além da CM ser sensível ao tamanho amostral, outros fatores podem influir no fato dos valores para similaridade desse método serem frequentemente mais baixos que os valores encontrados através das RS ou da KRZ. Por exemplo, a CM não considera a diagonal no seu cálculo. Embora os valores da diagonal nas matrizes de correlação sejam sempre iguais a um, ela faz parte da estrutura da matriz. Ao removê-la pode haver algum tipo de influência na análise, resultando em similaridades mais baixas. Análises futuras serão necessárias para elucidar as razões das diferenças nos resultados obtidos entre os métodos empregados.

Poderia ser alegado que a diferença nos resultados é principalmente em função de diferenças nas estruturas das matrizes de correlação e de covariância e não dos métodos. Em outras palavras, enquanto o padrão das matrizes de covariância é semelhante, o padrão das matrizes de correlação não é. Para explorar essa questão os métodos KRZ e RS foram utilizados para avaliar a similaridade nos padrões das matrizes de correlação no conjunto de dados 35D. Salienta-se que não existem impedimentos teóricos para o uso das RS ou da KRZ no teste de similaridade entre matrizes de correlação. Os resultados obtidos através desses métodos indicam 
resultados muito semelhantes aos obtidos para as matrizes de covariância (Tabela 1.30). Ao contrário dos resultados da CM, tanto as RS quanto a KRZ sugerem elevada similaridade nos padrões das matrizes de correlação (Tabela 1.30).

Tabela 1.30 - Similaridade observada através das adagas casualizadas (RS) e da projeção de Krzanowski (KRZ) para as matrizes de correlação dos Xenarthra no conjunto de distâncias 35D.

\begin{tabular}{|c|c|c|c|c|c|c|c|c|c|c|c|c|}
\hline RS & 1 & 2 & 3 & 4 & 5 & 6 & 7 & 8 & 9 & 10 & 11 & []12 \\
\hline 1. Zaedyus & 1 & 0.73 & 0.68 & 0.81 & 0.8 & 0.77 & 0.76 & 0.73 & 0.59 & 0.69 & 0.69 & 0.73 \\
\hline 2. Tolypeutes & 0.73 & 1 & 0.67 & 0.78 & 0.78 & 0.76 & 0.78 & 0.78 & 0.63 & 0.68 & 0.76 & 0.75 \\
\hline 3. Priodontes & 0.68 & 0.68 & 1 & 0.71 & 0.72 & 0.71 & 0.69 & 0.72 & 0.55 & 0.64 & 0.61 & 0.67 \\
\hline 4. Euphractus & 0.81 & 0.78 & 0.71 & 1 & 0.84 & 0.84 & 0.85 & 0.83 & 0.67 & 0.77 & 0.78 & 0.79 \\
\hline 5. Dasypus & 0.79 & 0.78 & 0.72 & 0.84 & 1 & 0.8 & 0.83 & 0.83 & 0.66 & 0.77 & 0.76 & 0.73 \\
\hline 6. Chaetophractus & 0.77 & 0.75 & 0.71 & 0.84 & 0.8 & 1 & 0.8 & 0.8 & 0.62 & 0.72 & 0.75 & 0.75 \\
\hline 7. Cabassous & 0.76 & 0.78 & 0.69 & 0.85 & 0.83 & 0.81 & 1 & 0.81 & 0.64 & 0.73 & 0.78 & 0.77 \\
\hline 8. Tamandua & 0.73 & 0.78 & 0.72 & 0.83 & 0.83 & 0.8 & 0.81 & 1 & 0.72 & 0.82 & 0.82 & 0.77 \\
\hline 9. Cyclopes & 0.59 & 0.62 & 0.55 & 0.67 & 0.65 & 0.62 & 0.64 & 0.71 & 1 & 0.69 & 0.65 & 0.62 \\
\hline 10. Myrmecophaga & 0.69 & 0.68 & 0.64 & 0.77 & 0.78 & 0.72 & 0.73 & 0.82 & 0.69 & 1 & 0.72 & 0.67 \\
\hline 11. Bradypus & 0.69 & 0.77 & 0.62 & 0.78 & 0.76 & 0.75 & 0.78 & 0.82 & 0.65 & 0.72 & 1 & 0.76 \\
\hline 12. Choloepus & 0.72 & 0.75 & 0.66 & 0.78 & 0.73 & 0.76 & 0.77 & 0.77 & 0.62 & 0.66 & 0.77 & 1 \\
\hline KRZ & 1 & 2 & 3 & 4 & 5 & 6 & 7 & 8 & 9 & 10 & 11 & 12 \\
\hline 1. Zaedyus & 1 & 0.7 & 0.63 & 0.72 & 0.72 & 0.73 & 0.73 & 0.63 & 0.51 & 0.63 & 0.65 & 0.64 \\
\hline 2. Tolypeutes & 0.7 & 1 & 0.67 & 0.74 & 0.7 & 0.72 & 0.74 & 0.71 & 0.58 & 0.66 & 0.69 & 0.65 \\
\hline 3. Priodontes & 0.63 & 0.67 & 1 & 0.7 & 0.69 & 0.67 & 0.7 & 0.69 & 0.56 & 0.69 & 0.64 & 0.67 \\
\hline 4. Euphractus & 0.72 & 0.74 & 0.7 & 1 & 0.71 & 0.78 & 0.73 & 0.7 & 0.56 & 0.7 & 0.64 & 0.66 \\
\hline 5. Dasypus & 0.72 & 0.7 & 0.69 & 0.71 & 1 & 0.69 & 0.73 & 0.7 & 0.54 & 0.68 & 0.63 & 0.64 \\
\hline 6. Chaetophractus & 0.73 & 0.72 & 0.67 & 0.78 & 0.69 & 1 & 0.71 & 0.67 & 0.57 & 0.67 & 0.66 & 0.65 \\
\hline 7. Cabassous & 0.73 & 0.74 & 0.7 & 0.73 & 0.73 & 0.71 & 1 & 0.68 & 0.56 & 0.66 & 0.64 & 0.64 \\
\hline 8. Tamandua & 0.63 & 0.71 & 0.69 & 0.7 & 0.7 & 0.67 & 0.68 & 1 & 0.6 & 0.78 & 0.71 & 0.68 \\
\hline 9. Cyclopes & 0.51 & 0.58 & 0.56 & 0.56 & 0.54 & 0.57 & 0.56 & 0.6 & 1 & 0.59 & 0.57 & 0.58 \\
\hline 10. Myrmecophaga & 0.63 & 0.66 & 0.69 & 0.7 & 0.68 & 0.67 & 0.66 & 0.78 & 0.59 & 1 & 0.71 & 0.68 \\
\hline 11. Bradypus & 0.65 & 0.69 & 0.64 & 0.64 & 0.63 & 0.66 & 0.64 & 0.71 & 0.57 & 0.71 & 1 & 0.68 \\
\hline 12. Choloepus & 0.64 & 0.65 & 0.67 & 0.66 & 0.64 & 0.65 & 0.64 & 0.68 & 0.58 & 0.68 & 0.68 & 1 \\
\hline
\end{tabular}

Tradicionalmente a similaridade entre duas matrizes de correlação é assessada através da CM (Cheverud, 1989; Marroig e Cheverud, 2001; Ackermann, 2002; Porto et al., 2009). No entanto, frente à discussão apresentada e os resultados obtidos através das RS e da KRZ em relação às matrizes de correlação é sugerido que: trabalhos futuros analisem as matrizes de correlação através das RS e da KRZ, ao invés da CM.

Esse trabalho trouxe uma contribuição inédita no âmbito de estudos com fósseis. Ele avaliou diretamente a similaridade das matrizes de covariância e correlação de gêneros extintos. Embora apenas dois gêneros tenham sido testados (dos mais de 200 gêneros conhecidos; 
McKenna e Bell, 1997) e também não houvesse razões a priori para crer que o padrão das matrizes de covariância e correlação dos grupos extintos fosse diferir do observado para os taxa atuais, essa ideia ainda não havia sido testada empiricamente. Os resultados obtidos para Paramylodon apontaram para padrões de similaridades com os demais taxa consistentes com os observados dentre os Xenarthra atuais. Por outro lado, Scelidotherium apresentou valores de similaridade baixos para as RS e a CM e muitas vezes não significativos. Isso provavelmente se deveu a baixa amostra obtida e não a uma diferença biológica nos padrões desse gênero em relação aos demais. Essa argumentação é favorecida ao se observar os valores da KRZ para esse gênero. As similaridade através da KRZ de Scelidotherium com os demais gêneros foram elevadas e semelhantes às demais similaridades observadas entre os Xenarthra para esse método. Como apresentado nos métodos, o KRZ apresenta a vantagem de minimizar a influência do erro associado à estimativa das matrizes na determinação do índice de similaridade. Isso porque ele considera em seus cálculos apenas uma parcela dos primeiros componentes principais extraídos de cada matriz de covariância. Ao fazer isso, uma parcela do erro associado aos dados originais é eliminada (Hair et al., 2010). Em resumo, os gêneros fósseis aparentemente seguem o padrão observado até o momento para os Xenarthra e demais mamíferos atuais.

Em comparação com os resultados obtidos para outros grupos de mamíferos (Catarrhini; Oliveira et al., 2009; Platyrrhini; Marroig e Cheverud, 2001; e Didelphimorphia; da Silva, 2010), os Xenarthra apresentaram resultados de similaridade semelhantes aos dos grupos de primatas já estudados, que também são mamíferos eutérios. Por outro lado, os Xenarthra apresentaram valores menores do que os dos marsupiais do novo mundo, que são o grupo de mamíferos com as matrizes de covariância e correlação mais similares que se tem conhecimento até o momento (da Silva, 2010). 
O padrão de similaridade observado nos Xenarthra esteve de moderado a fortemente correlacionado com a proximidade filogenética entre os taxa e não esteve correlacionado com as distâncias morfológicas ou ecológicas (dieta). Ou seja, embora as matrizes sejam todas bastante similares, grupos mais aparentados tendem a compartilhar estruturas de matrizes mais semelhantes.

Os resultados obtidos através da SRD mostraram que: 1) 18 distâncias variaram muito pouco entre os gêneros; 2) 12 variaram entre alguns gêneros, mas não em muitos; e 3) cinco variaram entre uma grande parcela de gêneros (PTTSP, ZSZI, APETTS, BRLD e BAOPI). Não houve aparente relação entre as distâncias mais divergentes entre os gêneros com a estrutura filogenética do grupo ou a região craniana a qual a distância pertence. Mesmo em gêneros que apresentam morfologia bem diferenciada, como Tamandua e Myrmecophaga que são caracterizados pelo rostro extremamente alongado, não se observou uma maior divergência com os demais gêneros em distâncias relacionadas à face. Não está claro, no momento, o motivo da grande maioria das distâncias ser resiliente a mudanças nos seus padrões de covariância e uma parcela pequena ser bastante lábil. Uma explicação para esses resultados pode ser que os caracteres que mudam bastate apresentam herdabilidade menor e acabam expressando de forma mais marcante o efeito da variação ambiental (Marroig et al., 2011).

A partir dos resultados obtidos quanto ao padrão de similaridade das matrizes de covariância e correlação dos Xenarthra atuais e extintos três conclusões foram obtidas. Primeiro, os gêneros dessa magnaordem compartilham um padrão comum nas suas matrizes-P de caracteres morfológicos cranianos, embora as matrizes não tenham sido estritamente constantes. Segundo, o padrão comum das matrizes do grupo foram observados independentemente da quantidade de distâncias utilizadas (35D, 32D, 28D e 25D). Terceiro, os padrões das matrizes 
são de pouco a moderadamente relacionados à semelhança filogenética e são independentes da semelhanças morfológicas ou ecológicas (dieta).

Como argumentado em outros trabalhos (Marroig e Cheverud, 2001; Marroig et al., 2009; Porto et al., 2009), os valores elevados encontrados para as similaridades entre praticamente todos os gêneros e níveis supragenéricos permitem determinar que as matrizes-P podem ser utilizadas como substitutas das respectivas matrizes-G. Esta assertiva fundamenta-se: 1) no fato que o fenótipo $(\mathbf{P})$ é determinado majoritariamente pelo efeito genético aditivo $(\mathbf{G})$ somado à variação do ambiente $(\mathbf{E})$, de acordo com a equação $\boldsymbol{P}=\boldsymbol{G}+\boldsymbol{E}$ (Falconer e MacKay, 1996); e 2) no raciocínio que a semelhança/proporcionalidade entre as matrizes-P de grande quantidade de taxa ocorre em virtude de uma base genética comum, e não de variações ambientais capazes de compensar diferenças nas matrizes-G ao ponto de gerar matrizes-P similares (Lande, 1979; Marroig e Cheverud, 2001). As semelhanças > 0,55, pelo menos para RS e KRZ, entre as matrizes-P de Xenarthra e as matrizes-G de dois roedores também favorecem esta interpretação. Nestes casos estão sendo comparadas matrizes-P diretamente às matrizes-G. A semelhança entre as matrizes-P também permite que elas sejam utilizadas em estudos macroevolutivos sobre os processos ou mecanismos envolvidos na diferenciação do grupo.

\section{Magnitude geral de integração}

As magnitudes gerais de integração obtidas estiveram entre 0,09 e 0,22. Elas não variaram sensivelmente entre os conjuntos de distâncias, a não ser nos casos em que houve uma elevação no tamanho amostral de um conjunto de distâncias em relação aos demais. Essas diferenças foram pronunciadas nos dois casos (Cyclopes e Myrmecophaga) em que o gênero esteve claramente subamostrado em um dos conjuntos de distâncias $(n<26)$ enquanto nos 
demais foi bem amostrado. Isso aliado aos resultados da análise de reamostragem sugere que o valor da magnitude geral de integração de Scelidotherium pode ser sensivelmente menor. Esse gênero também foi subamostrado. A explicação para isso é que matrizes mal estimadas por problemas amostrais concentram boa parte da variância no primeiro componente principal, simplesmente em função do erro associado à amostragem (Marroig et al., 2012). De acordo com a fórmula apresentada para o cálculo da magnitude geral de integração, quanto maior a porcentagem de variância explicada pelo primeiro componente principal, maior será a magnitude geral de integração. Ou seja, erros nas estimativas das matrizes baseadas em amostras pequenas resultarão na elevação da magnitude geral de integração.

As magnitudes gerais de integração estiveram fracamente correlacionadas com as distâncias filogenéticas e não estiveram correlacionadas com as distâncias morfológicas ou ecológicas (dieta). Apenas em um conjunto de distâncias e para um dos métodos (32D; KRZ) a magnitude geral de integração esteve fracamente correlacionada com o padrão de similaridade entre as matrizes $(r<0,26)$, o que permite supor que o padrão de similaridade entre as matrizes e a magnitude geral de integração sejam relativamente independentes um do outro.

Em termos absolutos, as magnitudes gerais de integração encontradas foram baixas já que o máximo teórico seria um. Contudo, os trabalhos realizados com mamíferos mostraram que a amplitude dessa métrica está entre 0,04 e 0,55 (Oliveira et al., 2009; Porto et al., 2009; da Silva, 2010; Shirai e Marroig, 2010). Dentro desta perspectiva, os valores observados para os Xenarthra podem ser considerados entre fracos a moderados. Eles se assemelham, em termos do grupo como um todo, aos primatas do velho mundo (Oliveira et al., 2009), tendo valores superiores aos primatas do novo mundo (Shirai e Marroig, 2010) e inferiores aos marsupiais do novo mundo (da Silva, 2010). 
Valores menores da magnitude geral de integração implicam, evolutivamente, que o grupo em questão tem o potencial para responder, mais frequentemente, de forma alinhada ao gradiente de seleção. Por outro lado, valores maiores para a magnitude geral de integração caracterizam, em geral, baixa capacidade de responder de forma alinhada a diferentes gradientes de seleção (Hansen e Houle, 2008; Marroig e Cheverud, 2009; Porto et al., 2009). Este assunto será melhor abordado no Capítulo III, mas frente ao exposto acima e com base nos valores observados para a magnitude geral de integração nos Xenarthra, é possível dizer que: por um lado, Choloepus, Priodontes, Chaetophractus e Cyclopes (desconsiderando o valor obtido para 35D) são os gêneros com maior capacidade de resposta alinhada a um eventual vetor de seleção direcional. Por outro lado, Myrmecophaga, Tamandua, Dasypus e Euphractus responderiam, geralmente, de forma menos alinhada ao gradiente de seleção. Os demais gêneros teriam respostas intermediárias. No momento, nada pode ser dito de Scelidotherium, já que o valor obtido pode ser em função de problemas amostrais.

\section{Conclusões}

As matrizes de covariância e correlação fenotípicas foram similares quanto as suas estruturas de relação dos caracteres. Elas podem ser utilizadas tanto como substitutas das matrizes-G como aplicadas no contexto macroevolutivo. As magnitudes gerais de integração variaram de fracas a moderadas. Tanto a estrutura das matrizes quanto a magnitude geral de integração delas estiveram correlacionadas com a história filogenética e não estiveram correlacionadas com a semelhança morfológica ou ecológica (dieta) dos taxa. Elas estiveram pouco ou nada correlacionadas entre si. Em outras palavras, mudanças nas estruturas e nas magnitudes gerais de integração das matrizes são relativamente independentes uma da outra. 


\section{Referências}

Ackermann, R.R., 2002. Patterns of covariation in the hominoid craniofacial skeleton: implications for paleoanthropological models. Journal of Human Evolution 43, 167-187.

Ackermann, R.R., Cheverud, J.M., 2002. Discerning evolutionary processes in patterns of tamarin (genus Saguinus) craniofacial variation. American Journal of Physical Anthropology $117,260-271$.

Arnold, S.J., Phillips, P.C., 1999. Hierarchical comparison of genetic variance-covariance matrices. II. Coastal-inland divergence in the garter snake, Thamnophis elegans. Evolution 53, 1516-1527.

Barton, N.H., Turelli, M., 1989. Evolutionary quantitative genetics: how little do we know. Annual Review of Genetics 23, 337-370.

Bininda-Emonds, O.R.P., Cardillo, M., Jones, K.E., MacPhee, R.D.E., Beck, R.M.D., Grenyer, R., Price, S.A., Vos, R.A., Gittleman, J.L., Purvis, A., 2007. The delayed rise of present-day mammals. Nature 446, 507-512.

Blows, M.W., Chenoweth, S.F., Hine, E., 2004. Orientation of the genetic variancecovariance matrix and the fitness surface for multiple male sexually selected traits. American Naturalist 163, 329-340.

Cheverud, J.M., 1982. Phenotypic, genetic, and environmental morphological integration in the cranium. Evolution 36, 499-516.

Cheverud, J.M., 1988. A comparison of genetic and phenotypic correlations. Evolution 42, 958-968. 
Cheverud, J.M., 1995. Morphological integration in the Saddle-back Tamarin (Saguinusfuscicollis) cranium. American Naturalist 145, 63-89.

Cheverud, J.M., 1996. Quantitative genetic analysis of cranial morphology in the cottontop (Saguinus oedipus) and saddle-back (S. fuscicollis) tamarins. Journal of Evolutionary Biology 9, 5-42.

Cheverud, J.M., Marroig, G., 2007. Comparing covariance matrices: Random skewers method compared to the common principal components model. Genetics and Molecular Biology 30, 461-469.

Cheverud, J.M., Wagner, G.P., Dow, M.M., 1989. Methods for the comparative analysis of variation patterns Systematic Zoology 38, 201-213.

Clark, A.A., 2010. "Ancient DNA from the extinct folivorous Xenarthrans, or sloths, with specific attention toward the Greater Antillean Megalonychids and the Patagonian Mylodontid, Mylodon darwinii." Unpublished PhD Thesis thesis, McMaster University.

da Silva, H.S., 2010. "Evolução morfológica em marsupiais (Mammalia, Dedelphimorphia) do Novo Mundo." Universidade de São Paulo.

de Conto, V., 2007. "Estratégias bionômicas e padrões de variância e covariância do crânio de Akodon cursor (Rodentia: Sigmodontidae)." Universidade Federal do Rio de Janeiro.

Delsuc, F., Catzeflis, F.M., Stanhope, M.J., Douzery, E.J.P., 2001. The evolution of armadillos, anteaters and sloths depicted by nuclear and mitochondrial phylogenies: implications for the status of the enigmatic fossil Eurotamandua. Proceedings of the Royal Society of London Series B-Biological Sciences 268, 1605-1615. 
Delsuc, F., Superina, M., Tilak, M.-K., Douzery, E.J.P., Hassanin, A., 2012. Molecular phylogenetics unveils the ancient evolutionary origins of the enigmatic fairy armadillos. Molecular Phylogenetics and Evolution 62, 673-680.

Eisenberg, J.F., Redford, K.H., 1999. Mammals of the Neotropics, Volume 3: The Central Neotropics: Ecuador, Peru, Bolivia, Brazil. The University of Chicago Press, Chicago

Elbroch, M., 2006. Animal skulls: a guide to North American species. Stackpole Books, Mechanicsburg.

Estes, S., Arnold, S.J., 2007. Resolving the paradox of stasis: models with stabilizing selection explain evolutionary divergence on all timescales. American Naturalist 169, 227-244.

Falconer, D.S., MacKay, T.F.C., 1996. Introduction to quantitative genetics. Longman, New York.

Game, E.T., Caley, M.J., 2006. The stability of P in coral reef fishes. Evolution 60, 814823.

Garcia, G., 2010. "Análise comparativa dos padrões de covariação genética e fenotípica no crânio e mandíbula de Calomys expulsus (Rodentia: Muroidea)." Universidade de São Paulo.

Gardner, A.L., 2007. Mammals of South America: volume 1: Marsupials, Xenarthrans, Shrews, and Bats. The University of Chicago Press, Chicago and London.

Gaudin, T.J., 2004. Phylogenetic relationships among sloths (Mammalia, Xenarthra, Tardigrada): the craniodental evidence. Zoological Journal of the Linnean Society 140, 255-305. 
Haber, A., 2011. A comparative analysis of integration indices. Evolutionary Biology 38, 476-488.

Hair, J.F., White, W.C., Babin, B.J., Anderson, R.E., 2010. Multivariate Data Analysis. Prentice Hall.

Hansen, T.F., Houle, D., 2008. Measuring and comparing evolvability and constraint in multivariate characters. Journal of Evolutionary Biology 21, 1201-1219.

Klingenberg, C.P., Monteiro, L.R., 2005. Distances and directions in multidimensional shape spaces: Implications for morphometric applications. Systematic Biology 54, 678-688.

Krzanowski, W.J., 1979. Between-groups comparison of principal components. Journal of the American Statistical Association 74, 703-707.

Lande, R., 1979. Quantitative genetic analysis of multivariate evolution, applied to brain body size allometry. Evolution 33, 402-416.

Lessells, C.M., Boag, P.T., 1987. Unrepeatable repeatabilities: a common mistake. Auk 104, 116-121.

Manly, B.F.J., 1986. Multivariate statistical methods: a primer. Chapman and Hall, NewYork.

Marroig, G., Cheverud, J., 2010. Size as a line of least resistance ii: direct selection on size or correlated response due to constraints? Evolution 64, 1470-1488. 
Marroig, G., Cheverud, J.M., 2001. A comparison of phenotypic variation and covariation patterns and the role of phylogeny. Ecology, and ontogeny during cranial evolution of new world monkeys. Evolution 55, 2576-2600.

Marroig, G., Cheverud, J.M., 2004. Did natural selection or genetic drift produce the cranial diversification of neotropical monkeys? American Naturalist 163, 417-428.

Marroig, G., Cheverud, J.M., 2009. Size and shape in callimico and marmoset skulls: allometry and heterochrony in the morphological evolution of small anthropoids. Em: Ford, S.M., Porter, L.M.,Davis, L.C. (Ed.), The smallest anthropoids: The marmoset/callimico radiation. . Springer, New York, pp. 331-353.

Marroig, G., Melo, D., Porto, A., Sebastiao, H., Garcia, G., 2011. Selection response decomposition (SRD): A new tool for dissecting differences and similarities between matrices. Evolutionary Biology 38, 225-241.

Marroig, G., Melo, D., Garcia, G., 2012. Modularity, noise, and natural selection. Evolution 66-5, 1506-1524.

Marroig, G., Shirai, L.T., Porto, A., de Oliveira, F.B., De Conto, V., 2009. The evolution of modularity in the mammalian skull II: evolutionary consequences. Evolutionary Biology 36, $136-148$.

McAfee, R.K., 2009. Reassessment of the cranial characters of Glossotherium and Paramylodon (Mammalia: Xenarthra: Mylodontidae). Zoological Journal of the Linnean Society $155,885-903$. 
McKenna, M.C., Bell, S.K., 1997. Classification of mammals above the species level. Columbia University Press, New York.

Meyer, K., Kirkpatrick, M. 2008. Perils of parsimony: properties of reduced-rank estimates of genetic covariance matrices. Genetics 180, 1153-1166.

Miño-Boilini, A.R., Carlini, A.A., 2009. The Scelidotheriinae Ameghino, 1904 (Phyllophaga, Xenarthra) from the Ensenadan-Lujanian Stage/Ages (Early Pleistocene to EarlyMiddle Pleistocene-Early Holocene) of Argentina. Quaternary International 210, 93-101.

Möller-Krull, M., Delsuc, F., Churakov, G., Marker, C., Superina, M., Brosius, J., Douzery, E.J.P., Schmitz, J., 2007. Retroposed elements and their flanking regions resolve the evolutionary history of xenarthran mammals (armadillos, anteaters, and sloths). Molecular Biology and Evolution 24, 2573-2582.

Murphy, W.J., Eizirik, E., Johnson, W.E., Zhang, Y.P., Ryder, O.A., O'Brien, S.J., 2001. Molecular phylogenetics and the origins of placental mammals. Nature 409, 614-618.

Oliveira, F.B.d., 2009. Evolução do crânio dos macacos do Velho Mundo: uma abordagem de genética quantitativa. Tese de Doutorado, Universidade de São Paulo.

Oliveira, F.B., Porto, A., Marroig, G., 2009. Covariance structure in the skull of Catarrhini: a case of pattern stasis and magnitude evolution. Journal of Human Evolution 56, 417-430.

Pavlicev, M., Cheverud, J.M., Wagner, G.P., 2009. Measuring morphological integration using eigenvalue variance. Evolutionary Biology 36, 157-170. 
Phillips, P.C., McGuigan, K.L., 2006. Evolution of genetic variance-covariance structure. Em: Fox, C.W.,Wolf, J.B. (Ed.), Evolutionary Genetics: Concepts and Case Studies. Oxford University Press, Oxford, pp. 310-325.

Porto, A., Oliveira, F.B.D., Shirai, L.T., Conto, V.D., Marroig, G., 2009. The evolution of modularity in the mammalian skull I: Morphological integration patterns and magnitudes. Evolutionary Biology 36, 118-135.

R Development Core Team, 2011. A language and environment for statistical computing. R Foundation for Statistical Computing, Vienna, Austria.

Redford, K.H., 1985. Food habits of armadillos (Xenarthra: Dasypodidae). Em: Montgomery, G.G. (Ed.), The evolution and ecology of armadillos, sloths and vermilinguas. Smithsonian Institution Press, Washington and London, pp. 429-437.

Redford, K.H., Eisenberg, J.F., 1992. Mammals of the neotropics. The southern cone. Volume 2. Chile, Argentina, Uruguay, Paraguay. The University of Chicago Press, Chicago.

Schluter, D., 1996. Adaptive radiation along genetic lines of least resistance. Evolution $50,1766-1774$.

Shirai, L.T., Marroig, G., 2010. Skull modularity in neotropical marsupials and monkeys: Size variation and evolutionary constraint and flexibility. Journal of Experimental Zoology Part B-Molecular and Developmental Evolution 314B, 663-683.

Simpson, G.G., 1980. Splendid isolation: The curious history of South American mammals. Yale University Press, New Haven and London. 
Steppan, S.J., 1997. Phylogenetic analysis of phenotypic covariance structure .1. Contrasting results from matrix correlation and common principal component analyses. Evolution 51, 571-586.

Steppan, S.J., Phillips, P.C., Houle, D., 2002. Comparative quantitative genetics: evolution of the G matrix. Trends in Ecology \& Evolution 17, 320-327.

Turelli, M., 1988. Phenotypic evolution, constant covariances, and the maintenance of additive variance. Evolution 42, 1342-1347. 


\section{Capítulo II - Diversificação morfológica craniana dos Xenarthra: deriva genética versus seleção natural}

\section{Introdução}

Em biologia, evolução significa mudança entre as gerações de uma linhagem evolutiva (Endler, 1992; Ridley, 2004). Após os trabalhos seminais de Darwin e Wallace (Darwin e Wallace, 1858; Darwin, 1859) sobre a teoria da evolução das espécies através da seleção natural, os termos evolução e seleção natural passaram a estar intimamente relacionados (Endler, 1992). No entanto, as alterações entre as gerações também podem ocorrer por deriva genética (Hagedoorn e Hagedoorn Vorstheuvel La Brand, 1921; Wright, 1931). Embora contraintuitivo, características complexas e vitais para uma espécie podem, em teoria, evoluir de forma aleatória (Lande, 1979).

Em geral, aceita-se que a seleção natural tenha sido a grande força atuante na diversificação morfológica animal (Simpson, 1980; Marroig e Cheverud, 2004), embora essa ideia tenha sido raramente testada (Marroig e Cheverud, 2004). A lógica subjacente a tal argumento é que a variação entre espécies nas estruturas morfológicas complexas é usualmente reconhecida como sendo adaptativa (Gould e Lewontin, 1979; Marroig e Cheverud, 2004). Para os Xenarthra isto não é exceção (Simpson, 1945, 1980; Patterson e Pascual, 1968; Rich et al., 1996; Benton, 2000). A visão clássica para a evolução dos diversos grupos dessa magnaordem é a seguinte: as linhagens evolutivas ocuparam por um longo período de tempo um grande território praticamente inabitado por outras formas de mamíferos e em isolamento quase completo de outras massas de terra, a América do Sul. Nesse continente, elas puderam explorar diversos nichos ecológicos desocupados. As diferentes linhagens de Xenarthra, em função da fartura de nichos, sofreram pulsos de evolução por seleção natural. Posteriormente, com o intercâmbio entre animais da América do Norte e do Sul, durante o Mioceno ( 23 - 5,3 Ma) e 
principalmente o Plioceno $(\sim 5,3-2,6 \mathrm{Ma})$, novas pressões foram criadas em virtude da competição/predação gerada pelos animais imigrantes. Novamente, a seleção natural teve papel importante na evolução dos Xenarthra (Simpson, 1945, 1980; Patterson e Pascual, 1968; Rich et al., 1996; Benton, 2000).

No entanto, nada foi feito até o momento para se testar através de métodos quantitativos e bem estabelecidos os processos envolvidos na evolução morfológica deste grupo nos seus diversos níveis taxonômicos. Um modo atrativo de se explorar essa questão é rejeitar a hipótese nula de que os caracteres morfológicos evoluíram apenas através da deriva genética (Marroig e Cheverud, 2004; Harmon e Gibson, 2006). Esse tipo de teste pode ser realizado considerando agentes seletivos a priori. Por exemplo, testar se mudanças em variáveis ambientais estão ou não correlacionadas com a variação observada entre os organismos ou populações. Contudo, essa abordagem não é conclusiva, pois fatores adaptativos importantes podem não estar inclusos nas análises (Harmon e Gibson, 2006). Outra estratégia, mais atrativa, é utilizar métodos que não definem agentes seletivos a priori, testando diretamente um modelo nulo de deriva genética (Marroig e Cheverud, 2004; Harmon e Gibson, 2006).

O modelo nulo de deriva genética parte de um cenário em que: 1) não existe seleção natural atuando na divergência entre as espécies; 2) as matrizes-G de cada linhagem são similares (ou proporcionais); e 3) no qual variações nos fenótipos médios sejam causadas por mudanças genéticas. Caso estes pressupostos sejam razoáveis, a teoria da genética quantitativa prevê que, apenas sob deriva genética, a divergência nos caracteres morfológicos entre as espécies estudadas deva ser proporcional ao padrão e magnitude de variação e covariação entre os caracteres da população ancestral (Lande, 1979; Marroig e Cheverud, 2004). Baseado nisto, é possível testar a hipótese nula que o padrão de diversificação morfológico entre linhagens 
evolutivas monofiléticas ocorreu apenas através do processo de deriva genética. Para tanto, compara-se as matrizes de variância/covariância intraespecíficas e interespecíficas dos grupos em estudo (para detalhes ver seção "Deriva genética versus seleção natural” mais abaixo; Lande, 1979; Lofsvold, 1988; Ackermann e Cheverud, 2002; Marroig e Cheverud, 2004). Rejeitar a hipótese nula sugere que seleção natural participou do processo de diversificação morfológica dos grupos estudados. Por outro lado, não refutar essa hipótese pode significar tanto que a deriva genética teve papel exclusivo nesse processo quanto que a seleção natural ocorreu uniformemente ao longo de todos os caracteres, mimetizando o resultado esperado apenas sob deriva genética (Marroig e Cheverud, 2004). Isto pode ser imaginado em um contexto que a seleção atua sobre uma via do desenvolvimento comum, resultando em padrões de variância e covariância dos caracteres semelhantes entre os taxa (Marroig e Cheverud, 2001, 2004).

O objetivo deste capítulo, portanto, foi testar a hipótese nula de que a diversificação morfológica craniana dos Xenarthra poderia ser explicada unicamente através de deriva genética, sem a ação da seleção natural. Com isso, buscou-se determinar quais processos estiveram envolvidos na evolução do grupo.

\section{Material e Métodos}

\section{Amostra, distâncias e matrizes de variância/covariância}

Neste capítulo foi utilizado o mesmo banco de dados do Capítulo I e os mesmos procedimentos para a obtenção das matrizes-P de variância/covariância de cada gênero. Conforme mostrado no capítulo anterior, as matrizes-P, independentemente do conjunto de distâncias utilizado (35D, 32D, 28D ou 25D), apresentaram resultados bastante semelhantes, sugerindo que: 1) elas compartilham estruturas similares; 2) podem ser utilizadas como 
substitutas das matrizes-G; e 3) a variação na quantidade de distâncias não influiu nos resultados obtidos. Em função disto, não houve necessidade de realizar as análises desse capítulo com todos os conjuntos de distâncias utilizados anteriormente. As análises foram desenvolvidas essencialmente para o conjunto de distâncias 35D. Apenas para os Folivora as análises foram realizadas no conjunto de distâncias 25D, para permitir a inclusão de oito gêneros fósseis (Tabela 2.1). Além de Paramylodon e Scelidotherium, estudados no capítulo anterior, seis novos gêneros extintos foram analisados (Tabela 2.1). O mesmo procedimento de reflexão de pontos utilizado para Paramylodon e Scelidotherium no Capítulo I foi adotado para esses novos taxa (ver Tabela 2.2 para detalhes de quais espécimes e quais distâncias foram refletidas).

Tabela 2.1 - Espécies e amostra dos Xenarthra fósseis estudados.

\begin{tabular}{cc}
\hline Espécie & Amostra \\
\hline Paramylodon harlani & 37 \\
Glossotherium robustum & 5 \\
Scelidotherium leptocephalum & 16 \\
Scelidotherium bravardi & 1 \\
Acratocnus odontrigonus & 5 \\
Acratocnus ye & 3 \\
Nothrotheriops shastensis & 5 \\
Neocnus comes & 6 \\
Neocnus Dousman & 1 \\
Megalonyx jeffersonii & 2 \\
Megalonyx leptostomus & 1 \\
Eremotherium laurillardi & 5 \\
\hline
\end{tabular}

Em função das amostras pequenas dos seis novos gêneros fósseis, não foi possível calcular a repetibilidade para eles como apresentado no capítulo anterior. Todos os gêneros que tiveram suas repetibilidades calculadas no Capítulo I apresentaram valores adequados. Em função disso, foi assumido para os novos gêneros fósseis que o erro associado à obtenção dos dados foi pequeno e não interferiu nas análises subsequentes. Esses gêneros também foram representados no restante das análises pela média das distâncias entre as duas mensurações. 
Tabela 2.2 - Espécimes utilizados que tiveram distâncias refletidas substituindo as originais.

\begin{tabular}{|c|c|c|}
\hline Espécie & ID & Distâncias refletidas \\
\hline Glossotherium robustum & MNHN441 & PMMT, PTEAM \\
\hline Paramylodon harlani & LACMHC645 & PMMT \\
\hline Paramylodon harlani & LACMHC827 & PTAS \\
\hline Paramylodon harlani & LACMHC831 & PTAS \\
\hline Paramylodon harlani & UCMP21172 & PTZYGO, ZYGOTSP \\
\hline Paramylodon harlani & UCMP23009 & PTAPET, PTTSP, ZYGOTSP \\
\hline Paramylodon harlani & UCMP23006 & PTAPET \\
\hline Paramylodon harlani & UCMP21170 & PTTSP, PTEAM \\
\hline Paramylodon harlanil & MNH15273 & ZITSP \\
\hline Scelidotherium bravardi & NHM37626 & ZIMT \\
\hline Scelidotherium leptocephalum & FMNHP14274 & ZSZI, ZITSP \\
\hline Scelidotherium leptocephalum & MLP3_408 & ZIZYGO \\
\hline Scelidotherium leptocephalum & MACN2215 & PMZI, PMMT, ZITSP \\
\hline Scelidotherium leptocephalum & MLP3_420 & ZIMT \\
\hline Scelidotherium leptocephalum & MLP3_770 & PMZS, ZSZI \\
\hline Scelidotherium leptocephalum & MLP35_III_1_1 & PMMT \\
\hline Scelidotherium leptocephalum & NHM32995 & PMMT, PMZI, PMZS, PTEAM, JPAS \\
\hline Acratocnus odontrigonus & AMNH17715 & PTZYGO, ZYGOTSP \\
\hline Acratocnus odontrigonus & AMNH17720 & PTZYGO, ZYGOTSP \\
\hline Acratocnus odontrigonus & UF156893 & PTZYGO, EAMZYGO, ZYGOTSP \\
\hline Acratocnus odontrigonus & UF76399 & PTEAM \\
\hline Acratocnus odontrigonus & UF76368 & PMZS, PMZI, PMMT, JPAS \\
\hline Neocnus comes & UF25702 & PTZYGO, EAMZYGO, ZYGOTSP \\
\hline Neocnus comes & UF131990 & PMZS, PMMT, PTAPET, PTEAM, , APETTS, PTAS \\
\hline Neocnus comes & UF170527 & ZIMT \\
\hline Eremotherium laurillardi & MCN PALEOMCL1702 & PTTSP, ZYGOTSP, PTAS, JPAS \\
\hline Eremotherium laurillardi & UF15004 & EAMZYGO \\
\hline Eremotherium laurillardi & MCN PALEOsnvenon & ZIMT \\
\hline
\end{tabular}

Como será explicado mais abaixo, as análises realizadas nesse capítulo necessitaram de matrizes-P ponderadas intragrupos (matriz-W) para representar o padrão de covariância da população ancestral que originou os gêneros em estudo. Devido às amostras pequenas, não foi possível estimar adequadamente matrizes-P para os seis novos gêneros estudados (Tabela 2.1). Contudo, a ausência de matrizes-P para esses grupos não foi considerada um problema face o padrão geral de relativa similaridade descrito anteriormente. As análises do capítulo anterior mostraram a semelhança estrutural entre as diversas matrizes-P testadas, incluindo a dos gêneros fósseis Paramylodon e Scelidotherium. Este teste empírico realizado permite supor aqui que as matrizes-P de todos os Xenarthra são semelhantes, mesmo que seja impossível obter matrizes-P para alguns dos taxa fósseis utilizados. Portanto, a matriz-W de cada clado estudado foi estimada 
através das matrizes-P existentes e foram consideradas adequadas para representar a respectiva população ancestral.

\section{Deriva genética versus seleção natural}

As forças evolutivas operantes na diversificação de populações são dependentes da variação intraespecífica (Ackermann e Cheverud, 2002). Apenas sob o efeito de deriva genética, a divergência entre os fenótipos médios no decorrer das gerações está atrelada: 1) à covariância genética; 2) ao tamanho efetivo da população; e 3) ao número de gerações desde o tempo de divergência entre as populações (Lande, 1979, 1980; Lofsvold, 1988; Ackermann e Cheverud, 2002); e pode ser expressa da forma apresentada abaixo.

$$
\boldsymbol{B}=\boldsymbol{G}\left(\frac{t}{N_{e}}\right)
$$

onde $\mathbf{B}$ é a matriz de covariância entre populações (matriz-B) na geração t, G é a matriz de covariância genética aditiva da população ancestral (matriz-G), t é o número de gerações desde o tempo de divergência das linhagens e $\mathrm{N}_{\mathrm{e}}$ é o tamanho efetivo da população. Partindo do conhecimento que: 1) quando não se possui a matriz-G ancestral a melhor estimativa para ela é a matriz-G ponderada intragrupo (Lande, 1979); 2) as matrizes-G podem ser substituídas pelas matrizes-P (ver Capítulo I); e 3) dado que $\mathrm{N}_{\mathrm{e}}$ e t são constantes em cada comparação, a equação apresentada acima pode ser simplificada para:

\section{$\boldsymbol{B} \propto \boldsymbol{W}$}

onde W representa a matriz ponderada de variância fenotípica intragrupo (i.e., matriz de covariância fenotípica da população ancestral; matriz-W). Ou seja, se a diversificação entre as populações (neste caso, gêneros) ocorreu por deriva genética, espera-se que o padrão da matriz 
de covariância fenotípica entre grupos (matriz-B) seja proporcional ao da matriz de covariância fenotípica dentro dos grupos (matriz-W; Ackermann e Cheverud, 2002).

Para facilitar as análises, a matriz-W e a matriz-B foram expressas de forma simplificada. A matriz-W foi decomposta em autovalores e autovetores através da análise de componentes principais. Os autovalores representam a variância associada a cada autovetor, que apresentam covariância nula entre si por definição. Portanto, através da decomposição da matriz foi possível obter uma matriz na qual a diagonal apresenta valores de variância intraespecífica e os elementos fora da diagonal são valores iguais a zero. Essa matriz diagonal passou a ser a nova representação da matriz-W. Para obter a matriz-B foi necessário gerar um vetor para cada espécie com suas projeções médias nos componentes principais da matriz-W. Para realizar essa tarefa foi calculada, para cada gênero, a soma do produto entre o vetor de médias dos caracteres e cada autovetor da matriz-W normalizado para norma igual a um (raiz da soma dos quadrados igual a um). A matriz-B foi estimada como sendo a variância entre as projeções médias em cada componente principal da matriz-W (Ackermann e Cheverud, 2002; Marroig e Cheverud, 2004).

O vetor de médias dos caracteres para cada gênero foi obtido através da média ponderada entre os fatores sexo, espécie, variação intraespecífica e animal cativo ou não. No entanto, para cada gênero só foram ponderados os fatores para os quais as análises realizadas no Capítulo I consideraram que eles atuaram como fontes de variação nas médias dos caracteres (ver Tabela 1.4). Por exemplo, para Tolypeutes os fatores espécie e animal cativo ou não foram fontes de variação nas médias dos caracteres. Para esse gênero, portanto, foi calculada a média ponderada entre animais cativos e não cativos dentro de cada espécie. Em seguida a média ponderada entre as espécies. De qualquer forma, salienta-se que a média ponderada e a média aritmética em todos os casos geraram valores muito semelhantes. Para os fósseis não apresentados no capítulo 
anterior, foi ponderada a média entre diferentes espécies nos gêneros representados por mais do que uma espécie (Tabela 2.1).

Na escala logarítmica a primeira equação apresentada pode ser escrita como uma equação de regressão linear (Ackermann e Cheverud, 2002):

$$
\ln \left(\boldsymbol{B}_{i}\right)=\ln \left(\frac{t}{N e}\right)+\beta \ln \left(\boldsymbol{W}_{\boldsymbol{i}}\right)
$$

onde $\mathbf{B}_{\mathbf{i}}$ e $\mathbf{W}_{\mathbf{i}}$ são a variância entre grupos e intragrupos para o inésimo autovetor, respectivamente; ou seja, tratados como observações pareadas e com número equivalente ao posto (número de caracteres) da matriz original. A partir dessa equação e das novas representações da matriz-W e da matriz-B, pode se calcular a inclinação da reta de regressão $(\beta)$. Como apresentado anteriormente, espera-se que sob um modelo evolutivo neutro (sem ação significativa de seleção natural) a matriz-W e a matriz-B sejam proporcionais. Na escala logarítmica, dois conjuntos de dados proporcionais apresentarão $\beta$ igual um e diferirão apenas no valor do intercepto. Ou seja, se a matriz-W for proporcional a matriz-B, na escala logarítmica $\beta$ será igual um. Uma diferença significativa desse valor, identificada quando os limites do intervalo de confiança de $95 \%$ não englobam o valor um, sugere que a diferenciação morfológica observada entre as espécies não ocorreu exclusivamente por deriva genética (Ackermann e Cheverud, 2002; Marroig e Cheverud, 2004).

Recentemente, Prôa e colaboradores (2012) desenvolveram uma série de simulações para avaliar a taxa de erro do tipo I no teste de regressão apresentado acima. A conclusão geral desses autores foi que se as matrizes-G forem semelhantes/proporcionais às matrizes-P, como é o caso neste estudo, não há uma elevação na taxa de erro do tipo I. O teste de regressão, portanto, é consistente. De qualquer forma, esses autores disponibilizaram uma simulação que calcula a 
inclinação da reta ( $\beta$ ) esperada e o intervalo de confiança para o teste de regressão. Ao utilizar o procedimento de simulação proposto por Prôa e colaboradores (2012), ao invés de avaliar se a matriz-W e a matriz-B diferem da inclinação teórica de um, testa-se se a inclinação observada difere da inclinação determinada pela simulação (Prôa et al., 2012). Para realizar essa simulação é necessário obter a matriz-W, a matriz-B, a razão entre o número de gerações desde o tempo de divergência entre as populações e o tamanho efetivo populacional $\left(t / N_{e}\right)$, o número de populações comparadas (gêneros analisados) e a quantidade de indivíduos em cada população. A partir desses dados essa simulação consiste em: 1) para cada população é gerado um vetor aleatório, com valores para cada distância, obtido através de uma distribuição normal multivariada considerando a média de cada caráter igual a zero e uma matriz de covariância entre os caracteres segundo a equação:

$$
\frac{t}{N e} \boldsymbol{G}
$$

onde $\mathbf{G}$ representa, nesse estudo, a matriz-W; 2) a partir de uma distribuição normal multivariada considerando a média dos caracteres como o vetor obtido na etapa anterior e uma matriz de covariância equivalente a matriz-B, para cada população foram geradas amostras aleatórias, com valores para cada distância, na quantidade equivalente ao número de indivíduos de cada população; 3) ao término da etapa anterior foram obtidos dados aleatórios para as populações originais. Esses respeitam tanto as propriedades de covariância entre os caracteres das populações, quanto o número de indivíduos dentro de cada uma delas. Com base nesse conjunto de dados foram estimadas a matriz-W e a matriz-B e a partir delas foi obtida a inclinação da reta de regressão conforme proposto por Ackerman e Cheverud (2002); 4) esse procedimento foi repetido 10000 vezes e a média de todos os $\beta$ obtidos representou o seu valor simulado. O 
intervalo de confiança foi obtido adicionando/subtraindo 1,96 vezes o desvio padrão da média da distribuição dos 10000 ßs. A lógica por trás dessa simulação é: 1) gerar, a partir dos parâmetros populacionais observados (matriz-W, matriz-B e $t / N_{e}$ ), diversos cenários distintos de evolução neutra. Note que os diferentes cenários são obtidos respeitando as propriedades de covariância do clado estudado; e 2) com base nos diversos cenários neutros gerados, determinar empiricamente qual seria a inclinação da reta apenas sob o efeito de deriva genética.

Para realizar essa simulação, a matriz-W foi representada como a matriz ponderada de variância/covariância fenotípica intragrupo. A matriz-B foi obtida como a diferença entre os produtos cruzados totais e os dentro de grupos, dividida pelos graus de liberdade (Simpson et al., 1960). Não foi possível determinar com precisão o número de gerações que ocorreram desde o tempo de divergência (t), mas acredita-se que ele seja elevado, já que: 1) o tempo de divergência dos grupos estudados é grande. A divergência mais recente estudada está entre 37 e 29 Ma (Delsuc et al., 2012); e 2) a gestação dura $\sim 2$ a 5 meses e a maturidade sexual ocorre após $\sim 1$ a 4 anos (Eisenberg e Redford, 1999). Assumindo que uma nova geração nos Xenarthra inicia-se a cada 10 anos, que é uma estimativa bastante conservadora dado as informações de gestação e maturidade sexual do grupo, teríamos uma estimativa mínima de $t=10^{5}$. Por outro lado, assumindo que haveria uma geração por ano, teríamos $t=10^{6}$.

Não foi possível determinar o número efetivo populacional para os Xenarthra, mas as estimativas padrões para o tamanho efetivo populacional em mamíferos é da ordem de $\sim 10^{4}-$ $10^{5}$ (Bedford et al., 2008). Ou seja, $t / N_{e}$ provavelmente é igual ou maior do que um. Desta forma, em função das incertezas envolvidas na determinação desta razão, os seguintes valores para $t / N_{e}$ foram utilizados nas simulações: um, 10, 100 e 1000 . 
As análises de simulação da inclinação da reta de regressão seguindo a proposta de Prôa e colaboradores (2012) foram realizadas para todos os casos estudados. $\mathrm{O}$ valor obtido para $\beta$ com os dados reais foi comparado tanto à expectativa teórica de um, denominado daqui para frente de teste de regressão teórico (TRT), quanto aos resultados obtidos através da simulação, denominado daqui para frente de teste de regressão por simulação (TRS).

Além dos testes de regressão, outra forma de detectar a influência da seleção natural na diversificação das espécies foi empregada; o teste de correlação entre as projeções médias dos taxa divergentes nos componentes principais (PC) da matriz-W (escores médios dos gêneros). Os PCs extraídos da matriz-W são, por definição, não correlacionados, ou seja, eles representam variáveis independentes. Os escores médios dos gêneros nada mais são do que os valores de cada gênero nessas novas variáveis independentes. Caso os grupos tenham evoluído apenas por deriva genética, espera-se que os escores médios dos gêneros nos diferentes PCs também não estejam correlacionados. Isso porque a evolução por deriva genética está relacionada a quantidade de variância das variáveis e de covariância entre elas. Como a covariância entre os PCs é zero, o esperado seria que os escores médios dos gêneros nos PCs fossem independentes uns dos outros. Em outras palavras, os escores médios de cada gênero no primeiro componente principal da matriz-W deveriam ser independentes dos escores médios de cada gênero no segundo componente principal da matriz-W e assim por diante. Correlações significativas entre os escores médios ao longo dos diferentes componentes principais da matriz-W significam que ocorreu seleção conjunta (coseleção) nas dimensões testadas (Marroig e Cheverud, 2004). Coseleção é definida como a covariância na distribuição dos caracteres em função da covariância nas mudanças desses caracteres devido à correlação de suas respectivas pressões seletivas (Felsenstein, 1988:452). O conceito de coseleção pode ser melhor entendido através de um 
exemplo. Períodos de temperaturas mais baixas podem selecionar mamíferos para apresentarem pelagem mais escura, membros mais curtos e tamanho corpóreo maior. Essas características favorecem a aptidão nessa condição ambiental. Em função disso, essas três características evoluem de forma previsível, ou seja, correlacionada. No entanto, não há a necessidade de correlação genética entre os caracteres. Todas essas características podem ser geneticamente independentes (Felsenstein, 1988).

Os testes de correlação foram realizados com n-1 componentes principais, sendo $\mathrm{n} o$ número de taxa comparados. O número máximo de componentes principais considerados foi de cinco. A significância estatística foi acessada através da probabilidade associada a cada correlação entre os componentes principais corrigida pelo critério de Bonferroni e o teste $\chi^{2}$ de Bartlett para significância das correlações de uma matriz (multivariado). No entanto, atingir a significância estatística apenas pelo segundo método não foi considerado evidência o suficiente para a rejeição da hipótese nula. Potenciais problemas quanto à normalidade das médias entre grupos podem prejudicar a eficiência desse método (Knapp e Smatriz-Woyer, 1967; Ackermann e Cheverud, 2002; Marroig e Cheverud, 2004).

\section{Nós da Filogenia analisados}

O número de taxa de cada nó analisado da filogenia correspondeu diretamente ao tamanho amostral no teste de correlação. Ele também influi na determinação do intervalo de confiança do teste de regressão (Oliveira, 2009). Por consequencia, não foram todos os nós da filogenia adotada que puderam ser testados para a hipótese nula, de que a diversificação a partir do nó em questão ocorreu apenas por deriva genética. Oliveira (2009) determinou através de análises considerando subamostras do seu banco de dados original que realizar as análises com 
menos do que quatro taxa é temerário. Sendo assim, neste trabalho foram estudados apenas os nós que continham ao menos quatro taxa (Figura 2.1).

Para os gêneros atuais (35D), as análises foram realizadas orientadas segundo a filogenia proposta por Möller-Krull e colaboradores (2007; Figura 2.1). Na comparação entre todos os Folivora (nó 5; Figura 2.1), grupo que englobou os fósseis analisados, foi considerada uma politomia (nó 5; Figura 2.1). Essa opção se justifica devido à incongruência entre as análises filogenéticas moleculares e morfológicas (Gaudin, 2004; Clark, 2010). Nas análises dos clados pertencentes à Folivora (nós 6, 7 e 8; Figura 2.1) foi seguida a proposta de Gaudin (2004). Nesses casos, as análises moleculares não apresentam detalhamento suficiente para gerar uma hipótese filogenética que inclua os gêneros fósseis estudados (Clark, 2010).

As matrizes-W abrangeram todos os taxa incluídos nas análises. Exceções a essa regra foram os casos que envolveram os gêneros fósseis. Para os nós 7 e 8 (Figura 2.1), elas corresponderam a matriz-P de Choloepus. Para o nó 6 (Figura 2.1) foram utilizadas as matrizes-P de Choloepus e Paramylodon e para o nó 5 (Figura 2.1), além dessas duas matrizes utilizou-se também a matriz de Bradypus.

Todas as análises realizadas nesse capítulo foram desenvolvidas através do $\mathrm{R}$ ( $\mathrm{R}$ Development Core Team, 2011). 


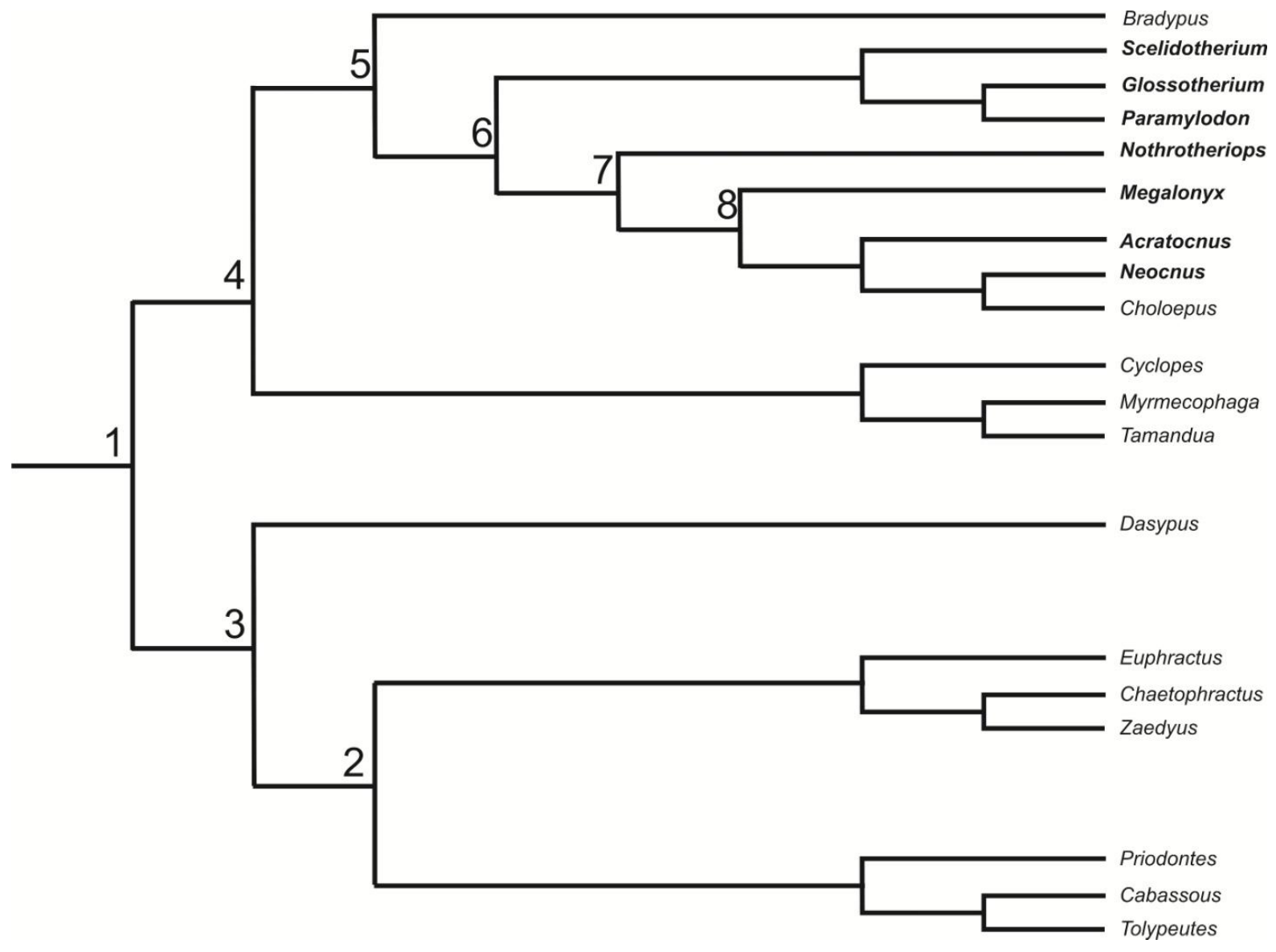

Figura 2.1 - Filogenia adaptada de Möller-Krull et al (2007) e para os Folivora de Gaudin (2004). Os números indicam os nós que foram testados para a hipótese nula de ausência de seleção. Gêneros fósseis estão realçados em negrito.

\section{Resultados}

Os testes para a hipótese nula de diversificação somente por deriva genética refutaram a $\mathrm{H}_{0}$ nos oito casos avaliados (Tabela 2.3). O teste de regressão teórico (TRT) rejeitou a $\mathrm{H}_{0}$ em três casos (nós 1, 3 e 4). Os testes de correlação também rejeitaram a $\mathrm{H}_{0}$ em três casos (nós 1, 5 e 6). Os resultados obtidos com o teste de regressão por simulação (TRS) variando ${ }^{t} / N_{e}$ entre um, 10 , 100 e 1000 mostraram que quanto maior o valor dessa razão, mais baixo é o $\beta$. Em todos os casos analisados o $\beta$ obtido foi maior que o intervalo de confiança gerado através das simulações com os diferentes valores para $t / N_{e}$. Em função disso, os resultados apresentados foram só os 
referentes a $t / N_{e}=1$. O TRS refutou a $\mathrm{H}_{0}$ nos oito casos testados (Tabela 2.3). A exceção dos nós 2, 7 e 8, os demais clados tiveram a $\mathrm{H}_{0}$ refutada por mais do que um método (Tabela 2.3).

Nos três nós em que o TRT rejeitou a $\mathrm{H}_{0}$, o primeiro componente principal (PC1) teve bastante influência no resultado. Dentre os cinco primeiros PCs, ele foi o que mais desviou da reta de regressão (Figura 2.2; Tabela 2.3). Ao realizar o TRT sem considerar o PC1, ele não rejeitou a $\mathrm{H}_{0}$ em nenhum caso (Tabela 2.4). 

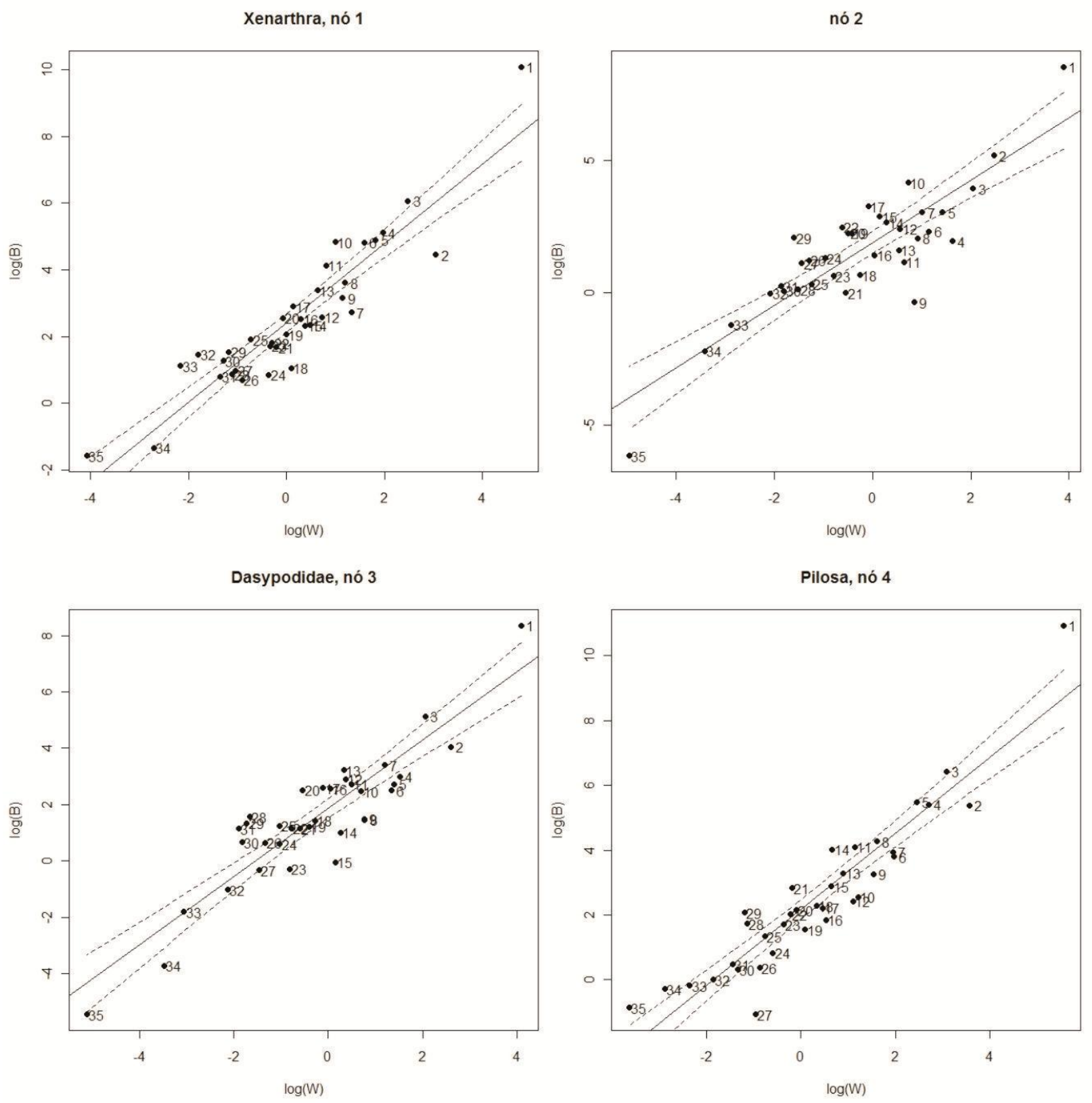

Figura 2.2 - Reta de regressão e intervalo de confiança (95\%) para a regressão da matriz$\mathrm{B}$ em relação à matriz-W nos quatro casos testados em 35D (Figura 2.1). Os pontos representam os componentes principais da matriz-W, sendo que os números os identificam. 
Tabela 2.3 - Testes de regressão considerando a inclinação da reta de regressão ( $\beta$ ) teórica de um (TRT) e a $\beta$ determinada pela simulação (TRS) e o teste de correlação. Para TRT, são apresentados o $\beta$ obtido, o intervalo de confiança (95\% IC) e, dentre os cinco primeiros componentes principais, os que divergiram significativamente da reta de regressão (PCs). O sinal de $>$ ou < que antecede o número indica se o componente divergiu para cima ou para baixo da linha de regressão. Para TRS, é apresentado o intervalo de confiança (95\% IC) da simulação realizada com $\mathrm{t} / \mathrm{N}_{\mathrm{e}}=1$. Para o teste de correlação são apresentados o número de componentes principais comparados (n PC comparados), o valor obtido para a estatística de Bartlett (Bartlett), seus graus de liberdade (gl), sua probabilidade [p (Bartlett)] e os valores das correlações significativas com os respectivos componentes identificados entre parênteses (r). Em negrito estão os casos em que a hipótese nula de evolução somente por deriva genética foi rejeitada. Os números entre parênteses na coluna dos taxa representam os nós da filogenia (Figura 2.1).

\begin{tabular}{|c|c|c|c|c|c|c|c|c|c|c|c|c|c|c|}
\hline \multirow{3}{*}{$\begin{array}{l}\text { Nó } \\
(2)\end{array}$} & \multirow{3}{*}{$\begin{array}{c}\begin{array}{c}\mathrm{n} \\
\operatorname{taxa}\end{array} \\
6\end{array}$} & \multirow{3}{*}{$\begin{array}{c}\begin{array}{c}\mathbf{n} \\
\text { crânios }\end{array} \\
345\end{array}$} & \multicolumn{4}{|c|}{ TRT } & \multicolumn{2}{|c|}{ TRS } & \multicolumn{5}{|c|}{ correlação } & \multirow{3}{*}{$\begin{array}{c}\begin{array}{c}\text { refutou a } \\
\text { hipótese nula? }\end{array} \\
\operatorname{sim}\end{array}$} \\
\hline & & & \multirow{2}{*}{$\begin{array}{c}\boldsymbol{\beta} \\
1,18\end{array}$} & \multicolumn{2}{|c|}{$95 \%$ IC } & \multirow{2}{*}{$\begin{array}{c}\text { PCs } \\
>1,<4\end{array}$} & \multicolumn{2}{|c|}{$95 \%$ IC } & \multirow{2}{*}{$\begin{array}{c}\begin{array}{c}\mathrm{n} \text { PC } \\
\text { comparados }\end{array} \\
5\end{array}$} & \multirow{2}{*}{$\begin{array}{c}\text { Bartlett } \\
20,22\end{array}$} & \multirow{2}{*}{$\begin{array}{l}\text { gl } \\
10\end{array}$} & \multirow{2}{*}{$\frac{p \text { (Bartlett) }}{0,03}$} & \multirow[t]{2}{*}{$r$} & \\
\hline & & & & 0,94 & 1,42 & & 0,26 & 0,63 & & & & & & \\
\hline Dasypodidae (3) & 7 & 564 & 1,21 & 1,01 & 1,41 & $>1,>3,<2,<4$ & 0,20 & 0,67 & 5 & 14,61 & 10 & 0,15 & & $\operatorname{sim}$ \\
\hline Pilosa (4) & 5 & 223 & 1,18 & 1,02 & 1,37 & $>1,>3,<2$ & 0,26 & 0,64 & 4 & 14,89 & 6 & 0,02 & & $\operatorname{sim}$ \\
\hline Xenarthra (1) & 12 & 787 & 1,19 & 1,02 & 1,36 & $>1,>3,<2$ & 0,47 & 0,88 & 5 & 51,39 & 10 & 0,00 & $-0,923(1 \times 4) ; 0,865(4 \times 5)$ & $\operatorname{sim}$ \\
\hline Folivora $(5)^{a}$ & 9 & 281 & 0,93 & 0,67 & 1,18 & $>1,>2,<3,<5$ & 0,17 & 0,47 & 5 & 52,00 & 10 & 0,00 & $\begin{array}{l}0,980(1 \times 2) ;-0,965(1 \times 5) \\
-0,961(2 \times 5) ;-0,915(3 \times 4)\end{array}$ & $\operatorname{sim}$ \\
\hline$(6)^{a}$ & 8 & 141 & 0,82 & 0,56 & 1,1 & $>1,>2,<3,<5$ & 0,19 & 0,51 & 5 & 40,93 & 10 & 0,00 & $\begin{array}{c}-0,975(1 \times 2) ; 0,963(1 \times 5) \\
-0,966(2 \times 5)\end{array}$ & $\operatorname{sim}$ \\
\hline$(7)^{a}$ & 5 & 82 & 0,85 & 0,52 & 1,18 & $>1,<2,<3,<4,>5$ & 0,30 & 0,73 & 4 & 62,29 & 10 & 0,00 & & sim \\
\hline Megalonychidae $(8)^{a}$ & 4 & 77 & 1,09 & 0,68 & 1,50 & $>1,<2$ & 0,21 & 0,83 & 3 & 5 & 3 & 0,19 & & $\operatorname{sim}$ \\
\hline
\end{tabular}

${ }^{a}$ baseado no conjunto 25D (ver detalhe no Capítulo I).

Tabela 2.4 - Testes de regressão considerando a inclinação da reta de regressão ( $\beta$ ) teórica de um (TRT) sem considerar o primeiro componente principal nas análises. $\beta$ representa a inclinação da reta de regressão e $95 \%$ IC o intervalo de confiança. Os números entre parênteses na coluna dos taxa representam os nós da filogenia (Figura 2.1).

\begin{tabular}{cccc}
\hline & \multicolumn{3}{c}{ TRT } \\
\hline táxon & $\boldsymbol{\beta}$ & \multicolumn{2}{c}{ 95\% IC } \\
\hline Dasypodidae (3) & 1,131 & 0,917 & 1,346 \\
Pilosa (4) & 1,045 & 0,887 & 1,203 \\
Xenarthra (1) & 1,061 & 0,888 & 1,233 \\
\hline
\end{tabular}


Além dos resultados referentes aos testes de deriva, convém reportar os resultados da interpretação dos componentes principais das diferentes matrizes-W estimadas. Isto porque, nos casos em que os testes sugeriram a ação da seleção natural atuando na diversificação morfológica, foi possível através da interpretação dos PCs da matriz-W compreender em quais dimensões pode ter ocorrido seleção (ver discussão).

Nos oito casos testados (nós 1, 2, 3, 4, 5, 6, 7 e 8 da Figura 2.1), os cinco primeiros componentes principais (PC) de cada matriz-W corresponderam ao menos a $73 \%$ da variância total explicada (Tabela 2.5). Nas análises em 35D (nós 1, 2, 3 e 4 da Figura 2.1), as correlações entre o PC1 de cada matriz, entre o PC2 de cada matriz e entre o PC3 de cada matriz apresentaram média absoluta $=0,94$ e desvio padrão absoluto $=0,05$. Dado os resultados obtidos, os três primeiros PCs puderam ser interpretados de forma semelhante em todos os casos. O PC1 representou tamanho alométrico já que esteve: 1) fortemente correlacionado com um vetor isométrico com mesmo número de elementos (correlações absolutas > 0,70) e 2) apresentou valores com o mesmo sinal em todas as variáveis (Tabela 2.6). O PC2 representou um contraste entre diminuição no comprimento do nasal e aumento da abóbada craniana e da profundidade da região nasal (ou vice-versa). O PC3 apresentou uma relação complexa entre aumento de algumas partes da face (sub-regiões oral) e de parte da abóbada craniana e diminuição de outras partes da abóbada e da sub-região do zigomático (ou o oposto).

Em 25D o cenário foi mais complexo. Os cinco primeiros PCs entre as matrizes-W dos nós 5 e 6 (Figura 2.1) foram semelhantes, apresentado correlações absolutas > 0,98. Por outro lado, a matriz-W dos nós 7 e 8 (Figura 2.1) apresentou correlações baixas com os respectivos PCs das demais matrizes-W (dos nós 5 e 6). Como em teoria os mesmos componentes principais de matrizes distintas podem ser extraídos em ordens distintas, foi realizada a análise de correlação entre os 
diferentes PCs das diferentes matrizes. Por exemplo, PC1 da matriz-W do nó 5 com os PC2, PC3, PC4 e PC5 da matriz-W do nó 6. No entanto, essas correlações não apresentaram valores significativos. Exceção foi o PC3 das matrizes-W dos nós 5 e 6 que foi semelhante ao PC2 da matriz-W dos nós 7 e 8 (correlação absoluta = 0,83). De qualquer forma, o PC1 para as três matrizes representou tamanho alométrico, pois a exceção de uma variável, todas apresentaram valores com o mesmo sinal e esse PC apresentou correlação com um vetor isométrico com mesmo número de elementos (correlações absolutas > 0,65; Tabelas 2.7 e 2.8). Os demais PCs não puderam ser interpretados de forma semelhante para todos os nós analisados em 25D (nós 5, 6, 7 e 8 da Figura 2.1).

Tabela 2.5 - Porcentagem de variância explicada pelos cinco primeiros componentes principais (\%PC). A última coluna representa a soma da variância explicada por eles.

\begin{tabular}{ccccccc}
\hline táxon & \%PC1 & \%PC2 & \%PC3 & \%PC4 & \%PC5 & somatório \\
\hline (2) & 46 & 11,1 & 7 & 4,8 & 3,9 & 73,1 \\
Dasypodidae (3) & 50,7 & 11,5 & 7 & 3,9 & 3,5 & 76,3 \\
Pilosa (4) & 65,4 & 9 & 6 & 3,8 & 3 & 86,7 \\
Xenarthra (1) & 58,6 & 10,3 & 6 & 3,5 & 3 & 81,2 \\
Folivora (5) & 36,8 & 25 & 7 & 6,1 & 5,2 & 80,5 \\
(6) & 37,7 & 25,4 & 7 & 6,2 & 5,4 & 81,9 \\
(7) & 36,8 & 25 & 7 & 6,1 & 5,2 & 80,5 \\
Megalonychidae (8) & 36,8 & 25 & 7 & 6,1 & 5,2 & 80,5 \\
\hline
\end{tabular}


Tabela 2.6 - As distâncias, suas regiões e sub-regiões e os cinco primeiros componentes principais (PC) da matriz de covariância ponderada entre gêneros (matriz-W) de Xenarthra (nó 1; Figura 2.1). Em negrito valores maiores que 0,24 ou menores que $-0,24$.

\begin{tabular}{|c|c|c|c|c|c|c|c|}
\hline Distância & Região & Sub-região & PC1 & PC2 & PC3 & PC4 & PC5 \\
\hline IS-PM & face & oral & $-0,04$ & $-0,01$ & $-0,08$ & 0,03 & $-0,06$ \\
\hline IS-NSL & face & nasal & $-0,04$ & 0,02 & $-0,06$ & $-0,05$ & $-0,05$ \\
\hline IS-PNS & face & oral, nasal & $-0,41$ & 0,00 & $-0,06$ & 0,46 & 0,13 \\
\hline PM-ZS & face & oral & $-0,31$ & $-0,12$ & 0,24 & $-0,09$ & 0,15 \\
\hline PM-ZI & face & oral & $-0,32$ & $-0,10$ & 0,21 & $-0,16$ & 0,13 \\
\hline PM-MT & face & oral & $-0,33$ & $-0,09$ & 0,07 & $-0,09$ & $-0,08$ \\
\hline NSL-NA & face & nasal & $-0,24$ & $-0,56$ & $-0,18$ & 0,25 & $-0,21$ \\
\hline NSL-ZS & face & nasal & $-0,36$ & $-0,12$ & 0,16 & $-0,12$ & 0,06 \\
\hline NSL-ZI & face & oral, nasal & $-0,37$ & $-0,10$ & 0,12 & $-0,18$ & 0,01 \\
\hline NA-BR & neurocrânio & abóbada & $-0,23$ & 0,58 & 0,30 & $-0,07$ & $-0,28$ \\
\hline NA-PNS & face & nasal & $-0,21$ & 0,47 & $-0,04$ & 0,15 & 0,23 \\
\hline BR-PT & neurocrânio & abóbada & $-0,05$ & 0,03 & $-0,08$ & 0,00 & $-0,08$ \\
\hline BR-APET & neurocrânio & abóbada & $-0,09$ & 0,04 & $-0,32$ & $-0,17$ & 0,07 \\
\hline PT-APET & neurocrânio & abóbada & $-0,07$ & 0,04 & $-0,22$ & $-0,14$ & $-0,03$ \\
\hline PT-BA & neurocrânio & abóbada & $-0,10$ & 0,08 & $-0,26$ & $-0,14$ & $-0,07$ \\
\hline PT-EAM & neurocrânio & abóbada & $-0,07$ & 0,06 & $-0,18$ & $-0,10$ & 0,02 \\
\hline PT-ZYGO & face & zigmoático & $-0,06$ & 0,04 & $-0,13$ & $-0,08$ & $-0,05$ \\
\hline PT-TSP & neurocrânio, face & abóbada, zigomático & $-0,04$ & $-0,01$ & $-0,08$ & $-0,03$ & $-0,15$ \\
\hline ZS-ZI & face & zigomático & $-0,02$ & 0,04 & $-0,08$ & $-0,02$ & $-0,08$ \\
\hline ZI-MT & face & zigomático & $-0,04$ & 0,00 & $-0,12$ & $-0,07$ & $-0,15$ \\
\hline ZI-ZYGO & face & zigomático & $-0,10$ & 0,12 & $-0,24$ & 0,28 & $-0,05$ \\
\hline ZI-TSP & face & zigomático & $-0,12$ & 0,07 & $-0,29$ & 0,20 & $-0,20$ \\
\hline MT-PNS & face & oral & $-0,05$ & 0,11 & $-0,08$ & 0,42 & 0,23 \\
\hline PNS-APET & neurocrânio & base & $-0,09$ & 0,01 & $-0,15$ & $-0,36$ & $-0,17$ \\
\hline APET-BA & neurocrânio & base & $-0,03$ & 0,03 & $-0,06$ & 0,02 & $-0,08$ \\
\hline APET-TS & neurocrânio & base & $-0,03$ & 0,00 & $-0,06$ & $-0,03$ & $-0,02$ \\
\hline BA-EAM & neurocrânio & base & $-0,06$ & 0,04 & $-0,13$ & $-0,05$ & $-0,13$ \\
\hline EAM-ZYGO & face & zigomático & $-0,05$ & 0,02 & $-0,10$ & $-0,10$ & $-0,08$ \\
\hline ZYGO-TSP & face & zigomático & $-0,05$ & 0,04 & $-0,07$ & $-0,02$ & $-0,06$ \\
\hline LD-AS & neurocrânio & abóbada & $-0,05$ & 0,05 & $-0,10$ & $-0,02$ & $-0,19$ \\
\hline BR-LD & neurocrânio & abóbada & $-0,05$ & 0,00 & $-0,35$ & $-0,28$ & 0,64 \\
\hline OPI-LD & neurocrânio & abóbada & $-0,08$ & 0,05 & $-0,14$ & $-0,04$ & $-0,26$ \\
\hline PT-AS & neurocrânio & abóbada & $-0,08$ & 0,09 & $-0,22$ & $-0,09$ & 0,06 \\
\hline JP-AS & neurocrânio & abóbada & $-0,05$ & 0,04 & $-0,10$ & 0,02 & $-0,03$ \\
\hline BA-OPI & neurocrânio & base & $-0,02$ & 0,01 & 0,00 & 0,01 & 0,01 \\
\hline autovalor & & & 119,35 & 20,95 & 11,91 & 7,11 & 6,13 \\
\hline \% de variância explicada & & & 0,59 & 0,10 & 0,06 & 0,03 & 0,03 \\
\hline
\end{tabular}


Tabela 2.7 - As distâncias, suas regiões e sub-regiões e os cinco primeiros componentes principais (PC) da matriz de covariância ponderada entre gêneros (matriz-W) de Folivora (nó 5; Figura 2.1). Em negrito valores maiores que 0,24 ou menores que $-0,24$.

\begin{tabular}{|c|c|c|c|c|c|c|c|}
\hline Distância & Região & Sub-região & PC1 & PC2 & PC3 & PC4 & PC5 \\
\hline PM-ZS & face & oral & 0,12 & 0,24 & 0,02 & $-0,33$ & 0,21 \\
\hline PM-ZI & face & oral & 0,10 & 0,22 & 0,15 & $-0,35$ & 0,29 \\
\hline PM-MT & face & oral & 0,12 & 0,36 & 0,01 & $-0,37$ & 0,04 \\
\hline NA-BR & neurocrânio & abóbada & 0,19 & 0,22 & $-0,65$ & $-0,13$ & $-0,05$ \\
\hline NA-PNS & face & nasal & 0,16 & 0,26 & $-0,03$ & $-0,09$ & 0,00 \\
\hline BR-PT & neurocrânio & abóbada & 0,30 & $-0,09$ & $-0,13$ & 0,03 & $-0,02$ \\
\hline BR-APET & neurocrânio & abóbada & 0,14 & 0,23 & 0,25 & 0,28 & 0,04 \\
\hline PT-APET & neurocrânio & abóbada & 0,35 & $-0,02$ & 0,11 & 0,06 & $-0,01$ \\
\hline PT-BA & neurocrânio & abóbada & 0,41 & $-0,03$ & $-0,03$ & 0,05 & $-0,03$ \\
\hline PT-EAM & neurocrânio & abóbada & 0,32 & $-0,07$ & 0,08 & 0,05 & $-0,04$ \\
\hline PT-TSP & neurocrânio, face & abóbada, zigomático & $-0,35$ & 0,48 & $-0,03$ & 0,11 & $-0,26$ \\
\hline ZS-ZI & face & zigomático & 0,06 & 0,07 & $-0,04$ & 0,07 & $-0,14$ \\
\hline ZI-MT & face & zigomático & 0,02 & 0,17 & $-0,14$ & $-0,08$ & $-0,17$ \\
\hline ZI-TSP & face & zigomático & 0,13 & 0,26 & $-0,10$ & 0,04 & $-0,07$ \\
\hline MT-PNS & face & oral & 0,03 & 0,06 & 0,04 & 0,01 & 0,05 \\
\hline PNS-APET & neurocrânio & base & 0,06 & 0,32 & 0,29 & 0,27 & $-0,11$ \\
\hline APET-BA & neurocrânio & base & 0,05 & 0,04 & $-0,08$ & $-0,01$ & $-0,01$ \\
\hline APET-TS & neurocrânio & base & 0,02 & 0,01 & 0,03 & 0,04 & $-0,02$ \\
\hline BA-EAM & neurocrânio & base & 0,08 & 0,06 & $-0,08$ & 0,03 & $-0,02$ \\
\hline LD-AS & neurocrânio & abóbada & 0,09 & 0,13 & $-0,11$ & 0,20 & $-0,49$ \\
\hline BR-LD & neurocrânio & abóbada & 0,02 & 0,12 & 0,53 & $-0,27$ & $-0,29$ \\
\hline OPI-LD & neurocrânio & abóbada & 0,11 & 0,21 & $-0,05$ & 0,49 & 0,22 \\
\hline PT-AS & neurocrânio & abóbada & 0,45 & $-0,22$ & 0,14 & $-0,06$ & $-0,26$ \\
\hline JP-AS & neurocrânio & abóbada & 0,11 & 0,15 & 0,07 & 0,25 & 0,54 \\
\hline BA-OPI & neurocrânio & base & 0,01 & 0,02 & 0,02 & 0,05 & $-0,03$ \\
\hline autovalor & & & 232,13 & 157,37 & 46,54 & 38,27 & 32,72 \\
\hline \% de variância explicada & & & 0,37 & 0,25 & 0,07 & 0,06 & 0,05 \\
\hline
\end{tabular}


Tabela 2.8 - As distâncias, suas regiões e sub-regiões e os cinco primeiros componentes principais (PC) da matriz de covariância ponderada entre gêneros (matriz-W) de Megalonychidae (nó 8; Figura 2.1). Em negrito valores maiores que 0,24 ou menores que -0,24.

\begin{tabular}{|c|c|c|c|c|c|c|c|}
\hline Distância & Região & Sub-região & PC1 & PC2 & PC3 & PC4 & PC5 \\
\hline PM-ZS & face & oral & $-0,15$ & $-0,03$ & 0,03 & $-0,10$ & 0,06 \\
\hline PM-ZI & face & oral & $-0,20$ & $-0,01$ & $-0,02$ & $-0,03$ & 0,02 \\
\hline PM-MT & face & oral & $-0,25$ & $-0,05$ & 0,09 & $-0,04$ & 0,20 \\
\hline NA-BR & neurocrânio & abóbada & $-0,30$ & $-0,59$ & $-0,09$ & $-0,42$ & $-0,09$ \\
\hline NA-PNS & face & nasal & $-0,32$ & $-0,04$ & 0,00 & $-0,10$ & $-0,45$ \\
\hline BR-PT & neurocrânio & abóbada & $-0,29$ & 0,09 & $-0,28$ & $-0,14$ & $-0,28$ \\
\hline BR-APET & neurocrânio & abóbada & $-0,34$ & 0,31 & $-0,19$ & 0,14 & 0,01 \\
\hline PT-APET & neurocrânio & abóbada & $-0,13$ & $-0,09$ & 0,34 & 0,18 & 0,28 \\
\hline PT-BA & neurocrânio & abóbada & $-0,23$ & $-0,07$ & 0,29 & 0,19 & 0,08 \\
\hline PT-EAM & neurocrânio & abóbada & $-0,14$ & $-0,05$ & 0,43 & 0,22 & 0,00 \\
\hline PT-TSP & neurocrânio, face & abóbada, zigomático & 0,09 & $-0,08$ & $-0,15$ & 0,08 & 0,33 \\
\hline ZS-ZI & face & zigomático & $-0,04$ & $-0,06$ & $-0,03$ & 0,01 & $-0,03$ \\
\hline ZI-MT & face & zigomático & $-0,12$ & $-0,05$ & 0,11 & 0,02 & 0,12 \\
\hline ZI-TSP & face & zigomático & $-0,25$ & 0,02 & $-0,17$ & $-0,10$ & 0,20 \\
\hline MT-PNS & face & oral & $-0,08$ & 0,02 & $-0,02$ & 0,03 & 0,06 \\
\hline PNS-APET & neurocrânio & base & $-0,31$ & 0,00 & $-0,13$ & $-0,10$ & 0,47 \\
\hline APET-BA & neurocrânio & base & $-0,11$ & $-0,01$ & 0,04 & 0,05 & $-0,13$ \\
\hline APET-TS & neurocrânio & base & $-0,01$ & $-0,05$ & 0,05 & $-0,01$ & 0,20 \\
\hline BA-EAM & neurocrânio & base & $-0,15$ & $-0,05$ & 0,00 & 0,06 & 0,09 \\
\hline LD-AS & neurocrânio & abóbada & $-0,13$ & $-0,14$ & $-0,32$ & 0,31 & 0,13 \\
\hline BR-LD & neurocrânio & abóbada & $-0,24$ & 0,69 & 0,12 & $-0,23$ & 0,05 \\
\hline OPI-LD & neurocrânio & abóbada & $-0,14$ & $-0,03$ & $-0,36$ & 0,64 & $-0,14$ \\
\hline PT-AS & neurocrânio & abóbada & $-0,25$ & $-0,09$ & 0,36 & 0,16 & $-0,20$ \\
\hline JP-AS & neurocrânio & abóbada & $-0,07$ & 0,00 & 0,15 & 0,18 & $-0,22$ \\
\hline BA-OPI & neurocrânio & base & $-0,03$ & $-0,04$ & $-0,05$ & $-0,02$ & 0,02 \\
\hline autovalor & & & 59,91 & 42,06 & 15,27 & 12,34 & 8,24 \\
\hline \% de variância explicada & & & 0,35 & 0,24 & 0,09 & 0,07 & 0,05 \\
\hline
\end{tabular}




\section{Discussão}

Em todos os casos em que foi possível testar a hipótese nula, de diversificação ocorrendo somente por deriva genética, ela foi refutada. Ou seja, pelo menos nos clados mais inclusivos de Xenarthra (magnaordem, ordem e algumas famílias), seleção natural parece ter atuado na diversificação morfológica entre os taxa. As análises, portanto, corroboraram a visão clássica apresentada por diversos autores de que a evolução dos Xenarthra ocorreu através de seleção natural (Simpson, 1945, 1980; Patterson e Pascual, 1968; Rich et al., 1996; Benton, 2000). Durante os primeiros $~ 40$ milhões de anos do Cenozoico, as linhagens de Xenarthra ocuparam a América do Sul relativamente inabitada por outras formas de mamíferos e isolada geograficamente de outros continentes. Provavelmente a época havia grande quantidades de nichos a serem ocupados (Simpson, 1980, Benton, 2000). Os resultados obtidos nesse capítulo sugerem que, durante esse intervalo de tempo, a diversificação dessa magnaordem ocorreu devido à seleção natural.

A dieta dos Xenarthra tem forte relação com a filogenia (Eisenberg e Redford, 1999; Gardner, 2007; Delsuc et al., 2012; Pujos et al., 2012). Essa afirmação é reforçada pelo fato que a matriz de distância filogenética molecular esteve positiva e moderadamente correlacionada com a matriz de dieta $(r=0,36 ; p=0,02)$. A matriz de distância filogenética com base em ramos iguais apresentou resultados semelhantes para a correlação com a matriz de dieta $(r=0,32 ; p=$ 0,02). Para saber os detalhes na obtenção das matrizes de distância filogenética e de dieta ver Capítulo I e Tabelas A2 e A3. A especialização da dieta entre os três clados principais da magnaordem aconteceu cedo na história evolutiva do grupo, a mais de 40 milhões de anos atrás (Eisenberg e Redford, 1999; Delsuc et al., 2012). Os Cingulata são insetívoro-carnívoro-onívoro, os Folivora são herbívoro e os Pilosa são especializados em se alimentar de formigas e cupins. Frente à especialização antiga dos hábitos alimentares no grupo, é plausível pensar que a seleção 
atuou no sentido de diversificar as linhagens em relação às suas capacidades de obter e processar alimentos. Neste sentido, a evolução promoveu a ocupação de novos nichos relacionados à dieta. Potencialmente, cada um dos três clados principais invadiu uma zona adaptativa relacionada à dieta, sendo que zona adaptativa pode ser definida como um conjunto de nichos distintos dos já ocupados por outras formas de vida (Simpson, 1953). Essa afirmação está embasada nos resultados obtidos para todos os Xenarthra (nó 1 da Figura 2.1). As análises realizadas nesse clado dispuseram da melhor amostra entre todos os clados testados. Além disso, os resultados dos testes de regressão e correlação obtidos através de um tamanho amostral como o utilizado para esse clado podem ser considerados bastante robustos (Oliveira, 2009). Após a divergência inicial, é possível pensar que ao longo da diversificação das linhagens de cada clado, essas zonas adaptativas relacionadas à dieta foram sucessivamente subdivididas.

Oliveira (2009) mostrou que utilizar menos do que quatro taxa nas analises de regressão e correlação geram resultados pouco confiáveis. Nessas análises amostras pequenas geram erros elevados na estimativa das estatísticas (Sokal e Rohf, 1995). O tamanho amostral e as estimativas de erros associadas aos cálculos das estatísticas estão vinculados ao número de taxa de cada nó. Quanto menor o número de taxa, menor o tamanho amostral e maior o erro associado aos cálculos das estatísticas. O número de taxa de cada nó é condicionado pela estrutura filogenética e pela diversidade do grupo. Assumindo que a hipótese filogenética e a taxonomia do grupo são confiáveis, não é possível adotar qualquer tipo de procedimento para elevar o tamanho das amostras ou diminuir as estimativas de erros nas análises. Em função disso, as análises desse capítulo ficaram limitadas aos clados mais inclusivos de Xenarthra, para os quais existem amostras maiores. Por consequência, não foi possível testar quais forças atuaram na diversificação das espécies, dos gêneros e das subfamílias. 
As análises permitiram determinar em quais direções do morfoespaço houve maior ou menor variação do que esperado segundo a hipótese de divergência entre as populações somente por deriva genética. Nos três casos em que o teste de regressão teórico refutou a $\mathrm{H}_{0}$, o PC1 e o PC3 estiveram acima do limite superior do intervalo de confiança. O PC1 representa tamanho alométrico e o PC3 representa o contraste das sub-regiões oral e de partes da abóbada em relação à sub-região zigomática e de outras partes da abóbada. Por outro lado, o PC2 que representa o contraste entre o comprimento do nasal e de algumas dimensões da abóbada craniana em relação à profundidade da região nasal esteve abaixo do limite inferior do intervalo de confiança. Isto sugere que o tamanho alométrico e uma complexa relação entre aumento e diminuição da face e da abóbada variaram mais que as demais dimensões do morfoespaço, segundo o esperado pela deriva genética. Já o comprimento e a profundidade do nasal e algumas dimensões do neurocrânio variaram menos.

É importante ter em mente que o desvio maior ou menor em relação à reta de regressão de um determinado componente principal (PC) é relativo aos demais PCs. Portanto, observar uma variação maior que o esperado pode ser em função tanto da variação no determinado PC ter aumentado, quanto a variação dos demais PCs terem diminuído e vice-versa. Os dois processos, no entanto, geram o mesmo resultado observado.

Frente ao exposto acima, a maior variação observada para os PC1 e PC3 pode ser decorrente: 1) ou de seleção direcional diversificadora atuando sobre essas dimensões, elevando a variância delas; 2) ou de seleção estabilizadora atuando sobre as demais dimensões, reduzindo a variância delas; 3) ou dos dois tipos de seleção atuando conjuntamente nos PCs conforme apresentado nos dois itens anteriores. Por outro lado, o resultado observado para o PC2 pode ser obtido ou através de seleção estabilizadora atuando sobre ele ou de seleção direcional 
diversificadora atuando sobre as outras dimensões ou ainda da ação conjunta de ambas. No momento não é possível determinar qual tipo de seleção atuou primariamente na geração do padrão observado. No entanto, é sugestivo pensar que houve seleção diversificadora para o tamanho (PC1), pois: 1) ao remover o PC1 do teste de regressão teórico os resultados não rejeitaram a $\mathrm{H}_{0}$; e 2) o PC1 divergiu do intervalo de confiança da reta de regressão mais que os demais PCs. Contudo, é importante frisar que isso não foi testado nesse trabalho e deve ser considerado como especulativo.

Os testes de correlação entre as projeções médias dos taxa divergentes nos componentes principais (PC) da matriz-W (escores médios dos gêneros) detectaram correlação significativa em três casos. Isso significa que em alguns clados testados ocorreu seleção simultânea (coseleção) em mais do que uma dimensão do morfoespaço. Por definição, não há covariância entre os componentes principais da matriz-W. Por consequência, a expectativa, sob deriva genética, é de ausência de correlação entre os escores médios dos gêneros nos diferentes PCs. A coseleção entre PCs pode ocorrer quando eles interagem entre si para realizar alguma função comum ou quando fatores ambientais resultam em seleção em mais do que uma dimensão do morfoespaço. Esta segunda forma de coseleção não necessariamente representa a execução de função comum no nível ecológico (Marroig e Cheverud, 2004). Por exemplo, condições ambientais podem simultaneamente favorecer alterações na abóbada em função de pressões para o desenvolvimento da parte de coordenação motora do cérebro e da sub-região zigomática devido à pressões para mudanças nas dimensões do masseter.

Nos três casos em que o teste de correlação refutou a $\mathrm{H}_{0}$, ao menos uma das correlações foi entre tamanho alométrico (PC1) e alguma outra dimensão do morfoespaço. Em Xenarthra (nó 1; Figura 2.1), houve correlação entre tamanho alométrico e um autovetor relacionado com a 
região da face e a sub-região da base (PC1 e PC4) e também entre a face e o neurocrânio (PC4 e PC5; Tabelas 2.3 e 2.6). Para Folivora (nó 5) ocorreu coseleção entre tamanho alométrico e as sub-regiões oral, nasal, abóbada, zigomática e base (PC1, PC2 e PC5; Tabelas 2.3 e 2.7) e também entre partes da região da face e do neurocrânio (PC2, PC3, PC4 e PC5; Tabelas 2.3 e 2.7). Já no nó 6 (todos Folivora menos Bradypus; Figura 2.1) ocorreu coseleção entre as subregiões oral, zigomática, base e abóbada e o tamanho alométrico (PC1, PC2 e PC5; ; Tabelas 2.3 e 2.7). O fato do tamanho alométrico ter sido coselecionado com outra dimensão do morfoespaço em alguns dos nós testados sustenta a visão da importância do tamanho na diversificação morfológica e isto deverá ser explorado em mais detalhes futuramente nos Xenarthra.

Os resultados obtidos com os testes de regressão e correlação sugerem que a diversificação dos Xenarthra nos níveis mais inclusivos ocorreu em função de seleção natural. Essa, por sua vez, possivelmente atuou sobre o tamanho alométrico, e pelo menos em alguns casos através da coseleção entre tamanho alométrico e regiões da face e da abóbada. Embora não seja possível testar no momento a ideia apresentada a seguir, os resultados podem ser interpretados segundo a visão de diversificação vinculada à invasão de zonas adaptativas relacionadas à dieta. As regiões e sub-regiões do crânio que sofreram (co)seleção apresentam relação com a dieta. A face relaciona-se com a obtenção e o processamento do alimento e na abóbada insere-se parte da musculatura relacionada à mastigação (Elbroch, 2006). Talvez a razão ecológica para a diversificação entre os Xenarthra tenha sido dieta e a maioria dessa diversificação ocorreu em função de variações e covariações associadas ao tamanho alométrico e a regiões da face e da abóbada.

Assim como para os Xenarthra, para os macacos do novo mundo foi proposto que a diversificação do grupo também esteve relacionada à dieta e foi principalmente em virtude de 
variações no tamanho alométrico (Marroig e Cheverud, 2004, 2005, 2010). Outros grupos de mamíferos apresentam relação estreita entre dieta e filogenia. Por exemplo, morcegos (Freeman, 2000) e ruminantes (Pérez-Barberia et al., 2001). No entanto, ainda não foram realizados testes para determinar quais processos evolutivos estiveram envolvidos na diversificação desses últimos grupos. A partir dos resultados obtidos para primatas do novo mundo e Xenarthra é possível especular que: a invasão através de seleção natural de zonas adaptativas relacionadas à dieta e mudanças coordenadas entre o tamanho alométrico e regiões do crânio sejam importantes na diversificação morfológica craniana de certos grupos de mamíferos.

O tamanho nos Xenarthra, assim como da grande maioria dos mamíferos, representa a dimensão multivariada de maior variância fenotípica (ver Capítulo III). Portanto, ele possivelmente representa a linha de menor resistência evolutiva (Schluter, 1996; Marroig e Cheverud, 2005). Através dessa linha, a evolução é facilitada, simplesmente porque ela contém a maior parcela de variação disponível para mudanças (Schluter, 1996). Essa linha pode, no entanto, também atuar como uma restrição à evolução (Marroig e Cheverud, 2005, 2009). Como ela contém a maior parcela de variação disponível para mudanças, mesmo vetores de seleção aplicados em direções muito diferentes do tamanho podem acabar respondendo na direção dele. Isso é valido ao menos em escala microevolutiva e com paisagens adaptivas relativamente estáveis (Marroig e Cheverud, 2005, 2009). Para primatas do novo mundo, Marroig e Cheverud (2010) apresentaram evidências de que a seleção esteve alinhada à dimensão do tamanho. Em função disso, a evolução morfológica do grupo foi facilitada. Essa descoberta suporta a interpretação da importância do tamanho alométrico na evolução morfológica.

Por último, três dos clados testados (nós 2, 7 e 8) refutaram a $\mathrm{H}_{0}$ apenas segundo o teste de regressão por simulação (TRS). Esse resultado pode ser um problema metodológico afetando 
os testes de correlação e de regressão teórico (TRT). O número pequeno de taxa incluído nestas análises faz com que os erros associados à estimativa da inclinação da reta de regressão sejam elevados e consequentemente o intervalo de confiança seja grande. Adicionalmente, apenas correlações muito elevadas serão consideradas significativas (Sokal e Rohf, 1995; Marroig e Cheverud, 2004). Por exemplo, no clado representado pelo nó $2, \beta$ é relativamente elevado $(1,18)$ e mesmo assim não diferiu de um. Ainda, para o nó 7, a correlação entre o PC1 e o PC4 foi de 0,93, mas não atingiu o nível de significância após a correção de Bonferroni. Salienta-se que essa correção é bastante conservadora. Ela dificulta a rejeição da hipótese nula de ausência de correlação entre as variáveis. A correção de Bonferroni afeta o poder estatístico, definido como a capacidade de um teste estatístico de detectar diferenças reais em um conjunto de dados. O poder estatístico é determinado como $1-\beta$ (erro tipo II). Ao dividir $\alpha$ (erro tipo I) pelo número de testes sendo realizados, a correção de Bonferroni reduz o valor do erro tipo I. Como $\alpha$ está inversamente relacionado a $\beta$, essa correção diminui o poder estatístico do teste (Hair et al., 2010). Por consequência, o efeito dela é diminuir a probabilidade de incorretamente rejeitar a hipótese nula (erro tipo I) e, em contrapartida, elevar a chance de erroneamente falhar em rejeitála (erro tipo II).

\section{Conclusão}

Para os clados que foram testados, a diversificação morfológica craniana em Xenarthra foi condicionada pela seleção natural. Essa potencialmente atuou em relação ao tamanho alométrico e através da coseleção entre o tamanho e outras dimensões do morfoespaço. A causa para a diferenciação morfológica em Xenarthra pode estar vinculada a zonas adaptativas relacionadas à dieta. Por motivos que envolvem a natureza do grupo em estudo e limitações metodológicas, as análises realizadas nesse capítulo não permitiram testar a hipótese nula de 
diversificação morfológica apenas por deriva genética em níveis mais terminais da filogenia dos Xenarthra.

\section{Referências}

Ackermann, R.R., Cheverud, J.M., 2002. Discerning evolutionary processes in patterns of tamarin (genus Saguinus) craniofacial variation. American Journal of Physical Anthropology $117,260-271$.

Ackermann, R.R., Cheverud, J.M., 2004. Detecting genetic drift versus selection in human evolution. Proceedings of the National Academy of Sciences of the United States of America 101, 17946-17951.

Bedford, T., Wapinski, I., Hartl, D.L., 2008. Overdispersion of the molecular clock varies between yeast, Drosophila and mammals. Genetics 179, 977-984.

Benton, M.J., 2000. Vertebrate paleontology. Blackwell Science, Oxford.

Clark, A.A., 2010. "Ancient DNA from the extinct folivorous Xenarthrans, or sloths, with specific attention toward the Greater Antillean Megalonychids and the Patagonian Mylodontid, Mylodon darwinii." Unpublished PhD Thesis, McMaster University.

Darwin, C.R., 1859. On the origin of the species by means of natural selection, or the preservation of favoured races in the struggle for life. John Murray, London.

Darwin, C.R., Wallace, A.F., 1858. On the tendecy of species to form variates; and on the perpetuation of varietes and species by natural means of selection. Journal of the Proceedings of the Linean Society of London. Zoology 3, 45-62. 
Delsuc, F., Superina, M., Tilak, M.-K., Douzery, E.J.P., Hassanin, A., 2012. Molecular phylogenetics unveils the ancient evolutionary origins of the enigmatic fairy armadillos. Molecular Phylogenetics and Evolution 62, 673-680.

Eisenberg, J.F., Redford, K.H., 1999. Mammals of the Neotropics, Volume 3: The Central Neotropics: Ecuador, Peru, Bolivia, Brazil. The University of Chicago Press, Chicago.

Elbroch, M., 2006. Animal skulls: a guide to North American species. Stackpole Books, Mechanicsburg.

Endler, J.A., 1992. Natural selection: current usages. Em: Keller, E.F.,Lloyd, E.A. (Ed.), Keyords in evolutionary biology. Harvard Universito Press, Cambridge, pp. 220-224.

Felsenstein, J. 1988. Phylogenies and quantitative characters. Annual Review of Ecology and Systematics 19, 445-471.

Freeman, P.W., 2000. Macroevolution in Microchiroptera: recoupling morphology and ecology with phylogeny. Evolutionary Ecology Research 2, 317-335.

Gaudin, T.J., 2004. Phylogenetic relationships among sloths (Mammalia, Xenarthra, Tardigrada): the craniodental evidence. Zoological Journal of the Linnean Society 140, 255-305.

Hair, J.F., White, W.C., Babin, B.J., Anderson, R.E., 2010. Multivariate Data Analysis. Prentice Hall.

Hagedoorn, A.L., Hagedoorn Vorstheuvel La Brand, A.C., 1921. The relative value of the processes causing evolution. The Hage: Martinus Nijhoff.

Hamilton, M.B., 2009. Population Genetics. Willey-Blackwell, Chichester. 
Harmon, L.J., Gibson, R., 2006. Multivariate phenotypic evolution among island and mainland populations of the ornate day gecko, Phelsuma ornata. Evolution 60, 2622-2632.

Knapp, T.R., Swoyer, V.H., 1967. Some empirical results concerning the power of Bartlett's test of the significance of a correlation matrix. American Educational Research Journal $4,13-17$.

Lande, R., 1979. Quantitative genetic analysis of multivariate evolution, applied to brain body size allometry. Evolution 33, 402-416.

Lande, R., 1980. Genetic-variation and phenotypic evolution during allopatric speciation. American Naturalist 116, 463-479.

Lofsvold, D., 1988. Quantitative genetics of morphological-differentiation in peromyscus .2. analysis of selection and drift. Evolution 42, 54-67.

Marroig, G., Cheverud, J.M., 2001. A comparison of phenotypic variation and covariation patterns and the role of phylogeny. Ecology, and ontogeny during cranial evolution of new world monkeys. Evolution 55, 2576-2600.

Marroig, G., Cheverud, J.M., 2004. Did natural selection or genetic drift produce the cranial diversification of neotropical monkeys? American Naturalist 163, 417-428.

Marroig, G., Cheverud, J.M., 2005. Size as a line of least evolutionary resistance: diet and adaptive morphological radiation in new world monkeys. Evolution 59, 1128-1142.

Marroig, G., Cheverud, J.M., 2010. Size as a line of least resistance II: direct selection on size or correlated response due to constraints? Evolution 64-5, 1470-1488. 
Möller-Krull, M., Delsuc, F., Churakov, G., Marker, C., Superina, M., Brosius, J., Douzery, E.J.P., Schmitz, J., 2007. Retroposed elements and their flanking regions resolve the evolutionary history of xenarthran mammals (armadillos, anteaters, and sloths). Molecular Biology and Evolution 24, 2573-2582.

Oliveira, F.B.d., 2009. "Evolução do crânio dos macacos do Velho Mundo: uma abordagem de genética quantitativa." Tese de Doutorado, Universidade de São Paulo.

Patterson, B., Pascual, R., 1968. Evolution of mammals on southern continents: V. fossil mammal fauna of south america. Quarterly Review of Biology 43, 409-451.

Pérez-Barbería, F.J., Gordon, I.J., Illius, A.W., 2001. Phylogenetic analysis of stomach adaptation in digestive strategies in African ruminants. Oecologia 129, 498-508.

Prôa, M., O'Higgins, P., Monteiro, L.R., 2012. Type I error rates for testing genetic drift with phenotypic covariance matrices: a simulation study. Evolution 67, 185-195.

Pujos, F., Gaudin, T.J., De Iuliis, G., Cartelle, C., 2012. Recent advances on variability, morpho-functional adaptations, dental terminology, and evolution of sloths. Journal of Mammalian Evolution 19, 159-169.

Rich, P.V., Rich, T.H., Fenton, M.A., Fenton, C.L., 1996. The fossil book: a record of prehistoric life. Dover Publication, Nematriz-W York.

Ridley, M., 2004. Evolution. Blackmatriz-Well Publishing, Malden, Oxford and Carlton.

Simpson, G.G., 1945. The principles of classification and a classification of mammals. Bulletin of the American Museum of Natural History 85, 1-307.

Simpson, G.G., 1953. Major features of evolution. Columbia University Press, NewYork. 
Simpson, G.G., 1980. Splendid isolation: The curious history of South American mammals. Yale University Press, New Haven and London.

Simpson, G.G., Roe, A., Lewontin, R.C., 1960. Quantitative Zoology. Revised Edition. Harcourt, Brace and Company inc., New York.

Sokal, R., Rohf, F.J., 1995. Biometry. W H Freeman and Company, New York.

Wright, S., 1931. Evolution in Mendelian populations. Genetics 16, 0097-0159. 


\section{Capítulo III - Magnitude geral de integração e padrão da modularidade craniana dos}

\section{Xenarthra}

\section{Introdução}

A matriz-G descreve a quantidade de variância e de covariância entre os caracteres que é herdável de forma linear e portanto previsível. Tanto a seleção natural quanto a deriva genética agem sobre a variação e a covariação genética existente nas populações (Falconer e Mackay, 1996). Em relação à seleção natural, a interação entre a matriz-G e a pressão seletiva determina a resposta evolutiva. Essa afirmação fica evidente ao se analisar a equação de resposta multivariada à seleção $\Delta \bar{z}=\boldsymbol{G} \beta$ (Lande, 1979). $\Delta \bar{z}$ é a resposta evolutiva e representa o vetor de diferenças nas médias dos caracteres entre as gerações, $\beta$ é o gradiente de seleção e representa a força da seleção direcional atuando independentemente sobre cada caráter e $\mathbf{G}$ é a matriz de variância/covariância genética aditiva (ou simplificando, matriz-G). Como pode ser observado nessa equação, a resposta evolutiva é o produto entre a matriz-G e o gradiente de seleção. O caso relatado abaixo exemplifica essa questão.

A intensa seca que ocorreu na ilha Daphne Major (Galápagos, Equador) durante o ano de 1977 resultou em drástica redução na quantidade de alimento disponível, restando majoritariamente sementes grandes e duras. Como consequência dessa seca, $85 \%$ da população local de Geospiza fortis (tentilhão terrestre médio) pereceu (Boag e Grant, 1981). Após esse fenômeno climático, a resposta evolutiva $(\Delta \bar{z})$ das novas gerações de G. fortis foi dos indivíduos apresentarem, em média, bicos tanto mais altos quanto mais largos do que as gerações anteriores. No entanto, o gradiente de seleção $(\beta)$ durante a fase seca foi positivo para a altura do bico e negativo para a largura. Em outras palavras, animais com bicos mais altos e mais estreitos teriam maior vantagem adaptativa do que animais com bicos mais baixos e mais largos, por possuírem 
uma combinação de caracteres mais favorável à obtenção de alimento (Price et al., 1984). Ou seja, o esperado segundo as forças de seleção atuantes seria que as gerações seguintes apresentassem bicos mais altos e estreitos e não ambos os caracteres maiores, como observado nos resultados empíricos. Essa aparente incongruência do $\Delta \bar{z}$ do bico desse tentilhão em relação ao $\beta$ ocorreu em virtude dos dois caracteres, largura e altura apresentarem correlação genética aditiva (matriz-G) forte e positiva. Além disso, a seleção positiva sobre o primeiro traço foi mais forte do que a seleção negativa sobre o segundo (Boag e Grant, 1981; Price et al., 1984; Grant e Grant, 1995; Herrel et al., 2005). Em resumo, a pressão seletiva no contexto da seca favorecia animais de bico alto e estreito. No entanto, em virtude da restrição imposta pela matriz-G, a resposta evolutiva foi de elevar os valores médios de ambos os caracteres entre as gerações.

Explicando de outra forma, a seleção natural atua sobre a aptidão (Falconer e Mackay, 1996). A aptidão de um indivíduo pode ser entendida como o número de seus descendentes na próxima geração. Quanto maior for esse número em relação aos demais indivíduos da população, maior será sua aptidão. A aptidão de um indivíduo também pode ser entendida como o quão bom é um determinado genótipo em deixar descendentes na próxima geração em relação aos demais genótipos (Falconer e Mackay, 1996). Essa aptidão é o resultado final de todos os processos ontogenéticos e fisiológicos que ocorrem ao longo da vida do indivíduo (Falconer e Mackay, 1996). Esses dois processos, por sua vez, são determinados por aspectos genéticos e ambientais (Futuyma, 2005). Diferenças entre indivíduos nesses processos são observados na variação de atributos mensuráveis, que são estudados através de caracteres métricos. Portanto, a variação de cada caráter métrico reflete em maior ou menor grau a variação da aptidão; e a variação da aptidão pode ser decomposta na variação dos caracteres (Falconer e Mackay, 1996:336). 
A seleção natural depende da relação entre fenótipo e aptidão e da relação entre genótipo e fenótipo através do desenvolvimento. Essas relações determinam a interação entre o genótipo e a aptidão e consequentemente determinam se ocorrerá evolução ou não. Afinal, para que uma população evolua por seleção natural é preciso haver herdabilidade dos caracteres (Futuyma, 2005). Diferentes caracteres do fenótipo se correlacionam geneticamente em diferentes intensidades com a aptidão (Freeman e Herron, 2007). Após esses esclarecimentos, retornemos ao exemplo dos tentilhões. Após a seca de 1977, e consequente restrição alimentar, a aptidão seria maior para animais com bicos mais altos e estreitos. No entanto, devido à forte e positiva correlação genética aditiva entre esses dois caracteres, as gerações futuras apresentaram bicos mais altos e mais largos. Isso porque a correlação genética da altura do bico com a aptidão foi maior do que a correlação genética entre a largura do bico e a aptidão (Freeman e Herron, 2007).

O caso dos tentilhões apresentado acima evidencia a relação entre a matriz-G e a seleção natural na determinação da resposta evolutiva. Esse exemplo mostra que caracteres podem evoluir de forma coordenada, mesmo quando a seleção favorece o aumento de um caráter e a diminuição de outro. A evolução coordenada entre caracteres é o reflexo da estrutura modular apresentada pelos seres vivos (Olson e Miller, 1958; Berg, 1960; Cheverud, 1982, 1995; Wagner et al., 2007; Porto et al., 2009). A modularidade ocorre em diversos níveis organizacionais, desde o molecular até o morfológico. Ela pode ser entendida como a rede de interações de caracteres organizados em conjuntos (módulos). As conexões dentro de cada módulo são mais fortes do que as correlações entre caracteres pertencentes a módulos distintos (Wagner et al., 2007). Por exemplo, em um caso hipotético dispomos dos valores de correlação entre quatro caracteres (A, B, C e D). As correlações entre A-B e C-D são relativamente elevadas e entre A-C, A-D, B-C e B-D são relativamente baixas. Com base nas correlações observadas entre esses caracteres, pode- 
se supor que eles estão organizados em dois módulos, A-B e C-D. No caso dos tentilhões, a largura e a altura do bico muito provavelmente fazem parte de um mesmo módulo.

Estruturas morfológicas complexas são formadas por diversos elementos com ontogenia, função e base genética diferentes. Elas são geralmente representadas por diversos caracteres. O crânio de mamíferos é um bom exemplo. Ele é formado por mais de 20 ossos e nesse estudo é representado por 35 distâncias lineares que em geral medem ossos individuais. Por sua vez, essa diversidade de ossos apresenta mais de uma: 1) origem embrionária; 2) via de desenvolvimento; e 3) tipo de função (Elbroch, 2006). Compreender o padrão modular das estruturas morfológicas complexas, ou seja, como seus caracteres estão organizados de forma que alguns compartilham correlações mais elevadas entre si do que em relação aos demais caracteres, apresenta papel fundamental no entendimento da evolução delas. Isso porque esse padrão pode facilitar ou restringir mudanças (Schluter, 1996; Marroig e Cheverud, 2001; Steppan et al., 2002; Marroig et al., 2004; Marroig e Cheverud, 2005; Wagner et al., 2007; Pavlicev et al., 2008). Por exemplo, no caso bivariado dos tentilhões apresentado anteriormente, o formato do bico alto e estreito seria teoricamente mais favorável às condições ambientais já que primordialmente sementes grandes e duras estavam disponíveis durante a seca de 1977. No entanto, devido à relação tanto fenotípica quanto genética entre esses caracteres, o bico não evoluiu desta forma (Boag e Grant, 1981; Price et al., 1984; Grant e Grant, 1995; Herrel et al., 2005).

A estrutura modular distribui-se entre dois extremos teóricos. O extremo máximo é quando a estrutura como um todo forma um único módulo (totalmente integrada). Já o mínimo é quando os caracteres da estrutura se comportam como módulo distintos (completamente desintegrada), ou seja, todos os caracteres são independentes e apresentam correlação zero. Nessas condições, no entanto, não haveria resposta evolutiva alinhada à seleção, ou seja, 
dificilmente a evolução dos caracteres ocorreria conforme a pressão seletiva. No primeiro caso, todos os caracteres evoluiriam conjuntamente, independentemente da pressão seletiva ocorrer sobre um, poucos ou vários deles. Já no segundo, não haveria nenhum tipo de coordenação na resposta evolutiva dos diferentes caracteres, a não ser que a seleção ocorresse sobre mais do que um ou poucos caracteres (Hansen, 2003).

Utilizando o crânio de mamíferos para exemplificar essa questão, partimos do fato que ele é estruturado em duas regiões com funções distintas. O neurocrânio, responsável, entre outras coisas, pela proteção e acomodação do cérebro e a face, que uma das funções está relacionada com a obtenção e processamento de alimentos (Cheverud, 1995; Marroig e Cheverud, 2001; Porto et al., 2009). Caso neurocrânio e face formassem apenas um módulo, qualquer mudança na face seria acompanhada de alterações no neurocrânio. Neste cenário, pressões seletivas demandando mudanças acentuadas na face não seriam respondidas eficientemente por essa região. Isso porque seria exigido também que o neurocrânio sofresse alterações substanciais que talvez não fossem viáveis, uma vez que exigiria mudanças profundas na reorganização/reestruturação do cérebro. No outro extremo, a região da face e a mandíbula representam um módulo. Esse módulo está vinculado, entre outras coisas, ao processamento adequado de alimentos. Para que haja a correta mastigação do alimento na boca, necessita-se da oclusão perfeita (Elbroch, 2006). Suponha por um momento que as regiões da face e da mandíbula fossem completamente desprovidas de módulos (i.e., caracteres completamente independentes). Uma pressão seletiva aplicada somente à região facial comprometeria a oclusão, já que as partes se comportam independentemente. A face, por exemplo, poderia ser selecionada para crescer, mas a mandíbula não evoluiria da mesma forma. Portanto, a evolução não coordenada entre essas partes prejudicaria a mastigação e o desenvolvimento do animal. 
Estudos teóricos indicam que a capacidade de uma estrutura complexa de um organismo responder à seleção é maximizada quando: sua estrutura modular encontra-se em uma faixa intermediária entre os extremos totalmente integrado e completamente desintegrado (Hansen, 2003). Para os crânios de mamíferos, estudos empíricos indicaram que sua estrutura modular, de fato, não atinge os extremos teóricos (Marroig et al., 2009; Porto et al., 2009, Shirai e Marroig, 2010).

A origem da estrutura modular ainda é um tema em debate (Wagner et al., 2007; Clune et al., 2013). De qualquer forma, sabe-se que a modularidade está associada a processos comuns de desenvolvimento e/ou ao compartilhamento de alguma função (Olson e Miller, 1958; Berg, 1960; Cheverud, 1982; Young e Hallgrimsson, 2005; Wagner et al., 2007). A partir do conhecimento teórico ou empírico sobre o desenvolvimento e/ou função de estruturas complexas, é possível criar hipóteses sobre o padrão modular delas. Com base nessas hipóteses são geradas matrizes teóricas que predizem as correlações entre os caracteres (módulos) dessas estruturas. Essas matrizes podem, por sua vez, ser comparadas às matrizes de correlação empíricas, que foram obtidas através de medidas dos caracteres (matrizes-P). Através dessa comparação é possível observar se as matrizes empíricas estão de acordo ou não com a hipótese de modularidade expressa pelas matrizes teóricas. Caso a previsão seja corroborada, pode-se dizer que a estrutura esta organizada de acordo com os módulos previstos (Cheverud, 1982, 1995; Marroig e Cheverud, 2001; Porto et al., 2009).

Além do padrão modular, ou seja, da estrutura da matriz, outro aspecto relevante na compreensão das relações entre os caracteres e suas possíveis consequências na evolução é a magnitude geral de integração, que representa a intensidade das relações observadas entre os caracteres. Como apresentado na Introdução Geral, tanto o padrão modular da matriz quanto a 
magnitude geral de integração podem estar relacionados com a taxa, a magnitude e a direção da evolução de caracteres sob seleção natural (Marroig e Cheverud, 2010). Portanto, para compreender a potencial influência das matrizes-P na evolução dos Xenarthra é necessário estudar conjuntamente o padrão modular e a magnitude geral de integração. Frente ao exposto, o objetivo desse capítulo foi compreender a estrutura modular craniana dos diferentes gêneros de Xenarthra, suas magnitudes gerais de integração e as possíveis consequências desses dois fatores na evolução dos fenótipos médios do grupo.

\section{Material e métodos}

\section{Amostra}

Neste capítulo foi utilizado o mesmo banco de dados do Capítulo I e os mesmos procedimentos para a obtenção das matrizes-P de cada gênero. Como mencionado no primeiro capítulo, a dificuldade em coletar alguns pontos e a vontade de incluir fósseis nas análises resultou na criação de quatro conjuntos de distância (35D, 32D, 28D e 25D). Os conjuntos com menos distâncias tem uma amostra maior e o inverso é verdadeiro para os conjuntos com mais distâncias. Trabalhar com um número de distâncias reduzido nas análises pode, em teoria, alterar a capacidade dos testes empregados em detectar a existência de um módulo. Isso porque os módulos passam a ser representados por uma quantidade menor de distâncias. Em função disso, as análises foram realizadas com os quatro conjuntos de distância (35D, 32D, 28D e 25D). O intuito com isso foi avaliar se a quantidade de distâncias e também variações no tamanho amostral entre os conjuntos de distância alteram a capacidade dos testes em detectar os módulos. 


\section{Magnitude geral de integração}

O estudo da magnitude geral da integração morfológica foi conduzido utilizando as matrizes de correlação (Pavlicev et al., 2009). A magnitude geral de integração foi medida através do método da variância relativa dos autovalores (relative variance of the eigenvalues; rVE; Pavlicev et al., 2009). O rVE para matrizes de correlação equivale à média das correlações ao quadrado (i.e., coeficiente de determinação r $^{2}$; Pavlicev et al., 2009; Haber, 2011). Para detalhes sobre essa análise ver o Capítulo I.

Adicionalmente, nesse capítulo foram realizadas correlações de Pearson entre o logaritmo da magnitude geral de integração e: 1) o logaritmo do tamanho craniano absoluto de cada gênero; e 2) a porcentagem da variação total explicada pelo primeiro componente principal (\%PC1) de cada matriz-P de correlação (Oliveira, 2009; Porto et al., 2009).

\section{Tamanho craniano}

Para os mamíferos em geral, o tamanho craniano pode ser representado pelos escores médios de cada população no primeiro componente principal (PC1). Essa afirmação também é verdadeira para os Xenarthra. O PC1 em praticamente todos os gêneros: 1) esteve fortemente correlacionado com um vetor isométrico com mesmo número de elementos; 2) apresentou valores com o mesmo sinal em todas as variáveis; e 3) gerou escores médios que se correlacionaram fortemente com os pesos médios corporais (Figura 3.1). Duas exceções foram identificadas. Choloepus apresentou PTTSP com sinal invertido das demais distâncias. No entanto, essa particularidade desse gênero não descaracterizou o PC1 como sendo tamanho. Já Paramylodon apresentou o segundo componente principal como sendo o que representa o tamanho, ao invés do primeiro. Como Paramylodon não apresentou o PC1 relacionado a 
tamanho do crânio, optou-se por quantificar o tamanho através da média ponderada entre todos os espécimes de cada gênero da soma das distâncias NSL-NA, NA-BR e BR-LD. Essa soma representa o comprimento do crânio em vista dorsal. O cálculo do tamanho foi baseado na amostra de cada gênero em 28D. Essa representação de tamanho também esteve fortemente correlacionada com o peso corporal dos grupos (Figura 3.2). Os resultados referentes ao tamanho foram apresentados aqui, e não na seção resultados, pois ele está relacionado aos métodos e não as análises desenvolvidas e discussão decorrente para compreender a magnitude geral de integração, o padrão da modularidade e suas possíveis consequências evolutivas. 


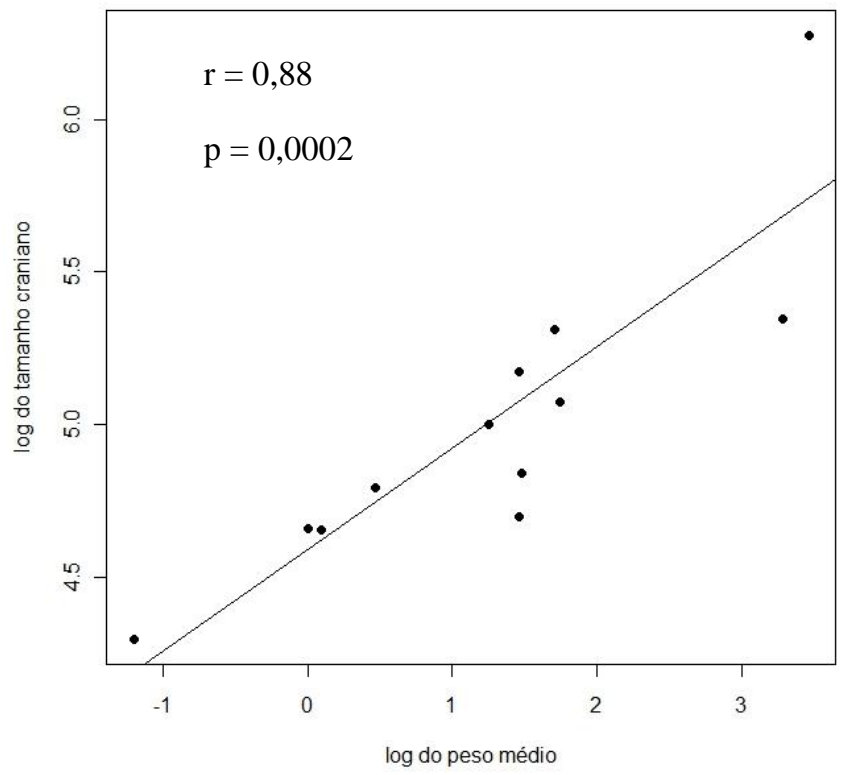

Figura 3.1 - Correlação entre peso médio corpóreo e o tamanho craniano (representado pelo primeiro componente principal; PC1) para os gêneros atuais em 35D. Dados referentes ao peso corpóreo foram extraídos de Redford e Eisenberg (1992), Eisenberg e Redford (1999) e Gardner (2007).

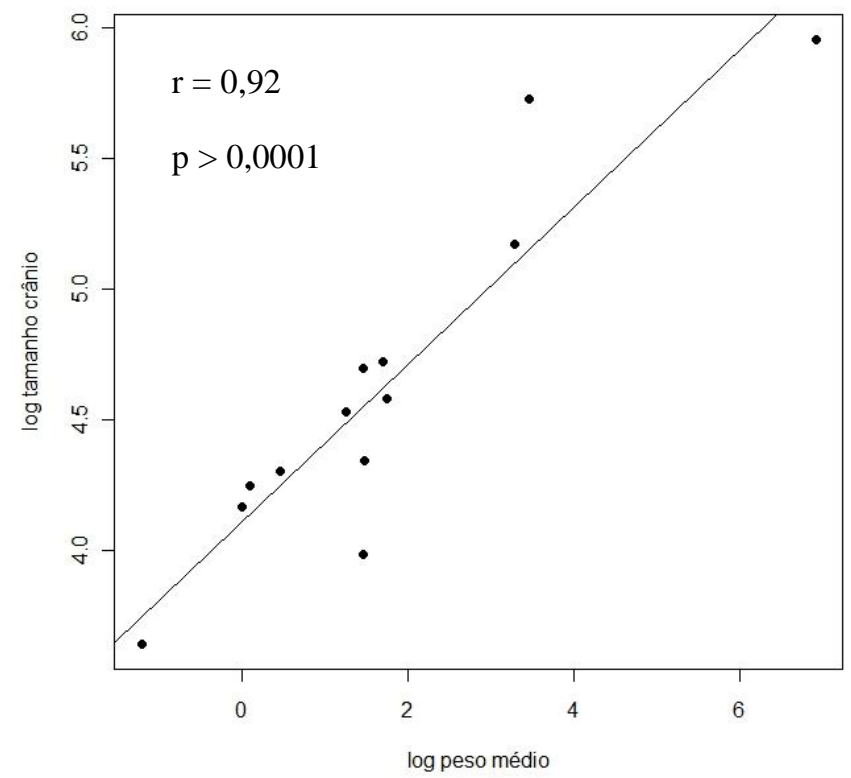

Figura 3.2 - Correlação entre peso médio corpóreo e o tamanho craniano (representado pela soma das distâncias NSL-NA, NA-BR e BR-LD) para os gêneros em 28D. Dados referentes ao peso corpóreo foram extraídos de Redford e Eisenberg (1992), Eisenberg e Redford (1999), Gardner (2007). 
Salienta-se que esse cálculo de tamanho não abrangeu Scelidotherium. Em 25D, que é o único conjunto de distância no qual esse gênero é representado, o ponto NSL não é considerado. No entanto, como será mostrado na discussão, os resultados referentes ao padrão de modularidade e a magnitude geral de integração para esse gênero foram, muito provavelmente, oriundos de erros na estimativa de sua matriz-P em função de problemas amostrais. Logo eles não apresentam interpretação biológica que considere sólida e, portanto, a ausência de uma estimativa de tamanho para Scelidotherium não foi considerada um problema.

\section{Padrões de modularidade}

O padrão de modularidade foi investigado de duas formas complementares. A primeira foi a realização de uma correlação de matrizes elemento a elemento entre as matrizes de correlação empíricas (matrizes-P) e as matrizes teóricas. A significância estatística foi acessada pelo teste de Mantel. As matrizes teóricas são as que contêm as hipóteses de modularidade obtidas através das relações de desenvolvimento e/ou função comum entre os caracteres. A expectativa nesse teste é: caso haja uma organização modular dos dados empíricos segundo alguma hipótese de modularidade (matrizes teóricas), haverá correlação entre as duas matrizes (Cheverud, 1995; Marroig e Cheverud, 2001; Porto et al., 2009). As relações dos caracteres (distâncias) em cada hipótese de modularidade foram embasadas em estudos anteriores que dividiram o crânio nas seguintes partes (módulos): regiões face e neurocrânio e sub-regiões da base, da abóbada, oral, zigomática e nasal (Tabela 3.1; Cheverud, 1995; Marroig e Cheverud, 2001; Porto et al., 2009). A partir dessas relações foram obtidas matrizes teóricas representando os módulos neural e facial independentemente, em duas matrizes separadas, e também representadas em apenas uma matriz teórica que soma os efeitos destas duas regiões. A última matriz descrita foi denominada matriz neurossomática. Matrizes teóricas também foram feitas 
para representar independentemente os módulos das sub-regiões da base, da abóbada, oral, zigomática e nasal. Por último, foi obtida uma matriz teórica representando conjuntamente todas as sub-regiões do crânio. Ela foi denominada matriz de integração total. Todas as matrizes teóricas foram obtidas atribuindo valor um para correlações pertencentes a um mesmo módulo e zero para correlações de módulos distintos (Marroig e Cheverud, 2001; Porto et al., 2009). Por exemplo, na hipótese de modularidade da face o elemento correspondente à correlação entre ZSZI e ZIMT foi representado pelo valor um e o entre ZSZI e PNSAPET pelo valor zero (Tabela 3.1). As matrizes teóricas podem ser observadas nas Tabelas A5-A13 dos anexos.

A segunda forma de avaliar a modularidade envolveu o cálculo da avg+/avg- (Marroig e Cheverud, 2001; Porto et al., 2009). A partir das matrizes-P de correlação, avg+ foi determinado como a média das correlações pertencentes ao(s) módulo(s) testado(s), com base nas matrizes teóricas. avg- foi obtida como a média das correlações externas ao(s) módulo(s) testado(s). Essa razão mede a magnitude geral de integração dos caracteres do(s) módulo(s) testado(s) contra os caracteres que não pertencem ao(s) módulo(s) testado(s). Em outras palavras, ela mostra quão distinguíveis são os caracteres dos módulos testados em relação aos caracteres que não fazem parte desses módulos. Caso os dados empíricos estejam estruturados segundo a hipótese testada, a razão será maior do que um, caso contrário ela será menor ou igual a um.

Por último, foram calculadas correlações de Pearson entre avg+/avg- e: 1) o logaritmo da magnitude geral de integração; e 2) o logaritmo do tamanho do crânio (Oliveira, 2009; Porto et al., 2009).

Antes de iniciar a apresentação dos resultados, convém explicitar que o teste da correlação elemento a elemento entre as matrizes teóricas e empíricas é bastante simplista. Por 
consequência, é pouco sensível à detecção de módulos. As matrizes teóricas são binárias. Elas reduzem a complexidade biológica da modularidade craniana apenas a ausência completa de correlação (zero) ou a correlação plena (um) e certamente não corresponde à realidade (Cheverud, 1982, 1995). Note também que este teste dentro deste contexto equivale a um teste-t de diferença na média dos dois grupos $(0$ e 1$)$ de correlações, mas com a significância propriamente controlada para levar em conta o fato que as correlações não são observações independentes (a correlação entre X e Y não é independente da correlação entre X e Z). Por consequência, correlações significativas $(\mathrm{p}<0,05)$ ou marginalmente significativas $(0,05<\mathrm{p}<$ 0,1) entre essas matrizes sugerem a presença dos módulos mais evidentes e devem ser consideradas como de provável importância biológica (Oliveira, 2009). Além disso, a própria existência de módulos mais nítidos oblitera a detecção de outros módulos, mais discretos (Porto et al., 2009). Ou seja, a não detecção de determinados módulos no teste de correlação não significa obrigatoriamente que eles não existam. Pode ser apenas que esses módulos não sejam pronunciados o suficiente para serem detectados ou que eles possam estar mascarados por outro(s) módulo(s) mais aparente(s). 
Tabela 3.1 - Distâncias euclidianas definidas a partir dos pontos medidos e suas relações com as diferentes hipóteses de modularidade (regiões e sub-regiões anatômicas).

\begin{tabular}{|c|c|c|c|c|c|}
\hline Distância & Região anatômica & Sub-região anatômica & Distância & Região anatômica & $\begin{array}{l}\text { Sub-região } \\
\text { anatômica }\end{array}$ \\
\hline ISPM & face & oral & ZSZI & face & zigomático \\
\hline ISNSL & face & nasal & ZIMT & face & zigomático \\
\hline ISPNS & face & oral, nasal & ZIZYGO & face & zigomático \\
\hline PMZS & face & oral & ZITSP & face & zigomático \\
\hline PMZI & face & oral & MTPNS & face & oral \\
\hline РMMT & face & oral & PNSAPET & neurocrânio & base \\
\hline NSLNA & face & nasal & APETBA & neurocrânio & base \\
\hline NSLZS & face & nasal & APETTS & neurocrânio & base \\
\hline NSLZI & face & oral, nasal & BAEAM & neurocrânio & base \\
\hline NABR & neurocrânio & abóbada & EAMZYGO & face & zigomático \\
\hline NAPNS & face & nasal & ZYGOTSP & face & zigomático \\
\hline BRPT & neurocrânio & abóbada & LDAS & neurocrânio & abóbada \\
\hline BRAPET & neurocrânio & abóbada & BRLD & neurocrânio & abóbada \\
\hline PTAPET & neurocrânio & abóbada & OPILD & neurocrânio & abóbada \\
\hline PTBA & neurocrânio & abóbada & PTAS & neurocrânio & abóbada \\
\hline PTEAM & neurocrânio & abóbada & JPAS & neurocrânio & abóbada \\
\hline PTZYGO & face & zigomático & BAOPI & neurocrânio & base \\
\hline PTTSP & neurocrânio e face & abóbada, zigomático & & & \\
\hline
\end{tabular}

\section{Flexibilidade evolutiva}

Para explorar a capacidade das matrizes-P de responder de forma alinhada a possíveis pressões seletivas, foi calculada a flexibilidade evolutiva (Hansen e Houle, 2008; Marroig et al., 2009). A partir da equação de resposta multivariada à seleção $(\Delta \bar{z}=\boldsymbol{G} \beta$; Lande, 1979$)$ essa estatística consiste em correlacionar o vetor de resposta evolutiva $(\Delta \bar{z})$ e o vetor de seleção $(\beta)$. Ela mede quão alinhada é a resposta evolutiva em relação à direção da seleção (Marroig et al., 2009). Para obter essa métrica cada uma das matrizes-P (substituindo G na equação de Lande) foi multiplicada por 10000 vetores aleatórios de seleção (equivalentes a $\beta$ na equação). Estes vetores foram obtidos através de uma distribuição normal com média zero e desvio padrão um e com o mesmo número de elementos que o posto das matrizes. Posteriormente eles foram normalizados para uma norma de 1 . O objetivo de utilizar grande quantidade de vetores 
aleatórios de seleção é explorar diversas possibilidades existentes no morfoespaço representado pelas matrizes-P. Para cada vetor aleatório ( $\beta$ ), computou-se a correlação entre ele e o respectivo vetor de resposta (equivalentes a $\Delta \bar{Z}$ na equação) através do cosseno do ângulo formado entre os dois vetores (Marroig et al., 2009). Na prática, o cosseno do ângulo equivale a soma dos produtos dos elementos dos dois vetores que, por sua vez, equivale a correlação de Pearson. Em seguida, a flexibilidade evolutiva foi calculada como a média das 10000 correlações. Valores próximos de um indicam que, na media, o táxon em questão responde de forma alinhada com os vetores aleatórios de seleção. Valores próximos de zero sugerem que, na média, o táxon não responde de forma alinhada às pressões seletivas.

Adicionalmente, a flexibilidade evolutiva foi correlacionada através de correlação de Pearson com: 1) o logaritmo da magnitude geral de integração; 2) o logaritmo do tamanho do crânio; 3) a avg+/avg- das diferentes hipóteses de modularidade; e 4) a porcentagem de variância total explicada pelo tamanho (PC1). A mesmas análises de correlação foram realizadas considerando uma amostra de 33 mamíferos, os 12 Xenarthra analisados nesse estudo e 21 gêneros de mamíferos estudados em Porto e colaboradores (2009) e Marroig e colaboradores (2009), a saber: Didelphis, Caenolestes, Antechinus, Macropus, Isodon, Procavia, Elephantulus, Tupaia, Sylvilagus, Cerdocyon, Tapirus, Mazama, Akodon, Gorilla, Homo, Pan, Papio, Alouatta, Cebus e Callithrix.

Todas as análises realizadas nesse capítulo foram desenvolvidas através do $\mathrm{R}$ ( $\mathrm{R}$ Development Core Team, 2011). 


\section{Resultados}

Os resultados obtidos através dos diferentes conjuntos de distância (35D, 32D, 28D e 25D) foram em geral consistentes tanto para a magnitude geral de integração quanto para os padrões de modularidade. Detalhes das diferenças nos resultados da magnitude geral de integração para os conjuntos de distância podem ser encontrados no Capítulo 1.

Em relação ao padrão de modularidade, na grande maioria dos gêneros e das hipóteses de modularidade os resultados foram congruentes. Todos os conjuntos de distâncias apresentaram o mesmo resultado, seja ele indicando a presença de determinado módulo ou não. Além disso, as avg+/avg- variaram pouco entre os conjuntos de distância (35D, 32D, 28D e 25D; Tabela 3.2). No geral, módulos foram detectados mais frequentemente no conjunto de distâncias 35D. Esse resultado era esperado dado que é o conjunto com o maior número de distâncias disponíveis. Exceções foram observadas em alguns dos gêneros que tiveram incremento na amostra entre 35D e os demais conjuntos de distância (Bradypus, Choloepus e Cyclopes; Tabela 3.2). Frente ao exposto, decidiu-se discutir apenas os resultados referentes a 35D e somente nos casos especificados a seguir, os resultados para outros conjuntos de distâncias. Para Scelidotherium os resultados se referem a 25D, pois é o único conjunto de distâncias disponível para o gênero. Optou-se por apresentar os resultados de Paramylodon para 28D, pois a ausência de distâncias representando a sub-região nasal em 25D impediu que se testasse a hipótese de modularidade nessa sub-região. Por último, como os resultados para 35D e 32D divergiram em Bradypus, Choloepus e Cyclopes, ambos foram discutidos. Para facilitar a visualização dos gêneros e respectivos conjuntos de distância discutidos, optou-se por apresentar na Tabela 3.3, as mesmas informações da Tabela 3.2, mas somente para os casos de interesse. 


\section{Magnitude geral de integração}

No Capítulo I foram obtidos dois resultados relevantes para esse capítulo. Primeiro, as magnitudes gerais de integração morfológica (rVE), medidas através da variância relativa dos autovalores, variaram entre 0,09 e 0,24 (Tabela 3.3). Segundo, foi encontrada correlação fraca entre a matriz de diferenças na magnitude geral de integração, que é definida como a diferença par a par entre gêneros no rVE, e a matriz de distância filogenética. Por outro lado não houve correlação entre a matriz de diferenças na magnitude geral de integração e matriz de distâncias morfológica ou de dieta.

Nas análises realizadas neste capítulo, não foi encontrada correlação entre tamanho absoluto do crânio e magnitude geral de integração (Figura 3.3). No entanto, a magnitude geral de integração correlacionou-se positiva e fortemente com a porcentagem de variância explicada pelo primeiro componente principal de cada matriz-P de correlação (Figura 3.4). 
Tabela 3.2 - Razão entre a média das correlações pertencentes ao(s) módulo(s) testado(s) (avg+) e a média das correlações externas ao(s) módulo(s) testado(s) (avg-) em cada hipótese de modularidade. Valores em negrito foram considerados marginalmente significativos $(0,05<\mathrm{p}<$ $0,1)$ e em negrito e sublinhado significativos $(\mathrm{p}<0,05)$ nos testes de significância de Mantel para as correlações elemento a elemento entre as matrizes empíricas e teóricas. A última coluna representa a contagem de resultados que apresentaram $\mathrm{p}<0,1$. NA: não foi possível testar a hipótese de modularidade.

\begin{tabular}{|c|c|c|c|c|c|c|c|c|c|c|c|}
\hline Táxon & $\begin{array}{c}\text { Conjunto } \\
\text { de } \\
\text { distâncias }\end{array}$ & Neurossomático & Facial & Neural & Oral & Nasal & Zigomática & Base & Abóbada & Total & $\begin{array}{c}n \\
\text { resultados } \\
p<0,1\end{array}$ \\
\hline \multirow{3}{*}{ Zaedyus } & 35D & 1,03 & 1,29 & 0,74 & $\underline{1,98}$ & $\underline{1,68}$ & 0,74 & 0,48 & 0,81 & 1,03 & 3 \\
\hline & 28D & 0,94 & $\underline{1,49}$ & 0,69 & $\underline{2,06}$ & 1,53 & 0,67 & 0,47 & 0,78 & 0,91 & 2 \\
\hline & 25D & 0,83 & $\underline{\underline{1,55}}$ & 0,61 & $\underline{1,99}$ & NA & 1,06 & 0,04 & 0,82 & 0,85 & 2 \\
\hline \multirow{2}{*}{ Tolypeutes } & 35D & 1,01 & $\overline{1,13}$ & 0,88 & 1,68 & 1,55 & 0,83 & 0,37 & 1,25 & 1,23 & 3 \\
\hline & 25D & 0,84 & 1,00 & 0,83 & 2,20 & NA & 0,18 & $-0,06$ & 1,35 & 1,15 & 1 \\
\hline \multirow{4}{*}{ Priodontes } & 35D & 1,03 & 0,92 & 1,13 & 2,18 & $\underline{2,90}$ & 0,45 & 0,11 & $\underline{1,87}$ & 1,77 & 4 \\
\hline & 32D & 1,12 & 0,80 & 1,37 & $\underline{2,92}$ & $\underline{3,14}$ & 0,50 & 0,12 & $\underline{2,25}$ & $\underline{1,94}$ & 4 \\
\hline & 28D & $\underline{1,50}$ & 1,31 & 1,26 & $\overline{2,73}$ & $\overline{2,93}$ & $-0,39$ & 0,11 & $\overline{2,15}$ & $\underline{2,10}$ & 5 \\
\hline & 25D & $\overline{1,19}$ & 0,83 & 1,31 & $\overline{2,30}$ & $\overline{N A}$ & 0,19 & $-0,37$ & $\overline{2,45}$ & $\overline{1,99}$ & 2 \\
\hline Euphractus & 35D & 0,94 & 1,10 & 0,80 & 1,64 & 1,27 & 0,88 & 0,52 & 0,95 & 1,04 & 1 \\
\hline \multirow{2}{*}{ Dasypus } & 28D & 1,07 & 1,09 & 1,02 & $\underline{1,71}$ & $\underline{1,70}$ & 0,26 & 0,62 & 1,20 & 1,19 & 3 \\
\hline & 25D & 1,04 & 0,96 & 1,06 & $\overline{1,56}$ & $\overline{N A}$ & 0,51 & 0,29 & 1,32 & 1,16 & 2 \\
\hline \multirow{4}{*}{ Chaetophractus } & 35D & 1,11 & $\underline{1,50}$ & 0,67 & $\underline{2,25}$ & 1,72 & 1,25 & 0,50 & 0,80 & 1,22 & 5 \\
\hline & 32D & 1,03 & $\overline{\underline{1,44}}$ & 0,70 & $\overline{2,55}$ & $\overline{1,56}$ & 1,32 & 0,52 & 0,84 & $\overline{1,14}$ & 2 \\
\hline & $28 \mathrm{D}$ & 0,97 & $\overline{1,57}$ & 0,69 & $\overline{2,63}$ & 1,59 & 1,42 & 0,53 & 0,85 & 1,11 & 2 \\
\hline & 25D & 0,84 & $\underline{1,49}$ & 0,64 & $\underline{2,55}$ & NA & 1,68 & 0,14 & 0,92 & 1,10 & 2 \\
\hline \multirow{4}{*}{ Cabassous } & 35D & 1,06 & $\underline{1,27}$ & 0,80 & 1,44 & 1,78 & 0,92 & 0,31 & 1,02 & 1,10 & 5 \\
\hline & 32D & 1,04 & $\underline{\underline{1,27}}$ & 0,82 & $\overline{1,55}$ & $\overline{1,98}$ & 0,95 & 0,32 & 1,05 & 1,06 & 3 \\
\hline & 28D & 1,00 & $\overline{1,38}$ & 0,79 & $\overline{1,54}$ & $\overline{1,96}$ & 0,74 & 0,31 & 1,04 & 1,06 & 3 \\
\hline & 25D & 0,92 & 1,28 & 0,79 & 1,47 & NA & 1,03 & $-0,10$ & 1,14 & 1,06 & 1 \\
\hline \multirow{2}{*}{ Myrmecophaga } & 35D & 1,09 & 1,10 & 1,00 & 1,63 & $\underline{1,71}$ & 0,75 & 0,59 & 1,15 & $\underline{1,18}$ & 4 \\
\hline & 32D & 1,08 & 1,09 & 1,02 & $\overline{1,70}$ & $\overline{1,75}$ & 0,76 & 0,60 & 1,17 & $\overline{1,11}$ & 3 \\
\hline \multirow{2}{*}{ Bradypus } & 28D & 0,93 & 1,38 & 0,72 & 1,60 & 1,98 & 1,00 & 0,62 & 0,77 & 0,93 & 3 \\
\hline & 25D & 0,85 & 1,30 & 0,71 & 1,55 & $\overline{N A}$ & 1,03 & 0,35 & 0,83 & 0,86 & 0 \\
\hline \multirow{4}{*}{ Choloepus } & 35D & 0,89 & 1,15 & 0,70 & 2,15 & 1,32 & 0,89 & 0,67 & 0,72 & 1,02 & 1 \\
\hline & 32D & 0,83 & 1,10 & 0,70 & $\underline{2,17}$ & $\underline{1,93}$ & 0,91 & 0,68 & 0,73 & 0,95 & 2 \\
\hline & 28D & 0,78 & 1,11 & 0,70 & $\overline{2,23}$ & $\overline{1,98}$ & 0,32 & 0,69 & 0,74 & 0,94 & 2 \\
\hline & 25D & 0,67 & 1,06 & 0,62 & $\overline{2,29}$ & $\overline{N A}$ & 0,56 & 0,23 & 0,76 & 0,78 & 1 \\
\hline \multirow{4}{*}{ Cyclopes } & 35D & 1,13 & 1,11 & 1,05 & 1,40 & 1,45 & 0,74 & 0,79 & 1,06 & 1,07 & 1 \\
\hline & $32 \mathrm{D}$ & 1,15 & 1,18 & 1,01 & 1,33 & $\underline{2,06}$ & 0,72 & 0,77 & 1,03 & 1,01 & 2 \\
\hline & $28 \mathrm{D}$ & 1,18 & 1,21 & 1,06 & 1,36 & $\underline{2,12}$ & 0,24 & 0,79 & 1,06 & 1,09 & 1 \\
\hline & 25D & 1,06 & 0,93 & 1,10 & 1,04 & $\overline{N A}$ & 0,40 & 0,43 & 1,17 & 0,99 & 0 \\
\hline
\end{tabular}


Tabela 3.3 - Magnitude geral de integração (rVE) e razão entre a média das correlações pertencentes ao(s) módulo(s) testado(s) (avg+) e a média das correlações externas ao(s) módulo(s) testado(s) (avg-) em cada hipótese de modularidade. Valores em negrito foram considerados marginalmente significativos $(0,05<\mathrm{p}<0,1)$ e em negrito e sublinhado significativos $(\mathrm{p}<0,05)$ nos testes de significância de Mantel para as correlações elemento a elemento entre as matrizes empíricas e teóricas. Os resultados apresentados se referem ao conjunto de distâncias 35D, a não ser nos casos salientados do contrário (parênteses ao lado do gênero).

\begin{tabular}{|c|c|c|c|c|c|c|c|c|c|c|c|}
\hline $\begin{array}{c}\text { Ordem/ } \\
\text { Subordem }\end{array}$ & Gênero & rVE & Neurossomático & Facial & Neural & Oral & Nasal & Zigomática & Base & Abóbada & Total \\
\hline \multirow{7}{*}{ 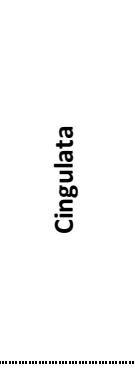 } & Zaedyus & 0,158 & 1,027 & 1,290 & 0,743 & $\underline{1,978}$ & $\underline{1,680}$ & 0,743 & 0,480 & 0,806 & 1,033 \\
\hline & Euphractus & 0,224 & 0,936 & 1,101 & 0,801 & $\underline{1,638}$ & 1,275 & 0,881 & 0,524 & 0,947 & 1,043 \\
\hline & Chaetophractus & 0,11 & $\underline{1,115}$ & $\underline{1,501}$ & 0,671 & $\underline{2,249}$ & $\underline{1,725}$ & 1,248 & 0,499 & 0,798 & 1,219 \\
\hline & Tolypeutes & 0,123 & 1,012 & 1,129 & 0,876 & $\underline{1,680}$ & 1,550 & 0,827 & 0,369 & 1,254 & 1,229 \\
\hline & Priodontes & 0,099 & 1,026 & 0,924 & 1,130 & $\underline{2,178}$ & $\underline{2,899}$ & 0,446 & 0,107 & $\underline{1,871}$ & $\underline{1,767}$ \\
\hline & Cabassous & 0,189 & 1,061 & $\underline{1,268}$ & 0,805 & $\underline{1,436}$ & $\underline{1,776}$ & 0,923 & 0,310 & 1,017 & 1,102 \\
\hline & Dasypus & 0,146 & 1,041 & 1,019 & 1,035 & $\underline{1,627}$ & $\underline{1,873}$ & 0,577 & 0,630 & 1,198 & $\underline{1,191}$ \\
\hline \multirow{4}{*}{ 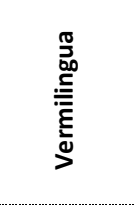 } & Myrmecophaga & 0,206 & 1,087 & 1,102 & 1,003 & $\underline{1,625}$ & $\underline{1,712}$ & 0,752 & 0,589 & 1,146 & $\underline{1,184}$ \\
\hline & Tamandua & 0,156 & $\underline{1,114}$ & $\underline{1,377}$ & 0,771 & $\underline{2,030}$ & $\underline{1,589}$ & 0,933 & 0,347 & 0,964 & $\underline{1,161}$ \\
\hline & Cyclopes & 0,190 & 1,131 & 1,115 & 1,045 & 1,405 & 1,446 & 0,743 & 0,788 & 1,056 & 1,074 \\
\hline & Cyclopes (32D) & 0,107 & 1,130 & 1,464 & 0,782 & $\underline{2,426}$ & $\underline{2,281}$ & 0,696 & 0,342 & 1,020 & 1,084 \\
\hline \multirow{6}{*}{$\begin{array}{l}\frac{\pi}{0} \\
\stackrel{3}{0} \\
\frac{0}{4}\end{array}$} & Bradypus & 0,204 & 0,987 & 1,240 & 0,738 & 1,328 & $\underline{1,760}$ & 1,081 & 0,606 & 0,768 & 1,006 \\
\hline & Bradypus (32D) & 0,177 & 0,94 & 1,27 & 0,72 & 1,54 & $\underline{1,90}$ & 1,07 & 0,60 & 0,75 & 0,93 \\
\hline & Choloepus & 0,158 & 0,893 & 1,150 & 0,696 & $\underline{2,153}$ & 1,323 & 0,889 & 0,666 & 0,718 & 1,024 \\
\hline & $\begin{array}{c}\text { Choloepus } \\
\text { (32D) }\end{array}$ & 0,135 & 0,83 & 1,10 & 0,70 & $\underline{2,17}$ & $\underline{1,93}$ & 0,91 & 0,68 & 0,73 & 0,95 \\
\hline & $\begin{array}{l}\text { Paramylodon } \\
\text { (28D) }\end{array}$ & 0,108 & $\underline{1,684}$ & $\underline{2,705}$ & 0,745 & $\underline{2,722}$ & $\underline{4,092}$ & 1,823 & 0,684 & 0,844 & $\underline{1,402}$ \\
\hline & $\begin{array}{c}\text { Scelidotherium } \\
\left(^{25 \mathrm{D})^{\mathrm{a}}}\right.\end{array}$ & 0,237 & 0,939 & 0,949 & 0,962 & 1,471 & - & 0,548 & 0,979 & 0,982 & 0,956 \\
\hline
\end{tabular}

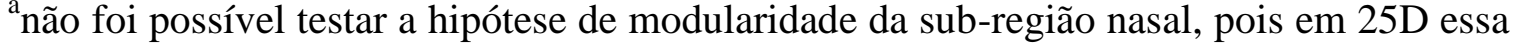
sub-região não foi representada. 


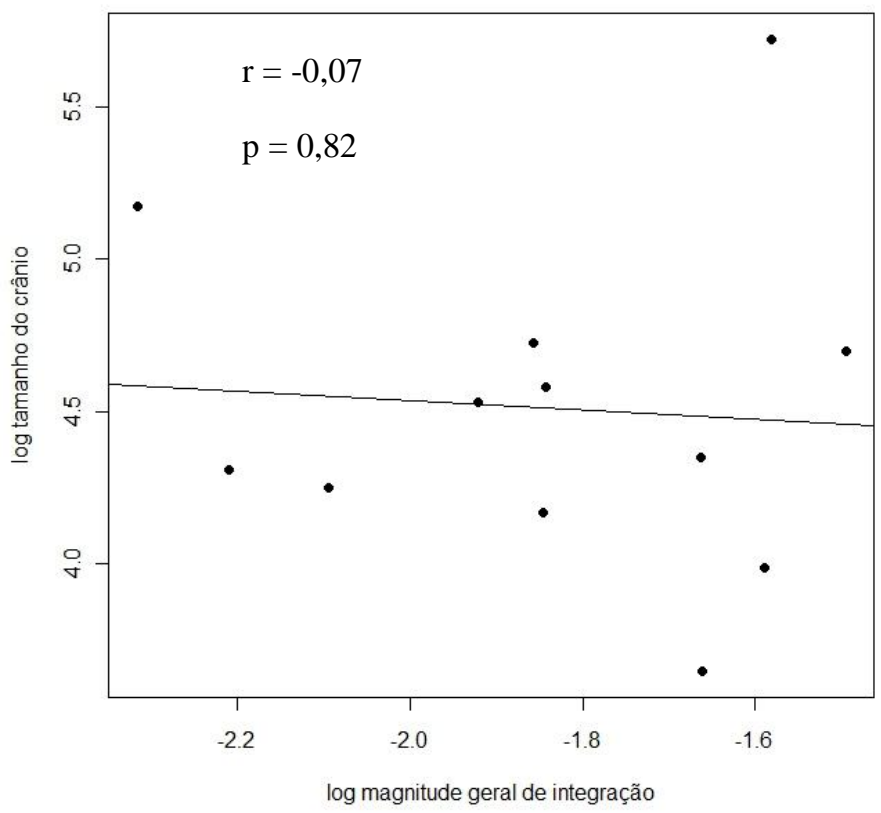

Figura 3.3 - Correlação entre a magnitude geral de integração e o tamanho craniano (representado pela soma de NSL-NA, NA-BR e BR-LD).

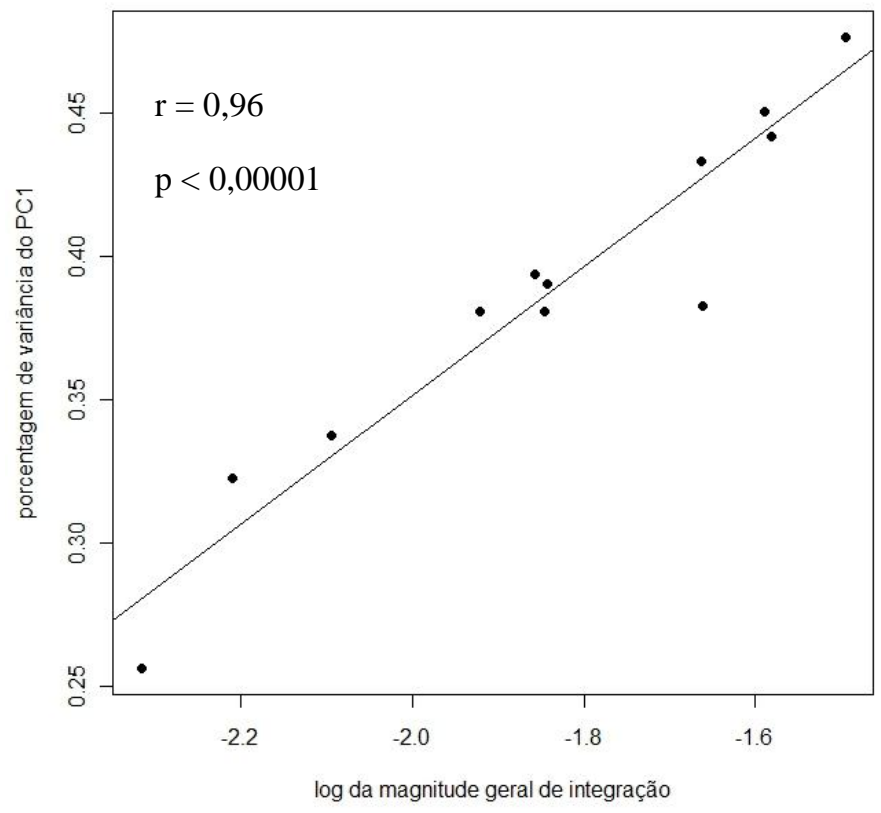

Figura 3.4 - Correlação entre a magnitude geral de integração e a porcentagem de variação explicada pelo primeiro componente principal (PC1). 


\section{Padrões de modularidade}

A matriz teórica representando a hipótese de modularidade da sub-região oral foi a que se correlacionou com as matrizes empíricas na maior quantidade de gêneros (13; Tabela 3.3). Apenas Cyclopes (35D), Bradypus (35D) e Scelidotherium apresentaram valores não significativos. Em seguida a sub-região nasal esteve correlacionada em 11 casos. A matriz teórica considerando todas as sub-regiões conjuntamente (total), a que representou a região da face (facial) e a que expressou simultaneamente os módulos facial e o neurocraniano (neurossomática) se correlacionaram marginalmente ou significativamente em metade dos gêneros. Se forem consideradas apenas as correlações significativas, esse valor é reduzido para

um terço. A sub-região da abóbada esteve correlacionada apenas em Priodontes. As matrizes teóricas da região neural e das sub-regiões zigomática e da base não se correlacionaram com as matrizes empíricas de nenhum gênero (Tabela 3.3).

Além disto, a correlação entre avg+/avg- e o tamanho do crânio não foi significativa em nenhuma hipótese de modularidade (Tabela 3.4). Por outro lado, as correlações entre magnitude geral de integração e avg+/avg- foram negativas e fortes para as hipóteses oral, nasal e total (Tabela 3.5; Figura 3.5). 
Tabela 3.4 - Correlação de Pearson (r) e significância estatística (p) para as diferentes hipóteses de modularidade entre a avg+/avg- e o logaritmo do tamanho craniano (soma das distâncias NSL-NA,NA-BR e BR-LD).

\begin{tabular}{ccc}
\hline & \multicolumn{1}{c}{$\mathbf{r}$} & $\mathbf{P}$ \\
\hline Neurossomático & -0.054 & 0.868 \\
Facial & -0.337 & 0.284 \\
Neural & 0.325 & 0.303 \\
Oral & 0.311 & 0.325 \\
Nasal & 0.362 & 0.248 \\
Zigomática & -0.349 & 0.266 \\
Base & -0.359 & 0.252 \\
Abóbada & 0.443 & 0.149 \\
Total & 0.472 & 0.121 \\
\hline
\end{tabular}

Tabela 3.5 - Correlação de Pearson (r) e significância estatística (p) para as diferentes hipóteses de modularidade entre a avg+/avg- e o logaritmo da magnitude geral de integração. Valores em negrito foram significativos $(\mathrm{p}<0,05)$.

\begin{tabular}{ccc}
\hline & $\mathbf{r}$ & $\mathbf{P}$ \\
\hline Neurossomático & $-0,153$ & 0,634 \\
Facial & $-0,007$ & 0,982 \\
Neural & $-0,147$ & 0,647 \\
Oral & $\mathbf{- 0 , 7 1 0}$ & $\mathbf{0 , 0 1 0}$ \\
Nasal & $\mathbf{- 0 , 6 0 0}$ & $\mathbf{0 , 0 3 9}$ \\
Zigomática & $\mathbf{0 , 1 8 0}$ & 0,575 \\
Base & $\mathbf{0 , 5 4 3}$ & $\mathbf{0 , 0 6 8}$ \\
Abóbada & $-0,495$ & $\mathbf{0 , 1 0 2}$ \\
Total & $\mathbf{- 0 , 7 3 0}$ & $\mathbf{0 , 0 0 7}$ \\
\hline
\end{tabular}



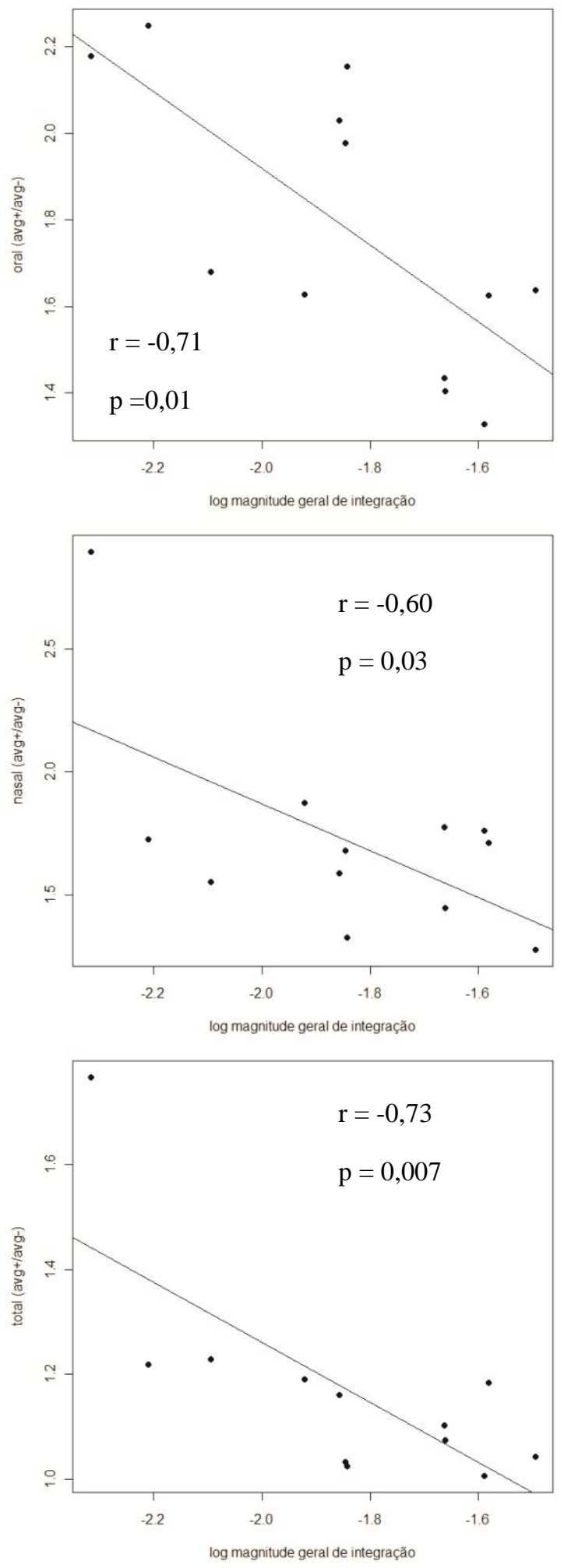

Figura 3.5 - Correlações entre a magnitude geral de integração e a avg+/avg- para as hipóteses de modularidade que apresentaram essa relação significativa. 


\section{Flexibilidade evolutiva}

Os resultados obtidos entre os conjuntos de distância (35D, 32D, 28D e 25D) diferiram em seus valores absolutos. Quanto menor o número de distâncias utilizado, maior o valor observado para a flexibilidade (Tabela 3.6). No entanto a hierarquia de quais gêneros apresentaram flexibilidades maiores ou menores foi mantida ao longo dos conjuntos de distâncias (Tabela 3.6). Por exemplo, Chaetophractus apresentou valor de 0,45 para 35D e 0,58 para 25D e em todos os conjuntos de distância foi o gênero com a maior flexibilidade. No outro extremo, Myrmecophaga apresentou os menores valores de flexibilidade em todos os conjuntos de distância. Eles variaram entre 0,24 e 0,34. Variações no tamanho amostral tiveram efeito mais intenso apenas em Cyclopes, entre 35D e 32D. Os demais gêneros que apresentaram variações no tamanho amostral entre os conjuntos de distância não apresentaram grande variação na flexibilidade evolutiva entre os conjuntos de distância em que ocorreu o incremento amostral (Myrmecohaga, Choloepus e Bradypus entre 35D e 32D e Paramylodon entre 28D e 25D).

Tabela 3.6 - Flexibilidade evolutiva observada para cada gênero em cada conjunto de distância.

\begin{tabular}{ccccc}
\hline & 35D & 32D & 28D & 25D \\
\hline Zaedyus & 0,368 & 0,389 & 0,406 & 0,459 \\
Tolypeutes & 0,405 & 0,427 & 0,451 & 0,484 \\
Priodontes & 0,439 & 0,470 & 0,492 & 0,512 \\
Euphractus & 0,350 & 0,373 & 0,386 & 0,421 \\
Dasypus & 0,327 & 0,346 & 0,355 & 0,417 \\
Chaetophactus & 0,448 & 0,478 & 0,492 & 0,580 \\
Cabassous & 0,367 & 0,399 & 0,417 & 0,470 \\
Myrmecophaga & 0,235 & 0,282 & 0,293 & 0,340 \\
Tamanduia & 0,312 & 0,342 & 0,356 & 0,409 \\
Cyclopes & 0,346 & 0,476 & 0,490 & 0,515 \\
Bradypus & 0,374 & 0,426 & 0,445 & 0,459 \\
Choloepus & 0,424 & 0,451 & 0,473 & 0,480 \\
Paramylodon & - & - & 0,451 & 0,441 \\
Scelidotherium & - & - & - & 0,393 \\
\hline
\end{tabular}

Segundo a teoria, o resultado observado de elevação no valor da flexibilidade evolutiva em função da diminuição de distâncias era esperado. Quanto menor o número de distâncias 
sendo considerado, menor o número de dimensões e menos complexo é o morfoespaço. Note que as dimensões desse morfoespaço equivalem ao número de distâncias. Em um morfoespaço determinado por poucas dimensões, em muitos casos a resposta evolutiva será alinhada com o vetor de seleção pelo fato de não haver muitas possibilidades de resposta ou de pressão seletiva no morfoespaço. Consequentemente, a flexibilidade será elevada. Já quando o número de dimensões aumenta, a complexidade do morfoespaço fica maior e existem mais opções para a pressão e a resposta seguirem. Isso resulta em flexibilidades menores. Intuitivamente esse resultado pode ser entendido como: uma estrutura é flexível quando a resposta evolutiva está alinhada a pressão de seleção. Em uma estrutura representada por duas distâncias, é relativamente fácil responder de forma alinhada a pressão. A justificativa para essa afirmação é que apenas dois caracteres precisam evoluir de forma coordenada. Por outro lado, em uma estrutura representada por 35 distâncias, para ocorrer evolução na mesma direção da pressão é necessário que ocorra resposta coordenada entre as 35 distâncias, algo muito mais dificil de ser obtido.

Para exemplificar essa questão, das matrizes-P dos 12 gêneros em 35D foram selecionadas aleatoriamente distâncias para compor novas matrizes de covariância com números de distâncias sucessivamente menores (30, 25, 20, 15, 10 e 5). Em seguida, foram calculadas as flexibilidades evolutivas em cada caso. Esse procedimento foi realizado 100 vezes e a média da flexibilidade para cada gênero em cada subconjunto de distâncias foi plotado em um gráfico (Figura 3.6). Como pode ser observado, a flexibilidade aumenta a medida que se diminui o número de distâncias. Em todos os gêneros essa estatística apresentou o mesmo comportamento. 


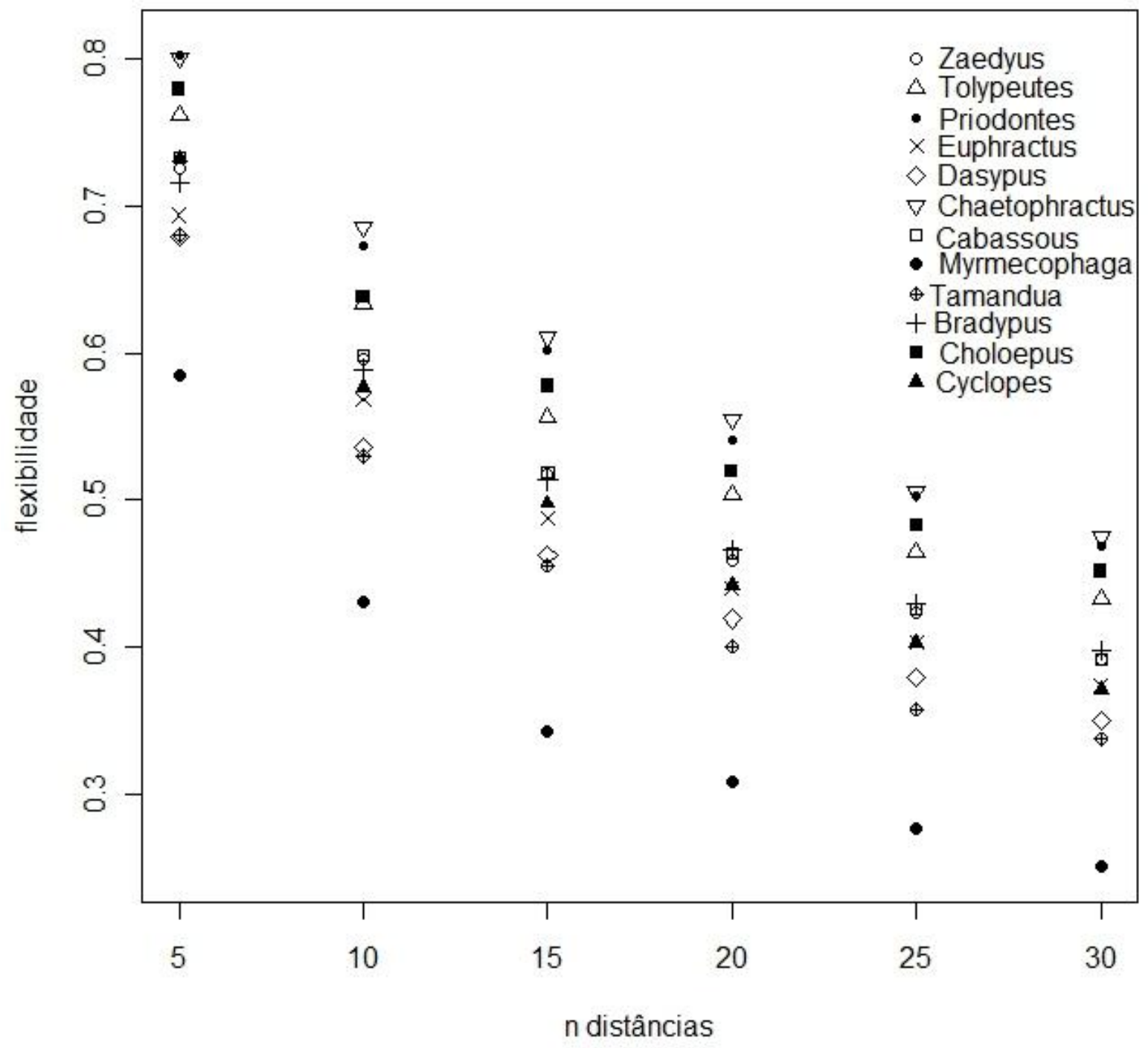

Figura 3.6 - Média da flexibilidade de 100 amostras aleatórias de diferentes conjuntos de distância (n distâncias) para cada gênero.

Frente ao exposto optou-se em focar o restante das análises e a discussão da flexibilidade evolutiva nos conjuntos de distância 35D e 28D. O primeiro se justifica por permitir comparar de forma direta os resultados obtidos para os Xenarthra com os demais mamíferos já analisados quanto a essa estatística (Marroig et al., 2009). O segundo para permitir a comparação dentre os 
Xenarthra, com a inclusão de um grupo fóssil (Paramylodon) e amostras melhores para alguns gêneros.

A flexibilidade esteve forte e negativamente correlacionada a magnitude geral de integração e a porcentagem de variância explicada pelo primeiro componente principal (Figura 3.7; Tabela 3.7). Por outro lado ela não se correlacionou com o tamanho absoluto do crânio (Figura 3.7) ou com as avg+/avg- das diferentes hipóteses de modularidade (Tabela 3.7). No entanto, quando a correlação da flexibilidade com os demais fatores foi analisada sob uma perspectiva mais ampla, ou seja, considerando tanto os resultados dos Xenarthra quanto os de 21 outros gêneros de mamíferos analisados em Porto e colaboradores (2009) e Marroig e colaboradores (2009) os resultados foram diferentes em alguns aspectos (Tabela 3.8). Na análise realizada com os 33 gêneros de mamíferos a flexibilidade, além de se correlacionar com a magnitude geral de integração e a \%PC1, também esteve correlacionada com quatro hipóteses de modularidade (oral, abóbada, neurossomática e total). 

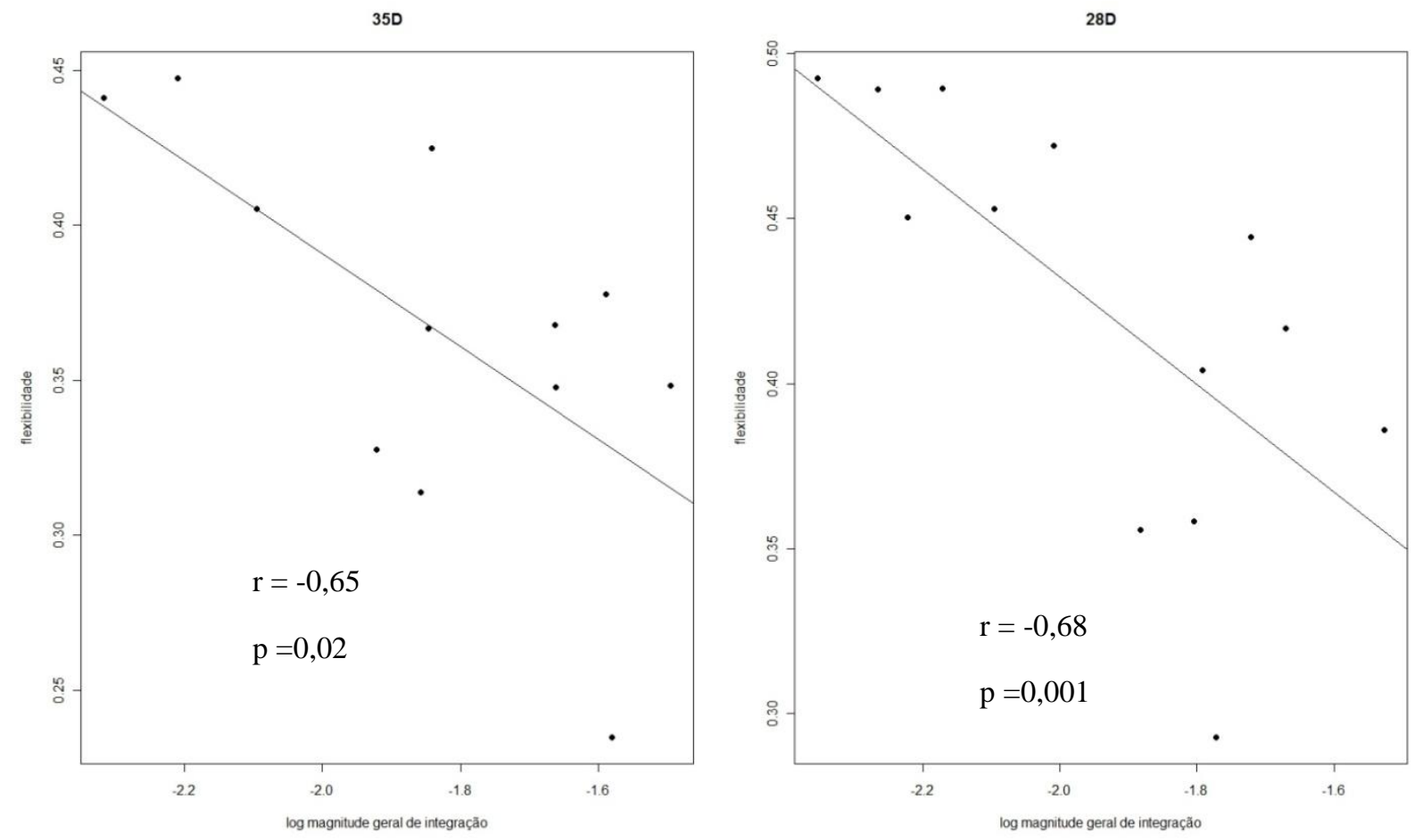

Figura 3.7 - Correlação entre flexibilidade evolutiva e magnitude geral de integração para os conjuntos de distância 35D e 25D.
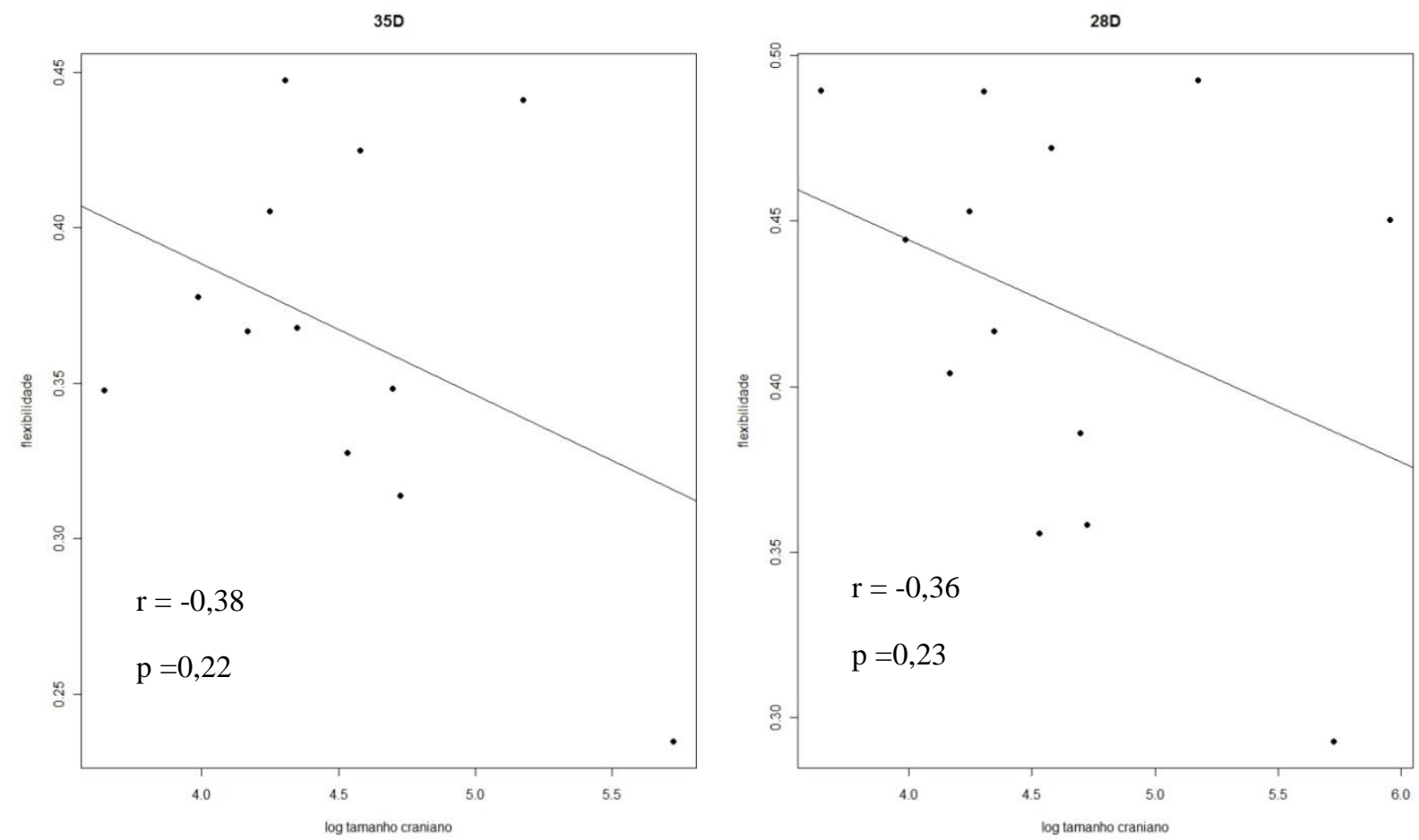

Figura 3.7 - Figura 3.7 - Correlação entre flexibilidade evolutiva e tamanho para os conjuntos de distância 35D e 28D. 
Tabela 3.7 - Correlação de Pearson (r) e significância estatística (p) entre a flexibilidade evolutiva e as seguintes métricas: porcentagem de variância explicada pelo primeiro componente principal (\%PC1); logaritmo da magnitude geral de integração (rVE); logaritmo do tamanho absoluto craniano; avg+/avg- das diferentes hipóteses de modularidade. Valores em negrito foram significativos $(\mathrm{p}<0,05)$.

\begin{tabular}{ccccc}
\hline & \multicolumn{2}{c}{ 35D } & \multicolumn{2}{c}{ 28D } \\
& $\mathbf{r}$ & $\mathbf{p}$ & $\mathbf{r}$ & $\mathbf{p}$ \\
\hline \%PC1 & $-\mathbf{0 . 9 5 3}$ & 0.000 & $-\mathbf{0 . 9 3 4}$ & 0.000 \\
rVE & $-\mathbf{0 . 6 5 0}$ & 0.020 & $-\mathbf{0 . 6 8 0}$ & 0.001 \\
Tamanho & -0.380 & 0.220 & -0.360 & 0.230 \\
Neurossomática & -0.316 & 0.316 & 0.052 & 0.867 \\
Facial & 0.088 & 0.787 & 0.359 & 0.228 \\
Neural & -0.319 & 0.312 & -0.300 & 0.319 \\
Oral & 0.445 & 0.147 & 0.438 & 0.135 \\
Nasal & 0.221 & 0.490 & 0.418 & 0.155 \\
Zigomática & 0.087 & 0.789 & 0.327 & 0.300 \\
Base & -0.369 & 0.238 & -0.450 & 0.123 \\
Abóbada & -0.047 & 0.885 & -0.003 & 0.993 \\
Total & 0.283 & 0.373 & 0.190 & 0.534 \\
\hline
\end{tabular}

Tabela 3.8 - Correlação de Pearson (r) e significância estatística (p) entre a flexibilidade evolutiva observada para os Xenarthra e outros 21 gêneros de mamíferos e as seguintes métricas: porcentagem de variância explicada pelo primeiro componente principal (\%PC1); logaritmo da magnitude geral de integração (rVE); avg+/avg- das diferentes hipóteses de modularidade. Valores em negrito foram significativos $(\mathrm{p}<0,05)$.

\begin{tabular}{ccc}
\hline & \multicolumn{2}{c}{ 35D } \\
& $\mathbf{r}$ & $\mathbf{p}$ \\
\hline \%PC1 & $\mathbf{- 0 , 9 4 4}$ & 0,000 \\
rVE & $\mathbf{- 0 , 7 5 5}$ & 0,000 \\
Neurossomática & $\mathbf{0 , 6 5 2}$ & 0,000 \\
Facial & 0,217 & 0,224 \\
Neural & 0,33 & 0,061 \\
Oral & $\mathbf{0 , 4 7 5}$ & 0,005 \\
Nasal & 0,077 & 0,671 \\
Zigomática & 0,149 & 0,409 \\
Base & 0,02 & 0,914 \\
Abóbada & $\mathbf{0 , 4 7 5}$ & 0,005 \\
Total & $\mathbf{0 , 7 2 3}$ & 0,000 \\
\hline
\end{tabular}




\section{Discussão}

Antes de iniciar a discussão propriamente dita, convém esclarecer ao leitor a relação entre o tamanho alométrico, a magnitude geral de integração e a nitidez dos módulos. Nos Xenarthra e nos demais mamíferos (Marroig et al., 2001, Oliveira et al., 2009; Porto et al., 2009) o primeiro componente principal representa, em geral, tamanho alométrico. A propriedade de um autovetor associado a tamanho alométrico é que todas, ou quase todas, as variáveis apresentam valores com o mesmo sinal. Isto implica que a tendência das variáveis é de ou todas aumentarem ou todas diminuírem conjuntamente. Em outras palavras, os caracteres de uma matriz sob o efeito do tamanho alométrico tendem a apresentar correlações positivas. Quanto maior a variação explicada pelo tamanho alométrico, mais intensas tenderão a ser as correlações. O inverso também é valido. Além disso, quanto maior a variação explicada pelo tamanho alométrico, mais homogêneas tenderão a ser as correlações.

A magnitude geral de integração para matrizes de correlação nada mais é do que a média das correlações ao quadrado entre os caracteres (Cheverud et al., 1989). Magnitudes gerais de integração elevadas significam que as correlações entre os caracteres representados na matriz tendem a ser mais fortes, sejam elas positivas ou negativas. No entanto, note que em mamíferos geralmente as correlações são positivas. Logo, magnitudes gerais de integração elevadas indicam correlações positivas mais fortes. Seguindo o mesmo raciocínio, magnitudes gerais de integração baixas implicam em correlações positivas mais baixas entre os caracteres. Outra forma de enxergar a mesma métrica é através da variância dos autovalores da matriz, segundo a equação abaixo (Pavlicev et al., 2009):

$$
r V E=\frac{\operatorname{Var}(\lambda)}{\operatorname{Var}_{\max }(\lambda)}
$$


onde $\operatorname{Var}(\lambda)$ representa a variância entre os autovalores da matriz em questão e $\operatorname{Var}_{\max }(\lambda)$ representa a variância máxima teórica dos autovalores. $\operatorname{Var}_{\max }(\lambda)$ é obtida ao considerar que toda a variância dos dados originais está contida apenas no primeiro autovalor. Sob a perspectiva dos autovalores, a magnitude geral de integração será maior quanto mais da variância total for explicada pelo primeiro autovalor. Em outras palavras, quanto maior o autovalor do primeiro componente principal, maior a magnitude geral de integração. Por outro lado, a magnitude geral de integração será menor, quanto mais distribuídas estiverem as variâncias explicadas por cada autovetor. Em relação às correlações da matriz, quanto mais variação for explicada pelo primeiro autovalor, mais intensas tenderão a ser as correlações da matriz. Como o primeiro autovalor nos mamíferos geralmente é tamanho alométrico, conclui-se que: quanto mais importante for o tamanho alométrico na determinação das relações dos caracteres de uma matriz, mais intensas e positivas tenderão a ser as correlações entre os caracteres e maior será a magnitude geral de integração.

Inserindo o conceito de módulos neste raciocínio, temos que: os módulos podem ser entendidos como a interação entre caracteres, sendo que alguns deles apresentam correlações mais intensas entre si (módulos) do que em relação a outros caracteres. Módulos nítidos, ou seja, avg+/avg- elevadas, são aqueles que apresentam grande distinção na intensidade das correlações dos caracteres dentro e entre os módulos. Por exemplo, a correlação média dentro dos módulos é de 0,8 e fora deles é de 0,2 . Já módulos pouco nítidos são os que as correlações dos caracteres dentro dos módulos são ligeiramente mais intensas do que os caracteres entre os módulos. Por exemplo, a correlação média dentro dos módulos é 0,9 (ou 0,3) e entre eles é 0,8 (ou 0,2). Ou seja, quanto mais discrepante for a intensidade das correlações dentro e entre módulos mais nítidos eles serão. Como apresentado anteriormente, o tamanho alométrico atua no sentido de 
homogeneizar as correlações entre os caracteres, logo, de diminuir a discrepância das correlações entre e dentro de módulos. Portanto, a relação entre tamanho alométrico, magnitude geral de integração e nitidez dos módulos é que quanto mais relevante for a variância explicada pelo tamanho (primeiro componente principal), maior será a magnitude geral de integração e menor será a nitidez dos módulos.

Tendo esclarecido isto, os resultados obtidos evidenciaram que o crânio dos Xenarthra está organizado de acordo com módulos, assim como diversas outras linhagens de mamíferos (Cheverud, 1996; Marroig e Cheverud, 2001; Ackermann e Cheverud, 2004; Goswami, 2006; Oliveira, 2009; Porto et al., 2009; Shirai e Marroig, 2010). Essa afirmação está baseada no fato que praticamente todas as matrizes empíricas dos gêneros se correlacionaram com ao menos uma das matrizes teóricas de modularidade. A única exceção foi Scelidotherium. Esse gênero não apresentou nenhum resultado significativo. No entanto, os resultados obtidos para Scelidotherium são, muito provavelmente, decorrentes de problemas amostrais e metodológicos. Por consequência, não refletem adequadamente aspectos da modularidade do grupo.

No Capítulo I foi mostrado que a magnitude geral de integração varia em função do tamanho amostral utilizado na estimativa da matriz. Quanto menor for a amostra, maior será o valor da magnitude geral de integração. Nos casos claramente subamostrados, como é a situação da matriz-P de Scelidotherium, este índice pode ser substancialmente maior que o valor obtido através de amostras grandes. A explicação para isso é que em matrizes mal estimadas em função de deficiências amostrais ocorre uma grande concentração de variância no primeiro componente principal. Esse acúmulo de variância é simplesmente em função do erro associado à amostragem (Marroig et al., 2012). Como apresentado anteriormente, há uma relação direta entre a porcentagem de variância explicada pelo primeiro componente principal e a magnitude geral de 
integração. A implicação dessa relação é que haverá uma inflação na magnitude geral de integração nas matrizes estimadas a partir de amostras pequenas. Em Scelidotherium, o primeiro componente principal representa tamanho alométrico. Portanto, nesse gênero, o componente principal relacionado ao tamanho explica grande parcela da variância. Isso tende a homogeneizar as correlações entre e dentro de módulos e dificultar a detecção dos módulos pelo teste utilizado (Porto et al., 2009). Além disto, quanto menor for a razão entre tamanho amostral e quantidade de caracteres medidos, pior é a representatividade da matriz estimada em relação aos parâmetros populacionais (Meyer e Kirkpatrick, 2008; Marroig et al., 2012). Simplesmente em função de erro amostral, pode ocorrer de correlações dentro de módulos serem inferiores aos valores encontrados na população, ou vice-versa. O mesmo fenômeno pode ocorrer em relação às covariações entre módulos. Essa questão por si só também pode contribuir para que os módulos sejam menos nítidos.

No geral, os gêneros de Xenarthra apresentaram um padrão de modularidade semelhante. Módulos nítidos foram identificados principalmente nas sub-regiões oral e nasal, mas também na face, no neurossomático e no total (considerando todas as sub-regiões conjuntamente). No entanto, alguns gêneros apresentaram algumas particularidades. As matrizes-P de Euphractus e Tolypeutes estiveram correlacionadas apenas com a hipótese de modularidade oral. Esses resultados não significam, contudo, que nesses grupos, ou em qualquer outro, só existam os módulos detectados no teste. A presença de módulos bastante evidentes, caracterizados por avg+/avg- elevados, dificulta a detecção de outros módulos (Marroig e Cheverud, 2001; Porto et al., 2009). Os módulos bastante evidentes possuem correlações altas dentro deles em comparação às correlações entre os demais módulos. Nas hipóteses de modularidade em que módulos bastante evidentes não são testados, ou seja, os caracteres deles são considerados como 
caracteres entre módulos, ocorrerá uma elevação das correlações entre módulos. Consequentemente, as correlações entre módulos se distanciarão da expectativa da matriz teórica de ausência de modularidade, ou seja, de correlação igual a zero. Em função disso, a detecção do padrão modular pelo teste empregado será mais difícil. Além disto, a nitidez dos demais módulos, a exceção do módulo conspícuo, diminuem pelo simples fato que a nitidez é determinada pela avg+/avg-. Quanto maior for avg- em relação à avg+, menor será o valor dessa razão.

Em estudos realizados com outros mamíferos (Porto et al., 2009; Shirai e Marroig, 2010), raramente detectou-se o módulo da sub-região da abóbada, pelo menos quando não se controlou as correlações para o efeito do tamanho do crânio (Shirai e Marroig, 2010). Nos Xenarthra, o único gênero com resultado significativo para a presença do módulo dessa sub-região foi Priodontes. Outra questão reforçada por este estudo foi que os resultados obtidos ampliaram o número de gêneros de mamíferos que não registraram modularidade na sub-região da base do crânio e para a qual a avg+/avg- apresentou valores relativamente baixos. Esse resultado favorece a interpretação que essa sub-região talvez não seja um módulo em si (Shirai e Marroig, 2010). Primeiro, sua origem é complexa. Parte dela se origina da mesoderme e parte da crista neural (Liemerman et al., 2000a). Segundo, ela seria uma região de integração entre a face e o neurocrânio (Lieberman et al., 2000b; Hallgrimsson et al., 2007). Terceiro, ela cumpre um papel de ligação importante entre o crânio e o resto do corpo via coluna vertebral. Isso porque o foramen magnun é uma característica dominante da base do crânio (Elbroch, 2006). Portanto, o esperado seria que o avg+/avg- fosse baixo, como foi observado nesse e em outros estudos (Porto et al., 2009; Shirai e Marroig, 2010). 
O desenvolvimento craniano nos Xenarthra é semelhante aos demais mamíferos eutérios (Hautier et al., 2011). Ao longo da ontogenia, o neurocrânio origina-se na mesoderme e tem seu desenvolvimento nos estágios iniciais, durante os períodos pré-natal e neonatal. Já a face, que tem origem na crista neural, se desenvolve em estágios posteriores, sob influência do hormônio do crescimento (Smith, 1996, 1997; Marroig e Cheverud, 2001; Ackermann e Cheverud, 2004; Hautier et al., 2011). Nos Xenarthra, os módulos da região da face, mais especificamente as subregiões oral e nasal, foram mais evidentes que todos os demais módulos testados (avg+/avgmais elevados). Em função disto, nessa magnaordem é provável que haja maior influência de fatores tardios do desenvolvimento do crânio na definição do padrão de modularidade do grupo, como o hormônio do crescimento (Marroig e Cheverud, 2001; Ackermann e Cheverud, 2004). A predominância desses módulos pode ser explicada pela possível importância da dieta na diversificação morfológica do grupo (Capítulo II). A sub-região oral está relacionada com a obtenção e processamento do alimento. Já a sub-região nasal com a localização do alimento, visto que os Xenarthra utilizam basicamente a olfação para localizá-los (Eisenberg e Redford, 1999). Módulos integrados nessas sub-regiões propiciam respostas mais coordenadas dos ossos envolvidos e das outras estruturas associadas a eles, potencialmente favorecendo as mudanças necessárias para a adaptação à dieta. Além disto, os Xenarthra começam a ingerir comidas sólidas relativamente cedo no seu desenvolvimento, ainda durante a primeira metade do período de lactação (Eisenberg e Redford, 1999; Langer, 2003). Esta condição do grupo sugere que a detecção, obtenção e processamento de alimentos sejam importantes desde estágios iniciais da vida extrauterina (Eisenberg e Redford, 1999; Langer, 2003). Essas sub-regiões do crânio, portanto, devem ser bastante enfatizadas ao longo de boa parte do desenvolvimento do animal, favorecendo maior nitidez dos seus módulos. A ênfase nessas partes do crânio ao longo do 
desenvolvimento pode também exercer restrições no desenvolvimento de outras regiões do crânio, diminuindo a nitidez de outros módulos (Smith, 1996, 1997; Porto et al., 2009), como os do neurocrânio.

Salienta-se, entretanto, que a região da face não foi identificada como um módulo em todos os gêneros. Isso se deve, provavelmente, por conta da sub-região zigomática, que computou valores baixos para a avg+/avg-. A não identificação da sub-região do zigomático como um módulo conspícuo não é coerente com o cenário apresentado acima. No arco zigomático se insere o masseter, um importante músculo relacionado à mastigação (Naples, 1982, 1999; Elbroch, 2006). Talvez, este resultado fosse esperado para os Vermilingua em função da drástica redução dessa estrutura e do masseter no grupo (Naples, 1999; observação pessoal). No entanto, para Folivora e Cingulata, que apresentam a região do arco zigomático bem desenvolvida (Naples, 1982; Smith e Redford, 1990), os resultados observados não eram esperados. Uma explicação para o resultado encontrado é que a sub-região zigomática é menos influenciada pelo tamanho alométrico que as demais sub-regiões da face. Embora tamanho alométrico tenha impacto sobre todas as correlações, ele não atua de forma uniforme sobre elas (Shirai e Marroig, 2010). Pelo menos para primatas e marsupiais do novo mundo, o módulo zigomático só foi detectado após a remoção do efeito do tamanho alométrico sobre as correlações dos caracteres (Shirai e Marroig, 2010). Outra alternativa é que as distâncias utilizadas para representar o módulo zigomático não são capazes de caracterizá-lo de forma apropriada. Consequentemente, não ocorre a identificação desse módulo pelo teste.

Os módulos neurossomático e total foram detectados em aproximadamente metade dos gêneros estudados. Isso sugere que os fatores do desenvolvimento envolvidos no começo da ontogenia craniana, mais relacionados ao neurocrânio, também sejam importantes na 
determinação do padrão modular nos crânios desse grupo (Marroig e Cheverud, 2001; Ackermann e Cheverud, 2004). O fato da região do neurocrânio ser um módulo menos conspícuos que a região facial pode ser explicado pelo desenvolvimento do neurocrânio, em especial da abóbada, estar atrelado ao desenvolvimento cerebral (Moore, 1981). Em mamíferos eutérios precoces, como os Xenarthra (Sibly e Brown, 2009), grande parcela do crescimento cerebral está relacionada a taxa de metabolismo basal e aos períodos de gestação e de amamentação. Quanto maior forem os valores desses três fatores, maior será o tamanho cerebral em relação à massa corporal do táxon (Weisbecker e Goswami, 2010). Os Xenarthra apresentam metabolismo basal baixo e períodos relativamente curtos de gestação e de amamentação (Eisenberg e Redford, 1999; Langer, 2003; McDonald, 2005). Por consequência, cérebros que se desenvolvem relativamente pouco e por um período de tempo curto. Potencialmente, portanto, há uma ênfase relativamente pequena no desenvolvimento dessa região que pode estar relacionado a uma menor nitidez desse módulo.

Colocando essa questão de outra forma, o tempo/energia do crescimento envolvido no desenvolvimento varia entre as diferentes regiões e sub-regiões do crânio. Portanto, também varia o impacto do tamanho alométrico nas correlações das diferentes partes do crânio. Como apresentado no início da seção discussão, quanto maior a variação explicada pelo tamanho alométrico, maiores tenderão a ser as correlações entre os caracteres. Nos Xenartha, a região da face apresenta tempo/energia do crescimento prolongado. Em função disso, ela será influenciada de forma acentuada pelo tamanho alométrico. Já o neurocrânio apresenta investimento menor em relação ao tempo/energia do crescimento. Logo, essa região será menos afetada pelo tamanho alométrico. Por consequência, a região da face apresenta correlações maiores entre seus caracteres do que a região do neurocrânio. 
Não existe aparente estruturação dos resultados do padrão modular em função da história filogenética do grupo (segundo proposta de Möller-Krull et al., 2007). Cingulata, Vermilingua e Folivora apresentaram os mesmos módulos como os mais conspícuos. Dentro de cada ordem/subordem/família ocorreram variações gênero a gênero entre os módulos detectados e suas intensidades. Por exemplo, dentre os Folivora, Paramylodon apresentou correlação com os módulos neurossomático, facial, oral, nasal e total, enquanto Bradypus e Choloepus somente com o oral e o nasal. No módulo nasal, inclusive, o avg+/avg- do gênero extinto foi aproximadamente duas vezes maior do que nos grupos atuais. Além da aparente ausência de estruturação filogenética nos resultados obtidos para o padrão, o tamanho dos crânios dos gêneros tampouco influiu na intensidade dos módulos. Em outras palavras, gêneros maiores ou menores em tamanho absoluto não geraram valores para a avg+/avg- em algum sentido específico, seja de elevar ou reduzir a razão. Por outro lado, existe uma correlação fraca entre a proximidade filogenética e a magnitude geral de integração. Grupos mais próximos filogeneticamente apresentam pequena tendência a apresentar valores mais próximos do que grupos distantes filogeneticamente.

A estreita e positiva correlação entre a magnitude geral de integração e a porcentagem de variância total explicada pelo primeiro componente principal reforça o raciocínio desenvolvido no começo da discussão. Quanto maior for a porcentagem da variância total explicada pelo primeiro componente principal, que representa tamanho do crânio, maior será a magnitude geral de integração. Dado que o tamanho apresenta o efeito de homogeneizar as correlações entre os caracteres, menos evidentes serão os módulos. Outra evidência dessa linha de argumentação foi a correlação negativa entre a magnitude geral de integração e a avg+/avg- em algumas hipóteses de 
modularidade (oral, nasal e total). Esse resultado sugere que quanto mais integrado for o crânio de um grupo (rVE elevado), menos evidentes serão os módulos (avg+/avg- baixos) e vice-versa.

As possíveis consequências evolutivas da porcentagem de variância total explicada pelo tamanho alométrico (\%PC1), da nitidez dos módulos (avg+/avg-) e da magnitude geral de integração na evolução dos fenótipos médios do grupo são que: quanto maior a contribuição do tamanho alométrico na determinação das relações da matriz-P de um táxon, menos alinhada tenderá a ser a resposta desse grupo a uma determinada pressão de seleção direcional, a não ser que ela ocorra justamente na direção do tamanho (Marroig e Cheverud, 2005, 2009; Hansen e Houle, 2008; Marroig et al., 2009). Isto porque a influência do tamanho tende a diminuir a nitidez dos módulos, ou seja, ocorrerá a diminuição do avg+/avg-. Com isso, promove-se a integração da estrutura como um todo, resultando na elevação da magnitude geral de integração. Por consequência, diminui-se a capacidade dessa estrutura em responder de forma mais alinhada a grande maioria das pressões seletivas (Porto et al., 2009; Marroig et al., 2009). Isso fica evidente nos resultados obtidos para a flexibilidade evolutiva. Essa estatística esteve forte e negativamente correlacionada principalmente a porcentagem de variância total explicada pelo tamanho alométrico, mas também a magnitude geral de integração. Ela também esteve positivamente correlacionada com diferentes hipóteses de modularidade, quando considerada a amostra de 33 mamíferos. Não foram constatadas correlações entre as hipóteses de modularidade e a flexibilidade evolutiva quando foram analisados somente os 12 Xenarthra. Esse resultado, no entanto, está provavelmente relacionado ao fato que quanto menor a amostra, maior deve ser a correlação para que ela seja considerada significativa (Sokal e Rohf, 1995). No caso do presente estudo estavamos lidando com apenas 12 pontos para o cálculo das correlações e, portanto, sem muito poder estatístico. 
Em resumo, a flexibilidade evolutiva mede a capacidade de uma determinada população responder de forma alinhada a diferentes pressões seletivas. Ela foi menor quando a contribuição do tamanho na determinação das relações entre os caracteres foi elevada e, consequentemente, a magnitude geral de integração foi alta e as avg+/avg- baixas e vice-versa. Sob essa perspectiva, os gêneros com maior capacidade de resposta alinhada a um eventual vetor de seleção direcional são Choloepus, Priodontes, Chaetophractus e Cyclopes. Por outro lado, Myrmecophaga, Tamandua, Dasypus e Euphractus responderiam, em média, de forma menos alinhada ao gradiente de seleção. Note que para Cyclopes, a afirmação acima só é valida se o valor obtido para 35D for desconsiderado. Como discutido no Capítulo I, a magnitude geral de integração para esse gênero em 35D é em função de problemas amostrais e não reflete o valor correto dessa estatística. Logo, faz sentido desconsiderá-lo. Salienta-se que a capacidade dos diferentes taxa de responder de forma mais ou menos alinhada às pressões seletivas pode ter influenciado a grande diversidade fenotípica observada nos Xenarthra. Isso porque para matrizes-P com o mesmo padrão de covariância, mas com magnitudes gerais de integração diferentes, a mesma pressão seletiva pode resultar em mudanças bastante diferentes nos fenótipos médios.

Os módulos mais evidentes detectados para os Xenarthra foram os mesmos que os identificados para os macacos do velho e do novo mundo e para outros mamíferos eutérios representantes de diversas ordens (Cheverud, 1996; Marroig e Cheverud, 2001; Ackermann e Cheverud, 2004; Oliveira, 2009; Porto et al., 2009; Shirai e Marroig, 2010). Essa semelhança no padrão de modularidade entre clados que divergiram a algumas dezenas de milhões de anos e evoluíram em contextos biogeográficos diferentes (Simpson, 1980; Marroig e Cheverud, 2001; Bininda-Emonds et al., 2007; Oliveira, 2009; O’Leary et al., 2013) sugere que: o padrão de modularidade dos mamíferos eutérios esteja relacionado a processos básicos de desenvolvimento 
e/ou de funções que sejam comuns aos diferentes grupos. Esses processos, por sua vez, devem ter sido mantidos por seleção estabilizadora atuando na manutenção dos efeitos pleiotrópicos responsáveis pela estruturação modular observada no nível fenotípico (Ehrich et al., 2003; Cheverud et al., 2004; Estes e Arnold, 2007; Kenney-Hunt et al., 2008; Wagner et al., 2008). Os Xenarthra, no entanto, apresentaram valores relativamente elevados para avg+/avg- em relação aos demais mamíferos eutérios, principalmente para as sub-regiões oral e nasal. Isso sugere que esses módulos sejam bastante conspícuos nesta magnaordem.

No entanto, diferenças no padrão modular e na nitidez dos módulos entre os mamíferos eutérios, metatérios e os monotremados (Goswami, 2006; Porto et al., 2009; Shirai e Marroig, 2010), ou mesmo diferenças pontuais dentro de clados de eutérios, indicam que a modularidade também evolua (Marroig e Cheverud, 2001; Ackermann e Cheverud, 2004; Wagner et al., 2007). No entanto, os resultados obtidos nesse e em outros trabalhos (Marroig e Cheverud, 2001; Oliveira et. al., 2009; Porto et al., 2009) mostram que: pelo menos dentre os eutérios, as mudanças aparentam ser mais frequentes no sentido de alterar a intensidade dos módulos mais nítidos e não de alterar quais são os módulos mais importantes.

Em outras palavras, o que evolui de maneira mais pronunciada é a magnitude geral de integração. A causa dessas mudanças pode estar atrelada a sua íntima relação com a porcentagem de variação total explicada pelo tamanho alométrico. Como apresentado anteriormente, variações no tempo/energia do crescimento ao longo da ontogenia dos grupos provavelmente influenciam o impacto do tamanho alométrico nas correlações entre os caracteres. Ou seja, ao mudar a proporção da variação total contida na morfologia craniana que é explicada pelo tamanho alométrico, altera-se os valores da magnitude geral de integração. Mudanças na magnitude geral de integração podem ser o resultado de deriva genética, seleção natural ou uma mescla de ambos 
(Jones et al. 2003). A magnitude geral de integração apresenta grande efeito no potencial evolutivo dos grupos. Portanto, é razoável pensar que a seleção atuou na diferenciação desse fator entre os distintos clados (Marroig et al., 2009). Uma explicação para a manutenção dos padrões das matrizes-P e variação nos valores da magnitude geral de integração pode ser que a seleção estabilizadora atua de forma mais intensa na manutenção dos módulos mais evidentes, mas é mais permissiva para a variação nas intensidades das correlações dos caracteres desses módulos. Pode ser também que a seleção direcional seja responsável pela variação existente entre as magnitudes gerais de integração.

Independentemente dos processos envolvidos na evolução da modularidade, para que ela evolua é necessário haver variabilidade genética na pleiotropia que, potencialmente, a determina. Isso porque a modularidade observada no nível fenotípico é provavelmente o reflexo da estruturação modular no nível genotípico, que, por sua vez, é condicionado por efeitos pleiotrópicos (Pavlicev et al., 2007; Wagner et al., 2008). Uma das possibilidades para geração de variação genética da pleiotropia é a epistasia diferencial atuando sobre os efeitos pleiotrópicos que determinam os módulos fenotípicos (Cheverud et al., 2004; Pavlicev et al., 2007). Para entender a epistasia diferencial, suponha um caso hipotético no qual os loci $\mathrm{X}$ e Y têm os possíveis efeitos nos caracteres A e B apresentados na Tabela 3.9. Para simplicidade, apenas os efeitos dos homozigotos foram apresentados. Como pode ser observado, o lócus X afeta o caráter B apenas quando o lócus $\mathrm{Y}$ é homozigoto recessivo, enquanto tem efeito no caráter A para qualquer homozigoto do lócus Y. Nesse exemplo, o padrão epistático é diferente para os dois caracteres no mesmo par de loci. Quando o alelo y for frequente na população, o lócus X apresenta efeito pleiotrópico em ambos os caracteres. Por outro lado quando a frequência do 
alelo y é baixa, o efeito do lócus X restringe-se ao caráter A. Portanto a evolução na frequência do lócus Y causa a evolução da pleiotropia expressa no lócus X (Cheverud et al., 2004).

Tabela 3.9 - Epistasia diferencial nos loci X e Y para os caracteres A e B.

\begin{tabular}{|c|c|c|}
\hline & \multicolumn{2}{|c|}{ Caráter A } \\
\hline & yy & YY \\
\hline $\mathbf{x x}$ & -2 & 0 \\
\hline \multirow[t]{3}{*}{$x x$} & 0 & 2 \\
\hline & \multicolumn{2}{|c|}{ Caráter B } \\
\hline & yy & YY \\
\hline$x x$ & -2 & 0 \\
\hline$X X$ & 0 & 0 \\
\hline
\end{tabular}

\section{Conclusões}

O crânio dos Xenarthra está organizado em módulos relacionados ao desenvolvimento e/ou a execução de função comum. A modularidade se mostrou mais conspícua na região facial. Em especial nas sub-regiões oral e nasal. No entanto, ela também foi detectada nas regiões neurossomática e total. A prevalência de módulos evidentes na região facial sugere que fatores tardios do desenvolvimento sejam mais importantes na ontogenia craniana do grupo.

A distinção (correlação significativa nos testes de modularidade) e a intensidade (avg+/avg-) dos módulos não estiveram correlacionadas com o tamanho absoluto dos crânios dos gêneros. Por outro lado, avg+/avg- correlacionou-se negativamente em alguns casos com a magnitude geral de integração, a qual esteve forte e positivamente correlacionada à porcentagem de variância total explicada pelo tamanho do crânio (\%PC1). As relações entre avg+/avg-, magnitude geral de integração e \% PC1 sugerem que: quanto maior a \%PC1, menos nítidos serão os módulos e mais intensa será a magnitude geral de integração. As possíveis consequências 
dessa relação na evolução dos fenótipos médios do grupo são que quanto maior a porcentagem da variância total explicada pelo tamanho do crânio, menos alinhadas, em média, serão as respostas evolutivas aos possíveis vetores de seleção direcional. De forma geral, essa magnaordem se mostrou, em termos da modularidade, semelhante aos demais mamíferos eutérios já estudados. Essa similaridade entre diversos grupos de mamíferos favorece a interpretação de que haja manutenção por seleção natural dos padrões de modularidade. Mesmo assim, foram detectadas diferenças entre os grupos estudados, sugerindo que esse padrão, embora conservado, evolua.

\section{Referências}

Ackermann, R.R., Cheverud, J.M., 2004. Morphological integration in primates evolution. Em: Pigliucci, M.,Preston, K. (Ed.), Phenotypic Integration. Oxford University Press, Oxford, pp. 302-309.

Berg, R.L., 1960. The ecological significance of correlation pleiades. Evolution 14, 171180.

Bininda-Emonds, O.R.P., Cardillo, M., Jones, K.E., MacPhee, R.D.E., Beck, R.M.D., Grenyer, R., Price, S.A., Vos, R.A., Gittleman, J.L., Purvis, A., 2007. The delayed rise of present-day mammals. Nature 446, 507-512.

Boag, P.T., Grant, P.R., 1981. Intense natural-selection in a population of Darwin's finches (Geospizinae) in the Galapagos. Science 214, 82-85.

Cheverud, J.M., 1982. Phenotypic, genetic, and environmental morphological integration in the cranium. Evolution 36, 499-516. 
Cheverud, J.M., 1995. Morphological integration in the Saddle-back Tamarin (Saguinusfuscicollis) cranium. American Naturalist 145, 63-89.

Cheverud, J.M., 1996. Quantitative genetic analysis of cranial morphology in the cottontop (Saguinus oedipus) and saddle-back (S. fuscicollis) tamarins. Journal of Evolutionary Biology 9, 5-42.

Cheverud, J.M., Ehrich, T.H., Vaughn, T.T., Koreishi, S.F., Linsey, R.B., Pletscher, L.S., 2004. Pleiotropic effects on mandibular morphology II: Differential epistasis and genetic variation in morphological integration. Journal of Experimental Zoology Part B: Molecular and Developmental Evolution 302B, 424-435.

Cheverud, J.M., Wagner, G.P., Dow, M.M., 1989. Methods for the comparative analysis of variation patterns. Systematic Zoology 38, 201-213.

Clune, J., Mouret, J., Lipson, H., 2013. The evolutionary origins of modularity. Proceedings of the Royal Society B 280, 20122863.

Ehrich, T.H., Vaughn, T.T., Koreishi, S., Linsey, R.B., Pletscher, L.S., Cheverud, J.M., 2003. Pleiotropic effects on mandibular morphology I. Developmental morphological integration and differential dominance. Journal of Experimental Zoology Part B-Molecular and Developmental Evolution 296B, 58-79.

Eisenberg, J.F., Redford, K.H., 1999. Mammals of the Neotropics, Volume 3: The Central Neotropics: Ecuador, Peru, Bolivia, Brazil. The University of Chicago Press, Chicago

Elbroch, M., 2006. Animal skulls: a guide to North American species. Stackpole Books, Mechanicsburg. 
Estes, S., Arnold, S.J., 2007. Resolving the paradox of stasis: Models with stabilizing selection explain evolutionary divergence on all timescales. American Naturalist 169, 227-244.

Freeman, S., Herron, J.C., 2007. Evolutionary Analysis. Peason Prentice Hall, New Jersey.

Futuyma, D.J., 2005. Evolution. Sinauer Associates, Inc., Sunderland, Massachusetts.

Goswami, A., 2006. Cranial modularity shifts during mammalian evolution. American Naturalist 168, 270-280.

Gardner, A.L., 2007. Mammals of South America: volume 1: Marsupials, Xenarthrans, Shrews, and Bats. The University of Chicago Press, Chicago and London.

Grant, P.R., Grant, B.R., 1995. Predicting microevolutionary responses to directional selection on heritable variation. Evolution 49, 241-251.

Haber, A., 2011. A comparative analysis of integration indices. Evolutionary Biology 38, 476-488.

Hallgrimsson, B., Lieberman, D.E., Liu, W., Ford-Hutchinson, A.F., Jirik, F.R., 2007. Epigenetic interactions and the structure of phenotypic variation in the cranium. Evolution $\&$ Development 9, 76-91.

Hansen, T.F., 2003. Is modularity necessary for evolvability?: Remarks on the relationship between pleiotropy and evolvability. Biosystems 69, 83-94.

Hansen, T.F., Houle, D., 2008. Measuring and comparing evolvability and constraint in multivariate characters. Journal of Evolutionary Biology 21, 1201-1219. 
Hautier, L., Weisbecker, V., Goswami, A., Knight, F., Kardjilov, N., Asher, R.J., 2011. Skeletal ossification and sequence heterochrony in xenarthran evolution. Evolution \& Development 13, 460-476.

Herrel, A., Podos, J., Huber, S.K., Hendry, A.P., 2005. Bite performance and morphology in a population of Darwin's finches: implications for the evolution of beak shape. Functional Ecology 19, 43-48.

Jones, A.G., Arnold, S.J., Borger, R., 2003. Stability of the G-matrix in a population experiencing pleiotropic mutation, stabilizing selection, and genetic drift. Evolution 57, 17471760.

Kenney-Hunt, J.P., Wang, B., Norgard, E.A., Fawcett, G., Falk, D., Pletscher, L.S., Jarvis, J.P., Roseman, C., Wolf, J., Cheverud, J.M., 2008. Pleiotropic patterns of quantitative trait loci for 70 murine skeletal traits. Genetics 178, 2275-2288.

Langer, P., 2003. Lactation, weaning period, food quality, and digestive tract differentiations in Eutheria. Evoultion 57, 1196-1215.

Lieberman, D.E., Ross, C.F., Ravosa, M.J., 2000a. The primate cranial base: Ontogeny, function, and integration. Yearbook of Physical Anthropology, Vol 43, 117-169.

Lieberman, D.E., Pearson, O.M., Mowbray, K.M., 2000b. Basicranial influence on overall cranial shape. Journal of Human Evolution 38, 291-315.

Marroig, G., Cheverud, J.M., 2001. A comparison of phenotypic variation and covariation patterns and the role of phylogeny. Ecology, and ontogeny during cranial evolution of new world monkeys. Evolution 55, 2576-2600. 
Marroig, G., Cheverud, J.M., 2005. Size as a line of least evolutionary resistance: Diet and adaptive morphological radiation in new world monkeys. Evolution 59, 1128-1142.

Marroig, G., Cheverud, J.M., 2009. Size and shape in Callimico and Marmoset skulls: allometry and heterochrony in the morphological evolution of small anthropoids. Em: Ford, S.M., Porter, L.M.,Davis, L.C. (Ed.), The smallest anthropoids: The marmoset/callimico radiation. . Springer, New York, pp. 331-353.

Marroig, G., de Vivo, M., Cheverud, J.M., 2004. Cranial evolution in sakis ( Pithecia , Platyrrhini ) II : evolutionary processes and morphological integration. Journal of Evolutionary Biology 17, 144-155.

Marroig, G., Shirai, L.T., Porto, A., de Oliveira, F.B., De Conto, V., 2009. The evolution of modularity in the mammalian skull II: evolutionary consequences. Evolutionary Biology 36, 136-148.

Marroig, G., Melo, D.A.R., Garcia, G., 2012. Modularity, noise, and natural selection. Evolution 66-5, 1506-1524.

McDonald, H.G., 2005. Paleoecology of extinct xenarthrans and the great American biotic interchange. Bulletin of the Florida Museum of Natural History 45, 313-333.

Meyer, K., Kirkpatrick, M. 2008. Perils of parsimony: properties of reduced-rank estimates of genetic covariance matrices. Genetics 180, 1153-1166.

Möller-Krull, M., Delsuc, F., Churakov, G., Marker, C., Superina, M., Brosius, J., Douzery, E.J.P., Schmitz, J., 2007. Retroposed elements and their flanking regions resolve the 
evolutionary history of xenarthran mammals (armadillos, anteaters, and sloths). Molecular Biology and Evolution 24, 2573-2582.

Moore, W.J., 1981. The mammalian skull. Cambridge, Cambridge University Press.

Naples, V.L., 1982. Cranial osteology and function in the tree sloths, Bradypus and Choloepus. American Museum Novitates 2739, 1-41.

Naples, V.L., 1999. Morphology, evolution and function of feeding in the giant anteater (Myrmecophaga tridactyla). Journal of Zoology 249, 19-41.

O’Leary, M.A., Bloch, J.I., Flynn, J.J., Gaudin. T.J., Giallombardo, A., Giannini, N.P., Goldberg, S.L., Kraatz, B.P., Luo, Z., Meng, J., Ni, X., Novacek, M.J., Perini, F.A., Randall, Z.S, Rougier, G.W., Sargis, E.J., Silcox, M.T., Simmons, N.B., Spaulding, M., Velazco, P.M., Weksler, M., Wible, J.R., Cirranello, A.L., 2013. The placental mammal ancestor and the postK-Pg radiation of placentals. Science 339, 662-667.

Oliveira, F.B.d., 2009. "Evolução do crânio dos macacos do Velho Mundo: uma abordagem de genética quantitativa." Unpublished $\mathrm{PhD}$ Thesis thesis, Universidade de São Paulo.

Oliveira, F.B., Porto, A., Marroig, G., 2009. Covariance structure in the skull of Catarrhini: a case of pattern stasis and magnitude evolution. Journal of Human Evolution 56, 417-430.

Olson, E.C., Miller, R.L., 1958. Morphological Integration. Chicago Press, Chicago.

Pavlicev, M., Cheverud, J.M., Wagner, G.P., 2009. Measuring morphological integration using eigenvalue variance. Evolutionary Biology 36, 157-170. 
Pavlicev, M., Kenney-Hunt, J.P., Norgard, E.A., Roseman, C.C., Wolf, J.B., Cheverud, J.M., 2007. Genetic variation in pleiotropy : differential epistasis as a source of variation in the allometric relationship between long bone lengths and body weight. Evolution 62, 199-213.

Pavlicev, M., Kenney-Hunt, J.P., Norgard, E.A., Roseman, C.C., Wolf, J.B., Cheverud, J.M., 2008. Genetic variation in pleiotropy: differential epistasis as a source of variation in the allometric relationship between long bone lengths and body weight. Evolution 62, 199-213.

Porto, A., Oliveira, F.B.D., Shirai, L.T., Conto, V.D., Marroig, G., 2009. The evolution of modularity in the mammalian skull I: morphological integration patterns and magnitudes. Evolutionary Biology 36, 118-135.

Price, T.D., Grant, P.R., Gibbs, H.L., Boag, P.T., 1984. Recurrent patterns of naturalselection in a population of Darwin's finches. Nature 309, 787-789.

R Development Core Team, 2011. A language and environment for statistical computing. R Foundation for Statistical Computing, Vienna, Austria.

Redford, K.H., Eisenberg, J.F., 1992. Mammals of the neotropics. The southern cone. Volume 2. Chile, Argentina, Uruguay, Paraguay. The University of Chicago Press, Chicago.

Schluter, D., 1996. Adaptive radiation along genetic lines of least resistance. Evolution 50, 1766-1774.

Shirai, L.T., Marroig, G., 2010. Skull modularity in neotropical marsupials and monkeys: Size variation and evolutionary constraint and flexibility. Journal of Experimental Zoology Part B-Molecular and Developmental Evolution 314B, 663-683. 
Sibly, R.M., Brown, J.H., 2009. Mammal Reproductive Strategies Driven by Offspring Mortality-Size Relationships. American Naturalist 173, E185-E199.

Simpson, G.G., 1980. Splendid isolation: The curious history of South American mammals. Yale University Press, New Haven and London.

Smith, K.K., 1996. Integration of craniofacial structures during development in mammals. American Zoologist 36, 70-79.

Smith, K.K., 1997. Comparative patterns of craniofacial development in Eutherian and Metatherian mammals. Evolution 51, 1663-1678.

Smith, K.K., Redford, K.H., 1997. The anatomy and function of the feeding apparatus in two armadillos (Dasypoda): anatomy is not destiny. Journal of Zoology 222, 27-47.

Sokal, R., Rohf, F.J., 1995. Biometry. W H Freeman and Company, New York.

Steppan, S.J., Phillips, P.C., Houle, D., 2002. Comparative quantitative genetics: evolution of the G matrix. Trends in Ecology \& Evolution 17, 320-327.

Wagner, G.P., Kenney-Hunt, J.P., Pavlicev, M., Peck, J.R., Waxman, D., Cheverud, J.M., 2008. Pleiotropic scaling of gene effects and the 'cost of complexity'. Nature 452, 470-473.

Weisbecker, V., Goswami, A., 2010. Brain size, life history, and metabolism at the marsupial/placental dichotomy. Proceedings of the National Academy of Science 107, 1621616221.

Young, N.M., Hallgrimsson, B., 2005. Serial homology and the evolution of mammalian limb covariation structure. Evolution 59, 2691-2704. 


\section{Capítulo IV - A dieta e a extinção dos Xenarthra fósseis do Quaternário Tardio}

\section{Introdução}

A causa (ou causas) da extinção dos mamíferos de grande porte (megafauna) do final do Quaternário vem sendo debatida desde o século XIX (Grayson, 1984; Koch e Barnosky, 2006; Rule et al., 2012). As hipóteses atuais variam entre as que favorecem a ação do homem como principal causa desse fenômeno, seja direta ou indiretamente, até as que defendem que variações ambientais tiveram papel fundamental na extinção desses animais (Koch e Barnosky, 2006). A ação humana direta é comumente interpretada como caça e a ação humana indireta como, por exemplo, alteração da paisagem e introdução de predadores. A diversidade de propostas para explicar esse evento global mostra a ausência de consenso quanto aos processos envolvidos no desaparecimento dessa fauna. Para a América do Sul, por exemplo, existe uma grande gama de hipóteses para explicar essa extinção.

Registros paleontológicos da megafauna brasileira foram utilizados para argumentar que a extinção ocorreu ao final do Pleistoceno devido a condições frias e secas do último máximo glacial (Cartelle, 1999). Dados do Equador, por outro lado, sugerem que uma fase árida seguida por elevação na umidade durante o final do Pleistoceno e o início do Holoceno foram a principal causa da extinção da megafauna (Ficcarelli et al., 2003). De Vivo e Carmignotto (2004) buscaram a resposta dessa extinção através da comparação da fauna atual e extinta da América do Sul e da África. Eles sugeriram que um aumento na proporção de fisionomias vegetais fechadas, em resposta a elevação na umidade ao final do Pleistoceno e início do Holoceno, resultou na extinção dos mamíferos de grande porte. Por outro lado, Steadman e colaboradores (2005) compilaram dados da distribuição cronológica das preguiças terrestres nas Américas. Eles 
concluíram que a caça humana foi o pivô da extinção desses animais e talvez outros mamíferos na América do Sul. Outros estudos (Cione et al., 2003, 2009) propuseram que variações climáticas do final do Pleistoceno e início do Holoceno limitaram os hábitats favoráveis a existência da megafauna. Isso fez com que essa fauna ficasse mais propensa a extinção, principalmente em função da caça humana. Barnosky e Lindsey (2010) também favoreceram o efeito sinérgico entre o homem e as variações climáticas como causadores da extinção dessa fauna. Segundo os autores, o impacto humano associado às rápidas alterações climáticas do final do Pleistoceno e início do Holoceno foi a causa da extinção. Por último, também foi sugerido que patógenos foram os causadores dessa extinção (Ferigolo, 1999).

Grande parte da discordância entre as hipóteses para explicar esse evento de extinção está relacionada à ampla necessidade de se gerar conhecimento sobre: 1) a distribuição cronológica e geográfica e a ecologia (autoecologia e sinecologia) das espécies extintas e do Homo sapiens; e 2) compreender as mudanças climáticas ao longo do Pleistoceno e do Holoceno (Barnosky et al., 2004; Koch e Barnosky, 2006). Uma das áreas do conhecimento citada acima para a qual estudos são particularmente escassos é a ecologia da megafauna. A carência de conhecimento nessa área se deve pelo menos a dois motivos. Primeiro, porque dispõe-se apenas de fósseis, o que dificulta encontrar material em condições apropriadas para estudo. Essa limitação também exige a adoção de formas alternativas de análises, diferentes das comumente utilizadas em estudos ecológicos com espécies atuais. $\mathrm{O}$ espectro de métodos utilizados para estudos paleoecológicos variam entre análises morfológicas, biomecânicas, de isótopos estáveis, de DNA e de relações tróficas (MacFadden, 2005; Vizcaino et al., 2008; Ramakrishnan e Hadly, 2009; Vizcaino et al., 2009). Segundo, devido à impossibilidade de utilizar o conhecimento sobre grupos modernos como fonte de informação para entender grupos extintos, já que a grande maioria das espécies extintas 
não possui um análogo atual (Vizcaino et al., 2009). Em outras palavras, é difícil adotar o princípio do atualismo, o qual diz que eventos/formas do passado podem ser compreendidos através da analogia com eventos/formas do presente.

A fonte mais abundante de dados sobre os fósseis do Quaternário são os ossos, devido a relativa facilidade deles serem preservados no registro sedimentar (Simpson, 1980; Paula Couto, 1979). Portanto, a maioria das informações paleoecológicas existentes sobre a megafauna são provenientes desse tipo de material. O princípio da correlação entre forma e função diz que uma determinada função pode ser inferida através da forma (Radinsky, 1987). Ossos são estruturas propícias para a utilização desse princípio (Vizcaino et al., 2008). O crânio dos mamíferos é um bom exemplo desse princípio. Sua morfologia, ou a morfologia de suas partes tem relação com diferentes capacidades de obter e de processar alimentos, de enxergar, de escutar, de cheirar, entre outras (Elbroch, 2006).

A partir de análises morfofuncionais baseadas justamente nos ossos, agregou-se, nas últimas décadas, quantidade considerável de informações sobre a paleoecologia dos Xenarthra fósseis. Pelo menos se levar em consideração o conhecimento existente para os demais mamíferos extintos nas Américas durante o final do Quaternário (Toledo, 1998; Bargo, 2003; Vizcaino et al., 2008; Vizcaino et al., 2009). Dos Xenarthra, Folivora e Cingulata foram melhor estudados devido a sua abundância fóssil, e atualmente acredita-se que: 1) eles apresentavam grande variedade de peso, da ordem de um kg até seis toneladas (Vizcaino et al., 2008); 2) apresentavam ampla gama de padrões locomotores e eram capazes de cavar o substrato em diferentes níveis, sendo atribuído tanto a preguiças quanto a tatus a construção de grandes condutos subterrâneos (paleotócas e crotovinas; Toledo, 1998; Bargo et al., 2000; Buchmann et al., 2009); e 3) exibiam exacerbada diversidade no tipo de dieta (folhas de árvores, gramíneas, 
frutos, tubérculos, raízes) e na forma de se alimentar, variando entre muito seletivos e pouco seletivos (Ruez, 2005; Bargo et al., 2006a; Bargo et al., 2006b; Green, 2009). Esses trabalhos, no entanto, foram geralmente baseados em amostras pequenas e pouco compreensivas da diversidade atual e extinta dos Xenarthra.

No intuito de contribuir para uma melhor compreensão da ecologia desses animais extintos, esse capítulo teve por objetivo realizar novas inferências funcionais sobre os hábitos alimentares de algumas espécies extintas de Xenarthra Quaternários. De forma mais específica, objetivou-se: 1) inferir os hábitos alimentares dos gêneros extintos através da comparação da forma craniana deles, tanto considerando tamanho quanto removendo-o, com os grupos atuais; e 2) confrontar os resultados obtidos com os dados disponíveis na literatura para as espécies estudadas ou de linhagens próximas a elas. O diferencial das análises desenvolvidas nesse capítulo em relação ao demais trabalhos já realizados foi utilizar uma amostra abrangente (e numerosa) de Xenartros atuais e extintos e conciliar análises de morfometria clássica e geométrica em 3D. A técnica em 3D foi uma abordagem inédita na tentativa de melhor compreender a paleoecologia dos Xenarthra.

\section{Material}

As análises de morfometria clássica e geométrica foram realizadas com base na mesma amostra. A partir de um banco de dados que contava com 2667 crânios medidos, selecionou-se somente uma espécie para representar cada gênero atual nas análises subsequentes. A espécie escolhida foi a melhor amostrada dentre cada gênero. Essas espécies foram classificados, segundo a literatura (Redford, 1985; Redford e Eisenberg, 1992; Eisenberg e Redford, 1999; 
Gardner, 2007), em uma das seguintes categorias de dieta: folivoro, folívoro-frugívoro, carnívoro-onívoro ou insetívoro (Tabela 4.1).

Já em relação aos fósseis, os espécimes contendo todos os marcos anatômicos estudados foram incluídos nas análises (Tabela 4.2). Por todos marcos anatômicos subentende-se apresentar os pontos unilaterais e ao menos um dos pontos dos marcos anatômicos bilaterais. Um problema do registro fóssil é a imperfeição da amostra devido a diversos fatores tafonômicos que agem nos ossos e em pacotes fossilíferos (Holz e Simões, 2002). Como consequência disso, não foi possível obter uma amostra uniforme, grande e representativa da diversidade fóssil de Xenarthra. Neste estudo, somente os Folivora fósseis foram relativamente bem amostrados. Os Cingulata foram representados por apenas uma espécie. Os Vermilingua fósseis não foram estudados (Tabela 4.1). Em virtude disso, foram privilegiadas análises considerando apenas os Folivora e Cingulata, tanto fósseis quanto atuais. Isso porque Vermilingua apresenta morfologia muito peculiar e adaptações muito específicas em relação aos seus hábitos alimentares mirmecófagos, como alongamento acentuado do rostro, ausência de dentes, simplificação da mandíbula e redução da musculatura associada à mastigação (Eisenberg e Redford, 1999; Gardner, 2007). De qualquer forma, foram realizadas algumas análises considerando os Vermilingua na amostra para avaliar as consequências da exclusão desse grupo na determinação da dieta dos grupos fósseis.

Ao todo foram analisados 935 crânios de espécimes adultos pertencentes a 21 espécies (ver Tabela 4.1 para detalhes quanto aos taxa e suas respectivas amostras). Animais foram considerados adultos quando apresentaram o basisfenóide fusionado ao basioccipital e a textura dos ossos lisa e uniforme (Cheverud, 1995; Elbroch, 2006; Porto et al., 2009). Os crânios analisados neste trabalho estão tombados nas seguintes instituições: American Museum of Natural History (AMNH, Nova York, EUA), California Academy of Science (CAS, São 
Francisco, EUA), Faculdad de Ciencias de la Universidad de la Republica (FC, Montevideo, Uruguai), Field Museum of Natural History (FMNH, Chicago, EUA), Museu Paraense Emílio Goeldi (MPEG, Belém, Brasil), Idaho Museum of Natural History (IMNH, Pocatelo, EUA), Los Angeles County Museum (LACM, Los Angeles, EUA), Page Museum (LACMHC, Los Angeles, EUA), Museo Argentino de Ciencias Naturales (MACN, Buenos Aires, Argentina), Museu de Ciências Naturais da PUC-MINAS (MCN, Belo Horizonte, Brasil), Museu de Ciências Naturais da Fundação Zoobotânica do Rio Grande do Sul (MCNRGS, Porto Alegre, Brasil), Museo de La Plata (MLP, La Plata, Argentina), Museu Nacional de Historia Natural de Montevideo (MNHN, Montevideo, Uruguai), University of California Museum of Vertebrate Zoology (MVZ, Berkeley, EUA), Museu de Zoologia da Universidade de São Paulo (MZUSP, São Paulo, Brasil), Natural History Museum (NHM, Londres, Inglaterra), University of California Museum of Paleontology (UCMP, Berkeley, EUA), Florida Museum of Natural History (UF, Gainesville, EUA), Smithsonian National Museum of Natural History (USNM, Wahington DC, EUA). Além do material depositado nestas instituições, foram medidos seis crânios de coleções particulares (dois de Mauro Teixeira - São Paulo, Brasil e quatro de Paulo Auricchio - São Paulo, Brasil). 
Tabela 4.1 - Espécies analisadas com respectivas dietas e amostras para os diferentes conjuntos de marcos anatômicos (crânio, crânio-IS, face e face-IS; ver detalhes dos conjuntos no texto) e para o conjunto de distâncias 25D.

\begin{tabular}{|c|c|c|c|c|c|c|c|c|}
\hline $\begin{array}{l}\text { Ordem/ } \\
\text { Subordem }\end{array}$ & Família & Espécie & Dieta & Crânio & Crânio-IS & Face & Face-IS & 25D \\
\hline Cingulata & Dasypodidae & Cabassous unicinctus & insetívoro & 20 & 20 & 20 & 20 & 20 \\
\hline Cingulata & Dasypodidae & Chaetophractus vellerosus & $\begin{array}{l}\text { carnívoro- } \\
\text { onívoro }\end{array}$ & 32 & 32 & 32 & 32 & 32 \\
\hline Cingulata & Dasypodidae & Dasypus novencinctus & $\begin{array}{l}\text { carnívoro- } \\
\text { onívoro }\end{array}$ & 159 & 159 & 159 & 159 & 159 \\
\hline Cingulata & Dasypodidae & Euphractus sexcinctus & $\begin{array}{l}\text { carnívoro- } \\
\text { onívoro }\end{array}$ & 67 & 67 & 67 & 67 & 67 \\
\hline Cingulata & Dasypodidae & Priodontes maximus & insetívoro & 16 & 16 & 16 & 16 & 16 \\
\hline Cingulata & Dasypodidae & Tolypeutes matacus & insetívoro & 21 & 21 & 21 & 21 & 21 \\
\hline Cingulata & Dasypodidae & Zaedyus pichiy & $\begin{array}{l}\text { carnívoro- } \\
\text { onívoro }\end{array}$ & 23 & 23 & 23 & 23 & 23 \\
\hline Cingulata & Pampatheriidae & Holmesina floridenus & - & 1 & 1 & 1 & 1 & 1 \\
\hline Vermilingua & Cyclopedidae & Cyclopes didactylus & insetívoto & - & 62 & 6 & 91 & 91 \\
\hline Vermilingua & Myrmecophagidae & Tamandua tetradactyla & insetívoto & 79 & 79 & 79 & 79 & 79 \\
\hline Vermilingua & Myrmecophagidae & Myrmecophaga tridactyla & insetívoto & 19 & 57 & 20 & 85 & 85 \\
\hline Folivora & Bradypodidae & Bradypus variegates & folívoro & 38 & 112 & 39 & 115 & 115 \\
\hline Folivora & Megalonychidae & Choloepus hoffmanni & $\begin{array}{l}\text { folívoro- } \\
\text { frugívoro }\end{array}$ & 18 & 29 & 19 & 31 & 31 \\
\hline Folivora & Megatheriidae & Megatherium sp. & - & - & 1 & - & 1 & 1 \\
\hline Folivora & Megalonychidae & Megalonyx jeffersoniil & - & 1 & 2 & 1 & 2 & 2 \\
\hline Folivora & Megalonychidae & Megalonyx leptostomus & - & 1 & 1 & 1 & 1 & 1 \\
\hline Folivora & Megalonychidae & Neocnus Dousman & - & - & 1 & - & 1 & 1 \\
\hline Folivora & Nothrotheriidae & Nothrotherium maquinense & - & - & 1 & - & 1 & 1 \\
\hline Folivora & Nothrotheriidae & Nothrotheriops shastensis & - & 1 & 5 & 1 & 5 & 5 \\
\hline Folivora & Mylodontidae & Paramylodon harlani & - & 2 & 30 & 2 & 32 & 32 \\
\hline Folivora & Mylodontidae & $\begin{array}{l}\text { Scelidotherium } \\
\text { leptocephalum }\end{array}$ & - & 4 & 6 & 4 & 6 & 6 \\
\hline
\end{tabular}

\section{Marcos Anatômicos e Distâncias}

De cada crânio foram tomadas coordenas em três dimensões de 41 pontos com um digitalizador Microscribe (MX ou MLX) em duas mensurações independentes. Os pontos são, via de regra, homólogos entre os gêneros estudados. No entanto, a determinação de alguns deles variou de acordo com o táxon. ZI e ZYGO foram considerados como tendo apenas homologia parcial entre todos os taxa (ver detalhes na Tabela 4.2). 
Tabela 4.2 - Definição dos pontos coletados nos crânios de Xenarthra.

\begin{tabular}{|c|c|}
\hline Ponto & Descrição \\
\hline \multicolumn{2}{|l|}{ Sagitais } \\
\hline IS & extremidade anterior da sutura entre os pré-maxilares \\
\hline NSL & extremidade anterior da sutura entre os nasais \\
\hline NA & sutura entre frontais e nasais \\
\hline BR & sutura entre frontais e parietais \\
\hline LD & sutura entre parietais e supra-occipital \\
\hline BA & ponto sagital ventral da margem do forâmen magno \\
\hline OPI & ponto sagital dorsal da margem do forâmen magno \\
\hline PNS & extremidade posterior da sutura entre os palatinos \\
\hline NU & ponto extremo da protuberância occipital externa \\
\hline \multicolumn{2}{|l|}{ Bilaterais } \\
\hline PM & extremidade latero-ventral da sutura entre pré-maxilar e maxilar \\
\hline ZS & sutura entre lacrimal, maxilar e jugal \\
\hline PT & sutura entre frontal, parietal e esquamosala ${ }^{a}$ ou alisfenóide ${ }^{b}$ \\
\hline TSP & sutura entre esquamosal, alisfenóide e parietal ${ }^{a}$ ou frontal ${ }^{b}$ \\
\hline AS & sutura entre esquamosal, parietal e supra-occipital \\
\hline $\mathrm{ZI}$ & extremidade ventral da sutura entre maxilar e jugal $^{c}$ \\
\hline MT & extremidade ventro-posterior da sutura entre maxilar e palatino \\
\hline APET & extremidade lateral da sutura entre baseoccipital e basesfenóide \\
\hline $\mathrm{JP}$ & extremidade ventral da sutura entre baseoccipital e esquamosal no foramen jugular \\
\hline TS & extremidade posterior da sutura entre esquamosal e alisfenóide \\
\hline EAM & meato auditivo externo anterior \\
\hline ZYGO & extremidade ventral da sutura entre esquamosal e jugal $^{d}$ \\
\hline CMZYGO & $\begin{array}{c}\text { extremo caudal da crista de inserção muscular associada ao início do processo zigomático do } \\
\text { esquamosal }\end{array}$ \\
\hline LFM & extremo lateral do foramen magnum, dorsalmente ao côndilo do occipital \\
\hline LNA & encontro das suturas entre os ossos nasal, frontal e maxilar ${ }^{\mathrm{e}}$ \\
\hline LNSL & extremo lateral do início da cavidade nasal \\
\hline \multicolumn{2}{|c|}{ aem Cingulata, Megalonychidae e Mylodontidae. } \\
\hline \multicolumn{2}{|c|}{ cem Cyclopes, extremidade latero-ventral do braço maxilar do arco zigomático. } \\
\hline e em & Mo frontol podo cor cubstituído polo \\
\hline
\end{tabular}



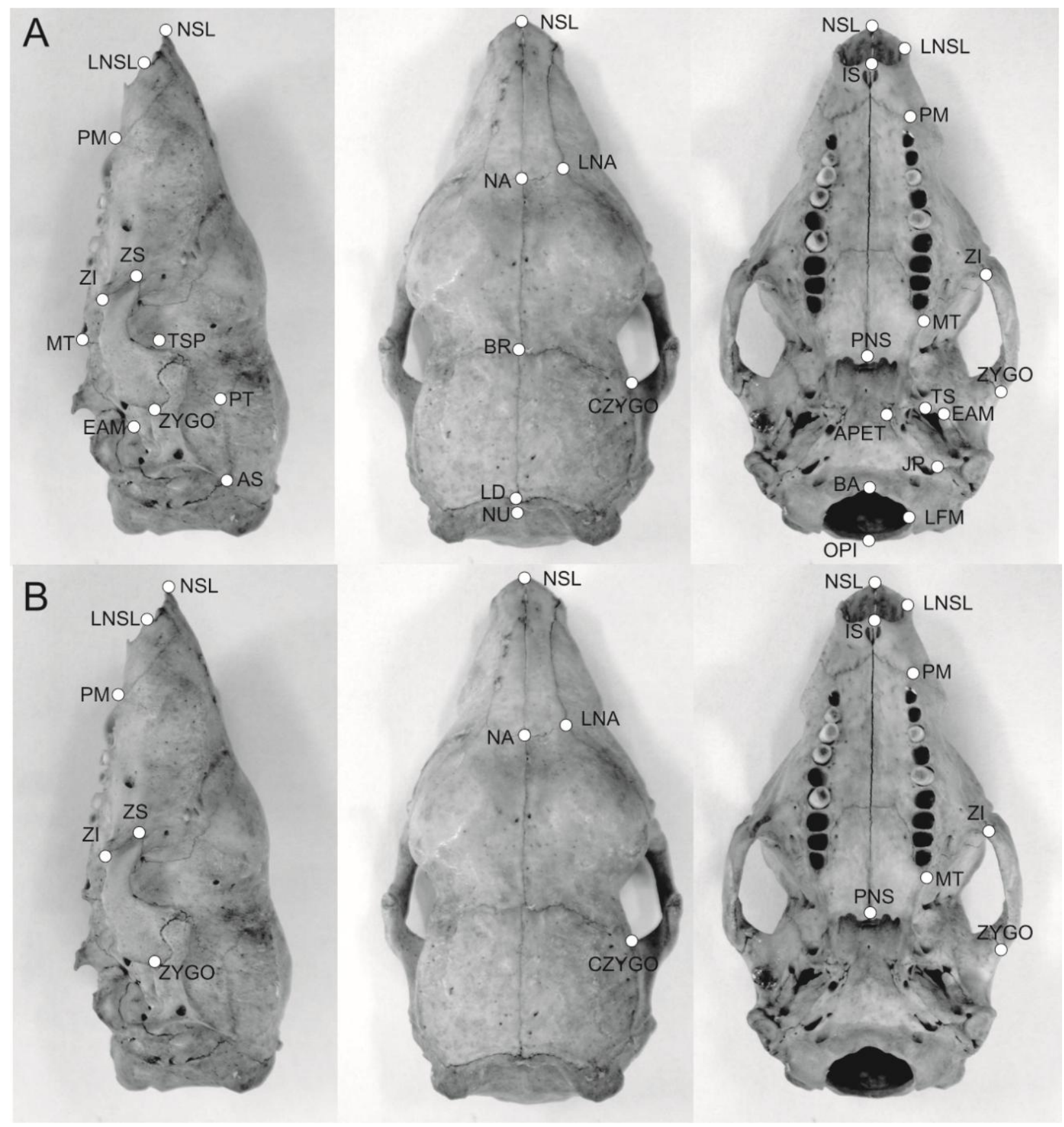

Figura 4.1 - Representação em crânio de Cabassous (tatu de rabo mole) dos pontos utilizados. Da esquerda para a direita, vistas lateral, dorsal e ventral. Nas vistas dorsal e ventral os pontos bilaterais estão representados apenas do lado direito da imagem. A: pontos do conjunto crânio; B: pontos do conjunto face.

As análises de morfometria geométrica foram realizadas através de dois conjuntos distintos de marcos anatômicos. O primeiro deles compreendeu os 41 pontos coletados e distribuídos ao longo de todo o crânio (Figura 4.1A; Tabela 4.2). O segundo representou apenas 
a região anatômica relacionada mais especificamente com a função alimentar (Figura 4.1B; Tabela 4.2), através de 20 desses 41 pontos. Esses conjuntos de pontos foram nomeados crânio e face, respectivamente. A justificativa de analisar somente os pontos mais diretamente relacionados com a face advém da ideia que estudar regiões mais especificamente relacionadas com a função de interesse podem gerar resultados mais precisos (Vizcaino et al., 1998, 2008).

Como em Folivora o pré-maxilar é frouxamente ligado ao maxilar, muitos espécimes analisados não apresentaram esse osso. Ao medi-los não foi possível coletar as coordenadas do ponto IS (ver maiores detalhes no Capítulo I). Devido à decisão adotada neste trabalho de utilizar somente espécimes sem dados faltantes e visando maximizar a amostra, dois novos conjuntos de pontos baseados em crânio e face foram criados, em que o ponto IS não foi considerado. Eles foram denominados crânio-IS e face-IS, respectivamente. Além da exclusão do IS, nesses dois novos conjuntos os pontos ZYGO e CZYGO também foram excluídos. Em muitos fósseis medidos eles estiveram ausentes. Todas as análises subsequentes foram realizadas com os quatro conjuntos de pontos (crânio, crânio-IS, face, face-IS).

Utilizando o mesmo procedimento apresentado no Capítulo I, para os espécimes extintos os pontos bilaterais ausentes em apenas um dos lados foram representados pelo espelhamento do ponto do outro lado.

A qualidade das medidas de cada espécime foi avaliada graficamente. Em primeiro lugar, os efeitos de rotação e translação entre as duas mensurações de cada crânio foram removidos através da superposição de Procrustes (Rohlf e Slice, 1990; Zeldich et al., 2004). Em seguida, os pontos de uma das mensurações foram plotados em relação aos da outra mensuração (alvo e referência). A partir da imagem formada foi possível observar a posição relativa dos marcos anatômicos homólogos no respectivo morfoespaço. Quando um indivíduo apresentou algum 
ponto com coordenadas muito discrepantes de uma medida em relação à outra ele foi removido das análises.

Para a morfometria clássica, as análises foram realizadas no conjunto de distância 25D apresentado no Capítulo I. A amostra foi a mesma utilizada nas análises de morfometria geométrica.

\section{Morfometria Geométrica}

Após avaliar graficamente a qualidade das medidas, cada crânio passou a ser representado pela média da forma e do tamanho entre as duas mensurações e entre os pontos bilaterais. Essa nova configuração foi utilizada nas análises subsequentes. Ou seja, o restante dos estudos foi conduzido utilizando apenas coordenadas de metade de um crânio, que representam a forma média entre as duas medidas e os dois lados do crânio. Para obter essa nova representação do crânio, foram realizados os seguintes procedimentos. Primeiro, obteve-se a forma e o tamanho médios entre as duas medidas de cada crânio após a superposição de Procrustes. Segundo, a partir desses, cada crânio foi dividido nas metades direita e esquerda. Cada uma delas continha os pontos da linha sagital e os respectivos pontos laterais. Terceiro, para remover os efeitos da assimetria craniana, foi produzida a imagem espelhada do lado direito do crânio. Em seguida, a ela foi sobreposta, por Procrustes, os pontos originais do lado esquerdo. Por último, foi obtida a média da forma e do tamanho, produzindo uma forma perfeitamente simétrica (Klingenberg et al., 2002) e representativa de metade de um crânio.

Com base nessa nova configuração dos marcos anatômicos dos espécimes foi realizada a superposição de Procrustes de todos os espécimes analisados conjuntamente. A partir da análise de componentes principais realizada após a projeção das coordenadas originais no espaço tangente da forma foram armazenados os autovalores e os autovetores (Rohlf, 1998; Monteiro e 
Reis, 1999; Zeldich et al., 2004) e os tamanhos dos centroides (CS). O tamanho do centroide é definido como a raiz quadrada da soma das distâncias quadradas de todos os marcos anatômicos até o centro geométrico (Zelditch et al., 2004). A quantidade de autovetores utilizados nas análises subsequentes correspondeu ao número de autovetores necessários para que a soma cumulativa da variância total explicada atingisse 95\% da variância total (Hair et al., 2010). Para os conjuntos crânio e crânio-IS esse número correspondeu a 10. Para face e face-IS, a seis.

\section{Morfometria Tradicional}

Nas análises de morfometria tradicional as 25 distâncias foram usadas diretamente nas análises, sem a necessidade de qualquer tipo de tratamento adicional.

\section{Análise Discriminante}

A análise discriminante linear foi utilizada para explorar a relação da forma, com e sem tamanho, com as categorias de dieta. Análises a partir de diferentes conjuntos de dados foram realizadas, sendo eles: 1) crânio, crânio-IS, face e face-IS desconsiderando o tamanho do centroide e Vermilingua; 2) face-IS considerando o tamanho do centroide e desconsiderando Vermilingua; 3) face-IS considerando o tamanho do centroide e Vermilingua; e 4) 25D considerando o tamanho do crânio e Vermilingua.

A disparidade no número de indivíduos e gêneros nas categorias de dieta enviesa as análises em função das categorias melhor amostradas (Zuur et al., 2007; Hair et al., 2010). Para circundar esse problema, adotou-se a seguinte estratégia: partindo da categoria de dieta com menor amostra, sorteou-se o mesmo número de indivíduos dela das demais categorias. Assim todas as categorias de dieta foram analisadas com uma mesma quantidade de espécimes. A categoria de dieta pior amostrada foi folívoro-frugívoro, que apresentou amostra de 18, 29, 19, 
31 e 31 indivíduos para os conjuntos de distância crânio, crânio-IS, face, face-IS e 25D, respectivamente (Tabela 4.1). Como as categorias de dieta insetívoros e carnívoro-onívoros apresentaram mais que um gênero, realizou-se o procedimento de reamostragem 500 vezes. O objetivo desse procedimento foi comparar os resultados obtidos e verificar sua congruência. Gêneros distintos, mesmo pertencentes a uma mesma classe de dieta, podem teoricamente alterar os resultados obtidos.

As duas primeiras funções discriminantes geradas para cada uma das 500 reamostragem foram empregadas para classificar os espécimes fósseis quanto às categorias de dieta. Apenas as duas primeiras funções foram utilizadas, pois em todos os conjuntos de marcos anatômicos (crânio, crânio-IS, face, face-IS e 25D) elas explicaram aproximadamente 95\% da variação total. A frequência com que cada espécime foi classificado em determinada categoria de dieta foi computada.

A capacidade das funções discriminantes em corretamente classificar espécimes nas distintas categorias de dieta foi acessada através da validação cruzada. Essa validação foi realizada da seguinte forma: excluiu-se um espécime por vez do banco de dados e calculou-se as funções discriminantes com base nos n-1 indivíduos. Em seguida, a partir das funções discriminantes obtidas foi feita a previsão da categoria de dieta do espécime excluído. Esse procedimento foi realizado para todos os espécimes utilizados na determinação da função discriminante. Em seguida foi determinada a proporção de casos em que o espécime foi corretamente classificado através da validação cruzada (Zuur et al., 2007). Essa validação consiste simplesmente em classificar cada observação sem ter a influencia dela na obtenção das funções discriminantes. Quanto maior o valor da validação cruzada, mais confiáveis são as funções discriminantes obtidas através do conjunto completo de dados em classificar indivíduos. 
Cada componente principal utilizado nas análises discriminantes foi correlacionado com o logaritmo do CS para avaliar o efeito alométrico (Chen et al., 2005). A contribuição de cada variável na determinação das funções discriminantes foi avaliada através da carga discriminante (ou escore canônico). Para tanto, se correlaciona os escores das funções discriminantes com cada variável original. As variáveis em que a correlação foi maior que 0,40 ou menor que $-0,40$ foram consideradas relevantes na determinação da respectiva função (Hair et al., 2010).

De acordo com o princípio do atualismo a relação entre morfologia e dieta dos gêneros atuais pode ser utilizada na determinação da dieta dos grupos extintos. No entanto, a diversidade morfológica dos Folivora fósseis estudados (n gêneros $=7$ ) é maior que a dos Folivora atuais (n gêneros $=2$ ). Por esse motivo talvez a maior parte das espécies extintas não possua um análogo moderno legítimo, o que poderia enviesar os resultados (Vizcaino et al., 2008). Em outras palavras, talvez o princípio do atualismo não seja aplicável nesse caso. Portanto, optou-se por realizar análises em que se incluiu a espécie extinta Nothrotheriops shastensis na determinação das funções discriminantes. Essa espécie apresenta, dentre todas as linhagens extintas estudadas, informações satisfatórias sobre seus hábitos alimentares. N. shastensis apresenta vasto registro de coprólitos (fezes fósseis). Com base nesse material e a partir de análises moleculares foi possível determinar com relativa precisão que essa preguiça se alimentava de material proveniente de árvores, ervas e gramas (Poinar et al., 1998; Hofreiter et al., 2000), sendo classificada como graminívoro-folívoro. Salienta-se, no entanto, que a inclusão dessa linhagem nas análises discriminantes pode gerar dois problemas. O primeiro deles é a determinação da dieta através de análises moleculares de coprólitos. Essa técnica apresenta o viés de identificar apenas material vegetal. Além disso, ela determina apenas a presença/ausência de determinado tipo vegetal, não sendo possível especificar a abundância de cada item vegetal na dieta (Hofreiter et al., 2000). O 
segundo advém do pequeno número de indivíduos utilizados nas análises discriminantes, apenas cinco. A baixa amostragem de um grupo pode gerar distorções nos resultados, favorecendo a classificação dos grupos fósseis nas classes de dieta melhor representadas (Morrison, 1969; Zuur et al., 2007; Hair et al., 2010).

Os mesmos procedimentos e análises adotados para a classificação da dieta dos fósseis baseada somente nas espécies atuais foram realizados após a inclusão de Nothrotheriops na determinação das funções discriminantes. As classes graminívoro-folívoro e a folívoro-frugívoro tiveram todos os espécimes considerados nas análises. As demais classes (folívoro, insetívoro e carnívoro-onívoro) tiveram o mesmo número de animais da classe folívoro-frugívoro selecionados aleatoriamente para compor cada grupo. A seleção aleatória dos espécimes não foi embasada na classe de dieta graminívoro-folívoro, pois essa classe não possui amostra adequada para análises discriminantes (Hair et al., 2010). A probabilidade a priori foi considerada igual entre todas as classes de dieta.

Todas as análises realizadas nesse trabalho foram desenvolvidas através do $\mathrm{R}(\mathrm{R}$ Development Core Team, 2011).

\section{Resultados}

Os resultados obtidos através dos diferentes conjuntos de dados (crânio, crânio-IS, face, face-IS e 25D) foram semelhantes. Eles apresentaram apenas diferenças mínimas. Por consequência, serão apresentados em detalhes abaixo somente os resultados obtidos com o conjunto de pontos face-IS sem considerar tamanho do centroide e Vermilingua.

A validação cruzada consiste em classificar cada observação sem ter a influencia dela na obtenção das funções discriminantes. O resultado dessa validação considerando somente as 
variáveis de forma, ou seja, os seis primeiros componentes principais, e somente os gêneros atuais na determinação das funções discriminantes mostrou que as funções obtidas foram eficientes em discriminar os espécimes atuais em suas respectivas classes de dieta. Valores para a validação cruzada ao longo das 500 reamostragens variaram entre 0,96 e 1, com média de 0,99 e desvio padrão de 0,01 .

A primeira função discriminante foi caracterizada pelos dois primeiros componentes principais. A segunda função foi caracterizada pelo segundo, terceiro, quarto e quinto componentes principais (Tabela 4.3). Em todas as reamostragens os dois primeiros componentes principais estiveram correlacionados $(\mathrm{p}<0,05)$ com o logaritmo do $\mathbf{C S}$, sendo no primeiro caso uma relação fraca e no segundo forte (Tabela 4.4).

O resultado da classificação dos fósseis em função da análise discriminante foi que: 1) Holmesina, o único Cingulata fóssil analisado, foi classificado todas as vezes como insetívoro (Tabela 4.5); e 2) os Folivora fósseis, independentemente do gênero, foram consistentemente classificados como folívoros. Dos 49 espécimes fósseis dessa subordem, 33 sempre foram designados à categoria folívoro, oito foram classificados nessa categoria entre 99 e $95 \%$ dos casos, três entre 94 e $85 \%$, dois entre 75 e $70 \%$ e três em menos que $62 \%$ das vezes. Em todos os casos que espécimes de Folivora não foram classificados como folívoros, eles foram considerados folívoro-frugívoros. A exceção para isso foi dois espécimes de Scelidotherium que foram classificados em alguns casos como insetívoros. Nothrotherium maquinense foi classificado mais vezes como folívoro-frugivoro do que folívoro, em $72 \%$ dos casos. Os taxa melhor amostrados (Nothrotheriops, Scelidotherium e Paramylodon) apresentaram resultados semelhantes para todos os espécimes de cada gênero. A exceção foi um espécime de Scelidotherium que teve elevada taxa de classificação como insetívoro (42\%). 
A inspeção dos 500 gráficos gerados a partir dos escores de todos os indivíduos nas duas funções discriminantes mostrou que: Scelidotherium, Holmesina e Megalonyx jeffersonii apresentaram-se consistentemente deslocados das classes de dieta as quais foram classificados (Figura 4.2).

Tabela 4.3 - Média das correlações entre os escores das duas funções discriminantes (DF) e os seis componentes principais das 500 reamostragens nas condições em que somente gêneros atuais (somente atuais) ou gêneros atuais e Nothrotheriops (considerando Nothrotheriops) foram utilizados para determinar as funções discriminantes. Em negrito estão as correlações superiores a 0,4 .

\begin{tabular}{cccccccc}
\hline & & PC1 & PC2 & PC3 & PC4 & PC5 & PC6 \\
\hline \multirow{2}{*}{ Somente atuais } & DF1 & $\mathbf{0 , 9 8 1}$ & $\mathbf{0 , 7 0 2}$ & 0,032 & 0,086 & 0,108 & 0,196 \\
& DF2 & 0,170 & $\mathbf{0 , 4 2 2}$ & $\mathbf{0 , 4 2 6}$ & $\mathbf{0 , 6 2 7}$ & $\mathbf{0 , 4 8 6}$ & 0,326 \\
\hline \multirow{2}{*}{ Considerando Nothrotheriops } & DF1 & $\mathbf{0 , 9 8 5}$ & $\mathbf{0 , 7 7 1}$ & 0,025 & 0,125 & 0,115 & 0,183 \\
& DF2 & 0,107 & 0,262 & $\mathbf{0 , 9 6 7}$ & 0,047 & $\mathbf{0 , 4 0 1}$ & $\mathbf{0 , 4 6 4}$ \\
\hline
\end{tabular}

Tabela 4.4 - Estatísticas básicas das correlações entre os dois primeiros componentes principais (PC1 e PC2) e o logaritmo do tamanho do centroide das 500 reamostragens nas condições em que somente gêneros atuais (somente atuais) ou gêneros atuais e Nothrotheriops (considerando Nothrotheriops) foram utilizados para determinar as funções discriminantes. Todas as correlações foram significativas ao nível de $5 \%$.

\begin{tabular}{cccccc}
\hline & & Mínimo & Máximo & Média & Desvio padrão \\
\hline \multirow{2}{*}{ Somente atuais } & PC1 & 0,178 & 0,382 & 0,259 & 0,034 \\
& PC2 & $-0,930$ & $-0,865$ & $-0,905$ & 0,011 \\
\hline \multirow{2}{*}{ Considerando Nothrotheriops } & PC1 & 0,150 & 0,362 & 0,256 & 0,034 \\
& PC2 & $-0,929$ & $-0,867$ & $-0,906$ & 0,010 \\
\hline
\end{tabular}

$\mathrm{Na}$ análise em que Nothrotheriops foi incluído na determinação das funções discriminantes, a validação cruzada suportou o poder discriminatório das funções geradas. Valores para a validação cruzada ao longo das 500 reamostragens variaram entre 0,90 e 1 , com média de 0,98 e desvio padrão de 0,01. Os dois primeiros componentes principais possuíram papel importante na primeira função discriminante. O terceiro, quinto e sexto componentes principais contribuíram majoritariamente para a segunda função discriminante (Tabela 4.3). Em todas as reamostragens os dois primeiros componentes principais estiveram correlacionados $(\mathrm{p}<$ 
0,05) com o logaritmo do CS. No primeiro caso foi uma relação fraca e no segundo forte (Tabela 4.4).

Holmesina foi classificado em $62 \%$ dos casos como insetívoro e no restante como carnívoro-onívoro (Tabela 4.5). Os 44 espécimes de Folivora, de modo geral, foram consistentemente classificados como graminívoro-folívoro: 11 espécimes foram identificados nessa classe todas as vezes, sete entre 98 e $89 \%, 12$ entre 88 e $70 \%, 11$ entre 66 e $15 \%$ e três não foram classificadas nessa classe. Sempre que um espécime não foi classificado como graminívoro-folívoro ele foi identificado como folívoro. Os três espécimes de Megalonyx foram os únicos Folivora classificados exclusivamente como folívoro. Seis Paramylodon tiveram uma taxa de classificação como folívoro superior a 50\%. Os resultados para as espécies melhor amostradas (Scelidotherium e Paramylodon) foram consistentes na classificação dos respectivos espécimes.

Para fins de comparação, a Tabela 4.6 apresenta os resultados obtidos para as análises discriminantes realizadas com os conjuntos de dados face-IS considerando o tamanho do centroide e desconsiderando Vermilingua, face-IS considerando o tamanho do centroide e Vermilingua e 25D considerando o tamanho do crânio e Vermilingua. Como pode ser observado, ao comparar as informações apresentadas nas Tabelas 4.5 e 4.6, os resultados foram bastante semelhantes.

A inspeção dos 500 gráficos gerados a partir dos escores de todos os indivíduos nas duas funções discriminantes mostrou que: Megalonyx, Paramylodon e Holmesina apresentaram-se consistentemente deslocados das classes de dieta as quais foram classificados (Figura 4.3). 


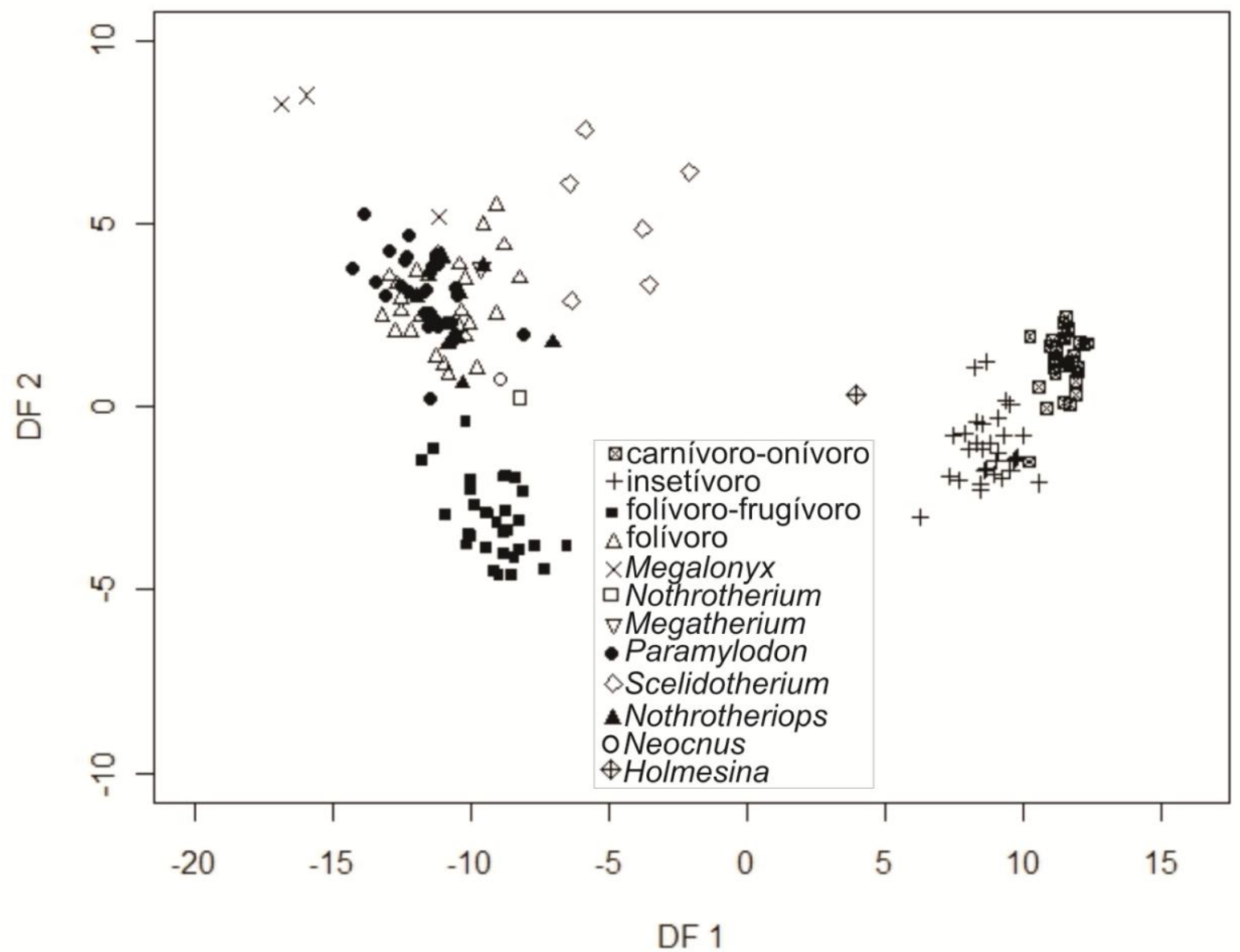

Figura 4.2 - Escores dos espécimes nas duas funções discriminantes obtidas a partir das classes dos gêneros atuais em uma das 500 reamostragens (todos os gráficos obtidos foram semelhantes). 


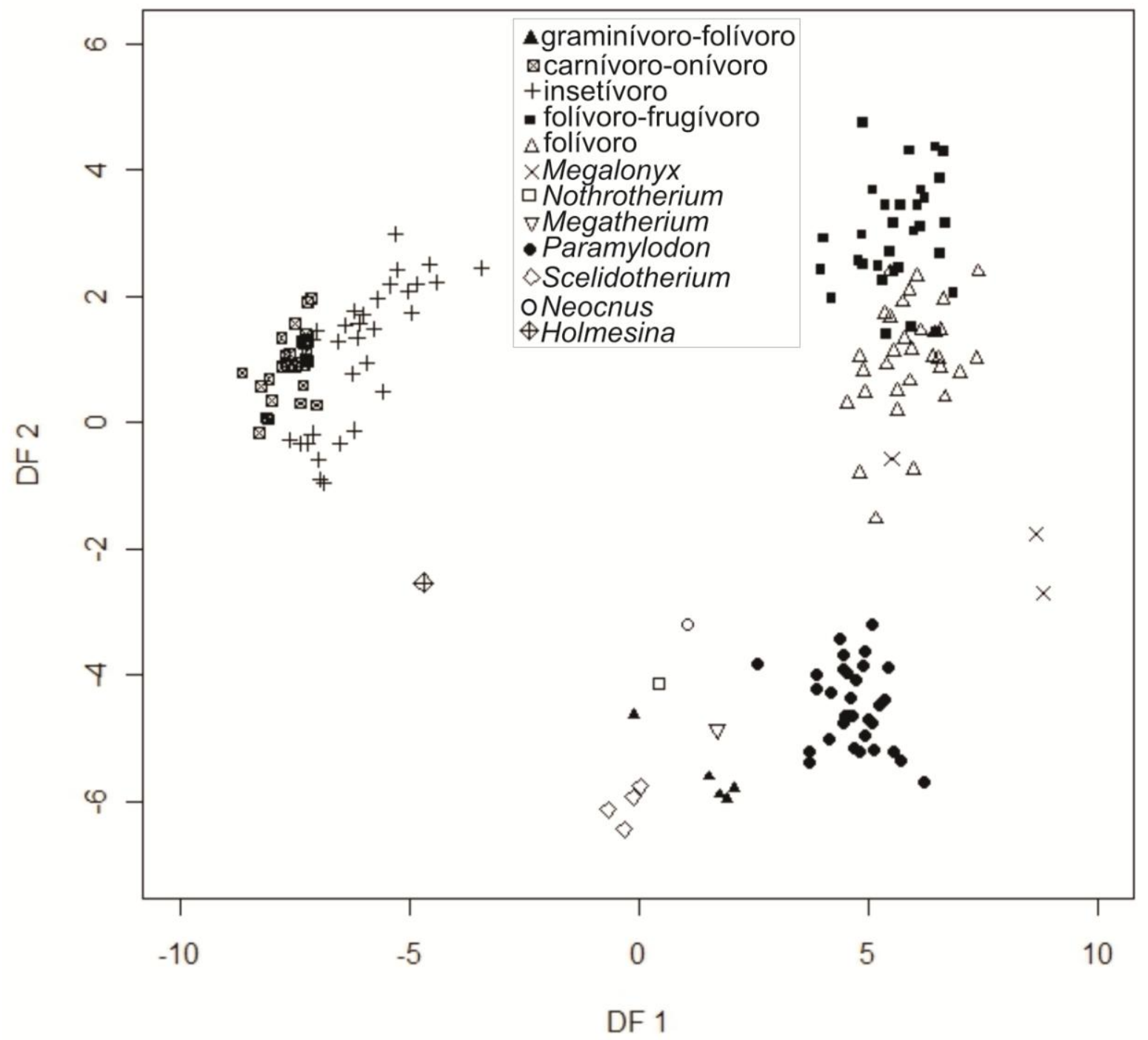

Figura 4.3 - Escores dos espécimes nas duas funções discriminantes obtidas a partir das classes dos gêneros atuais e Nothrotheriops em uma das 500 reamostragens (todos os gráficos obtidos foram semelhantes). 
Tabela 4.5 - Frequência de classificação nas diferentes classes alimentares para as 500 reamostragens nas condições em que somente gêneros atuais (somente atuais) ou gêneros atuais e Nothrotheriops (considerando Nothrotheriops) foram utilizados para determinar as funções discriminantes. FO: folívoro; FF: folívoro-frugívoro; CO: carnívoro-onívoro; IN: insetívoro; GF: graminívoro-folívoro.

\begin{tabular}{|c|c|c|c|c|c|c|c|c|c|c|}
\hline \multirow[b]{2}{*}{ Táxon } & \multirow[b]{2}{*}{ Sigla } & \multicolumn{4}{|c|}{ Somente atuais } & \multicolumn{5}{|c|}{ Considerando Nothrotheriops } \\
\hline & & FO & $\mathrm{FF}$ & CO & IN & FO & FF & $\mathrm{CO}$ & IN & GF \\
\hline \multirow{5}{*}{ Nothrotheriops shastensis } & LACM192 & 0,87 & 0,13 & 0 & 0 & & & & & \\
\hline & LACMHC208 & 1,00 & 0 & 0 & 0 & & & & & \\
\hline & LACMHC313 & 0,97 & 0,03 & 0 & 0 & & & & & \\
\hline & LACMHC632 & 0,99 & 0,01 & 0 & 0 & & & & & \\
\hline & LACMHCR52220 & 0,73 & 0,27 & 0 & 0 & & & & & \\
\hline Holmesina floridenus & UF191448 & 0 & 0 & 0 & 1,00 & 0 & 0 & 0,38 & 0,62 & 0 \\
\hline \multirow{2}{*}{ Megalonyx jeffersoniil } & MNH23094 & 1,00 & 0 & 0 & 0 & 1,00 & 0 & 0 & 0 & 0 \\
\hline & IMNH38001_87 & 1,00 & 0 & 0 & 0 & 1,00 & 0 & 0 & 0 & 0 \\
\hline Megalonyx leptostomus & UF216900 & 1,00 & 0 & 0 & 0 & 1,00 & 0 & 0 & 0 & 0 \\
\hline Megatherium $s p$. & FMNHP26970 & 1,00 & 0 & 0 & 0 & 0 & 0 & 0 & 0 & 1,00 \\
\hline Neocnus Dousman & UF76794 & 0,61 & 0,39 & 0 & 0 & 0 & 0 & 0 & 0 & 1,00 \\
\hline Nothrotherium maquinense & MCN_PALEOMCL1020 & 0,28 & 0,72 & 0 & 0 & 0 & 0 & 0 & 0 & 1,00 \\
\hline \multirow{32}{*}{ Paramylodon harlani } & AMNH16896 & 1,00 & 0 & 0 & 0 & 0,29 & 0 & 0 & 0 & 0,71 \\
\hline & AMNH2780 & 1,00 & 0 & 0 & 0 & 0 & 0 & 0 & 0 & 1,00 \\
\hline & FMNHPM3646 & 1,00 & 0 & 0 & 0 & 0,21 & 0 & 0 & 0 & 0,79 \\
\hline & FMNHsn & 1,00 & 0 & 0 & 0 & 0 & 0 & 0 & 0 & 1,00 \\
\hline & LACM696 & 1,00 & 0 & 0 & 0 & 0,04 & 0 & 0 & 0 & 0,96 \\
\hline & LACMHC14537 & 0,70 & 0,30 & 0 & 0 & 0,67 & 0 & 0 & 0 & 0,33 \\
\hline & LACMHC644 & 1,00 & 0 & 0 & 0 & 0,17 & 0 & 0 & 0 & 0,83 \\
\hline & LACMHC645 & 1,00 & 0 & 0 & 0 & 0,26 & 0 & 0 & 0 & 0,74 \\
\hline & LACMHC693 & 1,00 & 0 & 0 & 0 & 0,05 & 0 & 0 & 0 & 0,95 \\
\hline & LACMHC696 & 0,99 & 0,01 & 0 & 0 & 0,21 & 0 & 0 & 0 & 0,79 \\
\hline & LACMHC818 & 0,93 & 0,07 & 0 & 0 & 0,05 & 0 & 0 & 0 & 0,95 \\
\hline & LACMHC820 & 0,99 & 0,01 & 0 & 0 & 0,35 & 0 & 0 & 0 & 0,65 \\
\hline & LACMHC822 & 0,99 & 0,01 & 0 & 0 & 0,84 & 0 & 0 & 0 & 0,16 \\
\hline & LACMHC825 & 1,00 & 0 & 0 & 0 & 0,10 & 0 & 0 & 0 & 0,90 \\
\hline & LACMHC826 & 1,00 & 0 & 0 & 0 & 0,69 & 0 & 0 & 0 & 0,31 \\
\hline & LACMHC827 & 1,00 & 0 & 0 & 0 & 0,38 & 0 & 0 & 0 & 0,62 \\
\hline & LACMHC828 & 1,00 & 0 & 0 & 0 & 0,43 & 0 & 0 & 0 & 0,57 \\
\hline & LACMHC831 & 1,00 & 0 & 0 & 0 & 0,03 & 0 & 0 & 0 & 0,97 \\
\hline & LACMHC832 & 1,00 & 0 & 0 & 0 & 0,19 & 0 & 0 & 0 & 0,81 \\
\hline & LACMHC833 & 1,00 & 0 & 0 & 0 & 0,13 & 0 & 0 & 0 & 0,87 \\
\hline & LACMHC835 & 1,00 & 0 & 0 & 0 & 0,64 & 0 & 0 & 0 & 0,36 \\
\hline & LACMHCR49901 & 0,98 & 0,02 & 0 & 0 & 0,51 & 0 & 0 & 0 & 0,49 \\
\hline & UCMP21156 & 1,00 & 0 & 0 & 0 & 0,44 & 0 & 0 & 0 & 0,56 \\
\hline & UCMP21159 & 1,00 & 0 & 0 & 0 & 0,37 & 0 & 0 & 0 & 0,63 \\
\hline & UCMP21160 & 1,00 & 0 & 0 & 0 & 0,21 & 0 & 0 & 0 & 0,79 \\
\hline & UCMP21161 & 1,00 & 0 & 0 & 0 & 0,10 & 0 & 0 & 0 & 0,90 \\
\hline & UCMP21172 & 1,00 & 0 & 0 & 0 & 0,19 & 0 & 0 & 0 & 0,81 \\
\hline & UCMP21173 & 1,00 & 0 & 0 & 0 & 0,16 & 0 & 0 & 0 & 0,84 \\
\hline & UCMP23004 & 1,00 & 0 & 0 & 0 & 0,18 & 0 & 0 & 0 & 0,82 \\
\hline & UCMP23005 & 1,00 & 0 & 0 & 0 & 0,60 & 0 & 0 & 0 & 0,40 \\
\hline & UCMP23009 & 0,97 & 0,03 & 0 & 0 & 0,25 & 0 & 0 & 0 & 0,75 \\
\hline & UCMPsn1 & 1,00 & 0 & 0 & 0 & 0,09 & 0 & 0 & 0 & 0,91 \\
\hline \multirow{6}{*}{$\begin{array}{l}\text { Scelidotherium } \\
\text { leptocephalum }\end{array}$} & AMNH45910 & 0,58 & 0 & 0 & 0,42 & 0 & 0 & 0 & 0 & 1,00 \\
\hline & FMNHP14274 & 1,00 & 0 & 0 & 0 & 0 & 0 & 0 & 0 & 1,00 \\
\hline & MACN13883 & 0,92 & 0,04 & 0 & 0,04 & 0 & 0 & 0 & 0 & 1,00 \\
\hline & MLP3_402 & 1,00 & 0 & 0 & 0 & 0 & 0 & 0 & 0 & 1,00 \\
\hline & MLP3_408 & 1,00 & 0 & 0 & 0 & 0 & 0 & 0 & 0 & 1,00 \\
\hline & USNM5938 & 0,96 & 0,04 & 0 & 0 & 0 & 0 & 0 & 0 & 1,00 \\
\hline
\end{tabular}


Tabela 4.6 - Frequência de classificação a partir das 500 reamostragens na classe alimentar mais frequente e na condição em que os gêneros atuais e Nothrotheriops foram utilizados para determinar as funções discriminantes nos diferentes conjuntos de dados. 25D: conjunto de distâncias 25D considerando o tamanho do crânio e Vermilingua; 15V: face-IS considerando o tamanho do centroide e Vermilingua; 15: face-IS considerando o tamanho do centroide e desconsiderando Vermilingua.

\begin{tabular}{|c|c|c|c|c|}
\hline Táxon & Sigla & 25D & $15 \mathrm{~V}$ & 15 \\
\hline Holmesina floridenus & UF191448 & 0,51 insetívoro & 0,97 insetívoro & 1 insetívoro \\
\hline Megalonyx & $\mathrm{MNH} 23094$ & 1 graminívoro-folívoro & 0,65 folívoro & 0,89 folívoro \\
\hline jeffersoniil & IMNH38001_87 & 1 graminívoro-folívoro & 0,72 folívoro & 0,95 folívoro \\
\hline $\begin{array}{c}\text { Megalonyx } \\
\text { leptostomus }\end{array}$ & UF216900 & 1 folívoro-frugívoro & 0,52 folívoro & 1 folívoro \\
\hline Megatherium sp. & FMNHP26970 & 1 graminívoro-folívoro & 1 graminívoro-folívoro & 1 graminívoro-folívoro \\
\hline Neocnus Dousman & UF76794 & 0,96 graminívoro-folívoro & 0,69 graminívoro-folívoro & 1 graminívoro-folívoro \\
\hline $\begin{array}{c}\text { Nothrotherium } \\
\text { maquinense }\end{array}$ & $\begin{array}{c}\text { MCN_PALEO } \\
\text { MCL1020 }\end{array}$ & 1 graminívoro-folívoro & 1 graminívoro-folívoro & 1 graminívoro-folívoro \\
\hline \multirow{32}{*}{ Paramylodon harlani } & AMNH16896 & 1 graminívoro-folívoro & 1 graminívoro-folívoro & 0,54 graminívoro-folívoro \\
\hline & AMNH2780 & 1 graminívoro-folívoro & 1 graminívoro-folívoro & 1 graminívoro-folívoro \\
\hline & FMNHPM3646 & 1 graminívoro-folívoro & 1 graminívoro-folívoro & 0,67 graminívoro-folívoro \\
\hline & FMNHsn & 1 graminívoro-folívoro & 1 graminívoro-folívoro & 1 graminívoro-folívoro \\
\hline & LACM696 & 1 graminívoro-folívoro & 1 graminívoro-folívoro & 0,96 graminívoro-folívoro \\
\hline & LACMHC14537 & 1 graminívoro-folívoro & 1 graminívoro-folívoro & 0,64 folívoro \\
\hline & LACMHC644 & 1 graminívoro-folívoro & 1 graminívoro-folívoro & 0,63 graminívoro-folívoro \\
\hline & LACMHC645 & 1 graminívoro-folívoro & 1 graminívoro-folívoro & 0,56 graminívoro-folívoro \\
\hline & LACMHC693 & 1 graminívoro-folívoro & 1 graminívoro-folívoro & 0,9 graminívoro-folívoro \\
\hline & LACMHC696 & 1 graminívoro-folívoro & 1 graminívoro-folívoro & 0,65 graminívoro-folívoro \\
\hline & LACMHC818 & 1 graminívoro-folívoro & 1 graminívoro-folívoro & 0,67 graminívoro-folívoro \\
\hline & LACMHC820 & 1 graminívoro-folívoro & 1 graminívoro-folívoro & 0,51 graminívoro-folívoro \\
\hline & LACMHC822 & 1 graminívoro-folívoro & 0,99 graminívoro-folívoro & 0,87 folívoro \\
\hline & LACMHC825 & 1 graminívoro-folívoro & 1 graminívoro-folívoro & 0,81 graminívoro-folívoro \\
\hline & LACMHC826 & 1 graminívoro-folívoro & 1 graminívoro-folívoro & 0,74 folívoro \\
\hline & LACMHC827 & 1 graminívoro-folívoro & 1 graminívoro-folívoro & 0,67 graminívoro-folívoro \\
\hline & LACMHC828 & 1 graminívoro-folívoro & 1 graminívoro-folívoro & 0,6 graminívoro-folívoro \\
\hline & LACMHC831 & 1 graminívoro-folívoro & 1 graminívoro-folívoro & 0,9 graminívoro-folívoro \\
\hline & LACMHC832 & 1 graminívoro-folívoro & 1 graminívoro-folívoro & 0,64 graminívoro-folívoro \\
\hline & LACMHC833 & 1 graminívoro-folívoro & 1 graminívoro-folívoro & 0,63 graminívoro-folívoro \\
\hline & LACMHC835 & 1 graminívoro-folívoro & 0,98 graminívoro-folívoro & 0,72 graminívoro-folívoro \\
\hline & LACMHCR49901 & 1 graminívoro-folívoro & 1 graminívoro-folívoro & 0,65 folívoro \\
\hline & UCMP21156 & 1 graminívoro-folívoro & 1 graminívoro-folívoro & 0,54 graminívoro-folívoro \\
\hline & UCMP21159 & 1 graminívoro-folívoro & 1 graminívoro-folívoro & 0,75 graminívoro-folívoro \\
\hline & UCMP21160 & 1 graminívoro-folívoro & 1 graminívoro-folívoro & 0,76 graminívoro-folívoro \\
\hline & UCMP21161 & 1 graminívoro-folívoro & 1 graminívoro-folívoro & 0,86 graminívoro-folívoro \\
\hline & UCMP21172 & 1 graminívoro-folívoro & 1 graminívoro-folívoro & 0,86 graminívoro-folívoro \\
\hline & UCMP21173 & 1 graminívoro-folívoro & 1 graminívoro-folívoro & 0,78 graminívoro-folívoro \\
\hline & UCMP23004 & 1 graminívoro-folívoro & 1 graminívoro-folívoro & 0,8 graminívoro-folívoro \\
\hline & UCMP23005 & 1 graminívoro-folívoro & 1 graminívoro-folívoro & 0,7 folívoro \\
\hline & UCMP23009 & 1 graminívoro-folívoro & 1 graminívoro-folívoro & 0,65 graminívoro-folívoro \\
\hline & UCMPsn1 & 1 graminívoro-folívoro & 1 graminívoro-folívoro & 0,86 graminívoro-folívoro \\
\hline \multirow{6}{*}{$\begin{array}{l}\text { Scelidotherium } \\
\text { leptocephalum }\end{array}$} & AMNH45910 & 1 graminívoro-folívoro & 1 graminívoro-folívoro & 1 graminívoro-folívoro \\
\hline & FMNHP14274 & 1 graminívoro-folívoro & 1 graminívoro-folívoro & 1 graminívoro-folívoro \\
\hline & MACN13883 & 1 graminívoro-folívoro & 1 graminívoro-folívoro & 1 graminívoro-folívoro \\
\hline & MLP3_402 & 1 graminívoro-folívoro & 1 graminívoro-folívoro & 1 graminívoro-folívoro \\
\hline & MLP3_408 & 1 graminívoro-folívoro & 1 graminívoro-folívoro & 1 graminívoro-folívoro \\
\hline & USNM5938 & 1 graminívoro-folívoro & 1 graminívoro-folívoro & 1 graminívoro-folívoro \\
\hline
\end{tabular}




\section{Discussão}

Independente do conjunto de dados, seja ele oriundo da morfometria geométrica ou da clássica, considerando o tamanho nas análises ou não e incluindo Vermilingua na amostra ou não, os resultados da classificação dos fósseis nas categoria de dieta foram semelhantes. Isso sugere que os resultados obtidos sejam robustos. A discussão abaixo está focada nos resultado obtidos para o conjunto face-IS desconsiderando o tamanho do centroide e o grupo Vermilingua. Salienta-se que os resultados obtidos com os demais conjuntos de dados foram semelhantes.

Tanto na análise que considerou apenas as espécies atuais na determinação das funções discriminantes, quanto na que considerou Nothrotheriops, foram obtidos valores elevados na validação cruzada. Isso sugerindo que as análises foram robustas. Em ambos os casos ocorreu também uma contribuição alométrica na determinação das classes de dieta, principalmente na distinção entre insetívoro/carnívoro-onívoro das demais (primeira função discriminante). No entanto, os resultados obtidos entre as duas análises em termos da classificação dos fósseis foi muito diferente. Quando Nothrotheriops foi incluído, as espécies de preguiça fósseis passaram a ser majoritariamente classificadas em sua classe de dieta, graminívoro-folívoro. Esse resultado, sugere que os Xenarthra atuais não sejam um bom modelo para determinar a dieta dos Folivora fósseis. Isso porque a inclusão de uma nova classe alimentar fez com que as espécies extintas tivessem suas classes alimentares alteradas. Caso contrário, a adição desse gênero extinto na obtenção das funções não deveria ter influído nos resultados obtidos.

Partindo dessa ideia e com base nos resultados obtidos com a inclusão de Nothrotheriops na determinação das funções discriminantes, foi concluído que as preguiças extintas, de modo geral, possuíam uma dieta diferenciada das preguiças e tatus atuais. Exceções foram o gênero 
Megalonyx e Paramylodon. O primeiro foi consistentemente classificado como folívoro. Já o segundo, dependendo do conjunto de espécimes utilizado na determinação das funções discriminantes nas 500 reamostragens, apresentou variação na classificação dos indivíduos entre folívoro e graminívoro-folívoro. Além disso, a análise gráfica das funções discriminantes mostrou que: Megalonyx jeffersoni e Paramylodon apresentaram-se relativamente distantes dos espécimes que compunham as diferentes categorias de dieta existentes. A interpretação desse resultado é que: as dimensões do morfoespaço representadas pelas funções discriminantes sugerem que esses gêneros apresentavam dieta diferente das cinco classes de dieta utilizadas na determinação do morfoespaço. Essa ideia é reforçada pelo fato de diversos trabalhos apontarem para uma grande diversidade na dieta das preguiças extintas, maior do que a diversidade de dietas observada atualmente (McDonald, 1995; Farina, 1996; Poinar et al., 1998; Toledo, 1998; Hofreiter et al., 2000; Bargo, 2001; Bargo, 2003; Ruez, 2005; Bargo et al., 2006a, 2006b; Green, 2009; McAfee, 2011; Pujos et al., 2012).

A análise discriminante parte do conhecimento a priori de qual espécime pertence a qual categoria, nesse caso classe de dieta. A partir dessa informação ela extrai funções discriminantes que definem a direção do morfoespaço onde a diferença entre grupos é máxima. Posteriormente essas funções são utilizadas para classificar novos indivíduos em uma das categorias existentes (Hair et al., 2010). Como apresentado acima, essa análise mostrou que as preguiças extintas diferiam dos gêneros atuais quanto à dieta. Ainda, boa parte delas se assemelhou em termos de dieta a Nothrotheriops. Megalonyx e Paramylodon, no entanto, aparentemente apresentavam hábitos alimentares diferentes das categorias de dieta existentes. Por conta disso, optou-se por realizar uma análise de componentes principais. A justificativa para realizar essa análise foi não restringir o morfoespaço em função das categorias de dieta conhecidas. Apenas defini-lo a partir 
da variância de todos os dados conjuntamente (Hair et a., 2010). Essa análise foi realizada a partir das projeções dos pontos da face-IS após a superposição de Procrustes no espaço tangente da forma. Ela foi desenvolvida utilizando somente os gêneros de preguiça, tanto atuais quanto extintos. Ela foi realizada considerando o CS e desconsiderando-o. No caso em que o CS foi considerado, o primeiro componente principal, que explicou 93,5 da variância total dos dados, ordenou as espécies de acordo com os seus respectivos tamanhos e foi pouco informativa. Por outro lado, a projeção dos espécimes no morfoespaço representado pelos dois primeiros componentes principais da análise que desconsiderou o tamanho do centroide foi elucidativa. $\mathrm{O}$ primeiro componente principal explicou $71,03 \%$, enquanto o segundo $7,82 \%$ da variância total. A projeção dos espécimes no morfoespaço representado por esses componentes mostrou uma estruturação dos gêneros em três grupos. Um deles formados pelas preguiças atuais (Bradypus e Choloepus) e Megalonyx (grupo 1). Outro formado por Paramylodon (grupo 2) e um terceiro definido por Scelidotherium, Nothrotheriops e Nothrotherium (grupo 3). Megatherium e Neocnus não se enquadraram em nenhum grupo (Figura 4.4). O padrão de distribuição encontrado nessa análise foi concordante, na grande maioria dos casos, com as propostas de outros trabalhos sobre a dieta dos gêneros estudados (McDonald, 1995; Farina, 1996; Poinar et al., 1998; Toledo, 1998; Hofreiter et al., 2000; Bargo, 2001; Bargo, 2003; Ruez, 2005; Bargo et al., 2006a, 2006b; Green, 2009; McAfee, 2011; Pujos et al., 2012). Essa análise, sugeriu que: 1) a forma tenha relação com o tipo de dieta; e 2) a localização dos espécimes no morfoespaço desse estudo pode ser utilizada para determinar a dieta dos animais fósseis.

Desta forma, o grupo 1 representa os gêneros atuais cujas dietas são folívoro e folívorofrugívoro, e Megalonyx. A presença desse gênero nesse grupo suporta as interpretações de outros trabalhos (Toledo, 1998; Pujos et al., 2012) de que ele apresentava dieta baseada 
majoritariamente em folhas podendo também ter consumido frutos. A distinção de Paramylodon (grupo 2) dos demais gêneros sugere que ele tinha dieta diferenciada dos demais Folivora. Segundo a literatura ele seria, dentre a amostra analisada, o único representante dos majoritariamente graminívoros (Bargo, 2001; Bargo, 2003; Bargo et al., 2006a; Pujos et al., 2012). Por último, Nothrotheriops e Scelidotherium, pertencentes ao grupo 3, são classificados por trabalhos da área como graminívoros-folívoros (Poinar et al., 1998; Toledo, 1998; Hofreiter et al., 2000; Bargo, 2001; Bargo, 2003; Bargo et al., 2006a, 2006b; Green, 2009). A inserção de Nothrotherium no grupo 3 favorece a interpretação que ele também seria graminívoro-folívoro (Toledo, 1998) e não apenas folívoro como proposto em alguns trabalhos (McAfee, 2011; Pujos et al., 2012). Os demais componentes principais não apresentaram interpretação biológica evidente. As análises realizadas foram inconclusivas a respeito da dieta de Megatherium e Neocnus. O primeiro componente principal esteve fortemente correlacionado com o logaritmo do CS $(r=0,96 ; p<0,0001)$. Essa correlação sugere que variações na forma associadas ao tamanho (alometria) tenham forte relação com o tipo de dieta de cada gênero. Ela também favorece a interpretação que o tamanho do animal tenha estreita relação com seus hábitos alimentares (Vizcaino et al., 2008). Essa afirmação só é valida se o CS do crânio estiver positiva e altamente correlacionado com o tamanho corpóreo. Para os Xenarthra atuais, a correlação entre o CS obtido a partir do conjunto de dados face-IS e o peso corporal foi $r=0,90(p>0,001)$. Os demais componentes principais não estiveram correlacionados com o CS.

$\mathrm{O}$ resultado da análise de componentes principais foi, no geral, concordante com o resultado da análise discriminante. Ambas favoreceram a interpretação de que os hábitos alimentares dos gêneros fósseis diferiam em sua maioria dos grupos atuais. Elas também suportaram que: 1) Nothrotherium e Scelidotherium seriam graminívo-folívoro; 2) Paramylodon 
teria dieta diferente dos demais grupos estudados, tendo sido sugerida a dieta graminívora; 3) Megalonyx seria folívoro, mas talvez também consumisse frutos. Apenas para Megatherium e Neocnus os resultados das duas análises não foram semelhantes.

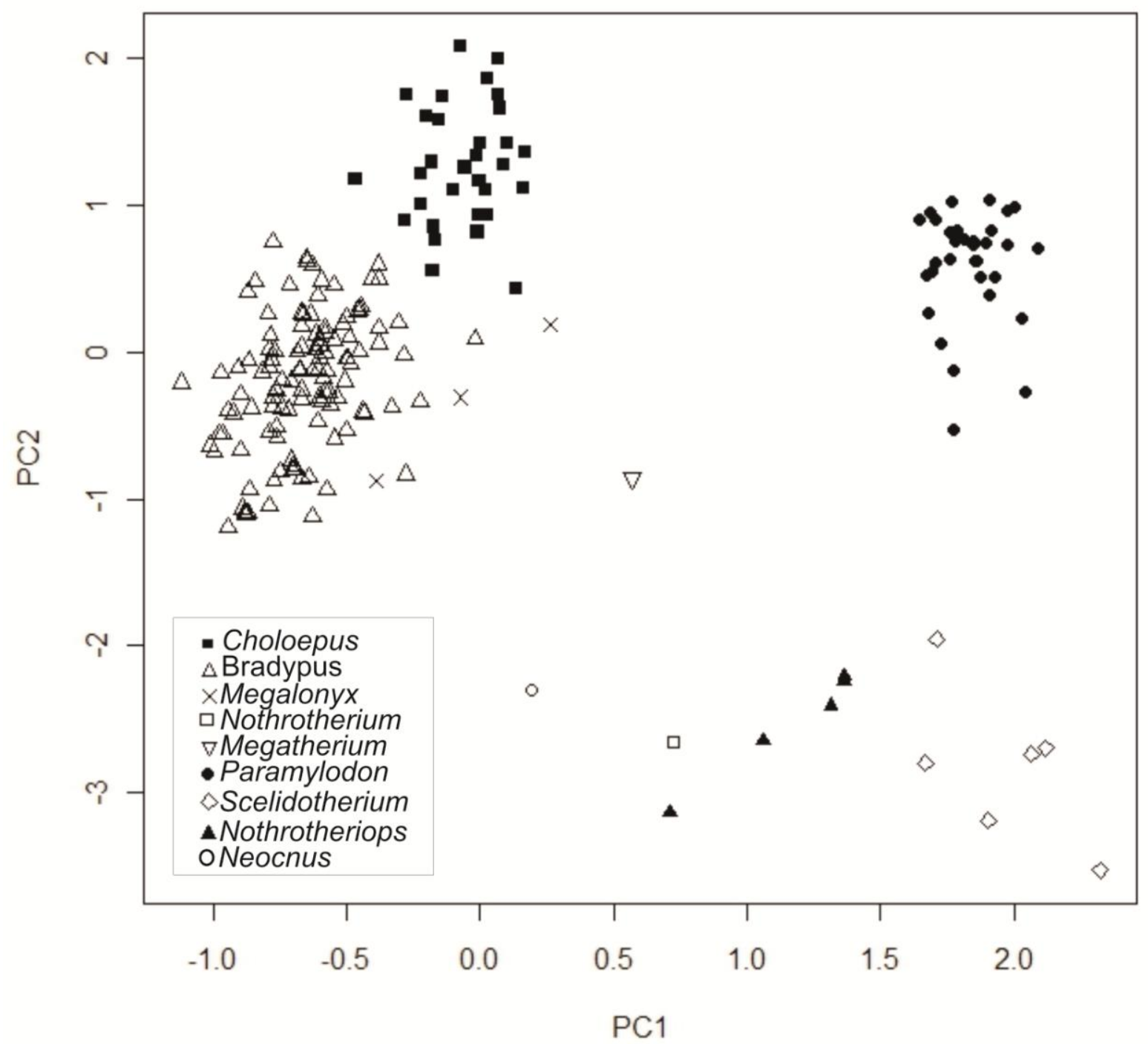

Figura 4.4 - Escores dos espécimes de Folivora em relação aos dois primeiros componentes principais (PC1 e PC2).

As análises discriminantes não foram conclusivas quanto à classe de dieta do único Cingulata fóssil analisado, Holmesina. A inclusão de Nothrotheriops fez com que o espécime 
estudado fosse classificado, dependendo do conjunto de dados das 500 reamostragens, entre insetívoro e carnívoro-onívoro. Tanto na análise considerando Nothrotheriops quanto na que utilizou somente os gêneros atuais, Holmesina mostrou-se distante, na visualização gráfica, das classes de dieta conhecidas. Mesmo extraindo funções discriminantes utilizando apenas os Cingulata modernos, esse gênero apresentou um posicionamento periférico ao grupo de dieta insetívoro (resultado não apresentado). Esse conjunto de resultados sugere que, assim como para os Folivora fósseis, os Xenarthra atuais não sejam adequados para determinar a dieta do Cingulata extinto estudado. Além disso, as análises morfométricas de grupos modernos e um fóssil com dieta conhecida possibilitou determinar que a dieta desse gênero provavelmente era diferente de todos os Xenarthra atuais estudados. Vizcaino e colaboradores (1998), ao comparar a morfologia dentária e craniana de Holmesina, Dasypus e Euphractus, concluíram que esse gênero fóssil era graminívoro. As análises apresentadas no presente trabalho não foram suficientes para corroborar diretamente a conclusão daqueles autores. Contudo, ela favorece a interpretação apresentada por eles ao sugerir que a dieta de Holmesina era diferente da apresentada pela ampla diversidade de gêneros atuais analisados.

Em resumo as análises discriminantes realizadas a partir da inclusão de Nothrotheriops na determinação das funções discriminantes evidenciou que as espécies fósseis apresentavam, em sua maioria, dietas distintas dos Xenarthra atuais. Essa análise, em conjunto com a análise de componentes principais realizada para os Folivora, suportou as hipóteses geradas por outras pesquisas sobre a dieta dos gêneros de preguiça extintos.

Por último, salienta-se que embora os pontos selecionados para representar a forma do crânio/face tenham sido bastante abrangentes, eles apresentaram algumas restrições. Limitações oriundas da fragmentação do material fóssil e da determinação de homologia entre pontos, fez 
com que algumas regiões potencialmente importantes na determinação da dieta tenham sido subrepresentadas. Por exemplo, a região do focinho nos Folivora é muito diversificada (Bargo et al., 2006b). Os pontos adotados nesse trabalho não representaram essa complexidade de forma minuciosa. Nesse sentido, pesquisas futuras visando trabalhar com inferências morfofuncionais em Xenarthra devem buscar melhor representar áreas supostamente importantes na definição do tipo de dieta, como o focinho ou o arco zigomático. Essa região também apresenta variações marcantes entre os Xenarthra. Uma alternativa seria utilizar métodos que não necessitam de comparações tão estreitas com grupos atuais sendo, portanto, mais generalizáveis. Como exemplo, podem ser citadas as análises isotópicas ou biomecânicas (MacFadden, 2005; Vizcaino et al., 2008).

\section{Implicações da diversidade alimentar na extinção dos Xenarthra no final do}

\section{Pleistoceno}

A extinção do final do Quaternário é debatida desde o século XIX (Grayson, 1984). Com base nas análises desenvolvidas e nas informações existentes na literatura sobre os Xenarthra fósseis (Toledo, 1998; Bargo, 2003; Vizcaino et al., 2008; Vizcaino et al., 2009, Pujos et al., 2012), a extinção para esse grupo parece ter sido seletiva. Em sua maioria, as linhagens de portes mais avantajados e os grupos com dieta graminívora e graminívora-folívora foram eliminados. No Pleistoceno tardio havia mais de 35 gêneros de Cingulata e Folivora. Atualmente restam apenas nove gêneros de tatus e dois de preguiças arborícolas que são, geralmente, menores que as linhagens extintas mais próximas (McDonald, 2005; Vizcaino et al., 2008; Vizcaino et al., 2009). Os tatus atuais se alimentam, em grande parte, de proteína animal. As preguiças viventes apresentam dieta fortemente relacionada ao consumo de folhas. 
A heterogeneidade alimentar sugerida para os Xenarthra fósseis está de acordo com a proposta do desequilíbrio coevolucionário (Graham e Lundelius, 1984). Essa hipótese sugere que a grande diversidade de herbívoros do Quaternário tardio era mantida por extensa partição de recursos. Assim como é observado hoje na África. Uma rápida transição do período glacial para o interglacial teria reorganizado a flora, desestruturando o sistema de partição e culminando na extinção dos grandes mamíferos. Além da supostamente grande diversidade de hábitos alimentares dos grupos extintos, essa hipótese foi recentemente favorecida pela detecção, ao menos nas Américas, de oscilações rápidas e sem precedentes entre fases úmidas e secas na transição do Último Máximo Glacial ( 21000 anos) ao Holoceno (Cruz et al., 2009; Cheng et al., 2012; Polyak et al., 2012). Essa nova informação paleoclimática é fundamental no suporte a hipóteses que favorecem o clima como principal responsável por esse evento de extinção. Isso porque essa vertente de hipóteses é geralmente criticada pela noção que as variações climáticas vinculadas ao último máximo glacial não foram mais intensas que as variações das fases de deglaciação anteriores. Portanto, as variações climáticas por si só não justificariam a extinção (Koch e Barnosky, 2006; Cione et al., 2009). Com a descoberta dessas variações climáticas sem precedentes, esse tipo de crítica perde força. No entanto, novos estudos são necessários para entender como essas variações climáticas de fato alteraram a flora. Ou qual a capacidade delas de romper as supostamente intricadas relações existentes entre fauna e flora, como supõe a hipótese do desequilíbrio coevolucionário. Estudos futuros também serão necessários para elucidar se essas variações gerariam mudanças na flora ao ponto de ocasionar a extinção dos animais.

A dieta pode ter também uma relação indireta com a extinção. Um estudo recente relacionou o risco de extinção da megafauna a taxa de reprodução (Johnson, 2002). Quanto menor for a taxa reprodutiva de uma espécie, maior a chance dela se extinguir. O tamanho 
corporal em mamíferos apresenta correlação forte e negativa com essa taxa. Quanto maior for o animal, menor será sua taxa reprodutiva (Johnson, 2002). Ou seja, tamanho avantajado por si só eleva as chances de uma espécie se tornar extinta. Como a grande maioria das espécies fósseis eram de porte avantajado, elas eram mais propensas a extinção. Outro fator que está negativamente correlacionado a taxa reprodutiva é a taxa de metabolismo basal (Hennemann III, 1983; McNab, 1985; McDonald, 2005). Por sua vez, o tipo de dieta de um animal está relacionado a taxa de metabolismo basal. Animais que ingerem alimentos pobres em termos nutricionais apresentam metabolismo basal mais baixo (Cruz-Neto e Bozinovic, 2004). Alimentos de origem vegetal são geralmente mais pobres no aspecto nutricional do que os alimentos de origem animal, mais especificamente vertebrados. Dentre os vegetais, gramíneas apresentam menor valor nutritivo do que folhas e frutos (Van Soest, 1994). Aparentemente, uma parcela das espécies de Xenarthra fósseis se alimentava ao menos em parte de gramíneas. Essas espécies deveriam ter um metabolismo basal relativamente mais baixo do que espécies de mesmo porte, mas de dieta mais nutritiva. Por consequência, uma taxa de reprodução também relativamente menor. Dado o tipo de dieta de parte dos grupos extintos, é possível supor que eles apresentavam uma taxa reprodutiva ainda mais baixa do que o esperado segundo o seu tamanho corpóreo. Consequentemente, apresentavam maior propensão à extinção.

\section{Conclusões}

As análises discriminantes realizadas contribuíram para melhorar a compreensão da dieta dos Xenarthra fósseis. As conclusões mais relevantes dessas análises foram: 1) a dieta dos grupos fósseis diferiu, em sua maioria, dos grupos atuais; 2) a interpretação de que Holmesina era graminívoro foi indiretamente favorecida; 3) em conjunto com a análise de componentes principais realizada somente com os Folivora, tanto atuais quanto extintos, corroborou as 
hipóteses geradas em outras pesquisas sobre a dieta da maioria dos gêneros fósseis estudados; 4) aparentemente, os hábitos alimentares dos Xenarthra atuais representam apenas uma fração da diversidade de hábitos alimentares que existiu dentro do grupo até o final do Pleistoceno/início do Holoceno.

A extinção dos Xenarthra na transição do Pleistoceno para o Holoceno pode estar relacionada a variações climáticas que desestruturaram a complexa partição dos recursos. Pode ser também que a dieta dos animais extintos, assim como seus tamanhos avantajados, tenham contribuído para que as espécies extintas tivessem taxa de reprodução relativamente baixa. Por consequência, maiores chances de se extinguirem. Por último, reforçar os achados obtidos por outros trabalhos sobre a dieta dos Xenarthra fósseis foi importante. Determinar a dieta dos animais extintos é um dos pilares para o melhor entendimento da ecologia deles (Vizcaino et al., 2008).

\section{Referências}

Bargo, M.S., 2001. The ground sloth Megatherium americanum: skull shape, bite forces, and diet. Acta Palaeontologica Polonica 46, 173-192.

Bargo, M.S., 2003. Biomechanics and palaeobiology of the Xenarthra: The state of the art (Mammalia, Xenarthra). Senckenbergiana Biologica 83, 41-50.

Bargo, M.S., De Iuliis, G., Vizcaino, S.F., 2006a. Hypsodonty in Pleistocene ground sloths. Acta Palaeontologica Polonica 51, 53-61.

Bargo, M.S., Toledo, N., Vizcaino, S.F., 2006b. Muzzle of South American Pleistocene ground sloths (Xenarthra, Tardigrada). Journal of Morphology 267, 248-263. 
Bargo, M.S., Vizcaino, S.F., Archuby, F.M., Blanco, R.E., 2000. Limb bone proportions, strength and digging in some Lujanian (Late Pleistocene-Early Holocene) mylodontid ground sloths (Mammalia, Xenarthra). Journal of Vertebrate Paleontology 20, 601610.

Barnosky, A.D., Koch, P.L., Feranec, R.S., Wing, S.L., Shabel, A.B., 2004. Assessing the causes of Late Pleistocene extinctions on the continents. Science 306, 70-75.

Barnosky, A.D., Lindsey, E.L., 2010. Timing of quaternary megafaunal extinction in South America in relation to human arrival and climate change. Quaternary International 217, $10-29$.

Blomberg, S.P., Garland Jr., T., 2002 Tempo and mode in evolution: phylogenetic inertia, adaptation and comparative methods. Journal of Evolutionary Biology 15, 899-910.

Buchmann, F.S., Lopes, R.P., Caron, F., 2009. Incnofósseis (paleotocas e crotovinas) atribuídos a mamíferos extintos no sudeste e sul do Brasil. Revista Brasileira de Paleontologia $12,247-256$.

Cartelle, C., 1999. Pleistocene mammals of the cerrado and caatinga of Brazil. Em: Eisenberg, J.F., Redford, K.H. (Ed.), Mammals of the Neotropics - The Central Neotropics. University of Chicago Press, Chicago, pp. 27-46.

Chen, X.M., Milne, N., O'Higgins, P., 2005. Morphological variation of the thoracolumbar vertebrae in Macropodidae and its functional relevance. Journal of Morphology $266,167-181$. 
Cheng, H., Sinha, A., Wang, X., Cruz, F.W., Edwards, R.L., 2012. The global paleomonsoon as seen through speleothem records from Asia and the Americas. Climate Dynamics 39, 1045-1062.

Cheverud, J.M., 1995. Morphological integration in the Saddle-back Tamarin (Saguinusfuscicollis) cranium. American Naturalist 145, 63-89.

Cheverud, J.M., Dow, M.M., Leutenegger, W., 1985. The quantitative assessment of phylogenetic constraints in comparative analyses: sexual dimorphism in body weight among primates. Evolution,39, 1335-1351.

Cione, A.L., Tonni, E.P., Dondas, A., 2003. The broken zig-zag: Late Cenozoic large mammal and turtle extinction in South America. Revista del Museo Argentino de Ciencias Naturales "Bernardino Rivadavia” 5, 1-19.

Cione, A.L., Tonni, E.P., Soibelzon, L., 2009. Did humans cause the late Pleistoceneearly Holocene mammalian extinctions in South America in a context of shrinking open areas? Em: Haynes, G. (Ed.), American megafaunal extinctions at the end of the Pleistocene. Springer, New York, pp. 125-144.

Cruz, F.W., Wang, X., Auler, A., Vuille, M., Burns, S.J., Edwards, R.L., Karmann, I., Cheng, H., 2009. Orbital and millennial-scale precipitation changes in Brazil from speleothem records. Em: Vimeux, F., Sylvestre, F.,Khodri, M. (Ed.), Past climate variability in South America and surrounding region: from the Last Glacial Maximum to the Holocene. Springer, New York, pp. 29-60. 
Cruz-Neto, A.P., Bozinovic, F., 2004 The relationship between diet quality and basal metabolic rate in endotherms: insights from intraspecific analysis. Physiological and Biochemical Zoology 77, 877-889.

de Vivo, M., Carmignotto, A.P., 2004. Holocene vegetation change and the mammal faunas of South America and Africa. Journal of Biogeography 31, 943-957.

Diniz-Filho, J.A.F., Sant`Ana, C.E.R., Bini, L.M., 1998. An Eigenvector Method for Estimating Phylogenetic Inertia. Evolution 52, 1247-1262.

Eisenberg, J.F., Redford, K.H., 1999. Mammals of the Neotropics, Volume 3: The Central Neotropics: Ecuador, Peru, Bolivia, Brazil. The University of Chicago Press, Chicago.

Elbroch, M., 2006. Animal skulls: a guide to North American species. Stackpole Books, Mechanicsburg.

Farina, R.A., 1996. Trophic relationships among Lujanian mammals. Evolutionary Theory and Review 11, 125-134.

Ferigolo, J., 1999. Late Pleistocene South-American land-mammal extinctions: the infection hypothesis. Quaternary of South America and Antarctic Peninsula 12, 279-310.

Ficcarelli, G., Coltorti, M., Moreno-Espinosa, M., Pieruccini, P.L., Rook, L., Torre, D., 2003. A model for the Holocene extinction of the mammal megafauna in Ecuador. Journal of South American Earth Sciences 15, 835-845.

Gardner, A.L., 2007. Mammals of South America: volume 1: Marsupials, Xenarthrans, Shrews, and Bats. The University of Chicago Press, Chicago and London. 
Graham, R.W., Lundelius, E.L., Jr., 1984. Coevolutionary disequilibrium and Pleistocene extinctions. Em: Martin, P.S.,G., K.R. (Ed.), Quaternary extinctions: a Prehistoric Revolution. University of Arizona Press, Tucson, pp. 223-249

Grayson, D.K., 1984. Nineteenth-century explanations of Pleistocene extinctions: a review and analysis. Em: Martin, P.S.,G., K.R. (Ed.), Quaternary extinctions: a Prehistoric Revolution. University of Arizona Press, Tucson, pp. 5-39.

Green, J.L., 2009. Dental microwear in the orthodentine of the Xenarthra (Mammalia) and its use in reconstructing the palaeodiet of extinct taxa: the case study of Nothrotheriops shastensis (Xenarthra, Tardigrada, Nothrotheriidae). Zoological Journal of the Linnean Society $156,201-222$.

Hair, J.F., White, W.C., Babin, B.J., Anderson, R.E., 2010. Multivariate Data Analysis. Prentice Hall.

Hennemann II, W.W., 1983. Relationship among body mass, metabolism rate and the intrinsic rate of natural increase in Mammals. Oecologia 56, 104-108.

Hingst-Zaher, E., Marcus, L.F., Cerqueira, R., 2000. Application of geometric morphometrics to the study of postnatal size and shapechanges in the skull of Calomys expulsus. Hystrix 11, 99-113.

Hofreiter, M., Poinar, H.N., Spaulding, W.G., Bauer, K., Martin, P.S., Possnert, G., Paabo, S., 2000. A molecular analysis of ground sloth diet through the last glaciation. Molecular Ecology 9, 1975-1984. 
Holz, M., Simões, M.G., 2002. Elementos fundamentais de tafonomia. Editora da Universidade - UFRS, Porto Alegre.

Johnson, C.N., 2002. Determinants of loss of mammal species during the Late Quaternary 'megafauna' extinctions: life history and ecology, but not body size. Proceedings of the Royal Society B-Biological Sciences 269, 2221-2227.

Klingenberg, C.P., Barluenga, M., Meyer, A., 2002. Shape analysis of symmetric structures: Quantifying variation among individuals and asymmetry. Evolution 56, 1909-1920.

Koch, P.L., Barnosky, A.D., 2006. Late quaternary extinctions: State of the debate(Ed.), Annual Review of Ecology Evolution and Systematics. Annual Review of Ecology Evolution and Systematics, pp. 215-250.

Lauder, G.V., 1981. Form and function: structural analysis in evolutionary morphology. Palaeobiology 7, 430-442.

MacFadden, B.J., 2005. Diet and habitat of toxodont megaherbivores (Mammalia, Notoungulata) from the late Quaternary of South and Central America. Quaternary Research 64, $113-124$.

McAfee, R.K., 2011. Feeding mechanics and dietary implications in the fossil sloth Neocnus (Mammalia: Xenarthra: Megalonychidae) from Haiti. Journal of Morphology 272, 1204-1216.

McDonald, H.G., 1995. Gravigrade xenarthrans from the Early Pleistocene Leisey Shell Pit 1A, Hillsborough County, Florida. Bulletin of the Florida Museum of Natural History 37, $345-373$. 
McDonald, H.G., 2005. Paleoecology of extinct xenarthrans and the great American biotic interchange. Bulletin of the Florida Museum of Natural History 45, 313-333.

McNab, B. K. 1985. Energetics, population biology, and distribution of xenarthrans, living and extinct. Em: Montgomery, G.G. (Ed.), The evolution and ecology of armadillos, sloths and vermilinguas. Smithsonian Institution Press, Washington and London, pp. 219-232.

Morrison, D.G., 1969. On the interpretation of discriminant analysis. Journal of Marketing Research 6, 156-163.

Paula Couto, C. 1979. Tratado de paleomastozoologia. Academia Brasileira de Ciências, Rio de Janeiro.

Poinar, H.N., Hofreiter, M., Spaulding, W.G., Martin, P.S., Stankiewicz, B.A., Bland, H., Evershed, R.P., Possnert, G., Paabo, S., 1998. Molecular coproscopy: Dung and diet of the extinct ground sloth Nothrotheriops shastensis. Science 281, 402-406.

Polyak, V.J., Asmerom, Y., Burns, S.J., Lachniet, M.S., 2012. Climatic backdrop to the terminal Pleistocene extinction of North American mammals. Geology 40, 1023-1026.

Porto, A., Oliveira, F.B.D., Shirai, L.T., Conto, V.D., Marroig, G., 2009. The evolution of modularity in the mammalian skull I: Morphological integration patterns and magnitudes. Evolutionary Biology 36, 118-135.

Pujos, F., Gaudin, T.J., De Iuliis, G., Cartelle, C., 2012. Recent advances on variability, morpho-functional adaptations, dental terminology, and evolution of sloths. Journal of Mammalian Evolution 19, 159-169. 
R Development Core Team, 2011. A language and environment for statistical computing. R Foundation for Statistical Computing, Vienna, Austria.

Radinsky, L.B., 1987. The evolution of vertebrate design. University of Chicago Press, Chicago.

Ramakrishnan, U., Hadly, E.A., 2009. Using phylochronology to reveal cryptic population histories: review and synthesis of 29 ancient DNA studies. Molecular Ecology 18, $1310-1330$.

Redford, K.H., 1985. Food habits of armadillos (Xenarthra: Dasypodidae). Em: Montgomery, G.G. (Ed.), The evolution and ecology of armadillos, sloths and vermilinguas. Smithsonian Institution Press, Washington and London, pp. 429-437.

Redford, K.H., Eisenberg, J.F., 1992. Mammals of the neotropics. The southern cone. Volume 2. Chile, Argentina, Uruguay, Paraguay. The University of Chicago Press, Chicago.

Rohlf, F.J., 1998. On applications of geometric morphometrics to studies of ontogeny and phylogeny. Systematic Biology 47, 147-158.

Rohlf, F.J., Slice, D., 1990. Extensions of the Procrustes method for the optimal superimposition of landmarks. Systematic Zoology 39, 40-59.

Ruez, D.R., 2005. Diet of Pleistocene Paramylodon Harlani (Xenarthra : Mylodontidae): review of methods and preliminary use of carbon isotopes. Texas Journal of Science 57, 329344. 
Rule, S., Brook, B.W., Haberle, S.G., Turney, C.S.M., Kershaw, A.P., Johnson, C.N., 2012. The aftermath of megafaunal extinction: ecosystem transformation in Pleistocene Australia. Science 335, 1483-1486.

Simpson, G.G., 1980. Splendid isolation: The curious history of South American mammals. Yale University Press, New Haven and London.

Steadman, D.W., Martin, P.S., MacPhee, R.D.E., Jull, A.J.T., McDonald, H.G., Woods, C.A.,Iturralde-Vinent, M., Hodgins, G.W.L., 2005. Asynchronous extinction of late Quaternary sloths on continents and islands. Proceedings of the National Academy of Sciences of the United States of America 102, 11763-11768.

Toledo, P.M.d., 1998. Locomotory Patterns within the Pleistocene Sloths. Museu Paraense Emílio Goeldi Press, Belém.

Van Soest, P.J., 1994. Nutritional ecology of the ruminant. Cornell University Press, Ithaca.

Vizcaino, S.F., Bargo, M.S., Farina, R.A., 2008. Form, function, and paleobiology in Xenarthrans. University Press of Florida, Gainesville.

Vizcaino, S.F., De Iuliis, G., Bargo, M.S., 1998. Skull shape, masticatory apparatus, and diet of Vassallia and Holmesina (Mammalia: Xenarthra: Pampatheriidae): when anatomy constrains destiny. Journal of Mammalian Evolution 5, 291-322.

Vizcaino, S.F., Bargo, M.S., Farina, R.A., 2008. Form, function and paleobiology of the Xenarthra. Em: Vizcaino, S.F. (Ed.), The Biology of the Xenarthra. University Press of Florida, Gainsville, pp. 86-99. 
Vizcaino, S.F., Farina, R.A., Fernicola, J.C., 2009. Young Darwin and the ecology and extinction of Pleistocene South American fossil mammals. Revista de la Asociacion Geologica Argentina 64, 160-169.

Zeldich, M.L., Donald, L.S., Sheets, H.D., Fink, W.L., 2004. Geometric morphometric for biologists: a primer. Elsevier Academic Press, New York.

Zuur, A.F., Ieno, E.N., Smith, G.M., 2007. Analysing Ecological Data. Springer. 


\section{Conclusões gerais}

Esta tese teve por objetivo principal iniciar a compreensão da evolução morfológica craniana dos Xenarthra através de uma abordagem integrativa (unindo genética quantitativa, morfometria e sistemática). Apesar da longa história evolutiva desta magnaordem (> 60 milhões de anos), as análises realizadas apontaram para a semelhança/proporcionalidade entre as matrizes-P dos gêneros do grupo. Isso sugere que elas podem ser utilizadas tanto como substitutas das matrizes-G quanto aplicadas no contexto macroevolutivo. Os resultados também mostraram que as matrizes-P são proporcionais entre grupos atuais e extintos. Embora não houvesse razões para desconfiar do contrário, antes desta tese isto não havia sido testado empiricamente para qualquer grupo de mamíferos (em grande parte devido a limitações amostrais impostas pelo registro fóssil). A similaridade/proporcionalidade entre as matrizes-P dos diversos gêneros de Xenarthra sugere que a seleção estabilizadora foi importante na manutenção das características dessas matrizes.

As análises realizadas sugerem que a seleção natural teve papel importante na diversificação morfológica dos Xenarthra, ao menos nos níveis mais inclusivos. Os estudos realizados também indicaram que a seleção natural potencialmente atuou na diversificação do grupo para invadir zonas adaptativas relacionadas à dieta. A invasão dessas zonas adaptativas possivelmente ocorreu através de mudanças associadas ao tamanho alométrico, e pelo menos em alguns casos através da coseleção entre tamanho alométrico e regiões da face e da abóbada.

O crânio dos Xenarthra está estruturado em módulos relacionados ao desenvolvimento e/ou a execução de função comum. Estes módulos são mais conspícuos na região facial, particularmente nas sub-regiões nasal e ora. Ainda, existe uma intrincada relação entre a 
influência do tamanho alométrico na determinação das dimensões das matrizes-P e a potencial capacidade de resposta alinhada à seleção direcional de um determinado táxon.

Por último, foram realizadas análises para inferir a dieta de espécies fosseis de Xenarthra. Os resultados obtidos corroboraram os resultados de outras pesquisas: os Xenarthra extintos ao final do Pleistoceno/início do Holoceno apresentavam grande diversidade de hábitos alimentares. 


\section{Resumo}

Os Xenarthra representam um clado de mamíferos eutérios. Pouco se sabe sobre a evolução morfológica craniana do grupo. Esta tese iniciou os estudos relativos a esta questão com base na genética quantitativa, na morfometria e na sistemática, e teve por objetivos específicos: 1) avaliar empiricamente se as matrizes de variância e covariância fenotípica (matriz-P) dos diversos gêneros de Xenarthra estudados podem ser utilizadas como substitutas das respectivas matrizes de variância e covariância genética aditiva (matriz-G), uma vez que não existem matrizes-G estimadas para os Xenarthra, e também se elas podem ser utilizadas em estudos macroevolutivos; 2) testar se a diversificação morfológica craniana no grupo ocorreu somente através de deriva genética; e 3) compreender como a relação entre os caracteres morfológicos (módulos) e a magnitude geral de integração podem influir na evolução morfológica craniana. Além destes objetivos focados na evolução do grupo, também foi escopo desta tese inferir o hábito alimentar de taxa fósseis do final do Pleistoceno/início do Holoceno para melhorar o conhecimento sobre a ecologia de alguns grupos fósseis. O banco de dados utilizado foi composto por medidas lineares de aproximadamente 1150 espécimes adultos, representando 12 dos 14 gêneros atuais e sete dos diversos gêneros extintos de Xenarthra. Com base nesses dados, matrizes-P de variância e covariância e de correlação foram estimadas para cada gênero. Essas matrizes foram posteriormente comparadas par a par para avaliar a semelhança na estrutura das diferentes matrizes. Também a partir dessas matrizes, foram obtidas as variâncias entre e intra populações para testar se a diversificação morfológica ocorreu de acordo com a expectativa teórica de diversificação sob a ação exclusiva de deriva genética. As mesmas matrizes-P foram comparadas a diferentes matrizes teóricas de hipóteses de modularidade craniana. As matrizes teóricas expressaram a relação entre os caracteres com base no desenvolvimento e/ou desempenho de 
função compartilhado pelas partes do crânio. Para cada matriz-P de correlação calculou-se a magnitude geral de integração. Além disto, a dieta dos grupos extintos foi inferida através de análises de funções discriminantes a partir da relação entre forma e função dos animais atuais. Os resultados obtidos indicam que as matrizes-P dos diversos gêneros são similares entre si, o que sugere que matrizes-P podem ser utilizadas tanto como substitutas das matrizes-G quanto no contexto macroevolutivo. Os resultados obtidos refutaram a hipótese nula da diversificação morfológica craniana ocorrendo somente por deriva genética, ao menos nos níveis mais inclusivos da filogenia dos Xenarthra. Consequentemente, a seleção natural provavelmente atuou neste processo de diversificação. Os resultados também sugeriram que o crânio desse grupo está organizado em módulos, sendo os módulos mais conspícuos os relacionados à face. Além disso, foi detectada grande variação na magnitude geral de integração entre gêneros. A variação no padrão modular, mas principalmente na magnitude geral de integração, faz com que os gêneros apresentem diferenças nas possíveis capacidades de responder de forma alinhada às pressões seletivas. Por último, as análises morfofuncionais indicaram elevada diversidade de hábitos alimentares entre os Xenarthra extintos. 


\section{Abstract}

Xenarthra are an eutherian mammal clade and little is known about their cranial morphological evolution. This thesis has initiated studies related to this topic and, based on quantitative genetics, morphometrics and systematics, aimed to: 1) empirically assess if the phenotypic variance and covariance matrices (P-matrix) of several genera can be used as surrogates for their respective additive genetic variance and covariance matrices (G-matrix), since G-matrices for Xenarthra are not available, and also if P-matrices can be used in macroevolutionary studies; 2) test whether the skull morphological diversification within the group occurred only through genetic drift; and 3) understand how the relationship between the traits (modules) and overall magnitude of integration may influence cranial morphological evolution. Besides these objectives focused on the evolution of the group, it was also within the scope of this thesis to infer the feeding habits of late Pleistocene/early Holocene fossil taxa to better understand the ecology of some fossil groups. The database used consist of linear measurements of approximately 1150 adult specimens, representing 12 of the 14 extant genera and seven of the several extinct genera of Xenarthra. The data gathered were used to estimate variance/covariance and correlation P-matrices for every genus. These matrices were compared between pairs of genera to evaluate the matrices' structural similarities. Based on these matrices, within and between population variances were obtained and it was tested whether morphological diversification was in accordance to the theoretical expectation of diversification under genetic drift alone. The same matrices were compared to theoretical matrices expressing modularity hypotheses. These theoretical matrices represent the relationship among traits in reference to the shared development and/or function of different skull's anatomical regions (modules). For every correlation P-matrix the overall magnitude of integration was calculated. Moreover, the extinct 
groups' diet was inferred through discriminant function analysis relying on the relationship between form and function of extant animals. Results indicate that P-matrices from several genera were structurally similar. This suggests that P-matrices can be used as surrogates of their G-matrices and in the macroevolutionary context. Results refuted the null hypothesis of cranial morphological diversification occurring only due to genetic drift, at least in more inclusive levels of Xenarthran phylogeny. Consequently, natural selection probably acted on this diversification process. The results also suggested that the Xenarthran skull is organized in modules, and the most conspicuous modules are in the face region. A large variation in the overall magnitude of integration among genera was detected. The variation in the modular pattern, but especially in the overall magnitude of integration, allows genera to differ in their potential capacity to respond aligned with selective pressures. Finally, morphofunctional analyses indicate a high diversity of feeding habits among extinct Xenarthra. 


\section{Anexos}

\section{Sigla das instituições}

AMNH: American Museum of Natural History; CAS: California Academy of Science; FC: Faculdad de Ciencias de la Universidad de la Republica; FMNH: Field Museum of Natural History; GOELDI: Museu Paraense Emílio Goeldi; IMNH: Idaho Museum of Natural History; LACM: Los Angeles County Museum; LACMHC: Page Museum; MACN: Museo Argentino de Ciencias Naturales; MCN-PALEO: Museu de Ciências Naturais da PUC-MINAS; MCNRS: Museu de Ciências Naturais da Fundação Zoobotânica do Rio Grande do Sul; MLP: Museo de La Plata; MNHN: Museu Nacional de Historia Natural de Montevideo; MNRJ: Museu Nacional da Universidade Federal do Rio de Janeiro; MVZ: University of California Museum of Vertebrate Zoology; MZUSP: Museu de Zoologia da Universidade de São Paulo; NHM: Natural History Museum; UCMP: University of California Museum of Paleontology; UF: Florida Museum of Natural History; USNM: Smithsonian National Museum of Natural History; CPMT: coleçãoparticular de Mauro Teixeira; CPA: coleção particular Paulo Auricchio.

\section{Lista do material examinado}

Acratocnus odontrigonus:

AMNH17722, AMNH17715, AMNH17720, AMNH17158, AMNH17721,

Acratocnus ye:

UF156893, UF76399, UF76368,

Bradypus pygmaeus:

USNM578413, USNM579171, USNM579173, USNM579174, USNM579175, USNM579177, USNM579178,

Bradypus torquatus:

MNRJ23911, MNRJ5899, MZUSP10074, USNM259473 
Bradypus tridactylus:

AMNH78968, AMNH95326, MZUSP23159, UF24821, UF25986, UF25987, USNM256676, USNM374818, USNM374821,

Bradypus variegates:

AMNH133419, AMNH31427, AMNH32700, AMNH74429, AMNH80447, AMNH92334, AMNH92845, AMNH93104, AMNH95102, AMNH95105, AMNH95106, AMNH96245, AMNH96248, AMNH96249, AMNH96251, AMNH96252, AMNH96253, CAS20747, FMNH140254, FMNH21551, FMNH25317, FMNH25318, FMNH25319, FMNH86879, GOELDI10239, GOELDI13271, GOELDI6749, LACM24679, LACM25990, LACM26679, LACM54555, MACN207, MACN50120, MVZ116813, MVZ157796, MVZ157797, MZUSP10061, MZUSP10417, MZUSP10666, MZUSP13498, MZUSP13501, MZUSP13502, MZUSP13510, MZUSP19924, MZUSP20003, MZUSP20005, MZUSP2299, MZUSP2300, MZUSP23501, MZUSP23505, MZUSP23519, MZUSP23527, MZUSP23529, MZUSP23532, MZUSP23533, MZUSP23536, MZUSP23541, MZUSP23547, MZUSP23550, MZUSP23555, MZUSP23556, MZUSP23559, MZUSP23562, MZUSP23566, MZUSP23567, MZUSP23568, MZUSP23569, MZUSP23570, MZUSP23571, MZUSP23573, MZUSP23576, MZUSP23578, MZUSP23582, MZUSP23583, MZUSP23589, MZUSP23590, MZUSP23592, MZUSP23596, MZUSP2893, MZUSP3650, MZUSP5300, MZUSP7117, MZUSP7528, MZUSP7701, MZUSP785, UF25981, USNM170889, USNM239454, USNM296293, USNM296409, USNM305593, USNM315852, USNM315853, USNM324252, USNM324261, USNM335466, USNM338776, USNM339632, USNM393816, USNM449525, USNM449527, USNM449529, USNM449530, USNM461731, USNM464850, USNM543921, USNM545912, USNM545915, USNM545917, USNM545919, USNM545920, USNM545926, USNM545930, USNM545934, USNM545936, USNM549523, USNM575379, USNM575380, USNM578416, USNM579170

Cabassous centralis:

UF24155, USNM281281, USNM281283, USNM281292, USNM314577,

Cabassous tatouay:

AMNH133314, AMNH133317, AMNH133321, AMNH242517, FMNH22437, MACN47377, MCNRS2556, MNRJ1854, MNRJ4665, MZUSP1083, MZUSP13798, MZUSP6491, NHM47-45-6, NHM48-5-6-15, USNM19545,

Cabassous unicinctus:

AMNH133318, AMNH133319, AMNH133334, AMNH133335, AMNH133336, AMNH133382, AMNH136256, AMNH14862, AMNH23441, AMNH366, AMNH60636, CPMTsn1, CPMTsn2, FMNH26471, GOELDI12487, GOELDI4667, GOELDI4668, 
MACN4388, MNRJ17508, MNRJ23983, MNRJ71, MZUSP6360, MZUSP7035, MZUSPAPC1203, NHM12-6-5-36, NHM71-2503, USNM113422,

Chaetophractus vellerosus:

AMNH246457, AMNH261305, FMNH54352, MACN14821, MACN14841, MACN1623, MACN236, MACN2926, MACN2927, MACN29726, MACN30396, MACN312, MACN34655, MACN35308, MACN35337, MACN38252, MACN39410, MACN42183, MACN47378, MACN48357, MACN48358, MACN48359, MACN48360, MACN48361, MACN48366, MACN49138, MACN5038, MACN5039, MACN5044, MLP1747, MVZ145361, NHM16-7-5-1, NHM2-1-5-15, NHM2-2-5-32, NHM2-2-5-33, NHM2-2-5-34, NHM2-2-5-35, NHM2-2-5-36, NHM21-4-8-22, NHM21-4-8-23, NHM21-4-8-24, NHM21-4-8-25, NHM25-5-6-3, NHM34-114-188, NHM90-2-20-7, CPA1130, UF14763,

Chaetophractus villosus:

AMNH173546, FC1152, FMNH24333, FMNH24334, FMNH24335, MACN13643, MACN13942, MACN2417, MACN26167, MACN27143, MACN27144, MACN28220, MACN28266, MACN28269, MACN2844, MACN29935, MACN34723, MACN36688, MACN3699, MACN36993, MACN39337, MACN39409, MACN4086, MACN4348, MACN47211, MACN48363, MACN48364, MACN49166, MNHN896, MVZ162188, MVZ164045, MVZ4833, USNM172752, USNM172754, USNM172758, USNM172759, USNM172763, USNM172764, USNM172768, USNM172769, USNM172778, USNM364527, USNM391014, USNM96514, USNM96515,

Choloepus didactylus:

AMNH133410, AMNH21307, AMNH75960, AMNH98531, FMNH65796, FMNH90058, MNRJ5039, MVZ121440, MZUSP2899, MZUSP5445, MZUSP5459, MZUSP781

Choloepus hoffmanni:

AMNH131821, AMNH135331, AMNH135332, AMNH141856, AMNH18898, AMNH26909, AMNH26920, AMNH29440, AMNH29649, AMNH29651, AMNH35513, CAS28747, CAS7222, FMNH156656, FMNH60549, MVZ155187, MVZ4825, MZUSP5461, NHM80-5-650, UF13490, UF25993, UF25994, USNM12856, USNM12858, USNM12859, USNM12862, USNM260865, USNM260868, USNM268206, USNM290465, USNM296413, USNM298708, USNM298709, USNM298710, USNM310369, USNM315858, USNM337562, USNM338822, USNM399053, USNM464860, USNM520771, USNM575390

Cyclopes didactylus:

AMNH139460, USNM248343, USNM304941, USNM314573, USNM314574, USNM583067, MVZ190355, AMNH16129, FMNH21719, FMNH34247, FMNH69969, USNM545910, 
AMNH135084, USNM148761, AMNH18887, AMNH30744, AMNH130107, FMNH44056, FMNH64187, FMNH93175, USNM19472, USNM77089, USNM78111, USNM294075, USNM297891, USNM297892, USNM314576, AMNH186442, FMNH44055, USNM100040, USNM100172, USNM100173, USNM100174, USNM337712, LACM27345, MVZ121210, MVZ157801, MZUSP3177, MZUSP4687, MZUSP4689, MZUSP4691, MZUSP4700, MZUSP19934, MZUSP19938, MZUSP19944, MZUSP3176, MZUSP4685, AMNH37786, AMNH75281, AMNH77354, AMNH77355, AMNH95506, AMNH96444, AMNH96446, AMNH96450, AMNH96451, AMNH96456, AMNH96457, AMNH96459, AMNH96463, AMNH96467, AMNH96468, AMNH96470, AMNH96471, AMNH98519, AMNH98526, FMNH19500, FMNH20033, FMNH50907, FMNH69971, FMNH71002, USNM143741, USNM364503, USNM554227, LACM56112, MZUSP3178, MZUSP19939, AMNH78636, AMNH96445, AMNH96449, AMNH96452, AMNH96454, AMNH96455, AMNH96461, AMNH96465, AMNH98520, AMNH98523, AMNH262656, FMNH19501, FMNH51889, MZUSP4693,

Dasypus hybridus:

AMNH205691, AMNH205707, FCsn2, FMNH29332, FMNH293334, FMNH29335, FMNH29336, MACN13220, MACN13900, MACN3017, MACN3315, MACN3319, MACN36980, MACN49460, MACN54156, MLP1I0365, MLP1I0371, MLP869, MNHN1816, MNHN1817, MNHN1927, MNHN2675, MNHN2761, MNHN2771, MNHN4300, MNHN4713, MNHN684, MNHN688, MNHN689, USNM96511

Dasypus kappleri:

AMNH136251, AMNH136253, AMNH136255, AMNH267011, AMNH48132, AMNH48222, AMNH64118, AMNH76933, AMNH77755, AMNH98464, AMNH98812, FMNH30348, FMNH87914, FMNH87915, GOELDI4676, GOELDIMG12331, MVZ157805, MZUSP19967, MZUSP19974, MZUSP24798, NHM14-4-25-87, NHM1493a, NHM80-5-6-71, USNM374825, USNM388210,

Dasypus novemcinctus:

AMNH128134, AMNH133265, AMNH133329, AMNH133338, AMNH133342, AMNH133346, AMNH133358, AMNH133361, AMNH133364, AMNH133365, AMNH133371, AMNH136254, AMNH171919, AMNH171921, AMNH205726, AMNH208910, AMNH211667, AMNH211668, AMNH24061, AMNH242339, AMNH242661, AMNH242662, AMNH242663, AMNH255865, AMNH255866, AMNH255868, AMNH255869, AMNH267012, AMNH35650, AMNH365, AMNH37356, AMNH40984, AMNH68607, AMNH73692, AMNH93116, AMNH93734, AMNH93735, AMNH95110, AMNH95111, AMNH95113, AMNH95116, AMNH95117, AMNH95128, CAS16591, CAS6062, FMNH11089, FMNH18748, FMNH18751, FMNH18753, FMNH18760, FMNH18761, FMNH28349, FMNH30476, FMNH30477, FMNH34191, FMNH34351, 
FMNH34353, FMNH39304, FMNH39305, FMNH51964, FMNH70817, FMNH70819, FMNH84244, FMNH88468, FMNH92354, FMNH92358, FMNH92960, FMNH94299, FMNH95452, LACM10015, LACM46145, MACN49391, MCNRS2788, MCNRS5249, MNHN1205, MNHNsn1, MVZ131027, MVZ131028, MVZ155193, MVZ155194, MVZ183662, MVZ98902, MZUSP1640, MZUSP1641, MZUSP19976, MZUSP19978, MZUSP20189, MZUSP27882, MZUSP27883, UCMP128145, UCMP128149, UF20653, UF20654, UF3233, UF5093, UF7866, UF9237, USNM105533, USNM11383, USNM244903, USNM244905, USNM258612, USNM271098, USNM281284, USNM283467, USNM296414, USNM296415, USNM29719, USNM33167, USNM33168, USNM33169, USNM33170, USNM33171, USNM33172, USNM33173, USNM33174, USNM331997, USNM335477, USNM337563, USNM337565, USNM337719, USNM337720, USNM339668, USNM339937, USNM34350, USNM34861, USNM36355, USNM406496, USNM406700, USNM416689, USNM442790, USNM442793, USNM442794, USNM442797, USNM449877, USNM464378, USNM464379, USNM464380, USNM464862, USNM464865, USNM53321, USNM553928, USNM565067, USNM568206, USNM575609, USNM575610, USNM575611, USNM575612, USNM575613, USNM575614, USNM575616, USNM575618, USNM575619, USNM575620, USNM575621, USNM575622, USNM575623, USNM575624, USNM575625, USNM575627, USNM575629, USNM578435, USNM579180, USNMA01409

Eremotherium laurillardi:

MCN-PALEOMCL1702, MCN-PALEOMCL1700, MCN-PALEOMCL7240, MCNPALEOsnvenon, UF15004,

Euphractus sexcinctus:

AMNH100075, AMNH133288, AMNH133296, AMNH133297, AMNH133302, AMNH133303, AMNH133306, AMNH133323, AMNH133343, AMNH133344, AMNH133345, AMNH133348, AMNH133349, AMNH133387, AMNH133390, AMNH133391, AMNH133401, AMNH135345, AMNH205685, AMNH260319, AMNH362, AMNH364, AMNH37156, AMNH4326, AMNH4345, AMNH4346, AMNH4349, AMNH5026, AMNH61803, AMNH70179, AMNH80098, AMNH80270, AMNH90108, AMNH90424, CPA031, FC1277, FC5538, FC5539, FMNH28352, FMNH28354, FMNH34349, FMNH54325, LACM10017, LACM60643, MACN1124, MACN239, MACN299, MACN34592, MACN34714, MACN4528, MACN4530, MACN4531, MACN4938, MACN50121, MCNPALEOsn1, MNHN2542, MNHN2543, MNHN2653, MNHN2758, MNHN3179, MNHN3195, MNHN5500, MNHN6184, MNHN692, MNHN781, MNHNsn1, MNHNsn2, MNHNsn3, MZUSP1005, MZUSP1099, MZUSP13735, MZUSP28811, MZUSP3138, MZUSP32196, MZUSP341, MZUSP495, MZUSP6359, USNM1482, USNM241105, USNM256115, USNM257915, USNM257968, USNM258603, USNM259462, USNM260213, USNM4030

Glossotherium robustum: 
MNHN1390, MNHN441, MNHN914, MNHNsn, NHM40483,

Megalonyx jeffersonii:

MNH23094, MNH38001-87

Megalonyx leptostomus:

UF216900,

Megatherium sp.:

FMNHP26970,

Myrmecophaga tridactyla:

AMNH73588, AMNH75983, AMNH100139, FMNH20014, FMNH26563, FMNH92078, GOELDI4658, MVZ155168, MVZ157804, -tridactylaUSNM362239, FMNH87898, FMNH87900, FMNH87901, MZUSP5454, MVZ185238, FMNH44086, FMNH49338, FMNH95014, MZUSP3683, MACN176, AMNH130242, AMNH135715, LACM52547, FMNH92251, AMNH133489, FMNH28309b, AMNH75349, AMNH77902, AMNH100068, AMNH136246, FMNH15966, FMNH88891, GOELDI1455, GOELDI4660, MACN50538, MVZ125980, -tridactylaUSNM361028, -tridactylaUSNM406490, -tridactylaUSNM281351, tridactylaUSNM388302, MZUSP5273, AMNH77561, AMNH78508, USNM269398, MACN50552, GOELDI4236, USNM239008, AMNH70308, FMNH98159, CAS9831, AMNH194, AMNH16137, AMNH36957, AMNH36958, AMNH75348, AMNH98512, AMNH130463, AMNH133490, AMNH136248, AMNH147492, FMNH28309, GOELDI22494, MACN2328, MACN30242, MVZ145368, UF8429, -tridactylaUSNM388199, MZUSP24254, MNHNsn1, MZUSP7480, AMNHCA2414, AMNH173552, AMNH149423, AMNH70041, AMNH80016, AMNH80292, AMNH100087, MCNRS2654, AMNH21302, tridactylaUSNM339666, -tridactylaUSNM388200, MZUSP1170, AMNH136249, GOELDI4230, MVZ137556,

Neocnus comes:

UF131990, UF170527, UF171281, UF25702, UF76356, UF76795

Neocnus dousman:

UF76794,

Nothrotheriops shastensis:

LACM192, LACMHC208, LACMHC313, LACMHC632, LACMHCR52220, Nothrotherium maquinense: 
MCN-PALEOMCL1020,

Paramylodon harlani:

AMNH16896, AMNH2780, FMNHPM3646, FMNHsn, LACM696, LACMHC14537, LACMHC644, LACMHC645, LACMHC693, LACMHC696, LACMHC818, LACMHC820, LACMHC822, LACMHC825, LACMHC826, LACMHC827, LACMHC828, LACMHC831, LACMHC832, LACMHC833, LACMHC835, LACMHCR49901, UCMP21156, UCMP21159, UCMP21160, UCMP21161， UCMP21172， UCMP21173， UCMP23004， UCMP23005, UCMP23009, UCMPsn1， UCMP23003， UCMP23006， LACMHC707， IMNH15273, UCMP21170completo, LACMHC834, LACMHC12369, UF83769

Priodontes maximus:

AMNH130122, AMNH130387, AMNH208104, AMNH64120, AMNH93418, FMNH25271, FMNH72913, FMNH87921, GOELDI1000, GOELDI4232, GOELDI4675, GOELDI980, GOELDI981, LACM52370, MACN1141, MACN15691， MACN4529, MNRJ1323, MNRJ32696, MZUSP12854, MZUSP3680, MZUSP3681, MZUSPSN1, NHM1963-2-5-1, NHM46-4-21-6, USNM261024, USNM270373, USNM406694, USNM406695,

Scelidotherium bravardi:

NHM37626,

Scelidotherium leptocephalum:

AMNH45910, FMNHP14274, MACN13880, MACN13883, MACN2215, MLP25, MLP3-402, MLP3-408, MLP3-420, MLP3-770, MLP35-III-1-1, MLP409, MLP671, MLPsn1, NHM32995, USNM5938

\section{Tamandua Mexicana:}

AMNH135975, AMNH141988, AMNH148801, AMNH190190, AMNH190192, FMNH14210, FMNH22398, FMNH30740, FMNH44070, FMNH68925, FMNH68926, LACM23986, MVZ131017, MVZ131020, AMNH23407, AMNH23408, AMNH23409, AMNH23410, AMNH23415, AMNH23416, AMNH23417, AMNH23419, AMNH23423, AMNH23427, AMNH23434, AMNH23435, AMNH23436, AMNH23439, AMNH23565, AMNH23567, AMNH33173, AMNH176664, AMNH207419, FMNH74915, MVZ98897, MVZ164795, FMNH13170, FMNH68924, FMNH90062, FMNH90064, FMNH13169, USNM443250, USNM443257, USNM281343, USNM297893, USNM306853, USNM314572, USNM315845, USNM318365, USNM362297, USNM464846, USNMA15962, USNM337709, USNM449541, USNM171482,

Tamandua tetradactyla: 
AMNH130464, AMNH130466, AMNH130467, AMNH130468, AMNH130470, AMNH130471, AMNH132789, AMNH136243, AMNH142249, AMNH142987, AMNH16936, AMNH17561, AMNH188191, AMNH203374, AMNH211657, AMNH246456, AMNH262655, AMNH42865, AMNH48147, AMNH61793, AMNH71818, AMNH74114, AMNH75984, AMNH76855, AMNH76902, AMNH95332, AMNH95829, AMNH96260, AMNH96262, AMNH96263, AMNH96264, AMNH96265, AMNH96267, AMNH96270, AMNH96277, AMNH96281, AMNH96283, AMNH96284, AMNH98575, CPA793, FMNH20973, FMNH46202, FMNH52490, FMNH89853, FMNH92965, FMNH93176, FMNH95439, FMNH95440, MACN14896, MNHN2959, MVZ153482, MVZ153483, MVZ153484, MVZ153487, MVZ155171, MVZ155172, MVZ155173, MVZ155176, MVZ155178, MVZ155181, MVZ157798, MVZ157799, MVZ157800, MZUSP1763, MZUSP1927, MZUSP19960, MZUSP23593, MZUSP23594, MZUSP31990, MZUSP4978, MZUSP5136, MZUSP5236, MZUSP5240, USNM114839, USNM339664, USNM372829, USNM406682, USNM406687, USNM406688, USNM441965, USNM441971, USNM461730, USNM546272,

Tolypeutes matacus:

AMNH173550, AMNH246460, AMNH246461, AMNH247658, AMNH248394, FMNH121540, FMNH122233, FMNH124570, FMNH153773, FMNH187452, FMNH28339, FMNH28340, FMNH28342, FMNH28345, FMNH54353, LACM27349, LACM27350, MACN22308, MACN29908, MACN30394, MACN47212, MACN5042, MLP1853, MVZ145365, MVZ145366, MVZ145367, NHM140a, NHM16-1-6-52, NHM46-7-28-36, NHM73-4-16-26, UF13834, UF14764, UF8869, USNM236356

Tolypeutes tricinctus:

MNRJ1503, MNRJ24030, MNRJ32440, MNRJ4292, MNRJ4294, MZUSP2654, MZUSP2656, MZUSP3134, MZUSP32632, MZUSPARP55, NHM41-601, NHM49-3-13-1, NHM730d, NHM76-1393, NHM76-1394,

Zaedyus pichiy:

AMNH173547, AMNH17448, AMNH25667, AMNH94327, FC1144, FMNH104817, FMNH23810, FMNH23811, FMNH25617, FMNH28505, FMNH28507, LACM59580, LACM59582, LACM59583, MACN28196, MACN2843, MACN297, MACN3014, MACN3033, MACN335, MACN341165, MACN4287, MLP1237a, MLP1237b, MLP1745, MLP1746, MLP1850, MLP1869, MLP889, MLP9XII0210, MNHN2676, MVZ164046, MVZ165808, NHM16-10-3-81, NHM21-6-7-16, NHM22-11-23-1, NHM27-6-4-56, NHM3-7-981, USNM12641, USNM172750, USNM236359, USNM395280 
Tabela A1 - Distâncias de Mahalanobis entre os Xenarthra para os conjuntos de dados 35D, 32D, 28D e 25D.

\begin{tabular}{|c|c|c|c|c|c|c|c|c|c|c|c|c|c|c|}
\hline 35D & 1 & 2 & 3 & 4 & 5 & 6 & 7 & 8 & 9 & 10 & 11 & 12 & & \\
\hline 1. Zaedyus & 0 & 233,2 & 1257,6 & 254,4 & 312,4 & 34,4 & 271,1 & 904,4 & 451,3 & 4299 & 668 & 1460,9 & & \\
\hline 2. Tolypeutes & 233,2 & 0 & 937,8 & 509,3 & 167,2 & 324,9 & 153,6 & 735,6 & 272,5 & 4006,7 & 448,6 & 1121 & & \\
\hline 3. Priodontes & 1257,6 & 937,8 & 0 & 1135,3 & 853,1 & 1301,7 & 654 & 1106,9 & 1462,8 & 3457,5 & 1342,2 & 1901,7 & & \\
\hline 4. Euphractus & 254,4 & 509,3 & 1135,3 & 0 & 592,9 & 142,9 & 495,6 & 1195,2 & 877,1 & 4359,1 & 778,7 & 1394,3 & & \\
\hline 5. Dasypus & 312,4 & 167,2 & 853,1 & 592,9 & 0 & 432,6 & 200 & 793,8 & 496,5 & 3891,3 & 793,7 & 1527,9 & & \\
\hline 6. Chaetophractus & 34,4 & 324,9 & 1301,7 & 142,9 & 432,6 & 0 & 340,1 & 986,5 & 580,1 & 4357,5 & 669,8 & 1429,1 & & \\
\hline 7. Cabassous & 271,1 & 153,6 & 654 & 495,6 & 200 & 340,1 & 0 & 718,2 & 463,2 & 3981,4 & 591,7 & 1247,1 & & \\
\hline 8. Tamandua & 904,4 & 735,6 & 1106,9 & 1195,2 & 793,8 & 986,5 & 718,2 & 0 & 502,1 & 2593 & 770,1 & 1412,9 & & \\
\hline 9. Cyclopes & 451,3 & 272,5 & 1462,8 & 877,1 & 496,5 & 580,1 & 463,2 & 502,1 & 0 & 4223,1 & 423,2 & 1020,8 & & \\
\hline 10. Myrmecophaga & 4299 & 4006,7 & 3457,5 & 4359,1 & 3891,3 & 4357,5 & 3981,4 & 2593 & 4223,1 & 0 & 4433,9 & 4819,8 & & \\
\hline 11. Bradypus & 668 & 448,6 & 1342,2 & 778,7 & 793,7 & 669,8 & 591,7 & 770,1 & 423,2 & 4433,9 & 0 & 474,9 & & \\
\hline 12. Choloepus & 1460,9 & 1121 & 1901,7 & 1394,3 & 1527,9 & 1429,1 & 1247,1 & 1412,9 & 1020,8 & 4819,8 & 474,9 & 0 & & \\
\hline 32D & 1 & 2 & 3 & 4 & 5 & 6 & 7 & 8 & 9 & 10 & 11 & 12 & & \\
\hline 1. Zaedyus & 0 & 218,6 & 1044,6 & 243,8 & 259,2 & 32,1 & 239,6 & 653,3 & 431,6 & 2685,3 & 582,4 & 1200,2 & & \\
\hline 2. Tolypeutes & 218,6 & 0 & 780,5 & 509,7 & 131 & 314,6 & 135,8 & 497,7 & 232,7 & 2408,4 & 342,5 & 834,8 & & \\
\hline 3. Priodontes & 1044,6 & 780,5 & 0 & 917,6 & 735,7 & 1060,4 & 547,9 & 1104,8 & 1356,2 & 2347,9 & 1101,9 & 1359,5 & & \\
\hline 4. Euphractus & 243,8 & 509,7 & 917,6 & 0 & 531 & 136,1 & 476 & 956,3 & 858,8 & 2823,9 & 746,2 & 1187,5 & & \\
\hline 5. Dasypus & 259,2 & 131 & 735,7 & 531 & 0 & 365,9 & 177,6 & 659,7 & 461,4 & 2452 & 609,9 & 1089,8 & & \\
\hline 6. Chaetophractus & 32,1 & 314,6 & 1060,4 & 136,1 & 365,9 & 0 & 301,9 & 719,2 & 557,3 & 2734,3 & 609,3 & 1200,3 & & \\
\hline 7. Cabassous & 239,6 & 135,8 & 547,9 & 476 & 177,6 & 301,9 & 0 & 598,2 & 465,1 & 2480,2 & 495,7 & 934,6 & & \\
\hline 8. Tamandua & 653,3 & 497,7 & 1104,8 & 956,3 & 659,7 & 719,2 & 598,2 & 0 & 297 & 1422 & 414,1 & 843,7 & & \\
\hline 9. Cyclopes & 431,6 & 232,7 & 1356,2 & 858,8 & 461,4 & 557,3 & 465,1 & 297 & 0 & 2377 & 289,2 & 759,2 & & \\
\hline 10. Myrmecophaga & 2685,3 & 2408,4 & 2347,9 & 2823,9 & 2452 & 2734,3 & 2480,2 & 1422 & 2377 & 0 & 2439,3 & 2625,5 & & \\
\hline 11. Bradypus & 582,4 & 342,5 & 1101,9 & 746,2 & 609,9 & 609,3 & 495,7 & 414,1 & 289,2 & 2439,3 & 0 & 353,7 & & \\
\hline 12. Choloepus & 1200,2 & 834,8 & 1359,5 & 1187,5 & 1089,8 & 1200,3 & 934,6 & 843,7 & 759,2 & 2625,5 & 353,7 & 0 & & \\
\hline 28D & 1 & 2 & 3 & 4 & 5 & 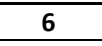 & 7 & 8 & 9 & 10 & 11 & 12 & 13 & \\
\hline 1. Zaedyus & 0 & 125,9 & 627 & 165,5 & 133,1 & 23 & 137,7 & 423,9 & 259,2 & 2239 & 315,8 & 565,4 & 8547,6 & \\
\hline 2. Tolypeutes & 125,9 & 0 & 542,3 & 379,9 & 91,9 & 194,1 & 94,9 & 342,8 & 139,2 & 2045,2 & 183,3 & 372,7 & 8326,7 & \\
\hline 3. Priodontes & 627 & 542,3 & 0 & 613,6 & 479,6 & 647,6 & 377,9 & 630,2 & 913,3 & 1593,7 & 717,3 & 803 & 6417,7 & \\
\hline 4. Euphractus & 165,5 & 379,9 & 613,6 & 0 & 378,6 & 83,2 & 355,3 & 640,3 & 626,4 & 2278,4 & 481,5 & 693,2 & 7982,4 & \\
\hline 5. Dasypus & 133,1 & 91,9 & 479,6 & 378,6 & 0 & 206,1 & 115,4 & 416,2 & 298 & 1923,7 & 393,9 & 584,8 & 8449,4 & \\
\hline 6. Chaetophractus & 23 & 194,1 & 647,6 & 83,2 & 206,1 & 0 & 186,1 & 462,4 & 353,3 & 2276,4 & 339,5 & 590,2 & 8394,9 & \\
\hline 7. Cabassous & 137,7 & 94,9 & 377,9 & 355,3 & 115,4 & 186,1 & 0 & 382,4 & 304,9 & 2062,4 & 308,8 & 490,6 & 7920 & \\
\hline 8. Tamandua & 423,9 & 342,8 & 630,2 & 640,3 & 416,2 & 462,4 & 382,4 & 0 & 255 & 1317,1 & 286,9 & 407,5 & 7478,1 & \\
\hline 9. Cyclopes & 259,2 & 139,2 & 913,3 & 626,4 & 298 & 353,3 & 304,9 & 255 & 0 & 2197,4 & 177 & 358,4 & 8327,6 & \\
\hline 10. Myrmecophaga & 2239 & 2045,2 & 1593,7 & 2278,4 & 1923,7 & 2276,4 & 2062,4 & 1317,1 & 2197,4 & 0 & 2163,1 & 2139,5 & 8027,2 & \\
\hline 11. Bradypus & 315,8 & 183,3 & 717,3 & 481,5 & 393,9 & 339,5 & 308,8 & 286,9 & 177 & 2163,1 & 0 & 158,4 & 7028 & \\
\hline 12. Choloepus & 565,4 & 372,7 & 803 & 693,2 & 584,8 & 590,2 & 490,6 & 407,5 & 358,4 & 2139,5 & 158,4 & 0 & 6196,5 & \\
\hline 13. Paramylodon & 8547,6 & 8326,7 & 6417,7 & 7982,4 & 8449,4 & 8394,9 & 7920 & 7478,1 & 8327,6 & 8027,2 & 7028 & 6196,5 & 0 & \\
\hline 25D & 1 & 2 & 3 & 4 & 5 & 6 & 7 & 8 & 9 & 10 & 11 & 12 & 13 & 14 \\
\hline 1. Zaedyus & 0 & 59,6 & 338,2 & 102,6 & 68,6 & 11,4 & 82,4 & 340 & 146,4 & 2058,2 & 201,1 & 360,7 & 4725,7 & 3116,5 \\
\hline 2. Tolypeutes & 59,6 & 0 & 284,6 & 159,3 & 69,7 & 69,7 & 66,2 & 244,3 & 90,3 & 1859,4 & 104,5 & 265,4 & 4655,1 & 3092,6 \\
\hline 3. Priodontes & 338,2 & 284,6 & 0 & 317,9 & 278,5 & 331,8 & 213,3 & 280,2 & 478,4 & 1343,6 & 349,4 & 486,8 & 3713 & 2453,5 \\
\hline 4. Euphractus & 102,6 & 159,3 & 317,9 & 0 & 179,7 & 57,3 & 193,5 & 451,8 & 318,9 & 2045,1 & 251,4 & 337,1 & 4313,9 & 2721 \\
\hline 5. Dasypus & 68,6 & 69,7 & 278,5 & 179,7 & 0 & 88 & 89,6 & 267,3 & 183,9 & 1711,4 & 241,9 & 411 & 4715,9 & 3134,7 \\
\hline 6. Chaetophractus & 11,4 & 69,7 & 331,8 & 57,3 & 88 & 0 & 91 & 356,2 & 179,7 & 2076,6 & 193 & 331,7 & 4598,3 & 2973,6 \\
\hline 7. Cabassous & 82,4 & 66,2 & 213,3 & 193,5 & 89,6 & 91 & 0 & 295,3 & 207,4 & 1919,9 & 206,5 & 379,9 & 4535,4 & 3100,2 \\
\hline 8. Tamandua & 340 & 244,3 & 280,2 & 451,8 & 267,3 & 356,2 & 295,3 & 0 & 202,1 & 1203,4 & 243,3 & 326,6 & 4191,8 & 2897 \\
\hline 9. Cyclopes & 146,4 & 90,3 & 478,4 & 318,9 & 183,9 & 179,7 & 207,4 & 202,1 & 0 & 1986,8 & 124,4 & 277 & 4621,1 & 3178,9 \\
\hline 10. Myrmecophaga & 2058,2 & 1859,4 & 1343,6 & 2045,1 & 1711,4 & 2076,6 & 1919,9 & 1203,4 & 1986,8 & 0 & 1978,9 & 1947,8 & 4971,2 & 3891,3 \\
\hline 11. Bradypus & 201,1 & 104,5 & 349,4 & 251,4 & 241,9 & 193 & 206,5 & 243,3 & 124,4 & 1978,9 & 0 & 100,2 & 3827,7 & 2487,1 \\
\hline 12. Choloepus & 360,7 & 265,4 & 486,8 & 337,1 & 411 & 331,7 & 379,9 & 326,6 & 277 & 1947,8 & 100,2 & 0 & 3346,8 & 2325,7 \\
\hline 13. Paramylodon & 4725,7 & 4655,1 & 3713 & 4313,9 & 4715,9 & 4598,3 & 4535,4 & 4191,8 & 4621,1 & 4971,2 & 3827,7 & 3346,8 & 0 & 1086,1 \\
\hline 14. Scelidotherium & 3116,5 & 3092,6 & 2453,5 & 2721 & 3134,7 & 2973,6 & 3100,2 & 2897 & 3178,9 & 3891,3 & 2487,1 & 2325,7 & 1086,1 & 0 \\
\hline
\end{tabular}


Tabela A2 - Distâncias filogenéticas entre os Xenarthra utilizadas. Taxa substituição: distâncias obtidas através dos comprimentos dos ramos correspondentes, segundo a proposta filogenética molecular de Möller-Krull et. al. (2007); ramos iguais: distâncias obtidas considerando os comprimentos dos ramos como sendo iguais a um; estruturado: distâncias obtidas considerando os comprimentos dos ramos como sendo iguais a um e considerando a filogenia de Folivora como resolvida; politomia: distâncias obtidas considerando os comprimentos dos ramos como sendo iguais a um e considerando a filogenia de Folivora como uma politomia.

\begin{tabular}{|c|c|c|c|c|c|c|c|c|c|c|c|c|c|c|}
\hline taxa substituição & 1 & 2 & 3 & 4 & 5 & 6 & 7 & 8 & 9 & 10 & 11 & 12 & & \\
\hline 1. Zaedyus & 0 & 5,2 & 4,41 & 1,16 & 8,69 & 1,02 & 4,85 & 15,24 & 14,87 & 15,48 & 13,94 & 13,32 & & \\
\hline 2. Tolypeutes & 5,2 & 0 & 3,24 & 4,99 & 8,74 & 5,18 & 3,48 & 15,29 & 14,92 & 15,53 & 13,99 & 13,38 & & \\
\hline 3. Priodontes & 4,41 & 3,24 & 0 & 4,2 & 7,95 & 4,39 & 2,88 & 14,5 & 14,13 & 14,74 & 13,2 & 12,58 & & \\
\hline 4. Euphractus & 1,16 & 4,99 & 4,2 & 0 & 8,47 & 1,14 & 4,63 & 15,03 & 14,65 & 15,26 & 13,72 & 13,11 & & \\
\hline 5. Dasypus & 8,69 & 8,74 & 7,95 & 8,47 & 0 & 8,67 & 8,38 & 16,14 & 15,76 & 16,37 & 14,83 & 14,22 & & \\
\hline 6. Chaetophractus & 1,02 & 5,18 & 4,39 & 1,14 & 8,67 & 0 & 4,83 & 15,22 & 14,85 & 15,46 & 13,92 & 13,31 & & \\
\hline 7. Cabassous & 4,85 & 3,48 & 2,88 & 4,63 & 8,38 & 4,83 & 0 & 14,94 & 14,56 & 15,17 & 13,63 & 13,02 & & \\
\hline 8. Tamandua & 15,24 & 15,29 & 14,5 & 15,03 & 16,14 & 15,22 & 14,94 & 0 & 8,46 & 2,57 & 11,87 & 11,26 & & \\
\hline 9. Cyclopes & 14,87 & 14,92 & 14,13 & 14,65 & 15,76 & 14,85 & 14,56 & 8,46 & 0 & 8,7 & 11,49 & 10,88 & & \\
\hline 10. Myrmecophaga & 15,48 & 15,53 & 14,74 & 15,26 & 16,37 & 15,46 & 15,17 & 2,57 & 8,7 & 0 & 12,11 & 11,49 & & \\
\hline 11. Bradypus & 13,94 & 13,99 & 13,2 & 13,72 & 14,83 & 13,92 & 13,63 & 11,87 & 11,49 & 12,11 & 0 & 3,3 & & \\
\hline 12. Choloepus & 13,32 & 13,38 & 12,58 & 13,11 & 14,22 & 13,31 & 13,02 & 11,26 & 10,88 & 11,49 & 3,3 & 0 & & \\
\hline ramos iguais & 1 & 2 & 3 & 4 & 5 & 6 & 7 & 8 & 9 & 10 & 11 & 12 & & \\
\hline 1. Zaedyus & 0 & 3 & 3 & 2 & 4 & 1 & 3 & 5 & 5 & 5 & 5 & 5 & & \\
\hline 2. Tolypeutes & 3 & 0 & 2 & 3 & 4 & 3 & 1 & 5 & 5 & 5 & 5 & 5 & & \\
\hline 3. Priodontes & 3 & 2 & 0 & 3 & 4 & 3 & 2 & 5 & 5 & 5 & 5 & 5 & & \\
\hline 4. Euphractus & 2 & 3 & 3 & 0 & 4 & 2 & 3 & 5 & 5 & 5 & 5 & 5 & & \\
\hline 5. Dasypus & 4 & 4 & 4 & 4 & 0 & 4 & 4 & 5 & 5 & 5 & 5 & 5 & & \\
\hline 6. Chaetophractus & 1 & 3 & 3 & 2 & 4 & 0 & 3 & 5 & 5 & 5 & 5 & 5 & & \\
\hline 7. Cabassous & 3 & 1 & 2 & 3 & 4 & 3 & 0 & 5 & 5 & 5 & 5 & 5 & & \\
\hline 8. Tamandua & 5 & 5 & 5 & 5 & 5 & 5 & 5 & 0 & 2 & 1 & 3 & 3 & & \\
\hline 9. Cyclopes & 5 & 5 & 5 & 5 & 5 & 5 & 5 & 2 & 0 & 2 & 3 & 3 & & \\
\hline 10. Myrmecophaga & 5 & 5 & 5 & 5 & 5 & 5 & 5 & 1 & 2 & 0 & 3 & 3 & & \\
\hline 11. Bradypus & 5 & 5 & 5 & 5 & 5 & 5 & 5 & 3 & 3 & 3 & 0 & 1 & & \\
\hline 12. Choloepus & 5 & 5 & 5 & 5 & 5 & 5 & 5 & 3 & 3 & 3 & 1 & 0 & & \\
\hline resolvida & 1 & 2 & 3 & 4 & 5 & 6 & 7 & 8 & 9 & 10 & 11 & 12 & 13 & 14 \\
\hline 1. Zaedyus & 0 & 3 & 3 & 2 & 4 & 1 & 3 & 5 & 5 & 5 & 5 & 5 & 5 & 5 \\
\hline 2. Tolypeutes & 3 & 0 & 2 & 3 & 4 & 3 & 1 & 5 & 5 & 5 & 5 & 5 & 5 & 5 \\
\hline 3. Priodontes & 3 & 2 & 0 & 3 & 4 & 3 & 2 & 5 & 5 & 5 & 5 & 5 & 5 & 5 \\
\hline 4. Euphractus & 2 & 3 & 3 & 0 & 4 & 2 & 3 & 5 & 5 & 5 & 5 & 5 & 5 & 5 \\
\hline 5. Dasypus & 4 & 4 & 4 & 4 & 0 & 4 & 4 & 5 & 5 & 5 & 5 & 5 & 5 & 5 \\
\hline 6. Chaetophractus & 1 & 3 & 3 & 2 & 4 & 0 & 3 & 5 & 5 & 5 & 5 & 5 & 5 & 5 \\
\hline 7. Cabassous & 3 & 1 & 2 & 3 & 4 & 3 & 0 & 5 & 5 & 5 & 5 & 5 & 5 & 5 \\
\hline 8. Tamandua & 5 & 5 & 5 & 5 & 5 & 5 & 5 & 0 & 2 & 1 & 4 & 4 & 4 & 4 \\
\hline 9. Cyclopes & 5 & 5 & 5 & 5 & 5 & 5 & 5 & 2 & 0 & 2 & 4 & 4 & 4 & 4 \\
\hline 10. Myrmecophaga & 5 & 5 & 5 & 5 & 5 & 5 & 5 & 1 & 2 & 0 & 4 & 4 & 4 & 4 \\
\hline 11. Bradypus & 5 & 5 & 5 & 5 & 5 & 5 & 5 & 4 & 4 & 4 & 0 & 3 & 3 & 3 \\
\hline 12. Choloepus & 5 & 5 & 5 & 5 & 5 & 5 & 5 & 4 & 4 & 4 & 3 & 0 & 2 & 2 \\
\hline 13. Paramylodon & 5 & 5 & 5 & 5 & 5 & 5 & 5 & 4 & 4 & 4 & 3 & 2 & 0 & 1 \\
\hline 14. Scelidotherium & 5 & 5 & 5 & 5 & 5 & 5 & 5 & 4 & 4 & 4 & 3 & 2 & 1 & 0 \\
\hline politomia & 1 & 2 & 3 & 4 & 5 & 6 & 7 & 8 & 9 & 10 & 11 & 12 & 13 & 14 \\
\hline 1. Zaedyus & 0 & 3 & 3 & 2 & 4 & 1 & 3 & 5 & 5 & 5 & 5 & 5 & 5 & 5 \\
\hline 2. Tolypeutes & 3 & 0 & 2 & 3 & 4 & 3 & 1 & 5 & 5 & 5 & 5 & 5 & 5 & 5 \\
\hline 3. Priodontes & 3 & 2 & 0 & 3 & 4 & 3 & 2 & 5 & 5 & 5 & 5 & 5 & 5 & 5 \\
\hline 4. Euphractus & 2 & 3 & 3 & 0 & 4 & 2 & 3 & 5 & 5 & 5 & 5 & 5 & 5 & 5 \\
\hline 5. Dasypus & 4 & 4 & 4 & 4 & 0 & 4 & 4 & 5 & 5 & 5 & 5 & 5 & 5 & 5 \\
\hline 6. Chaetophractus & 1 & 3 & 3 & 2 & 4 & 0 & 3 & 5 & 5 & 5 & 5 & 5 & 5 & 5 \\
\hline 7. Cabassous & 3 & 1 & 2 & 3 & 4 & 3 & 0 & 5 & 5 & 5 & 5 & 5 & 5 & 5 \\
\hline 8. Tamandua & 5 & 5 & 5 & 5 & 5 & 5 & 5 & 0 & 2 & 1 & 3 & 3 & 3 & 3 \\
\hline 9. Cyclopes & 5 & 5 & 5 & 5 & 5 & 5 & 5 & 2 & 0 & 2 & 3 & 3 & 3 & 3 \\
\hline 10. Myrmecophaga & 5 & 5 & 5 & 5 & 5 & 5 & 5 & 1 & 2 & 0 & 3 & 3 & 3 & 3 \\
\hline 11. Bradypus & 5 & 5 & 5 & 5 & 5 & 5 & 5 & 3 & 3 & 3 & 0 & 1 & 1 & 1 \\
\hline 12. Choloepus & 5 & 5 & 5 & 5 & 5 & 5 & 5 & 3 & 3 & 3 & 1 & 0 & 1 & 1 \\
\hline 13. Paramylodon & 5 & 5 & 5 & 5 & 5 & 5 & 5 & 3 & 3 & 3 & 1 & 1 & 0 & 1 \\
\hline 14. Scelidotherium & 5 & 5 & 5 & 5 & 5 & 5 & 5 & 3 & 3 & 3 & 1 & 1 & 1 & 0 \\
\hline
\end{tabular}


Tabela A3 - Distância ecológicas (dieta) entre os Xenarthra.

\begin{tabular}{lcccccccccccc}
\hline & $\mathbf{1}$ & $\mathbf{2}$ & $\mathbf{3}$ & $\mathbf{4}$ & $\mathbf{5}$ & $\mathbf{6}$ & $\mathbf{7}$ & $\mathbf{8}$ & $\mathbf{9}$ & $\mathbf{1 0}$ & $\mathbf{1 1}$ & $\mathbf{1 2}$ \\
\hline 1. Zaedyus & 0 & 0,8 & 2,6 & 0 & 0,2 & 0 & 2,6 & 2,6 & 2,6 & 2,6 & 3 & 2,67 \\
2. Tolypeutes & 0,8 & 0 & 2,5 & 0,8 & 0,6 & 0,8 & 2,5 & 2,5 & 2,5 & 2,5 & 3 & 2,4 \\
3. Priodontes & 2,6 & 2,5 & 0 & 2,6 & 2,6 & 2,6 & 0 & 0 & 0 & 0 & 3 & 3 \\
4. Euphractus & 0 & 0,8 & 2,6 & 0 & 0,2 & 0 & 2,6 & 2,6 & 2,6 & 2,6 & 3 & 2,67 \\
5. Dasypus & 0,2 & 0,6 & 2,6 & 0,2 & 0 & 0,2 & 2,6 & 2,6 & 2,6 & 2,6 & 3 & 2,5 \\
6. Chaetophractus & 0 & 0,8 & 2,6 & 0 & 0,2 & 0 & 2,6 & 2,6 & 2,6 & 2,6 & 3 & 2,67 \\
7. Cabassous & 2,6 & 2,5 & 0 & 2,6 & 2,6 & 2,6 & 0 & 0 & 0 & 0 & 3 & 3 \\
8. Tamandua & 2,6 & 2,5 & 0 & 2,6 & 2,6 & 2,6 & 0 & 0 & 0 & 0 & 3 & 3 \\
9. Cyclopes & 2,6 & 2,5 & 0 & 2,6 & 2,6 & 2,6 & 0 & 0 & 0 & 0 & 3 & 3 \\
10. Myrmecophaga & 2,6 & 2,5 & 0 & 2,6 & 2,6 & 2,6 & 0 & 0 & 0 & 0 & 3 & 3 \\
11. Bradypus & 3 & 3 & 3 & 3 & 3 & 3 & 3 & 3 & 3 & 3 & 0 & 2 \\
12. Choloepus & 2,67 & 2,4 & 3 & 2,67 & 2,5 & 2,67 & 3 & 3 & 3 & 3 & 2 & 0 \\
\hline
\end{tabular}


Tabela A4 -Similaridade obtida (abaixo da diagonal) através da correlação de matrizes para as matrizes 35D, 32D, 28D e 25D dos gêneros de Xenarthra. A diagonal contém a repetibilidade de cada matriz segundo forma analítica e acima dela estão os valores de similaridade ajustados. Valores em negrito não foram significativos a $1 \%$ e valores em negrito e sublinhado não foram significativos a $5 \%$.

\begin{tabular}{|c|c|c|c|c|c|c|c|c|c|c|c|c|c|c|}
\hline 35D & 1 & 2 & 3 & 4 & 5 & 6 & 7 & 8 & 9 & 10 & 11 & 12 & & \\
\hline 1. Zaedyus & 0,62 & 0,68 & 0,64 & 0,86 & 0,72 & 0,78 & 0,74 & 0,54 & 0,67 & 0,71 & 0,45 & 0,65 & & \\
\hline 2. Tolypeutes & 0,43 & 0,65 & 0,60 & 0,79 & 0,68 & 0,60 & 0,81 & 0,70 & 0,91 & 0,72 & 0,82 & 0,88 & & \\
\hline 3. Priodontes & 0,36 & 0,34 & 0,51 & 0,65 & 0,55 & 0,58 & 0,78 & 0,55 & 0,65 & 0,56 & 0,24 & 0,57 & & \\
\hline 4. Euphractus & 0,59 & 0,56 & 0,41 & 0,77 & 0,66 & 0,85 & 0,83 & 0,73 & 0,97 & 0,91 & 0,69 & 0,91 & & \\
\hline 5. Dasypus & 0,53 & 0,52 & 0,37 & 0,55 & 0,90 & 0,60 & 0,74 & 0,61 & 0,84 & 0,87 & 0,56 & 0,50 & & \\
\hline 6. Chaetophractus & 0,53 & 0,41 & 0,36 & 0,64 & 0,49 & 0,73 & 0,94 & 0,67 & 0,66 & 0,70 & 0,60 & 0,63 & & \\
\hline 7. Cabassous & 0,43 & 0,49 & 0,41 & 0,54 & 0,52 & 0,60 & 0,55 & 0,72 & 1,07 & 0,85 & 0,84 & 0,73 & & \\
\hline 8. Tamandua & 0,40 & 0,52 & 0,36 & 0,60 & 0,54 & 0,54 & 0,50 & 0,87 & 1,25 & 1,07 & 0,77 & 0,68 & & \\
\hline 9. Cyclopes & 0,22 & 0,31 & 0,19 & 0,36 & 0,33 & 0,24 & 0,34 & 0,49 & 0,18 & 1,83 & 1,03 & 0,89 & & \\
\hline 10. Myrmecophaga & 0,38 & 0,39 & 0,27 & 0,54 & 0,56 & 0,41 & 0,43 & 0,68 & 0,52 & 0,46 & 0,81 & 0,65 & & \\
\hline 11. Bradypus & 0,30 & 0,56 & 0,14 & 0,52 & 0,45 & 0,43 & 0,53 & 0,61 & 0,37 & 0,47 & 0,72 & 0,85 & & \\
\hline 12. Choloepus & 0,39 & 0,54 & 0,31 & 0,62 & 0,37 & 0,41 & 0,42 & 0,49 & 0,29 & 0,34 & 0,56 & 0,60 & & \\
\hline 32D & 1 & 2 & 3 & 4 & 5 & 6 & 7 & 8 & 9 & 10 & 11 & 12 & & \\
\hline 1. Zaedyus & 0,63 & 0,68 & 0,61 & 0,86 & 0,69 & 0,75 & 0,72 & 0,53 & 0,43 & 0,66 & 0,52 & 0,68 & & \\
\hline 2. Tolypeutes & 0,44 & 0,65 & 0,60 & 0,83 & 0,69 & 0,61 & 0,79 & 0,67 & 0,66 & 0,68 & 0,78 & 0,87 & & \\
\hline 3. Priodontes & 0,35 & 0,35 & 0,51 & 0,62 & 0,53 & 0,56 & 0,71 & 0,57 & 0,47 & 0,70 & 0,32 & 0,62 & & \\
\hline 4. Euphractus & 0,60 & 0,59 & 0,39 & 0,77 & 0,66 & 0,83 & 0,81 & 0,75 & 0,66 & 0,77 & 0,72 & 0,86 & & \\
\hline 5. Dasypus & 0,52 & 0,52 & 0,36 & 0,55 & 0,90 & 0,60 & 0,72 & 0,62 & 0,60 & 0,68 & 0,57 & 0,56 & & \\
\hline 6. Chaetophractus & 0,51 & 0,42 & 0,34 & 0,62 & 0,48 & 0,73 & 0,94 & 0,67 & 0,50 & 0,65 & 0,58 & 0,64 & & \\
\hline 7. Cabassous & 0,43 & 0,47 & 0,38 & 0,53 & 0,51 & 0,60 & 0,56 & 0,72 & 0,58 & 0,68 & 0,79 & 0,70 & & \\
\hline 8. Tamandua & 0,39 & 0,50 & 0,38 & 0,62 & 0,54 & 0,53 & 0,50 & 0,87 & 0,85 & 0,92 & 0,70 & 0,73 & & \\
\hline 9. Cyclopes & 0,31 & 0,48 & 0,30 & 0,53 & 0,52 & 0,39 & 0,39 & 0,72 & 0,83 & 0,82 & 0,66 & 0,74 & & \\
\hline 10. Myrmecophaga & 0,45 & 0,48 & 0,43 & 0,59 & 0,56 & 0,48 & 0,44 & 0,75 & 0,65 & 0,75 & 0,59 & 0,64 & & \\
\hline 11. Bradypus & 0,38 & 0,59 & 0,21 & 0,59 & 0,50 & 0,46 & 0,55 & 0,61 & 0,56 & 0,48 & 0,87 & 0,82 & & \\
\hline 12. Choloepus & 0,43 & 0,57 & 0,36 & 0,62 & 0,43 & 0,44 & 0,42 & 0,55 & 0,55 & 0,45 & 0,62 & 0,66 & & \\
\hline $28 \mathrm{D}$ & 1 & 2 & 3 & 4 & 5 & 6 & 7 & 8 & 9 & 10 & 11 & 12 & 13 & \\
\hline 1. Zaedyus & 0,65 & 0,68 & 0,68 & 0,84 & 0,72 & 0,74 & 0,61 & 0,57 & 0,53 & 0,67 & 0,54 & 0,68 & 0,56 & \\
\hline 2. Tolypeutes & 0,45 & 0,66 & 0,70 & 0,83 & 0,74 & 0,65 & 0,85 & 0,70 & 0,72 & 0,74 & 0,78 & 0,87 & 0,56 & \\
\hline 3. Priodontes & 0,39 & 0,40 & 0,50 & 0,68 & 0,61 & 0,60 & 0,75 & 0,62 & 0,56 & 0,80 & 0,37 & 0,68 & 0,69 & \\
\hline 4. Euphractus & 0,61 & 0,61 & 0,43 & 0,80 & 0,68 & 0,79 & 0,80 & 0,76 & 0,70 & 0,79 & 0,72 & 0,82 & 0,48 & \\
\hline 5. Dasypus & 0,56 & 0,57 & 0,41 & 0,58 & 0,91 & 0,60 & 0,76 & 0,67 & 0,68 & 0,75 & 0,59 & 0,58 & 0,51 & \\
\hline 6. Chaetophractus & 0,52 & 0,46 & 0,36 & 0,61 & 0,49 & 0,75 & 0,90 & 0,71 & 0,57 & 0,71 & 0,60 & 0,62 & 0,49 & \\
\hline 7. Cabassous & 0,37 & 0,52 & 0,40 & 0,54 & 0,55 & 0,59 & 0,58 & 0,77 & 0,68 & 0,71 & 0,88 & 0,72 & 0,75 & \\
\hline 8. Tamandua & 0,43 & 0,53 & 0,41 & 0,64 & 0,60 & 0,57 & 0,55 & 0,88 & 0,88 & 0,93 & 0,74 & 0,74 & 0,58 & \\
\hline 9. Cyclopes & 0,39 & 0,54 & 0,36 & 0,58 & 0,59 & 0,45 & 0,47 & 0,76 & 0,84 & 0,86 & 0,72 & 0,76 & 0,46 & \\
\hline 10. Myrmecophaga & 0,48 & 0,53 & 0,50 & 0,63 & 0,63 & 0,54 & 0,47 & 0,77 & 0,70 & 0,78 & 0,65 & 0,67 & 0,58 & \\
\hline 11. Bradypus & 0,41 & 0,59 & 0,25 & 0,61 & 0,53 & 0,49 & 0,63 & 0,65 & 0,62 & 0,54 & 0,88 & 0,82 & 0,55 & \\
\hline 12. Choloepus & 0,46 & 0,59 & 0,40 & 0,61 & 0,46 & 0,44 & 0,46 & 0,57 & 0,58 & 0,49 & 0,64 & 0,69 & 0,59 & \\
\hline 13. Paramylodon & 0,34 & 0,34 & 0,37 & 0,33 & 0,37 & 0,32 & 0,43 & 0,41 & 0,32 & 0,39 & 0,39 & 0,37 & 0,57 & \\
\hline 25D & 1 & 2 & 3 & 4 & 5 & 6 & 7 & 8 & 9 & 10 & 11 & 12 & 13 & $\overline{14}$ \\
\hline 1. Zaedyus & 0,60 & 0,64 & 0,59 & 0,82 & 0,68 & 0,77 & 0,64 & 0,56 & 0,46 & 0,61 & 0,54 & 0,67 & 0,77 & 0,58 \\
\hline 2. Tolypeutes & 0,40 & 0,64 & 0,61 & 0,78 & 0,72 & 0,61 & 0,88 & 0,66 & 0,67 & 0,68 & 0,76 & 0,88 & 0,68 & 0,96 \\
\hline 3. Priodontes & 0,33 & 0,35 & 0,53 & 0,63 & 0,50 & 0,46 & 0,69 & 0,54 & 0,44 & 0,67 & $\underline{0,26}$ & 0,60 & 0,77 & 0,70 \\
\hline 4. Euphractus & 0,56 & 0,55 & 0,41 & 0,78 & 0,64 & 0,81 & 0,84 & 0,77 & 0,68 & 0,77 & 0,70 & 0,81 & 0,71 & 0,70 \\
\hline 5. Dasypus & 0,50 & 0,54 & 0,35 & 0,54 & 0,89 & 0,52 & 0,73 & 0,62 & 0,63 & 0,69 & 0,53 & 0,52 & 0,53 & 0,82 \\
\hline 6. Chaetophractus & 0,50 & 0,41 & 0,28 & 0,60 & 0,41 & 0,71 & 0,87 & 0,63 & 0,48 & 0,55 & 0,58 & 0,57 & 0,56 & $\underline{0,39}$ \\
\hline 7. Cabassous & 0,37 & 0,52 & 0,37 & 0,56 & 0,51 & 0,55 & 0,56 & 0,69 & 0,61 & 0,63 & 0,89 & 0,66 & 0,76 & 0,74 \\
\hline 8. Tamandua & 0,41 & 0,49 & 0,37 & 0,63 & 0,55 & 0,50 & 0,48 & 0,87 & 0,86 & 0,92 & 0,72 & 0,68 & 0,63 & 0,46 \\
\hline 9. Cyclopes & 0,33 & 0,49 & 0,29 & 0,54 & 0,54 & 0,37 & 0,41 & 0,73 & 0,83 & 0,83 & 0,70 & 0,71 & 0,46 & 0,74 \\
\hline 10. Myrmecophaga & 0,41 & 0,47 & 0,42 & 0,58 & 0,56 & 0,40 & 0,41 & 0,74 & 0,65 & 0,74 & 0,60 & 0,60 & 0,69 & 0,58 \\
\hline 11. Bradypus & 0,39 & 0,57 & $\underline{0,18}$ & 0,58 & 0,47 & 0,46 & 0,62 & 0,63 & 0,60 & 0,48 & 0,88 & 0,80 & 0,61 & 0,68 \\
\hline 12. Choloepus & 0,43 & 0,59 & 0,36 & 0,59 & 0,41 & 0,40 & 0,41 & 0,53 & 0,54 & 0,44 & 0,62 & 0,70 & 0,77 & 1,04 \\
\hline 13. Paramylodon & 0,46 & 0,41 & 0,43 & 0,48 & 0,38 & 0,36 & 0,43 & 0,45 & 0,32 & 0,46 & 0,43 & 0,49 & 0,58 & 0,96 \\
\hline 14. Scelidotherium & 0,23 & 0,39 & 0,26 & 0,32 & 0,40 & 0,17 & 0,28 & 0,22 & 0,35 & 0,26 & 0,33 & 0,44 & 0,38 & 0,26 \\
\hline
\end{tabular}


Tabela A5 - Matriz teórica contendo a hipótese de modularidade da sub-região da base.

\begin{tabular}{|c|c|c|c|c|c|c|c|c|c|c|c|c|c|c|c|c|c|c|c|c|c|c|c|c|c|c|c|c|c|c|c|c|c|c|c|}
\hline & 1 & 2 & 3 & 4 & 5 & 6 & 7 & 8 & 9 & 10 & 11 & 12 & 13 & 14 & 15 & 16 & 17 & 18 & 19 & 20 & 21 & 22 & 23 & 24 & 25 & 26 & 27 & 28 & 29 & 30 & 31 & 32 & 33 & 34 & 35 \\
\hline 1. ISPM & 1 & 0 & 0 & 0 & 0 & 0 & 0 & 0 & 0 & 0 & 0 & 0 & 0 & 0 & 0 & 0 & 0 & 0 & 0 & 0 & 0 & 0 & 0 & 0 & 0 & 0 & 0 & 0 & 0 & 0 & 0 & 0 & 0 & 0 & 0 \\
\hline 2. ISNSL & 0 & 1 & 0 & 0 & 0 & 0 & 0 & 0 & 0 & 0 & 0 & 0 & 0 & 0 & 0 & 0 & 0 & 0 & 0 & 0 & 0 & 0 & 0 & 0 & 0 & 0 & 0 & 0 & 0 & 0 & 0 & 0 & 0 & 0 & 0 \\
\hline 3. ISPNS & 0 & 0 & 1 & 0 & 0 & 0 & 0 & 0 & 0 & 0 & 0 & 0 & 0 & 0 & 0 & 0 & 0 & 0 & 0 & 0 & 0 & 0 & 0 & 0 & 0 & 0 & 0 & 0 & 0 & 0 & 0 & 0 & 0 & 0 & 0 \\
\hline 4. PMZS & 0 & 0 & 0 & 1 & 0 & 0 & 0 & 0 & 0 & 0 & 0 & 0 & 0 & 0 & 0 & 0 & 0 & 0 & 0 & 0 & 0 & 0 & 0 & 0 & 0 & 0 & 0 & 0 & 0 & 0 & 0 & 0 & 0 & 0 & 0 \\
\hline 5. PMZI & 0 & 0 & 0 & 0 & 1 & 0 & 0 & 0 & 0 & 0 & 0 & 0 & 0 & 0 & 0 & 0 & 0 & 0 & 0 & 0 & 0 & 0 & 0 & 0 & 0 & 0 & 0 & 0 & 0 & 0 & 0 & 0 & 0 & 0 & 0 \\
\hline 6. PMMT & 0 & 0 & 0 & 0 & 0 & 1 & 0 & 0 & 0 & 0 & 0 & 0 & 0 & 0 & 0 & 0 & 0 & 0 & 0 & 0 & 0 & 0 & 0 & 0 & 0 & 0 & 0 & 0 & 0 & 0 & 0 & 0 & 0 & 0 & 0 \\
\hline 7. NSLNA & 0 & 0 & 0 & 0 & 0 & 0 & 1 & 0 & 0 & 0 & 0 & 0 & 0 & 0 & 0 & 0 & 0 & 0 & 0 & 0 & 0 & 0 & 0 & 0 & 0 & 0 & 0 & 0 & 0 & 0 & 0 & 0 & 0 & 0 & 0 \\
\hline 8. NSLZS & 0 & 0 & 0 & 0 & 0 & 0 & 0 & 1 & 0 & 0 & 0 & 0 & 0 & 0 & 0 & 0 & 0 & 0 & 0 & 0 & 0 & 0 & 0 & 0 & 0 & 0 & 0 & 0 & 0 & 0 & 0 & 0 & 0 & 0 & 0 \\
\hline 9. NSLZI & 0 & 0 & 0 & 0 & 0 & 0 & 0 & 0 & 1 & 0 & 0 & 0 & 0 & 0 & 0 & 0 & 0 & 0 & 0 & 0 & 0 & 0 & 0 & 0 & 0 & 0 & 0 & 0 & 0 & 0 & 0 & 0 & 0 & 0 & 0 \\
\hline 10. NABR & 0 & 0 & 0 & 0 & 0 & 0 & 0 & 0 & 0 & 1 & 0 & 0 & 0 & 0 & 0 & 0 & 0 & 0 & 0 & 0 & 0 & 0 & 0 & 0 & 0 & 0 & 0 & 0 & 0 & 0 & 0 & 0 & 0 & 0 & 0 \\
\hline 11. NAPNS & 0 & 0 & 0 & 0 & 0 & 0 & 0 & 0 & 0 & 0 & 1 & 0 & 0 & 0 & 0 & 0 & 0 & 0 & 0 & 0 & 0 & 0 & 0 & 0 & 0 & 0 & 0 & 0 & 0 & 0 & 0 & 0 & 0 & 0 & 0 \\
\hline 12. BRPT & 0 & 0 & 0 & 0 & 0 & 0 & 0 & 0 & 0 & 0 & 0 & 1 & 0 & 0 & 0 & 0 & 0 & 0 & 0 & 0 & 0 & 0 & 0 & 0 & 0 & 0 & 0 & 0 & 0 & 0 & 0 & 0 & 0 & 0 & 0 \\
\hline 13. BRAPET & 0 & 0 & 0 & 0 & 0 & 0 & 0 & 0 & 0 & 0 & 0 & 0 & 1 & 0 & 0 & 0 & 0 & 0 & 0 & 0 & 0 & 0 & 0 & 0 & 0 & 0 & 0 & 0 & 0 & 0 & 0 & 0 & 0 & 0 & 0 \\
\hline 14. PTAPET & 0 & 0 & 0 & 0 & 0 & 0 & 0 & 0 & 0 & 0 & 0 & 0 & 0 & 1 & 0 & 0 & 0 & 0 & 0 & 0 & 0 & 0 & 0 & 0 & 0 & 0 & 0 & 0 & 0 & 0 & 0 & 0 & 0 & 0 & 0 \\
\hline 15. PTBA & 0 & 0 & 0 & 0 & 0 & 0 & 0 & 0 & 0 & 0 & 0 & 0 & 0 & 0 & 1 & 0 & 0 & 0 & 0 & 0 & 0 & 0 & 0 & 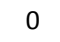 & 0 & 0 & c & 0 & 0 & 0 & 0 & 0 & 0 & 0 & 0 \\
\hline 16. PTEAM & 0 & 0 & 0 & 0 & 0 & 0 & 0 & 0 & 0 & 0 & 0 & 0 & 0 & 0 & 0 & 1 & 0 & 0 & 0 & 0 & 0 & 0 & 0 & 0 & 0 & 0 & c & 0 & 0 & 0 & 0 & 0 & 0 & 0 & 0 \\
\hline 17. PTZYGO & 0 & 0 & 0 & 0 & 0 & 0 & 0 & 0 & 0 & 0 & 0 & 0 & 0 & 0 & 0 & 0 & 1 & 0 & 0 & 0 & 0 & 0 & 0 & 0 & 0 & 0 & 0 & 0 & 0 & 0 & 0 & 0 & 0 & 0 & 0 \\
\hline 18. PTTSP & 0 & 0 & 0 & 0 & 0 & 0 & 0 & 0 & 0 & 0 & 0 & 0 & 0 & 0 & 0 & 0 & 0 & 1 & 0 & 0 & 0 & 0 & 0 & 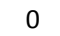 & 0 & 0 & 0 & 0 & 0 & 0 & 0 & 0 & 0 & 0 & 0 \\
\hline 19. ZSZI & 0 & 0 & 0 & 0 & 0 & 0 & 0 & 0 & 0 & 0 & 0 & 0 & 0 & 0 & 0 & 0 & 0 & 0 & 1 & 0 & 0 & 0 & 0 & 0 & 0 & 0 & 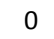 & 0 & 0 & 0 & 0 & 0 & 0 & 0 & 0 \\
\hline 20. ZIMT & 0 & 0 & 0 & 0 & 0 & 0 & 0 & 0 & 0 & 0 & 0 & 0 & 0 & 0 & 0 & 0 & 0 & 0 & 0 & 1 & 0 & 0 & 0 & 0 & 0 & 0 & 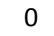 & 0 & 0 & 0 & 0 & 0 & 0 & 0 & 0 \\
\hline 21. ZIZYGO & 0 & 0 & 0 & 0 & 0 & 0 & 0 & 0 & 0 & 0 & 0 & 0 & 0 & 0 & 0 & 0 & 0 & 0 & 0 & 0 & 1 & 0 & 0 & 0 & 0 & 0 & 0 & 0 & 0 & 0 & 0 & 0 & 0 & 0 & 0 \\
\hline 22. ZITSP & 0 & 0 & 0 & 0 & 0 & 0 & 0 & 0 & 0 & 0 & 0 & 0 & 0 & 0 & 0 & 0 & 0 & 0 & 0 & 0 & 0 & 1 & 0 & 0 & 0 & 0 & 0 & 0 & 0 & 0 & 0 & 0 & 0 & 0 & 0 \\
\hline 23. MTPNS & 0 & 0 & 0 & 0 & 0 & 0 & 0 & 0 & 0 & 0 & 0 & 0 & 0 & 0 & 0 & 0 & 0 & 0 & 0 & 0 & 0 & 0 & 1 & O & 0 & 0 & O & 0 & 0 & 0 & 0 & 0 & 0 & 0 & 0 \\
\hline 24. PNSAPET & 0 & 0 & 0 & 0 & 0 & 0 & 0 & 0 & 0 & 0 & 0 & 0 & 0 & 0 & 0 & 0 & 0 & 0 & 0 & 0 & 0 & 0 & 0 & 1 & 1 & 1 & 1 & 0 & 0 & 0 & 0 & 0 & 0 & 0 & 1 \\
\hline 25. APETBA & 0 & 0 & 0 & 0 & 0 & 0 & 0 & 0 & 0 & 0 & 0 & 0 & 0 & 0 & 0 & 0 & 0 & 0 & 0 & 0 & 0 & 0 & 0 & 1 & 1 & 1 & 1 & 0 & 0 & 0 & 0 & 0 & 0 & 0 & 1 \\
\hline 26. APETTS & 0 & 0 & 0 & 0 & 0 & 0 & 0 & 0 & 0 & 0 & 0 & 0 & 0 & 0 & 0 & 0 & 0 & 0 & 0 & 0 & 0 & 0 & 0 & 1 & 1 & 1 & 1 & 0 & 0 & 0 & 0 & 0 & 0 & 0 & 1 \\
\hline 27.BAEAM & 0 & 0 & 0 & 0 & 0 & 0 & 0 & 0 & 0 & 0 & 0 & 0 & 0 & 0 & 0 & 0 & 0 & 0 & 0 & 0 & 0 & 0 & 0 & 1 & 1 & 1 & 1 & 0 & 0 & 0 & 0 & 0 & 0 & 0 & 1 \\
\hline 28. EAMZYGO & 0 & 0 & 0 & 0 & 0 & 0 & 0 & 0 & 0 & 0 & 0 & 0 & 0 & 0 & 0 & 0 & 0 & 0 & 0 & 0 & 0 & 0 & 0 & 0 & 0 & 0 & 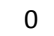 & 1 & 0 & 0 & 0 & 0 & 0 & 0 & 0 \\
\hline 29. ZYGOTSP & 0 & 0 & 0 & 0 & 0 & 0 & 0 & 0 & 0 & 0 & 0 & 0 & 0 & 0 & 0 & 0 & 0 & 0 & 0 & 0 & 0 & 0 & 0 & 0 & 0 & 0 & 0 & 0 & 1 & 0 & 0 & 0 & 0 & 0 & 0 \\
\hline 30. LDAS & 0 & 0 & 0 & 0 & 0 & 0 & 0 & 0 & 0 & 0 & 0 & 0 & 0 & 0 & 0 & 0 & 0 & 0 & 0 & 0 & 0 & 0 & 0 & 0 & 0 & 0 & 0 & 0 & 0 & 1 & 0 & 0 & 0 & 0 & 0 \\
\hline 31. BRLD & 0 & 0 & 0 & 0 & 0 & 0 & 0 & 0 & 0 & 0 & 0 & 0 & 0 & 0 & 0 & 0 & 0 & 0 & 0 & 0 & 0 & 0 & 0 & 0 & 0 & 0 & 0 & 0 & 0 & 0 & 1 & 0 & 0 & 0 & 0 \\
\hline 32. OPILD & 0 & 0 & 0 & 0 & 0 & 0 & 0 & 0 & 0 & 0 & 0 & 0 & 0 & 0 & 0 & 0 & 0 & 0 & 0 & 0 & 0 & 0 & 0 & 0 & 0 & 0 & 0 & 0 & 0 & 0 & 0 & 1 & 0 & 0 & 0 \\
\hline 33. PTAS & 0 & 0 & 0 & 0 & 0 & 0 & 0 & 0 & 0 & 0 & 0 & 0 & 0 & 0 & 0 & 0 & 0 & 0 & 0 & 0 & 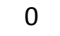 & 0 & 0 & 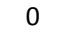 & 0 & 0 & . & 0 & 0 & 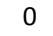 & 0 & 0 & 1 & 0 & 0 \\
\hline 34. JPAS & 0 & 0 & 0 & 0 & 0 & 0 & 0 & 0 & 0 & 0 & 0 & 0 & 0 & 0 & 0 & 0 & 0 & 0 & 0 & 0 & 0 & 0 & 0 & 0 & 0 & 0 & 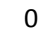 & 0 & 0 & 0 & 0 & 0 & 0 & 1 & 0 \\
\hline 35. BAOPI & 0 & 0 & 0 & 0 & 0 & 0 & 0 & 0 & 0 & 0 & 0 & 0 & 0 & 0 & 0 & 0 & 0 & 0 & 0 & 0 & 0 & 0 & 0 & 1 & 1 & 1 & 1 & 0 & 0 & 0 & 0 & 0 & 0 & 0 & 1 \\
\hline
\end{tabular}


Tabela A6 - Matriz teórica contendo a hipótese de modularidade da sub-região da abóbada.

\begin{tabular}{|c|c|c|c|c|c|c|c|c|c|c|c|c|c|c|c|c|c|c|c|c|c|c|c|c|c|c|c|c|c|c|c|c|c|c|c|}
\hline & 1 & 2 & 3 & 4 & 5 & 6 & 7 & 8 & 9 & 10 & 11 & 12 & 13 & 14 & 15 & 16 & 17 & 18 & 19 & 20 & 21 & 22 & 23 & 24 & 25 & 26 & 27 & 28 & 29 & 30 & 31 & 32 & 33 & 34 & 35 \\
\hline 1. ISPM & 1 & 0 & 0 & 0 & 0 & 0 & 0 & 0 & 0 & 0 & 0 & 0 & 0 & 0 & 0 & 0 & 0 & 0 & 0 & 0 & 0 & 0 & 0 & 0 & 0 & 0 & 0 & 0 & 0 & 0 & 0 & 0 & 0 & 0 & 0 \\
\hline 2. ISNSL & 0 & 1 & 0 & 0 & 0 & 0 & 0 & 0 & 0 & 0 & 0 & 0 & 0 & 0 & 0 & 0 & 0 & 0 & 0 & 0 & 0 & 0 & 0 & 0 & 0 & 0 & 0 & 0 & 0 & 0 & 0 & 0 & 0 & 0 & 0 \\
\hline 3. ISPNS & 0 & 0 & 1 & 0 & 0 & 0 & 0 & 0 & 0 & 0 & 0 & 0 & 0 & 0 & 0 & 0 & 0 & 0 & 0 & 0 & 0 & 0 & 0 & 0 & 0 & 0 & 0 & 0 & 0 & 0 & 0 & 0 & 0 & 0 & 0 \\
\hline 4. PMZS & 0 & 0 & 0 & 1 & 0 & 0 & 0 & 0 & 0 & 0 & 0 & 0 & 0 & 0 & 0 & 0 & 0 & 0 & 0 & 0 & 0 & 0 & 0 & 0 & 0 & 0 & 0 & 0 & 0 & 0 & 0 & 0 & 0 & 0 & 0 \\
\hline 5. PMZI & 0 & 0 & 0 & 0 & 1 & 0 & 0 & 0 & 0 & 0 & 0 & 0 & 0 & 0 & 0 & 0 & 0 & 0 & 0 & 0 & 0 & 0 & 0 & 0 & 0 & 0 & 0 & 0 & 0 & 0 & 0 & 0 & 0 & 0 & 0 \\
\hline 6. PMMT & 0 & 0 & 0 & 0 & 0 & 1 & 0 & 0 & 0 & 0 & 0 & 0 & 0 & 0 & 0 & 0 & 0 & 0 & 0 & 0 & 0 & 0 & 0 & 0 & 0 & 0 & 0 & 0 & 0 & 0 & 0 & 0 & 0 & 0 & 0 \\
\hline 7. NSLNA & 0 & 0 & 0 & 0 & 0 & 0 & 1 & 0 & 0 & 0 & 0 & 0 & 0 & 0 & 0 & 0 & 0 & 0 & 0 & 0 & 0 & 0 & 0 & 0 & 0 & 0 & 0 & 0 & 0 & 0 & 0 & 0 & 0 & 0 & 0 \\
\hline 8. NSLZS & 0 & 0 & 0 & 0 & 0 & 0 & 0 & 1 & 0 & 0 & 0 & 0 & 0 & 0 & 0 & 0 & 0 & 0 & 0 & 0 & 0 & 0 & 0 & 0 & 0 & 0 & 0 & 0 & 0 & 0 & 0 & 0 & 0 & 0 & 0 \\
\hline 9. NSLZI & 0 & 0 & 0 & 0 & 0 & 0 & 0 & 0 & 1 & 0 & 0 & 0 & 0 & 0 & 0 & 0 & 0 & 0 & 0 & 0 & 0 & 0 & 0 & 0 & 0 & 0 & 0 & 0 & 0 & 0 & 0 & 0 & 0 & 0 & 0 \\
\hline 10. NABR & 0 & 0 & 0 & 0 & 0 & 0 & 0 & 0 & 0 & 1 & 0 & 1 & 1 & 1 & 1 & 1 & 0 & 1 & 0 & 0 & 0 & 0 & 0 & 0 & 0 & 0 & 0 & 0 & 0 & 1 & 1 & 1 & 1 & 1 & 0 \\
\hline 11. NAPNS & 0 & 0 & 0 & 0 & 0 & 0 & 0 & 0 & 0 & 0 & 1 & 0 & 0 & 0 & 0 & 0 & 0 & 0 & 0 & 0 & 0 & 0 & 0 & 0 & 0 & 0 & 0 & 0 & 0 & 0 & 0 & 0 & 0 & 0 & 0 \\
\hline 12. BRPT & 0 & 0 & 0 & 0 & 0 & 0 & 0 & 0 & 0 & 1 & 0 & 1 & 1 & 1 & 1 & 1 & 0 & 1 & 0 & 0 & 0 & 0 & 0 & 0 & 0 & 0 & 0 & 0 & 0 & 1 & 1 & 1 & 1 & 1 & 0 \\
\hline 13. BRAPET & 0 & 0 & 0 & 0 & 0 & 0 & 0 & 0 & 0 & 1 & 0 & 1 & 1 & 1 & 1 & 1 & 0 & 1 & 0 & 0 & 0 & 0 & 0 & 0 & 0 & 0 & 0 & 0 & 0 & 1 & 1 & 1 & 1 & 1 & 0 \\
\hline 14. PTAPET & 0 & 0 & 0 & 0 & 0 & 0 & 0 & 0 & 0 & 1 & 0 & 1 & 1 & 1 & 1 & 1 & 0 & 1 & 0 & 0 & 0 & 0 & 0 & 0 & 0 & 0 & 0 & 0 & 0 & 1 & 1 & 1 & 1 & 1 & 0 \\
\hline 15. PTBA & 0 & 0 & 0 & 0 & 0 & 0 & 0 & 0 & 0 & 1 & 0 & 1 & 1 & 1 & 1 & 1 & 0 & 1 & 0 & 0 & 0 & 0 & 0 & 0 & 0 & 0 & 0 & 0 & 0 & 1 & 1 & 1 & 1 & 1 & 0 \\
\hline 16. PTEAM & 0 & 0 & 0 & 0 & 0 & 0 & 0 & 0 & 0 & 1 & 0 & 1 & 1 & 1 & 1 & 1 & 0 & 1 & 0 & 0 & 0 & 0 & 0 & 0 & 0 & 0 & 0 & 0 & 0 & 1 & 1 & 1 & 1 & 1 & 0 \\
\hline 17. PTZYGO & 0 & 0 & 0 & 0 & 0 & 0 & 0 & 0 & 0 & 0 & 0 & 0 & 0 & 0 & 0 & 0 & 1 & 0 & 0 & 0 & 0 & 0 & 0 & 0 & 0 & 0 & 0 & 0 & 0 & 0 & 0 & 0 & 0 & 0 & 0 \\
\hline 18. PTTSP & 0 & 0 & 0 & 0 & 0 & 0 & 0 & 0 & 0 & 1 & 0 & 1 & 1 & 1 & 1 & 1 & 0 & 1 & 0 & 0 & 0 & 0 & 0 & 0 & 0 & 0 & 0 & 0 & 0 & 1 & 1 & 1 & 1 & 1 & 0 \\
\hline 19. ZSZI & 0 & 0 & 0 & 0 & 0 & 0 & 0 & 0 & 0 & 0 & 0 & 0 & 0 & 0 & 0 & 0 & 0 & 0 & 1 & 0 & 0 & 0 & 0 & 0 & 0 & 0 & 0 & 0 & 0 & 0 & 0 & 0 & 0 & 0 & 0 \\
\hline 20. ZIMT & 0 & 0 & 0 & 0 & 0 & 0 & 0 & 0 & 0 & 0 & 0 & 0 & 0 & 0 & 0 & 0 & 0 & 0 & 0 & 1 & 0 & 0 & 0 & 0 & 0 & 0 & 0 & 0 & 0 & 0 & 0 & 0 & 0 & 0 & 0 \\
\hline 21. ZIZYGO & 0 & 0 & 0 & 0 & 0 & 0 & 0 & 0 & 0 & 0 & 0 & 0 & 0 & 0 & 0 & 0 & 0 & 0 & 0 & 0 & 1 & 0 & 0 & 0 & 0 & 0 & 0 & 0 & 0 & 0 & 0 & 0 & 0 & 0 & 0 \\
\hline 22. ZITSP & 0 & 0 & 0 & 0 & 0 & 0 & 0 & 0 & 0 & 0 & 0 & 0 & 0 & 0 & 0 & 0 & 0 & 0 & 0 & 0 & 0 & 1 & 0 & 0 & 0 & 0 & 0 & 0 & 0 & 0 & 0 & 0 & 0 & 0 & 0 \\
\hline 23. MTPNS & 0 & 0 & 0 & 0 & 0 & 0 & 0 & 0 & 0 & 0 & 0 & 0 & 0 & 0 & 0 & 0 & 0 & 0 & 0 & 0 & 0 & 0 & 1 & 0 & 0 & 0 & 0 & 0 & 0 & 0 & 0 & 0 & 0 & 0 & 0 \\
\hline 24. PNSAPET & 0 & 0 & 0 & 0 & 0 & 0 & 0 & 0 & 0 & 0 & 0 & 0 & 0 & 0 & 0 & 0 & 0 & 0 & 0 & 0 & 0 & 0 & 0 & 1 & 0 & 0 & 0 & 0 & 0 & 0 & 0 & 0 & 0 & 0 & 0 \\
\hline 25. APETBA & 0 & 0 & 0 & 0 & 0 & 0 & 0 & 0 & 0 & 0 & 0 & 0 & 0 & 0 & 0 & 0 & 0 & 0 & 0 & 0 & 0 & 0 & 0 & 0 & 1 & 0 & 0 & 0 & 0 & 0 & 0 & 0 & 0 & 0 & 0 \\
\hline 26. APETTS & 0 & 0 & 0 & 0 & 0 & 0 & 0 & 0 & 0 & 0 & 0 & 0 & 0 & 0 & 0 & 0 & 0 & 0 & 0 & 0 & 0 & 0 & 0 & 0 & 0 & 1 & 0 & 0 & 0 & 0 & 0 & 0 & 0 & 0 & 0 \\
\hline 27.BAEAM & 0 & 0 & 0 & 0 & 0 & 0 & 0 & 0 & 0 & 0 & 0 & 0 & 0 & 0 & 0 & 0 & 0 & 0 & 0 & 0 & 0 & 0 & 0 & 0 & 0 & 0 & 1 & 0 & 0 & 0 & 0 & 0 & 0 & 0 & 0 \\
\hline 28. EAMZYGO & 0 & 0 & 0 & 0 & 0 & 0 & 0 & 0 & 0 & 0 & 0 & 0 & 0 & 0 & 0 & 0 & 0 & 0 & 0 & 0 & 0 & 0 & 0 & 0 & 0 & 0 & 0 & 1 & 0 & 0 & 0 & 0 & 0 & 0 & 0 \\
\hline 29. ZYGOTSP & 0 & 0 & 0 & 0 & 0 & 0 & 0 & 0 & 0 & 0 & 0 & 0 & 0 & 0 & 0 & 0 & 0 & 0 & 0 & 0 & 0 & 0 & 0 & 0 & 0 & 0 & 0 & 0 & 1 & 0 & 0 & 0 & 0 & 0 & 0 \\
\hline 30. LDAS & 0 & 0 & 0 & 0 & 0 & 0 & 0 & 0 & 0 & 1 & 0 & 1 & 1 & 1 & 1 & 1 & 0 & 1 & 0 & 0 & 0 & 0 & 0 & 0 & 0 & 0 & 0 & 0 & 0 & 1 & 1 & 1 & 1 & 1 & 0 \\
\hline 31. BRLD & 0 & 0 & 0 & 0 & 0 & 0 & 0 & 0 & 0 & 1 & 0 & 1 & 1 & 1 & 1 & 1 & 0 & 1 & 0 & 0 & 0 & 0 & 0 & 0 & 0 & 0 & 0 & 0 & 0 & 1 & 1 & 1 & 1 & 1 & 0 \\
\hline 32. OPILD & 0 & 0 & 0 & 0 & 0 & 0 & 0 & 0 & 0 & 1 & 0 & 1 & 1 & 1 & 1 & 1 & 0 & 1 & 0 & 0 & 0 & 0 & 0 & 0 & 0 & 0 & 0 & 0 & 0 & 1 & 1 & 1 & 1 & 1 & 0 \\
\hline 33. PTAS & 0 & 0 & 0 & 0 & 0 & 0 & 0 & 0 & 0 & 1 & 0 & 1 & 1 & 1 & 1 & 1 & 0 & 1 & 0 & 0 & 0 & 0 & 0 & 0 & 0 & 0 & 0 & 0 & 0 & 1 & 1 & 1 & 1 & 1 & 0 \\
\hline 34. JPAS & 0 & 0 & 0 & 0 & 0 & 0 & 0 & 0 & 0 & 1 & 0 & 1 & 1 & 1 & 1 & 1 & 0 & 1 & 0 & 0 & 0 & 0 & 0 & 0 & 0 & 0 & 0 & 0 & 0 & 1 & 1 & 1 & 1 & 1 & 0 \\
\hline 35. BAOPI & 0 & 0 & 0 & 0 & 0 & 0 & 0 & 0 & 0 & 0 & 0 & 0 & 0 & 0 & 0 & 0 & 0 & 0 & 0 & 0 & 0 & 0 & 0 & 0 & 0 & 0 & 0 & 0 & 0 & 0 & 0 & 0 & 0 & 0 & 1 \\
\hline
\end{tabular}


Tabela A7 - Matriz teórica contendo a hipótese de modularidade da sub-região oral.

\begin{tabular}{|c|c|c|c|c|c|c|c|c|c|c|c|c|c|c|c|c|c|c|c|c|c|c|c|c|c|c|c|c|c|c|c|c|c|c|c|}
\hline & 1 & 2 & 3 & 4 & 5 & 6 & 7 & 8 & 9 & 10 & 11 & 12 & 13 & 14 & 15 & 16 & 17 & 18 & 19 & 20 & 21 & 22 & 23 & 24 & 25 & 26 & 27 & 28 & 29 & 30 & 31 & 32 & 33 & 34 & 35 \\
\hline 1. ISPM & 1 & 0 & 1 & 1 & 1 & 1 & 0 & 0 & 1 & 0 & 0 & 0 & 0 & 0 & 0 & 0 & 0 & 0 & 0 & 0 & 0 & 0 & 1 & 0 & 0 & 0 & 0 & 0 & 0 & 0 & 0 & 0 & 0 & 0 & 0 \\
\hline 2. ISNSL & 0 & 1 & 0 & 0 & 0 & 0 & 0 & 0 & 0 & 0 & 0 & 0 & 0 & 0 & 0 & 0 & 0 & 0 & 0 & 0 & 0 & 0 & 0 & 0 & 0 & 0 & 0 & 0 & 0 & 0 & 0 & 0 & 0 & 0 & 0 \\
\hline 3. ISPNS & 1 & 0 & 1 & 1 & 1 & 1 & 0 & 0 & 1 & 0 & 0 & 0 & 0 & 0 & 0 & 0 & 0 & 0 & 0 & 0 & 0 & 0 & 1 & 0 & 0 & 0 & 0 & 0 & 0 & 0 & 0 & 0 & 0 & 0 & 0 \\
\hline 4. PMZS & 1 & 0 & 1 & 1 & 1 & 1 & 0 & 0 & 1 & 0 & 0 & 0 & 0 & 0 & 0 & 0 & 0 & 0 & 0 & 0 & 0 & 0 & 1 & 0 & 0 & 0 & 0 & 0 & 0 & 0 & 0 & 0 & 0 & 0 & 0 \\
\hline 5. PMZI & 1 & 0 & 1 & 1 & 1 & 1 & 0 & 0 & 1 & 0 & 0 & 0 & 0 & 0 & 0 & 0 & 0 & 0 & 0 & 0 & 0 & 0 & 1 & 0 & 0 & 0 & 0 & 0 & 0 & 0 & 0 & 0 & 0 & 0 & 0 \\
\hline 6. PMMT & 1 & 0 & 1 & 1 & 1 & 1 & 0 & 0 & 1 & 0 & 0 & 0 & 0 & 0 & 0 & 0 & 0 & 0 & 0 & 0 & 0 & 0 & 1 & 0 & 0 & 0 & 0 & 0 & 0 & 0 & 0 & 0 & 0 & 0 & 0 \\
\hline 7. NSLNA & 0 & 0 & 0 & 0 & 0 & 0 & 1 & 0 & 0 & 0 & 0 & 0 & 0 & 0 & 0 & 0 & 0 & 0 & 0 & 0 & 0 & 0 & 0 & 0 & 0 & 0 & 0 & 0 & 0 & 0 & 0 & 0 & 0 & 0 & 0 \\
\hline 8. NSLZS & 0 & 0 & 0 & 0 & 0 & 0 & 0 & 1 & 0 & 0 & 0 & 0 & 0 & 0 & 0 & 0 & 0 & 0 & 0 & 0 & 0 & 0 & 0 & 0 & 0 & 0 & 0 & 0 & 0 & 0 & 0 & 0 & 0 & 0 & 0 \\
\hline 9. NSLZI & 1 & 0 & 1 & 1 & 1 & 1 & 0 & 0 & 1 & 0 & 0 & 0 & 0 & 0 & 0 & 0 & 0 & 0 & 0 & 0 & 0 & 0 & 1 & 0 & 0 & 0 & 0 & 0 & 0 & 0 & 0 & 0 & 0 & 0 & 0 \\
\hline 10. NABR & 0 & 0 & 0 & 0 & 0 & 0 & 0 & 0 & 0 & 1 & 0 & 0 & 0 & 0 & 0 & 0 & 0 & 0 & 0 & 0 & 0 & 0 & 0 & 0 & 0 & 0 & 0 & 0 & 0 & 0 & 0 & 0 & 0 & 0 & 0 \\
\hline 11. NAPNS & 0 & 0 & 0 & 0 & 0 & 0 & 0 & 0 & 0 & 0 & 1 & 0 & 0 & 0 & 0 & 0 & 0 & 0 & 0 & 0 & 0 & 0 & 0 & 0 & 0 & 0 & 0 & 0 & 0 & 0 & 0 & 0 & 0 & 0 & 0 \\
\hline 12. BRPT & 0 & 0 & 0 & 0 & 0 & 0 & 0 & 0 & 0 & 0 & 0 & 1 & 0 & 0 & 0 & 0 & 0 & 0 & 0 & 0 & 0 & 0 & 0 & 0 & 0 & 0 & 0 & 0 & 0 & 0 & 0 & 0 & 0 & 0 & 0 \\
\hline 13. BRAPET & 0 & 0 & 0 & 0 & 0 & 0 & 0 & 0 & 0 & 0 & 0 & 0 & 1 & 0 & 0 & 0 & 0 & 0 & 0 & 0 & 0 & 0 & 0 & 0 & 0 & 0 & 0 & 0 & 0 & 0 & 0 & 0 & 0 & 0 & 0 \\
\hline 14. PTAPET & 0 & 0 & 0 & 0 & 0 & 0 & 0 & 0 & 0 & 0 & 0 & 0 & 0 & 1 & 0 & 0 & 0 & 0 & 0 & 0 & 0 & 0 & 0 & 0 & 0 & 0 & 0 & 0 & 0 & 0 & 0 & 0 & 0 & 0 & 0 \\
\hline 15. PTBA & 0 & 0 & 0 & 0 & 0 & 0 & 0 & 0 & 0 & 0 & 0 & 0 & 0 & 0 & 1 & 0 & 0 & 0 & 0 & 0 & 0 & 0 & 0 & 0 & 0 & 0 & 0 & 0 & 0 & 0 & 0 & 0 & 0 & 0 & 0 \\
\hline 16. PTEAM & 0 & 0 & 0 & 0 & 0 & 0 & 0 & 0 & 0 & 0 & 0 & 0 & 0 & 0 & 0 & 1 & 0 & 0 & 0 & 0 & 0 & 0 & 0 & 0 & 0 & 0 & 0 & 0 & 0 & 0 & 0 & 0 & 0 & 0 & 0 \\
\hline 17. PTZYGO & 0 & 0 & 0 & 0 & 0 & 0 & 0 & 0 & 0 & 0 & 0 & 0 & 0 & 0 & 0 & 0 & 1 & 0 & 0 & 0 & 0 & 0 & 0 & 0 & 0 & 0 & 0 & 0 & 0 & 0 & 0 & 0 & 0 & 0 & 0 \\
\hline 18. PTTSP & 0 & 0 & 0 & 0 & 0 & 0 & 0 & 0 & 0 & 0 & 0 & 0 & 0 & 0 & 0 & 0 & 0 & 1 & 0 & 0 & 0 & 0 & 0 & 0 & 0 & 0 & 0 & 0 & 0 & 0 & 0 & 0 & 0 & 0 & 0 \\
\hline 19. ZSZI & 0 & 0 & 0 & 0 & 0 & 0 & 0 & 0 & 0 & 0 & 0 & 0 & 0 & 0 & 0 & 0 & 0 & 0 & 1 & 0 & 0 & 0 & 0 & 0 & 0 & 0 & 0 & 0 & 0 & 0 & 0 & 0 & 0 & 0 & 0 \\
\hline 20. ZIMT & 0 & 0 & 0 & 0 & 0 & 0 & 0 & 0 & 0 & 0 & 0 & 0 & 0 & 0 & 0 & 0 & 0 & 0 & 0 & 1 & 0 & 0 & 0 & 0 & 0 & 0 & 0 & 0 & 0 & 0 & 0 & 0 & 0 & 0 & 0 \\
\hline 21. ZIZYGO & 0 & 0 & 0 & 0 & 0 & 0 & 0 & 0 & 0 & 0 & 0 & 0 & 0 & 0 & 0 & 0 & 0 & 0 & 0 & 0 & 1 & 0 & 0 & 0 & 0 & 0 & 0 & 0 & 0 & 0 & 0 & 0 & 0 & 0 & 0 \\
\hline 22. ZITSP & 0 & 0 & 0 & 0 & 0 & 0 & 0 & 0 & 0 & 0 & 0 & 0 & 0 & 0 & 0 & 0 & 0 & 0 & 0 & 0 & 0 & 1 & 0 & 0 & 0 & 0 & 0 & 0 & 0 & 0 & 0 & 0 & 0 & 0 & 0 \\
\hline 23. MTPNS & 1 & 0 & 1 & 1 & 1 & 1 & 0 & 0 & 1 & 0 & 0 & 0 & 0 & 0 & 0 & 0 & 0 & 0 & 0 & 0 & 0 & 0 & 1 & 0 & 0 & 0 & 0 & 0 & 0 & 0 & 0 & 0 & 0 & 0 & 0 \\
\hline 24. PNSAPET & 0 & 0 & 0 & 0 & 0 & 0 & 0 & 0 & 0 & 0 & 0 & 0 & 0 & 0 & 0 & 0 & 0 & 0 & 0 & 0 & 0 & 0 & 0 & 1 & 0 & 0 & 0 & 0 & 0 & 0 & 0 & 0 & 0 & 0 & 0 \\
\hline 25. APETBA & 0 & 0 & 0 & 0 & 0 & 0 & 0 & 0 & 0 & 0 & 0 & 0 & 0 & 0 & 0 & 0 & 0 & 0 & 0 & 0 & 0 & 0 & 0 & 0 & 1 & 0 & 0 & 0 & 0 & 0 & 0 & 0 & 0 & 0 & 0 \\
\hline 26. APETTS & 0 & 0 & 0 & 0 & 0 & 0 & 0 & 0 & 0 & 0 & 0 & 0 & 0 & 0 & 0 & 0 & 0 & 0 & 0 & 0 & 0 & 0 & 0 & 0 & 0 & 1 & 0 & 0 & 0 & 0 & 0 & 0 & 0 & 0 & 0 \\
\hline 27.BAEAM & 0 & 0 & 0 & 0 & 0 & 0 & 0 & 0 & 0 & 0 & 0 & 0 & 0 & 0 & 0 & 0 & 0 & 0 & 0 & 0 & 0 & 0 & 0 & 0 & 0 & 0 & 1 & 0 & 0 & 0 & 0 & 0 & 0 & 0 & 0 \\
\hline 28. EAMZYGO & 0 & 0 & 0 & 0 & 0 & 0 & 0 & 0 & 0 & 0 & 0 & 0 & 0 & 0 & 0 & 0 & 0 & 0 & 0 & 0 & 0 & 0 & 0 & 0 & 0 & 0 & 0 & 1 & 0 & 0 & 0 & 0 & 0 & 0 & 0 \\
\hline 29. ZYGOTSP & 0 & 0 & 0 & 0 & 0 & 0 & 0 & 0 & 0 & 0 & 0 & 0 & 0 & 0 & 0 & 0 & 0 & 0 & 0 & 0 & 0 & 0 & 0 & 0 & 0 & 0 & 0 & 0 & 1 & 0 & 0 & 0 & 0 & 0 & 0 \\
\hline 30. LDAS & 0 & 0 & 0 & 0 & 0 & 0 & 0 & 0 & 0 & 0 & 0 & 0 & 0 & 0 & 0 & 0 & 0 & 0 & 0 & 0 & 0 & 0 & 0 & 0 & 0 & 0 & 0 & 0 & 0 & 1 & 0 & 0 & 0 & 0 & 0 \\
\hline 31. BRLD & 0 & 0 & 0 & 0 & 0 & 0 & 0 & 0 & 0 & 0 & 0 & 0 & 0 & 0 & 0 & 0 & 0 & 0 & 0 & 0 & 0 & 0 & 0 & 0 & 0 & 0 & 0 & 0 & 0 & 0 & 1 & 0 & 0 & 0 & 0 \\
\hline 32. OPILD & 0 & 0 & 0 & 0 & 0 & 0 & 0 & 0 & 0 & 0 & 0 & 0 & 0 & 0 & 0 & 0 & 0 & 0 & 0 & 0 & 0 & 0 & 0 & 0 & 0 & 0 & 0 & 0 & 0 & 0 & 0 & 1 & 0 & 0 & 0 \\
\hline 33. PTAS & 0 & 0 & 0 & 0 & 0 & 0 & 0 & 0 & 0 & 0 & 0 & 0 & 0 & 0 & 0 & 0 & 0 & 0 & 0 & 0 & 0 & 0 & 0 & 0 & 0 & 0 & 0 & 0 & 0 & 0 & 0 & 0 & 1 & 0 & 0 \\
\hline 34. JPAS & 0 & 0 & 0 & 0 & 0 & 0 & 0 & 0 & 0 & 0 & 0 & 0 & 0 & 0 & 0 & 0 & 0 & 0 & 0 & 0 & 0 & 0 & 0 & 0 & 0 & 0 & 0 & 0 & 0 & 0 & 0 & 0 & 0 & 1 & 0 \\
\hline 35. BAOPI & 0 & 0 & 0 & 0 & 0 & 0 & 0 & 0 & 0 & 0 & 0 & 0 & 0 & 0 & 0 & 0 & 0 & 0 & 0 & 0 & 0 & 0 & 0 & 0 & 0 & 0 & 0 & 0 & 0 & 0 & 0 & 0 & 0 & 0 & 1 \\
\hline
\end{tabular}


Tabela A8 - Matriz teórica contendo a hipótese de modularidade da sub-região nasal.

\begin{tabular}{|c|c|c|c|c|c|c|c|c|c|c|c|c|c|c|c|c|c|c|c|c|c|c|c|c|c|c|c|c|c|c|c|c|c|c|c|}
\hline & 1 & 2 & 3 & 4 & 5 & 6 & 7 & 8 & 9 & 10 & 11 & 12 & 13 & 14 & 15 & 16 & 17 & 18 & 19 & 20 & 21 & 22 & 23 & 24 & 25 & 26 & 27 & 28 & 29 & 30 & 31 & 32 & 33 & 34 & 35 \\
\hline 1. ISPM & 1 & 0 & 0 & 0 & 0 & 0 & 0 & 0 & 0 & 0 & 0 & 0 & 0 & 0 & 0 & 0 & 0 & 0 & 0 & 0 & 0 & 0 & 0 & 0 & 0 & 0 & 0 & 0 & 0 & 0 & 0 & 0 & 0 & 0 & 0 \\
\hline 2. ISNSL & 0 & 1 & 1 & 0 & 0 & 0 & 1 & 1 & 1 & 0 & 1 & 0 & 0 & 0 & 0 & 0 & 0 & 0 & 0 & 0 & 0 & 0 & 0 & 0 & 0 & 0 & 0 & 0 & 0 & 0 & 0 & 0 & 0 & 0 & 0 \\
\hline 3. ISPNS & 0 & 1 & 1 & 0 & 0 & 0 & 1 & 1 & 1 & 0 & 1 & 0 & 0 & 0 & 0 & 0 & 0 & 0 & 0 & 0 & 0 & 0 & 0 & 0 & 0 & 0 & 0 & 0 & 0 & 0 & 0 & 0 & 0 & 0 & 0 \\
\hline 4. PMZS & 0 & 0 & 0 & 1 & 0 & 0 & 0 & 0 & 0 & 0 & 0 & 0 & 0 & 0 & 0 & 0 & 0 & 0 & 0 & 0 & 0 & 0 & 0 & 0 & 0 & 0 & 0 & 0 & 0 & 0 & 0 & 0 & 0 & 0 & 0 \\
\hline 5. PMZI & 0 & 0 & 0 & 0 & 1 & 0 & 0 & 0 & 0 & 0 & 0 & 0 & 0 & 0 & 0 & 0 & 0 & 0 & 0 & 0 & 0 & 0 & 0 & 0 & 0 & 0 & 0 & 0 & 0 & 0 & 0 & 0 & 0 & 0 & 0 \\
\hline 6. PMMT & 0 & 0 & 0 & 0 & 0 & 1 & 0 & 0 & 0 & 0 & 0 & 0 & 0 & 0 & 0 & 0 & 0 & 0 & 0 & 0 & 0 & 0 & 0 & 0 & 0 & 0 & 0 & 0 & 0 & 0 & 0 & 0 & 0 & 0 & 0 \\
\hline 7. NSLNA & 0 & 1 & 1 & 0 & 0 & 0 & 1 & 1 & 1 & 0 & 1 & 0 & 0 & 0 & 0 & 0 & 0 & 0 & 0 & 0 & 0 & 0 & 0 & 0 & 0 & 0 & 0 & 0 & 0 & 0 & 0 & 0 & 0 & 0 & 0 \\
\hline 8. NSLZS & 0 & 1 & 1 & 0 & 0 & 0 & 1 & 1 & 1 & 0 & 1 & 0 & 0 & 0 & 0 & 0 & 0 & 0 & 0 & 0 & 0 & 0 & 0 & 0 & 0 & 0 & 0 & 0 & 0 & 0 & 0 & 0 & 0 & 0 & 0 \\
\hline 9. NSLZI & 0 & 1 & 1 & 0 & 0 & 0 & 1 & 1 & 1 & 0 & 1 & 0 & 0 & 0 & 0 & 0 & 0 & 0 & 0 & 0 & 0 & 0 & 0 & 0 & 0 & 0 & 0 & 0 & 0 & 0 & 0 & 0 & 0 & 0 & 0 \\
\hline 10. NABR & 0 & 0 & 0 & 0 & 0 & 0 & 0 & 0 & 0 & 1 & 0 & 0 & 0 & 0 & 0 & 0 & 0 & 0 & 0 & 0 & 0 & 0 & 0 & 0 & 0 & 0 & 0 & 0 & 0 & 0 & 0 & 0 & 0 & 0 & 0 \\
\hline 11. NAPNS & 0 & 1 & 1 & 0 & 0 & 0 & 1 & 1 & 1 & 0 & 1 & 0 & 0 & 0 & 0 & 0 & 0 & 0 & 0 & 0 & 0 & 0 & 0 & 0 & 0 & 0 & 0 & 0 & 0 & 0 & 0 & 0 & 0 & 0 & 0 \\
\hline 12. BRPT & 0 & 0 & 0 & 0 & 0 & 0 & 0 & 0 & 0 & 0 & 0 & 1 & 0 & 0 & 0 & 0 & 0 & 0 & 0 & 0 & 0 & 0 & 0 & 0 & 0 & 0 & 0 & 0 & 0 & 0 & 0 & 0 & 0 & 0 & 0 \\
\hline 13. BRAPET & 0 & 0 & 0 & 0 & 0 & 0 & 0 & 0 & 0 & 0 & 0 & 0 & 1 & 0 & 0 & 0 & 0 & 0 & 0 & 0 & 0 & 0 & 0 & 0 & 0 & 0 & 0 & 0 & 0 & 0 & 0 & 0 & 0 & 0 & 0 \\
\hline 14. PTAPET & 0 & 0 & 0 & 0 & 0 & 0 & 0 & 0 & 0 & 0 & 0 & 0 & 0 & 1 & 0 & 0 & 0 & 0 & 0 & 0 & 0 & 0 & 0 & 0 & 0 & 0 & 0 & 0 & 0 & 0 & 0 & 0 & 0 & 0 & 0 \\
\hline 15. PTBA & 0 & 0 & 0 & 0 & 0 & 0 & 0 & 0 & 0 & 0 & 0 & 0 & 0 & 0 & 1 & 0 & 0 & 0 & 0 & 0 & 0 & 0 & 0 & 0 & 0 & 0 & 0 & 0 & 0 & 0 & 0 & 0 & 0 & 0 & 0 \\
\hline 16. PTEAM & 0 & 0 & 0 & 0 & 0 & 0 & 0 & 0 & 0 & 0 & 0 & 0 & 0 & 0 & 0 & 1 & 0 & 0 & 0 & 0 & 0 & 0 & 0 & 0 & 0 & 0 & 0 & 0 & 0 & 0 & 0 & 0 & 0 & 0 & 0 \\
\hline 17. PTZYGO & 0 & 0 & 0 & 0 & 0 & 0 & 0 & 0 & 0 & 0 & 0 & 0 & 0 & 0 & 0 & 0 & 1 & 0 & 0 & 0 & 0 & 0 & 0 & 0 & 0 & 0 & 0 & 0 & 0 & 0 & 0 & 0 & 0 & 0 & 0 \\
\hline 18. PTTSP & 0 & 0 & 0 & 0 & 0 & 0 & 0 & 0 & 0 & 0 & 0 & 0 & 0 & 0 & 0 & 0 & 0 & 1 & 0 & 0 & 0 & 0 & 0 & 0 & 0 & 0 & 0 & 0 & 0 & 0 & 0 & 0 & 0 & 0 & 0 \\
\hline 19. ZSZI & 0 & 0 & 0 & 0 & 0 & 0 & 0 & 0 & 0 & 0 & 0 & 0 & 0 & 0 & 0 & 0 & 0 & 0 & 1 & 0 & 0 & 0 & 0 & 0 & 0 & 0 & 0 & 0 & 0 & 0 & 0 & 0 & 0 & 0 & 0 \\
\hline 20. ZIMT & 0 & 0 & 0 & 0 & 0 & 0 & 0 & 0 & 0 & 0 & 0 & 0 & 0 & 0 & 0 & 0 & 0 & 0 & 0 & 1 & 0 & 0 & 0 & 0 & 0 & 0 & 0 & 0 & 0 & 0 & 0 & 0 & 0 & 0 & 0 \\
\hline 21. ZIZYGO & 0 & 0 & 0 & 0 & 0 & 0 & 0 & 0 & 0 & 0 & 0 & 0 & 0 & 0 & 0 & 0 & 0 & 0 & 0 & 0 & 1 & 0 & 0 & 0 & 0 & 0 & 0 & 0 & 0 & 0 & 0 & 0 & 0 & 0 & 0 \\
\hline 22. ZITSP & 0 & 0 & 0 & 0 & 0 & 0 & 0 & 0 & 0 & 0 & 0 & 0 & 0 & 0 & 0 & 0 & 0 & 0 & 0 & 0 & 0 & 1 & 0 & 0 & 0 & 0 & 0 & 0 & 0 & 0 & 0 & 0 & 0 & 0 & 0 \\
\hline 23. MTPNS & 0 & 0 & 0 & 0 & 0 & 0 & 0 & 0 & 0 & 0 & 0 & 0 & 0 & 0 & 0 & 0 & 0 & 0 & 0 & 0 & 0 & 0 & 1 & 0 & 0 & 0 & 0 & 0 & 0 & 0 & 0 & 0 & 0 & 0 & 0 \\
\hline 24. PNSAPET & 0 & 0 & 0 & 0 & 0 & 0 & 0 & 0 & 0 & 0 & 0 & 0 & 0 & 0 & 0 & 0 & 0 & 0 & 0 & 0 & 0 & 0 & 0 & 1 & 0 & 0 & 0 & 0 & 0 & 0 & 0 & 0 & 0 & 0 & 0 \\
\hline 25. APETBA & 0 & 0 & 0 & 0 & 0 & 0 & 0 & 0 & 0 & 0 & 0 & 0 & 0 & 0 & 0 & 0 & 0 & 0 & 0 & 0 & 0 & 0 & 0 & 0 & 1 & 0 & 0 & 0 & 0 & 0 & 0 & 0 & 0 & 0 & 0 \\
\hline 26. APETTS & 0 & 0 & 0 & 0 & 0 & 0 & 0 & 0 & 0 & 0 & 0 & 0 & 0 & 0 & 0 & 0 & 0 & 0 & 0 & 0 & 0 & 0 & 0 & 0 & 0 & 1 & 0 & 0 & 0 & 0 & 0 & 0 & 0 & 0 & 0 \\
\hline 27.BAEAM & 0 & 0 & 0 & 0 & 0 & 0 & 0 & 0 & 0 & 0 & 0 & 0 & 0 & 0 & 0 & 0 & 0 & 0 & 0 & 0 & 0 & 0 & 0 & 0 & 0 & 0 & 1 & 0 & 0 & 0 & 0 & 0 & 0 & 0 & 0 \\
\hline 28. EAMZYGO & 0 & 0 & 0 & 0 & 0 & 0 & 0 & 0 & 0 & 0 & 0 & 0 & 0 & 0 & 0 & 0 & 0 & 0 & 0 & 0 & 0 & 0 & 0 & 0 & 0 & 0 & 0 & 1 & 0 & 0 & 0 & 0 & 0 & 0 & 0 \\
\hline 29. ZYGOTSP & 0 & 0 & 0 & 0 & 0 & 0 & 0 & 0 & 0 & 0 & 0 & 0 & 0 & 0 & 0 & 0 & 0 & 0 & 0 & 0 & 0 & 0 & 0 & 0 & 0 & 0 & 0 & 0 & 1 & 0 & 0 & 0 & 0 & 0 & 0 \\
\hline 30. LDAS & 0 & 0 & 0 & 0 & 0 & 0 & 0 & 0 & 0 & 0 & 0 & 0 & 0 & 0 & 0 & 0 & 0 & 0 & 0 & 0 & 0 & 0 & 0 & 0 & 0 & 0 & 0 & 0 & 0 & 1 & 0 & 0 & 0 & 0 & 0 \\
\hline 31. BRLD & 0 & 0 & 0 & 0 & 0 & 0 & 0 & 0 & 0 & 0 & 0 & 0 & 0 & 0 & 0 & 0 & 0 & 0 & 0 & 0 & 0 & 0 & 0 & 0 & 0 & 0 & 0 & 0 & 0 & 0 & 1 & 0 & 0 & 0 & 0 \\
\hline 32. OPILD & 0 & 0 & 0 & 0 & 0 & 0 & 0 & 0 & 0 & 0 & 0 & 0 & 0 & 0 & 0 & 0 & 0 & 0 & 0 & 0 & 0 & 0 & 0 & 0 & 0 & 0 & 0 & 0 & 0 & 0 & 0 & 1 & 0 & 0 & 0 \\
\hline 33. PTAS & 0 & 0 & 0 & 0 & 0 & 0 & 0 & 0 & 0 & 0 & 0 & 0 & 0 & 0 & 0 & 0 & 0 & 0 & 0 & 0 & 0 & 0 & 0 & 0 & 0 & 0 & 0 & 0 & 0 & 0 & 0 & 0 & 1 & 0 & 0 \\
\hline 34. JPAS & 0 & 0 & 0 & 0 & 0 & 0 & 0 & 0 & 0 & 0 & 0 & 0 & 0 & 0 & 0 & 0 & 0 & 0 & 0 & 0 & 0 & 0 & 0 & 0 & 0 & 0 & 0 & 0 & 0 & 0 & 0 & 0 & 0 & 1 & 0 \\
\hline 35. BAOPI & 0 & 0 & 0 & 0 & 0 & 0 & 0 & 0 & 0 & 0 & 0 & 0 & 0 & 0 & 0 & 0 & 0 & 0 & 0 & 0 & 0 & 0 & 0 & 0 & 0 & 0 & 0 & 0 & 0 & 0 & 0 & 0 & 0 & 0 & 1 \\
\hline
\end{tabular}


Tabela A9 - Matriz teórica contendo a hipótese de modularidade da sub-região zigomática.

\begin{tabular}{|c|c|c|c|c|c|c|c|c|c|c|c|c|c|c|c|c|c|c|c|c|c|c|c|c|c|c|c|c|c|c|c|c|c|c|c|}
\hline & 1 & 2 & 3 & 4 & 5 & 6 & 7 & 8 & 9 & 10 & 11 & 12 & 13 & 14 & 15 & 16 & 17 & 18 & 19 & 20 & 21 & 22 & 23 & 24 & 25 & 26 & 27 & 28 & 29 & 30 & 31 & 32 & 33 & 34 & 35 \\
\hline 1. ISPM & 1 & 0 & 0 & 0 & 0 & 0 & 0 & 0 & 0 & 0 & 0 & 0 & 0 & 0 & 0 & 0 & 0 & 0 & 0 & 0 & 0 & 0 & 0 & 0 & 0 & 0 & 0 & 0 & 0 & 0 & 0 & 0 & 0 & 0 & 0 \\
\hline 2. ISNSL & 0 & 1 & 0 & 0 & 0 & 0 & 0 & 0 & 0 & 0 & 0 & 0 & 0 & 0 & 0 & 0 & 0 & 0 & 0 & 0 & 0 & 0 & 0 & 0 & 0 & 0 & 0 & 0 & 0 & 0 & 0 & 0 & 0 & 0 & 0 \\
\hline 3. ISPNS & 0 & 0 & 1 & 0 & 0 & 0 & 0 & 0 & 0 & 0 & 0 & 0 & 0 & 0 & 0 & 0 & 0 & 0 & 0 & 0 & 0 & 0 & 0 & 0 & 0 & 0 & 0 & 0 & 0 & 0 & 0 & 0 & 0 & 0 & 0 \\
\hline 4. PMZS & 0 & 0 & 0 & 1 & 0 & 0 & 0 & 0 & 0 & 0 & 0 & 0 & 0 & 0 & 0 & 0 & 0 & 0 & 0 & 0 & 0 & 0 & 0 & 0 & 0 & 0 & 0 & 0 & 0 & 0 & 0 & 0 & 0 & 0 & 0 \\
\hline 5. PMZI & 0 & 0 & 0 & 0 & 1 & 0 & 0 & 0 & 0 & 0 & 0 & 0 & 0 & 0 & 0 & 0 & 0 & 0 & 0 & 0 & 0 & 0 & 0 & 0 & 0 & 0 & 0 & 0 & 0 & 0 & 0 & 0 & 0 & 0 & 0 \\
\hline 6. PMMT & 0 & 0 & 0 & 0 & 0 & 1 & 0 & 0 & 0 & 0 & 0 & 0 & 0 & 0 & 0 & 0 & 0 & 0 & 0 & 0 & 0 & 0 & 0 & 0 & 0 & 0 & 0 & 0 & 0 & 0 & 0 & 0 & 0 & 0 & 0 \\
\hline 7. NSLNA & 0 & 0 & 0 & 0 & 0 & 0 & 1 & 0 & 0 & 0 & 0 & 0 & 0 & 0 & 0 & 0 & 0 & 0 & 0 & 0 & 0 & 0 & 0 & 0 & 0 & 0 & 0 & 0 & 0 & 0 & 0 & 0 & 0 & 0 & 0 \\
\hline 8. NSLZS & 0 & 0 & 0 & 0 & 0 & 0 & 0 & 1 & 0 & 0 & 0 & 0 & 0 & 0 & 0 & 0 & 0 & 0 & 0 & 0 & 0 & 0 & 0 & 0 & 0 & 0 & 0 & 0 & 0 & 0 & 0 & 0 & 0 & 0 & 0 \\
\hline 9. NSLZI & 0 & 0 & 0 & 0 & 0 & 0 & 0 & 0 & 1 & 0 & 0 & 0 & 0 & 0 & 0 & 0 & 0 & 0 & 0 & 0 & 0 & 0 & 0 & 0 & 0 & 0 & 0 & 0 & 0 & 0 & 0 & 0 & 0 & 0 & 0 \\
\hline 10. NABR & 0 & 0 & 0 & 0 & 0 & 0 & 0 & 0 & 0 & 1 & 0 & 0 & 0 & 0 & 0 & 0 & 0 & 0 & 0 & 0 & 0 & 0 & 0 & 0 & 0 & 0 & 0 & 0 & 0 & 0 & 0 & 0 & 0 & 0 & 0 \\
\hline 11. NAPNS & 0 & 0 & 0 & 0 & 0 & 0 & 0 & 0 & 0 & 0 & 1 & 0 & 0 & 0 & 0 & 0 & 0 & 0 & 0 & 0 & 0 & 0 & 0 & 0 & 0 & 0 & 0 & 0 & 0 & 0 & 0 & 0 & 0 & 0 & 0 \\
\hline 12. BRPT & 0 & 0 & 0 & 0 & 0 & 0 & 0 & 0 & 0 & 0 & 0 & 1 & 0 & 0 & 0 & 0 & 0 & 0 & 0 & 0 & 0 & 0 & 0 & 0 & 0 & 0 & 0 & 0 & 0 & 0 & 0 & 0 & 0 & 0 & 0 \\
\hline 13. BRAPET & 0 & 0 & 0 & 0 & 0 & 0 & 0 & 0 & 0 & 0 & 0 & 0 & 1 & 0 & 0 & 0 & 0 & 0 & 0 & 0 & 0 & 0 & 0 & 0 & 0 & 0 & 0 & 0 & 0 & 0 & 0 & 0 & 0 & 0 & 0 \\
\hline 14. PTAPET & 0 & 0 & 0 & 0 & 0 & 0 & 0 & 0 & 0 & 0 & 0 & 0 & 0 & 1 & 0 & 0 & 0 & 0 & 0 & 0 & 0 & 0 & 0 & 0 & 0 & 0 & 0 & 0 & 0 & 0 & 0 & 0 & 0 & 0 & 0 \\
\hline 15. PTBA & 0 & 0 & 0 & 0 & 0 & 0 & 0 & 0 & 0 & 0 & 0 & 0 & 0 & 0 & 1 & 0 & 0 & 0 & 0 & 0 & 0 & 0 & 0 & 0 & 0 & 0 & 0 & 0 & 0 & 0 & 0 & 0 & 0 & 0 & 0 \\
\hline 16. PTEAM & 0 & 0 & 0 & 0 & 0 & 0 & 0 & 0 & 0 & 0 & 0 & 0 & 0 & 0 & 0 & 1 & 0 & 0 & 0 & 0 & 0 & 0 & 0 & 0 & 0 & 0 & 0 & 0 & 0 & 0 & 0 & 0 & 0 & 0 & 0 \\
\hline 17. PTZYGO & 0 & 0 & 0 & 0 & 0 & 0 & 0 & 0 & 0 & 0 & 0 & 0 & 0 & 0 & 0 & 0 & 1 & 1 & 1 & 1 & 1 & 1 & 0 & 0 & 0 & 0 & 0 & 1 & 1 & 0 & 0 & 0 & 0 & 0 & 0 \\
\hline 18. PTTSP & 0 & 0 & 0 & 0 & 0 & 0 & 0 & 0 & 0 & 0 & 0 & 0 & 0 & 0 & 0 & 0 & 1 & 1 & 1 & 1 & 1 & 1 & 0 & 0 & 0 & 0 & 0 & 1 & 1 & 0 & 0 & 0 & 0 & 0 & 0 \\
\hline 19. ZSZI & 0 & 0 & 0 & 0 & 0 & 0 & 0 & 0 & 0 & 0 & 0 & 0 & 0 & 0 & 0 & 0 & 1 & 1 & 1 & 1 & 1 & 1 & 0 & 0 & 0 & 0 & 0 & 1 & 1 & 0 & 0 & 0 & 0 & 0 & 0 \\
\hline 20. ZIMT & 0 & 0 & 0 & 0 & 0 & 0 & 0 & 0 & 0 & 0 & 0 & 0 & 0 & 0 & 0 & 0 & 1 & 1 & 1 & 1 & 1 & 1 & 0 & 0 & 0 & 0 & 0 & 1 & 1 & 0 & 0 & 0 & 0 & 0 & 0 \\
\hline 21. ZIZYGO & 0 & 0 & 0 & 0 & 0 & 0 & 0 & 0 & 0 & 0 & 0 & 0 & 0 & 0 & 0 & 0 & 1 & 1 & 1 & 1 & 1 & 1 & 0 & 0 & 0 & 0 & 0 & 1 & 1 & 0 & 0 & 0 & 0 & 0 & 0 \\
\hline 22. ZITSP & 0 & 0 & 0 & 0 & 0 & 0 & 0 & 0 & 0 & 0 & 0 & 0 & 0 & 0 & 0 & 0 & 1 & 1 & 1 & 1 & 1 & 1 & 0 & 0 & 0 & 0 & 0 & 1 & 1 & 0 & 0 & 0 & 0 & 0 & 0 \\
\hline 23. MTPNS & 0 & 0 & 0 & 0 & 0 & 0 & 0 & 0 & 0 & 0 & 0 & 0 & 0 & 0 & 0 & 0 & 0 & 0 & 0 & 0 & 0 & 0 & 1 & 0 & 0 & 0 & 0 & 0 & 0 & 0 & 0 & 0 & 0 & 0 & 0 \\
\hline 24. PNSAPET & 0 & 0 & 0 & 0 & 0 & 0 & 0 & 0 & 0 & 0 & 0 & 0 & 0 & 0 & 0 & 0 & 0 & 0 & 0 & 0 & 0 & 0 & 0 & 1 & 0 & 0 & 0 & 0 & 0 & 0 & 0 & 0 & 0 & 0 & 0 \\
\hline 25. APETBA & 0 & 0 & 0 & 0 & 0 & 0 & 0 & 0 & 0 & 0 & 0 & 0 & 0 & 0 & 0 & 0 & 0 & 0 & 0 & 0 & 0 & 0 & 0 & 0 & 1 & 0 & 0 & 0 & 0 & 0 & 0 & 0 & 0 & 0 & 0 \\
\hline 26. APETTS & 0 & 0 & 0 & 0 & 0 & 0 & 0 & 0 & 0 & 0 & 0 & 0 & 0 & 0 & 0 & 0 & 0 & 0 & 0 & 0 & 0 & 0 & 0 & 0 & 0 & 1 & 0 & 0 & 0 & 0 & 0 & 0 & 0 & 0 & 0 \\
\hline 27.BAEAM & 0 & 0 & 0 & 0 & 0 & 0 & 0 & 0 & 0 & 0 & 0 & 0 & 0 & 0 & 0 & 0 & 0 & 0 & 0 & 0 & 0 & 0 & 0 & 0 & 0 & 0 & 1 & 0 & 0 & 0 & 0 & 0 & 0 & 0 & 0 \\
\hline 28. EAMZYGO & 0 & 0 & 0 & 0 & 0 & 0 & 0 & 0 & 0 & 0 & 0 & 0 & 0 & 0 & 0 & 0 & 1 & 1 & 1 & 1 & 1 & 1 & 0 & 0 & 0 & 0 & 0 & 1 & 1 & 0 & 0 & 0 & 0 & 0 & 0 \\
\hline 29. ZYGOTSP & 0 & 0 & 0 & 0 & 0 & 0 & 0 & 0 & 0 & 0 & 0 & 0 & 0 & 0 & 0 & 0 & 1 & 1 & 1 & 1 & 1 & 1 & 0 & 0 & 0 & 0 & 0 & 1 & 1 & 0 & 0 & 0 & 0 & 0 & 0 \\
\hline 30. LDAS & 0 & 0 & 0 & 0 & 0 & 0 & 0 & 0 & 0 & 0 & 0 & 0 & 0 & 0 & 0 & 0 & 0 & 0 & 0 & 0 & 0 & 0 & 0 & 0 & 0 & 0 & 0 & 0 & 0 & 1 & 0 & 0 & 0 & 0 & 0 \\
\hline 31. BRLD & 0 & 0 & 0 & 0 & 0 & 0 & 0 & 0 & 0 & 0 & 0 & 0 & 0 & 0 & 0 & 0 & 0 & 0 & 0 & 0 & 0 & 0 & 0 & 0 & 0 & 0 & 0 & 0 & 0 & 0 & 1 & 0 & 0 & 0 & 0 \\
\hline 32. OPILD & 0 & 0 & 0 & 0 & 0 & 0 & 0 & 0 & 0 & 0 & 0 & 0 & 0 & 0 & 0 & 0 & 0 & 0 & 0 & 0 & 0 & 0 & 0 & 0 & 0 & 0 & 0 & 0 & 0 & 0 & 0 & 1 & 0 & 0 & 0 \\
\hline 33. PTAS & 0 & 0 & 0 & 0 & 0 & 0 & 0 & 0 & 0 & 0 & 0 & 0 & 0 & 0 & 0 & 0 & 0 & 0 & 0 & 0 & 0 & 0 & 0 & 0 & 0 & 0 & 0 & 0 & 0 & 0 & 0 & 0 & 1 & 0 & 0 \\
\hline 34. JPAS & 0 & 0 & 0 & 0 & 0 & 0 & 0 & 0 & 0 & 0 & 0 & 0 & 0 & 0 & 0 & 0 & 0 & 0 & 0 & 0 & 0 & 0 & 0 & 0 & 0 & 0 & 0 & 0 & 0 & 0 & 0 & 0 & 0 & 1 & 0 \\
\hline 35. BAOPI & 0 & 0 & 0 & 0 & 0 & 0 & 0 & 0 & 0 & 0 & 0 & 0 & 0 & 0 & 0 & 0 & 0 & 0 & 0 & 0 & 0 & 0 & 0 & 0 & 0 & 0 & 0 & 0 & 0 & 0 & 0 & 0 & 0 & 0 & 1 \\
\hline
\end{tabular}


Tabela A10 - Matriz teórica contendo a hipótese de modularidade da região da facial.

\begin{tabular}{|c|c|c|c|c|c|c|c|c|c|c|c|c|c|c|c|c|c|c|c|c|c|c|c|c|c|c|c|c|c|c|c|c|c|c|c|}
\hline & 1 & 2 & 3 & 4 & 5 & 6 & 7 & 8 & 9 & 10 & 11 & 12 & 13 & 14 & 15 & 16 & 17 & 18 & 19 & 20 & 21 & 22 & 23 & 24 & 25 & 26 & 27 & 28 & 29 & 30 & 31 & 32 & 33 & 34 & 35 \\
\hline 1. ISPM & 1 & 1 & 1 & 1 & 1 & 1 & 1 & 1 & 1 & 0 & 1 & 0 & 0 & 0 & 0 & 0 & 1 & 1 & 1 & 1 & 1 & 1 & 1 & 0 & 0 & 0 & 0 & 1 & 1 & 0 & 0 & 0 & 0 & 0 & 0 \\
\hline 2. ISNSL & 1 & 1 & 1 & 1 & 1 & 1 & 1 & 1 & 1 & 0 & 1 & 0 & 0 & 0 & 0 & 0 & 1 & 1 & 1 & 1 & 1 & 1 & 1 & 0 & 0 & 0 & 0 & 1 & 1 & 0 & 0 & 0 & 0 & 0 & 0 \\
\hline 3. ISPNS & 1 & 1 & 1 & 1 & 1 & 1 & 1 & 1 & 1 & 0 & 1 & 0 & 0 & 0 & 0 & 0 & 1 & 1 & 1 & 1 & 1 & 1 & 1 & 0 & 0 & 0 & 0 & 1 & 1 & 0 & 0 & 0 & 0 & 0 & 0 \\
\hline 4. PMZS & 1 & 1 & 1 & 1 & 1 & 1 & 1 & 1 & 1 & 0 & 1 & 0 & 0 & 0 & 0 & 0 & 1 & 1 & 1 & 1 & 1 & 1 & 1 & 0 & 0 & 0 & 0 & 1 & 1 & 0 & 0 & 0 & 0 & 0 & 0 \\
\hline 5. PMZI & 1 & 1 & 1 & 1 & 1 & 1 & 1 & 1 & 1 & 0 & 1 & 0 & 0 & 0 & 0 & 0 & 1 & 1 & 1 & 1 & 1 & 1 & 1 & 0 & 0 & 0 & 0 & 1 & 1 & 0 & 0 & 0 & 0 & 0 & 0 \\
\hline 6. PMMT & 1 & 1 & 1 & 1 & 1 & 1 & 1 & 1 & 1 & 0 & 1 & 0 & 0 & 0 & 0 & 0 & 1 & 1 & 1 & 1 & 1 & 1 & 1 & 0 & 0 & 0 & 0 & 1 & 1 & 0 & 0 & 0 & 0 & 0 & 0 \\
\hline 7. NSLNA & 1 & 1 & 1 & 1 & 1 & 1 & 1 & 1 & 1 & 0 & 1 & 0 & 0 & 0 & 0 & 0 & 1 & 1 & 1 & 1 & 1 & 1 & 1 & 0 & 0 & 0 & 0 & 1 & 1 & 0 & 0 & 0 & 0 & 0 & 0 \\
\hline 8. NSLZS & 1 & 1 & 1 & 1 & 1 & 1 & 1 & 1 & 1 & 0 & 1 & 0 & 0 & 0 & 0 & 0 & 1 & 1 & 1 & 1 & 1 & 1 & 1 & 0 & 0 & 0 & 0 & 1 & 1 & 0 & 0 & 0 & 0 & 0 & 0 \\
\hline 9. NSLZI & 1 & 1 & 1 & 1 & 1 & 1 & 1 & 1 & 1 & 0 & 1 & 0 & 0 & 0 & 0 & 0 & 1 & 1 & 1 & 1 & 1 & 1 & 1 & 0 & 0 & 0 & 0 & 1 & 1 & 0 & 0 & 0 & 0 & 0 & 0 \\
\hline 10. NABR & 0 & 0 & 0 & 0 & 0 & 0 & 0 & 0 & 0 & 1 & 0 & 0 & 0 & 0 & 0 & 0 & 0 & 0 & 0 & 0 & 0 & 0 & 0 & 0 & 0 & 0 & 0 & 0 & 0 & 0 & 0 & 0 & 0 & 0 & 0 \\
\hline 11. NAPNS & 1 & 1 & 1 & 1 & 1 & 1 & 1 & 1 & 1 & 0 & 1 & 0 & 0 & 0 & 0 & 0 & 1 & 1 & 1 & 1 & 1 & 1 & 1 & 0 & 0 & 0 & 0 & 1 & 1 & 0 & 0 & 0 & 0 & 0 & 0 \\
\hline 12. BRPT & 0 & 0 & 0 & 0 & 0 & 0 & 0 & 0 & 0 & 0 & 0 & 1 & 0 & 0 & 0 & 0 & 0 & 0 & 0 & 0 & 0 & 0 & 0 & 0 & 0 & 0 & 0 & 0 & 0 & 0 & 0 & 0 & 0 & 0 & 0 \\
\hline 13. BRAPET & 0 & 0 & 0 & 0 & 0 & 0 & 0 & 0 & 0 & 0 & 0 & 0 & 1 & 0 & 0 & 0 & 0 & 0 & 0 & 0 & 0 & 0 & 0 & 0 & 0 & 0 & 0 & 0 & 0 & 0 & 0 & 0 & 0 & 0 & 0 \\
\hline 14. PTAPET & 0 & 0 & 0 & 0 & 0 & 0 & 0 & 0 & 0 & 0 & 0 & 0 & 0 & 1 & 0 & 0 & 0 & 0 & 0 & 0 & 0 & 0 & 0 & 0 & 0 & 0 & 0 & 0 & 0 & 0 & 0 & 0 & 0 & 0 & 0 \\
\hline 15. PTBA & 0 & 0 & 0 & 0 & 0 & 0 & 0 & 0 & 0 & 0 & 0 & 0 & 0 & 0 & 1 & 0 & 0 & 0 & 0 & 0 & 0 & 0 & 0 & 0 & 0 & 0 & 0 & 0 & 0 & 0 & 0 & 0 & 0 & 0 & 0 \\
\hline 16. PTEAM & 0 & 0 & 0 & 0 & 0 & 0 & 0 & 0 & 0 & 0 & 0 & 0 & 0 & 0 & 0 & 1 & 0 & 0 & 0 & 0 & 0 & 0 & 0 & 0 & 0 & 0 & 0 & 0 & 0 & 0 & 0 & 0 & 0 & 0 & 0 \\
\hline 17. PTZYGO & 1 & 1 & 1 & 1 & 1 & 1 & 1 & 1 & 1 & 0 & 1 & 0 & 0 & 0 & 0 & 0 & 1 & 1 & 1 & 1 & 1 & 1 & 1 & 0 & 0 & 0 & 0 & 1 & 1 & 0 & 0 & 0 & 0 & 0 & 0 \\
\hline 18. PTTSP & 1 & 1 & 1 & 1 & 1 & 1 & 1 & 1 & 1 & 0 & 1 & 0 & 0 & 0 & 0 & 0 & 1 & 1 & 1 & 1 & 1 & 1 & 1 & 0 & 0 & 0 & 0 & 1 & 1 & 0 & 0 & 0 & 0 & 0 & 0 \\
\hline 19. ZSZI & 1 & 1 & 1 & 1 & 1 & 1 & 1 & 1 & 1 & 0 & 1 & 0 & 0 & 0 & 0 & 0 & 1 & 1 & 1 & 1 & 1 & 1 & 1 & 0 & 0 & 0 & 0 & 1 & 1 & 0 & 0 & 0 & 0 & 0 & 0 \\
\hline 20. ZIMT & 1 & 1 & 1 & 1 & 1 & 1 & 1 & 1 & 1 & 0 & 1 & 0 & 0 & 0 & 0 & 0 & 1 & 1 & 1 & 1 & 1 & 1 & 1 & 0 & 0 & 0 & 0 & 1 & 1 & 0 & 0 & 0 & 0 & 0 & 0 \\
\hline 21. ZIZYGO & 1 & 1 & 1 & 1 & 1 & 1 & 1 & 1 & 1 & 0 & 1 & 0 & 0 & 0 & 0 & 0 & 1 & 1 & 1 & 1 & 1 & 1 & 1 & 0 & 0 & 0 & 0 & 1 & 1 & 0 & 0 & 0 & 0 & 0 & 0 \\
\hline 22. ZITSP & 1 & 1 & 1 & 1 & 1 & 1 & 1 & 1 & 1 & 0 & 1 & 0 & 0 & 0 & 0 & 0 & 1 & 1 & 1 & 1 & 1 & 1 & 1 & 0 & 0 & 0 & 0 & 1 & 1 & 0 & 0 & 0 & 0 & 0 & 0 \\
\hline 23. MTPNS & 1 & 1 & 1 & 1 & 1 & 1 & 1 & 1 & 1 & 0 & 1 & 0 & 0 & 0 & 0 & 0 & 1 & 1 & 1 & 1 & 1 & 1 & 1 & 0 & 0 & 0 & 0 & 1 & 1 & 0 & 0 & 0 & 0 & 0 & 0 \\
\hline 24. PNSAPET & 0 & 0 & 0 & 0 & 0 & 0 & 0 & 0 & 0 & 0 & 0 & 0 & 0 & 0 & 0 & 0 & 0 & 0 & 0 & 0 & 0 & 0 & 0 & 1 & 0 & 0 & 0 & 0 & 0 & 0 & 0 & 0 & 0 & 0 & 0 \\
\hline 25. APETBA & 0 & 0 & 0 & 0 & 0 & 0 & 0 & 0 & 0 & 0 & 0 & 0 & 0 & 0 & 0 & 0 & 0 & 0 & 0 & 0 & 0 & 0 & 0 & 0 & 1 & 0 & 0 & 0 & 0 & 0 & 0 & 0 & 0 & 0 & 0 \\
\hline 26. APETTS & 0 & 0 & 0 & 0 & 0 & 0 & 0 & 0 & 0 & 0 & 0 & 0 & 0 & 0 & 0 & 0 & 0 & 0 & 0 & 0 & 0 & 0 & 0 & 0 & 0 & 1 & 0 & 0 & 0 & 0 & 0 & 0 & 0 & 0 & 0 \\
\hline 27.BAEAM & 0 & 0 & 0 & 0 & 0 & 0 & 0 & 0 & 0 & 0 & 0 & 0 & 0 & 0 & 0 & 0 & 0 & 0 & 0 & 0 & 0 & 0 & 0 & 0 & 0 & 0 & 1 & 0 & 0 & 0 & 0 & 0 & 0 & 0 & 0 \\
\hline 28. EAMZYGO & 1 & 1 & 1 & 1 & 1 & 1 & 1 & 1 & 1 & 0 & 1 & 0 & 0 & 0 & 0 & 0 & 1 & 1 & 1 & 1 & 1 & 1 & 1 & 0 & 0 & 0 & 0 & 1 & 1 & 0 & 0 & 0 & 0 & 0 & 0 \\
\hline 29. ZYGOTSP & 1 & 1 & 1 & 1 & 1 & 1 & 1 & 1 & 1 & 0 & 1 & 0 & 0 & 0 & 0 & 0 & 1 & 1 & 1 & 1 & 1 & 1 & 1 & 0 & 0 & 0 & 0 & 1 & 1 & 0 & 0 & 0 & 0 & 0 & 0 \\
\hline 30. LDAS & 0 & 0 & 0 & 0 & 0 & 0 & 0 & 0 & 0 & 0 & 0 & 0 & 0 & 0 & 0 & 0 & 0 & 0 & 0 & 0 & 0 & 0 & 0 & 0 & 0 & 0 & 0 & 0 & 0 & 1 & 0 & 0 & 0 & 0 & 0 \\
\hline 31. BRLD & 0 & 0 & 0 & 0 & 0 & 0 & 0 & 0 & 0 & 0 & 0 & 0 & 0 & 0 & 0 & 0 & 0 & 0 & 0 & 0 & 0 & 0 & 0 & 0 & 0 & 0 & 0 & 0 & 0 & 0 & 1 & 0 & 0 & 0 & 0 \\
\hline 32. OPILD & 0 & 0 & 0 & 0 & 0 & 0 & 0 & 0 & 0 & 0 & 0 & 0 & 0 & 0 & 0 & 0 & 0 & 0 & 0 & 0 & 0 & 0 & 0 & 0 & 0 & 0 & 0 & 0 & 0 & 0 & 0 & 1 & 0 & 0 & 0 \\
\hline 33. PTAS & 0 & 0 & 0 & 0 & 0 & 0 & 0 & 0 & 0 & 0 & 0 & 0 & 0 & 0 & 0 & 0 & 0 & 0 & 0 & 0 & 0 & 0 & 0 & 0 & 0 & 0 & 0 & 0 & 0 & 0 & 0 & 0 & 1 & 0 & 0 \\
\hline 34. JPAS & 0 & 0 & 0 & 0 & 0 & 0 & 0 & 0 & 0 & 0 & 0 & 0 & 0 & 0 & 0 & 0 & 0 & 0 & 0 & 0 & 0 & 0 & 0 & 0 & 0 & 0 & 0 & 0 & 0 & 0 & 0 & 0 & 0 & 1 & 0 \\
\hline 35. BAOPI & 0 & 0 & 0 & 0 & 0 & 0 & 0 & 0 & 0 & 0 & 0 & 0 & 0 & 0 & 0 & 0 & 0 & 0 & 0 & 0 & 0 & 0 & 0 & 0 & 0 & 0 & 0 & 0 & 0 & 0 & 0 & 0 & 0 & 0 & 1 \\
\hline
\end{tabular}


Tabela A11 - Matriz teórica contendo a hipótese de modularidade da região neural.

\begin{tabular}{|c|c|c|c|c|c|c|c|c|c|c|c|c|c|c|c|c|c|c|c|c|c|c|c|c|c|c|c|c|c|c|c|c|c|c|c|}
\hline & 1 & 2 & 3 & 4 & 5 & 6 & 7 & 8 & 9 & 10 & 11 & 12 & 13 & 14 & 15 & 16 & 17 & 18 & 19 & 20 & 21 & 22 & 23 & 24 & 25 & 26 & 27 & 28 & 29 & 30 & 31 & 32 & 33 & 34 & 35 \\
\hline 1. ISPM & 1 & 0 & 0 & 0 & 0 & 0 & 0 & 0 & 0 & 0 & 0 & 0 & 0 & 0 & 0 & 0 & 0 & 0 & 0 & 0 & 0 & 0 & 0 & 0 & 0 & 0 & 0 & 0 & 0 & 0 & 0 & 0 & 0 & 0 & 0 \\
\hline 2. ISNSL & 0 & 1 & 0 & 0 & 0 & 0 & 0 & 0 & 0 & 0 & 0 & 0 & 0 & 0 & 0 & 0 & 0 & 0 & 0 & 0 & 0 & 0 & 0 & 0 & 0 & 0 & 0 & 0 & 0 & 0 & 0 & 0 & 0 & 0 & 0 \\
\hline 3. ISPNS & 0 & 0 & 1 & 0 & 0 & 0 & 0 & 0 & 0 & 0 & 0 & 0 & 0 & 0 & 0 & 0 & 0 & 0 & 0 & 0 & 0 & 0 & 0 & 0 & 0 & 0 & 0 & 0 & 0 & 0 & 0 & 0 & 0 & 0 & 0 \\
\hline 4. PMZS & 0 & 0 & 0 & 1 & 0 & 0 & 0 & 0 & 0 & 0 & 0 & 0 & 0 & 0 & 0 & 0 & 0 & 0 & 0 & 0 & 0 & 0 & 0 & 0 & 0 & 0 & 0 & 0 & 0 & 0 & 0 & 0 & 0 & 0 & 0 \\
\hline 5. PMZI & 0 & 0 & 0 & 0 & 1 & 0 & 0 & 0 & 0 & 0 & 0 & 0 & 0 & 0 & 0 & 0 & 0 & 0 & 0 & 0 & 0 & 0 & 0 & 0 & 0 & 0 & 0 & 0 & 0 & 0 & 0 & 0 & 0 & 0 & 0 \\
\hline 6. PMMT & 0 & 0 & 0 & 0 & 0 & 1 & 0 & 0 & 0 & 0 & 0 & 0 & 0 & 0 & 0 & 0 & 0 & 0 & 0 & 0 & 0 & 0 & 0 & 0 & 0 & 0 & 0 & 0 & 0 & 0 & 0 & 0 & 0 & 0 & 0 \\
\hline 7. NSLNA & 0 & 0 & 0 & 0 & 0 & 0 & 1 & 0 & 0 & 0 & 0 & 0 & 0 & 0 & 0 & 0 & 0 & 0 & 0 & 0 & 0 & 0 & 0 & 0 & 0 & 0 & 0 & 0 & 0 & 0 & 0 & 0 & 0 & 0 & 0 \\
\hline 8. NSLZS & 0 & 0 & 0 & 0 & 0 & 0 & 0 & 1 & 0 & 0 & 0 & 0 & 0 & 0 & 0 & 0 & 0 & 0 & 0 & 0 & 0 & 0 & 0 & 0 & 0 & 0 & 0 & 0 & 0 & 0 & 0 & 0 & 0 & 0 & 0 \\
\hline 9. NSLZI & 0 & 0 & 0 & 0 & 0 & 0 & 0 & 0 & 1 & 0 & 0 & 0 & 0 & 0 & 0 & 0 & 0 & 0 & 0 & 0 & 0 & 0 & 0 & 0 & 0 & 0 & 0 & 0 & 0 & 0 & 0 & 0 & 0 & 0 & 0 \\
\hline 10. NABR & 0 & 0 & 0 & 0 & 0 & 0 & 0 & 0 & 0 & 1 & 0 & 1 & 1 & 1 & 1 & 1 & 0 & 1 & 0 & 0 & 0 & 0 & 0 & 1 & 1 & 1 & 1 & 0 & 0 & 1 & 1 & 1 & 1 & 1 & 1 \\
\hline 11. NAPNS & 0 & 0 & 0 & 0 & 0 & 0 & 0 & 0 & 0 & 0 & 1 & 0 & 0 & 0 & 0 & 0 & 0 & 0 & 0 & 0 & 0 & 0 & 0 & 0 & 0 & 0 & 0 & 0 & 0 & 0 & 0 & 0 & 0 & 0 & 0 \\
\hline 12. BRPT & 0 & 0 & 0 & 0 & 0 & 0 & 0 & 0 & 0 & 1 & 0 & 1 & 1 & 1 & 1 & 1 & 0 & 1 & 0 & 0 & 0 & 0 & 0 & 1 & 1 & 1 & 1 & 0 & 0 & 1 & 1 & 1 & 1 & 1 & 1 \\
\hline 13. BRAPET & 0 & 0 & 0 & 0 & 0 & 0 & 0 & 0 & 0 & 1 & 0 & 1 & 1 & 1 & 1 & 1 & 0 & 1 & 0 & 0 & 0 & 0 & 0 & 1 & 1 & 1 & 1 & 0 & 0 & 1 & 1 & 1 & 1 & 1 & 1 \\
\hline 14. PTAPET & 0 & 0 & 0 & 0 & 0 & 0 & 0 & 0 & 0 & 1 & 0 & 1 & 1 & 1 & 1 & 1 & 0 & 1 & 0 & 0 & 0 & 0 & 0 & 1 & 1 & 1 & 1 & 0 & 0 & 1 & 1 & 1 & 1 & 1 & 1 \\
\hline 15. PTBA & 0 & 0 & 0 & 0 & 0 & 0 & 0 & 0 & 0 & 1 & 0 & 1 & 1 & 1 & 1 & 1 & 0 & 1 & 0 & 0 & 0 & 0 & 0 & 1 & 1 & 1 & 1 & 0 & 0 & 1 & 1 & 1 & 1 & 1 & 1 \\
\hline 16. PTEAM & 0 & 0 & 0 & 0 & 0 & 0 & 0 & 0 & 0 & 1 & 0 & 1 & 1 & 1 & 1 & 1 & 0 & 1 & 0 & 0 & 0 & 0 & 0 & 1 & 1 & 1 & 1 & 0 & 0 & 1 & 1 & 1 & 1 & 1 & 1 \\
\hline 17. PTZYGO & 0 & 0 & 0 & 0 & 0 & 0 & 0 & 0 & 0 & 0 & 0 & 0 & 0 & 0 & 0 & 0 & 1 & 0 & 0 & 0 & 0 & 0 & 0 & 0 & 0 & 0 & 0 & 0 & 0 & 0 & 0 & 0 & 0 & 0 & 0 \\
\hline 18. PTTSP & 0 & 0 & 0 & 0 & 0 & 0 & 0 & 0 & 0 & 1 & 0 & 1 & 1 & 1 & 1 & 1 & 0 & 1 & 0 & 0 & 0 & 0 & 0 & 1 & 1 & 1 & 1 & 0 & 0 & 1 & 1 & 1 & 1 & 1 & 1 \\
\hline 19. ZSZI & 0 & 0 & 0 & 0 & 0 & 0 & 0 & 0 & 0 & 0 & 0 & 0 & 0 & 0 & 0 & 0 & 0 & 0 & 1 & 0 & 0 & 0 & 0 & 0 & 0 & 0 & 0 & 0 & 0 & 0 & 0 & 0 & 0 & 0 & 0 \\
\hline 20. ZIMT & 0 & 0 & 0 & 0 & 0 & 0 & 0 & 0 & 0 & 0 & 0 & 0 & 0 & 0 & 0 & 0 & 0 & 0 & 0 & 1 & 0 & 0 & 0 & 0 & 0 & 0 & 0 & 0 & 0 & 0 & 0 & 0 & 0 & 0 & 0 \\
\hline 21. ZIZYGO & 0 & 0 & 0 & 0 & 0 & 0 & 0 & 0 & 0 & 0 & 0 & 0 & 0 & 0 & 0 & 0 & 0 & 0 & 0 & 0 & 1 & 0 & 0 & 0 & 0 & 0 & 0 & 0 & 0 & 0 & 0 & 0 & 0 & 0 & 0 \\
\hline 22. ZITSP & 0 & 0 & 0 & 0 & 0 & 0 & 0 & 0 & 0 & 0 & 0 & 0 & 0 & 0 & 0 & 0 & 0 & 0 & 0 & 0 & 0 & 1 & 0 & 0 & 0 & 0 & 0 & 0 & 0 & 0 & 0 & 0 & 0 & 0 & 0 \\
\hline 23. MTPNS & 0 & 0 & 0 & 0 & 0 & 0 & 0 & 0 & 0 & 0 & 0 & 0 & 0 & 0 & 0 & 0 & 0 & 0 & 0 & 0 & 0 & 0 & 1 & 0 & 0 & 0 & 0 & 0 & 0 & 0 & 0 & 0 & 0 & 0 & 0 \\
\hline 24. PNSAPET & 0 & 0 & 0 & 0 & 0 & 0 & 0 & 0 & 0 & 1 & 0 & 1 & 1 & 1 & 1 & 1 & 0 & 1 & 0 & 0 & 0 & 0 & 0 & 1 & 1 & 1 & 1 & 0 & 0 & 1 & 1 & 1 & 1 & 1 & 1 \\
\hline 25. APETBA & 0 & 0 & 0 & 0 & 0 & 0 & 0 & 0 & 0 & 1 & 0 & 1 & 1 & 1 & 1 & 1 & 0 & 1 & 0 & 0 & 0 & 0 & 0 & 1 & 1 & 1 & 1 & 0 & 0 & 1 & 1 & 1 & 1 & 1 & 1 \\
\hline 26. APETTS & 0 & 0 & 0 & 0 & 0 & 0 & 0 & 0 & 0 & 1 & 0 & 1 & 1 & 1 & 1 & 1 & 0 & 1 & 0 & 0 & 0 & 0 & 0 & 1 & 1 & 1 & 1 & 0 & 0 & 1 & 1 & 1 & 1 & 1 & 1 \\
\hline 27.BAEAM & 0 & 0 & 0 & 0 & 0 & 0 & 0 & 0 & 0 & 1 & 0 & 1 & 1 & 1 & 1 & 1 & 0 & 1 & 0 & 0 & 0 & 0 & 0 & 1 & 1 & 1 & 1 & 0 & 0 & 1 & 1 & 1 & 1 & 1 & 1 \\
\hline 28. EAMZYGO & 0 & 0 & 0 & 0 & 0 & 0 & 0 & 0 & 0 & 0 & 0 & 0 & 0 & 0 & 0 & 0 & 0 & 0 & 0 & 0 & 0 & 0 & 0 & 0 & 0 & 0 & 0 & 1 & 0 & 0 & 0 & 0 & 0 & 0 & 0 \\
\hline 29. ZYGOTSP & 0 & 0 & 0 & 0 & 0 & 0 & 0 & 0 & 0 & 0 & 0 & 0 & 0 & 0 & 0 & 0 & 0 & 0 & 0 & 0 & 0 & 0 & 0 & 0 & 0 & 0 & 0 & 0 & 1 & 0 & 0 & 0 & 0 & 0 & 0 \\
\hline 30. LDAS & 0 & 0 & 0 & 0 & 0 & 0 & 0 & 0 & 0 & 1 & 0 & 1 & 1 & 1 & 1 & 1 & 0 & 1 & 0 & 0 & 0 & 0 & 0 & 1 & 1 & 1 & 1 & 0 & 0 & 1 & 1 & 1 & 1 & 1 & 1 \\
\hline 31. BRLD & 0 & 0 & 0 & 0 & 0 & 0 & 0 & 0 & 0 & 1 & 0 & 1 & 1 & 1 & 1 & 1 & 0 & 1 & 0 & 0 & 0 & 0 & 0 & 1 & 1 & 1 & 1 & 0 & 0 & 1 & 1 & 1 & 1 & 1 & 1 \\
\hline 32. OPILD & 0 & 0 & 0 & 0 & 0 & 0 & 0 & 0 & 0 & 1 & 0 & 1 & 1 & 1 & 1 & 1 & 0 & 1 & 0 & 0 & 0 & 0 & 0 & 1 & 1 & 1 & 1 & 0 & 0 & 1 & 1 & 1 & 1 & 1 & 1 \\
\hline 33. PTAS & 0 & 0 & 0 & 0 & 0 & 0 & 0 & 0 & 0 & 1 & 0 & 1 & 1 & 1 & 1 & 1 & 0 & 1 & 0 & 0 & 0 & 0 & 0 & 1 & 1 & 1 & 1 & 0 & 0 & 1 & 1 & 1 & 1 & 1 & 1 \\
\hline 34. JPAS & 0 & 0 & 0 & 0 & 0 & 0 & 0 & 0 & 0 & 1 & 0 & 1 & 1 & 1 & 1 & 1 & 0 & 1 & 0 & 0 & 0 & 0 & 0 & 1 & 1 & 1 & 1 & 0 & 0 & 1 & 1 & 1 & 1 & 1 & 1 \\
\hline 35. BAOPI & 0 & 0 & 0 & 0 & 0 & 0 & 0 & 0 & 0 & 1 & 0 & 1 & 1 & 1 & 1 & 1 & 0 & 1 & 0 & 0 & 0 & 0 & 0 & 1 & 1 & 1 & 1 & 0 & 0 & 1 & 1 & 1 & 1 & 1 & 1 \\
\hline
\end{tabular}


Tabela A12 - Matriz teórica contendo a hipótese de modularidade neurossomática.

\begin{tabular}{|c|c|c|c|c|c|c|c|c|c|c|c|c|c|c|c|c|c|c|c|c|c|c|c|c|c|c|c|c|c|c|c|c|c|c|c|}
\hline & 1 & 2 & 3 & 4 & 5 & 6 & 7 & 8 & 9 & 10 & 11 & 12 & 13 & 14 & 15 & 16 & 17 & 18 & 19 & 20 & 21 & 22 & 23 & 24 & 25 & 26 & 27 & 28 & 29 & 30 & 31 & 32 & 33 & 34 & 35 \\
\hline 1. ISPM & 1 & 1 & 1 & 1 & 1 & 1 & 1 & 1 & 1 & 0 & 1 & 0 & 0 & 0 & 0 & 0 & 1 & 1 & 1 & 1 & 1 & 1 & 1 & 0 & 0 & 0 & 0 & 1 & 1 & 0 & 0 & 0 & 0 & 0 & 0 \\
\hline 2. ISNSL & 1 & 1 & 1 & 1 & 1 & 1 & 1 & 1 & 1 & 0 & 1 & 0 & 0 & 0 & 0 & 0 & 1 & 1 & 1 & 1 & 1 & 1 & 1 & 0 & 0 & 0 & 0 & 1 & 1 & 0 & 0 & 0 & 0 & 0 & 0 \\
\hline 3. ISPNS & 1 & 1 & 1 & 1 & 1 & 1 & 1 & 1 & 1 & 0 & 1 & 0 & 0 & 0 & 0 & 0 & 1 & 1 & 1 & 1 & 1 & 1 & 1 & 0 & 0 & 0 & 0 & 1 & 1 & 0 & 0 & 0 & 0 & 0 & 0 \\
\hline 4. PMZS & 1 & 1 & 1 & 1 & 1 & 1 & 1 & 1 & 1 & 0 & 1 & 0 & 0 & 0 & 0 & 0 & 1 & 1 & 1 & 1 & 1 & 1 & 1 & 0 & 0 & 0 & 0 & 1 & 1 & 0 & 0 & 0 & 0 & 0 & 0 \\
\hline 5. PMZI & 1 & 1 & 1 & 1 & 1 & 1 & 1 & 1 & 1 & 0 & 1 & 0 & 0 & 0 & 0 & 0 & 1 & 1 & 1 & 1 & 1 & 1 & 1 & 0 & 0 & 0 & 0 & 1 & 1 & 0 & 0 & 0 & 0 & 0 & 0 \\
\hline 6. PMMT & 1 & 1 & 1 & 1 & 1 & 1 & 1 & 1 & 1 & 0 & 1 & 0 & 0 & 0 & 0 & 0 & 1 & 1 & 1 & 1 & 1 & 1 & 1 & 0 & 0 & 0 & 0 & 1 & 1 & 0 & 0 & 0 & 0 & 0 & 0 \\
\hline 7. NSLNA & 1 & 1 & 1 & 1 & 1 & 1 & 1 & 1 & 1 & 0 & 1 & 0 & 0 & 0 & 0 & 0 & 1 & 1 & 1 & 1 & 1 & 1 & 1 & 0 & 0 & 0 & 0 & 1 & 1 & 0 & 0 & 0 & 0 & 0 & 0 \\
\hline 8. NSLZS & 1 & 1 & 1 & 1 & 1 & 1 & 1 & 1 & 1 & 0 & 1 & 0 & 0 & 0 & 0 & 0 & 1 & 1 & 1 & 1 & 1 & 1 & 1 & 0 & 0 & 0 & 0 & 1 & 1 & 0 & 0 & 0 & 0 & 0 & 0 \\
\hline 9. NSLZI & 1 & 1 & 1 & 1 & 1 & 1 & 1 & 1 & 1 & 0 & 1 & 0 & 0 & 0 & 0 & 0 & 1 & 1 & 1 & 1 & 1 & 1 & 1 & 0 & 0 & 0 & 0 & 1 & 1 & 0 & 0 & 0 & 0 & 0 & 0 \\
\hline 10. NABR & 0 & 0 & 0 & 0 & 0 & 0 & 0 & 0 & 0 & 1 & 0 & 1 & 1 & 1 & 1 & 1 & 0 & 1 & 0 & 0 & 0 & 0 & 0 & 1 & 1 & 1 & 1 & 0 & 0 & 1 & 1 & 1 & 1 & 1 & 1 \\
\hline 11. NAPNS & 1 & 1 & 1 & 1 & 1 & 1 & 1 & 1 & 1 & 0 & 1 & 0 & 0 & 0 & 0 & 0 & 1 & 1 & 1 & 1 & 1 & 1 & 1 & 0 & 0 & 0 & 0 & 1 & 1 & 0 & 0 & 0 & 0 & 0 & 0 \\
\hline 12. BRPT & 0 & 0 & 0 & 0 & 0 & 0 & 0 & 0 & 0 & 1 & 0 & 1 & 1 & 1 & 1 & 1 & 0 & 1 & 0 & 0 & 0 & 0 & 0 & 1 & 1 & 1 & 1 & 0 & 0 & 1 & 1 & 1 & 1 & 1 & 1 \\
\hline 13. BRAPET & 0 & 0 & 0 & 0 & 0 & 0 & 0 & 0 & 0 & 1 & 0 & 1 & 1 & 1 & 1 & 1 & 0 & 1 & 0 & 0 & 0 & 0 & 0 & 1 & 1 & 1 & 1 & 0 & 0 & 1 & 1 & 1 & 1 & 1 & 1 \\
\hline 14. PTAPET & 0 & 0 & 0 & 0 & 0 & 0 & 0 & 0 & 0 & 1 & 0 & 1 & 1 & 1 & 1 & 1 & 0 & 1 & 0 & 0 & 0 & 0 & 0 & 1 & 1 & 1 & 1 & 0 & 0 & 1 & 1 & 1 & 1 & 1 & 1 \\
\hline 15. PTBA & 0 & 0 & 0 & 0 & 0 & 0 & 0 & 0 & 0 & 1 & 0 & 1 & 1 & 1 & 1 & 1 & 0 & 1 & 0 & 0 & 0 & 0 & 0 & 1 & 1 & 1 & 1 & 0 & 0 & 1 & 1 & 1 & 1 & 1 & 1 \\
\hline 16. PTEAM & 0 & 0 & 0 & 0 & 0 & 0 & 0 & 0 & 0 & 1 & 0 & 1 & 1 & 1 & 1 & 1 & 0 & 1 & 0 & 0 & 0 & 0 & 0 & 1 & 1 & 1 & 1 & 0 & 0 & 1 & 1 & 1 & 1 & 1 & 1 \\
\hline 17. PTZYGO & 1 & 1 & 1 & 1 & 1 & 1 & 1 & 1 & 1 & 0 & 1 & 0 & 0 & 0 & 0 & 0 & 1 & 1 & 1 & 1 & 1 & 1 & 1 & 0 & 0 & 0 & 0 & 1 & 1 & 0 & 0 & 0 & 0 & 0 & 0 \\
\hline 18. PTTSP & 1 & 1 & 1 & 1 & 1 & 1 & 1 & 1 & 1 & 1 & 1 & 1 & 1 & 1 & 1 & 1 & 1 & 1 & 1 & 1 & 1 & 1 & 1 & 1 & 1 & 1 & 1 & 1 & 1 & 1 & 1 & 1 & 1 & 1 & 1 \\
\hline 19. ZSZI & 1 & 1 & 1 & 1 & 1 & 1 & 1 & 1 & 1 & 0 & 1 & 0 & 0 & 0 & 0 & 0 & 1 & 1 & 1 & 1 & 1 & 1 & 1 & 0 & 0 & 0 & 0 & 1 & 1 & 0 & 0 & 0 & 0 & 0 & 0 \\
\hline 20. ZIMT & 1 & 1 & 1 & 1 & 1 & 1 & 1 & 1 & 1 & 0 & 1 & 0 & 0 & 0 & 0 & 0 & 1 & 1 & 1 & 1 & 1 & 1 & 1 & 0 & 0 & 0 & 0 & 1 & 1 & 0 & 0 & 0 & 0 & 0 & 0 \\
\hline 21. ZIZYGO & 1 & 1 & 1 & 1 & 1 & 1 & 1 & 1 & 1 & 0 & 1 & 0 & 0 & 0 & 0 & 0 & 1 & 1 & 1 & 1 & 1 & 1 & 1 & 0 & 0 & 0 & 0 & 1 & 1 & 0 & 0 & 0 & 0 & 0 & 0 \\
\hline 22. ZITSP & 1 & 1 & 1 & 1 & 1 & 1 & 1 & 1 & 1 & 0 & 1 & 0 & 0 & 0 & 0 & 0 & 1 & 1 & 1 & 1 & 1 & 1 & 1 & 0 & 0 & 0 & 0 & 1 & 1 & 0 & 0 & 0 & 0 & 0 & 0 \\
\hline 23. MTPNS & 1 & 1 & 1 & 1 & 1 & 1 & 1 & 1 & 1 & 0 & 1 & 0 & 0 & 0 & 0 & 0 & 1 & 1 & 1 & 1 & 1 & 1 & 1 & 0 & 0 & 0 & 0 & 1 & 1 & 0 & 0 & 0 & 0 & 0 & 0 \\
\hline 24. PNSAPET & 0 & 0 & 0 & 0 & 0 & 0 & 0 & 0 & 0 & 1 & 0 & 1 & 1 & 1 & 1 & 1 & 0 & 1 & 0 & 0 & 0 & 0 & 0 & 1 & 1 & 1 & 1 & 0 & 0 & 1 & 1 & 1 & 1 & 1 & 1 \\
\hline 25. APETBA & 0 & 0 & 0 & 0 & 0 & 0 & 0 & 0 & 0 & 1 & 0 & 1 & 1 & 1 & 1 & 1 & 0 & 1 & 0 & 0 & 0 & 0 & 0 & 1 & 1 & 1 & 1 & 0 & 0 & 1 & 1 & 1 & 1 & 1 & 1 \\
\hline 26. APETTS & 0 & 0 & 0 & 0 & 0 & 0 & 0 & 0 & 0 & 1 & 0 & 1 & 1 & 1 & 1 & 1 & 0 & 1 & 0 & 0 & 0 & 0 & 0 & 1 & 1 & 1 & 1 & 0 & 0 & 1 & 1 & 1 & 1 & 1 & 1 \\
\hline 27.BAEAM & 0 & 0 & 0 & 0 & 0 & 0 & 0 & 0 & 0 & 1 & 0 & 1 & 1 & 1 & 1 & 1 & 0 & 1 & 0 & 0 & 0 & 0 & 0 & 1 & 1 & 1 & 1 & 0 & 0 & 1 & 1 & 1 & 1 & 1 & 1 \\
\hline 28. EAMZYGO & 1 & 1 & 1 & 1 & 1 & 1 & 1 & 1 & 1 & 0 & 1 & 0 & 0 & 0 & 0 & 0 & 1 & 1 & 1 & 1 & 1 & 1 & 1 & 0 & 0 & 0 & 0 & 1 & 1 & 0 & 0 & 0 & 0 & 0 & 0 \\
\hline 29. ZYGOTSP & 1 & 1 & 1 & 1 & 1 & 1 & 1 & 1 & 1 & 0 & 1 & 0 & 0 & 0 & 0 & 0 & 1 & 1 & 1 & 1 & 1 & 1 & 1 & 0 & 0 & 0 & 0 & 1 & 1 & 0 & 0 & 0 & 0 & 0 & 0 \\
\hline 30. LDAS & 0 & 0 & 0 & 0 & 0 & 0 & 0 & 0 & 0 & 1 & 0 & 1 & 1 & 1 & 1 & 1 & 0 & 1 & 0 & 0 & 0 & 0 & 0 & 1 & 1 & 1 & 1 & 0 & 0 & 1 & 1 & 1 & 1 & 1 & 1 \\
\hline 31. BRLD & 0 & 0 & 0 & 0 & 0 & 0 & 0 & 0 & 0 & 1 & 0 & 1 & 1 & 1 & 1 & 1 & 0 & 1 & 0 & 0 & 0 & 0 & 0 & 1 & 1 & 1 & 1 & 0 & 0 & 1 & 1 & 1 & 1 & 1 & 1 \\
\hline 32. OPILD & 0 & 0 & 0 & 0 & 0 & 0 & 0 & 0 & 0 & 1 & 0 & 1 & 1 & 1 & 1 & 1 & 0 & 1 & 0 & 0 & 0 & 0 & 0 & 1 & 1 & 1 & 1 & 0 & 0 & 1 & 1 & 1 & 1 & 1 & 1 \\
\hline 33. PTAS & 0 & 0 & 0 & 0 & 0 & 0 & 0 & 0 & 0 & 1 & 0 & 1 & 1 & 1 & 1 & 1 & 0 & 1 & 0 & 0 & 0 & 0 & 0 & 1 & 1 & 1 & 1 & 0 & 0 & 1 & 1 & 1 & 1 & 1 & 1 \\
\hline 34. JPAS & 0 & 0 & 0 & 0 & 0 & 0 & 0 & 0 & 0 & 1 & 0 & 1 & 1 & 1 & 1 & 1 & 0 & 1 & 0 & 0 & 0 & 0 & 0 & 1 & 1 & 1 & 1 & 0 & 0 & 1 & 1 & 1 & 1 & 1 & 1 \\
\hline 35. BAOPI & 0 & 0 & 0 & 0 & 0 & 0 & 0 & 0 & 0 & 1 & 0 & 1 & 1 & 1 & 1 & 1 & 0 & 1 & 0 & 0 & 0 & 0 & 0 & 1 & 1 & 1 & 1 & 0 & 0 & 1 & 1 & 1 & 1 & 1 & 1 \\
\hline
\end{tabular}


Tabela A13 - Matriz teórica contendo a hipótese de modularidade total.

\begin{tabular}{|c|c|c|c|c|c|c|c|c|c|c|c|c|c|c|c|c|c|c|c|c|c|c|c|c|c|c|c|c|c|c|c|c|c|c|c|}
\hline & 1 & 2 & 3 & 4 & 5 & 6 & 7 & 8 & 9 & 10 & 11 & 12 & 13 & 14 & 15 & 16 & 17 & 18 & 19 & 20 & 21 & 22 & 23 & 24 & 25 & 26 & 27 & 28 & 29 & 30 & 31 & 32 & 33 & 34 & 35 \\
\hline 1. ISPM & 1 & 0 & 1 & 1 & 1 & 1 & 0 & 0 & 1 & 0 & 0 & 0 & 0 & 0 & 0 & 0 & 0 & 0 & 0 & 0 & 0 & 0 & 1 & 0 & 0 & 0 & 0 & 0 & 0 & 0 & 0 & 0 & 0 & 0 & 0 \\
\hline 2. ISNSL & 0 & 1 & 1 & 0 & 0 & 0 & 1 & 1 & 1 & 0 & 1 & 0 & 0 & 0 & 0 & 0 & 0 & 0 & 0 & 0 & 0 & 0 & 0 & 0 & 0 & 0 & 0 & 0 & 0 & 0 & 0 & 0 & 0 & 0 & 0 \\
\hline 3. ISPNS & 1 & 1 & 1 & 1 & 1 & 1 & 1 & 1 & 1 & 0 & 1 & 0 & 0 & 0 & 0 & 0 & 0 & 0 & 0 & 0 & 0 & 0 & 1 & 0 & 0 & 0 & 0 & 0 & 0 & 0 & 0 & 0 & 0 & 0 & 0 \\
\hline 4. PMZS & 1 & 0 & 1 & 1 & 1 & 1 & 0 & 0 & 1 & 0 & 0 & 0 & 0 & 0 & 0 & 0 & 0 & 0 & 0 & 0 & 0 & 0 & 1 & 0 & 0 & 0 & 0 & 0 & 0 & 0 & 0 & 0 & 0 & 0 & 0 \\
\hline 5. PMZI & 1 & 0 & 1 & 1 & 1 & 1 & 0 & 0 & 1 & 0 & 0 & 0 & 0 & 0 & 0 & 0 & 0 & 0 & 0 & 0 & 0 & 0 & 1 & 0 & 0 & 0 & 0 & 0 & 0 & 0 & 0 & 0 & 0 & 0 & 0 \\
\hline 6. PMMT & 1 & 0 & 1 & 1 & 1 & 1 & 0 & 0 & 1 & 0 & 0 & 0 & 0 & 0 & 0 & 0 & 0 & 0 & 0 & 0 & 0 & 0 & 1 & 0 & 0 & 0 & 0 & 0 & 0 & 0 & 0 & 0 & 0 & 0 & 0 \\
\hline 7. NSLNA & 0 & 1 & 1 & 0 & 0 & 0 & 1 & 1 & 1 & 0 & 1 & 0 & 0 & 0 & 0 & 0 & 0 & 0 & 0 & 0 & 0 & 0 & 0 & 0 & 0 & 0 & 0 & 0 & 0 & 0 & 0 & 0 & 0 & 0 & 0 \\
\hline 8. NSLZS & 0 & 1 & 1 & 0 & 0 & 0 & 1 & 1 & 1 & 0 & 1 & 0 & 0 & 0 & 0 & 0 & 0 & 0 & 0 & 0 & 0 & 0 & 0 & 0 & 0 & 0 & 0 & 0 & 0 & 0 & 0 & 0 & 0 & 0 & 0 \\
\hline 9. NSLZI & 1 & 1 & 1 & 1 & 1 & 1 & 1 & 1 & 1 & 0 & 1 & 0 & 0 & 0 & 0 & 0 & 0 & 0 & 0 & 0 & 0 & 0 & 1 & 0 & 0 & 0 & 0 & 0 & 0 & 0 & 0 & 0 & 0 & 0 & 0 \\
\hline 10. NABR & 0 & 0 & 0 & 0 & 0 & 0 & 0 & 0 & 0 & 1 & 0 & 1 & 1 & 1 & 1 & 1 & 0 & 1 & 0 & 0 & 0 & 0 & 0 & 0 & 0 & 0 & 0 & 0 & 0 & 1 & 1 & 1 & 1 & 1 & 0 \\
\hline 11. NAPNS & 0 & 1 & 1 & 0 & 0 & 0 & 1 & 1 & 1 & 0 & 1 & 0 & 0 & 0 & 0 & 0 & 0 & 0 & 0 & 0 & 0 & 0 & 0 & 0 & 0 & 0 & 0 & 0 & 0 & 0 & 0 & 0 & 0 & 0 & 0 \\
\hline 12. BRPT & 0 & 0 & 0 & 0 & 0 & 0 & 0 & 0 & 0 & 1 & 0 & 1 & 1 & 1 & 1 & 1 & 0 & 1 & 0 & 0 & 0 & 0 & 0 & 0 & 0 & 0 & 0 & 0 & 0 & 1 & 1 & 1 & 1 & 1 & 0 \\
\hline 13. BRAPET & 0 & 0 & 0 & 0 & 0 & 0 & 0 & 0 & 0 & 1 & 0 & 1 & 1 & 1 & 1 & 1 & 0 & 1 & 0 & 0 & 0 & 0 & 0 & 0 & 0 & 0 & 0 & 0 & 0 & 1 & 1 & 1 & 1 & 1 & 0 \\
\hline 14. PTAPET & 0 & 0 & 0 & 0 & 0 & 0 & 0 & 0 & 0 & 1 & 0 & 1 & 1 & 1 & 1 & 1 & 0 & 1 & 0 & 0 & 0 & 0 & 0 & 0 & 0 & 0 & 0 & 0 & 0 & 1 & 1 & 1 & 1 & 1 & 0 \\
\hline 15. PTBA & 0 & 0 & 0 & 0 & 0 & 0 & 0 & 0 & 0 & 1 & 0 & 1 & 1 & 1 & 1 & 1 & 0 & 1 & 0 & 0 & 0 & 0 & 0 & 0 & 0 & 0 & 0 & 0 & 0 & 1 & 1 & 1 & 1 & 1 & 0 \\
\hline 16. PTEAM & 0 & 0 & 0 & 0 & 0 & 0 & 0 & 0 & 0 & 1 & 0 & 1 & 1 & 1 & 1 & 1 & 0 & 1 & 0 & 0 & 0 & 0 & 0 & 0 & 0 & 0 & 0 & 0 & 0 & 1 & 1 & 1 & 1 & 1 & 0 \\
\hline 17. PTZYGO & 0 & 0 & 0 & 0 & 0 & 0 & 0 & 0 & 0 & 0 & 0 & 0 & 0 & 0 & 0 & 0 & 1 & 1 & 1 & 1 & 1 & 1 & 0 & 0 & 0 & 0 & 0 & 1 & 1 & 0 & 0 & 0 & 0 & 0 & 0 \\
\hline 18. PTTSP & 0 & 0 & 0 & 0 & 0 & 0 & 0 & 0 & 0 & 1 & 0 & 1 & 1 & 1 & 1 & 1 & 1 & 1 & 1 & 1 & 1 & 1 & 0 & 0 & 0 & 0 & 0 & 1 & 1 & 1 & 1 & 1 & 1 & 1 & 0 \\
\hline 19. ZSZI & 0 & 0 & 0 & 0 & 0 & 0 & 0 & 0 & 0 & 0 & 0 & 0 & 0 & 0 & 0 & 0 & 1 & 1 & 1 & 1 & 1 & 1 & 0 & 0 & 0 & 0 & 0 & 1 & 1 & 0 & 0 & 0 & 0 & 0 & 0 \\
\hline 20. ZIMT & 0 & 0 & 0 & 0 & 0 & 0 & 0 & 0 & 0 & 0 & 0 & 0 & 0 & 0 & 0 & 0 & 1 & 1 & 1 & 1 & 1 & 1 & 0 & 0 & 0 & 0 & 0 & 1 & 1 & 0 & 0 & 0 & 0 & 0 & 0 \\
\hline 21. ZIZYGO & 0 & 0 & 0 & 0 & 0 & 0 & 0 & 0 & 0 & 0 & 0 & 0 & 0 & 0 & 0 & 0 & 1 & 1 & 1 & 1 & 1 & 1 & 0 & 0 & 0 & 0 & 0 & 1 & 1 & 0 & 0 & 0 & 0 & 0 & 0 \\
\hline 22. ZITSP & 0 & 0 & 0 & 0 & 0 & 0 & 0 & 0 & 0 & 0 & 0 & 0 & 0 & 0 & 0 & 0 & 1 & 1 & 1 & 1 & 1 & 1 & 0 & 0 & 0 & 0 & 0 & 1 & 1 & 0 & 0 & 0 & 0 & 0 & 0 \\
\hline 23. MTPNS & 1 & 0 & 1 & 1 & 1 & 1 & 0 & 0 & 1 & 0 & 0 & 0 & 0 & 0 & 0 & 0 & 0 & 0 & 0 & 0 & 0 & 0 & 1 & 0 & 0 & 0 & 0 & 0 & 0 & 0 & 0 & 0 & 0 & 0 & 0 \\
\hline 24. PNSAPET & 0 & 0 & 0 & 0 & 0 & 0 & 0 & 0 & 0 & 0 & 0 & 0 & 0 & 0 & 0 & 0 & 0 & 0 & 0 & 0 & 0 & 0 & 0 & 1 & 1 & 1 & 1 & 0 & 0 & 0 & 0 & 0 & 0 & 0 & 1 \\
\hline 25. APETBA & 0 & 0 & 0 & 0 & 0 & 0 & 0 & 0 & 0 & 0 & 0 & 0 & 0 & 0 & 0 & 0 & 0 & 0 & 0 & 0 & 0 & 0 & 0 & 1 & 1 & 1 & 1 & 0 & 0 & 0 & 0 & 0 & 0 & 0 & 1 \\
\hline 26. APETTS & 0 & 0 & 0 & 0 & 0 & 0 & 0 & 0 & 0 & 0 & 0 & 0 & 0 & 0 & 0 & 0 & 0 & 0 & 0 & 0 & 0 & 0 & 0 & 1 & 1 & 1 & 1 & 0 & 0 & 0 & 0 & 0 & 0 & 0 & 1 \\
\hline 27.BAEAM & 0 & 0 & 0 & 0 & 0 & 0 & 0 & 0 & 0 & 0 & 0 & 0 & 0 & 0 & 0 & 0 & 0 & 0 & 0 & 0 & 0 & 0 & 0 & 1 & 1 & 1 & 1 & 0 & 0 & 0 & 0 & 0 & 0 & 0 & 1 \\
\hline 28. EAMZYGO & 0 & 0 & 0 & 0 & 0 & 0 & 0 & 0 & 0 & 0 & 0 & 0 & 0 & 0 & 0 & 0 & 1 & 1 & 1 & 1 & 1 & 1 & 0 & 0 & 0 & 0 & 0 & 1 & 1 & 0 & 0 & 0 & 0 & 0 & 0 \\
\hline 29. ZYGOTSP & 0 & 0 & 0 & 0 & 0 & 0 & 0 & 0 & 0 & 0 & 0 & 0 & 0 & 0 & 0 & 0 & 1 & 1 & 1 & 1 & 1 & 1 & 0 & 0 & 0 & 0 & 0 & 1 & 1 & 0 & 0 & 0 & 0 & 0 & 0 \\
\hline 30. LDAS & 0 & 0 & 0 & 0 & 0 & 0 & 0 & 0 & 0 & 1 & 0 & 1 & 1 & 1 & 1 & 1 & 0 & 1 & 0 & 0 & 0 & 0 & 0 & 0 & 0 & 0 & 0 & 0 & 0 & 1 & 1 & 1 & 1 & 1 & 0 \\
\hline 31. BRLD & 0 & 0 & 0 & 0 & 0 & 0 & 0 & 0 & 0 & 1 & 0 & 1 & 1 & 1 & 1 & 1 & 0 & 1 & 0 & 0 & 0 & 0 & 0 & 0 & 0 & 0 & 0 & 0 & 0 & 1 & 1 & 1 & 1 & 1 & 0 \\
\hline 32. OPILD & 0 & 0 & 0 & 0 & 0 & 0 & 0 & 0 & 0 & 1 & 0 & 1 & 1 & 1 & 1 & 1 & 0 & 1 & 0 & 0 & 0 & 0 & 0 & 0 & 0 & 0 & 0 & 0 & 0 & 1 & 1 & 1 & 1 & 1 & 0 \\
\hline 33. PTAS & 0 & 0 & 0 & 0 & 0 & 0 & 0 & 0 & 0 & 1 & 0 & 1 & 1 & 1 & 1 & 1 & 0 & 1 & 0 & 0 & 0 & 0 & 0 & 0 & 0 & 0 & 0 & 0 & 0 & 1 & 1 & 1 & 1 & 1 & 0 \\
\hline 34. JPAS & 0 & 0 & 0 & 0 & 0 & 0 & 0 & 0 & 0 & 1 & 0 & 1 & 1 & 1 & 1 & 1 & 0 & 1 & 0 & 0 & 0 & 0 & 0 & 0 & 0 & 0 & 0 & 0 & 0 & 1 & 1 & 1 & 1 & 1 & 0 \\
\hline 35. BAOPI & 0 & 0 & 0 & 0 & 0 & 0 & 0 & 0 & 0 & 0 & 0 & 0 & 0 & 0 & 0 & 0 & 0 & 0 & 0 & 0 & 0 & 0 & 0 & 1 & 1 & 1 & 1 & 0 & 0 & 0 & 0 & 0 & 0 & 0 & 1 \\
\hline
\end{tabular}

